\title{
FOSSIL ENERGY ADVANCED RESEARCH AND TECHNOLOGY DEVELOPMENT (AR\&TD) MATERIALS PROGRAM SEMIANNUAL PROGRESS REPORT FOR THE PERIOD ENDING SEPTEMBER 30, 1992
}

\author{
Compiled by \\ N. C. Cole \\ R. R. Judkins
}

Contributions by

3M Company

Argonne National Laboratory

Babcock \& Wilcox

Battelle Columbus Laboratories

Colorado School of Mines

Georgia Institute of Technology

Idaho National Engineering Laboratory

National Institute of Standards and

Technology

Oak Ridge Associated Universities
Oak Ridge K-25 Site

Oak Ridge National Laboratory

Pacific Northwest Laboratory

Rensselaer Polytechnic Institute Sandia National Laboratories The Carborundum Company University of Tennessee

Virginia Polytechnic Institute and State University

Westinghouse Hanford Company

Date Published: December 1992

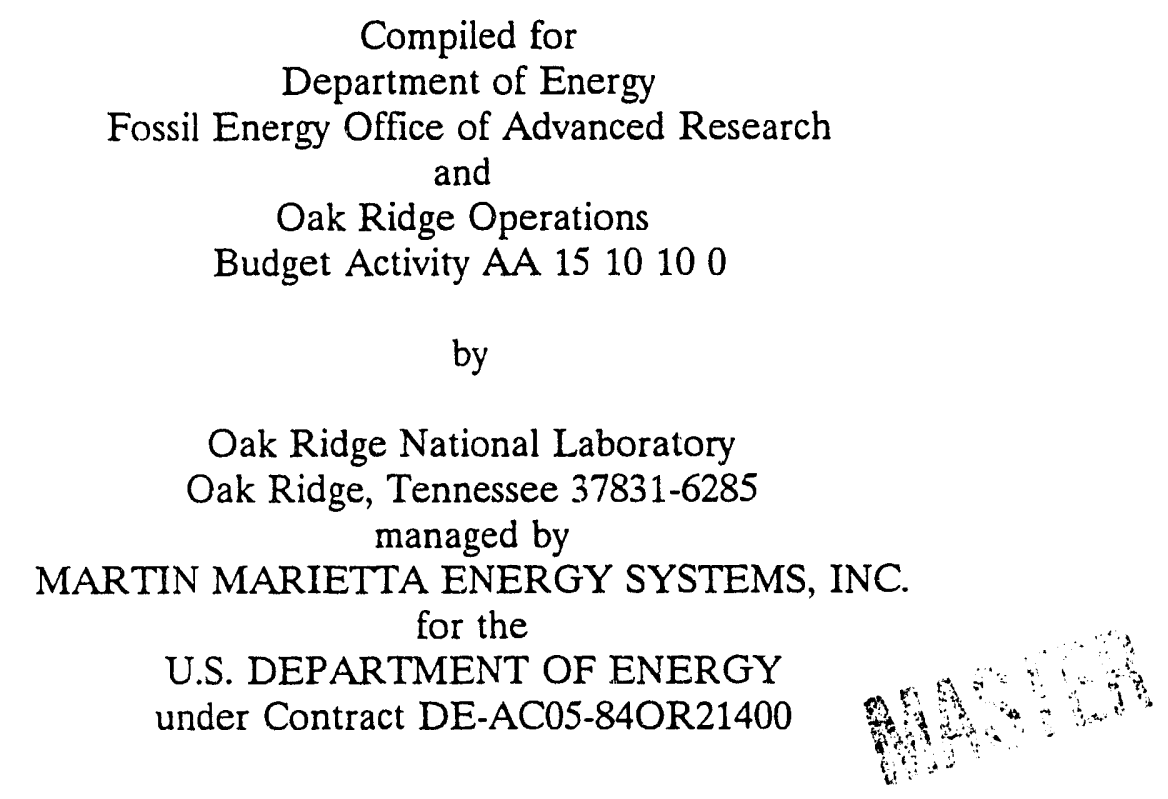




\section{PREVIOUS REPORTS IN THIS SERIES}

ORNL/FMP-81/1

ORNL/FMP-81/2

ORNL/FMP-81/3

ORNL/FMP-81/4

ORNL/FMP-82/1

ORNL/FMP-82/2

ORNL/FMP-82/3

ORNL/FMP-S2/4

ORNL/FMP-83/1

ORNL/FMP-83/2

ORNL/FMP-83/3

ORNL/FMP-83/4

ORNL/FMP-84/1

OKNL/FMP-84/2

ORNL/FMP-84/3
AR\&TD Fossil Energy Materials Program Quarterly Progress Report for Period Ending December 31, 1980.

AR\&TD Fossil Energy Materials Program Quarterly Progress Report for Period Ending March 31, 1981.

AR\&TD Fossil Energy Materials Program Quarterly Progress Report for Period Ending June 30, 1981.

AR\&TD Fossil Energy Materials Program Quarterly Progress Report for Period Ending September 30, 1981.

AR\&TD Fossil Energy Materials Program Quarterly Progress Report for Period Ending December 31, 1981.

AR\&TD Fossil Energy Materials Program Quarterly Progress Report for Period Ending March 31, 1982.

AR\&TD Fossil Energy Materials Program Quarterly Progress Report for Period Ending June 30, 1982.

AR\&TD Fossil Energy Materials Program Quarterly Progress Report for Period Ending September 30, 1982.

AR\&TD Fossil Energy Materials Program Quarterly Progress Report for Period Ending Decemuer 31, 1982.

AR\&TD Fossil Energy Materials Program Quarterly Progress Report for Period Ending March 31, 1983.

AR\&TD Fossil Energy Materials Program Quarterly Progress Report for Period Ending June 30, 1983.

AR\&TD Fossil Energy Materials Program Quarterly Progress Report for Period Ending September 30, 1383.

AR\&TD Fossil Energy Materials Program Quarterly Progress Report for Period Ending December 31, 1983.

AR\&TD Fossil Energy Materials Program Quarterly Progress Report for Period Ending March 31, 1984.

AR\&FD Fossil Energy Materials Program Quarterly Progress Report for Period Ending June 30, 1984. 
ORNL/FMP-84/4

ORNL/FMP-85/1

ORNL/FMP-85/2

ORNL/FMP-85/3

ORNL/FMP-85/4

ORNL/FMP-86/1

ORNL/FMP-86/2

ORNL/FMP-86/3

ORNL/FMP-86/4

ORNL/FMP-87/1

ORNL/FMP-S7/2

ORNL/FMP-88/1

ORNL/FMP-SS/2

ORNL/FMP-89/1

ORNL/FMP-89/2

ORNL/FMP-90/1
AR\&TD Fossil Energy Materials Program Quartcrly Progress Report for Period Ending September 30, 1984.

AR\&TD Fossil Energy Materials Program Quarterly Progress Report for Period Ending December 31, 1984.

AR\&TD Fossil Energy Materials Program Quarterly Progress Report for Period Ending March 31, 1985.

AR\&TD Fossil Energy Materials Program Quarterly Progress Report for Period Ending June 30, 1985.

AR\&TD Fossil Energy Materials Program Quar:erly Progress Report for Period Ending September 30, 1985.

AR\&TD Fossil Energy Materials Program Quarterly Progress Report for Period Ending December 31, 1985.

AR\&TD Fossil Energy Materials Program Quarterly Progress Report for Period Ending March 31, 1986.

AR\&TD Fossil Energy Materials Program Quarterly Progress Report for Period Ending June 30, 1986.

AR\&TD Fossil Erergy Materials Program Quarterly Progress Report for Period Ending September 30, 1986.

AR\&TD Fossil Energy Materials Program Semiannual Progress Report for Period Ending March 31, 1987.

AR\&TD Fossil Energy Materials Program Semiannual Progress Report for Period Ending September 30, 1987.

AR\&TD Fossil Energy Materials Program Semiannual Progress Report for Period Ending March 31, 1988.

AR\& TD Fossil Energy Materials Program Semiannual Progress Report for Period Ending September 30, 1988.

AR\&TD Fossil Energy Materials Program Semiannual Progress Report for Period Ending March 31, 1989.

Fossil Energy AR\&TD Materials Program Semiannual Progress Report for Period Ending September 30, 1989.

Proceedings of the Fourth Annual Conference on Fossil Energy Materials, (August 1990). 
ORNL/FMP-90/2

ORNL/FMP-91/1

ORNL/FMP-91/2

ORNL/FMP-92/1
Fossil Energy AR\&TD Materials Program Semiannual Progress Report for Period Ending September 30, 1990.

Proceedings of the Fifth Annual Conference on Fossil Energy Materials, (September 1991).

Fossil Energy AR\&TD Materials Program Semiannual Progress Report for Period Ending September 30, 1991.

Proceedings of the Sixth Annual Conference on Fossil Energy Materials, (July 1992). 
TABLE OF CONTENTS

PART I - INTRODUCTION

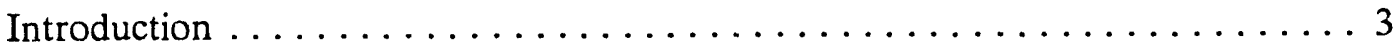

PART II - CERAMICS $\ldots \ldots \ldots \ldots \ldots \ldots \ldots \ldots \ldots \ldots \ldots \ldots$

ANI-1*, Development of Nondestructive Characterization Methods for and Effects of Flaws on the Fracture Behavior of Structural Ceramics . . . . . . 11

GT-1(A), Modeling of Fibrous Preforms for CVD Infiltration $\ldots \ldots \ldots \ldots 27$

GT-1, Development of Advanced Fiber Reinforced Ceramics . . . . . . . . . 39

INEL-1(B), Joining of Silicon Carbide Ceramics and Composites . . . . . . 47

NIST-1(A), Low-Temperature Fabrication of Transparent Silicon Nitride . . . . 55

K25-1, Development of Ceramic Membranes for Gas Separation ......... 65

ORNL-1(A), Fabrication of Fiber-Reinforced Composites $\ldots \ldots \ldots \ldots \ldots$

ORNL-1(C), Interfaces and Mechanical Properties of Continuous

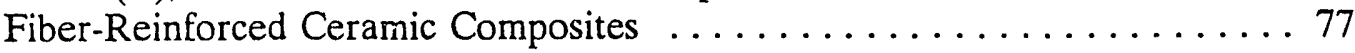

ORNL-1(D), Microwave Sintering of Ceramics for Fuel Cells . . . . . . . 87

PNL-1, Advanced Materials and Electrochemical Processes Involving Solid Electrolytes $\ldots \ldots \ldots \ldots \ldots \ldots \ldots \ldots \ldots \ldots \ldots \ldots \ldots \ldots$

SNL-1, Ceramic Catalyst Supports: Hydrous Metal Oxide Ion-Exchange

Supports for Direct Coal Liquefaction . . . . . . . . . . . . . . . . . . . 109

UTN-1, Sol-Gel Oxide Interface Coatings for Nicalon/Sic Composites . . . . 121

VPI-1, Investigation of Properties and Performance of Ceramic

Composite Components . . . . . . . . . . . . . . . . . . . 131

*The acronym preceding the title of the contribution designates the responsible contractor and the program work element. See Table 1 of Part I for further information. 
ANL-3, Corrosion and Mechanical Properties of Alloys in FBC and

Mixed-Gas Environments .............................. 147

CSM-2, Weldability of Polycrystalline Iron Aluminides $\ldots \ldots \ldots \ldots \ldots \ldots$

INEL-2, The Influence of Thermomechanical Processing on Microstructure and Properties of Iron Aluminides ................... 167

ORNL-2(A), Environmental Effects on Iron Aluminides $\ldots \ldots \ldots \ldots \ldots 175$

ORNL-2(B), Investigation of Austenitic Alloys for Advanced Heat Recovery and Hot-Gas Cleanup System ...................... 183

ORNL-2(D), Ultrahigh Temperature Intermetallic Alloys ........... 191

ORNL-2(F), Development of Iron Aluminides . . . . . . . . . . . . 197

ORNL-2(G). Microalloyed Iron Aluminides . ............... 207

ORNL-2(H), Low-Aluminum Content Iron-Aluminum Alloys . . . . . . . . 213

ORNL-3(A), Corrosion Protection of Ultrahigh Temperature

Intermetallic Alloys ............................... 219

RPI-2, Investigation of Moisture-Induced Embrittlement of

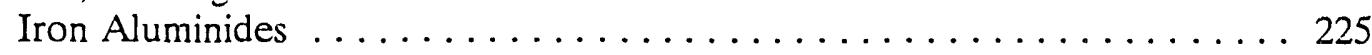

UTN-2, Investigation of the Weldability of Modified 800H Alloys ....... 229

UTN-3, Aqueous Corrosion of Iron Aluminides in Chloride and

Sulfur-Compound Solutions $\ldots \ldots \ldots \ldots \ldots \ldots \ldots \ldots \ldots \ldots \ldots \ldots \ldots \ldots$

WHC-2, Electro-Spark Deposited Coatings for Fossil Energy Environments .. 253

PART IV - TECHNOLOGY DEVELOPMENT AND TRANSFER $\ldots \ldots \ldots \ldots 261$

3M-4, Fabrication of Commercial-Scale Fiber-Reinforced Hot-Gas Filters by Chemical Vapor Deposition ..................... 263

B\&W-4, Evaluation of the Fabricability of Advanced Iron Aluminide-Clad Austenitic Stainless Steel Tubing . . . . . . . . . . . . . . . . . 271

BCL-4, Materials and Components in Fossil Energy Applications

Newsletter . . . . . . . . . . . . . . . . . . . . . . . . . . . . . . . . 279 
CARB-4, Engineering-Scale Development of the Vapor-Liquid-Solid

(VLS) Process for the Production of Silicon Carbide Fibrils ......... 281

ORAU-4, Solidification Behavior of Iron Aluminides ............. 293

ORNL-4(B), Coal Conversion and Utilization Plant Support Services ...... 303 
PART I - INTRODUCTION 


\title{
INTRODUCTION
}

\author{
N. C. Cole and R. R. Judkins \\ Oak Ridge National Laboratory \\ Oak Ridge, Tennessee 37831
}

The objective of the Fossil Energy Advanced Research and Technology Development (AR\&TD) Materials Program is to conduct research and development on materials for fossil energy applications with a focus on the longer-term and generic needs of the various fossil fuel technologies. The Program includes research aimed toward a better understanding of materials behavior in fossil energy environments and the development of new materials capable of substantial enhancement of plant operations and reliability.

The management of the Program has been decentralized to the Department of Energy (DOE) Oak Ridge Field Office (OR) and the Oak Ridge National Laboratory (ORNL) as technical support contractor. The organizational relationships among DOE Headquarters, OR, and ORNL are illustrated in Fig. 1. A substantial portion of the work on the AR\&TD Materials Program is performed by participating subcontractor organizations. The performing institution and principal investigator for each project are shown in Table 1.

This combined semiannual progress report of activities on the Program is in accordance with a work breakdown structure in which projects are organized according to materials research areas. These areas are (1) Ceramics, (2) New Alloys: Iron Aluminides, Advanced Austenitics and Chromium Niobium Alloys, and (3) Technology Development and Transfer. A schematic summary of this organization is provided in Fig. 2.

These Fossil Energy AR\&TD Materials Program semiannual progress reports are intended to aid in the dissemination of information developed on the Program. Highlights of projects that are part of this program are provided in the bimonthly DOE newsletter, Materials and Components in Fossil Energy Applications, published by Battelle Columbus Laboratories. 


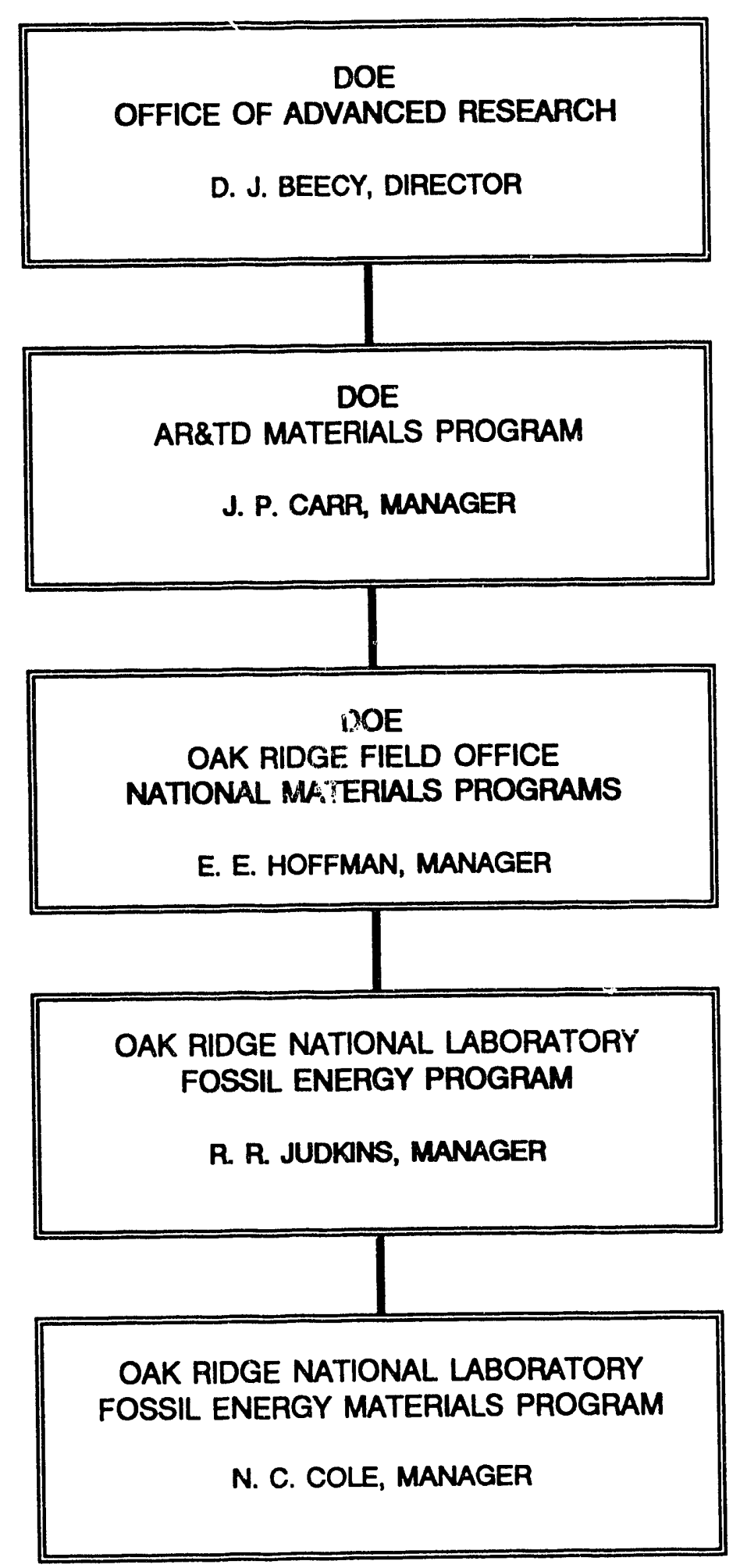

Fig. 1. Organizational relationships among DOE Headquarters, DOE Oak Ridge Field Office, and Oak Ridge National Laboratory for the AR\&'TD Materials Program. 


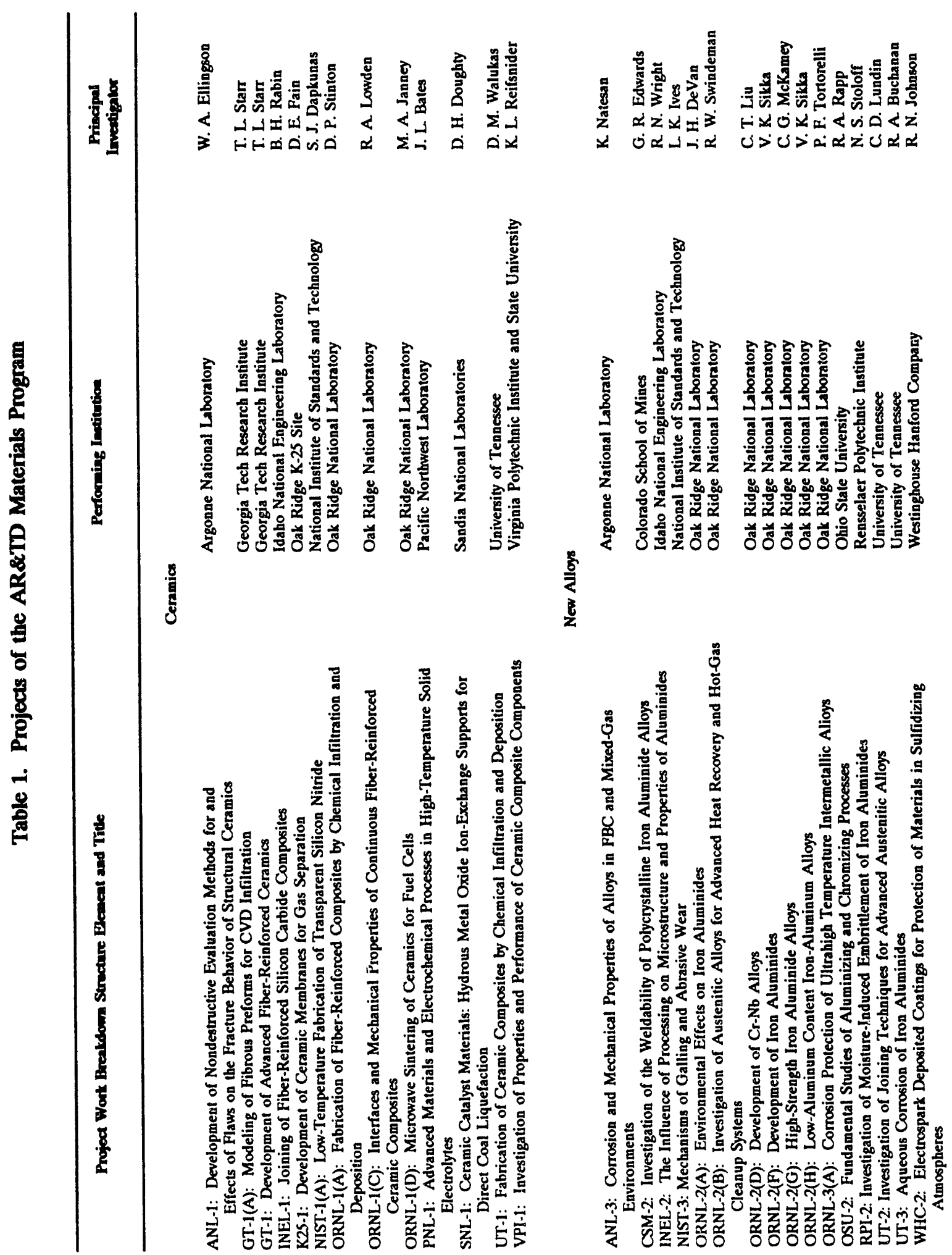




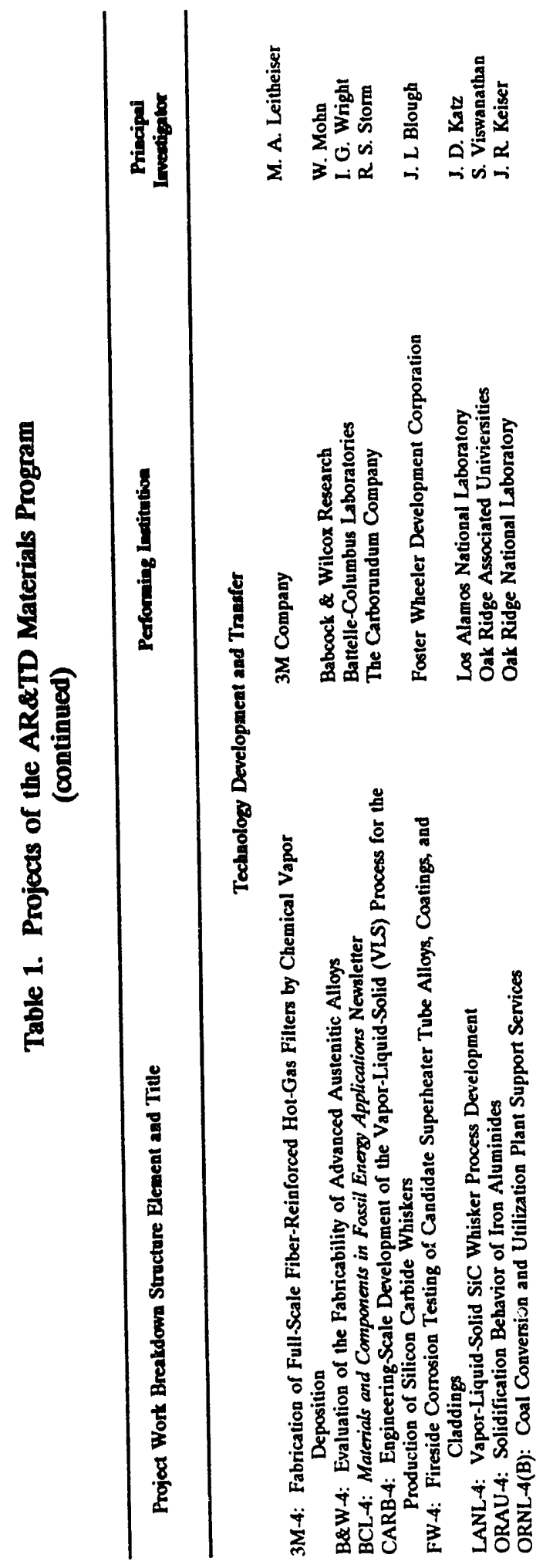




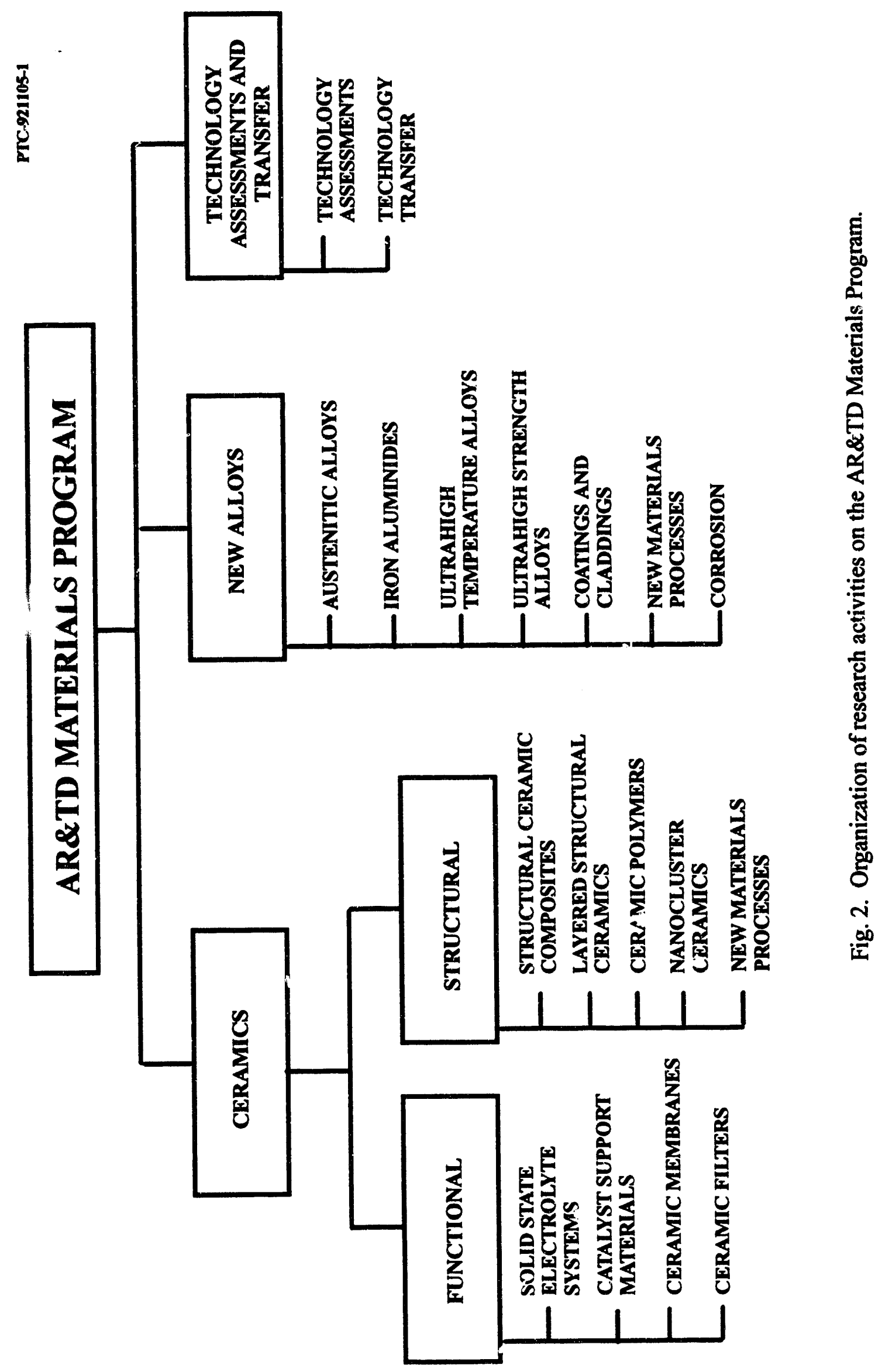


PART II - CERAMICS 
ANL-1 - DEVELOPMENT OF NONDESTRUCTIVE CHARACTERIZATINN METHODS FOR ANU EFEECTS OF FLAWS ON THE FRACTURE BEHAVIC OF STRUCTURAL CERAMICS

W. A. Ellingson, J. P. Singh, E. A. Sivers, D. Singh, R. Sayre, S. H. Sheen, S. L. Dieckman, D. L. Holloway

Argonne National Laboratory

Materials and Components Technology Division

Argonne, IL 60439

\section{INTRODUCTION}

The purpose of this program is to (1) develop nondestructive characterization (NDC) methods and protocols that can be used to characterize structural ceramics and composites (with emphasis on continuous-fiber ceramic/ceramic composites), and (2) evaluate the effects of various flaws and processing parameters on fracture behavior, and (3) correlate NDC results with mechanical properties to provide information for establishing accept/reject criteria. The NDC techniques being developed include (1) three-dimensional X-ray microcomputed tomography, (2) nuclear magnetic resonance (imaging and spectroscopy), (3) bulk body and surface acoustics with advanced signal processing, and (4) digital image processing for data analysis. 


\section{DISCUSSION OF CURRENT ACTIVITIES}

Development of Nondestructive Characterization Methods and Protocols for Ceramics

1. Develonment of Three-Dimensional Microfocus X-ray Imaging to

Ceramic-Matrix Composites

Activity in the X-ray computerized tomography (XRCT) section this period centered on the installation of a new $1024 \times 1024$-pixel photometrics CCD camera and 14-bit analog-to-digital ( $A D C$ ) converter, which has been coupled to the existing Precise Optics image intensifier and IRT microfocus X-R-tube. This system is now operational and has more than doubled the spatial resolution capabilities of the system. In addition, the new camera has been demonstrated to be extremely linear with low noise, permitting increased contrast detectability. The 14-bit ADC accommodates the increased dynamic range.

A theoretical study has been conducted to quantify the capabilities of the new system and to plan for future improvements. The theoretical model, which is two-thirds complete, parameterizes the X-R-CT system noise and resolution capabilities in terms of the X-ray tube flux, X-ray energy, integration time, detector size and type, and light coupling mechanism to the camera. When complete, the model will allow us to predict contrast detectability and spatial resolution for the complete XRCT system, including the effects of system magnification and number of projections used in image reconstruction. The model will enable us to determine the X-ray flux and integration time needed to resolve such features as $\mathrm{SiC}$ fibers in $\mathrm{SiC}$ matrix components. The fibers differ in density from the bulk of a component by $\approx 10 \%$. It is expected that the low noise of the new camera and the increased dynamic range of the ADC will provide better performance than is currently needed to see these fibers.

Initial studies have produced an analysis that compares the signal-to-noise (SNR) capabilities of the present system, which consists of an image intensifier coupled, via lenses to the CCD camera, to seven other detector configurations. This study indicates that the noise performance of the present image intensifier is very well suited to the X-ray output of the present system. The study also shows that the image intensifier provides more than adequate sensitivity to perform optimally with the CCD camera. 
Results from the SNR study with the current microfocus X-ray source and the CCD camera are given in Tables 1 and 2 and shown in Fig. 1. In addition to the image intensifier/lens combination. seven other detector confiturations were examined this period: 2.5-mm-thick CsI screen/lens, Kodak Lanex regular rare-earth screen/lens, Kodak Lanex fine rare-earth screen/lens, 2-mm-thick Lockheed fiber-optic scintillator (FOS)/Icns, 12.7-mm-thick Lockheed FOS/lens, 2-mm-thick Lockheed FOS/Fiber-optic taper (FOT), and $12.7 \mathrm{~mm}$-thick Lockheed FOS/FOT. The active area of the image intensifier, CsI screen, and the two Kodak screens used in the analysis was $4 \times 4$ in. The active area of the FOS screens used in the analysis was $2 \times 2$ in. In the analysis the detectors were placed $1 \mathrm{~m}$ from the X-ray source.

The model was verified by comparison with experimental data obtain from the ANL system and with data from a Lockheed FOS/lers system. For the present comparison, the analysis used an X-ray source maximum voltage of $120 \mathrm{kVp}$ and an integration time of $0.33 \mathrm{sec}$ (about $20 \mathrm{R} / \mathrm{hr}$ at $1 \mathrm{~m}$ ). For simplicity, the average energy of the X-ray source, $60 \mathrm{kev}$, was used. The relatively low flux of the X-ray source is due to the small size (10-micron) focal spot, which is used to obtain high resolution. Other parameters in the model include the stopping power of the screens, ${ }^{1,2,3}$ the X-ray-to-light photon conversion factors, ${ }^{1}$ the light coupling efficiency of the lens and the FOT, the conversion efficiency of the CCD camera, ${ }^{1}$ the dark noise of the camera, and the read noise of the camera.

The present CCD camera is operated in the cooled mode and requires 5 sec for a $1024 \times 1024$ readout. In addition, it is linear up to a full well of $\approx 300,000$ electrons. This full-well limit dictates the maximum integration time for a particular configuration. Table 1 gives the full-well integration times for the eight detector configurations and provides the corresponding SNR. Although the image intensifier has the lowest SNR for full-well integration, the integration times for the other systems are unacceptably long for this X-ray flux. Combining the $3.3 \mathrm{sec}$ for full-well data acquisition of the image intensifier and the 5-sec readout time results in an acceptable acquisition time of $8.3 \mathrm{sec}$ per CT projection. Table 2 shows that, given this time limitation, the image intensifier provides the highest SNR of the detector systems configured. 
Tạble 1. Full-Well SNR and Full-Well integration time for eight detector/light coupling configurations. ${ }^{a}$

\begin{tabular}{|c|c|c|c|}
\hline Detector & Coupling & Full-Well & $\begin{array}{l}\text { Full-Well } \\
\text { Integration } \\
\text { Time (sec) } \\
\end{array}$ \\
\hline Image intensifie* & Lens & 15G8:1 & 3.29 \\
\hline 2.5-mm CsI screen & Lens & $4354: 1$ & 31.13 \\
\hline Kodak Lanex Reg. & Lens & $500: 1$ & 210.57 \\
\hline Kodak Lanex Fine & Lens & 498:1 & 358.7 \\
\hline 2mm-Lockheed FOS & Lens & $425: 1$ & 130.8 \\
\hline 12.7-mm Lockheed & Lens & $425: 1$ & 124.8 \\
\hline 2-mm Lockheed FOS & Fiber Optic Taper & $203: 1$ & 13.67 \\
\hline 12.7-mm Lockheed & Fiber Optic Taper & 203:1 & 13.05 \\
\hline $\begin{array}{l}\text { aUnattenuated source } \\
9.5 \times 10^{-5} \mathrm{~cm}^{2} \text { for th } \\
\text { for the last four det }\end{array}$ & $\begin{array}{l}\text { ngth: } 20 \mathrm{R} / \mathrm{hr} @ \mathrm{Im} \\
\text { st four detector con } \\
\text { configuratinns. }\end{array}$ & $\begin{array}{l}.33 \mathrm{~mA}) . \mathrm{Pi} \\
\text { Irations and }\end{array}$ & $10^{-5} \mathrm{~cm}^{2}$ \\
\hline Detector & $\begin{array}{r}\text { Ligh } \\
\text { Coupl } \\
\end{array}$ & & $\begin{array}{l}\text { Max SNR } \\
\text { for } 8.3 \text {-scc } \\
\text { acquisition } \\
\text { time } \\
\end{array}$ \\
\hline Image intensifier & Len & & $156: 1$ \\
\hline 2.5-mm CsI screen & Len & & $141: 1$ \\
\hline Kodak Lanex Reg. & Len & & $61: 1$ \\
\hline Kodak Lanex Fine & Len & & $458: 1$ \\
\hline 2-mm Lockheed FOS & Len & & $67: 1$ \\
\hline 12.7-mm Lockheed & Len & & $69: 1$ \\
\hline 2-mm Lockheed FOS & Fiber Opti & aper & $100: 1$ \\
\hline 12.7-mm Lockheed & Fiber Opti & aper & $102: 1$ \\
\hline
\end{tabular}

aUnattenuated source strength: $20 \mathrm{R} / \mathrm{hr}$ (1) $1 \mathrm{~m}(0.33 \mathrm{~mA})$. Pixel size is $9.5 \times 10^{-5} \mathrm{~cm}^{2}$ for the last four detector configurations. 


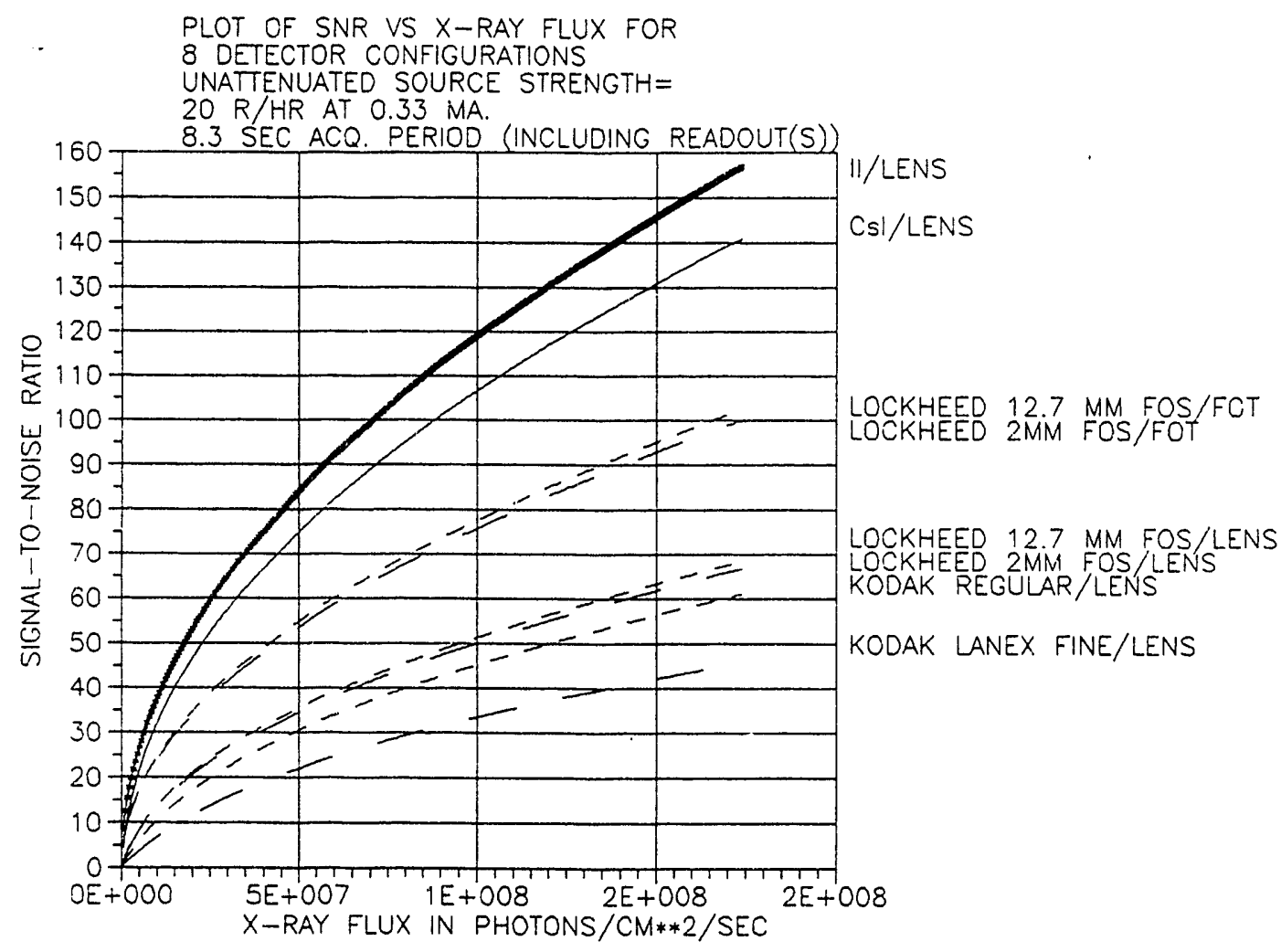

Fig. 1. Theoretically predicted signal-to-noise ratio as a function of X-ray flux for eight detector configurations using an unattenuated X-ray source with strength $20 \mathrm{R} / \mathrm{hr}$ at $0.33 \mathrm{Ma}$ during a 7.3-sec acquisition period.

Although camera noise is negligible compared to the Poisson noise of the unattenuated X-ray sigial, is can be comparable to X-ray noise of the attenuated signal. This can be seen in Fig. 1, which shows the SNR as a function of incident flux for an 8.3-sec data acquisition time. The deviations from linearity are due to camera noise.

The results of this study will be used in a model of the XRCT system to predict the contrast detectability and resolvability in continuous-fiber ceramic matrix composites to show small features as a function of their size and X-ray attenuation. Contrast and resolution also depend upon the size of the component, the flux of the $\mathrm{X}$-ray tube, and the geometrical magnification of the scanner, in addition to the inherent resolution and noise capabilities of the detector configuration. 


\section{Image Processing Development}

This period we began an initial effort to quantify the volumes of the features we detect by three-dimensional X-ray microfocus tomography. We need to quantify these feature volumes so that the data can be used in fracture mechanics models for predicting fracture behavior. We used our new SUN Sparc II/GS work station for all of this analytical work.

Determining feature size was a three-stage process that required finding the feature, determing the outer boundary of the feature to be examined (edge detection), and calculating the size from a volume whose edges are known. The first two processes were the most difficult. The last was quite straight forward assuming the first two were done well.

To find the location of the features of interest, three approaches were considered: (1) train a neui al network to learn the characteristics of the object under study and then scan the object for anomalies, (2) determine a multi-dimensional characteristic vector for the solid object and use a rule-based approach to determine features, and (3) use a gradient field of the attenuation to help locate anomalies.

The neural network approach was a very workable idea and is currently being examined as a parallel activity. While this is proving to be an interesting technique, a more conventional approach was needed to allow for an eventual basis for comparison to test the training of the neural network. The multi-dimensional approach was not used because the search space was simply too large and the reduced front-end processing did not justify this time expenditure. This method was also susceptible to a noisy environment, which added a great deal of computation to the process. The high noise may come in part from the 8-bit limit of the old detector. The new low-noise 14-bit CCD camera may aleviate part of this problem.

Use of the gradient was chosen, because it afforded a direct approach to locating anomalies. This approach was very susceptible to a noisy system and some thought was given to methods of smoothing the data before proceeding. The smoothing techniques were not used because the computational time proved significant, while not improving the performance significantly. 
The information used in this initial image processing work came from two sources: real data from XR-CT images of ceramic objects, and synthesized data from a program written by Anne Sivers. The synthesized data was used extensively, because it is the only way to test the various approaches.

To use the real ceramic object data, the data were cut into an arbitrary number of slices of predetermined width. Each slice was a matrix of voxels (usually $512 \times 512$ ) of predetermined size. The slices had a finite thickness and therefore a metrix allowed the user to obtain a volume and not simply an area.

As has been stated, the procedure to find the feature sizes consisted of three steps:

1. Determine an area to be a candidate for a feature. This was accomplished in the chosen algorithm by using the gradients of the attenuation from the ceramic body. It was decided that the gradients would give an indication of where the anomalies existed and would reduce the search space where flaws might exist. If the ceramic body was wholly contained in the X-ray, the algorithm started at the outer edge of the attenuation matrix and cleansed the extraneous data. The attenuation levels were then preprocessed to form a grid that was the same size as the original attenuation information. This grid was then used to locate the largest attenuation gradient that was contained in the data. The position of the largest gradient was used as the place to look for a feature of interest.

To determine if a feature existed near this point, an original characteristic vector for the solid material was compared with eight characteristic vectors obtained from eight directions radiating from the point ( $N, N E, E, S E, S, S W, W, N W$ ). If a vector was determined to be significantly different from the solid characteristic vector, a search was done in that direction.

2. Tracing the outer edge. Once the candidate feature had been located, the algorithm had also determined a characteristic for that feature. This value was used as an anchor to trace the edge. The approach that best allowed this was that in which the edge should try to stay in the solid area, tracing a path along the highest gradient, while also keeping the characteristic of the feature near its original value. Although this was difficult to implement, it produced excellent results in tracing the outer edge of each individual feature (see Fig. 2). The propensity to move away from 
the feature, and the rule to maintain the feature characteristic vector usually combined to obtain a closed area.

3. Determining the volume. Individual closed areas were obtained on separate "slices" of the original data. The algorithm then combined slice information by correlating the characteristics and the location of each slice. The volumes were then obtained by summing over the correlated voxels of all slices.

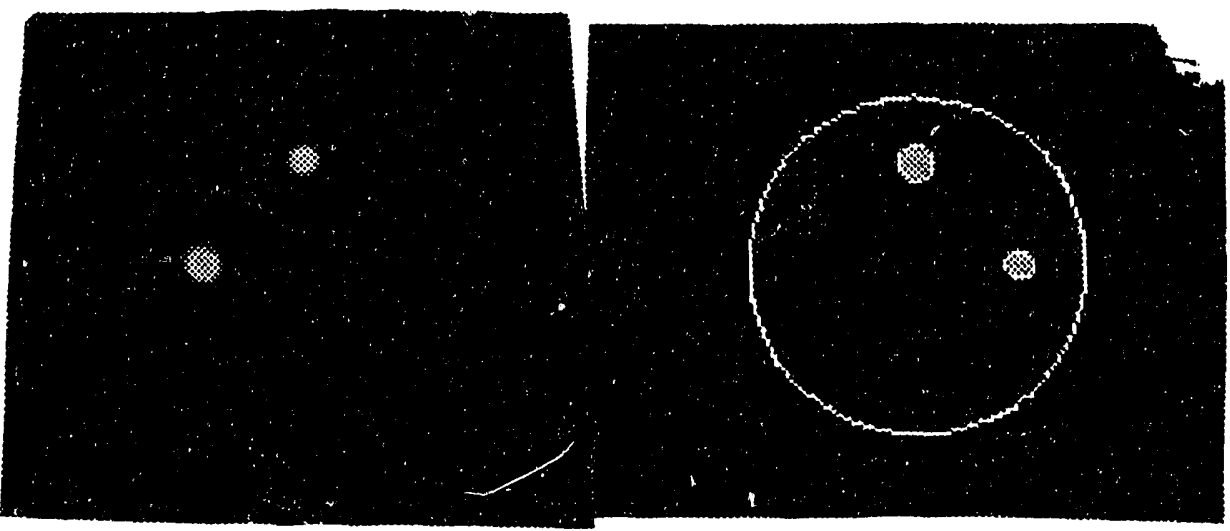

(a)

(b)

Fig. 2. X-R-CT-reconstructed image from synthesized data to show how gradient edge detection algorithm determines edges of two simulated voids; (a) data as observed, (b) white outlines show detected edges. 


\section{Nuclear Magnetic Resenance Spectroscopy of Ceramic Composites}

Multi-nuclear $\left({ }^{1} \mathrm{H},{ }^{13} \mathrm{C}\right.$, and $\left.{ }^{29} \mathrm{Si}\right) \mathrm{NMR}$ spectroscopic studies are being designed to investigate (a) the composition of bulk ceramic materials, (b) the surface chemistry of these materials, (c) the chemistry of the ceramic interfacial regions, (d) and the chemistry of the whisker and fiber coatings. Emphasis of these studies is being directed the increased understanding of continuous fiber composites.

NMR spectroscopic properties of many types of nuclei are generally sensitive to their local chemical environment. These properties often exhibit a strong dependence upon the variety, location, and chemical bonding of the surrounding nuclei. ${ }^{29}$ Si exhibits such sensitivity, and can thus be used as a probe for the bulk, surface, and interface characterization in ceramics and ceramic composite materials. For example, with ${ }^{29} \mathrm{Si}$ NMR "Magic-Angle" spinning (MAS), it has been demonstrated that NMR can quantify crystal type in $\mathrm{Si}_{3} \mathrm{~N}_{4}$ (i.e. a, b, and amorphous ) materials, as well as determine surface coatings such as silica concentration and oxynitrides concentration. Note that NMR has a distinct and significant advantage over X-ray crystallographic methods in its ability to quantify the amorphous materials. When dealing with materials that are comprised of mixed polytypes, such as SiC, NMR is often capable of quantifying the individual polytypes. Additionally, ${ }^{13} \mathrm{C}$ NMR can be used to characterize and quantify carboniferous coatings on whisker and fibers. These analysis can all be performed as a function of specimen preparation (i.e. mixing conditions, sintering conditions, and atmospheric constituents).

In work reported during the previous reporting period, ${ }^{29} \mathrm{Si}$ NMR MAS spectra have been obtained for the compositional and morphological analysis of $\mathrm{Si}_{3} \mathrm{~N}_{4}$ (i.e. $\mathrm{a}, \mathrm{b}$, and amorphous materials) powders and $\mathrm{SiC}$ whisker/ $\mathrm{Si}_{3} \mathrm{~N}_{4}$ matrix powder mixtures. NMR results indicated that these materials exhibit reasonably low but detectable levels of silicon oxynitrides and the silicon oxides. Additional studies NMR's verified the utility of this technique for determining bulk compositional variations using a series of calibrated $\mathrm{SiC}$ whisker/ $\mathrm{Si}_{3} \mathrm{~N}_{4}$ matrix mixtures.

During this reporting period, work was performed to further establish NMR's sensitivity limits for determining the chemical environment of particle surfaces. In these studies, ${ }^{29} \mathrm{Si}$ NMR MAS spectra of commercially available $\mathrm{Si}_{3} \mathrm{~N}_{4}$ materials 
showed significant levels of both the silicon-oxynitrides and the silicon-oxides constituents, see Fig. 3(A). Additionally, NMR MAS experiments were performed on $\mathrm{Si}_{3} \mathrm{~N}_{4}$ specimens which had undergone mild oxidation ( $24 \mathrm{~h}$ at $300 \mathrm{C}$ in air). These specimens showed increased levels of surface oxidation and thus increased levels of the oxynitride and the oxide constituents, see Fig. 4(B).

In an effort to determine the sensitivity of NMR to determine the chemical nature of the interface, ${ }^{29} \mathrm{Si}$ NMR spectroscopic experiments were also performed on hot-pressed $15 \% \mathrm{SiC}$-fiber $/ \mathrm{Al}_{2} \mathrm{O}_{3}$ composites. These composites were obtained from Dr. J. P. Singh of the Ceramics Section in the Material and Components Technology Division at Argonne National Láboratory. These composites varied in SiC surface oxygen concentration and the individual specimens were subject to variations in processing conditions (i.e., vacuum vs. argon hip environment). The resultant composites showed significant differences in toughness characteristics as previously reported (S.M. Smith et.al., J. Am. Ceram. Soc., 72 [7], 1252(1989)). Preliminary NMR experiments performed on the specimens containing low surface oxygen concentrations on the $\mathrm{SiC}$ fibers exhibited a wealth of spectral information. Such information included the identification (and with further experimentation the eventual quantification) of $\mathrm{SiC}$ polymorphism, $\mathrm{SiO}_{3} \mathrm{C}, \mathrm{SiO}_{2} \mathrm{C}_{2}$, $\mathrm{SiO}_{4}$, and the probable identification of various silicon-aluminates (i.e., $\mathrm{SiO}_{3} \mathrm{Al}$, $\mathrm{SiO}_{2} \mathrm{Al}_{2}$, and $\mathrm{SiO}_{1} \mathrm{Al}_{3}$ ). Furthermore, significant differences in spectral properties and concentrations of the silica and silicon-aluminate constituents were observed between the vacuum and argon processed specimens. Because the silica and silicon-aluminates define the chemistry of the fiber matrix interaction, these results clearly demonstrate the ability of NMR to measure interface interactions within composite specimens that result in differences in physical properties (i.e., fracture toughness). Additional work will continue on these specimens in the coming months. 


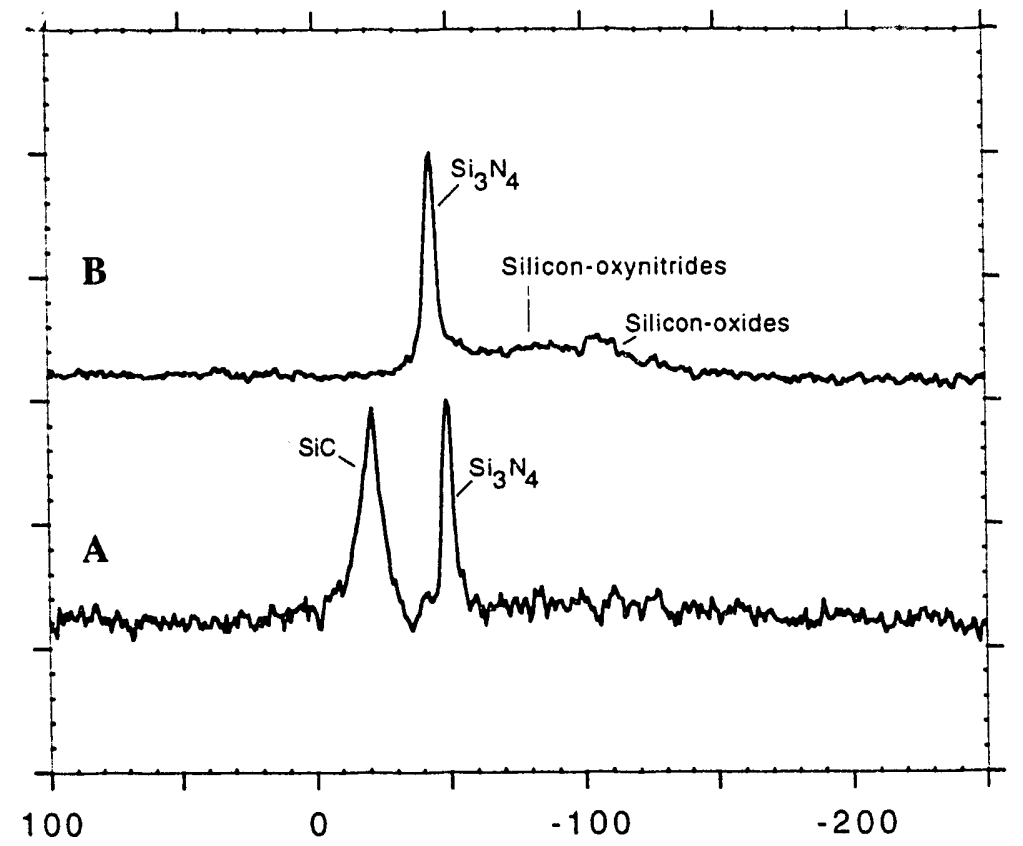

Chemical Shift (PPM)

Fig. 3. ${ }^{29} \mathrm{Si}$ NMR MAS spectrum of a-Si3 $\mathrm{N}_{4}$ powder in (A) as received and (B) after undergoing mild oxidation.

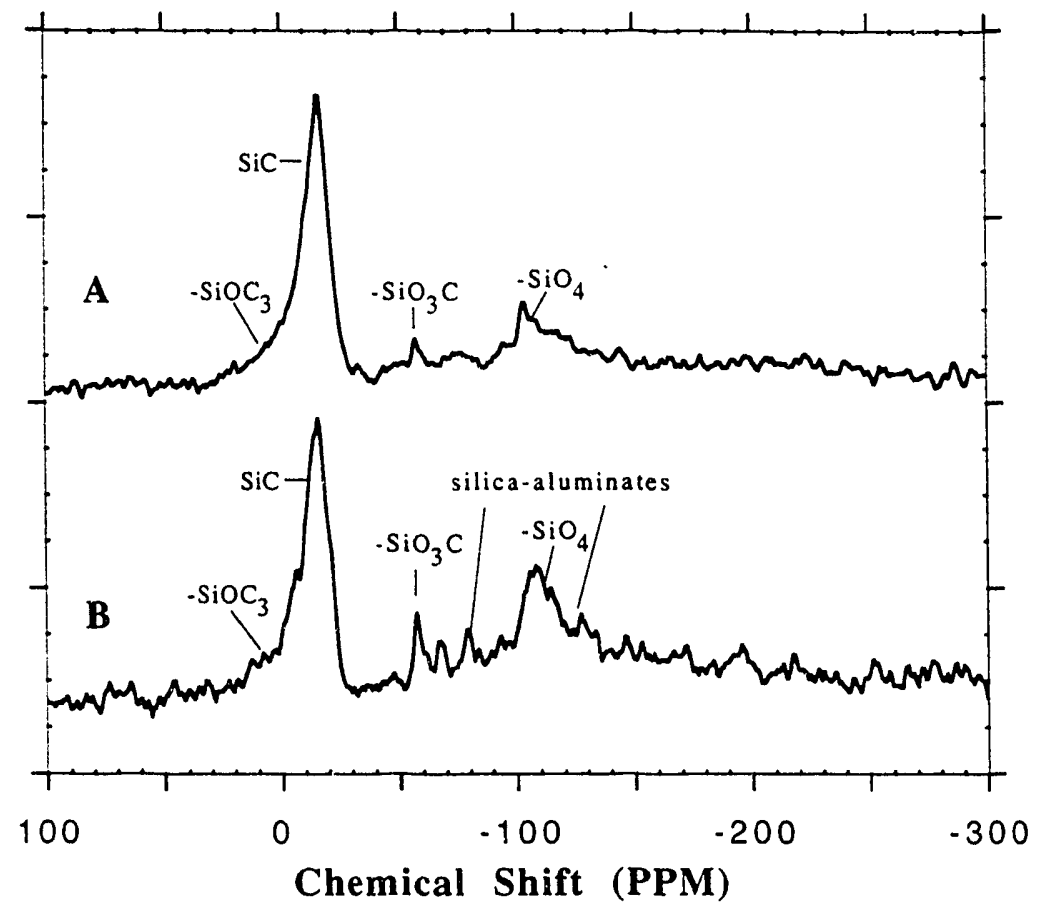

Fig. 4. ${ }^{29} \mathrm{Si}$ NMR MAS spectra of two $\mathrm{HIPed} \mathrm{Al}_{2} \mathrm{O}_{3} / \mathrm{SiC}(85 / 15 \%$ by weight) reinforced ceramic composite specimens. The specimens were composed of (A) high surface $\mathrm{O2}$ (on the $\mathrm{SiC}$ ) processed in vacuum and (B) low surface $\mathrm{O} 2$ (on the $\mathrm{SiC}$ ) and processed in Argon. 
Effects of Flaws on Fracture Behavior

The purpose of this part of Task ANL-1 is to characterize the fracture behavior of structural ceramics and composites and to correlate fracture behavior with critical flaws. The effort during this reporting period has concentrated on continous-SiC-fiber-reinforced $\mathrm{SiC}$ matrix composites. For these composites, the effects of processing on flaw generation are evaluated and correlated with mechanical properties and results of nondestructive evaluation (NDE). To evaluate the effects of processing methods on flaw generation and resulting strength degradation in composites, the strength of fibers was evaluated in as-fabricated composites and in composites after chemical vapor infiltration processing. The two strength distributions were compared to assess any processing-related damage of the fibers.

The fiber bundle test ${ }^{4}$ was employed to determine the distribution of singlefiber strength in as-fabricated Nicalon fibers. Bundle tests were conducted on a universal testing system on fiber tows with gage lengths ranging from 27 to $100 \mathrm{~mm}$, under ambient conditions, and at a loading rate of $0.5 \mathrm{~mm} / \mathrm{min} .5$

Load-versus-strain curves obtained during the bundle test were used to determine Weibull parameters by the approach described by Chi et al. 6 Weibull distribution used to describe fiber fracture strength was as follows: ${ }^{7}$

$$
F(\sigma)=1-\exp \left[-\frac{L}{L_{0}}\left(\frac{\sigma}{\sigma_{0}}\right)^{m}\right]
$$

In this representation, $F(\sigma)$ is the cumulative failure probability at an applied stress $\sigma, L_{0}$ is the fiber gage length at which Weibull paramters are estimated, $L$ is the standard gage length taken to be $10 \mathrm{~mm}, \sigma_{0}$ is the scale parameter signifying a characteristic strength of the distribution, and $m$ is the Weibull modulus that characterizes the flaw distribution in the material. Results based on seven bundle tests gave an average value for Weibull modulus and scale parameter of 7.1 and $3.45 \mathrm{GPa}$, respectively, at a standard gage length of $10 \mathrm{~mm}$. 
The strength distribution parameters of fibers in the composite were evaluated from characteristic features on the fractured fiber surfaces in composites tested in the four-point-bend mode. Strength of fractured fibers was determined from the measured values of fracture mirror radii, as shown in Fig. 5 and an empirical relationship proposed by Kirchner and Gruver. ${ }^{8}$ As reported previously, 5 values of the scale and Weibull parameters were $2.3 \mathrm{GPa}$ and 6.0, respectively. For convenience, earlier it was assumed that the gage length of fractured fibers in composites was equal to the standard gage length of $10 \mathrm{~mm}$. But, gage length of fibers over which uniform stress acts in composites is expectec to be much smaller, on the order of fiber pullout lengths (as shown in Fig. 6). Therefore, for a reliable prediction of strength distribution, an accurate evaluation of gage length, $\mathrm{L}_{0}$, is needed which can be used for better estimation of $\sigma_{0}$.

To this end. scanning electron microscopy (SEM) of fracured composites was used to determine fiber pullout leagth distribution (as shown in Fig. 7), from which the gage iength of fractured fibers was determined. Fiber gige length was taken to be twice the average pullout length and was found to be $340 \mu \mathrm{m}$. Using this value of fiber gage length, the value of $\sigma_{0}$ was estiprated to be $1.31 \mathrm{GPa}$. Currently, these results are being incorporated in Eq. i to determine the strength distributions of the Nicalon fibers in composites. Subsequently, the strength distribution of the fibers in composites will be compared with that in as-received composites to give a more reliable assessments of the effects of processing on fiber degradation.

Fig. 5.

Micrograph of Fractured Nicalon Fibers in SiC Matrix Composite, Showing Characteristic Fracture Features, and Surfac Defects as the Failure Origins.

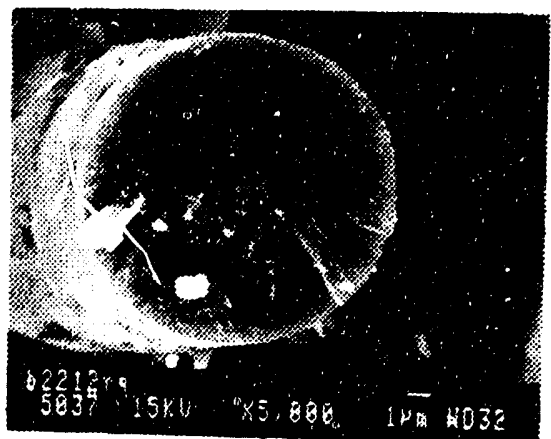




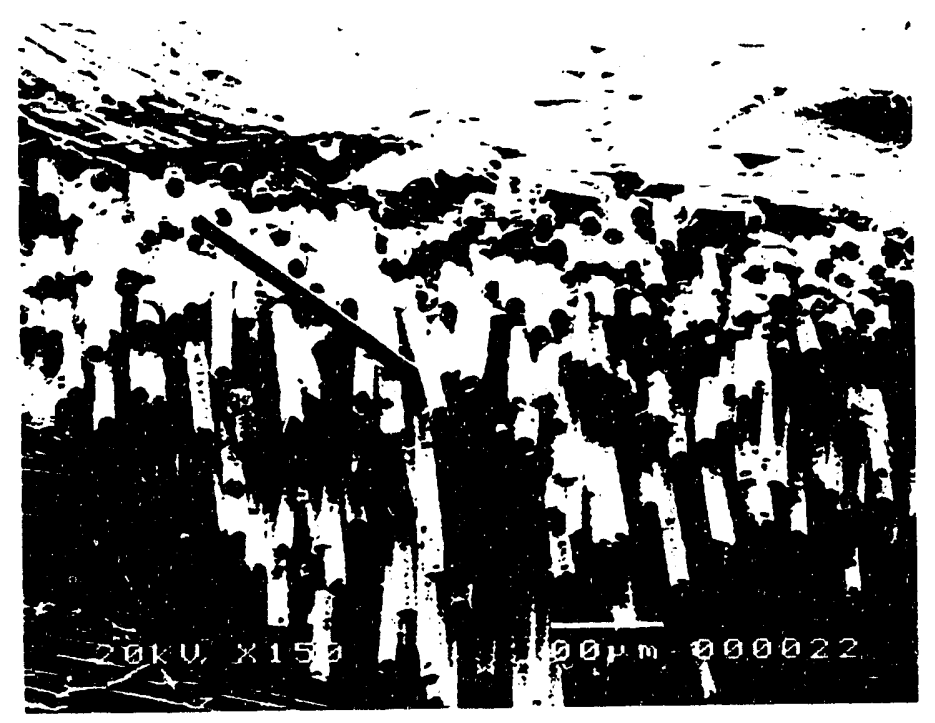

Fig. 6. SEM Micrograph Showing Fiber Pullout on the Fracture Surface of Nicalon Fiber-Reinforced SiC Matrix Composite.

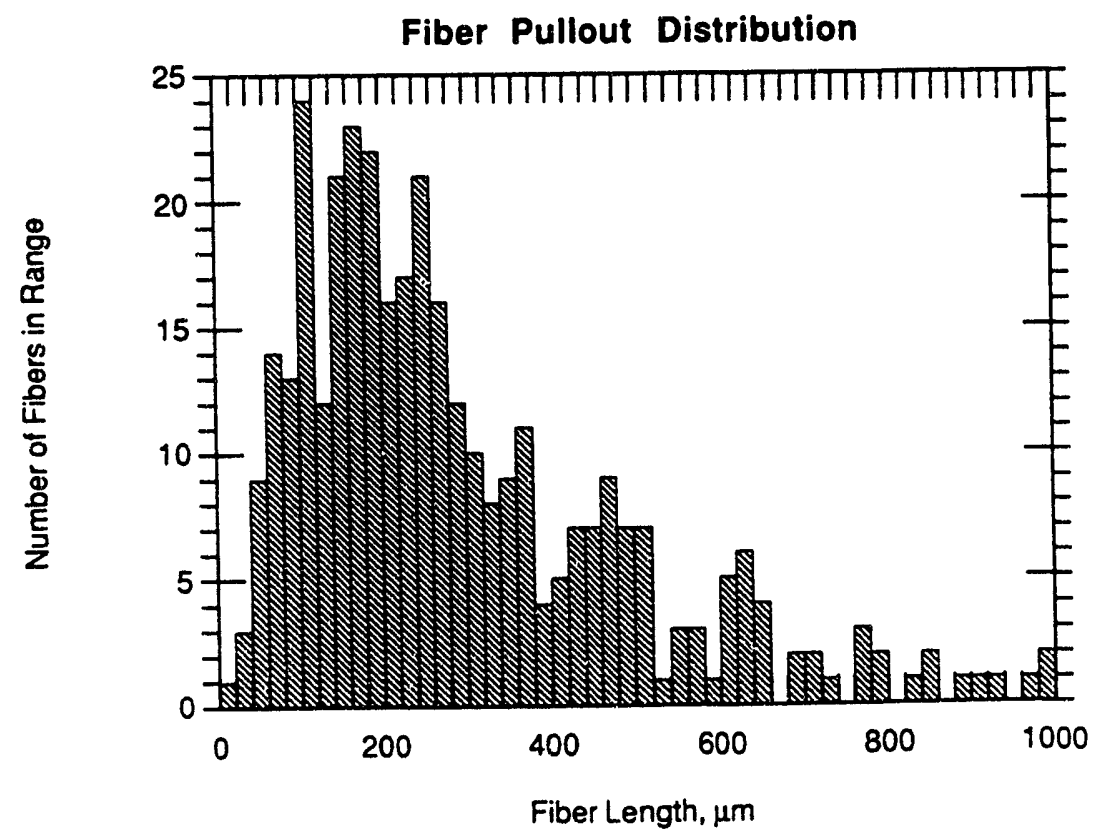

Fig. 7. Fiber Pullout Length Distribution Obtained For Nicalon Fiber-Reinforced SiC Matrix Composites. 


\section{Keferences}

1. Precise Optics, 239 T.S. Sehr Way, Bay Shore, NY.

2. Eastman Kodak, Health Sciences Div., Room 16, Bldg. 81, Rochester, NY.

3. C. Rueno, M. D. Borkor, P. E. Condon, R. A. Betz, "Solid-State C-ray Imaging Methodology," Lockheed WL-TR-92-4003.

4. P. W. Manders and T. W. Chou, "Variability of Carbon and Glass Fibers, and the Strength of Aligned Composites," J. Reinf. Plastic Composites, 2 4359 (1983).

5. D. Singh and J. P. Singh, "Effect of Processing on Strength of Nicalon Fibers in Nicalon Fiber-SiC Matrix Composites," Ceram. Eng. Sci. Proc., 13 (7-8) 257-266 (1992).

6. Z. Chi, T-Wei Chou, and G. Shen, "Determination of Single Fiber Strength Distribution From Fiber Bundle Testings," J. Mat. Sci., 19 (10) 3319-3324 (1984).

7. $\mathrm{K}$ Goda and H. Fukunaga, "The Evaluation of the Strength Distribution of Silicon Carbide and Alumina Fibers by a Multi-Mmodal Weibull Distribution," J. Mat. Sci., 21 (12) 4475-4480 (1986).

8. H. P. Kirchner and R. M. Gruver, "Fractiure Mirror in Alumina Ceramics," Phil. Mag. 27 1433-46 (1973). 
GT-1A-MODELING OF FIBROUS PREFORMS FOR CVD INFILTRATION

\author{
T. I. Starr and A. W. Smith \\ Materials Science and Technology Laboratory \\ Georgia Tech Research Institute \\ Atlanta, Georgia 30332
}

INTRODUCTION

\begin{abstract}
Chemical vapor infiltration (CVI) has demonstrated considerable promise as a technique for fabrication of fiber reinforced ceramic composites. An analytical model provides insight into the CVI process, helps identify key processing parameters and guides experimental process optimization efforts. A three-dimensional model, GTCVI, has been developed to simulate the densification process with a cloth lay-up preform. This model can be used to support scale-up of the cVI process for larger, more complex structural components.
\end{abstract}

\title{
DISCUSSION OF CURRENT ACTIVITIES
}

Efforts this period have focused on application of the model to CVI densification of tube shapes.

Model for ORNL Tube Infiltration system

The model will be used to assist process optimization for CVI densification of filament-wound tubes at Oak Ridge National Laboratory ${ }^{1}$. A schematic of this reactor is shown in Figure 1 . A preform is formed onto a hollow, porous mandrel and placed inside a furnace. Gas flows through a water-cooled tube to the center of the preform where it is directed radially toward the preform. The mandrel includes channels to allow the gas to flow axially inside the preform. After passing through the preform the gas exits the reactor. 


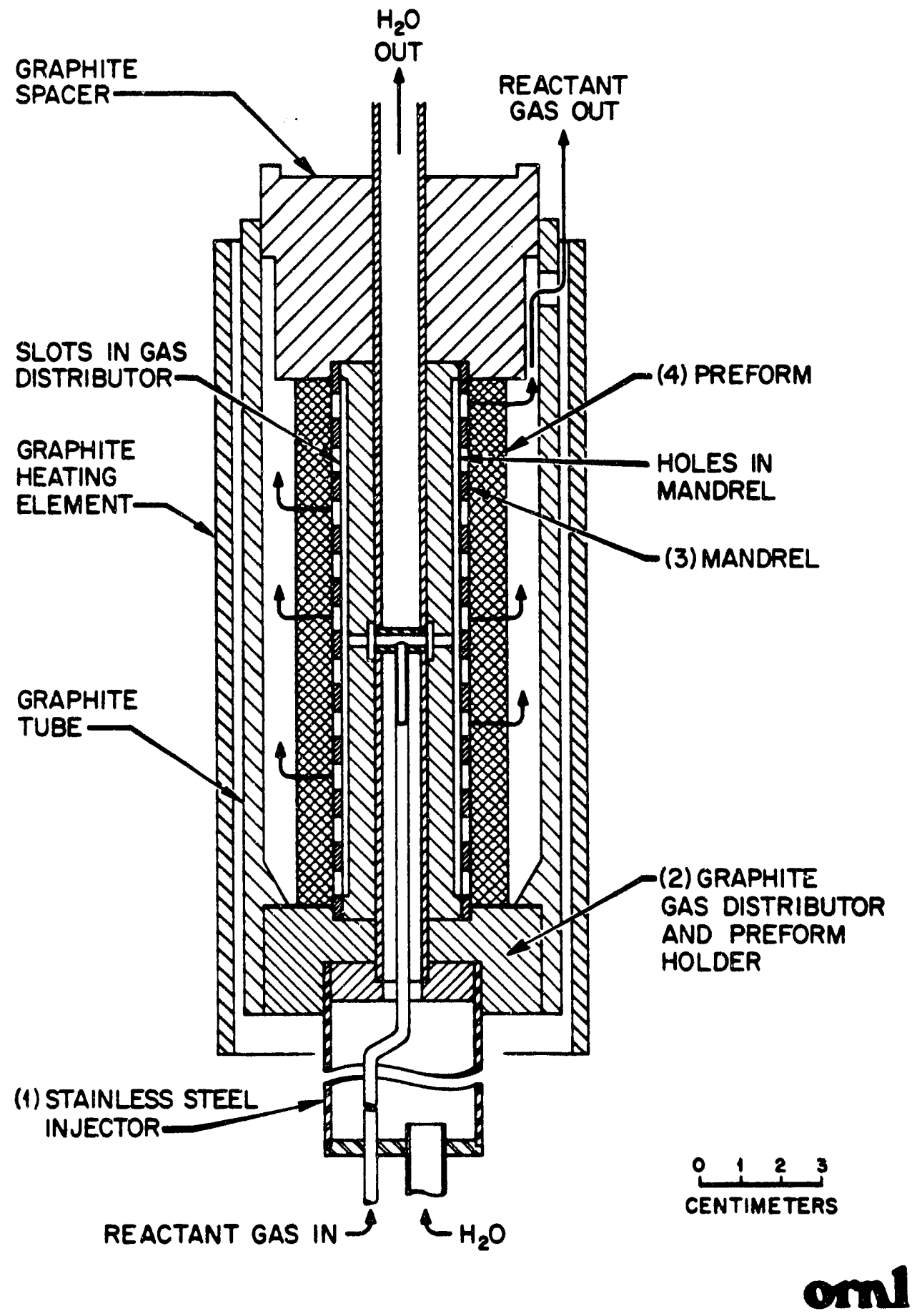

Figure 1. Schematic of infiltration system for tube-shaped preforms. 
This CVI system represents a significant departure from previous experience with disk-shaped components. Major differences include the heat transfer mode within the CVI furnace and the filament wound preform architecture.

With the disk CVI system the graphite lid forms a well defined boundary for the model. Experimentally this surface is maintained at constant temperature by the furnace control system. Heat from this boundary flows to the cool gas injector by conduction through the lid, the preform and other parts of the graphite holder. Model calculation of the temperature profile, which includes conduction and convection, matches experimental measurements and produces good agreement with actual densification behavior.

With the tube CVI system heat flow from the hot, constant temperature boundary (the outside of the reactor tube) includes radiative transfer from the inside of the tube wall to the preform. This mode of heat transfer is not included in the current version of GTCVI. Although we are working to add this capability for the future, at present we can approximate this radiative transfer by artificially increasing the thermal conductivity of the gas.

Figure 2 shows the calculated temperature profile in the radial direction for the tube CVI system, using a simple 1-D model. The temperature at the outer edge of the preform varies from 400 to $1000^{\circ} \mathrm{C}$ for gas conductivity values from 0.01 to $0.20 \mathrm{w} / \mathrm{cm} / \mathrm{K}$. Experimental measurements of the temperature between the preform and the mandre ${ }^{2}$ are closest to the model profile resulting from the $0.05 \mathrm{w} / \mathrm{cm} / \mathrm{K}$ value. We use this value for more detailed modeling using GTCVI.

Figure 3 shows a $20 \times 20$ numerical grid used to model the infiltration process. Of the 400 volume elements only 105 represent the preform itself. The remaining elements represent parts of the furnace and fixtures. Figure 4 shows the density as a function of process time for run conditions of $50^{\circ} \mathrm{C}$ water temperature, $1200^{\circ} \mathrm{C}$ furnace temperature, 750 sccm of a $9: 1 \mathrm{H}_{2}:$ MTS gas mixture. The extremely long processing time is in good agreement with experimental results and is due to the relatively 


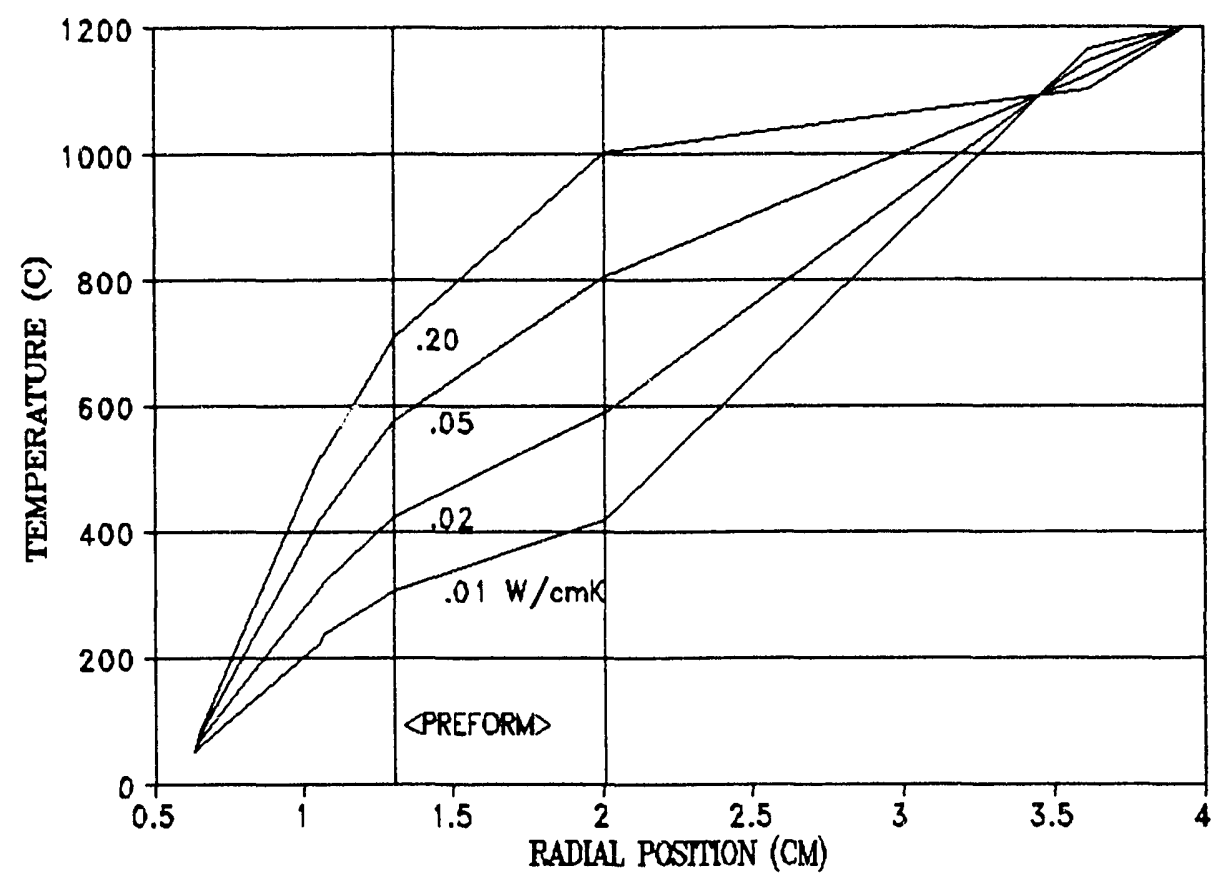

Figure 2. Temperature profile in the tube CVI reactor is shown for four values of gas thermal conductivity. Values shown are in $\mathrm{w} / \mathrm{cm} / \mathrm{K}$. 


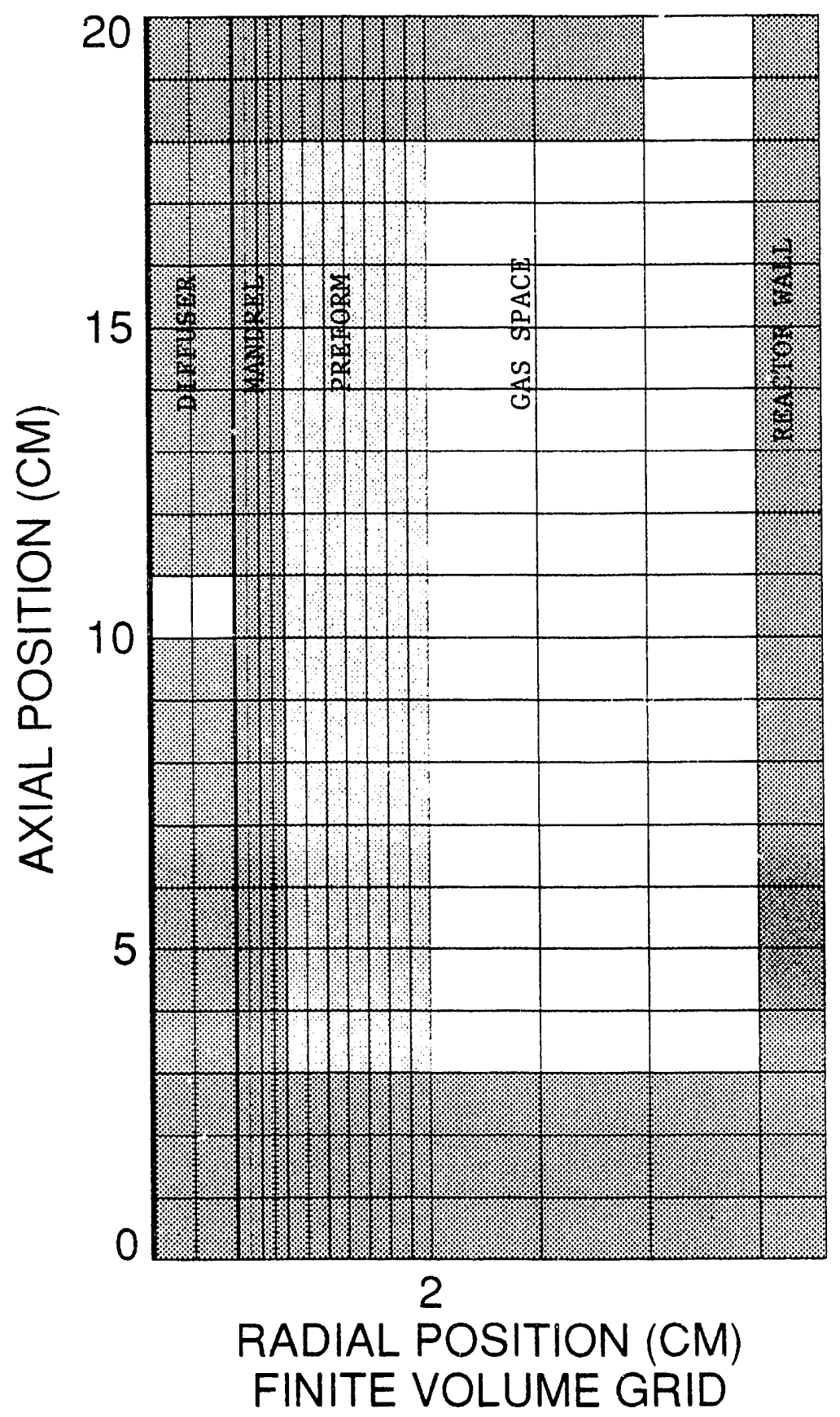

Figure 3. Schematic and finite element grid of the ORNL tube infiltration system. 


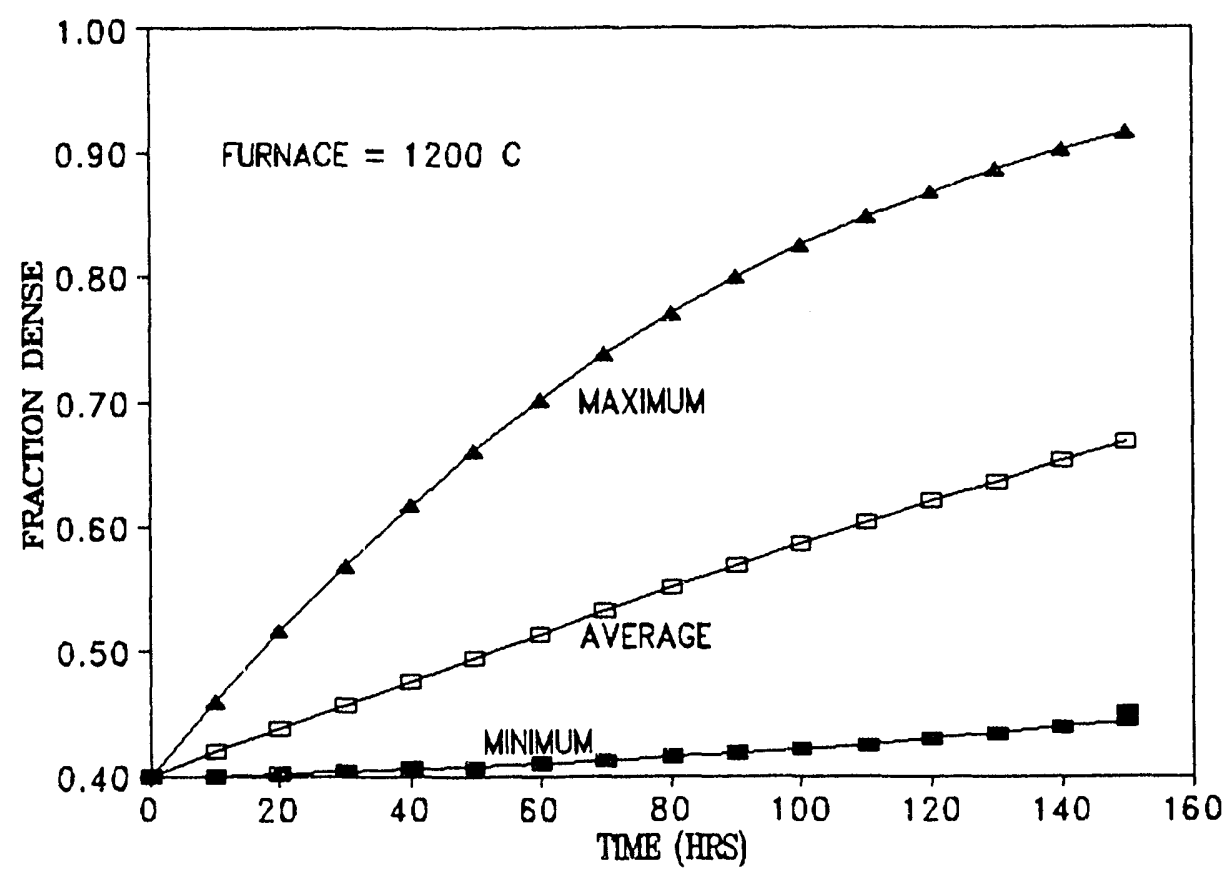

Figure 4. Densification is slow at $1200^{\circ} \mathrm{C}$ furnace temperature with a large density gradient through the preform. 
low temperature in the preform (Figure 5). The preform density profile after 150 hours of infiltration (Figure 6) shows progressive densification from the outside of the tube with a region of lowest density along the inner diameter of the tube at the end of the run.

Increasing the temperature at the reactor wall to $1400^{\circ} \mathrm{C}$ produces higher temperatures in the preform (Figure 7) and more rapid densification (Figure 8). Even at this high reactor wall temperature, though, the temperature in the preform is less than $900^{\circ} \mathrm{C}$. Clearly better heat transfer from the furnace to the preform is critical for gaining improved densification results.

Process Monitoring

A method for real-time monitoring of the densification process is important for CVI process control. Previously, modeling of the disk infiltration system related the temperature at the cool face of the preform to the degree of densification. Subsequent experiments confirmed this relationship and temperature measurement within the preform holder is now routine for monitoring the process and for adjusting process parameters when using different reinforcement fibers or preform architectures.

similarly, for the tube infiltration system, the temperature at the cool side of the preform, next to the mandrel, will rise with densification and thermocouple measurements can be used for real-time monitoring. However, with the tube system, another temperature measurement may offer an easier monitoring method. The temperature rise in the cooling water as it passes through the CVI furnace depends on the thermal conductivity of the preform and, thus, may be a measure of the degree of densification.

We can test this hypothesis by making some estimates of heat flows. Measurements at ORNL indicate that water temperature rises approximately $25^{\circ} \mathrm{C}$ as it passes through the furnace. At a flow rate of $2.3 \mathrm{gal} / \mathrm{min}$ this corresponds to a heat flow of $15 \mathrm{~kW}$. Model calculations with the $1200^{\circ} \mathrm{C}$ 


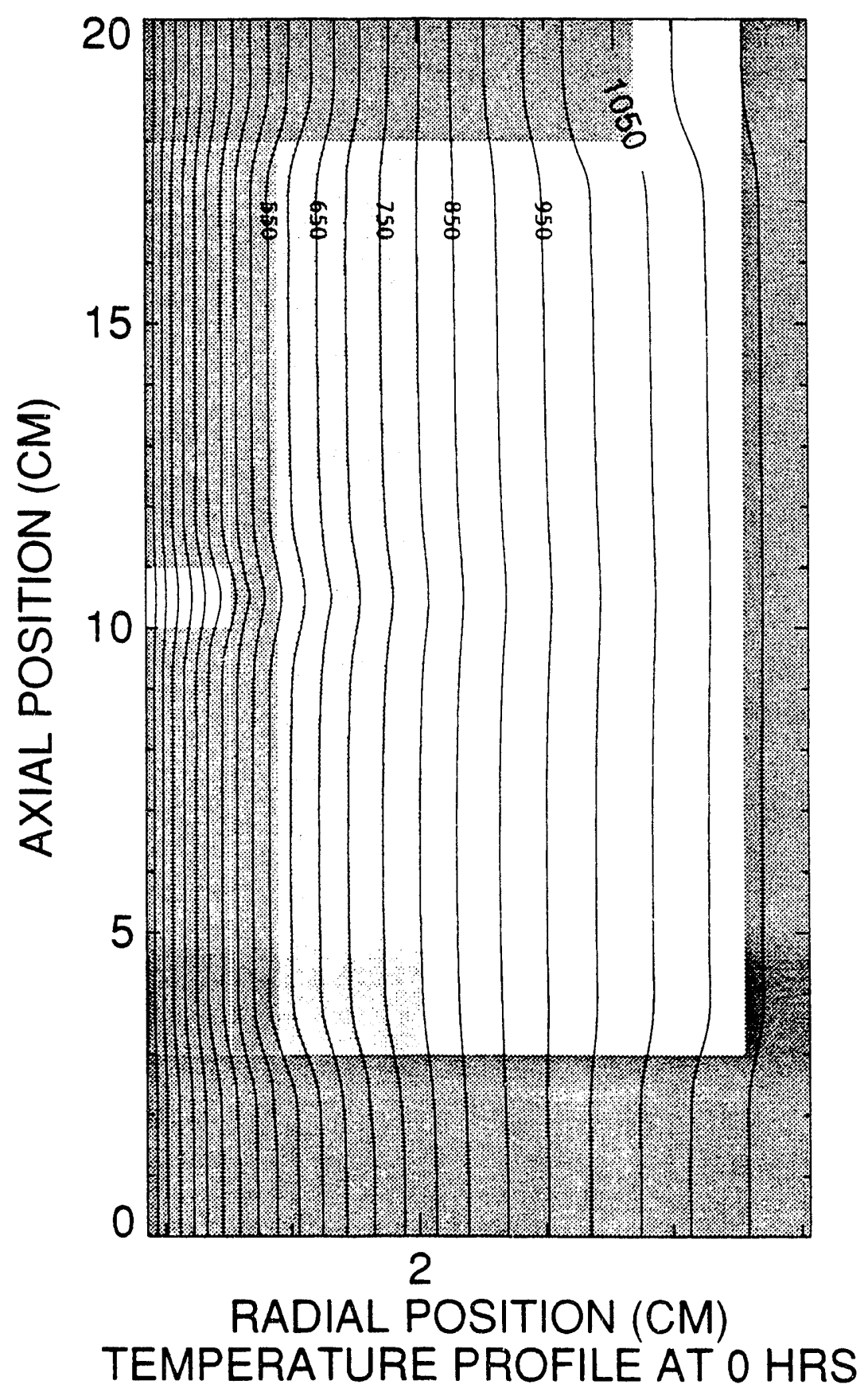

Figure 5. With furnace temperature of $1200^{\circ} \mathrm{C}$ temperature profile at beginning of infiltration shows temperatures between 550 and $800^{\circ} \mathrm{C}$ in preform. 


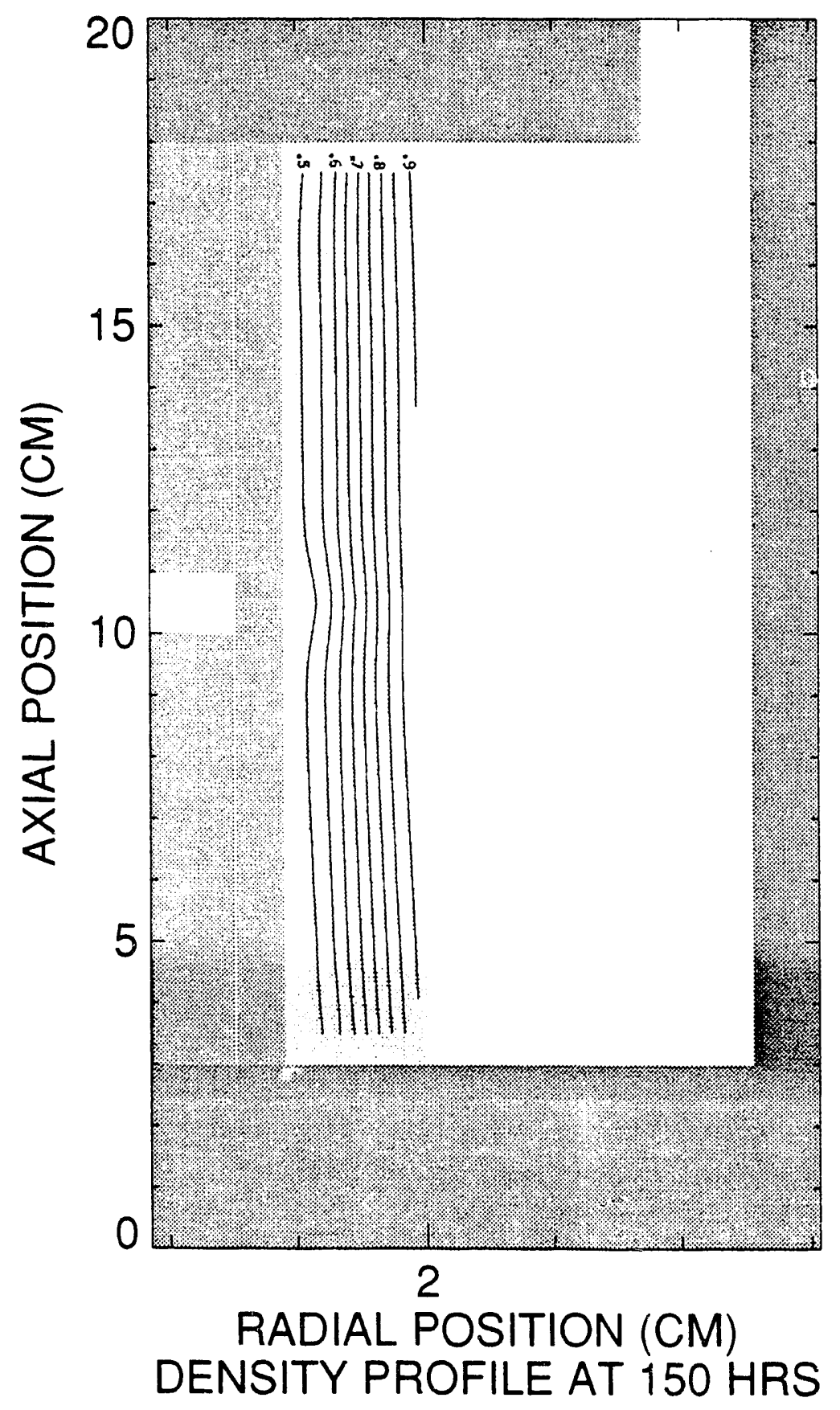

Figure 6. Density profile after 150 hours of infiltration shows progressive densification from the outside of the tube. 


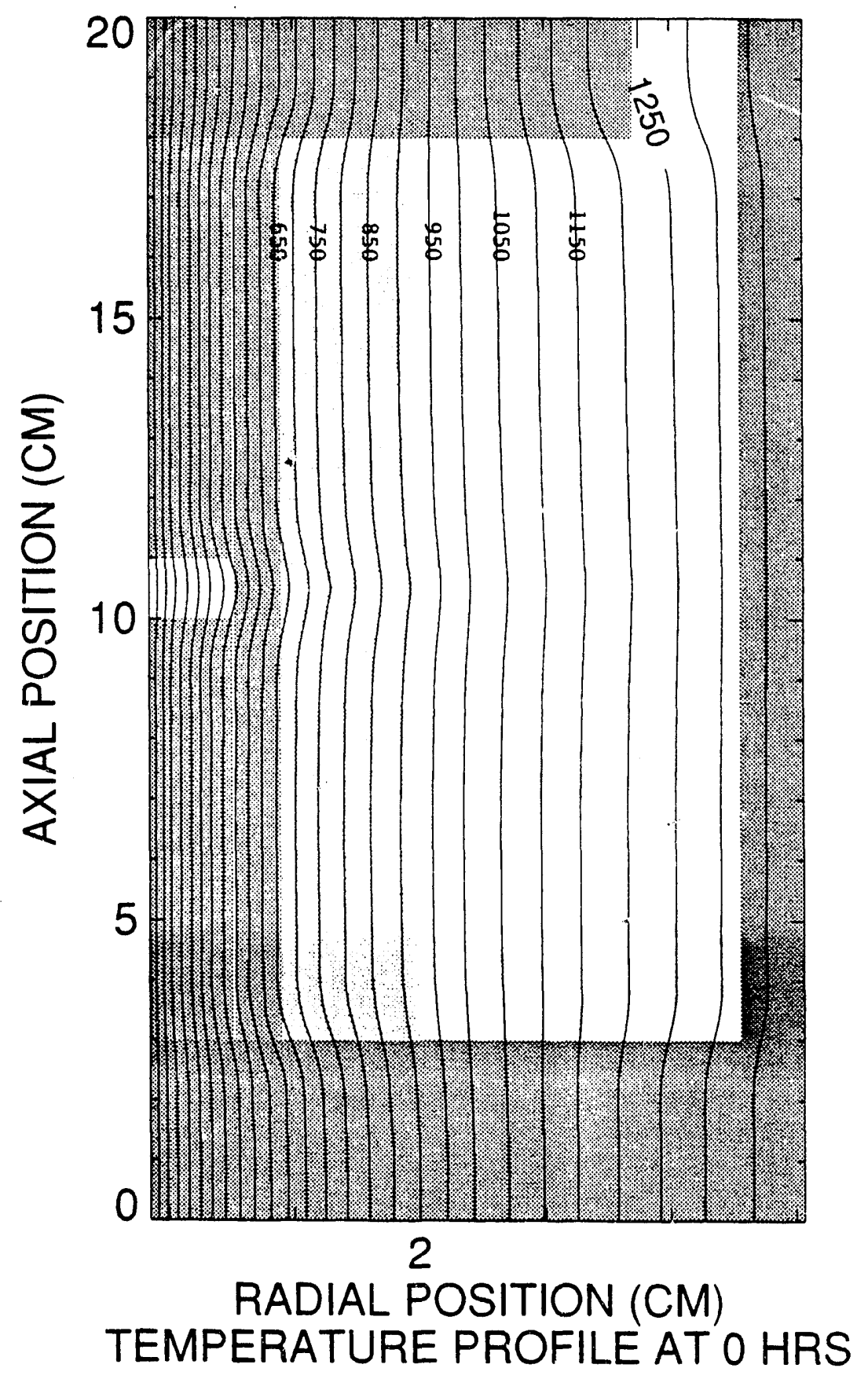

Figure 7. With furnace temperature of $1400^{\circ} \mathrm{C}$ temperature profile at beginning of infiltration shows temperatures between 650 and $900^{\circ} \mathrm{C}$ in preform. 


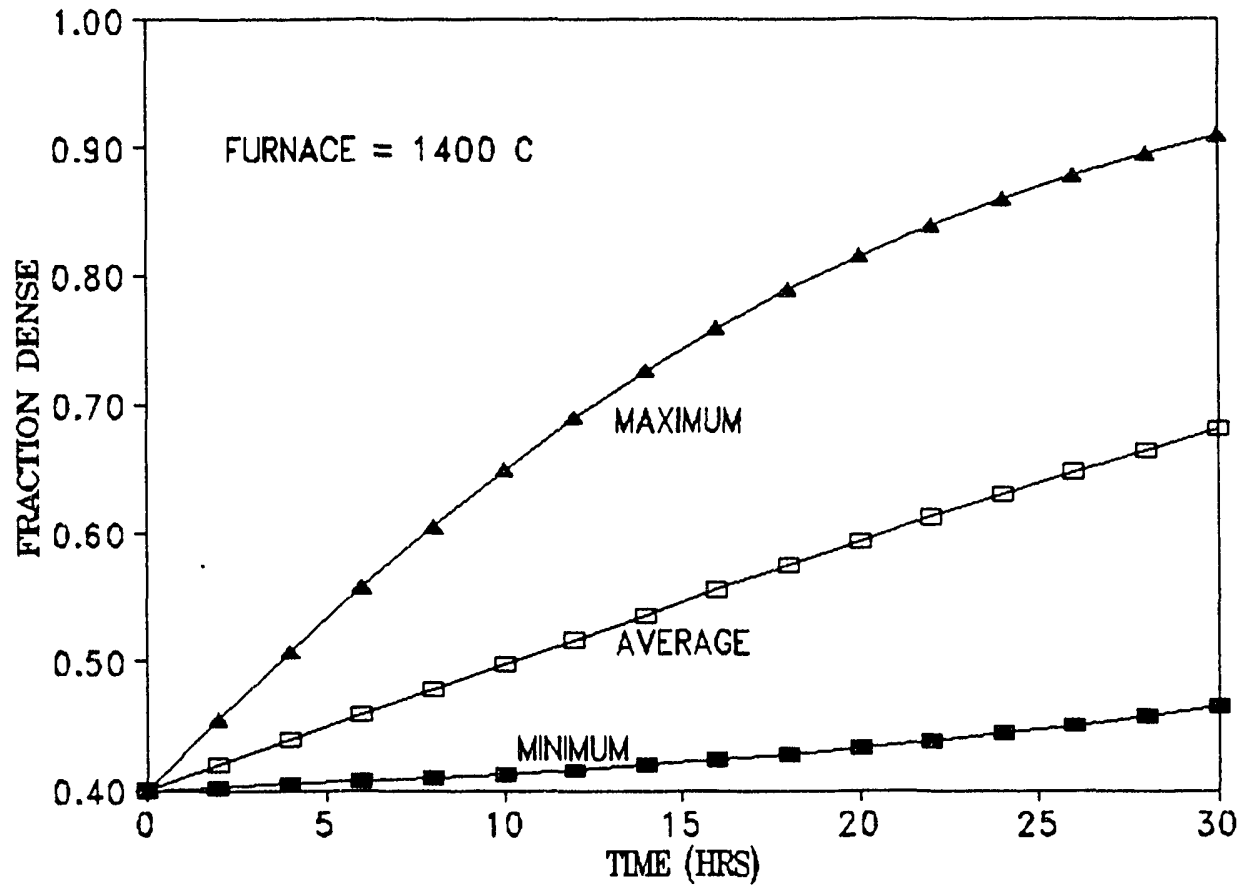

Figure 8. Increasing the furnace temperature to $1400^{\circ}$ results in more rapid densification. 
furnace temperature indicate a heat flow into the cooling water of $3.4 \mathrm{~kW}$ at the start of infiltration (fraction dense $=0.400$ ) and $3.7 \mathrm{~kW}$ after 150 hours (fraction dense $=0.668$ ). These estimates suggest that heat flow through the preform is roughly 258 of the heat flow into the cooling water (the remainder of the heat flow is due to conduction through other parts of the furnace hardware) and that densification of the preform may produce a temperature rise on the order of $1-3^{\circ} \mathrm{C}$. Further refinement our model may significantly alter these estimates but experimental testing of this process monitoring method is suggested.

\section{SUMMARY}

The modeling described above utilized preform transport properties derived for a Nicalon cloth lay-up preform. Adjustment of these properties to those of the filament-wound preform and proper incorporation radiative heat transfer will be needed to produce guantitative simulation of experimental densification vehavior. However, initial model results are consistent with experiment showing extremely long processing times for the standard $1200^{\circ} \mathrm{C}$ furnace temperature. The model suggests that increasing the furnace temperature should significantly increase the densification rate. Further, mudeling suggests that measurement of the cooling water temperature rise may provide a real-time monitor of the infiltration process.

\section{REFERENCES}

1. D.P. Stinton, R.A. Lowulen and T.M. Besmann, "Fiber-Reinforced Tubular Composites by Chemical vapor Infiltration, " Proceedings of the Sixth Annual Conference on Fossil Energy Materials, ORNL Report FMP-92/1 (July 19S2).

2. Personal communication from D.P. Stinton, Oak Ridge National Lakoratc=y, August 1992. 


\title{
GT-1-DEVELOPMENT OF ADVANCED EIBER REINFORCED CERAMICS
}

T. I. Starr and D. L. Mohr

\author{
Materials Science and Technology Laboratory \\ Georgia Tech Research Institute \\ Atlanta, Georgia 30332
}

\section{INTRODUCTION}

Ceramic composites continue to offer great promise for increasing the efficiency of fossil fuel utilization. Fabricability is an important factor in such applications, particularly for the relatively large and complex shapes used for fossil energy conversion systems. The objective of this program is to develop a near-net-shape fabrication method for silicon nitride ceramic composites using lay-up techniques and reaction sintering. Two factors limit the mechanical performance of such composites, t:he density and distribution of matrix material, and the bonding between fiber and matrix. Fabrication techniques are needed that will produce a uniform matrix microstructure and provide better distribution of load to the reinforcing fibers. In addition, a fiber coating is needed that is stable in the reaction sintering environment and provides good debonding between the fiber and matrix during crack propagation.

\section{DISCUSSION OF CURRENT ACTIVITIES}

Our work over this period has focused on fabrication and characterization of composite tube shapes. Continuous fiber reinforced silicon nitride matrix composites have been fabricated by filament winding ceramic fiber tow impregnated with silicon powder. The silicon is converted to silicon nitride by heating in a nitrogen atmosphere. 
Impregnation of Fibrous structures

The first step in this process involves achieving effective impregnation of the fiber bundle (or tow) with silicon powder. Uniform impregnation of the tow is very important in achieving maximum composite density and properties.

There are several important considerations in achieving good powder impregnation. The powder should be of an appropriate size to fill voids in a well packed fiber assembly. Additionally, the powder particles should be well dispersed, as agglomerated particles are effectively the same as larger particles. Wetting of the powder and the fibers by the carrier liquid is important. In addition, the process should be designed to encourage impregnation via agitation of the slurry bath, spreading of the fiber tow, and other factors.

The attritor milling process reduced the silicon particle size distribution so that nitriding could be performed using moderate processing conditions, reducing fiber degradation. The size distributions of particles produced using various milling conditions were characterized via TEM, sedimentation experiments, and other methods. The number average diameter of these particles ranged from 0.2 to 0.5 micrometers, which allowed the particles to fill the regions between the Nicalon (Nippon carbon Company) fibers (diameter approximately 15 micrometers). There was some apparent agglomeration of particles based upon the relatively short time which was required for particles to settle out of a dilute dispersion and the final settled volume which resulted for all of the mill runs (which was less than $32 \%$ dense).

A series of dispersants with different chemical compositions were examined in the attritor milled silicon/ethanol system. Sedimentation experiments showed a wide variation in the settling velocity and settled volume for the various dispersants. The best dispersant of those examined for this system was a sodium salt of a carboxy functional polymer (Tamol 731, manufactured by Rohm and Haas Company, Philadelphia, PA), which 
decreased agglomeration as indicated by both decreased settling velocity and settled density (which increased to 528 solids).

The attritor milled silicon powder contained a very small number of larger particles (one to four micrometer diameter). Removing these particles may improve nitriding performance and infiltration of powder into a fiber preform. Sedimentation techniques were utilized to remove these large particles, then the particle size distribution was characterized. These modified dispersions will be evaluated in composite structures to examine impregnation performance.

Filament winding of Impregnated Fiber Tow

Tubular composites were fabricated using the filament winding technique. Ceramic grade Nicalon fiber tows were passed through a slurry containing attritor milled silicon powder and a fugitive binder in ethanol (Figure 1). This impregnation process produced composite tows which exhibited good distribution of powder in the fiber bundle. A range of slurry impregnation conditions were evaluated, including variation of the speed of the fiber through the slurry bath, volume fraction of silicon powder in the slurry, and agitation in the bath.

The optimal distribution of powder in the composite would be such that the fibers are packed as closely as possible, with the sub-micron silicon powder completely filling the voids between fibers. Winding the impregnated fiber tows on a porous mandrel allows the partial removal of the ethanol from the silicon slurry through a casting mechanism. As the ethanol passes through the fiber compact into the porous mandrel, the silicon powder packs to a greater density in the compact.

Cylindrical porous slip cast fused silica mandrels were fabricated and multiple layer composites were laid-up on the mandrels via filament winding. Typical conditions indicated a tow speed of $1 \mathrm{~cm} / \mathrm{s}$ and a spacing of $0.5 \mathrm{~mm}$ between fiber tows. Winding six to eight layers resulted in a composite with wall thickness of 3 to $4 \mathrm{~mm}$. Typical tubular composites are shown in Figure 2 . 


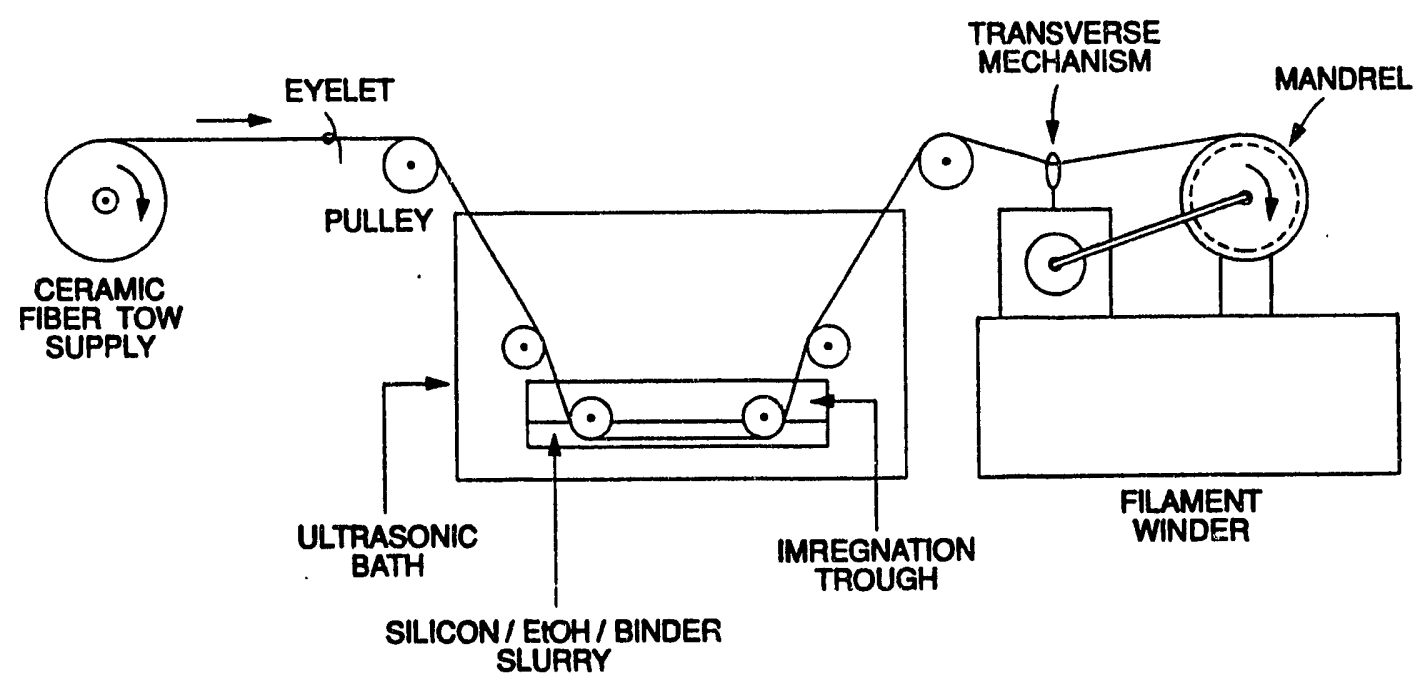

Figure 1. Apparatus for impregnating and winding silicon nitride matrix composite tubes.

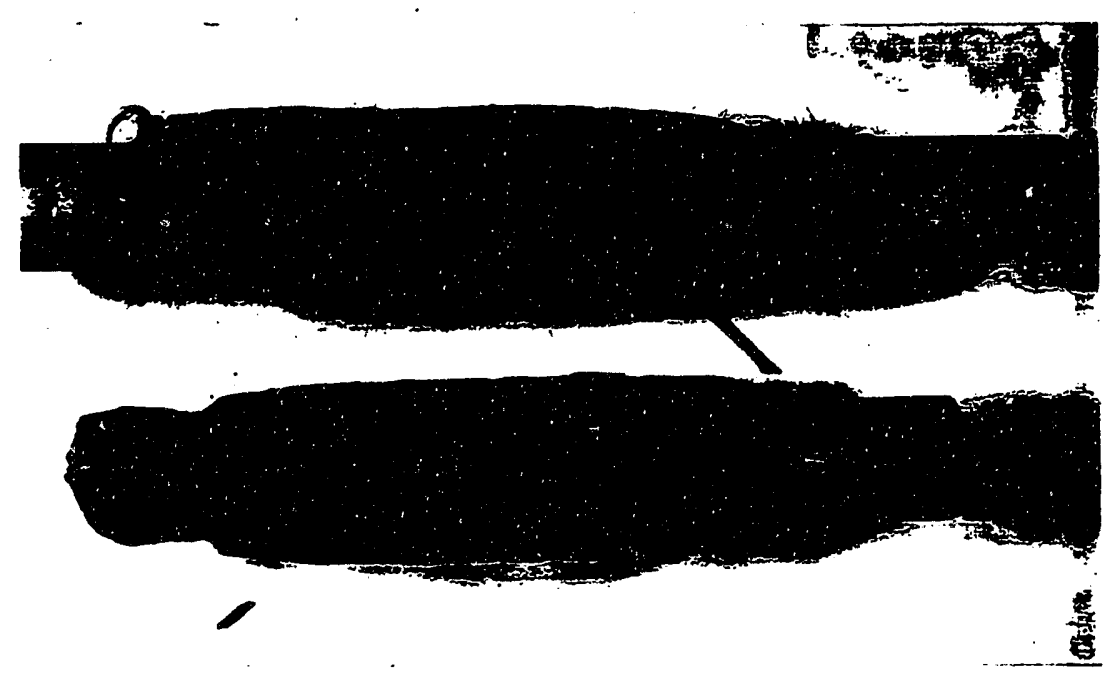

Figure 2. Filament wound composite tube (on mandrel) prior to nitriding (top) and after nitriding (bottom). 
Nitriding of Tubular Composites

Traditional reaction sintering processes typically involve heating silicon metal to temperatures approaching $1400 \mathrm{C}$ over a long time period. Attritor milling reduces the silicon powder to sub-micron size, thus enabling the nitriding process to be performed at lower temperatures and shorter times, which reduces the degradation of the ceramic fiber properties during processing.

The composites fabricated via filament winding were nitriding using a computer controlled nitriding system developed earlier ${ }^{1}$. The green composite samples were heated under vacuum to $900 \mathrm{C}$, after which the furnace was filled with a nitrogen/58 hydrogen gas mixture. The furnace was then quickly heated to $1100 \mathrm{c}$, followed by the nitriding process in which the temperature was ramped to $1200 \mathrm{C}$ at $1 / 2$ degree/minute, while the nitrogen utilized by the nitriding reaction was replenished. After a hold at maximum temperature for up to three hours, samples were cooled and removed from the furnace. After nitriding the composite sample, the ceramic mandrel was removed.

\section{Composite Tube Characterization}

Bulk density of ceramic samples was evaluated via a water displacement method. Density increased in subsequent samples as the large defects were eliminated during processing, ranging from $1.5 \mathrm{~g} / \mathrm{cc}$ to 1.9 g/cc.

Morphology of the fiber and composite samples was examined using optical and electron microscopy. SEM showed that the matrix was better distributed in these samples than the fabric reinforced composites fabricated earlier ${ }^{2}$. Fiber tows appeared to be well impregnated with matrix material, but some large pores remained. Optical microscopy coupled with image analysis techniques are being employed to determine the size distribution and location of porosity in the composite. This 
information will be used to indicate direction for further process development.

Strength of cylindrical samples was determined using the c-ring technique. Cylindrical ring samples nominally $4 \mathrm{~mm}$ in width were cut from the cylindrical filament wound composite, which had an i.d of approximately $18.5 \mathrm{~mm}$. A notch was cut out of each ring to form the cring. The c-ring samples were then tested by compressing the ring with the notch at 90 deg to the direction of the compressive deflection, creating a bending moment in the opposite section of the c-ring. The average strength of c-ring specimens produced from a typical tube sample (density $1.8 \mathrm{~g} / \mathrm{cm}^{3}$ ) was $126 \mathrm{MPa}$, with individual specimens exhibiting strength as high as $192 \mathrm{MPa}$. C-ring specimens exhibited significant loadbearing capabilities after maximum load was attained (Figure 3). Fracture initiated on the tensile surface of the c-ring specimens, after which the crack propagated gracefully, exhibiting crack deflection and partial delamination (Figure 4). These data will be complemented by investigation of other mechanical test methods for ring-shaped samples, such as "split ring" tests (which approximate tensile failure in the samples) and hydrostatic testing. Also, high temperature mechanical properties will be measured during the upcoming period.

Discussion

The combination of the filament winding fabrication technique with the reaction sintering method for matrix densification of fiber reinforced ceramic composite structures offers a viable alternative for low cost composite fabrication. Filament winding takes advantage of existent technology commonly used to fabricate large resin matrix composites. In addition, filament winding is particularly suited to automation in the fabrication process. Reaction sintering silicon powder is relatively simple and inexpensive and is a near-net shape process. Scaling up the size of parts fabricated via slurry impregnation of a ceramic fiber tow followed by filament winding and reaction sintering to make large shaped 


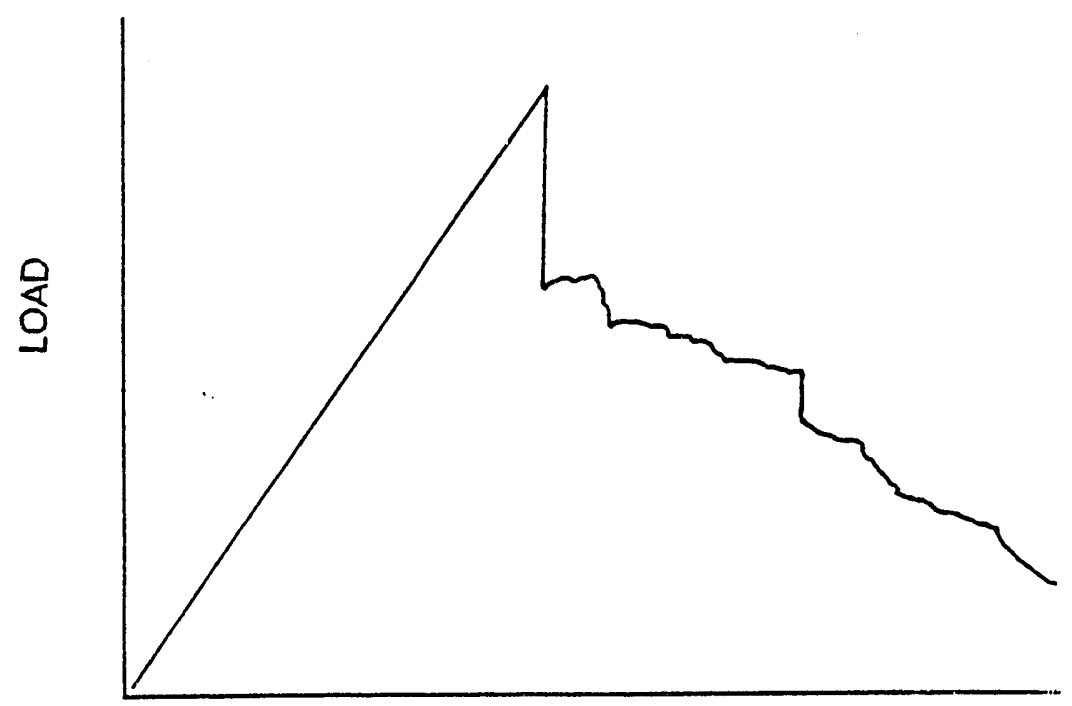

\section{DISPLACEMENT}

Figure 3. Load-deflection curve for C-ring test shows extended load carrying capacity after reaching the maximum load.

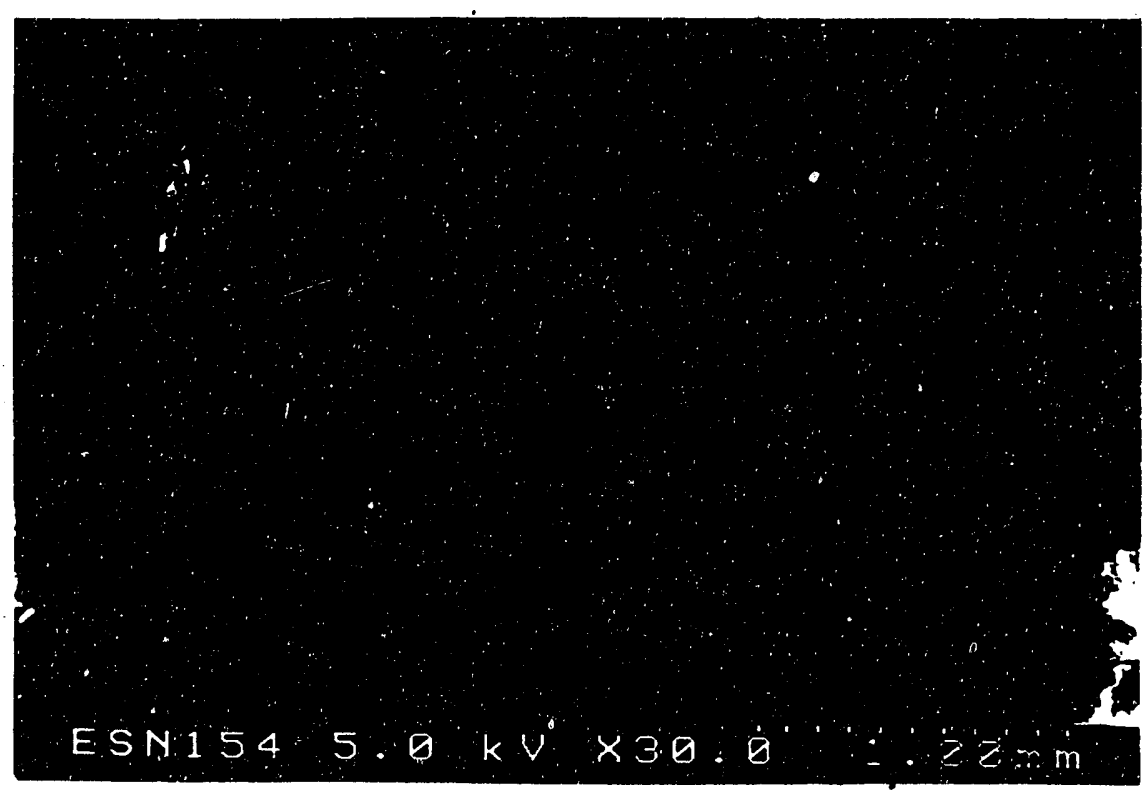

Figure 4. Fracture surface of c-ring specimen shows tortuous crack path and evidence of fiber bridging. 
parts should impose few additional technical complications. Thus, coupling finent winting with reaction sintering may provide economic and practical advantages for the formation of ceramic composite structures.

Summary

Tubular fiber reinforced samples have been fabricated via filament winding using a reaction sintered silicon nitride matrix. The use of the c-ring technique allowed evaluation the strength of these samples. These samples exhibited good strength and graceful failure characteristics, with significant strength retention after maximum load had been attained.

\section{REFERENCES}

1. T. L. Starr, J. N. Harris, G. B. Freeman and D. I. Mohr, "Low Temperature Processing of Reaction Sintered Silicon Nitride", Oak Ridge National Laboratory report ORNL/Sub/87-00184/01 (July 1989).

2. T. L. Starr, J. N. Harris, G. B. Freeman and D. L. Mohr, "Reaction Bonded Silicon Nitride Composites with Continuous Fiber Reinforcement", Proc. Fifth Annual Conf. on Fossil Energy Materials, pp. 47-54 (Oak Ridge National Laboratory report ORNL/FMP-91/1, September 1991). 


\title{
INEL-1(B) - JOINING OF SILICON CARBIDE CERAMICS AND COMPOSITES
}

\author{
B. H. Rabin and G. A. Moore \\ Idaho National Engineering Laboratory \\ P.O. Box 1625 \\ Idaho Falls, ID 83415-2218
}

\section{INTRODUCTION}

Silicon carbide $(\mathrm{SiC})$ matrix composites produced by chemical vapor infiltration (CVI) are under development for use in applications at temperatures exceeding $1000^{\circ} \mathrm{C}^{1-3}$. These composites typically contain $\sim 40$ vol.\% of fiber reinforcement, and are infiltrated to $\sim 85 \%$ of theoretical density with silicon carbide. Practical and reliable ceramic-ceramic and ceramic-metal joining methods are needed to allow the fabrication of large or complex shaped parts, and the integration of structural components into existing systems.

Joining of silicon carbide fiber-reinforced silicon carbide matrix composites ( $\mathrm{SiC} / \mathrm{SiC}$ ) is comparable to joining of dense $\mathrm{SiC}$; however, the presence of the fiber reinforcement introduces additional concerns. The type of fiber and the presence of fiber/matrix interfacial coatings must be considered when developing a joining process. For example, in the case of $\mathrm{SiC} / \mathrm{SiC}$ composites containing Nicalon fibers, strength losses result from prolonged exposure to processing or service temperatures above $\sim 1200^{\circ} \mathrm{C}$ due to fiber degradation ${ }^{4-6}$. Exposure to oxidizing atmospheres at these temperatures can also result in a decrease in fracture toughness due to oxidation of the carbon-rich fiber/matrix interfacial coating. Property reductions can be minimized by coating the components with an external protective layer of $\mathrm{SiC}$, and by using fibers more resistant to thermal degradation ${ }^{4,7}$. It is expected that future developments will lead to composites capable of use at temperatures exceeding $1200^{\circ} \mathrm{C}$. Ceramic-ceramic joints must therefore also be useful at these temperatures, and appropriate joining methods must avoid property degradation of the composite during the joining process.

Prior work on this project identified reaction bonding as a suitable method for meeting the above joining requirements ${ }^{8}$. Bulk reaction bonded ceramic silicon carbide (RBSC) is produced by capillary infiltration of molten silicon into compacts containing SiC and $\mathrm{C}$, and consists of $\mathrm{SiC}$ grains "bonded" with 5-15\% of free Si. The processing, microstructures, and properties of these ceramics have been studied extensively9-16. 
Alternatively, infiltration of $\mathrm{SiC}+\mathrm{C}$ precursor materials placed between two $\mathrm{SiC}$ ceramic parts results in simultaneous reaction bonding and joint formation.

Joining by reaction bonding is attractive, particularly for $\mathrm{SiC} / \mathrm{SiC}$ composites, since infiltration can be carried out at temperatures as low as $1460^{\circ} \mathrm{C}$, and joints with excellent elevated temperature mechanical properties can be produced. Similar to brazing, external pressure is not required for infiltration, thus the process is extremely practical compared to many alternative joining methods that require hot pressing equipment. Previous publications demonstrated joining of dense $\mathrm{SiC}$ and $\mathrm{SiC} / \mathrm{SiC}$ composites using reaction bonding techniques 8,17 . This report presents recent results concerning further development of the joining method and microstructural characterization of the joined materials.

\section{DISCUSSION OF CURRENT ACTIVITIES}

The research effort during this report period has focused on (1) process modification and optimization for preparation of joining precursor materials (2) fabrication of joined SiC specimens in support of mechanical property measurements, and (3) demonstration of joining using localized external heating.

\section{Precursor Material Preparation}

Several modifications were made to the tape casting slurry formulation used to fabricate thin $\mathrm{SiC}+\mathrm{C}$ joining precursor materials. The goal of these modifications was to decrease the number and size of processing related defects in the tape, and also to increase the carbon density within the tape to achieve more desirable reaction bonded microstructures after infiltration.

A method was developed for effectively removing entrained air from the ball milled slurry without the formation of detrimental dried aggregates or viscosity gradients. De-airing was accomplished by continually stirring the slurry under a partial vacuum. Slurry viscosity could also be increased to the desired level during this process by the homogeneous removal of the carrier solvent. Elimination of entrained air, along with increased slurry viscosity prior to tape casting resulted in decreased migration and segregation of $C$ that was previously observed in the tape during the drying process.

A polysorbate surfactant, Tween 40 , was determined to be an effective agent for stabilizing the tape casting slurry. Additions of $4 \mathrm{wt} . \%$ of Tween 40 to the slurry 
formulation allowed a stable homogeneous mixture of $\mathrm{SiC}+\mathrm{C}$ to be obtained using a simple ultrasonic dispersion treatment rather then the extensive ball milling that was previously required.

Further adjustments to the slurry formulations were made in an effort to achieve higher carbon densities in the as-cast tapes produced using only ultrasonic dispersion. Previously, using the ball milled slurry, tapes in the as-cast condition had carbon densities too low, resulting in excess free $\mathrm{Si}$ in the reaction bonded joint interlayer. Uniaxial pressing of the as-cast tapes was used in past experiments to increase the carbon de asity, however, inhomogeneities and defects were sometimes introduced into the $\mathrm{SiC}+\mathrm{C}$ precursor during handling and pressing. It was thus desirable to achieve improved powder packing in the as-cast tapes in an effort to eliminate the need for tape pressing. Initial studies were conducted to investigate the use of mixtures of different $\mathrm{SiC}$ particle sizes in the slurry to achieve improved powder packing. The modified tape casting formulation used is shown in Table 1. Using a mixture of $70 \%-325$ mesh $\mathrm{SiC}$ grit and $30 \% 3.0 \mu \mathrm{m}$ $\mathrm{SiC}$ powders it was possible to achieve approximately equivalent $\mathrm{C}$ densities with ultrasonic dispersion as was previously obtained using ball milling of the -325 mesh $\mathrm{SiC}$. Figure 1 compares joint microstructures obtained with this slurry formulation for tapes used in the as-cast condition, and after uniaxial pressing at $140 \mathrm{MPa}$. The joint produced using the as-cast tape exhibits a microstructure almost identical to those previously obtained using a ball milled -325 mesh $\mathrm{SiC}$ slurry, i.e. there is a large amount of excess free $\mathrm{Si}$ indicating the $\mathrm{C}$ density in the precursor was too low. The joint produced using the pressed tape exhibits a significantly reduced amount of free $\mathrm{Si}$ in the microstructure owing to the higher carbon density in the precursor. It is believed that with further refinements to the weight and particle size ratios of the $\mathrm{SiC}$ powders in the slurry, higher $\mathrm{C}$ densities can

Table 1. Modified Tape Casting Formulation

\begin{tabular}{|c|c|c|}
\hline material & type/vendor & $\begin{array}{c}\text { amount, } \\
\text { wt. } \%\end{array}$ \\
\hline$\overline{\mathrm{SiC}}$ & -325 mesh, $99 \%$, Cerac Inc, Milwaukee, WI & 20.0 \\
\hline$\overline{\mathrm{SiC}}$ & $3.0 \mu \mathrm{m}$, Grade A1, Hermann C. Starck, Goslar, Germany & 8.6 \\
\hline graphite & $1.0 \mu \mathrm{m}$, type 7 X99, Cummings-Moore, Inc., Detroit, MI & 11.9 \\
\hline Solvent & ethanol, Quantum Chemical Corp., Tuscola, $\mathbb{L}$ & 36.8 \\
\hline Solvent & toluene, Fisher Scientific, Fair Lawn, NJ & 17.1 \\
\hline binder & Ethocel "Standard", Dow Chemical Co., Midland, MI & 2.6 \\
\hline plasticizer & glycerin, Fisher Scientific, Fair Lawn, NJ & 0.2 \\
\hline surfactant & Tween 40, ICI Americas, Inc., Wilmington, DE & 2.8 \\
\hline
\end{tabular}


be achieved in as-cast tapes resulting in improved joint microstructures.

\section{Fabrication of Joined SiC Specimens}

A number of joined $\mathrm{SiC}$ bars were produced to provide specimens for the ongoing mechanical property studies that will be discussed in the next report period. Joints were produced using two pieces of $12.5 \mathrm{~mm} \times 12.5 \mathrm{~mm} \times 25.0 \mathrm{~mm}$ bars of $\alpha-S i C$, clamped

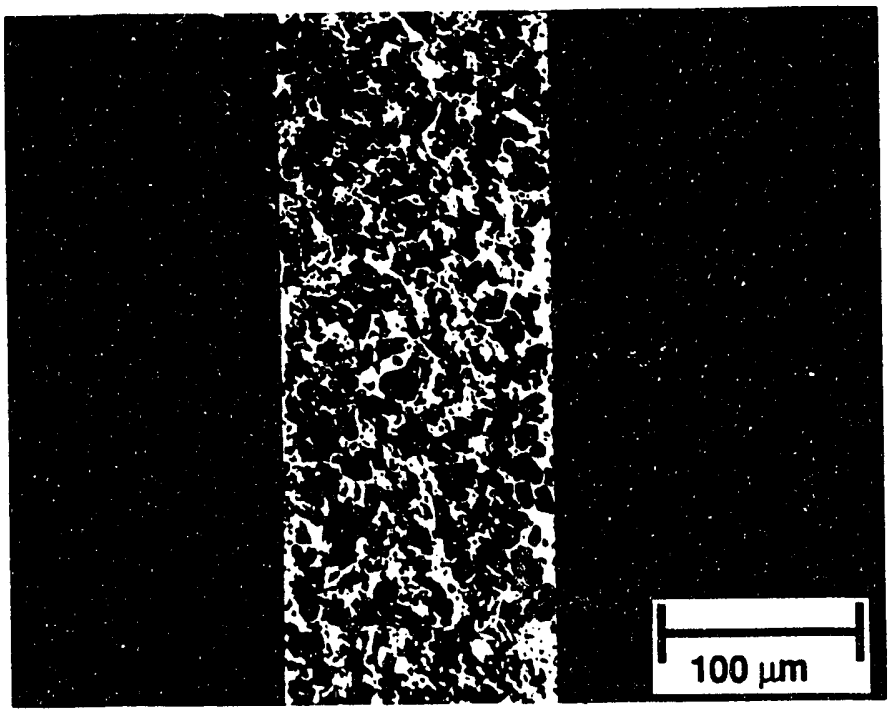

(a)

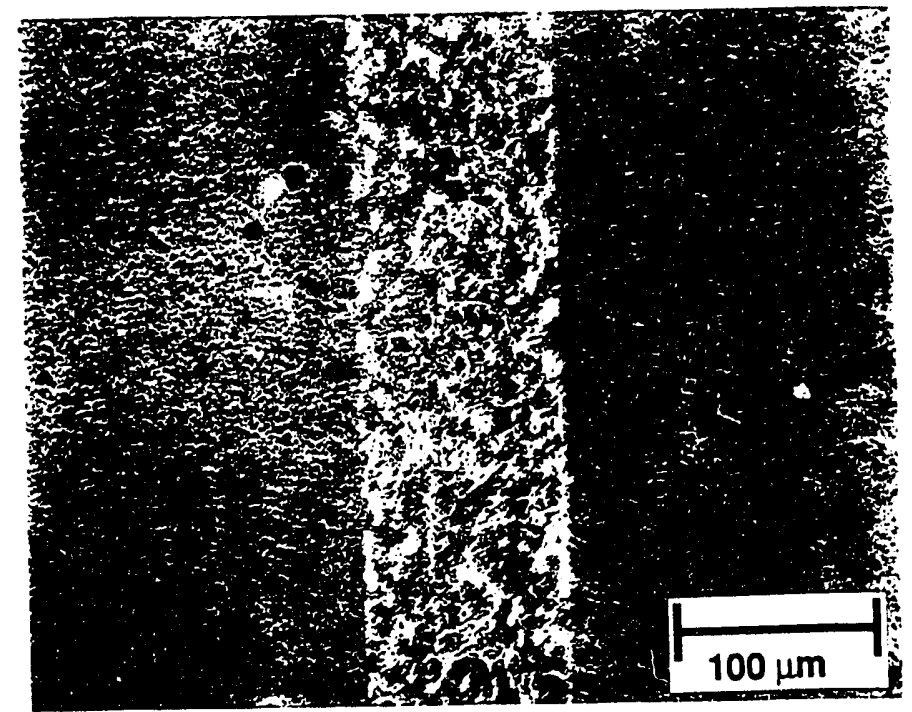

(b)

Figure 1. Microstructures of $\mathrm{SiC}-\mathrm{SiC}$ joints produced by $\mathrm{Si}$ infiltration of $\mathrm{SiC}+\mathrm{C}$ tapes cast from a slurry containing $70 \%-325$ mesh $\mathrm{SiC}$ and $30 \% 3.0 \mu \mathrm{m} \mathrm{SiC}$ with (a) tape used in the as-cast condition, and (b) tape pressed at $140 \mathrm{MPa}$. 
together in a simple graphite jig as shown in Figure 2. The $\mathrm{SiC}+\mathrm{C}$ precursor tape was placed between the ceramic pieces to be joined, and the samples were fixed in place using the threaded graphite rod. Although significant external pressure is not required to produce acceptable joints, it is necessary to insure that the samples remain in intimate contact during infiltration, otherwise a thin layer of excess free $\mathrm{Si}$ is observed at the interface between the joint material and the ceramic pieces. Thus, it was necessary to place a thin $\mathrm{ZrO}_{2}$ spacer between the $\mathrm{SiC}$ bars and the threaded rod that, because of its higher thermal expansion coefficient, produces a small clamping pressure on the $\mathrm{SiC}$ bars during heating of the assembly. For infiltration, a small piece of lump $\mathrm{Si}$ was glued in place adjacent to the joint region. The entire assembly was then heated in a tube furnace. Infiltration was carried out at $1480^{\circ} \mathrm{C}$ for $60 \mathrm{~min}$ in flowing argon.

\section{Joining Using Localized External Heating}

In order to investigate whether the reaction bonding methods can successfully be used to join large or complex-shaped parts, localized external heating techniques were investigated. The initial demonstration studies employed $\mathrm{RF}$ induction heating, along with the same graphite jig used to produce the joined $\mathrm{SiC}-\mathrm{SiC}$ bars by furnace heating. Figure 3a shows a schematic of the experimental setup. Joints were produced using approximately the same heating schedule as in furnace heating, and a flowing argon

Figure 2. Macrophotograph showing an assembled graphite jig used to produce SiC-SiC joints for mechanical properties testing. 


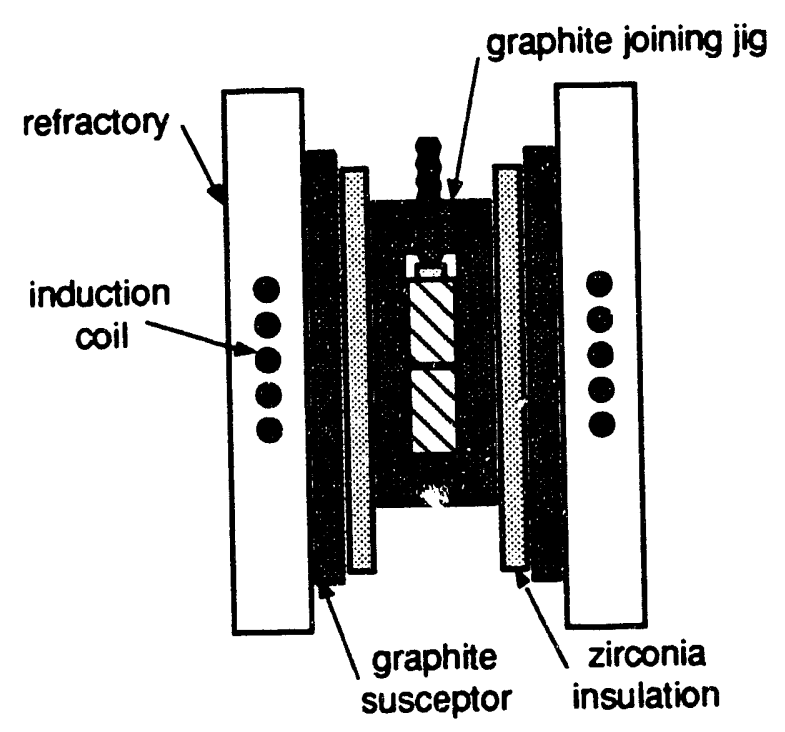

(a)

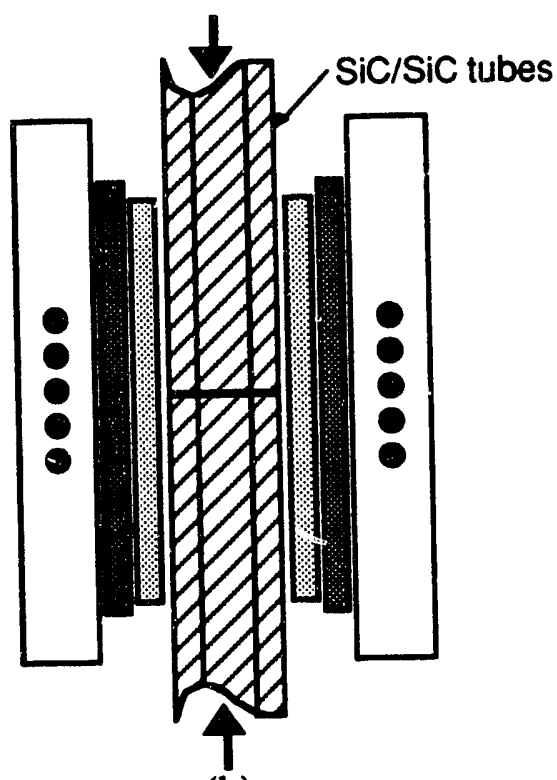

(b)

Figure 3. Schematic of the experimental setup used to demonstrate joining using RF induction heating.

atmosphere was used. It was found that the microstructures of the joints produced using this method were essentially identical to those produced by furnace heating. These results suggest it should be possible to use localized induction heating to join, for example, long $\mathrm{SiC} / \mathrm{SiC}$ composite tubes for heat exchanger applications. The proposed method for conducting such experiments is shown schematically in Figure 3b. The small amount of clamping pressure needed to effect joining could be applied directly to the parts away from the localized heating area. Actual joining expe: ments on $\mathrm{SiC} / \mathrm{SiC}$ tubes are expected to be carried out in the future.

\section{REFERENCES}

1. D. P. Stinton, A. J. Caputo and R. A. Lowden, "Synthesis of Fiber-Reinforced SiC Composites by Chemical Vapor Infiltration," Amer. Ceram. Soc. Bull., 65(2), pp. 347-350, 1986.

2. A. J. Caputo, et al., "Fiber-Reinforced SiC Composites with Improved Mechanical Properties," Amer. Ceram. Soc. Bull., 66(2), pp. 368-372, 1987.

3. P. J. Lamicq, et al., "SiC/SiC Composite Ceramics," Amer. Ceram. Soc. Bull., 65(2), pp. 336-338, 1986. 
4. D. P. Stinton, R. A. Lowden and R. H. Krabill, "Mechanical Property Characterization of Fiber-Reinforced SiC Matrix Cr mposites," ORNL/TM-11524, Oak Ridge National Laboratory, Oak Ridge, TN, / pril, 1990.

5. T. Mah, et al., "Thermal Stability of SiC Fibres (Nicalon ${ }^{\circledR}$ )," J. Mater. Sci., 19, pp. 1191-1201, 1984.

6. G. Simon and A. R. Bunsell, "Creep Behavior and Structural Characterization at High Temperatures of Nicalon SiC Fibers," J. Mater. Sci., 19, pp. 3658-3670, 1984.

7. R. A. Lowden and R. D. James, "Effects of Oxidizing and Combustion Environments on the Interface and Mechanical Properties of Nicalon ${ }^{\circledR} / \mathrm{SiC}$ Composites," pp. 33-46, ORNL/FMP-91/1, Oak Ridge National Laboratory, Oak Ridge, TN, September, 1991.

8. B. H. Rabin and G. A. Moore, "Joining of $\mathrm{SiC}$ and $\mathrm{SiC} / \mathrm{SiC}$ Composites," pp. 131-142, ORNL/FMP-92/1, Oak Ridge National Laboratory, Oak Ridge, TN, July, 1992.

9. P. Popper, "The Preparation of Dense Self-Bonded Silicon Carbide," Special Ceramics, Heywood, London, p. 209, 1960.

10. C. W. Forrest, P. Kennedy and J. V. Shennan, "The Fabrication and Properties of Self-Bonded Silicon Carbide Bodies," Special Ceramics 5, P. Popper (ed.), British Ceramic Research Association, Stoke-on-Trent, p. 99, 1972.

11. W. B. Hillig, et al., "Silicon/Silicon Carbide Composites," Amer. Ceram. Soc. Bull., 54(12), pp. 1054-1056, 1975.

12. J. N. Ness and T. F. Page, "Microstructural Evolution in Reaction-Bonded Silicon Carbide," J. Mater. Sci., 21(4), pp. 1377-1397, 1986.

13. D. F. Carrol, et al., "High Temperature Mechanical Properties of Siliconized Silicon Carbide Composites," Tailoring Multiphase and Composite Ceramics, Materials Science Research, vol. 20, R. E. Tressler et al. (eds.), Plenum Press, New York, pp. 775-788, 1986.

14. R. P. Messner and Y-M. Chiang, "Processing of Reaction-Bonded Silicon Carbide Without Residual Silicon Phase," Ceram. Eng. Sci. Proc., 9(7-8), pp. 1052-1060, 1988.

15. R. P. Messner and Y-M. Chiang, "Liquid-Phase Reaction-Bonding of Silicon Carbide Using Alloyed Silicon-Molybdenum Melts," J. Amer. Ceram. Soc., 73(5), pp. 1193-1200, 1990.

16. Y-M. Chiang et al., "Reaction-Formed Silicon Carbide," Mater. Sci. Eng., A144, pp. $63-74,1991$.

17. B. H. Rabin and G. A. Moore, "Joining of SiC-Based Ceramics by Reaction Bonding Methods," J. Mater. Synthesis and Proc., 1992, in press. 
NIST-I.(A) - Low-Temperature Fabrication of Transparent Silicon Nitride

Wei Chen, A. Pechenik, G. Piermarini, and S. G. Malghan

Ceramics Division

National Institute of Standards and Technology

Gaithersburg, MD 20899

\section{Introduction}

Particles with characteristic sizes between 1 and $100 \mathrm{~nm}$ are termed nanosize particles. Powders made of nanosize particles offer a number of potential advantages over conventional microsize ceramic powders. Ever since the theoretical work of Frenkel [1], it has been known that reducing particle size should lead to improved sintering of powder compacts. Herring [2] further developed the sintering equations to include different mechanisms of atomic diffusion. He found that different diffusion mechanisms had different functional dependance of sintering rate on particle size, but for all sintering mechanisms, sintering rate increased as particle size decreased. Thus, it was established that decreasing particle size allows sintering at lower temperatures and for shorter times.

Experimental investigations supported this theoretical conclusion. Rhodes [3] produced densely-packed compacts of nanosize zirconia particles and observed sintering of the compacts to near theoretical density at much lower temperatures than are used in sintering coarse zirconia particles. Recently Hahn, et al., [4] sintered nanosize titania at $800{ }^{\circ} \mathrm{C}$ - well below conventional sintering temperatures for conventional titania powders.

These results suggest that nanosize particles might be used as a starting material for sintering silicon nitride ceramics. Accordingly, in a number of recent investigations, powdexs consisting of nanosize 
particles of silicon nitride have been synthesized and applied to fabricate bulk material [5]. However, these attempts have generally been unsuccessful due to the difficulty in fabricating densely-packed compacts from the starting powders. When particles are small, strong aggregating forces usually prevent the particles from packing efficiently during compaction. As a result of aggregation and subsequent agglomeration of primary particles, compacts of nanosize silicon nitride particles have low packing density which precludes achieving high density after sintering.

Past work at NIST, which utilized a diamond anvil cell for compacting nanosize particles of amorphous silicon nitride, revealed that at low temperatures and high pressures drastic improvements in the packing density of nanosize particles can be achieved. The improvements allowed fabrication of very small dense compacts, which, even prior to sintering, are transparent in visible light. These transparent, densely-packed compacts, allowed pressureless sintering of amorphous transparent silicon nitride at temperatures significantly lower than those used conventionally for hot-pressing of silicon nitride.

The current project takes the above-mentioned work one step further toward fabricating large-size transparent silicon nitride ceramics from the nanosize particles. To achieve this goal of fabricating significantly larger samples than the ones produced using the diamond cell in the previous work, one must understand the ratedependent or time-dependent behavior of compacting nanosize particles at various temperatures and under a variety of cover gasses used for lubricating the surface of compacting particles. Th: novel equipment built for this purpose permits the control of: (1) the temperature inside the working chamber, (2) the pressure applied to the compact, (3) the gas pressure of the cover gas, and (4) the rate of compaction. At the same time, the new equipment allows accurate measurements of the rate of compaction, frictional forces between the compacting particles and the walls of the cylinder, and other important parameters which 
later will be used to understand the rheological laws of flow of the nanosize particles based on the Navier-Stoakes equation.

Specifically, the primary objectives of the current project are to:

1. Establish optimal processing parameters for fabricating transparent greenware from nanosize particles of silicon nitride. The most important parameters are: (a) temperature of compaction, (b) rate of pressure application, (c) maximum pressure applied to the sample, (d) the type of cover gas used during compaction, and (e) gas pressure of cover gas during compaction.

2. Investigate pressureless sintering and hot-forging of the transparent greenware made of densely packed nanosize particles of silicon nitride. The most important parameters for sintering and hot-forging are: (a) processing temperature, (b) pressure, (c) time, and (d) environment. This project will concentrate on understanding the microstructure development during sintering the transparent compacts at 1400 to $1600^{\circ} \mathrm{C}$ for 1 to 10 hours. SEM and TEM will be used as primary tools to characterize the microstructure of sintered compacts.

3. Characterize hardness and fracture toughness of the silicon nitride material fabricated via the nanosize particle processing route. This will be done using the microindentation technique.

DISCUSSION OF CURRENT ACTIVITIES

\subsection{Equipment Fabrication and Calibration}

The major activity during this reporting period was fabrication and calibration of the equipment for compacting nanosize particles under controlled atmosphere. Most of the equipment has been fabricated, assembled, and calibrated. Schematics of the experimental set-up are 
shown in Fig. 1. This equipment allows fabricating $3 \mathrm{~mm}$-diameter discshaped samples from starting powders of nanosize particles under vacuum or in a selected gas environment. Inside of the environmental chamber, the piston-cylinder apparatus can be cooled to liquid nitrogen temperature or heated to $200{ }^{\circ} \mathrm{C}$ for outbaking under vacuum. Two load cells measure both the load applied to the sample and the frictional force between the sample and the walls of the die. This fracture is unique and very valuable because it permits one to measure not only the total force applied to the piston, but also the frictional force between the sample and the walls of the die. Normally, in the past studies, only the force applied to the top cylinder is measured and reported as the total pressure applied to the sample, which misleading if the frictional force is large. A displacement transducer measures displacement of the piston and thus, changes in volume of the sample as a function of time and the applied pressure. Pressure to the top piston is applied using a computer-controlled Instron, which allows a precise control of the rate of pressure application.

Prior to conducting experiments with silicon nitride powder, a series of experiments with other powders were conducted. The goal at this stage is to check and calibrate the equipment for elastic deformation of the die. Figure 2 shows the rheology of compaction of nanosize gamma-alumina powder which has been used for calibration procedures. The data are displayed as the sample volume vs. applied pressure, density vs. pressure, density vs.time, pressure vs. time, temperature vs. time, and the frictional force. Thus a very accurate description of the compaction is possible.

Gamma-alumina does not have any phase transitions in the range of conditions that is accessible to the new device, however, there are a number of materials that undergo volume changing phase transformations at pressures below $2 \mathrm{GPa}$. One such material is $\mathrm{RbCl}$ which transforms to a denser phase at about $0.6 \mathrm{GPa}$. Figure 3 shows how accurately the novel setup depicts the volume-changing transition in $\mathrm{RbCl}$. It can be 

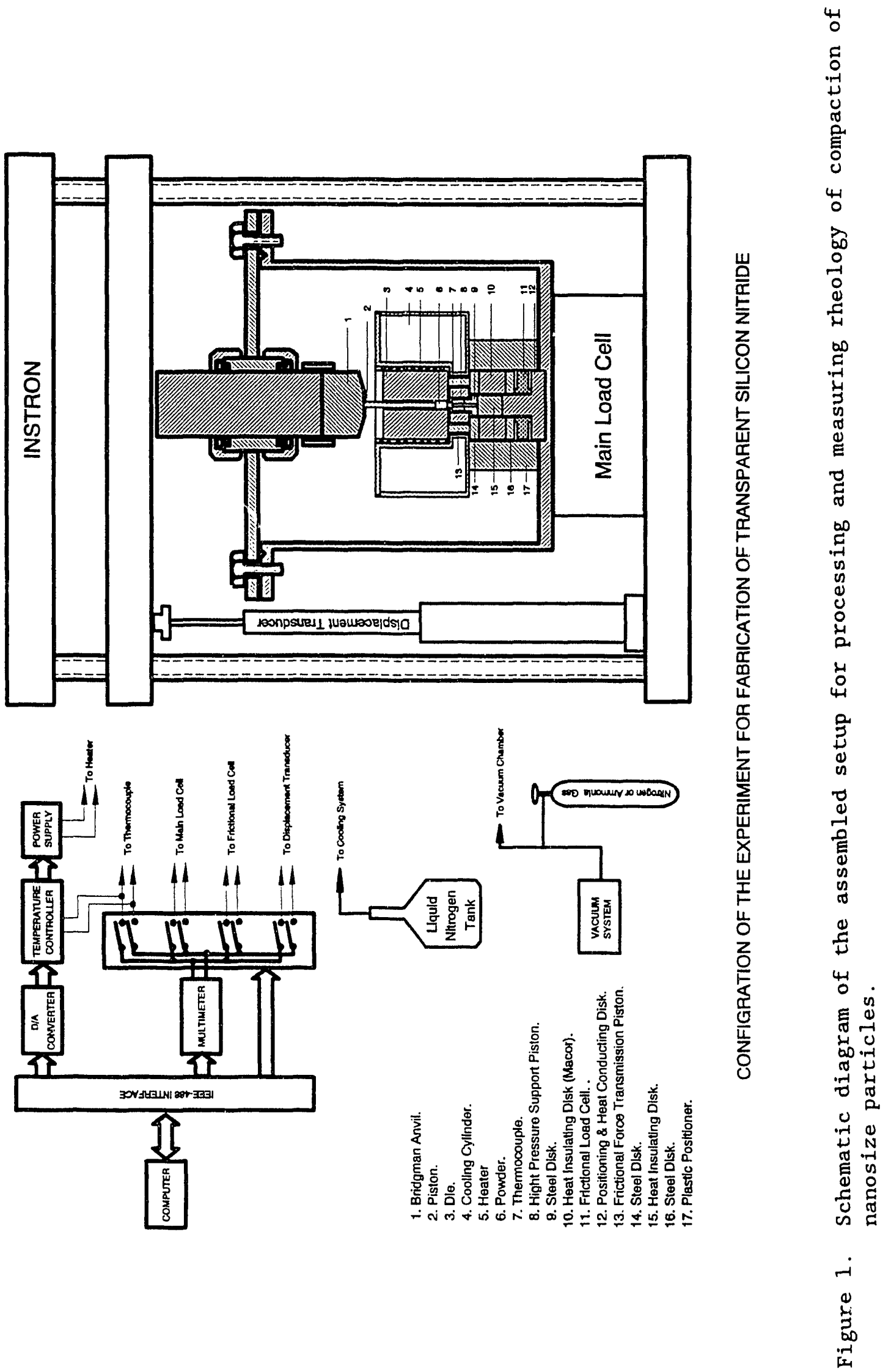


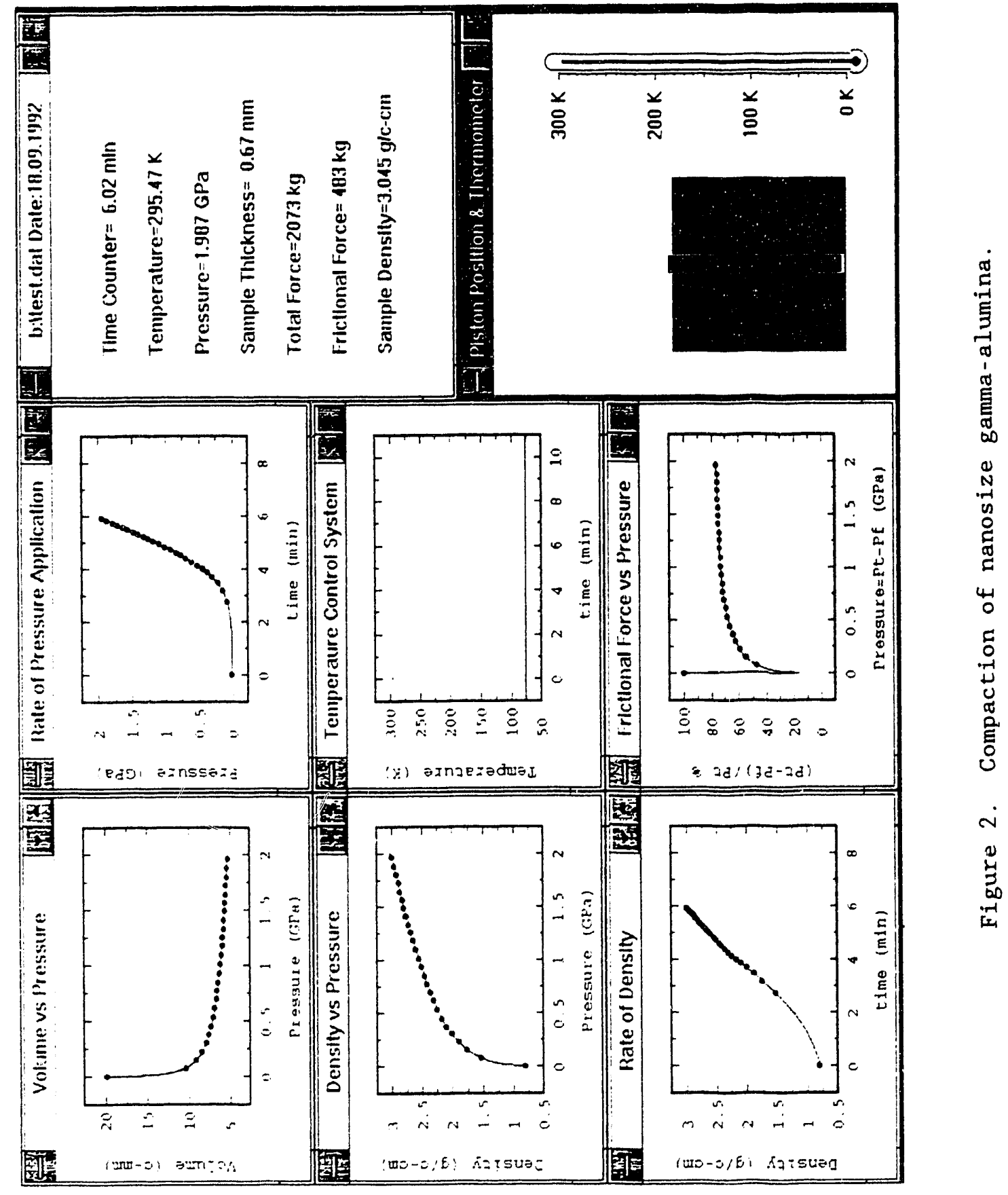




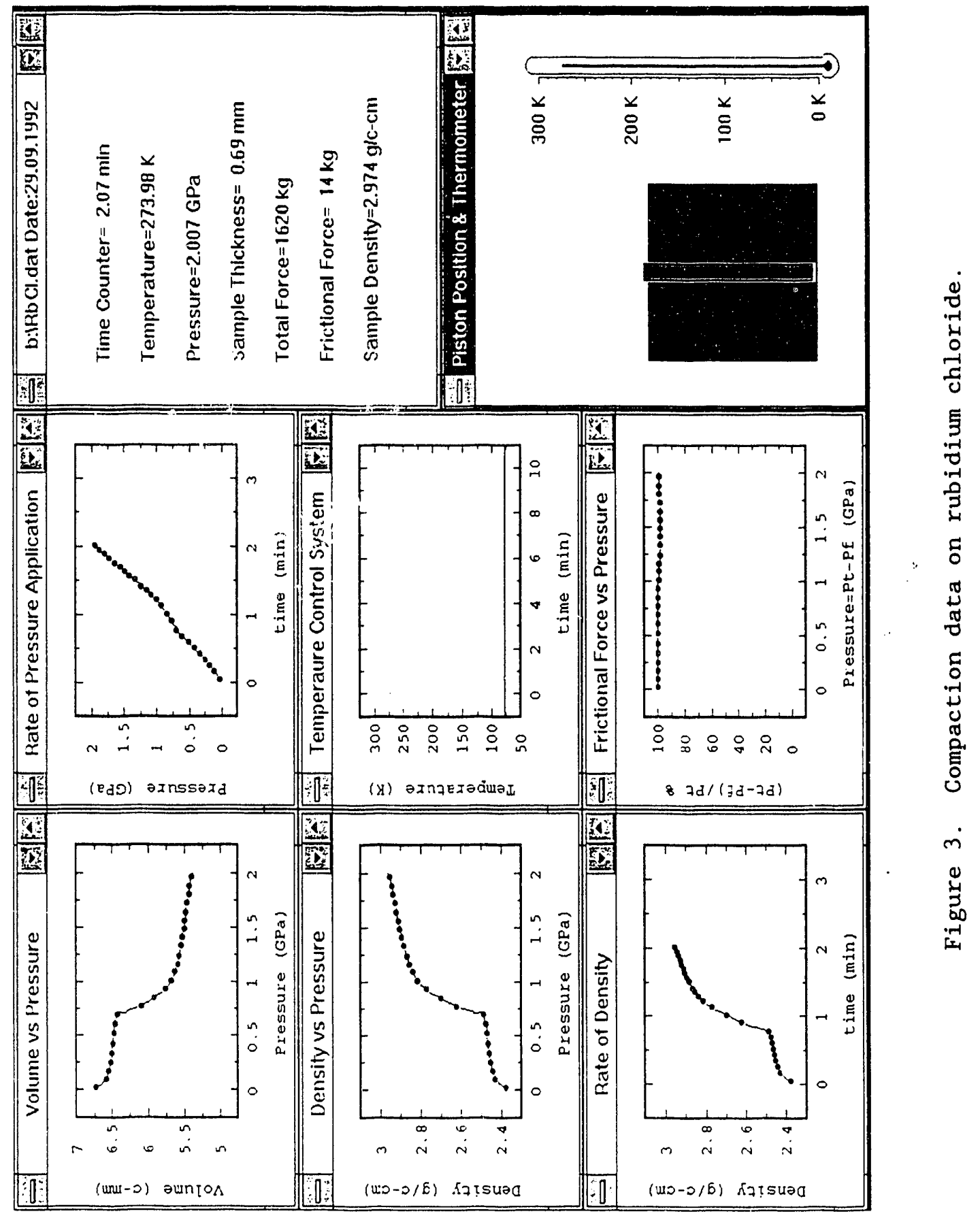


seen from the plot of volume vs. pressure, that the 14 vol\% change accompanying this transformation has been correctly measured by the equi.pment.

One of the attractive features of the new compaction equipment is that the setup allows processing nanosize particles without ever exposing them to the ambient atmosphere. The as-received virgin powder is usually stored in an inert atmosphere box under dry nitrogen. The die is loaded inside of the box, then the chamber is assembled inside of the box, sealed, and taken out of the box. Next the chamber is outgassed, if necessary, filled with appropriate gas lubricant, cooled to a selected temperature and the sample is compacted while the data are being accumulated and the entire compaction procedure is controlled by a computer.

\subsection{Silicon Nitride Fabrication}

So far four samples have been fabricated from nanosize powder exposed to ambient atmosphere. Two of these samples showed some degree of translucency before sintering. After sintering, one of these samples is still optically transmittant. The pressing parameters have not been optimized, yet. And we expect that, after optimization, the optical clarity of the samples will improve. Presently, an evaluation of the microstructure of the samples is being carried out. The work is concentrated on processing the so-called "exposed" powder, which has been exposed to ambient environment and thus acquired about 6 wt.\% of oxygen. After investigating the exposed powder, we plan to fabricate samples from unexposed powder, or powder which has been handled under dry nitrogen. It is known that such powders have less than 0.2 wt\% of oxygen. 


\section{REFERENCES}

1. Frenke1, J. Physics (U.S.S.R) 8 p. 385 (1945).

2. C. Herring, "Effect of Change of Scale on Sintering Phenomena", J. App1. Phys., v.21, pp. 301-303, (1950).

3. W. H. Rhodes, "Agglomerate and Particle Size Effects on Sintering Yttria-Stabilized Zirconia", J. Am. Ceram. Soc., 64 [1] 19-22 (1981).

4. G. Skandan, H. Hahn, and J.C. Parker, "Nanostructured $\mathrm{Y}_{2} \mathrm{O}_{3}$ :Synthesis and Relation to Microstructure and Properties", Scripta Metallurgical, vol. 25, 2389-2393 (1991).

5. W. Symons and S. C. Danforth, "Hot Isostatic Pressing of Laser Synthesized Silicon Nitride Powder", Ceramic Materials and Components for Engines, ed. V. J. Tennery, American Ceramic Society, Westerville, $\mathrm{OH}, 67-75$.

6. A. Pechenik, G. Piermarini, and S. C. Danforth, "Fabrication of Transparent Silicon Nitride From Nanosize Particles", J. Amer. Ceram. Society, in press. 


\section{K25-1 - DEVELOPMENT OF CERAMIC MEMBRANES FOR GAS SEPARATION}

D. E. Fain

G. E. Roettger

K. D. Adcock

Oak Ridge K-25 Site

P. O. Box 2003

Oak Ridge, TN 37831-7271

\section{INTRODUCTION}

Development work is being carried out at the Oak Ridge K-25 Site to develop a ceramic membrane that will effectively separate hydrogen from gasified coal at temperatures of $1000^{\circ} \mathrm{F}$ or higher. One of the objectives of the project during the current report period was to produce membranes having sufficiently small pores to provide molecular sieving and high separation factors. Since the mean pore radii of the experimental membranes being fabricated for this project were approaching the lower measurement limit of the Dynamic Pore Size test $(5 \dot{\AA})$, new testing capability was needed in order to monitor continuing development efforts aimed at reducing the pore size further. A second key objective of the project (directed at this measurement need) was to develop a permeance test system capable of providing high-precision flow measurements on the membranes at elevated temperatures. By measuring pure gas flows in such a system with different test gases, high temperature separation factors of the membranes could be determined. The determination of high temperature separation factors would provide a realistic criteria for defining the performance of the membranes and for monitoring the progress of membrane development efforts. A third objective of the project was to further develop and utilize a mathematical model for gas transport through inorganic membranes to interpret empirical data and to help direct the experimental work.

\section{DISCUSSION OF CURRENT ACTIVITIES}

High Temperature Permeance Test System

Much of the project effort during the second half of FY 1992 was directed toward completing the development of a high-temperature permeance test system and initiating testing with the system. The components of the system were assembled with the membrane holder installed in a heat chamber capable of providing temperatures up to $275^{\circ} \mathrm{C}$. After completing all tie-ins, the 
system was leak tested successfully. Operational checkout and certification of the system were carried out by calibrating the measurement elements and then measuring the permeance of a membrane at room temperature, analyzing the resulting data, and comparing data from the new system with data from an existing system that operates at room temperature.

Following successful certification of the new test system, initial testing was begun on a ceramic membrane having a mean pore radius of $8.9 \dot{A}$. Permeance data were measured on the membrane at $24^{\circ} \mathrm{C}, 100^{\circ} \mathrm{C}, 200^{\circ} \mathrm{C}$, and $250^{\circ} \mathrm{C}$ using helium, nitrogen, carbon dioxide, and carbon tetrafluoride as test gases. The operation of the system was completely successful, although some seal revisions were required for successful operation at the higher temperatures. Initial use of a high-temperature fluoroelastomer material for sealing the membrane in the system proved unsatisfactory at $200^{\circ} \mathrm{C}$ as problems were encountered with leaks. Replacement of the original seals with a fluoropolymer material resulted in good performance through $250^{\circ} \mathrm{C}$, which is the highest temperature evaluated to date.

The measurement precision and reproducibility of the test system have proven to be excellent. For example, measurements made on the membrane with helium at $200^{\circ} \mathrm{C}$ in three separate tests are shown in Fig. 1, in which the permeance data is plotted against average pressure (mean of the membrane forepressure and backpressure). Data from the three tests, which were performed on three different days, show excellent agreement.

Data from permeance measurements made on the alumina membrane at $24^{\circ} \mathrm{C}$ with helium, nitrogen, carbon dioxide, and carbon tetrafluoride are shown in Fig. 2. As observed with previous Jata taken at room temperature, the current data show relatively higher permeances for the heavier gases (and particularly for $\mathrm{CO}_{2}$ ) than would be attributed to molecular weight considerations alone, i.e., to Knudsen diffusion. The higher $\mathrm{CO}_{2}$ permeance has been predicted by the gas transport model. This enhanced transport of $\mathrm{CO}_{2}$ at room temperature results from surface flow of an adsorbed layer of $\mathrm{CO}_{2}$ on the walls of the pores. This adsorption and surface flow, which complicates the interpretation of room temperature flow data for small-pored membranes, should be greatly reduced when the membrane is operated at higher temperatures. Consequently, the $\mathrm{He} / \mathrm{CO}_{2}$ separation factor should be higher at higher temperatures.

Permeance data obtained on the same membrane at $200^{\circ} \mathrm{C}$ are plotted in Fig. 3. At this higher temperature where adsorption and surface flow effects are reduced, the permeances for the four gases decrease in the order of increasing molecular weights. 


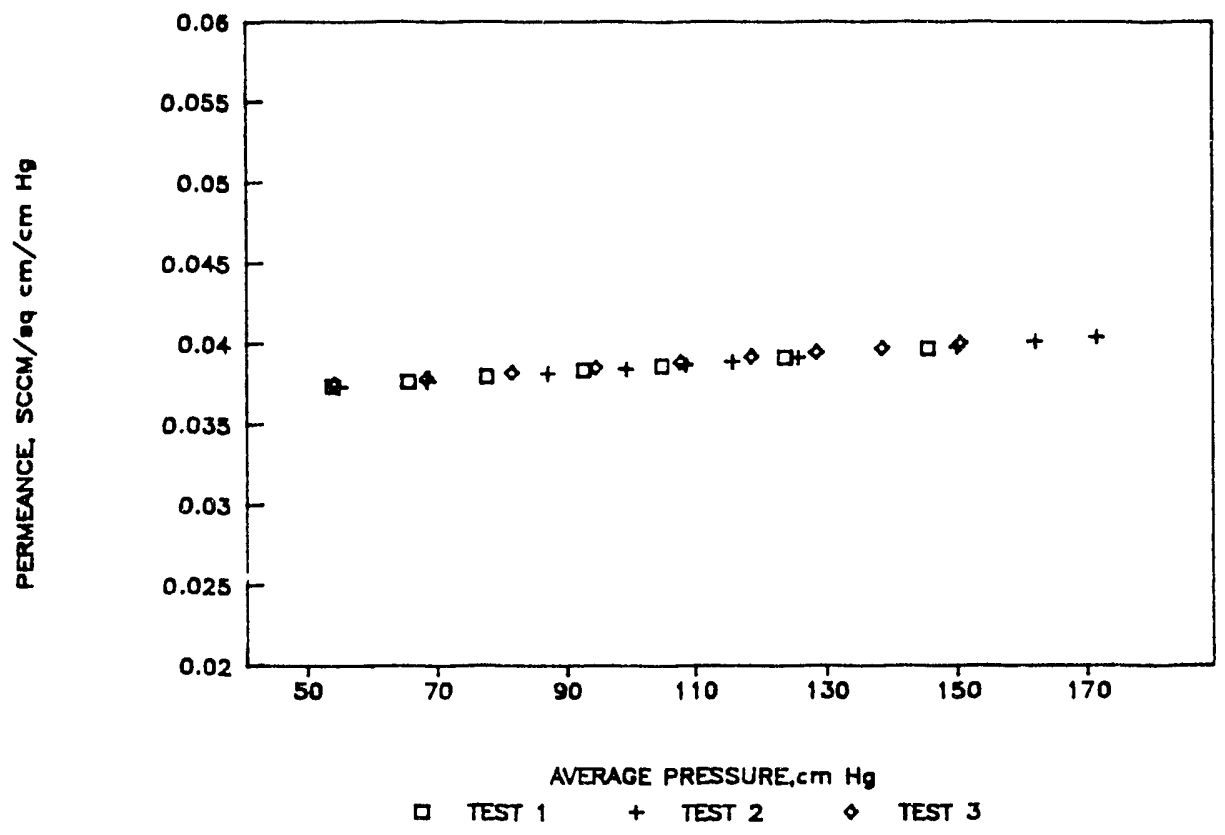

Fig. 1. Permeance data from repeat tests with helium at $200^{\circ} \mathrm{C}$ showing good reproducibility with new test system.

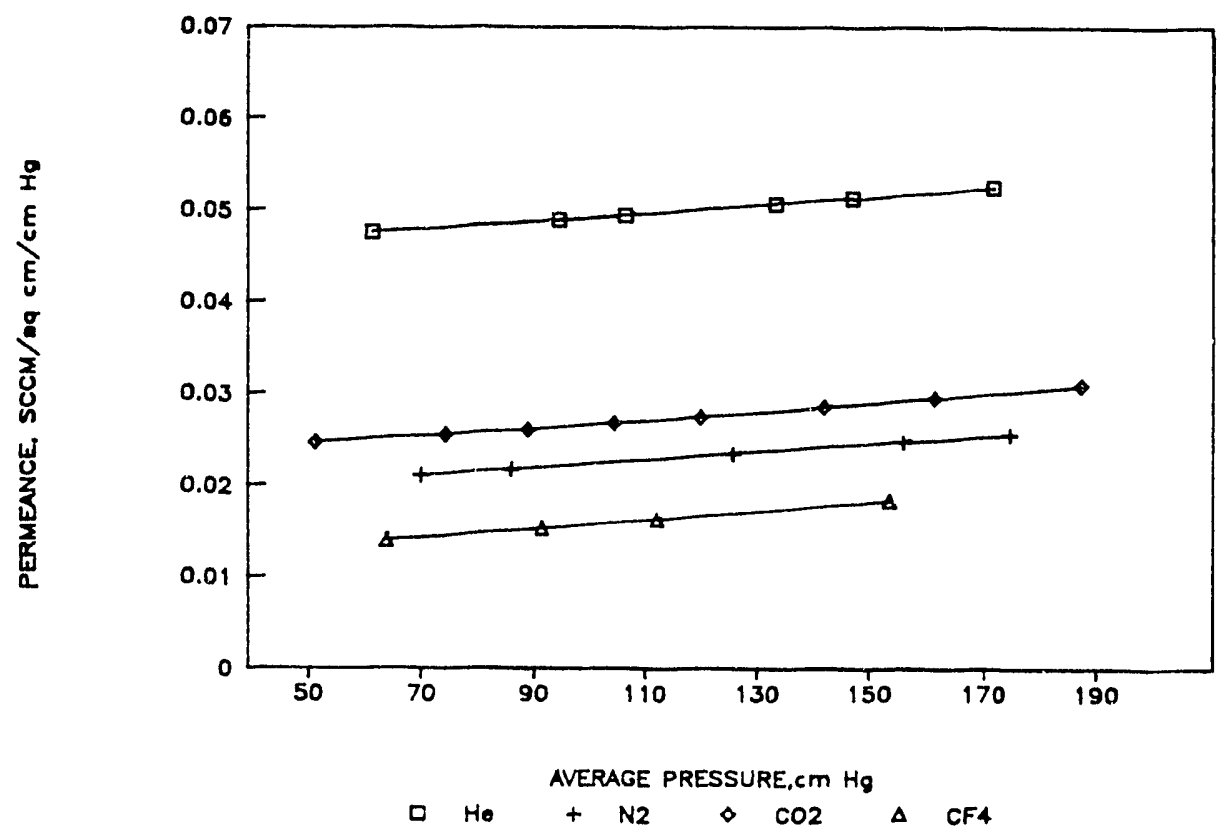

Fig. 2. Permeance measured on $8.9 \dot{\AA}$ mean pore radius membrane at $24^{\circ} \mathrm{C}$ with four gases. 


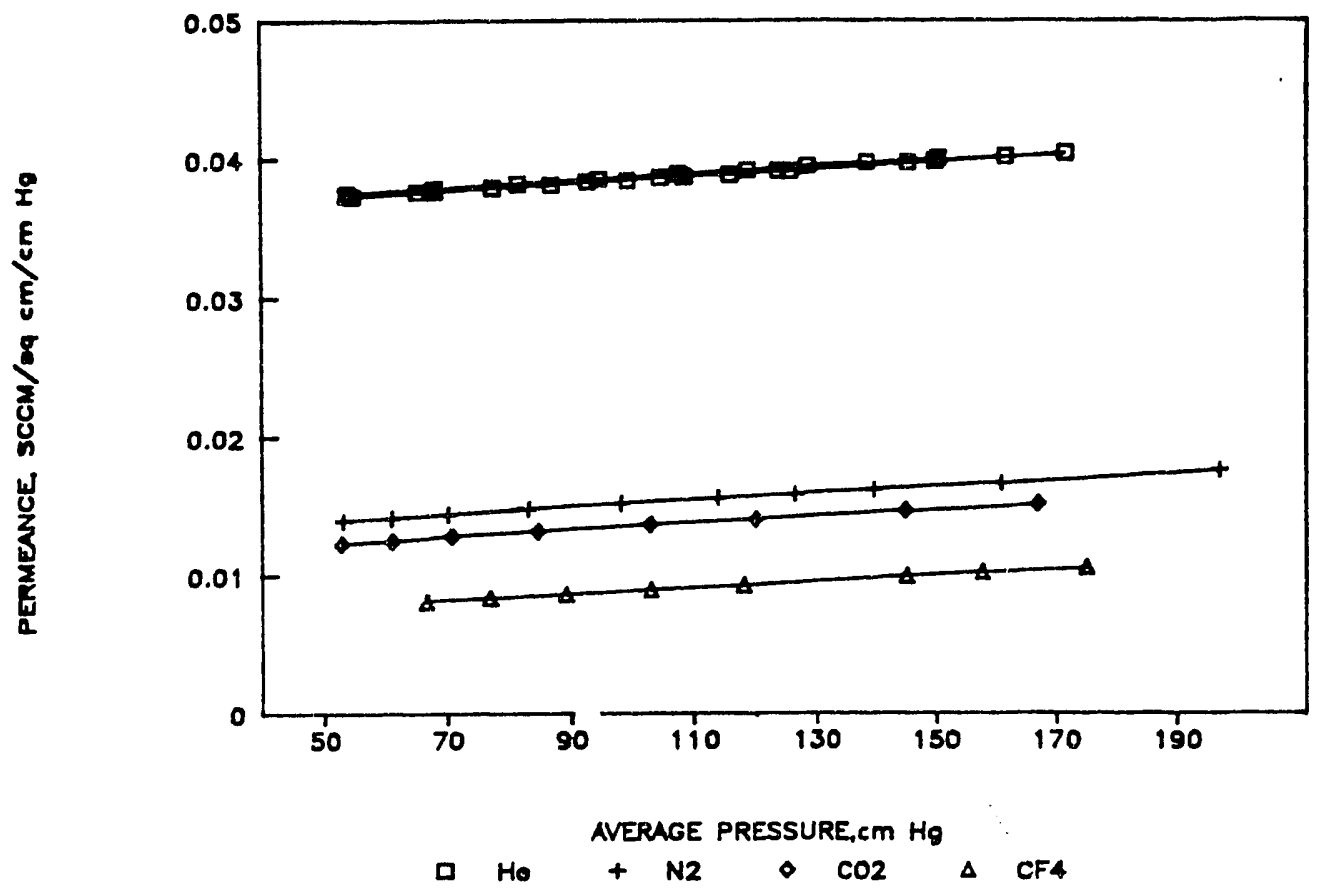

Fig. 3. Permeance measured on $8.9 \dot{A}$ mean pore radius membrane at $200^{\circ} \mathrm{C}$ with four gases.

Separation Factors at Higher Temperatures

Separation factors were determined from the pure gas flow data by calculating the ratios of specific flows for the gas pairs $\mathrm{He} / \mathrm{N}_{2}, \mathrm{He} / \mathrm{CO}_{2}$ and $\mathrm{He} / \mathrm{CF}_{4}$. The separation factors determined at $24^{\circ} \mathrm{C}, 100^{\circ} \mathrm{C}, 200^{\circ} \mathrm{C}$, and $250^{\circ} \mathrm{C}$ are plotted in Fig. 4 as a function of temperature. The data show higher separation factors at higher temperatures for each of the gas pairs as expected. The separation factor determined for the membrane at $250^{\circ} \mathrm{C}$ for the $\mathrm{He} / \mathrm{CF}_{4}$ gas pair was 5.6. This is higher than the theoretical value for Knudsen diffusion, providing initial empirical evidence of the effects of molecular sieving. Based on the gas transport model, the separation factor would be expected to approach 6.3 for this membrane (which has a mean pore radius of $8.9 \dot{A}$ ) at the high temperature limit (which is described below). Testing of the membrane at $275^{\circ} \mathrm{C}$ is currently in progress, with results contingent upon seal performance. 


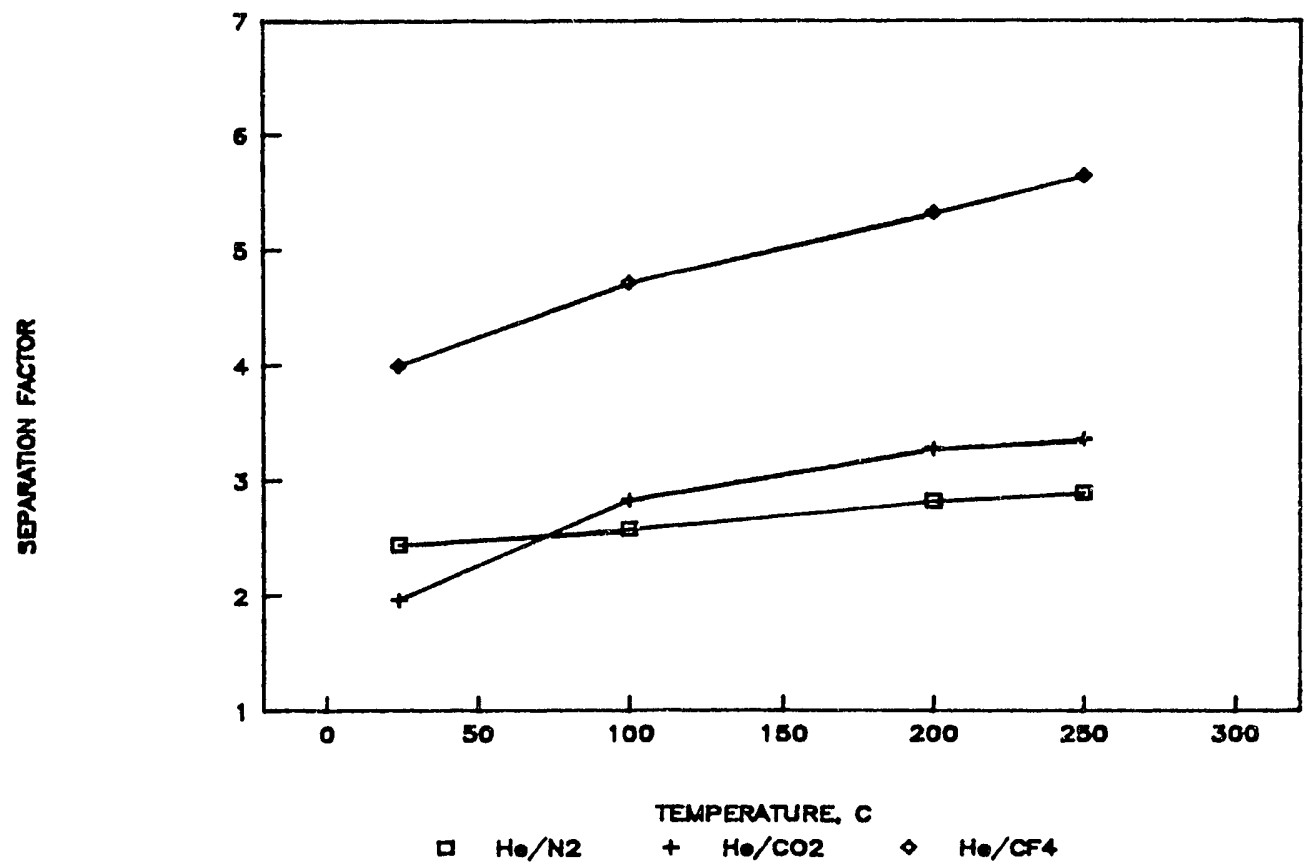

Fig. 4. Separation factors of $8.9 \dot{A}$ mean pore radius membrane determined at various temperatures.

\section{Gas Transport Model Predictions for High Temperature}

The mathematical model for gas transport through inorganic membranes has been utilized to predict separation factors at a "high temperature limit" where adsorption and surface flow are eliminated. These model results were discussed in the previous report. ${ }^{1}$ The separation factors predicted by the model at room temperature and at the high temperature limit for the $\mathrm{He} / \mathrm{CO}_{2}$ gas pair are plotted in Fig. 5 as a function of membrane pore size. The model results predict higher separation factors at higher temperature for a given pore size as was observed with the experimental data presented above (Fig. 4). The high-temperature separation factors predicted by the model are much higher for membranes having smaller pores. 


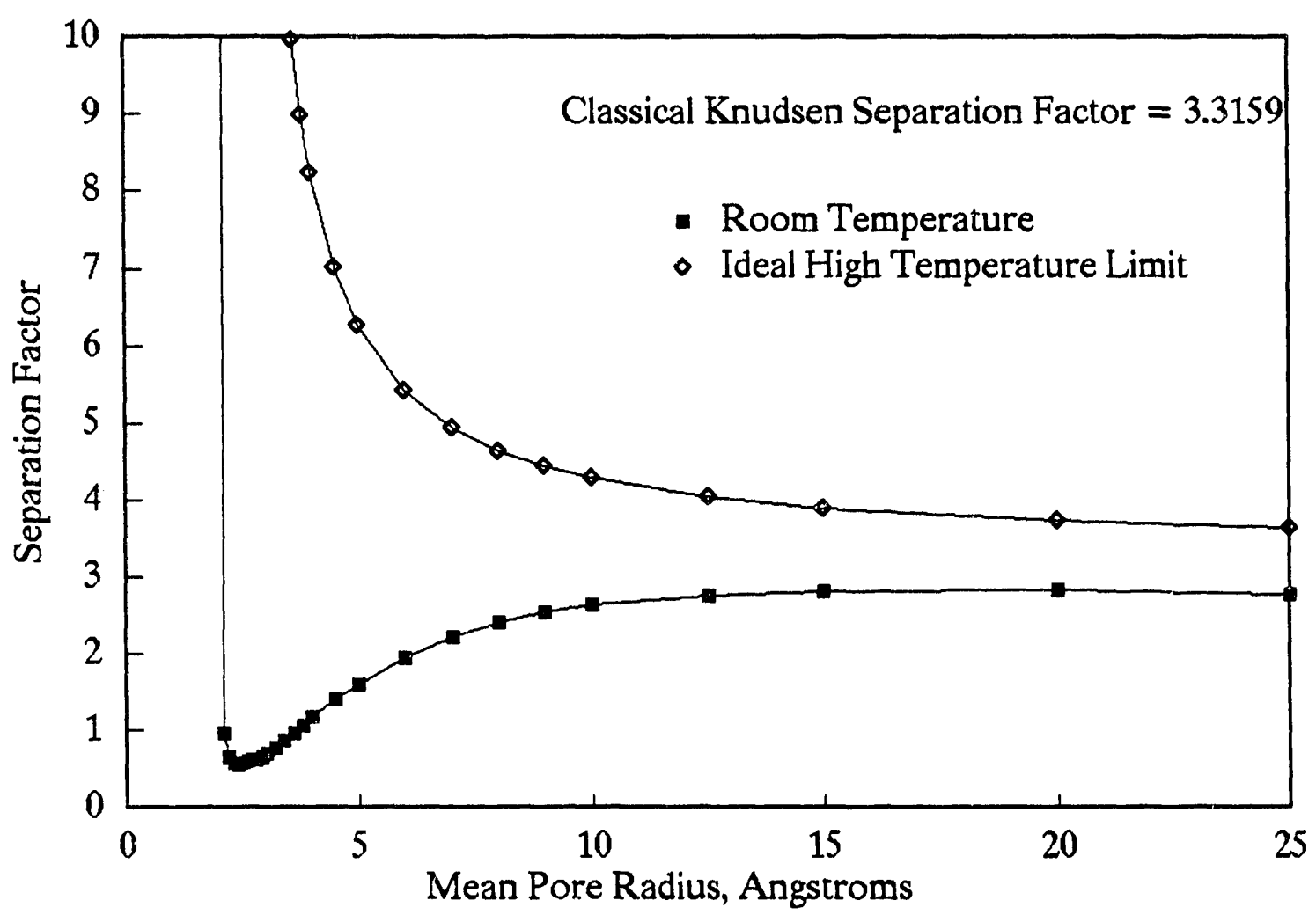

Fig. 5. Transport model calculations for $\mathrm{He}-\mathrm{CO}_{2}$ separation factors at room temperature and at the ideal high temperature limit.

\section{Membrane Development}

Further development of membrane fabrication procedures during the current report period provided experimental alumina membranes whose measured mean pore radii were at the lower measurement limit $(5 \dot{A})$ of the Dynamic Pore Size test, indicating that their mean pore radii were $5 \dot{A}$ or smaller. These membranes are scheduled for pure gas flow testing in the high-temperature permeance test system to determine their separation factors. Considerably higher separation factors are expected with these smaller-pore membranes than observed with the membrane initially tested, which had a mean pore radius of $8.9 \AA$. Emphasis is being placed on reducing the backlog of samples awaiting testing in the new high-temperature test system, so the test system can provide timely evaluation of new membranes in the near future. 


\section{REFERENCES}

1. D. E. Fain, G. E. Roettger, D. E. White, "Ceramic Membranes for High Temperature Hydrogen Separation," in Proceedings of the Sixth Annual Conference on Fossil Energy Materials, ORNL/FMP-92/1, p. 167-177, Oak Ridge, Tennessee, May 12-14, 1992, Martin Marietia Energy Systems, Inc., Oak Ridge National Laboratory, Oak Ridge, Tennessee, July 1992. 


\title{
ORNL-1(A)-FABRICATION OF FIBER-REINFORCED COMPOSITES
}

\author{
D. P. Stinton, J. C. McLaughlin, and T. M. Besmann \\ Metals and Ceramics Division \\ Oak Ridge National Laboratory \\ Oak Ridge, Tennessee 37831-6063
}

\section{INTRODUCTION}

The purpose of this task is to develop a ceramic composite having higher than normal strength and toughness yet retaining the normal ceramic attributes of refractoriness and high resistance to abrasion and corrosion. Ceramic fiber-ceramic matrix composites are being fabricated by infiltrating fibrous structures with vapors that deposit on and between the fibers to form the matrix of the composites.

Fiber composites are in the limelight as a result of exceptionally high toughness values recently achieved for glass ceramics reinforced with silicon carbide fibers. Because use of ceramics is frequently restricted by inadequate toughness, any progress toward toughening ceramics will greatly expand their potential market. However, a generic problem that must be overcome is that normal ceramic fabrication processes tend to damage fibers mechanically and chemically when the fibers are consolidated within a ceramic matrix. The purpose of this task is to form the matrix by a comparatively low-stress, low-temperature chemical vapor deposition (CVD) infiltration process that will avoid the pitfalls of conventional ceramic processing.

As reported previously, others have used CVD infiltration for fabricating ceramic composites. The vapor consolidation technique has been used to prepare fiber composites with matrices of carbon and/or such ceramics as $\mathrm{SiC}, \mathrm{Si}_{3} \mathrm{~N}_{4}, \mathrm{~B}_{4} \mathrm{C}, \mathrm{BN}$, and $\mathrm{TiB}_{2}$. Our goal is to demonstrate a rapid process for fabricating, via chemical vapor infiltration, a ceramic fiberceramic matrix composite consisting of materials of high interest to the fossil energy community. An initial assessment identified $\mathrm{SiC}$ fibers and matrices of $\mathrm{Si}_{3} \mathrm{~N}_{4}$ and $\mathrm{SiC}$ as being promising. An infiltrating process utilizing a thermal gadient combined with forced flow of the reactants is being pursued. 


\section{DISCUSSION OF CURRENT ACTIVITIES}

Fiber-reinforced SiC matrix composites of thick-walled tubular geometry $(2.5 \mathrm{~cm} \mathrm{ID}$ by $0.6 \mathrm{~cm}$ wall thickness by $\approx 15 \mathrm{~cm}$ long) were fabricated by forced chemical vapor infiltration for nondestructive evaluation and mechanical property testing. Fibrous preforms of different fiber architectures (filament wound, cloth wrapped, or 3-dimensionally braided) were investigated to accommodate components with different mechanical property requirements. Nondestructive evaluation (radiography and computed tomography) was performed at ORNL prior to sending the tubes to Virginia Polytechnic Institute for mechanical property testing. Composite tubes will be mechanically evaluated in tension as well as torsion during the first quarter of FY 1993. The mechanical properties of the composite tubes will then be correlated with the results of the nondestructive evaluation.

A CRADA was signed with The 3M Company to establish a base line for oxide fiber$\mathrm{SiC}$ matrix composites. Using the forced CVI process developed at ORNL, composites were fabricated using four different 3M fibers; Nextel 312 and 440 (aluminaboriasilica), Nextel 550 (aluminasilica), and Nextel 610 (alumina). Different interface treatments (CVD carbon and organic based carbon) were incorporated into the composites of each type. In addition, experiments were performed on the reactor configuration. Because the oxide fibers are much more insulating than Nicalon fibers, the bottom temperature was much cooler than desired. The goal of these experiments was to manipulate the temperature gradient (raise the bottom temperature) that the composite experiences during infiltration. The ability to control this bottom temperature is important in achieving dense composites of various fibers and shapes.

Because fiber-reinforced SiC-matrix composites are susceptible to sodium and potassium corrosion at high temperatures, a chemical vapor deposition process was developed during the past year to apply coatings that reduce or eliminate corrosion. Statistically designed experiments were used to identify deposition conditions that produce dense continuous $\mathrm{Ta}_{2} \mathrm{O}_{5}$ coatings. Coated composite samples have been corrosion tested this period. These tests consisted of applying 10 to $20 \mathrm{mg} / \mathrm{cm}^{2}$ of sodium sulfate to the surface of a $\mathrm{Ta}_{2} \mathrm{O}_{5}$ coated composite. Materials were then annealed at $1000^{\circ} \mathrm{C}$ for 100 hours and examined by optical microscopy, scanning electron microscopy, and x-ray diffraction. Observation of the 
annealed samples by optical and scanning electron microscopy revealed no visible reaction between the sodium sulfate and the $\mathrm{Ta}_{2} \mathrm{O}_{5}$. Examination of the materials by $\mathrm{x}$-ray diffraction showed that the $\mathrm{Ta}_{2} \mathrm{O}_{5}$ was unaffected by the exposure to sodium sulfate. 


\title{
ORNL 1-(C): INTERFACES AND MECHANICAL PROPERTIES OF CONTINUOUS FIBER-REINFORCED CERAMIC COMPOSITES
}

\author{
R. A. Lowden, K. L. More, and O. J. Schwarz \\ Oak Ridge National Laboratory \\ P. O. Box 2008 \\ Oak Ridge, Tennessee 37831-6063
}

\section{INTRODUCTION}

The purpose of this task is to examine fiber-matrix interfaces and optimize the mechanical behavior of continuous fiber-reinforced ceramic composites fabricated utilizing a forced-flow, thermal-gradient chemical vapor infiltration technique. The strength and toughness of fiberreinforced ceramic composites are controlled by the properties of the interface between the fiber and the matrix, thus emphasis is to be placed on developing methods to characterize the fibermatrix interface and measure interfacial stresses in fiber-reinforced ceramic composite systems. Coating or pretreatment processes can then be utilized to tailor the fiber-matrix interface within various composite systems and to optimize the strength and toughness of the composite.

It is well known that although the fibers and matrix play major roles in determining the final properties of a composite, the fiber-matrix interface has a significant influence on the fracture behavior and mechanical properties of reinforced ceramics. Typically, coatings are used to protect ceramic fibers from chemical attack during processing and to control interfacial forces. Carbon, whether intentionally deposited on the fibers prior to consolidation ${ }^{1-3}$ or formed serendipitously during processing, ${ }^{4}$ is the most commonly used interlayer in ceramic composites today. Carbon coatings have performed well in a variety of systems; however, the poor oxidation resistance of carbonaceous materials has prompted intense scrutiny of their usefulness at elevated temperatures in oxidizing environments.

Carbon begins to oxidize at temperarures around $700 \mathrm{~K}$ and oxidation is rapid in air at temperatures above $1173 \mathrm{~K}$. It has been shown that the oxidation of $\mathrm{Nicalon} / \mathrm{SiC}$ composites begins by attack of the carbon interface coating at exposed fiber ends. ${ }^{5,6}$ Once the carbon is removed along the entire fiber length, the matrix and fiber oxidize to form a silica layer that eventually bonds the components together. The strong bond at the fiber-matrix interface does not permit debonding and sliding, resulting in brittle behavior. Also, oxidation degrades the properties of the fiber, enhancing the embrittlement of the composite. 
The poor oxidation resistance of carbon has lead to the examination of alternate coating materials or new concepts for controlling the force at the fiber-matrix interface in ceramicceramic composites. Hexagonal boron nitride possesses a structure and mechanical properties similar to those of graphitic carbon, however, BN offers a distinct improvement in oxidation resistance. ${ }^{7.8}$ Due to these attributes, it is expected BN could be used as a direct replacement for carbon. Earlier in this program, favorable results were achieved using a limited supply of CVDcoated fabric. ${ }^{9}$ This and the reported success of others in employing $\mathrm{BN}$ as an interlayer in ceramic composites, ${ }^{10-12}$ prompted the re-evaluation of $\mathrm{BN}$ as an interface layer for Nicalon fiberreinforced $\mathrm{SiC}$ composites.

\section{DISCUSSION OF CURRENT ACTIVITIES}

\section{SUMMARY}

Boron nitride was examined as an interface coating for Nicalon $/ \mathrm{SiC}$ composites. Boron nitride coatings were deposited on fibrous preforms from gas mixtures containing boron trichloride $\left(\mathrm{BCl}_{3}\right)$, ammonia $\left(\mathrm{NH}_{4}\right)$, and hydrogen $\left(\mathrm{H}_{2}\right)$ prior to densification with silicon carbide employing chemical vapor infiltration. Interlayer deposition conditions were controlied to produce a polycrystalline hexagonal $\mathrm{BN}$ with a microstructure comparable to that of graphitic carbon. Room-temperature flexure strengths of as-fabricated composites, and specimens exposed in air at $1273 \mathrm{~K}$, were measured to assess the effectiveness of the interface layer. As for composites with graphitic carbon interlayers, the properties of the composites were influenced by the thickness of the $\mathrm{BN}$ coating. The composites with $\mathrm{BN}$ interface coatings demonstrated significantly improved strength retention after short-term $(24 \mathrm{~h})$ oxidation, however, the toughness of the composites was degraded. The composition and microstructure of the fiber coating and the composite interfaces, prior to and after elevated-temperature exposure, were characterized using electron microscopy. No interaction between the BN interlayer and the fibers and matrix was observed for as-fabricated composites, however, a distinct change was noted at the Nicalon fiber-BN coating boundary after oxidation. The embrittlement of the composites was attributed to changes at this interface and decomposition of the Nicalon reinforcement that was accelerated by oxygen contamination in the as-deposited BN layers. 


\section{COMPOSITE FABRICATION}

Fibrous preforms were fabricated by stacking multiple layers of ceramic-grade Nicalon plain-weave fabric rotated in a $0 \pm 30^{\circ}$ sequence within the cavity of a graphite holder. The layers were hand compressed to produce a preform with a nominal fiber loading of 40 vol. \% and were held in place by a perforated graphite lid pinned to the holder. The polyvinylacetate cloth sizing was removed through multiple washings with acetone. The nominal size of the fibrous preforms was $45 \mathrm{~mm}$ in diameter and $12.5 \mathrm{~mm}$ thick.

Preforms were next coated with the boron nitride interface layers. The coatings were deposited using a forced-flow, isothermal chemical vapor infiltration approach from gas mixtures containing boron trichloride $\left(\mathrm{BCl}_{3}\right)$, ammonia $\left(\mathrm{NH}_{3}\right)$, and hydrogen $\left(\mathrm{H}_{2}\right)$, a preform temperature of $1373 \mathrm{~K}$, and a reactor pressure of $\approx 5 \mathrm{kPa}$. The ratio of boron to nitrogen in the reactant gas mixture was held constant at unity. Reactant flows and concentrations were modified to produce: (i) deposition rates similar to those for the standard graphitic carbon layer, (ii) microstructures comparable to those of graphitic carbon, and (iii) a uniform layer throughout the preform. Layer deposition times were then varied to control coating thickness. The final thicknesses of the interface layers were calculated from preform weight gains.

The preforms were densified with silicon carbide using the forced-flow, thermal-gradient chemical vapor infiltration (FCVI) process. $^{2,23}$ The $\mathrm{SiC}$ matrix was produced by the decomposition of methyltrichlorosilane $\left(\mathrm{CH}_{3} \mathrm{SiCl}_{3}\right.$ or $\left.\mathrm{MTS}\right)$ in hydrogen at a hot-surface temperature of $1473 \mathrm{~K}$ and atmospheric pressure. The preforms were infiltrated with $\mathrm{SiC}$ to a maximum of 85 to $90 \%$ of theoretical density in $\approx 20 \mathrm{~h}$.

\section{CHARACTERIZATION AND TESTING}

Test bars were cut from the composite samples parallel to the $0^{\circ}$ orientation of the top layer of cloth using a diamond saw, and tensile and compression surfaces were ground parallel to the long axis of the specimen. The average dimensions of the specimens were $2.5 \times 3 \times 40$ $\mathrm{mm}$ and all specimens were measured and weighed to determine densities. Half of the specimens were oxidized in static air at $1273 \mathrm{~K}$ for 24 hours. Flexure bars were placed on an alumina plate in the cavity of an atmospheric box furnace and heated to temperature at a rate of $300^{\circ} / \mathrm{h}$. Once the furnace achieved equilibrium, the final temperature was measured and set using a hand-held 
optical pyrometer, and then maintained using a thermocouple-controlled programmer. At the specified time, the furnace was shut off and allowed to cool unassisted.

Room-temperature flexure strengths for as-fabricated and heat-treated composites were measured in four-point bending. A support span of $25 \mathrm{~mm}$ and a loading span of $6 \mathrm{~mm}$ were used with a crosshead speed of $0.50 \mathrm{~mm} / \mathrm{min}$. The load was applied perpendicular to the layers of cloth. Load-displacement curves were recorded to examine the fracture process and determine the loads for ultimate strength calculations. The fracture surfaces of the specimens were examined using a scanning electron microscope (SEM).

The composition and microstructure of the $\mathrm{BN}$ interlayers were examined using transmission electron microscopy. Specimens were prepared such that the area for analysis contained a quantity of fibers oriented perpendicular to the surface. The specimens were mechanically ground, polished, dimpled, and ion-milled to perforation using standard techniques. Microstructural characterization was conducted on a high resolution transmission electron microscope (HRTEM) operated at $400 \mathrm{kV}$. The BN layers were also analyzed by parallel electron loss spectroscopy (PEELS), conducted at $100 \mathrm{kV}$ using a transmission electron microscope with a field emission gun in the diffraction mode (image coupled).

\section{MECHANICAL PROPERTIES}

Typical flexure load-displacement curves for the Nicalon/SiC composites with boron nitride interface coatings are shown in Figure 1. The composites exhibited good strength and composite behavior, ie. failed gradually with fiber pull-out. The strength and toughness of the composites was influenced by coatings thickness (Table 1). Thicker coatings produced greater strain to failure, but also reduced strength beyond a given maximum.

Exposure to $1273 \mathrm{~K}$ in air for $24 \mathrm{~h}$ produced a slight discoloration of all specimens suggesting some degree of surface oxidation. As given in Table 1, control specimens with a carbon interface coating experienced a significant loss in flexure strength after the $24 \mathrm{~h}$ exposure. The composites with the BN interface coatings exhibited improved strength retention, with one sample experiencing virtually no loss in flexure strength after oxidation. The oxidized specimens, however, displayed lower toughness than for comparable untreated specimens. The loss in toughness, as defined as a decrease in strain to failure, was noted as a more rapid drop in the load-deflection curve beyond maximum load (Figure 2). 


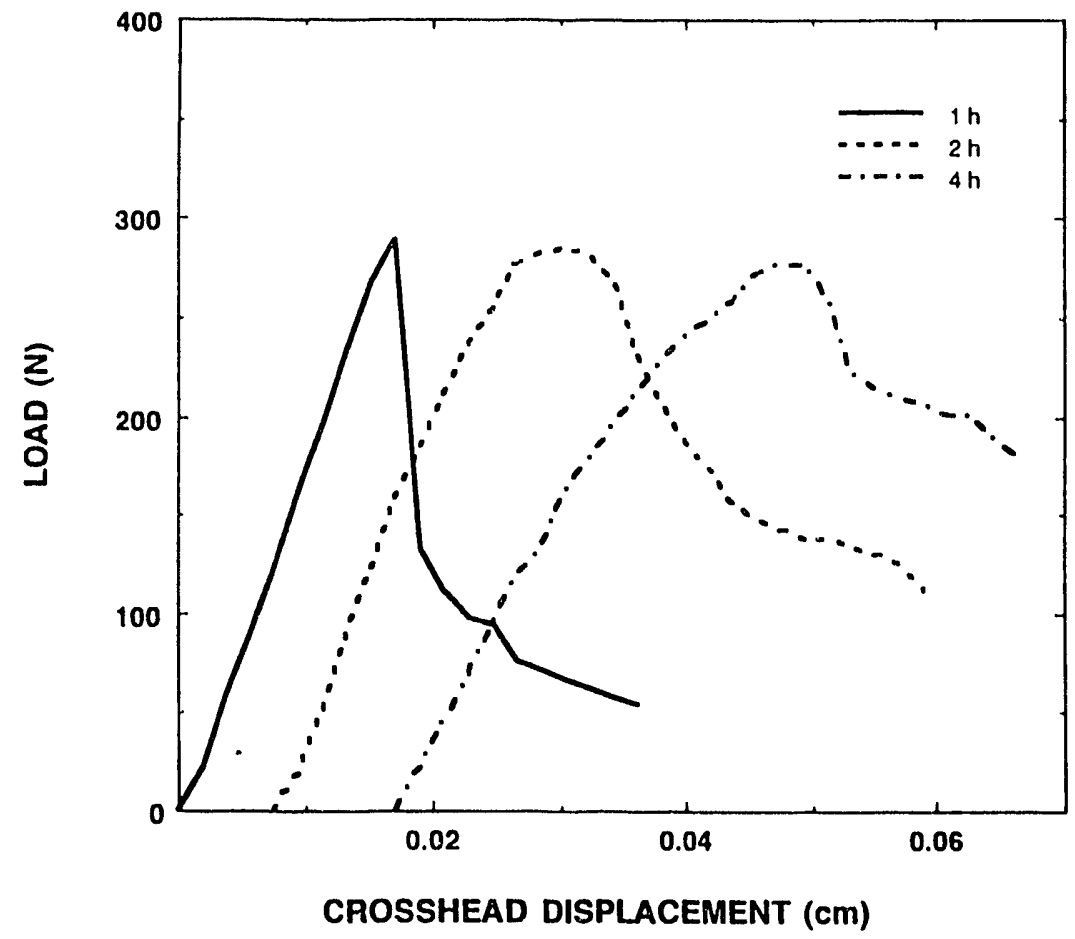

Figure 1. Representative load-deflection curves for composites with boron nitride interface soatings of varying thickness. [Curves are offset horizontally for clarity.]

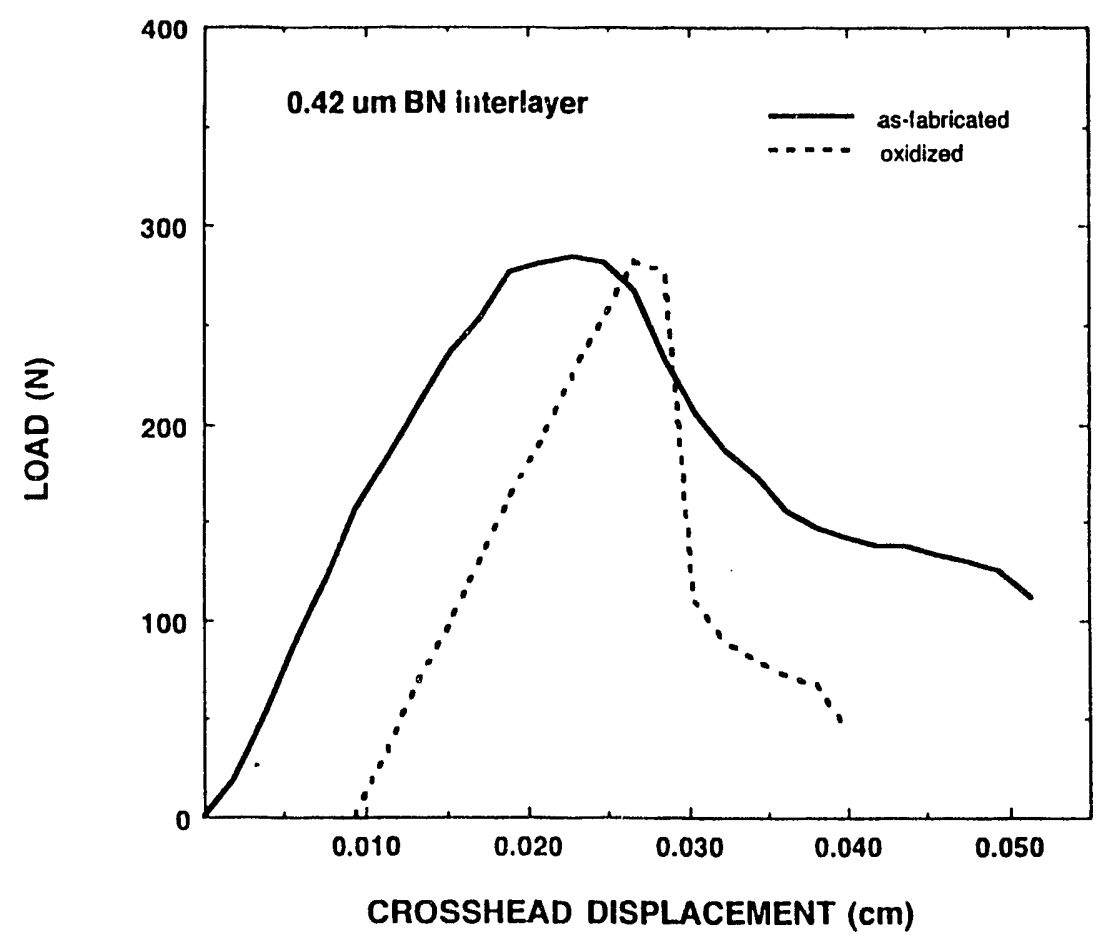

Figure 2. Representative load-deflection curves for as fabricated and oxidized composites with boron nitride interface coatings. [Curves are offset horizontally for clarity.] 
Table 1. Mechanical Properties of Nicalon $/ \mathrm{SiC}$ Composites with $\mathrm{BN}$ and Carbon Interfaces, Prior To and After Oxidation.

\begin{tabular}{|c|c|c|c||}
\hline $\begin{array}{c}\text { Deposition } \\
\text { Time } \\
(\mathrm{h})\end{array}$ & $\begin{array}{c}\text { Thickness } \\
(\mu \mathrm{m})\end{array}$ & $\begin{array}{c}\text { As-Fabricated } \\
\text { Strength } \\
(\mathbf{M P a})\end{array}$ & $\begin{array}{c}\text { Post-Exposure } \\
\text { Strength } \\
(\mathbf{M P a})\end{array}$ \\
\hline Boron Nitride & & & \\
\hline 1.0 & 0.20 & $417 \pm 68$ & $284 \pm 63$ \\
\hline 2.0 & 0.47 & $406 \pm 72$ & $345 \pm 36$ \\
\hline 2.0 & 0.42 & $419 \pm 67$ & $409 \pm 76$ \\
\hline 4.0 & 0.63 & $389 \pm 59$ & $282 \pm 62$ \\
\hline Carbon ${ }^{\dagger}$ & & & - \\
\hline 1.0 & 0.13 & $421 \pm 27$ & $108 \pm 14$ \\
\hline 2.0 & 0.39 & $404 \pm 67$ & --- \\
\hline 4.0 & 0.61 & $304 \pm 30$ & \\
\hline
\end{tabular}

[Values are average of 9 test specimens.]

$\dagger^{\dagger}$ graphitic carbon coating deposited from propylene $e^{1,10}$

\section{CHARACTERIZATION}

Characterization of the fracture surfaces employing scanning electron microscopy revealed more information regarding the failure process. Fiber pull-out was observed for the as-fabricated specimens, which was anticipated due to the extended strain to failure observed during flexure testing. The level of pull-out was dependent upon coating thickness. Thicker coatings produced more pull-out and longer protruding fiber lengths. Debonding was observed at the BN layerNicalon ${ }^{\circ}$ fiber interface in all characterized specimens. Fiber surfaces were relatively clean and the BN coating remained bonded to the matrix. Decreased levels of fiber pull-out were found for the oxidized specimens, however, debonding was evident and, as in the as-fabricated composites, occurred at the BN layer-Nicalon fiber interface.

Transmission electron microscopic analysis of the fiber coating for the as-fabricated composites with a BN deposition time of $2 \mathrm{~h}$ found the layer to be uniform throughout the 
preform and $\approx 0.45 \mu \mathrm{m}$ thick (Figure 3 ). This thickness measurement was in good agreement with the thickness calculated from weight gain (Table 1). The BN layer was turbostratic, composed of small, randomly-oriented hexagonal grains with the c-axis $=0.333 \mathrm{~nm}$. Highresolution TEM characterization of the BN layer-fiber and the $\mathrm{BN}$ layer-SiC matrix interfaces in the as-fabricated state was conducted to examine chemical interactions that may have occurred during processing. No interaction was observed at the BN-fiber interface as shown by the clean transition from the featureless structure of the fiber to the turbostratic nature of the BN coating. A thin amorphous region $(\approx 5 \mathrm{~nm})$ was found between the $\mathrm{SiC}$ matrix and the $\mathrm{BN}$ interlayer.

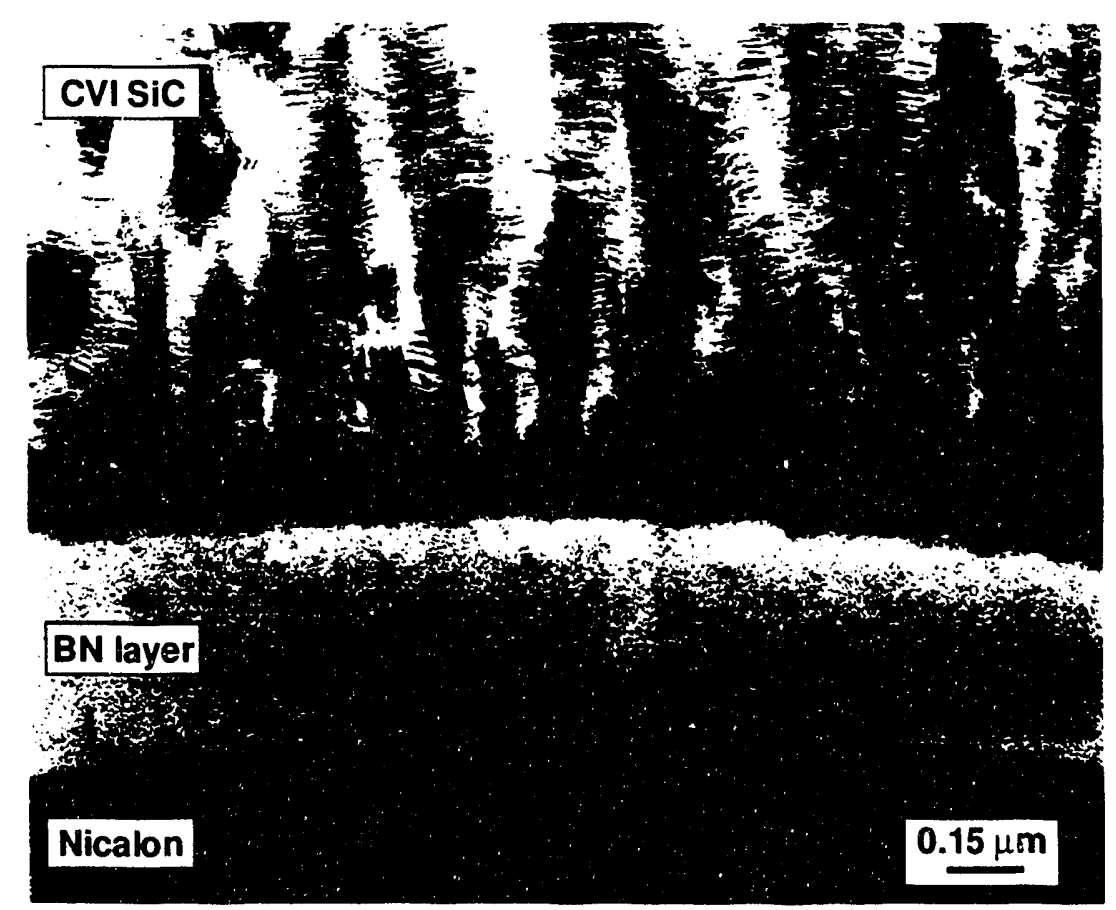

Figure 3. TEM image of the BN coating on Nicalon in the as-fabricated composite. The coatings were uniform in thickness at $\approx 0.45 \mu \mathrm{m}$. 
PEELS analysis of several BN interlayers in as-fabricated composites revealed a significant amount of oxygen in the as-fabricated coating. The oxygen content was uniform across the thickness of the coating. Elemental analysis of the BN coating after oxidation using PEELS showed no discernable difference in composition. Electron microscopic characterization of the composites after oxidation did reveal significant changes at the boundary between the Nicalon fiber and the BN interface layer (Figure 4). High resolution electron microscopy revealed a series of thin layers, beginning with a parallel alignment of the BN microstructure close to the fiber surface. Beyond this layer was an amorphous film, most likely composed of $\mathrm{SiO}_{2}$, followed by a graphitic carbon layer. PEELS analysis of the two layers nearest the fiber surface found carbon and oxygen but no boron. In addition to the formation of the $\mathrm{SiO}_{2} / \mathrm{C}$ sequence, there appeared to be a higher density of silicon carbide crystallites close to the surface of the Nicalon ${ }^{\bullet}$ fiber. This region is designated by the arrows in Figure 4.

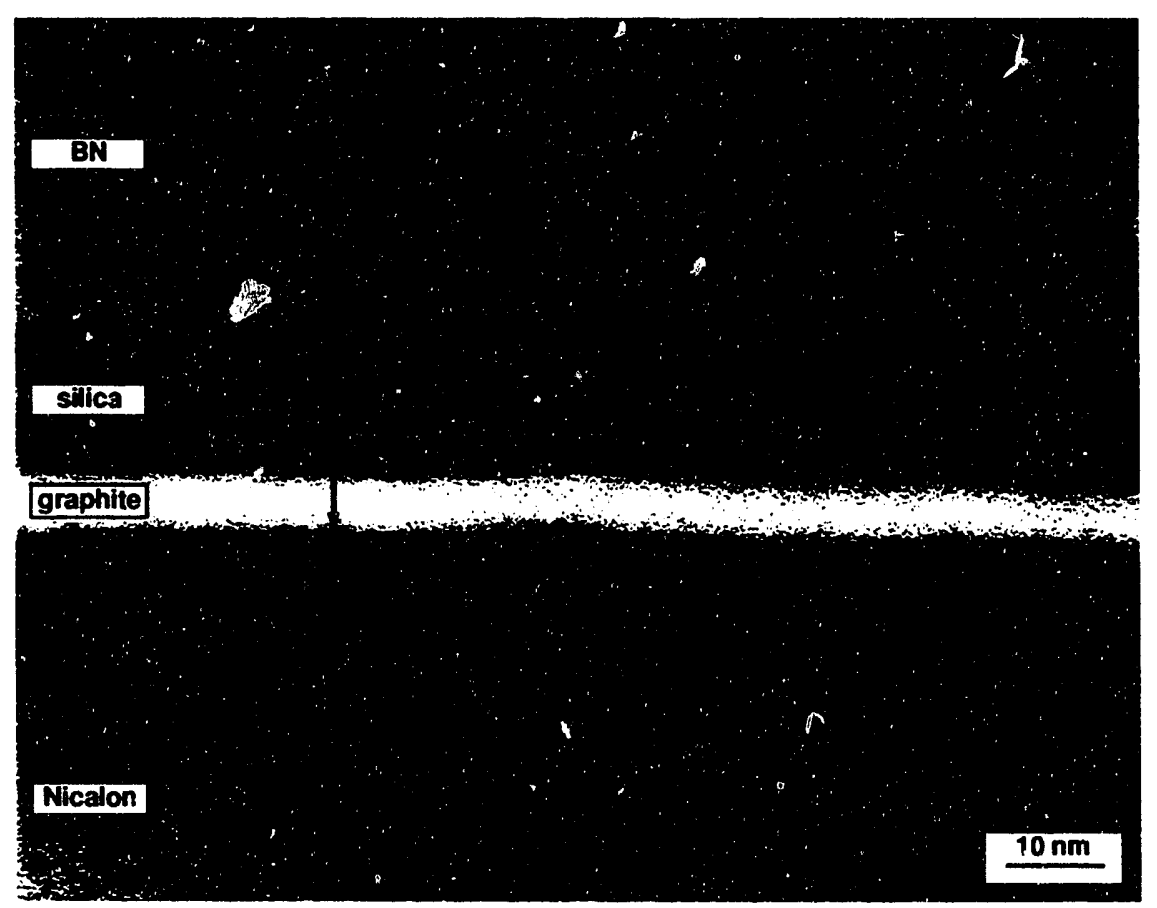

Figure 4. Low-magnification TEM image of the BN/Nicalon interface following oxidation of the composite for $24 \mathrm{~h}$ at $1273 \mathrm{~K}$. The nature of this interface changed significantly compared to that observed prior to oxidation and consisted of a layered structure, as labelled on the micrograph. 


\section{CONCLUSIONS}

A boron nitride interlayer proved to be an effective method for improving the short-term oxidation resistance of the Nicalon $/ \mathrm{SiC}$ composites. Polycrystalline hexagonal BN fiber coatings with a turbostratic structure were deposited on fibrous preforms which were densified with a SiC matrix employing the FCVI technique. Strengths and toughnesses of comparable to composites with graphitic carbon interlayers were observed, and mechanical properties and fracture behavior were influenced by the thickness of the BN coating. Although strength loss after exposure in air at $1273 \mathrm{~K}$ for $24 \mathrm{~h}$ was minimal, toughness was diminished. This decrease appears to be in part due to the decomposition of the fiber. $\mathrm{A} \mathrm{SiO}_{2} / \mathrm{C}$ dual layer was found at the $\mathrm{BN}$ layer-fiber interface in the heat-treated specimens. This layer is formed from interaction of the BN fiber coating and the fiber. Oxygen contamination in the as-deposited layers and diffusing into the coating during oxidation, caused the amorphous Si-C-O phase of the fiber to decompose and subsequently react to produce the $\mathrm{SiO}_{2} / \mathrm{C}$ sequence. The deterioration lead to a decrease in reinforcement strength and a loss of toughness.

\section{REFERENCES}

1. R. A. Lowden, "Fiber Coatings and the Mechanical Properties of a Fiber-Reinforced Ceramic Composite," pp. 619-630 in Ceramic Transactions, Vol. 19, Advanced Composite Materials, ed. by Michael D. Sacks, The American Ceramic Society, Westerville, Ohio (1991).

2. Fretty, N. and M. Boussuge, "Relationship Between High-Temperature Development of Fiber-Matrix Interfaces and the Mechanical Behavicr of SiC-SiC Composites," Composites Science and Technology 37, 177-189 (1990).

3. Kmetz, M. A., Laliberte, J. M., and Suib, S. L., "Synthesis, Characterization, and

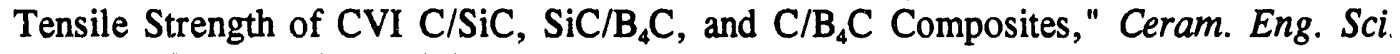
Proc. 13[9-10], 743-751 (1992).

4. J. J. Brennan, "Interfacial Characterization of Glass and Glass-Ceramic Matrix/Nicalon SiC Fiber Composites," pp. 549-560 in MRS Proceedings, Vol. 20, Tailoring Multiphase and Composite Ceramics, ed. R. E. Tressler et al., Plenum Publishing Corporation (1986).

5. R. A. Lowden and R. D. James, High Temperature Corrosion of Nicalon/SiC Composites, ORNL/TM-11893, August 1991. 
6. R. D. James, R. A. Lowden, and K. L. More, "The Effects of Oxidation and Corrosion on the Properties of Nicalon /SiC Composites," pp. 925-935 in Ceramic Transactions, Vol. 19, Advanced Composite Materials, ed. by Michael D. Sacks, The American Ceramic Society, Westerville, Ohio (1991).

7. Archer, N. J., "The Preparation and Properties of Pyrolytic Boron Nitride," pp. 167-181 in High Temperature Chemistry of Inorganic and Ceramic Materials, Special Publication No. 30, Edited by F. P. Giasser and P. E. Potter, The Chemical Society, London (1976).

8. Matsuda, T., "Stability to Moisture for Chemically Vapour-Deposited Boron Nitride," J. Mater. Sci. 24, 2353-2358 (1989).

9. R. A. Lowden and K. L. More, "The Effect of Fiber Coatings on Interfacial Shear Strength and the Mechanical behavior of Ceramic Composites," pp. 205-214 in the MRS Symposium Proceedings, Vol. 170, "Tailored Interfaces in Composite Materials," ed. by C. G. Pantano and E. J. H. Chin, Boston, MS (1989).

10. R. A. Lowden, Characterization and Control of the Fiber-Matrix Interface in Ceramic Matrix Composites, ORNL/TM-11039, March 1989.

11. R. Naslain, O. Dugne, and A. Guette, "Boron Nitride Interphase in Ceramic matrix Composites," J. Am. Ceram. Soc. 74[10], 2482-2488 (1991).

12. Bender, B., D. Shadwell, C. Bulik, L. Incorvati, and D. Lewis III, "Effect of Fiber Coatings and Composite Processing on Properties of Zirconia-Based Matrix SiC Fiber Composites," Am. Ceram. Soc. Bull. 65[2], 363-369 (1986). 


\title{
ORNL-1(D)-MICROWAVE SINTERING OF CERAMICS FOR FUEL CELLS
}

\author{
M. A. Janney, M. L. Jackson and H. D. Kimrey \\ Metals and Ceramics Division \\ Oak Ridge National Laboratory \\ Oak Ridge, Tennessee 37831-6087
}

\section{INTRODUCTION}

The study of microwave processing of ceramic materials at ORNL has shown that some materials exhibit a significant "microwave effect" but that others exhibit little or no "microwave effect." (The "microwave effect" is manifested as lower temperature sintering or faster kinetics at a given temperature.) The biggest difference between the two classes of ceramics is their electrical conductivity. Materials that exhibit a "microwave effect" are either nonconductors or ionic conductors; materials that do not exhibit a "microwave effect" are electronic conductors. The purpose of the current investigation is to investigate both of these classes of materials in a single materials system. The system chosen for study is the $\mathrm{ZrO}_{2}$ $\mathrm{CeO}_{2}-\mathrm{Y}_{2} \mathrm{O}_{3}$ system.

The $\mathrm{ZrO}_{2}-\mathrm{CeO}_{2}-\mathrm{Y}_{2} \mathrm{O}_{3}$ system is attractive for study for a number of reasons. Its total electrical conductivity can be varied over several orders of magnitude. Its conductivity can be altered from being predominantly ionic to predominantly electronic in nature. The addition of $\mathrm{Y}_{2} \mathrm{O}_{3}$ to the system provides a means to fix the level of ionic conductivity in the system by the creation of oxygen vacancies. Electronic conductivity can be adjusted by varying the partial pressure of oxygen in the processing furnace, which reduces $\mathrm{Ce}^{+4}$ to $\mathrm{Ce}^{+3}$ and establishes electron charge carriers in the material.

An investigation of the role that ionic and electronic conductivity play in determining the "microwave effect" has been initiated. Initial tests have been made with $\mathrm{ZrO}_{2}-12 \mathrm{~mol} \% \mathrm{CeO}_{2}$. Subsequent studies are being conducted using $\mathrm{YO}_{1.5}$ levels between 0 and $4 \mathrm{~mol} \%$ and a $\mathrm{CeO}_{2}$ level of $16 \mathrm{~mol} \%$. 


\title{
RESULTS AND DISCUSSION
}

\author{
Microwave Sintering of $\mathrm{ZrO}_{2}-12 \mathrm{~mol} \% \mathrm{CeO}_{2}$
}

The sintering results for both microwave and conventional firing in air and $\mathrm{N}_{2}-4 \%$ $\mathrm{H}_{2}$ atmospheres are shown in Figure 1. There are substantial differences between the air

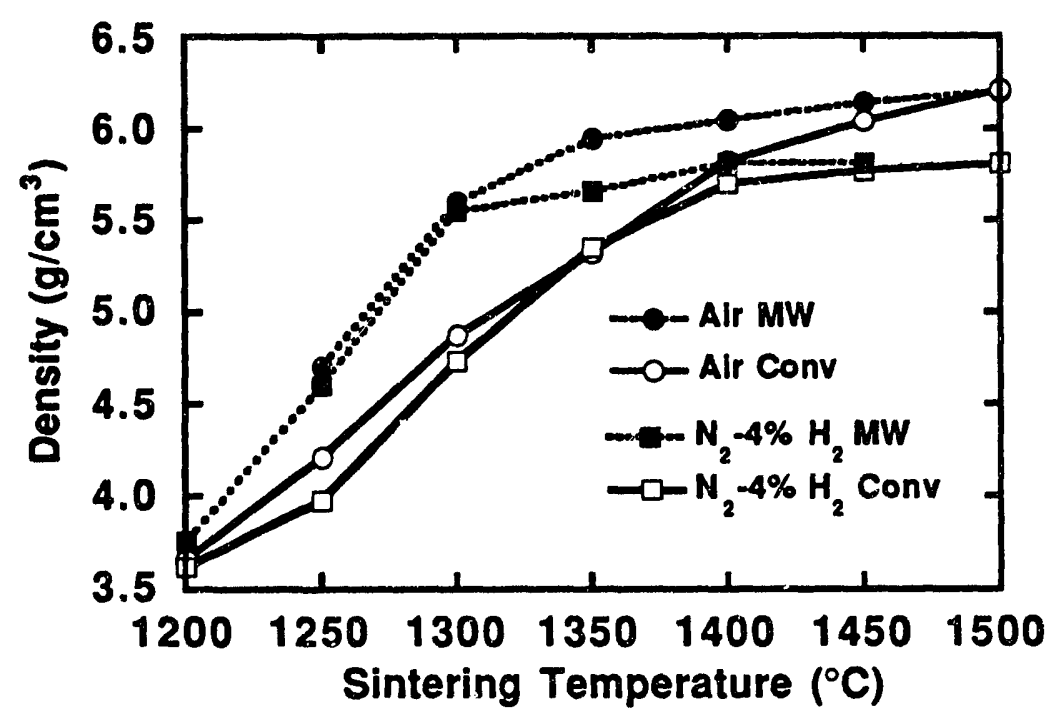

Figure 1. Sintering curves for $\mathrm{ZrO}_{2}-12 \mathrm{~mol} \% \mathrm{CeO}_{2}$ in air and $\mathrm{N}_{2}-4 \% \mathrm{H}_{2}$ under conventional and microwave conditions.

and $\mathrm{N}_{2}-4 \% \mathrm{H}_{2}$ firings and between the microwave and conventional firings. For both conventional and microwave sintering, the samples fired in air sintered to higher final densities than those fired in $\mathrm{N}_{2}-4 \% \mathrm{H}_{2}$. For both air and $\mathrm{N}_{2}-4 \% \mathrm{H}_{2}$ sintering, the samples that were microwave fired sintered to higher densities than those conventionally fired. The differences among the four test conditions can be understood as follows.

The difference in final density between the air and $\mathrm{N}_{2}-4 \% \mathrm{H}_{2}$ samples is caused by differences in the phase composition of the samples. The samples fired in air are completely in the tetragonal zirconia phase, as determined by $x$-ray diffraction. The samples fired in $\mathrm{N}_{2}-4 \% \mathrm{H}_{2}$ exhibit no tetragonal phase; the phase that is present does not appear to be monoclinic either, which is the phase that one would expect to observe. Effort is continuing to determine what this phase is that is stabilized by the reducing atmosphere. 
Furthermore, the conversion of the tetragonal phase, which is present during sintering, to this other phase during cool-down leads to severe checking and cracking of the samples.

The differences in sintering temperatures required to achieve a particular density by microwave and conventional firing can be explained by the presence of a "microwave effect." For both the air and $\mathrm{N}_{2}-4 \% \mathrm{H}_{2}$ firings, the samples fired in the microwave furnace sintered at $\sim 50^{\circ} \mathrm{C}$ lower than those fired in a conventional furnace. At temperatures up to $1300^{\circ} \mathrm{C}$, the microwave sintering behavior of samples fired in air and $\mathrm{N}_{2}-4 \% \mathrm{H}_{2}$ were the same. The deviation of the two curves at temperatures above $1300^{\circ} \mathrm{C}$ can be explained in terms of their different phase compositions as outlined above. The "microwave effect" was of the same magnitude for the samples fired in air and those fired in $\mathrm{N}_{2}-4 \% \mathrm{H}_{2}$.

\section{Synthesis of $\mathrm{ZrO}_{2}-16 \mathrm{~mol} \% \mathrm{CeO}_{2}-\mathrm{xYO}_{1.5}$ Powders}

A large effort was made during the past six months to synthesize the powders that are required to perform the electronic/ionic conductivity experiments. The particular compositions that were chosen were $\mathrm{ZrO}_{2}-16 \mathrm{~mol} \% \mathrm{CeO}_{2}-0.0,2.0$, \& $4.0 \mathrm{~mol} \% \mathrm{YO}_{1.5}$. These compositions were chosen in order to meet the following constraints. First, the materials must be single phase tetragonal $\mathrm{ZrO}_{2}$ at the sintering temperature. This simplifies the interpretation of the sintering kinetics. Also, the dielectric properties should change continuously with composition since no phase boundaries are crossed. Second, the materials should have a large electronic component in their conductivity under reducing conditions. Figure 2 shows that there is a factor of five difference in conductivity between air and argon atmospheres at $16 \mathrm{~mol} \% \mathrm{CeO}_{2}$. The increase in conductivity at low $\mathrm{pO}_{2}$ is totally due to electronic conduction. Third, the materials should have a substantial increase in ionic conductivity with increasing $\mathrm{YO}_{1.5}$ concentration. Chiou, et al2 have shown that the ionic conductivity of $\mathrm{ZrO}_{2}-10 \mathrm{~mol} \% \mathrm{CeO}_{2}-\mathrm{Y}_{2} \mathrm{O}_{3}$ alloys increases linearly by a factor of $\sim 20$ as the $\mathrm{YO}_{1.5}$ concentration increases from 0 to $4 \mathrm{~mol} \%$. The behavior of the $\mathrm{ZrO}_{2}$ $16 \mathrm{~mol} \% \mathrm{CeO}_{2}-\mathrm{YO}_{1.5}$ system should be similar.

The powders were synthesized using a coprecipitation route. Aqueous $\mathrm{Zr}, \mathrm{Ce}$, and $\mathrm{Y}$ acetate solutions were combined in appropriate molar ratios at their natural $\mathrm{pH}$ of $\sim \mathrm{pH} 4$. Concentrated $\mathrm{NH}_{4} \mathrm{OH}$ solution was added slowly to raise the $\mathrm{pH}$ to $\sim \mathrm{pH} 8$ at which point a combined $\mathrm{Zr}, \mathrm{Ce}$, and $\mathrm{Y}$ hydroxide gel was precipitated from solution. The gel was dried at $150^{\circ} \mathrm{C}$ to remove the excess water. Then it was calcined at $550^{\circ} \mathrm{C}$ to burn off the acetate 
residue and to convert the hydroxide to an oxide phase. After calcining, the powder was milled in an attritor mill to reduce the powders to primary particles. $\mathrm{ZrO}_{2}-12 \mathrm{~mol} \% \mathrm{CeO}_{2}$ milling media that had been fabricated at ORNL were used to prevent contaminating the $\mathrm{ZrO}_{2}-16 \mathrm{~mol} \% \mathrm{CeO}_{2}-\mathrm{xYO}_{1.5}$ powders with other cations. The final powders had an average particle size around $0.7 \mu \mathrm{m}$.

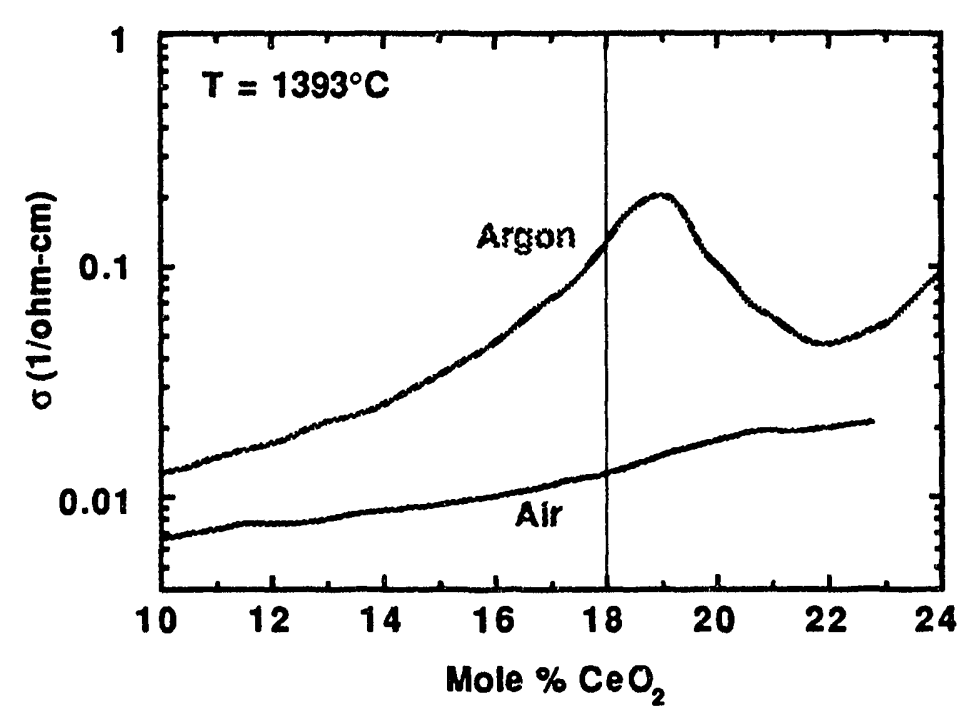

Figure 2. Conductivity of $\mathrm{ZrO}_{2}-\mathrm{CeO}_{2}$ alloys as a function of $\mathrm{CeO}_{2}$ concentration in air $\left(\mathrm{pO}_{2}=0.21\right)$ and in argon $\left(\mathrm{pO}_{2} \sim 4 \times 10^{-5}\right)$. The vertical line at $18 \mathrm{~mol} \% \mathrm{CeO}_{2}$ represents the phase boundary of the tetragonal phase. Redrawn from the data of Millet and Guillou. 1

\section{SUMMARY AND CONCLUSIONS}

It has been shown that the sintering of $\mathrm{ZrO}_{2}-12 \mathrm{~mol}^{2} \mathrm{CeO}_{2}$ is affected by the atmosphere that is used during sintering and by the method of heating that is used, conventional vs. microwave. The "microwave effect" that is observed consists of lowering the sintering temperature for both air and $\mathrm{N}_{2}-4 \% \mathrm{H}_{2}$ fired samples by $\sim 50^{\circ} \mathrm{C}$. Samples fired in $\mathrm{N}_{2}-4 \% \mathrm{H}_{2}$ were transformed from the tetragonal phase to another phase that is at present unidentified.

Powders were synthesized in the $\mathrm{ZrO}_{2}-16$ mol\% $\mathrm{CeO}_{2}-\mathrm{YO}_{1.5}$ system with $0.0,2.0$, \& 4.0 mol\% additions of $\mathrm{YO}_{1.5}$. These samples will be sintered in conventional and 
microwave conditions in the coming months to determine the role of total ionic conductivity and electronic conductivity in the "microwave effect."

\section{REFERENCES}

1. J. Millet and M. Guillou, "Determination de la Semi-Conduction Electronique dans L'Oxide Binaire Zircone-Oxyde de Cerium," J. Chim. Phys., 64, 1726-33 (1967).

2. B.-S. Chiou, H.-T. Dai, and J.-G. Duh, "Electrical Behavior of Ceria-Stabilized Zirconia with Rare-Earth Oxide Additives," J. Am. Ceram. Soc., 73 (4) 866-71 (1990). 


\title{
PNL-1: ADVANCED MATERIALS AND ELECTROCHEMICAL PROCESSES INVOLVING SOLID ELECTROLYTES
}

\author{
J. L. Bates, J. J. Kingsley, L. R. Peàerson, A. S. Rupaal, \\ W. J. Weber, C. F. Windisch Jr., and G. E. Youngblood \\ Pacific Northwest Laboratory \\ Richland, Washington 99352
}

\begin{abstract}
Impedance spectroscopy, in combination with an unbonded interface cell design, has been used successfully to assess the electrocatalytic rates of oxygen reduction at the electrode-electrolytegas interface. Intrinsic electrocatalytic activities of substituted yttrium and lanthanum manganite cathodes were determined as a function of temperature and oxygen partial pressure, independent of the morphology of those solids. The method provides a convenient means to screen the activity of electrode materials for use in energy conversion applications. Extrinsic electronic conductivity was introduced into predominantly ionically conducting zirconia-ceria solid solutions by doping with single and multivalent rare earth ions. Conductivities were further enhanced by partial reduction in hydrogen, particularly for ceria-rich compositions doped with multivalent ions. For zirconia-rich compositions, total conductivity decreased with increased dopant ion size due to steric effects. Lattice parameters increased linearly with the ceria concentration, and were sensitive to whether the dopant was of single or multiple valence.
\end{abstract}

\section{INTRODUCTION}

The purpose of this project is to develop advanced ceramic materials for utilization in solid oxide fuel cells and other electrochemical technologies related to the broad, clean and efficient use of fossil fuels, especially coal. New ceramic materials are being developed for use as electrolytes, electrodes, bipolar interconnections, membranes and catalysts in solid state electrochemical devices operating at high temperatures. Novel synthesis and fabrication methodologies enable new materials, forms and structures to be produced. Measurement techniques are developed that permit the kinetics and mechanisms of electrocatalytic reactions occurring at electrode/electrolyte interfaces to be probed.

Evaluation of intrinsic electrocatalytic activities of electrode materials by complex impedance spectroscopy and the preparation and characterization of mixed electronic-ionic conductors in the zirconia-ceria system are described in this paper. Methods have been developed to measure catalyzed rates of oxygen reduction at the electrode/electrolyte/gas interface that is independent of morphology of the solids, thus providing a convenient means to screen electrode materials for use in energy conversion devices. Extrinsic electronic conductivity was introduced by doping of single and multivalent ions into predominantly ionically-conducting solids. The mixed conductors are potentially useful as electrode materials and as gas separation membranes. 


\section{ELECTROCHEMICAL PROCESSES}

The performance of high-temperature $\left(\mathrm{T} \geq 800^{\circ} \mathrm{C}\right)$ solid electrolyte systems often is dependent upon the kinetics of electrochemical processes that occur at solid-gas interfaces. Changes at these interfaces can alter both the reaction mechanisms and the rates of the reactions. The purpose of this research is to determine these electrochemical reactions and how they are influenced by material and interfacial properties, electrical current and potential, temperature, gaseous environment and time.

Solid oxide fuel cell (SOFC) performance can be limited by low or deteriorating rates of oxygen reduction at the cathode-electrolyte interface. Oxygen reduction rates depend upon: (1) the rate at which reacting constituents arrive at reaction sites, $(2)$ the number of available reaction sites, (3) the activation energy for reaction and temperature, and (4) the oxygen activity at the reaction sites. The first item depends on diffusion pathways through the cathode material (cathode morphology) and is very important in SOFC design and performance. However, this research initially is directed at optimizing intrinsic electrochemical properties of the cathode materialelectrolyte interface. Consequently the effects of morphology were eliminated.

An experimental method has been designed to quantify the cathodic performance of a particular electrode material. The method utilizes ac impedance measurements in conjunction with a unique unbonded interface cell (UIC) design. Details of the UIC design were reported previously. 1 In this cell design, a small pellet of electrode material with a flat, roughened surface was pressed against a similarly roughened electrolyte material. It is estimated that the rough mating surfaces make only about ten electrical contact points $/ \mathrm{cm}^{2}$ cross-sectional area. The surrounding gas atmosphere had sufficient access to the contact points to reach uniformly the physical boundary line between the solid and gas phases. This boundary line is called the triple phase boundary (tpb). The length of the tpb is proportional to a localized surface region at which oxygen reduction takes place. This ryaction surface is referred to as the "effective reaction length" or the ERL. The ERL can be determined using impedance spectroscopy (IS) with the UIC design. It also can be determined by direct measurement of the circumference of a single point contact electrode.

Once the ERL was determined for a particular interface, the electrochemical activity could then be determined independently of the surface morphology. The normalized reaction rate, or "specific activity" (Sp Act), is defined by:

$$
\text { Sp Act }=\left(E R L \times R_{p}\right)^{-1}(S / c m)
$$

where $R_{p}$ is a polarization resistance obtained from IS measurements. The specific activity, with units of electrical conductivity, is an intrinsic material property independent of morphology. 
For electrode-electrolyte surfaces with multiple point contacts separated by distances that are large in comparison to the radii " $r$ " of the point contacts, the net contact resistance for " $i$ " parallel point contact resistances is given by the expression:2

$$
R_{c}=\left(4 \sigma \sum r_{i}\right)^{-1}
$$

where $\sigma$ is the ionic conductivity of the electrolyte. Taking the ERL as the total length of tpb between surfaces with multiple point contacts as $2 \pi \sum r_{i}$, the ERL can be expressed as:

$$
\mathrm{ERL}=\pi /\left(2 \sigma \mathrm{R}_{\mathrm{c}}\right)
$$

When using the UIC design, $\mathrm{R}_{\mathrm{c}}, \mathrm{R}_{\mathrm{p}}$, ERL and $\mathrm{Sp}$ Act are determined in situ from a single IS scan as a function of temperature, oxygen partial pressure $\mathrm{p}\left(\mathrm{O}_{2}\right)$, applied dc potential, time and material composition.

Choice of cathode materials can be of significant importance in minimizing the cathodic contribution to the overall polarization resistance in an SOFC, which typically is $25-75 \%$ of the overall value depending on SOFC design. ${ }^{3}$ Anodic performance, diffusional processes, and electrolyte conductivity also contribute to the overall polarization. If the cathodic polarization resistance were to be lowered to perhaps $0.2 \Omega-\mathrm{cm}^{2}$ or less, other contributions to the overall polarization would dominate.

Specification of a maximum cathodic polarization resistance, $R_{p} c$, also defines the minimum specific activity for cathode materials, following Equation (1). A typical value of the ERL for a thin, porous oxide cathode material sintered onto a dense zirconia electrolyte is $10^{3}$ $\mathrm{cm} / \mathrm{cm}^{2}$ electrode surface area, although this value can vary considerably. ${ }_{4}$ For a $R_{\mathrm{p}} \mathrm{climited}$ to $0.2 \Omega-\mathrm{cm}^{2}$, the limit on the cathodic specific activity is given by:

$$
\text { Sp Act } \geq 1 /\left(0.2 \Omega-\mathrm{cm}^{2}\right)\left(10^{3} \mathrm{~cm} / \mathrm{cm}^{2}\right)=0.005 \mathrm{~S} / \mathrm{cm} \text {. }
$$

This minimum value for specific activity, an intrinsic material property, provides a useful benchmark by which the suitability of cathode compositions may be assessed. Clearly, a low and stable cathodic polarization resistance, the goal for an acceptable SOFC cathode material-electrolyte interface, requires both a high and stable specific activity and ERL. 


\section{Experimental Approach, Electrochemical Processes}

Several calcium- or strontium-doped lanthanum manganite compositions were prepared by the glycine-nitrate process. ${ }^{5}$ Calcium-doped yttrium manganite compositions were prepared by the Pechini process. 6 All of the $\mathrm{ABO}_{3}$-type perovskite compounds were prepared to have an A-to-B site ratio of one. The code $\mathrm{YCxM}$ is used to represent the compositional series $\mathrm{Y}_{1-\mathrm{x}} \mathrm{Ca}_{\mathrm{x}} \mathrm{MnO}_{3}$ with the doping mole fraction $x$ in tenths, $\mathrm{LSxM}$ refers to the series $\mathrm{La}_{1-\mathrm{x}} \mathrm{Sr}_{\mathrm{x}} \mathrm{MnO}_{3}$ and $\mathrm{LCxM}$ refers to the series $\mathrm{La}_{1-\mathrm{x}} \mathrm{Ca}_{\mathrm{x}} \mathrm{MnO}_{3}$.

The prepared powders were pressed into discs and sintered at temperatures in the range of $1250-1450^{\circ} \mathrm{C}$ in air for times required to achieve at least $90 \%$ of theoretical density. The actual cathode used in the UIC was a small, 2-6 mm-diameter pellet that was core-drilled from the discs. Generally, the flat pellet surfaces were rough-ground on a $15 \mu \mathrm{m}$ diamond wheel. In some cases, the flat surfaces were polished to a $1-\mu \mathrm{m}$ diamond finish or more coarsely ground to a $30 \mu \mathrm{m}$ diamond finish. Examination by SEM of the roughened surfaces revealed many large, $\approx 10 \mu \mathrm{m}$ wide, surface grooves and a surface texture similar in appearance to an intergranular fracture surface. Except for the $1 \mu \mathrm{m}$ diamond-polished surfaces, it was obvious that only a few protruding grains could make intimate contact with the electrolyte surface in the UIC design. For reference, a solid platinum disc coarsely grooved with 280 -grit SiC. A single-point contact, platinum-bead sample with a truncated-cone shape also were prepared.

Each cathode material was mounted for IS analysis with an electrolyte disc ( 8.0 mole percent yttria-stabilized zirconia or $8 Y S Z$ ) in a three-electrode UIC configuration. At the conclusion of each IS run, since the interface was unbonded, samples could be exchanged without changing the zirconia electrolyte disc.

The electrode-electrolyte UIC was mounted inside an alumina tube in a furnace and heated in flowing air to $900^{\circ} \mathrm{C}$ and allowed to remain at that temperature for two or three days before commencing IS measurements. Impedance data were collected over a frequency range of $0.1 \mathrm{~Hz}$ to $60 \mathrm{kHz}$ using either of the two following IS acquisition systems: (1) a Solartron 1255 Frequency Response Analyzer, an EG\&G PAR model 273 Potentiostat; or (2) a Solartron 1250 Frequency Response Analyzer and a Solartron 1286 Electrochemical Interface. To match SOFC operating conditions as closely as possible, the oxygen partial pressure $\mathrm{p}\left(\mathrm{O}_{2}\right)$ was varied from 1.0 to $10^{-4} \mathrm{~atm}$. by appropriate mixing of air or oxygen with argon gas and the temperature range was maintained between 700 and $950^{\circ} \mathrm{C}$. This temperature range assured easy exchange of sample or electrolyte disc at the conclusion of the IS runs by minimizing possible interfacial reactions.

The IS data were analyzed using either the software program EQUIVCRT7 or ZSIM/CNLS8 and with either an LR(RQ)(RQ)(RQ) or an LR(RQ)(RQ)(RQ)(RQ) equivalent circuit model. In these models, the $\mathrm{L}$ component is an inductance in series with the UIC and is attributed 
to the length of loosely coiled platinum lead wire connected to the working electrode or cathode material side of the UIC. For similar test conditions, the least-squares fitting routine generally assigned the same values for $L$. The first $R$, in series with $L$, represents the contact resistance $R_{c}$. Small corrections to $R_{c}$ (2-10 ohms, depending upon temperature) were applied to account for the resistance of the platinum lead wire and the bulk resistance of the electrolyte disc. The remaining R's and Q's within the parentheses represent the resistive-like and capacitive-like electrochemical characteristics of the oxygen reduction reaction at the multiple point contact interface between the cathode material and the zirconia electrnlyte.

\section{Results and Discussion, Electrochemical Processes}

From single IS scans at each condition of temperature, oxygen partial pressure, applied dc potential, and electrode composition, specific activities were calculated. A typical scan is given in Figure 1. The solid line through the data points indicates a satisfactory model-fit. Extrapolation of the model-fit to the real axis at the high $(60 \mathrm{kHz})$ or low $(0.1 \mathrm{~Hz})$ frequency ends of the IS curve yielded $R_{c}$ and $R_{1 f}$, respectively. The cathodic polarization resistance $R_{p} c$ was calculated from the difference $R_{l f}-R_{c}$.

Effective reaction lengths that were determined from IS scans were found to depend on surface treatment and were generally in good agreement with values determined by direct measurement using microscopy. The magnitude of the calculated ERL increased with increased coarseness of the polishing media: the use of 1,15 and $30 \mu \mathrm{m}$ diamond paste gave ERL values of $0.2,0.8-2.5$, and $3.0-8.5 \mathrm{~cm} / \mathrm{cm}^{2}$, respectively. For the single platinum point, the ERL value determined from Equation (3) agreed within $20 \%$ with direct measurements by SEM of the circumference of the platinum tip.

Conventionally-sintered, porous electrode/electrolyte combinations typically yisld ERL values a factor of 1000 larger than those obtained using the UIC approach. Mizusaki et al. 4 reported ERL ranging from 2000 to $10,000 \mathrm{~cm} / \mathrm{cm}^{2}$, dep 'ding on sintering temperature, for porous $\mathrm{La}_{0.6} \mathrm{Ca}_{0.4} \mathrm{MnO}_{3}$ electrodes sintered onto dense stabilized zirconia. These were determined by SEM examination of cross-sectioned interfaces. Small ERL values are desired in the UIC approach, because polarization resistances are increased by the same margin for a given cathodic specific activity, following Equation (1). High polarization resistances, although obviously not desirable in an operating fuel cell, simplify the assessment of specific cathodic activity and other important processes by impedance spectroscopy. 


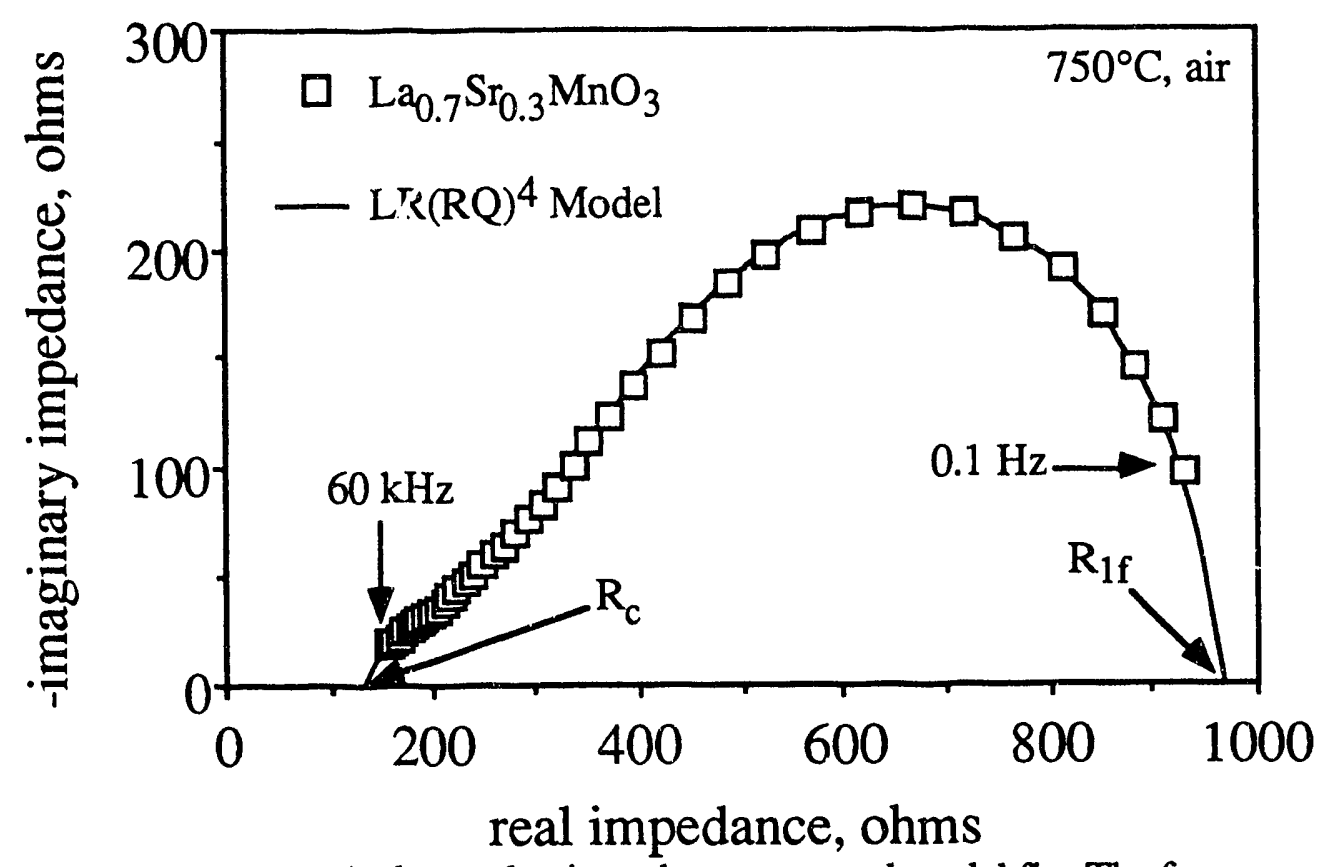

Figure 1. Typical complex impedance scan and model fit. The frequency range was $0.1-60 \mathrm{kHz}$. Resistances $R_{c}$ and $R_{1 f}$ are indicated along the real impedance axis. The cathodic polarization resistance, $R_{p}$, was obtained from $R_{1 f}-R_{c}$.

For the cathode material-electrolyte combinations tested, it was observed that the contact resistance $R_{c}$ decreased as the test temperature was increased. The contact resistance, defined in Equation (3), depends on the conductivity of the electrolyte as well as on multiple contact points between the electrode and electrolyte. As expected, activation energies for substituted manganite electrodes, calculated from plots of $\log T / R_{c}$ vs $1 / T$, were consistent with that for ionic conduction $(0.92 \mathrm{eV})$ measured for Toson 8YSZ. Activation energies obtained using platinum electrodes also were consistent with ionic conduction in stabilized zirconia. Generaily, the ERL values were reproducible after temperature cycling in the 700 to $950^{\circ} \mathrm{C}$ range and did not depend upon $\mathrm{p}\left(\mathrm{O}_{2}\right)$ wilhin a $10^{-3}$ to 1 atm range.

In the operating SOFC temperature range $\left(900-1000^{\circ} \mathrm{C}\right)$, all of the tested perovskite cathode materials gave intrinsic specific activity values that exceeded what is considered to be the lower acceptability limit of $0.005 \mathrm{~S} / \mathrm{cm}$ (cathodic polarization resistance of $0.2 \Omega-\mathrm{cm}^{2}$ in a practical SOFC), and therefore would be acceptable cathode materials by this criteria. Specific activities are given as a function of reciprocal temperature in Figure 2. As a family, the LCxM compositions gave the highest specific activity values. The specific activity of LC5M sarnple was somewhat higher at all temperatures tested than the LC2M sample, which has a lower level of calcium doping. Specific activity values for both of these LCxM compositions in air exceeded $0.005 \mathrm{~S} / \mathrm{cm}$ down to about $700^{\circ} \mathrm{C}$. The specific activity values for the LS3M sample were abcut a factor of four higher 


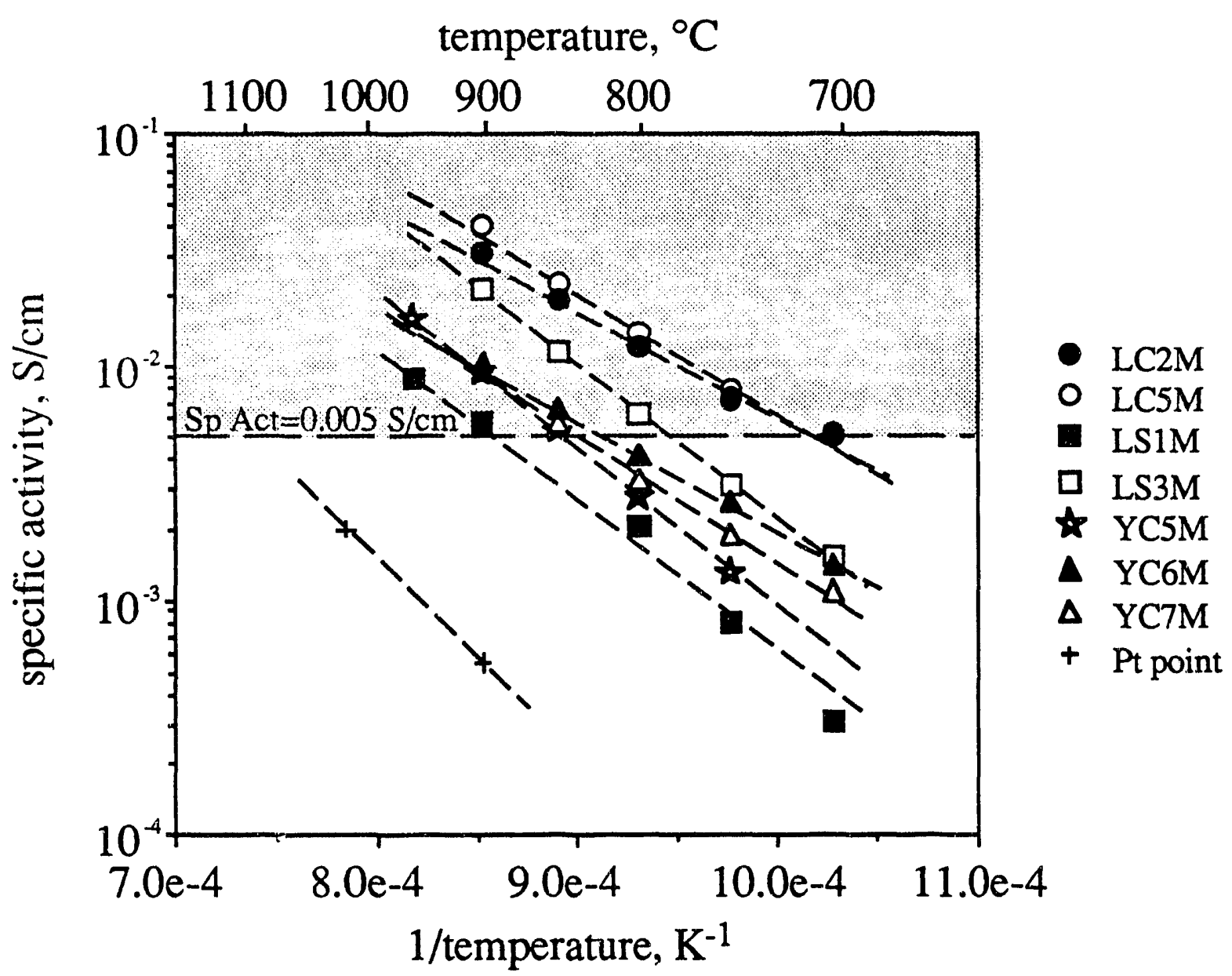

Figure 2. Temperature dependence of the specific activity in air for platinum and several perovskite cathodes. A specific activity of $0.005 \mathrm{~S} / \mathrm{cm}$ is considered the minimum practical value for use as a cathode in a solid oxide fuel cell.

than values for the LS IM sample, a reference SOFC cathode composition. 9 In fact, the specific activity of LS $1 \mathrm{M}$ just exceeded the $0.005 \mathrm{~S} / \mathrm{cm}$ limit at $900^{\circ} \mathrm{C}$, while the LS3M specific activity exceeded this limit down to about $800^{\circ} \mathrm{C}$. There was little difference in the specific activity values for the three $\mathrm{YCxM}$ compositions $\left(\mathrm{x}=0.5,0.6\right.$ and $0.7 \mathrm{Ca}$ ) in the $900-1000^{\circ} \mathrm{C}$ temperature range.

For all the perovskite cathode materials tested, more detailed examination of the shapes of the impedance spectra revealed that the overall polarization process for oxygen reduction was rather complex and made up of at least two or more fundamental steps. By deconvolution of the overall polarization into its separate components, the existence of a unique higher and a unique lower frequency process was indicated. The relative specific activity of the higher frequency process was $\mathrm{p}\left(\mathrm{O}_{2}\right)$ independent, with activation energies in the 0.5 to $0.9 \mathrm{eV}$ range. The relative specific activity of the lower frequency process depended on $\mathrm{p}\left(\mathrm{O}_{2}\right)^{\mathrm{n}}$ with $\mathrm{n}$ in the $0.5-1$ range and gave activation energies in the 1.1 to $1.9 \mathrm{eV}$ range. 
High and low frequency processes are believed to be associated with charge transfer and oxygen dissociation, respectively. The relative influence of each process on oxygen reduction rates changed significantly with temperature and $\mathrm{p}\left(\mathrm{O}_{2}\right)$. Oxygen dissociation was rate-limiting at lower temperatures and/or lower $\mathrm{p}\left(\mathrm{O}_{2}\right)$. The relative influence of these two processes accounts for much of the variation of the apparent activation energies, especially for the YCxM compositions. In general, under typical SOFC operating conditions, high and low frequency processes appeared to influence the overall oxygen reduction rate to a similar extent. All perovskite compositions tested so far behaved similarly with regard to the overall oxygen reduction process.

The shapes of the IS curves and the magnitudes of the specific activites could be changed dramatically by an applied external dc bias potential or by treating the UIC for a short period of time with a fairly large $(\geq \pm 500 \mathrm{mV}) \mathrm{dc}$ potential. Application of an anodic potential increased the specific activity of a YC5M sample by more than 20 percent, while application of a cathodic potential lowered the specific activity by approximately a factor of two. The original activity could be restored by the re-application of an anodic potential. The electrocatalytic activity of LSxM samples could also be enhanced, but by an applied cathodic potential. This finding has important consequences when considering the electrochemical stability of different cathode compositions. It is possible that a deteriorating specific activity can be enhanced by in situ electrocherinical treatment. Likewise, it may be possible to electrochemically enhance the specific activity of a cathode material with attractive processing properties but relatively low electrocatalytic activity.

\section{Summary, Electrochemical Processes}

Specific activity values for oxygen reduction were determined as a function of temperature and $\mathrm{p}\left(\mathrm{O}_{2}\right)$ for substituted lanthanum manganite and yturium manganite perovskite cathodes and for platinum, using an unbonded interface cell design and ac impedance spectroscopy. All of the perovskite material compositions tested had acceptable $(\geq 0.005 \mathrm{~S} / \mathrm{cm})$ specific activities in air in the SOFC temperature operating range $\left(900-1000^{\circ} \mathrm{C}\right)$. Also, their specific activites exceeded that of platinum by at least an order of magnitude.

By deconvolution of impedance spectra, overall oxygen reduction process appeared to be composed of three or more fundamental processes. Two of these jrocesses, charge transfer and oxygen dissociation, were about equally important in limiting the oxygen reduction rate for typical operating conditions of temperature and $\mathrm{p}\left(\mathrm{O}_{2}\right)$ for an SOFC cathode.

Impedance spectral shapes and the magnitudes of the specific activities could be dramatically changed by an applied external dc bias potential or by treating the UIC for a short period of time with a fairly large $(\geq 500 \mathrm{mV}) \mathrm{dc}$ potential. These results suggest that a deteriorating specific activity in an operating fuel cell could be enhanced in situ by electrochemical treatment. 


\section{MIXED ELECTRONIC CONDUCTORS}

Mixed ionic-electronic conductors (MIEC's) are technologically important materials, with applications as semipermeable membranes in gas separation, as electrodes in solid oxide fuel cells, and as electrocatalysts. In such a material, oxygen transport can occur under open circuit conditions, driven only by a gradient in the chemical potential of oxygen. Oxygen ion currents will flow across a membrane from regions of high oxygen partial pressure to low partial pressure, charge-compensated by electron flow in the opposite direction. For steam dissociated at elevated temperatures, for example, mixed conductors can be used efficiently to separate oxygen from hydrogen.10 An increase in the rate of charge transfer reactions and a reduction in polarization effects are among the advantages of the use of mixed conductors as electrode materials in solid oxide fuel cells.

The approach used in this study was to introduce extrinsic electronic conductivity in zirconia-based materials that exhibited high ionic conductivity initially, thereby producing mixed ionic-electronic conductors. 10,11 This was accomplished through doping with metal oxides that are found in multiple valence states. Such doping is believed to enhance electronic conduction via small polaron hopping at reduced oxygen partial pressures. 12 Zirconia-ceria solid solutions were modified by doping with yttria, ytterbia, terbia, and praseodymia. All of these dopants are known to stabilize zirconia in the fluorite structure. All can exist in the +3 state; however, $\operatorname{Pr}$ and $\mathrm{Tb}$ can also exhibit a valence of +4 . Cerium also is a multivalent ion. At high temperature or low $\mathrm{pO}_{2}, \mathrm{a}$ redox equilibrium exists between $\mathrm{Ce}^{+4}$ and $\mathrm{Ce}^{+3}$, accountable for $\mathrm{n}$-type electronic conductivity in cerium oxide. 12 When more than one multivalent ion is included, interactions between those ions can be an important factor in determining conductivities. For example, higher valence states of $\operatorname{Pr}$ $(>+3)$ are reported to be favored and controlled by $\mathrm{Ce}^{+4}$ ions in Ce-Pr-O systems. ${ }^{13-15}$ Mixed conductors prepared in this study exhibited relatively high conductivities, depending on the identity and concentration of the dopant and on the extent of reduction. Such materials are potentially useful as advanced electrodes and as gas separation membranes.

\section{Experimental Approach, Mixed Conductors}

Compositions that were prepared in this study are $\left(\mathrm{MO}_{\mathbf{y}}\right)_{0.2}\left(\mathrm{ZrO}_{2}\right)_{0.8-\mathrm{x}}\left(\mathrm{CeO}_{2}\right)_{\mathbf{x}}$, where $\mathrm{M}=\mathrm{Y}, \mathrm{Yb}, \mathrm{Tb}$ and $\mathrm{Pr}, \mathrm{x}=0-0.8, \mathrm{y}=1.5$ for $\mathrm{Y}$ and $\mathrm{Yb}$ and $\mathrm{y}=1.5-2.0$ for $\mathrm{Tb}$ and Pr. These materials were synthesized using Glycine-Nitrate Process (GNP). 5 The powders had BET surface area of $22-64 \mathrm{~m}^{2} / \mathrm{g}$. Powder were passed through a 200-mesh sieve and pressed into bars for conductivity measurements. The powders were uniaxially pressed in a rectangular die at $10,000 \mathrm{psi}$ and subsequently cold isostatically pressed at $20,000 \mathrm{psi}$. The bars were sintered in air 
at $1575^{\circ} \mathrm{C}$ for $20 \mathrm{hrs}$. Bulk densities of the sintered specimens were $90-95 \%$ of the theoretical density depending on the Ce content, measured using Archimedes immersion method in ethanol. The open porosity was much less $(0.4-0.7 \%)$ for compositions with $x<0.6$ and about $4 \%$ for compositions with $x>0.6$. The closed porosity was about $10 \%$ for compositions with $x<0.2$ and about $2-4 \%$ for samples with $x>0.2$.

Structural parameters and electrical conductivities were evaluated for the sintered samples. Precise lattice parameters were calculated from $\mathrm{x}$-ray diffraction (XRD) data using least square cell refinement procedures. The DC electrical conductivity was measured using a four probe dc pulse method. The measurements were made in air from $500-1200^{\circ} \mathrm{C}$ and in $\mathrm{Ar} / 4 \% \mathrm{H}_{2}\left(10^{-10} \mathrm{~Pa}\right.$ oxygen pressure) from $500-1050^{\circ} \mathrm{C}$. Samples were annealed at $1050^{\circ} \mathrm{C}$ for $12 \mathrm{hrs}$ in $\mathrm{Ar} / 4 \% \mathrm{H}_{2}$ prior to the conductivity measurement in the same atmosphere. Samples are referred to as YZC, YbZC, PZC and $\mathrm{TbZC}$ with corresponding numbers to represent their composition (e.g. YbZC-271 represents $\left(\mathrm{YbO}_{1.5}\right)_{0.2}\left(\mathrm{ZrO}_{2}\right)_{0.7}\left(\mathrm{CeO}_{2}\right)_{0.1}$ composition).

\section{Results and Discussion, Mixed Conductors}

All solid solutions in the series $\left(\mathrm{MO}_{\mathbf{y}}\right)_{0.2}\left(\mathrm{ZrO}_{2}\right)_{0.8-\mathrm{x}}\left(\mathrm{CeO}_{2}\right)_{\mathbf{x}}$, where $\mathrm{M}=\mathrm{Y}, \mathrm{Yb}, \mathrm{Tb}$, and Pr, were found by $\mathrm{x}$-ray diffraction to exhibit a cubic fluorite-type structure. Lattice parameters for each series increased linearly with the veria content, as shown in Figure 3. The linear increase in lattice parameters with ceria additions is indicative of a uniform dispersion of dopants in these ternary compositions. The first term of each expression included in Figure 3 corresponds to the lattice parameter of zirconia stabilized only by $\mathrm{Y}, \mathrm{Yb}, \mathrm{Tb}$, and $\operatorname{Pr}$ (no ceria); this term increases in the order $\mathrm{Yb}<\mathrm{Y}<\mathrm{Tb}<\mathrm{Pr}$ due to their increasing ionic sizes. The PZC-280 composition (no ceria) showed traces of monoclinic $\mathrm{ZrO}_{2}$. Apparently, in the absence of ceria, higher percentages of praseodymia are required for complete stabilization.

The lattice expansion within each series occurred as a consequence of the substitution of zirconium ions by cerium ions of larger ionic radius $\left(\mathrm{Zr}^{4+}=0.84 \AA, \mathrm{Ce}^{4+}=0.97 \AA\right) .16$ The slope in the linear equations is identical within experimental error for $\mathrm{Y}$ and $\mathrm{Yb}$, neither of which exhibit multiple oxidation states. The ions of $\operatorname{Pr}$ and $\mathrm{Tb}$ have a variable oxidation state of +3 and between +3 and +4 and the slopes are 0.301 and 0.317 , respectively. It has been reported that the oxidation states of Pr in Ce-Pr-O system is controlled by the cerium content.13-15 Similar effects could influence the oxidation states of $\mathrm{Pr}$ and $\mathrm{Tb}$ in the present $\mathrm{Zr}-\mathrm{Ce}-\mathrm{O}$ systems and cause the variation in linear dependance of lattice parameters with $\mathrm{Ce}$ content. Such an rffect would not only affect the structure (lattice parameters) but also the electrical properties. 


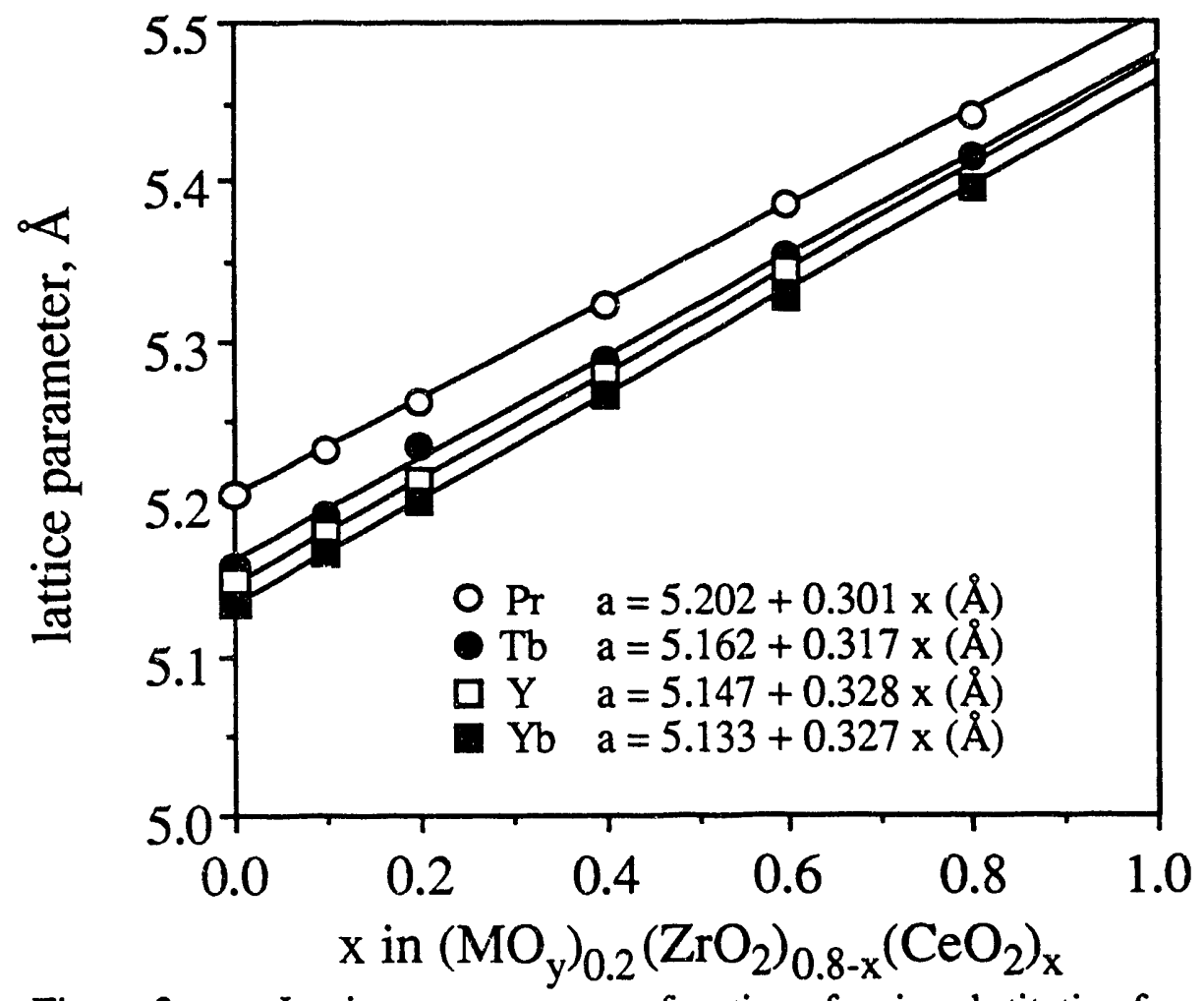

Figure 3. Lattice parameters as a function of ceria substitution for zirconia.

Electrical conductivities for all four series of solid solutions were sensitive to the extent of ceria additions. Overall conductivities measured in air initially decreased with increased ceria content up to $\mathrm{x}=0.4$, and then increased with ceria content for $\mathrm{x}>0.4$. Results obtained for the four series at $1000^{\circ} \mathrm{C}$ in air are given in Figure 4. Results for the TbZC samples measured in a reducing environment, also included in Figure 4, gave lower conductivities at low ceria content, but higher conductivities at high ceria content than when measured in air. The initial decrease in conductivity with increased ceria content is attributed to a lowering of the ionic component of the overall conductivity. Introduction of small amounts of ceria is believed to increase the lattice strain, accompanied by an increase in: the defect association energy. Such behavior leads to large defect pair formation enthalpies and clecreased ionic conductivity. 17 However, at $x>0.4$, the lattice expansion due to larger sized Ce4+ (Figure 3), could be sufficiently high to introduce more open paths for the vacancy mobility and lead to increased conductivity.

Electrical conductivities decreased with increased dopant cation size for zirconia-rich s? mples $(x<0.4)$, as can be seen in Figure 4. Radii of the stabilizing ions increase in the order $\mathrm{Yb}^{3}+(0.985 \AA)<\mathrm{Y}^{3}+(1.019 \AA)<\mathrm{Tb}^{3}+(1.04 \AA)<\mathrm{PT}^{3}+(1.126 \AA)$ for 8 -fold coordination, 16 whereas conductivities follow the opposite trend. This can be explained in terms of a steric blocking effect, where the migration of oxygen vacancies is more effectively blocked by larger 


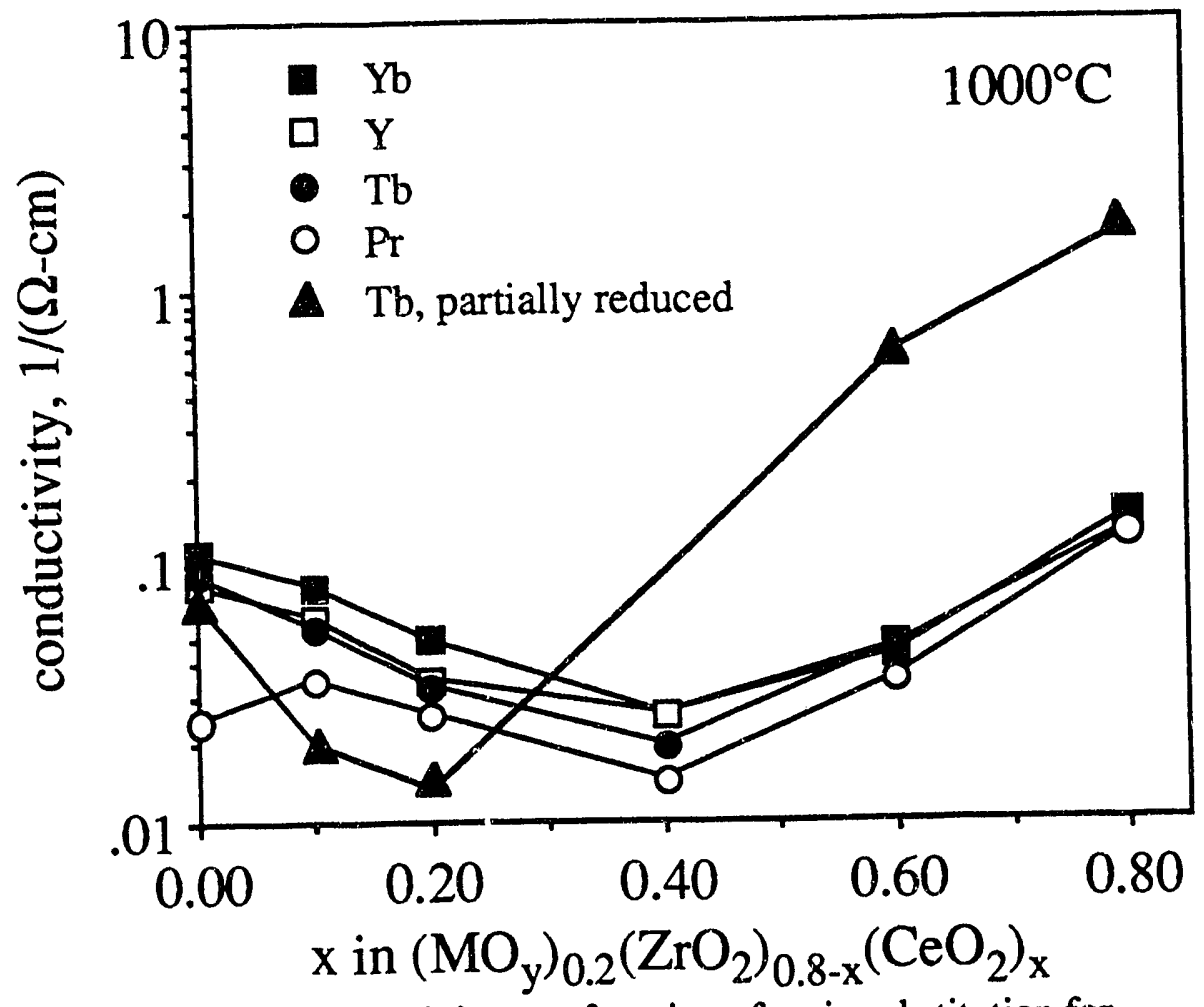

Figure 4. Conductivity as a function of ceria substitution for zirconia. Partial reduction of the Tb-containing sample was performed in $4 \% \mathrm{H}_{2} / \mathrm{Ar}$ at $1050^{\circ} \mathrm{C}$.

dopant cations. 18 This trend was no longer apparent for compositions where $\mathrm{x}>0.4\left(\mathrm{CeO}_{2}\right.$-rich compositions). As shown in Figure 3, lattice dimensions increased with cerium content, presumably because the $\mathrm{Ce}^{4+}$ ion is larger than the $\mathrm{Zr}^{4+}$ ion. A given dopant would thus be expected to introduce less strain in a ceria-rich composition than in a zirconia-rich material.

Under reducing conditions, the minima in conductivity versus ceria content was shifted towards lower ceria concentrations, and conductivities for ceria-rich samples are much enhanced, also included in Figure 4. Without changing the basic fluorite structure, $\mathrm{CeO}_{2}$ can be reduced to about $\mathrm{CeO}_{1.67}$ at $1000^{\circ} \mathrm{C} .12$ This partial reduction would introduce an oxide ion vacancy concentration of $16.5 \%$ of the oxide ion sites in the $\mathrm{CeO}_{2}$ crystal lattice. In fact, the composition investigated presently showed considerable weight losses (up to $2 \mathrm{wt} . \%$ ) during pre-treatment in $\mathrm{Ar} / 4 \% \mathrm{H}_{2}$ at $1050^{\circ} \mathrm{C}$. Some of these vacancies are mobile and could increase the ionic conductivity. Also, the reduction introduces mobile electrons, which are associated with the $\mathrm{Ce}^{4+}$ ions (polarons). Partial reduction is thus expected to enhance both the ionic and electronic contributions to the overall conductivity. 
The electrical conductivity parameters , pre-exponential factor (C) and the activation energy $\left(E_{a}\right)$ were determined using the expression:

$$
\sigma \mathrm{T}=\mathrm{C} \exp \left(-\mathrm{E}_{\mathrm{a}} / \mathrm{kT}\right)
$$

Plots of $\sigma \mathrm{T}$ versus reciprocal temperature are given in Figures 5 and 6 for TbZC samples measured in air and in hydrogen, respectively. For fixed valent $\mathrm{Y}$ and $\mathrm{Yb}$ ions, the pre-exponential factor (C) for the entire composition was in the $10^{6}$ range. For the mixed valent $\mathrm{Tb}$ and $\mathrm{Pr}$, preexponential factors were approximately $10^{6}$ for samples with low cerium content $(x=0.0=0.2)$ and $10^{5}$ and $10^{4}$, respectively, for samples with high cerium content (at and above $x=0.4$ ). This indicates that number of charge carriers was lowered in such compositions, which is attributed to the trapping of charge carriers (electrons) by mixed valent $\mathrm{Pr}$ and $\mathrm{Tb}$ ions, both of which have higher reduction potentials than Ce4+.19 Interestingly, conductivity of TbZC-208 PZC-262 and 208 (in air) samples showed a non-linear behavior at lower temperatures $<750^{\circ} \mathrm{C}$. Such a behavior has been observed in $\mathrm{Tb}-\mathrm{Ce}-\mathrm{O}$ system earlier, which has been attributed to a redox equilibrium between the co-existing, mixed valent ions. 20

Differences in the activation energies for fixed valent and mixed valent stabilizers are also evident. For $\mathrm{YbZC}$ and $\mathrm{YZC}$ compositions, activation energies were nearly constant at $1.2 \pm 0.1$ $\mathrm{eV}$ for $0<\mathrm{x}<0.8$. But in the mixed valent TbZC and $\mathrm{PZC}$ compositions, $\mathrm{E}_{\mathrm{a}}$ decreased continuously from 1.2 to $0.6 \mathrm{eV}$ as the $\mathrm{CeO}_{2}$ content is increased from $\mathrm{x}=0$ to 0.8 . This effect was more pronounced in compositions of PZC than TbZC. This could be due to a decreased tendency to form associated defects with mixed valent $\mathrm{Tb}$ and $\mathrm{Pr}$ than with $\mathrm{Y}$ or $\mathrm{Yb}$ ions. 17 The lowered activation energy more likely reflects the enhanced contribution of the electronic portion to the overall conductivity, through the creation of small polaron sites by multivalent dopants.

In consideration of both structural and electrical conductivity results, it would appear that the addition of stabilizers of mixed valence, such as $\mathrm{Tb}$ and $\mathrm{Pr}$, is an effective means to obtain mixed conduction in zirconia-ceria systems. Partial reduction can be used to substantially enhance electrical conductivities. The materials are potentially useful as electrodes in electrochemical devices operating at high temperatures and as a gas separation membrane.

\section{ACKNOWLEDGEMENTS}

The authurs gratefully acknowledge Dr. J. Stevenson, University of Missouri-Rolla, for providing three yttrium calcium manganite samples used in this study, R. W. Stephens for performing electrical conductivity measurements and B. W. Arey for assisting with ac impedance measurements. 


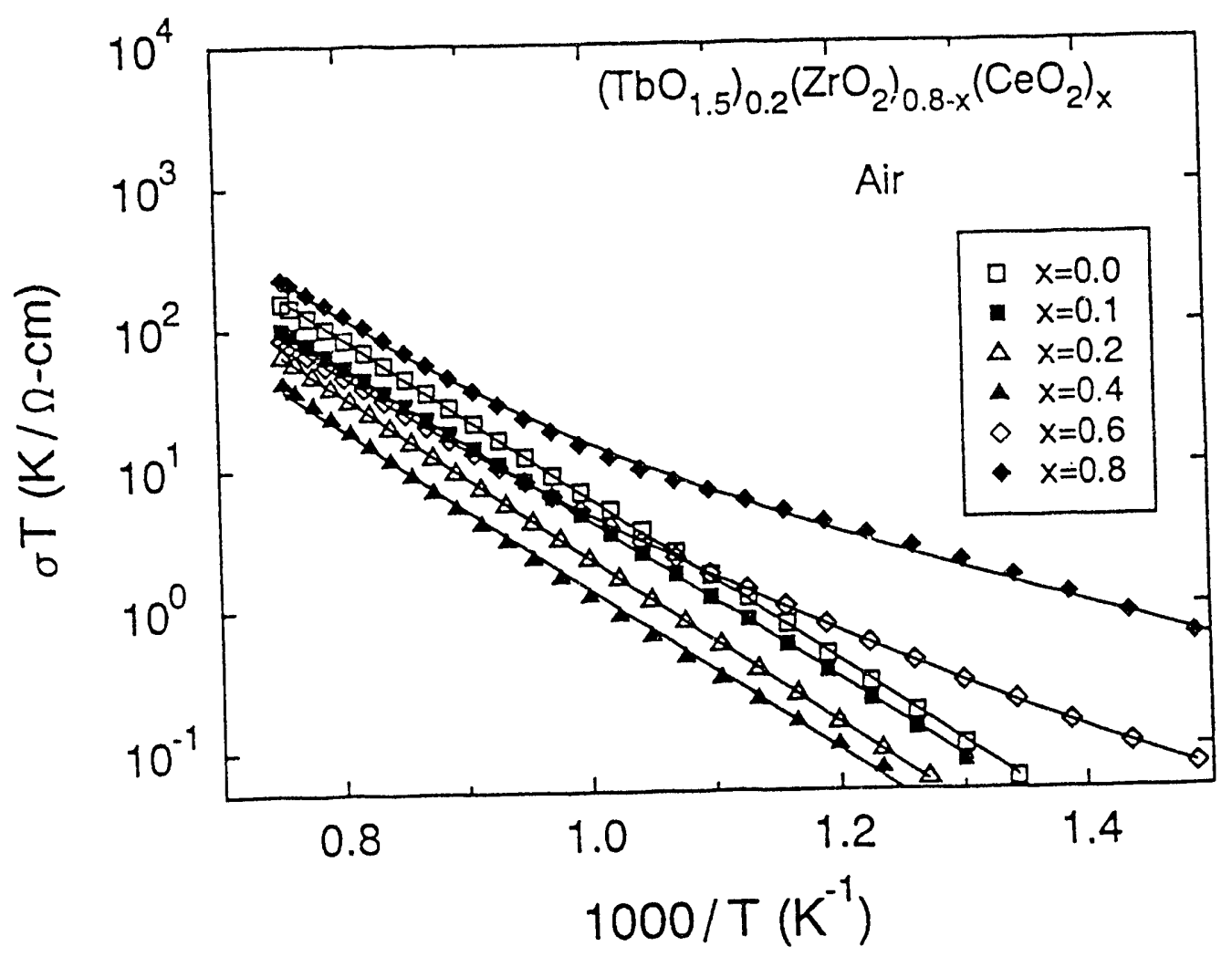

Figure 5. Conductivity behavior for $\mathrm{Tb}-\mathrm{Zr}-\mathrm{Ce}$ compositions in air.

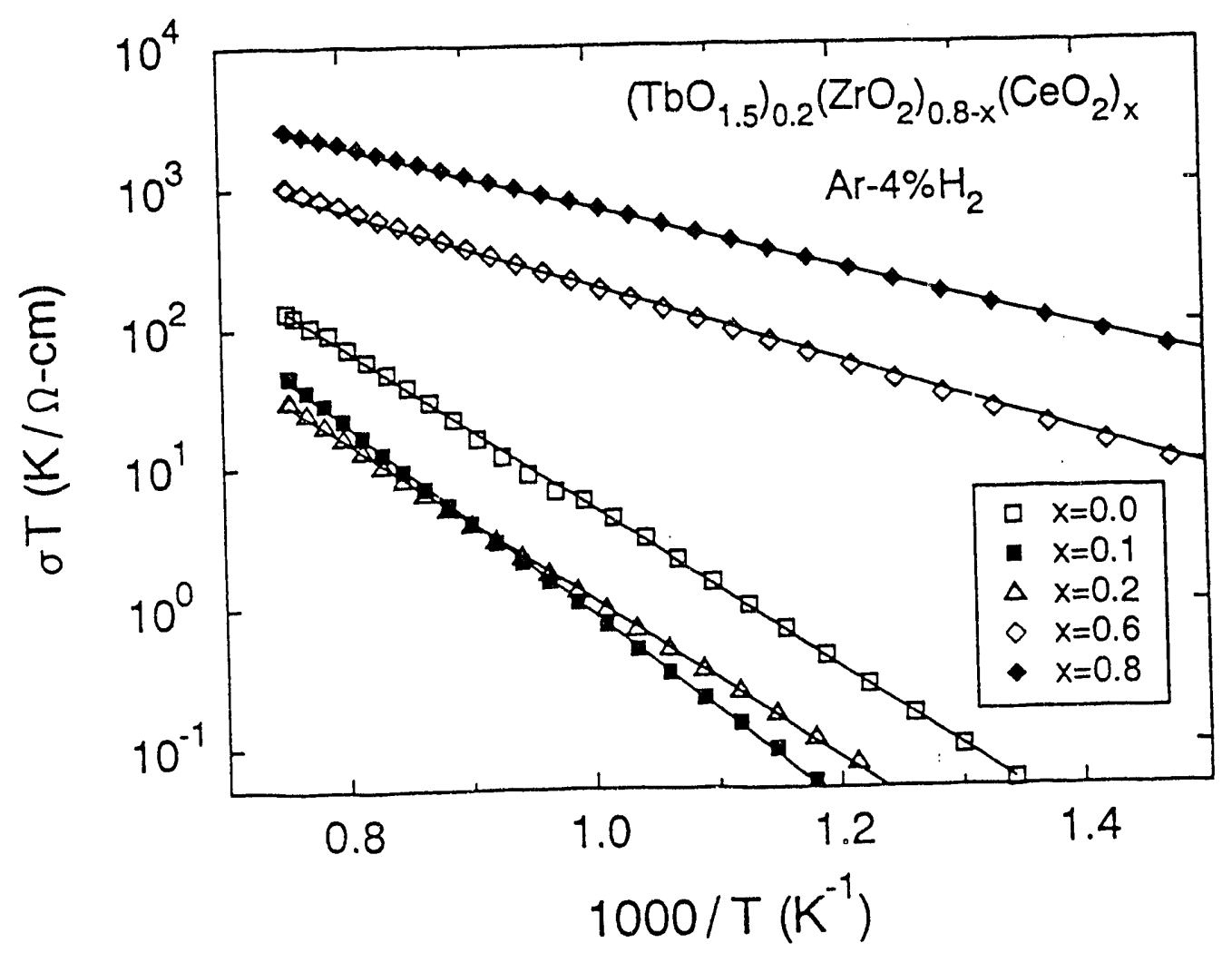

Figure 6. Conductivity behavior for $\mathrm{Tb}-\mathrm{Zr}-\mathrm{Ce}$ compositions in $4 \% \mathrm{H}$. $/ \mathrm{Ar}$. 


\section{REFERENCES}

1. J. L. Bates, L. A. Chick, G. D. Maupin, L. R. Pederson, W. J. Weber, and G. E. Youngblood, J. Hurst, A. E. Bell, D. W. Grainger, S. B. Rananavare, D. K. Roe, and D. H. Thompson, Proc. 6th Ann. Conf. Fossil Energy Materials, Ed. N. C. Cole and R. R. Judkins, ORNL/FMP-92/1 (Oak Ridge National Laboratory, Oak Ridge, TN, 1992), p. 157.

2. J. Newman, J. Electrochem. Soc., 113, 501, 1966.

3. M. Liu, A. Khandkar, and M. Timper, "Planar Solid Oxide Fuel Cell Design, Characterization, and Investigation", in 1990 Fuel Cell Seminar, Nov. 25-28, 1990, Phoenix, AZ. Program and Abstracts, (Courtesy Associates, Inc., Washington D.C.), p. 571.

4. J. Mizusaki, H. Tagawa, K. Tsuneyoshi, and A. Sowata, J. Electrochem. Soc. 138(7), p. $1867-1873,1991$.

5. L. A. Chick, J. L. Bates, L. R. Pederson and H. E. Kissinger, Proc. 1st Int. Symp.on Solid Oxide Fuel Cells, Ed. by S. C. Singhal (Electrochemical Society, Pennington, 1989) p. 170.

6. M. P. Pechini, US Patent 3,330,697, 1967.

7. B. A. Boukamp, Solid State Ionics, 18-19, 136, 1986.

8. "ZSIM/CNLS" models developed by J. Ross MacDonald and Schribner Associates, Inc. Available Schlumberger Instruments, Billerica, MA.

9. A. Tsunoda, T. Yoshida and S. Sakurada, Proc. 1st Int. Symp. on Solid Oxide Fuel Cells, Ed. by S. C. Sirghal (Electrochemical Society, Pennington, 1989) p. 170.

10. K. W. Browall and R. H. Doremus, J. Am. Ceram. Soc. 60, 262, 1977.

11. B. Cales and J. F. Baumard, J. Electrochem. Soc. 131(10), 2407, 1984.

12. H. L. Tuller, in: Non-Stoichiometric Oxides, Ed. by O. T. Sorensen, p. 271 (Academic Press, New York, 1981).

13. G. Brauer and B. Willaredt, Proc. 10th Rare Earth Research Conf., Ed. by C. J. Kerane and T. Moeller, 1973, p.176.

14. G. Brauer and B. Willaredt, J. Less-Common Metals, 61, 83, 1978.

15. Y. Takasu, T. Sugino, Y. Matsuda, J. App. Elect. Chem., 14 ,79, 1984.

16. R. D. Shannon, Acta Cryst., A32, 751, 1976.

17. C. Leach, N. Khan and B. C. H. Steel, J. Mater. Sci. 27 , 3812, 1992.

18. R. J. Stafford, S. J. Rothman and J. L. Routbort, Solid State Ionics, 37, 67, 1989.

19. D. L. Maricle, T. E. Swarr and S. Karavolis, Solid State Ionics, 52, 173, 1992.

20. H. Arashi, H. Naitoh, and M. Ishigami, Solid State Ionics, 40-41, 539, 1990 
SNL-1-CERAMIC CATALYST SUPPORTS: HYDROUS METAL OXIDE ION-EXCHANGE SUPPORTS FOR DIRECT COAL LIQUEFACTION

\author{
D.H. Doughty, C.S. Ashley, T.J. Gardner, and C.H.F. Peden \\ Sandia National Laboratories \\ Albuquerque, NM 87185-5800
}

\begin{abstract}
The goal of our experimental effort is to develop and optimize the use of a unique catalyst support material, the hydrous titanium oxide ion-exchangers. In part, we seek to understand how the activity of a catalyst is related to the concentration and dispersion of active metals on the catalyst supports. Such information is critical to designing materials having optimum catalytic properties. We have developed synthetic techniques for controlling both the concentration and dispersion of nickel, molybdenum and rhodium on hydrous sodium titanate catalyst supports. The techniques were based on and required an understanding of the solution chemistry of both the support material and dissolved metal species. In addition, studies of the local molecular structure by Raman, and solid-state ${ }^{17} \mathrm{O}$ NMR spectroscopies are being pursued because of the importance of thr local structure in determining the ion-exchange properties of these materials. By de cloping an understanding of the appropriate catalyst preparation procedures, we have improved catalytic performance of more recently prepared materials. Studies aimed at providing the optimum processing procedures have also been undertaken and are described here. Currently, we have begun to explore the development of methods to deposit thin films of the HTO ion-exchangers. Catalysts prepared on such materials have the greatest potential to significantly impact the economies of coal liquefaction processes. Finally, we have also initiated studies of structure/activity relationships in the final catalyst materials in order to provide further guidance to the synthesis effort as to the most desirable physical properties. Some of this work is detailed here.
\end{abstract}

\title{
INTRODUCTION
}

Coal is our most abundant fossil fuel energy source. However, it requires extensive chemical treatment and processing to convert it from a hydrogen-poor "dirty" solid to a "clean" premium liquid fuel such as gasoline. One of the missions of the Department of Energy's AR\&TD research is to permit expanded use of coal-based systems by providing a focus for the exploration of ideas pertaining to coal science, conversion and utilization. This project seeks to accomplish that mission by exploring the synthesis and evaluation of new ceramic catalytic materials for efficient, direct conversion of coal to clean liquid fuels. Because the recoverable U.S. supplies of coal are 50 to 100 times that of crude oil, development of new catalysts for efficient conversion of coal to environmentally acceptable liquid fuels would have an enormous impact on extending our usable energy reserves. 
The focus of this program is to conduct research and development on catalytic materials for fossil energy applications. In this way, we are obtaining a better understanding of these materials that will impact the long-term, generic needs of various fossil fuel technologies. However, sufficient testing of the hydrous metal oxide ion-exchange catalysts with coal and coal-derived feeds has been accomplished to demonstrate that they show great promise for enduse process applications. 1

The specific materials under study in this AR\&TD project are from a group of hydrous oxide ion-exchange compounds of $\mathrm{Ti}, \mathrm{Zr}, \mathrm{Nb}$, and $\mathrm{Ta}$ developed at Sandia National Laboratories. These compounds have been used to prepare catalysts by a novel synthesis route involving the incorporation of active metals by ion exchange. ${ }^{2}$ Hydrous oxide ion-exchange compounds were originally developed at Sandia for use in the decontamination of aqueous nuclear waste and as precursors for ceramic materials. ${ }^{3}$ The use of these compounds as ceramic catalyst supports arises from the unique properties which these systems exhibit: 1) any metal or mixture of metals can be incorporated ir:to the materials over a wide concentration range by a simple process; 2 ) the materials have high surface area; 3) they exhibit good chemical stability; 4) solution chemistry or more conventional high temperature reactions can be used to provide control of the active metal oxidation state; 5) acidity and basicity of the substrate can be modified by ion exchange; 6 ) the catalysts can be prepared on transition metal-oxide supports ( $\mathrm{Ti}, \mathrm{Nb}$, and $\mathrm{Ta}$ ) known to undergo a so-called "strong metal support interaction" (SMSI); and 7) the materials are readily prepared as thin films that can be deposited on other high surface area oxide materials.

The hydrous metal oxides investigated in this study belong to a group of inorganic ionexchange compounds that can be represented by the empirical formula $M\left(M_{x}{ }_{x} O_{y} H_{z}\right)_{n}$, where $M$ is an exchangable cation and $\mathrm{M}^{\prime}$ is $\mathrm{Ti}, \mathrm{Nb}, \mathrm{Zr}$, or $\mathrm{Ta}$. When added to a solution of aqueous metal cations, these powdered materials will react to form amorphous precipitates containing the dissolved metal which has replaced the exchangable cation, M. Catalytic activity has been measured at Sandia for materials synthesized in this manner. ${ }^{1,4}$ For example, catalysts prepared using the hydrous titania (HTO) ion exchangers are equally effective for conversion of coal to low molecular weight products as a commercial Ni-Mo/alumina catalyst containing $15 \%$ by weighi active metals even at low (1\%) active metal loadings. ${ }^{1}$

One possible reason for the improved performance of the catalysts prepared from the hydrous titanate materials may be that active metals are dispersed more completely via the ionexchange process than when loaded by traditional incipient wetness techniques. As such, these materials offer a method to prepare greatly improved heterogeneous catalysts for many applications, provided we understand the important variables in the synthesis. 
Our goal is to develop a fundamental understanding of the preparation and properties of these unique materials. Specifically, we have been investigating the following areas:

l) molecular and extended macroscopic structure of the hydrous titanate and how this relates to its other material properties;

2) determination of how the synthesis of the HTO powders affects its structure, and correspondingly its material properties;

3) mechanism of incorporation of catalytic metals;

4) catalytic and reactivity studies of the metal-loaded catalysts;

5) development of structure/activity relationships for catalytic liquefaction reactions in order to determine the nature of optimum materials; ind,

6) determination of the optimum procedures to prepare these materials in thin film form.

After developing this basic unders nding, we envision being able to tailor catalyst properties for specific applications, as weli as roviding a foundation for further catalyst development. This report summarizes recent work on this project carried out in the last six months. Specifically, we describe studies in categories 4,5 and 6 from the list above. Further background information, previous results, and experimental details are summarized in earlier publications.

\section{RESULTS AND DISCUSSION}

\section{Slipport Crystallization Effects on Bulk Ni/HTO Catalyst Activation}

Our previous work ${ }^{5}$ identified many separate and potentially competing processes (e.g., metal reduction, loss of surface area, loss of volatiles, and metal/support structural evolution) which occur during the activation of bulk Ni/HTO catalysts. In order to optimize HTOsupported catalyst performance, it is important to identify which of these processes control the activation behavior and thus the resulting metal dispersion and catalyst reactivity. We have recently completed a study investigating the effect of the crystallographic phase evolution of the HTO support on catalyst activation. Thermal analysis (DTA and TGA) results have been supplemented by $x$-ray and electron diffraction (TEM) of catalyst samples activated under different conditions (temperature, time, and atmosphere). The separate effects of $\mathrm{Na}^{+}, \mathrm{Ni}^{+}$, and $\mathrm{Ni}^{0}$ on the crystallization behavior of the amorphous HTO support were also evaluated. 
DTA results have shown that the presence of $\mathrm{Ni}^{+}, \mathrm{Ni}^{0}$, and $\mathrm{Na}^{+}$have a significant effect on the crystallization behavior of the HTO support phase. Table 1 summarizes these results by listing the peak temperature for the major phase transformation which occurs on sample heating in a given atmosphere. The as-prepared $\mathrm{Na} 0.5 \mathrm{Ti}$ material, which contains $\sim 10$ wt. \% $\mathrm{Na}^{+}$, transforms from an amorphous phase to a crystalline sodium titanate phase at $-600^{\circ} \mathrm{C}$. Previous work has determined that a sodium titanate phase of unknown structure initially forms, followed by the formation of a mixture of $\mathrm{Na}_{2} \mathrm{Ti}_{3} \mathrm{O}_{7}$ and $\mathrm{Na}_{2} \mathrm{Ti}_{6} \mathrm{O}_{13}$ crystalline phases ut higher temperature. ${ }^{6-8}$ This amorphous to crystalline transformation is unaffected by the heat treatment atmosphere (air vs. $\mathrm{H}_{2}$ ). The effect of $\mathrm{Na}^{+}$on the HTO support phase crystallization is clear when the $\mathrm{Na} 0.5^{\mathrm{Ti}}$ results are compared with the $\mathrm{H}^{+} / \mathrm{HTO}$ results. Since complete ion exchange of $\mathrm{H}^{+}$for $\mathrm{Na}^{+}$has occurred in this material, the HTO support would be expected to crystallize similarly to other hydrous forms of $\mathrm{TiO}_{2}$. The phase evolution of $\mathrm{TiO}_{2}$ is known to be dependent on a wide range of processing variables, including method of preparation, impurities, and atmosphere. 9 The $\mathrm{H}^{+} / \mathrm{HTO}$ initially transforms from the as-prepared amorphous state to anatase, followed by a subsequent transformation from anatase to rutile. Suprisingly, there is no effect of atmosphere on the anatise to rutile phase transformation temperature. Previous work has shown that this phase transformation is enhanced by reducing atmospheres. ${ }^{10-12}$

Table 1. DTA Results*

\begin{tabular}{|l|c|c|c|}
\hline \multicolumn{1}{|c|}{ Sample Description } & Atmosphere & $\begin{array}{c}\text { Peak } \\
\text { Temperature }\left({ }^{\circ} \mathrm{C}\right)\end{array}$ & Phase Transformation \\
\hline $\mathrm{Na}_{0.5} \mathrm{Ti}(\mathrm{HTO})$ & Air & 596 & Amorphous $\rightarrow \mathrm{Na}_{x} \mathrm{Ti}_{\mathrm{y}} \mathrm{O}_{\mathrm{Z}}$ \\
\hline $\mathrm{Na}_{0.5} \mathrm{Ti}(\mathrm{HTO})$ & $5 \% \mathrm{H}_{2} / 95 \% \mathrm{Ar}$ & 595 & Amorphous $\rightarrow \mathrm{Na}_{x} \mathrm{Ti}_{\mathrm{y}} \mathrm{O}_{2}$ \\
\hline $\mathrm{H}^{+}$exchanged $\mathrm{HTO}$ & Air & 453 & Anatase $\rightarrow$ Rutile \\
\hline $\mathrm{H}^{+}$exchanged HTO & $5 \% \mathrm{H}_{2} / 95 \% \mathrm{Ar}$ & 452 & Anatase $\rightarrow$ Rutile \\
\hline $\mathrm{Ni}^{+2}$ exchanged HTO $(\sim 5$ wt. \%) & Air & 509 & Anatase $\rightarrow$ Rutile \\
\hline $\mathrm{Ni}^{+2}$ exchanged HTO $(\sim 5$ wt. \%) & $5 \% \mathrm{H}_{2} / 95 \% \mathrm{Ar}$ & 463 & Anatase $\rightarrow$ Rutile \\
\hline
\end{tabular}

* Experimental Details: Sample Heating Rate $=10^{\circ} \mathrm{C} / \mathrm{min}$; Gas Flow Rate $=75 \mathrm{sccm}$.

Interesting results were obtained for the $\mathrm{Ni}^{+2} / \mathrm{HTO}$ sample, which contained no $\mathrm{Na}^{+}$and $\sim 5 \mathrm{wt} . \% \mathrm{Ni}^{+2}$. The testing atmosphere was found to have a significant effect on the anatase to rutile phase transformation for these samples. In a reducing atmosphere $\left(5 \% \mathrm{H}_{2} / 95 \% \mathrm{Ar}\right)$, the 
anatase to rutile phase transformation was observed at a temperature $\sim 50^{\circ} \mathrm{C}$ lower than when heated in an oxidizing atmosphere (air). The lower anatase-rutile transformation temperature for the $\mathrm{Ni}^{+2}$ / HTO sample heated in $\mathrm{H}_{2}$ was very similar to the transformation temperature of the $\mathrm{H}^{+} / \mathrm{HTO}$ sample heated in either an oxidizing or a reducing atmosphere. Although the effect of foreign ions on the anatase to rutile transformation has been extensively studied, almost all of this work has examined only oxidizing atmospheres, or reduction following a calcin in procedure in air. ${ }^{13-16}$ In oxidizing atmospheres, appropriately sized foreign ions of luwer valence can substitute for $\mathrm{Ti}^{+4}$ ions in the anatase structure, resulting in the formation of charge compensating oxygen vacancies. The removal of oxygen atoms from the structure can facilitate the collapse of the oxygen framework which is necessary for the relatively oper a natase structure to transform to the rutile structure. 10 However, the DTA results show that the $\mathrm{Ni}^{+2} /$ HTO sample heated in air actually transforms at a higher temperature than the control sample $\left(\mathrm{H}^{+} / \mathrm{HTO}\right)$ containing no $\mathrm{Ni}^{+2}$ addition (see Table 1 ).

Although the DTA results for the ion exchanged $\mathrm{Ni}^{+2}$ or $\mathrm{H}^{+} / \mathrm{HTO}$ catalysts heated in $\mathrm{H}_{2}$ were similar, the phase evolution of the $\mathrm{TiO}_{2}$ phase is significantly different. Figure 1 summarizes the differences in phase evolution of the $\mathrm{TiO}_{2}$ phase as a function of $\mathrm{Ni}+2$ loading. Activation of the $\mathrm{Ni}^{+2} / \mathrm{HTO}$ catalyst in $\mathrm{H}_{2}$ initially results (at $\sim 300^{\circ} \mathrm{C}$ ) in the formation of crystalline $\mathrm{Ni}^{0}$ prior to the crystallization of the HTO support phase. At higher activation temperatures $\left(-350^{\circ} \mathrm{C}\right)$, the HTO support phase crystallizes to form a mixture ( 1:1 ratio) of poorly crystalline (crystallite size 5-10 $\mathrm{nm}$ ) anatase and rutile. This behavior is in contrast to the $\mathrm{H}^{+} / \mathrm{HTO}$, where the sample either remains amorphous or initially converts to only poorly crystalline anatase (see the $x$-ray diffraction patterns in Figure 2 for examples of initial crystallization of $\mathrm{Ni}^{+2} / \mathrm{HTO}$ and $\mathrm{H}^{+} / \mathrm{HTO}$ samples). As shown in Figure 1, rutile formation in this material requires more aggressive activation conditions (i.e., higher temperatures or longer times at temperature). I'hus, although the $\mathrm{Ni}+2$ /HTO sample heated in $\mathrm{H}_{2}$ has an anatase. rutile transformation tzmperature very similar to the $\mathrm{H}^{+} / \mathrm{HTO}$ sample (see Table 1), it appears that the crystalline $\mathrm{Ni}^{\mathrm{O}}$ catalyzes the partial transformation of anatase to rutile at low temperatures $\left(-350^{\circ} \mathrm{C}\right)$. The influence of specific metals on the phase evolution of $\mathrm{TiO}_{2}$ has not been studied extensively. 17 


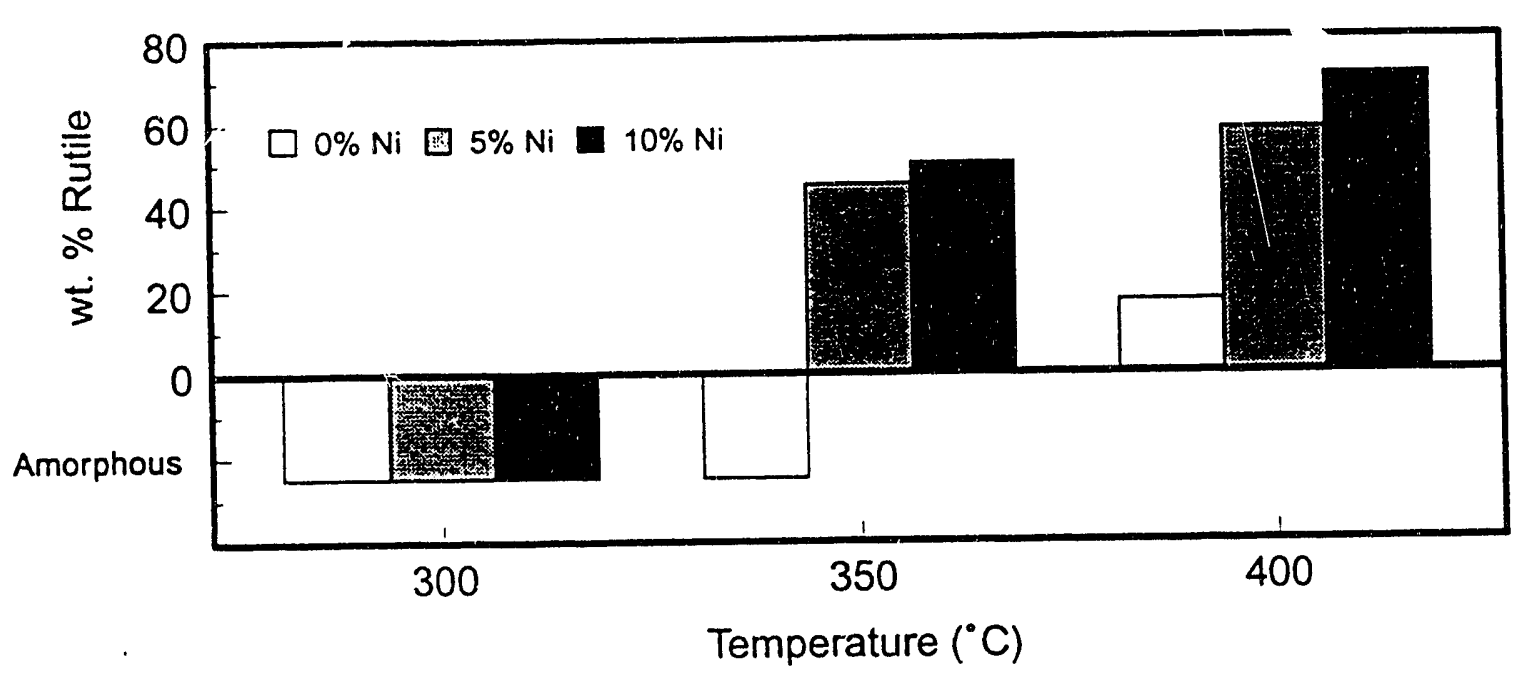

Figure 1. Ni Loading Effects on HTO Support Phase Crystallization. All samples were heat treated for $18.5 \mathrm{~h}$ in flowing $\mathrm{H}_{2}(20 \mathrm{sccm})$. Note that the wt. \% rutile designation on the positive vertical axis does not imply that the samples are $100 \%$ crystalline. X-ray line broadening measurements have shown that all samples represented in this Figure are poorly crystalline at best.

The original $\mathrm{Na} 0.5^{\mathrm{Ti}}$ material remains amorphous to $\sim 600^{\circ} \mathrm{C}$, showing that $\mathrm{Na}^{+}$can have a profound effect on phase evolution of HTO-supported metal catalysts. Although it has been shown that small amounts of $\mathrm{Na}^{+}$can catalyze the anatase-rutile transformation, ${ }^{12}$ it is obvious that both the quantity of $\mathrm{Na}^{+}$(up to $10 \mathrm{wt.} \%$ ) and the nature of its structural incorporation cause significant differences in the phase evolution of the HTO support. Subsequent addition of $\mathrm{Ni}^{+2}$ to non or partially ion exchanged $\mathrm{HTO}$ samples $\left(\mathrm{Na}^{+}\right.$leveis ranging from 3-10 wt. \%) does not change the crystallization behavior relative to the original $\mathrm{Na}_{0.5} \mathrm{Ti}$ material.

Coupling these results with our previous data shows that the crystallization of the HTO support phase does not play an important role in the activation of $\mathrm{Ni}^{+2} / \mathrm{HTO}$ catalysts. 5 This is determined by the fact that these catalysts can be activated at lower temperatures $\left(300^{\circ} \mathrm{C}\right)$ than those required for HTO support phase crystallization. This means that the mechanisms controlling Ni particle formation, crystallization, and/or encapsulation are not affected by the crystallization of the support phase. It is interesting to note that the range of temperature in which support phase crystallization is observed correlates well with the temperature range where the surface area of the $\mathrm{Ni}^{+2} / \mathrm{HTO}$ catalysts decreases significantly. $4 \mathrm{j}$ We will continue to 

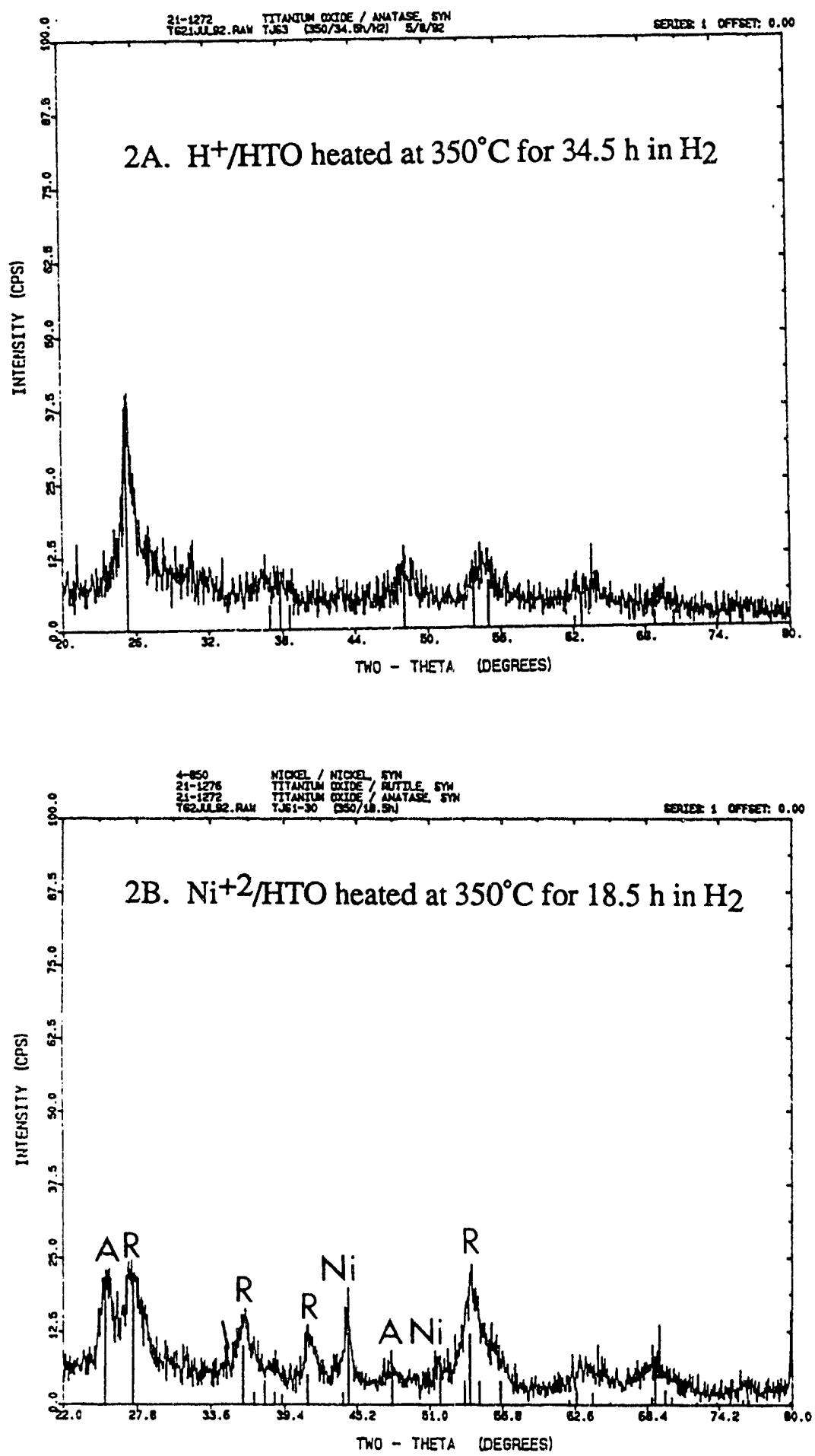

Figure 2. Initial $x$-ray observation of crystallization of $\mathrm{H}^{+} / \mathrm{HTO}(2 \mathrm{~A})$ and $\mathrm{Ni}+\ddot{\alpha} / \mathrm{HTO}$ (2B) samples activated in $\mathrm{H}_{2}$. Only poorly crystalline anatase is observed in Figure $2 \mathrm{~A}$. The major refelections for anatase $(A)$, rutile $(R)$, and Ni are identified in Figure $2 B$ (all phases identified are poorly crystalline. 
evaluate other possible mechanisms which may control $\mathrm{Ni}^{+2} / \mathrm{HTO}$ catalyst activation in order to explain why high $\mathrm{Ni}$ dispersions cannot be obtained.

\section{Preparation of HTO Materials in Thin-Film Form}

Thin film HTO catalysts are expected to be much more affordable than catalysts prepared on bulk HTO powders because relatively cheap oxide materials supporting the film will comprise the bulk of the catalyst. Besides this advantage, Dosch and coworkers ${ }^{1 \mathrm{c}}$ have demonstrated that higher pyrene hydrogenation activities can be realized on thin-film HTOsupported catalysts. Using thin film HTO materials supported on porous oxides will also allow meso and macropore size distributions to be tailored by varying the oxide structure, while micropore size distribution will be determined by thin film synthesis conditions. Control of HTO thin film properties will be realized by understanding and controlling the chemical and physical processes that control the development of film porosity. We have identified the empirical variables that control film porosity. The important variables are solution concentration, solution age, water content, coating atmosphere, and film deposition method. The first three variables influence the hydrolysis and condensation reactions that determine the nature of the inorganic titanate polymer formed prior to solution deposition. The latter two variables predominately influence the inorganic titanate polymer deposition conditions which influence film microstructure.

Solution age effects are commonly seen in sol-gel derived films since the metal alkoxide precursors continue to react to form inorganic polymeric clusters of increasing molecular weight and size as aging time increases. We have seen significant differences in films prepared from HTO solutions (1:3 dilution of sodium titanate in toluene, $0.55 \mathrm{M} \mathrm{Ti}$ ) which are aged for varying times prior to film deposition. Films deposited from sols aged for short times $(1 \mathrm{hr})$ are completely featureless when spin coated on flat, single crystal Si surfaces. In contrast, a film formed from a solution aged for 5 days shows extensive, visible porosity due to cracking.

Likewise, solution concentration affects both the growth of polymeric clusters and the rates of hydrolysis and condensation, and thus is critical to control of film microstructure. An advantaze of more dilute systems is enhanced solution stability which will naturally lead to greater process control. Table 2 summarizes the effect of coating method, concentration and aging time on film properties. HTO films spin-deposited from solutions prepared at a Ti concentration of $0.55 \mathrm{M}$ generally have refractive index values $>1.8$ and consistently low surface areas, i.e., 1-5 $\mathrm{cm}^{2} / \mathrm{cm}^{2}$. In contrast, less concentrated solutions ( $1: 5$ dilution, $0.37 \mathrm{M} \mathrm{Ti}$ ) result in films with refractive indices $<1.8$ which suggests the development of porosity. A film deposited from a 0.37 
M Ti solution, which was aged for 30 days shows a surface area of $14.2 \mathrm{~cm}^{2} / \mathrm{cm}^{2}$. As expected, a $0.37 \mathrm{M}$ Ti solution prepared with moderate aging (3-5 days) has reproducibly yielded films with surface areas of $20-22 \mathrm{~cm}^{2} / \mathrm{cm}^{2}$. Further exploration of these important process parameters at a molecular level will permit a detailed understanding of the chemical and physical mechanisms that control film microstructure.

TABLE 2

SAW/BET Analysis ${ }^{18}$ of Hydrous Titanate Films Shows Increased Surface Area with Decreased Concentration

\begin{tabular}{ccccc}
$\begin{array}{c}\text { Coating } \\
\text { Method }\end{array}$ & $\begin{array}{c}\text { [Ti] } \\
\mathrm{M}\end{array}$ & $\begin{array}{c}\text { Aging Time } \\
\text { (Days @ RT) }\end{array}$ & $\begin{array}{c}\text { Refractive } \\
\text { Index }\end{array}$ & $\begin{array}{c}\text { Surface Area } \\
\mathrm{cm}^{2} / \mathrm{cm}^{2} \text { (des) }\end{array}$ \\
Dip & 0.55 & 1 & 2.03 & 3.7 \\
Spin & 0.55 & 1 & 1.92 & 2.1 \\
Spin & 0.55 & 5 & 1.98 & 1.6 \\
Spin & 0.37 & 3 & 1.77 & 21.98 \\
Spin & 0.37 & 30 & 1.72 & 14.24 \\
\hline
\end{tabular}

Besides their use as supports for uniformly distributing catalytically active metals, thin films of $\mathrm{TiO}_{2}$ can be very active catalysts themselves, particularly for oxidation reactions. Notably, the catalytic behavior of dispersed (thin film) oxides is often remarkably different from that of the bulk oxide. For example, Table 3 shows the result of catalytic measurements of the rates of methanol oxidation on several catalysts including bulk $\mathrm{SiO}_{2}, \mathrm{TiO}_{2}$ and a dispersed $\mathrm{TiO}_{2}$ on $\mathrm{SiO}_{2}$ with several weight loadings of titania. ${ }^{19}$ Clearly evident in the table is the marked change in selectivity of the reaction on the dispersed titania catalysts to the more desirable intermediate oxidation products, formaldehyde ( $\mathrm{HCOH}$ ) and methyl formate (MF). We are using this property as a test of the uniformity of coatings that we prepare in our thin film 
studies. In addition, there is a great opportunity to probe the chemical properties of the HTO thin films and possibly discover some unique and important catalytic behavior.

TABLE 3

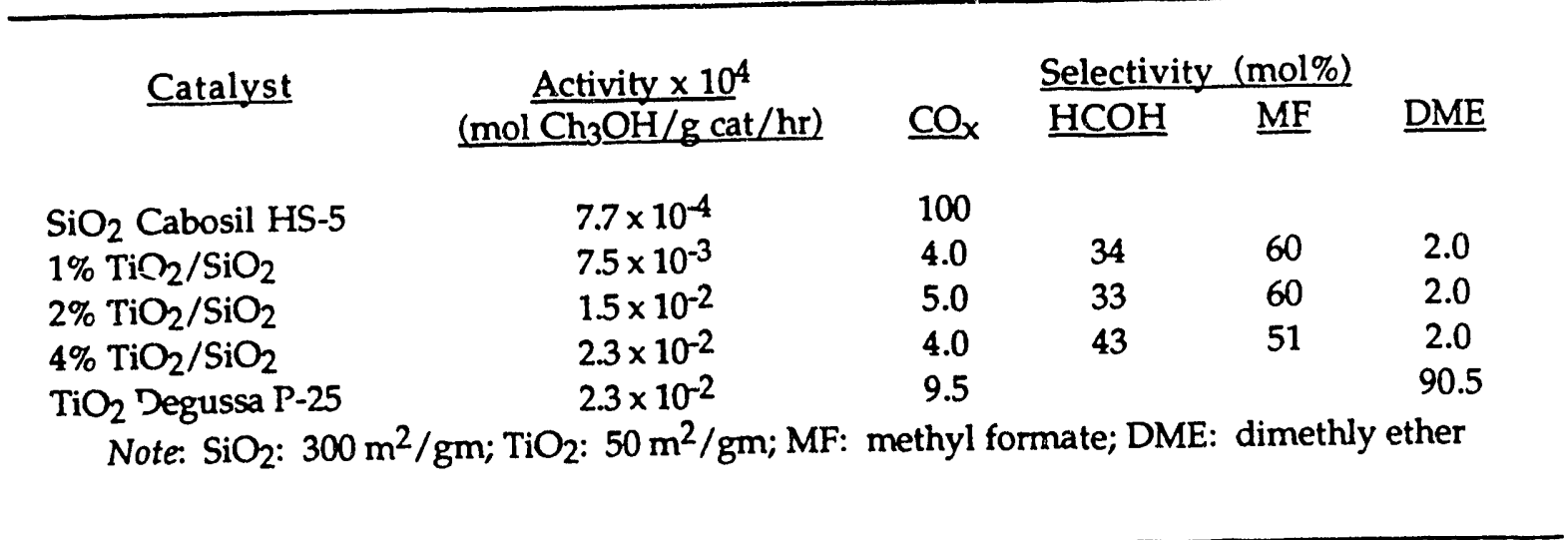

\section{ACKNOWLEDGMENTS}

Sandia National Laboratories is supported by the U.S. Dept. of Energy under contract No. DE-AC04-76DP00789. The authors would like to thank Prof. A. K. Datye of the University of New Mexico for involvement in much of this work, and Prof. I. E. Wachs of Lehigh University for collaborations on the dispersed titania catalysis studies. In addition, coworkers at Sandia are acknowledged for participation in this work; notably, T. Bohuszewicz for SAW device measurement, [ Goodnow for thermal analyses, and M. Eatough and M. Gonzales for performing $x$-ray diffraction

\section{REFERENCES}

1. (a) R. G. Dosch, H. P. Stephens, F. V. Stohl, B. C. Bunker and C. H. F. Peden, "Hydrous Metal Oxide-Supported Catalysts: Part I. Preparation Chemistry and Physical and Chemical Properties," Sandia Report (SAND89-2399). (b) R. G. Dosch, H. P. Stephens and F. V. Stohl, "Hydrous Metal Oxide-Supported Catalysts: Part II. Catalytic Properties and Applications," Sandia Report (SAND89-2400). (c) R. G. Dosch and L. I. McLaughlin, "Hydrous Metal-Oxide Supported Catalysts: Part III. Development of NiMoHMO Catalysts," Sandia Report (SAND92-0388).

2. H. P. Stephens, R. G. Dosch and F. V. Stohl, "Catalysis Using Hydrous Metal Oxide Ion Exchangers," U. S. Patent \#4,511,455; April 16, 1985. 
3. R. G. Dosch, T. J. Headley and P. Hlava, "Crystalline Titanate Ceramic Nuclear Waste Forms: Processing and Microstructure," J. Am. Ceram. Soc. 67 (1984) 354 .

4. (a) B. C. Bunker, C. H. F. Peden and S. L. Martinez, "Ceramic Catalyst Materials: Hydrous Metal Oxide Ion-Exchange Supports for Direct Coal Liquefaction," ARETD Materials Semiannual Report, March - September, 1987; ORNL/FMP-87/2, p. 213. (b) C. H. F. Peden, B. C. Bunker and S. L. Martinez, ibid., October, 1987 - March, 1988; ORNL/FMP-88/1, p. 171. (c) C. H. F. Peden, B. C. Bunker and S. L. Martinez, ibid., April - September, 1988; ORNL/FMP-88/2, p. 207. (d) B. C. Bunker , C. H. F. Peden and S. L. Martinez , ibid., October, 1988 - March, 1989; ORNL/FMP-89/1, p. 18j. (e) C. H. F. Peden, B. C. Bunker and S. L. Martinez, ibid., April - September, 1989; ORNL/FMP-89/2, p. 179. (f) C. H. F. Peden, B. C. Bunker, S. L. Martinez and D. H. Doughty, ibid., October, 1989 March, 1990; ORNL/FMP-90/1, p. 171. (g) C. H. F. Peden, F. D. Hardcastle and K. B. Kidd, ibid., April - September, 1990; ORNL/FMP-90/2, p. 143. (h) C. H. F. Peden, ibid., October, 1990 - March, 1991; ORNL/FMP-91/1, p. 107. (i) C. H. F. Peden, ibid., April September, 1991; ORNL/FMP-91/2, in press, (j) C. H. F. Peden, C. S. Ashley, D. H. Doughty, and T. J. Gardner, ibid, October, 1991-April, 1992; ORNL/FMP92/1 in press.

5. T. J. Gardner, C. H. F. Peden, and A. K. Datye, "Activation Behavior of Ni/hydrous titanium oxide (HTO) catalysts," Catal. Lett., 15, 111 (1992).

6. P. S. Peercy, R. G. Dosch, and B. Morosin, "Preparation and Structural Studies of the Hydrolysis Products of Titanium, Niobium, and Zirconium," Sandia Report (SAND760556).

7. J. Lehto, "Sodium Titanate for Solidification of Radioactive Wastes - Preparation, Structure, and Ion Exchange Properties," Academic Dissertation, University of Helsinki.

8. F. D. Hardcastle, C. H. F. Peden, and K. B. Kidd, "Molecular Structures of Hydrous Sodium Titanates by Raman Spectroscopy," submitted to Chemistry of Materials.

9. A. Dabler, A. Feltz, J. Jung, W. Ludwig, and E. Kaisc berger, "Characterization of Rutile and Anatase Powders by Thermal Analysis," J. Therm. Anal., 33, 803, 1988.

10. R. D. Shannon, "Phase Transformation Studies in $\mathrm{TiO}_{2}$ Supporting Different Defect Mechanisms in Vacuum-Reduced and Hydrogen-Reduced Rutile," J. Appl. Phys., 35 [11], 3414,1964

11. R. D. Shannon and J. A. Pask, "Kinetics of the Anatase-Rutile Transformation," J. Amer. Ceram. Soc., 48 [8], 391, 1965.

12. Y. Iida and S. Ozaki, "Grain Growth and Phase Transformation of Titanium Oxide During Calcination," J. Amer. Ceram. Soc., 44 [3], 120, 1961.

13. A. Nobile. Jr. and M. W. Davis, Jr., "Importance of the Anatase-Rutile Phase Transition and Titania Grain Growth Enlargement in the Strong Metal-Support Interaction Phenomenon in $\mathrm{Fe} / \mathrm{TiO}_{2}$ Catalysts," J. Catal., 116, 383, 1989.

14. G. Sankar, K. R. Kannan, and C. N. R. Rao, "Anatase-Rutile Transformation in $\mathrm{Fe} / \mathrm{TiO}_{2}$, $\mathrm{Th} / \mathrm{TiO}_{2}$, and $\mathrm{Cu} / \mathrm{TiO}_{2}$ Catalysts and Its Possible Role in Metal-Support Interaction,"

Catal. Lett., 8, 27, 1991. 
15. G. Sankar, C. N. R. Rao, and T.Rayment, "Promotion of the Metal-Oxide Support Interaction in the $\mathrm{Ni} / \mathrm{TiO}_{2}$ Catalyst: Crucial Role of the Preparation, the Structure of the $\mathrm{TiO}_{2}$, and the $\mathrm{NiTiO}_{3}$ Intermediate," J. Mater. Chem., 1 [2], 299, 1991.

16. R. A. Eppler, "Effect of Antimony Oxide on the Anatase-Rutile Transformation in Titanium Dioxide, J. Amer. Ceram. Soc., 70 [4], C-64, 1987.

17. A. G. Shastri, A. K. Datye, and J. Schwank, "Gold-Titania Interactions: Temperature Dependence of Surface Area and Crystallinity of $\mathrm{TiO}_{2}$ and Gold Dispersion," J. Catal., 87, $265,1984$.

18. A. J. Ricco, G. C. Frye, S. J. Martin, "BET Surface Areas of Porous Thin Films Using Surface Acoustic Wave Devices," Langmuir 5, 273 (1989).

19. S. Srinivasan, A. K. Datye, M. Hampden-Smith, I. E. Wachs, G. Deo, J. M. Jehng, A. M. Turek and C. H. F. Peden, "The Fornation of Titanium Oxide Monolayer Coatings on Silica Surfaces," J. Catal. 131, 260 (1991). 


\title{
UTN-1-SOL-GEL OXIDE INTERFACE COATINGS FOR NICALON/SiC COMPOSITES
}

\author{
D.M. Walukas \\ University of Tennessee \\ Knoxville, TN \\ R. A. Lowden and KL. More \\ Oak Ridge National Laboratory \\ P. O. Box 2008 \\ Oak Ridge, TN 37831-6063
}

\section{INTRODUCTION}

Continuous fiber-reinforced silicon carbide matrix composites are being developed for use in high-temperature corrosive environments. ${ }^{1,2}$ These materials typically use a graphitic carbon fiber coating to limit the forces acting at the fiber-matrix interface and control mechanical properties. ${ }^{3.5}$ However, the poor oxidation resistance of the carbon interlayer limits the elevated temperature stability of these materials. Nicalon $/ \mathrm{SiC}$ composites with a graphitic carbon interface layer exhibit properties favorable for use in fossil energy applications, and thus have been exposed to oxidizing and simulated fossil fuel environments to assess their stability. ${ }^{6,7}$ Composite specimens with and without an external $\mathrm{SiC}$ surface coating were oxidized in air and exposed to a variety of combustion environments at elevated temperatures. The mechanical properties of unprotected Nicalon $/ \mathrm{SiC}$ specimens were degraded after short periods of exposure, due to the oxidation of the carbon interface coating. Longer exposures resulted in the oxidation of the fibers and matrix to form silica, which with time bonded the components together, and produced brittle behavior. Combustion environments hastened the embrittlement of the composites.

The specimens protected with a SiC surface coating experienced no decrease in strength after exposure to oxidative or combustion environments. The $\mathrm{SiC}$ layer sealed off the surface of the composites, protecting the exposed fibers ends, and thus prohibiting oxidation at the fiber-matrix interface. The surface coating was essential to protect the interface from corrosion. However, efforts in the application of topical coatings and sealants to carbon-carbon composites have demonstrated that there are many difficulties associated with the use of protective surface

Nicalon', Nippon Carbon Company, Tokyo, Japan. 
layers. ${ }^{8}$ Processing flaws, and cracks in the coating caused by thermal expansion mismatch stresses or applied loads, can expose the substrate, leaving the coating susceptible to oxidation. It is generally accepted that these surface protection measures are only one component of a more complex protection system. A complete system may require combinations of surface layers, oxidation inhibitors, and fiber coatings.

These issues must be addressed in the development of environmentally-stable ceramic composites. If surface coatings cannot adequately protect the fiber-matrix interface from exposure, and subsequent degradation, then coatings with improved oxidation resistance must be developed. In an attempt to improve the stability of the interface in Nicalon $\otimes / \mathrm{SiC}$ composites, alternate coatings with better oxidation resistance are being investigated. It is, therefore, quite natural to explore the use of metal oxides, which are stable to extremely high temperatures and already highly oxidized. Due to the difficulty in depositing oxides by chemical vapor deposition a sol-gel process was chosen to fabricate the coatings. This paper describes an effort to assess the feasibility of using oxide interface coatings in a non-oxide composite system. The stability of the coatings with respect to the fiber and matrix during processing was examined. The effects of sol-gel oxide coating composition and thickness on the mechanical properties of Nicalon ${ }^{\oplus} / \mathrm{SiC}$ were investigated and compared to similar composites with a graphitic carbon interlayer.

\section{DISCUSSION OF CURRENT ACTIVITIES}

Sol-gel oxides were investigated as interface coatings for $\mathrm{Nicalon} \otimes / \mathrm{SiC}$ composites. The oxide interface coatings were applied to Nicalon ${ }^{\oplus}$ fabric samples using sol-gel techniques. In scoping experiments, composites with alumina, titania, and zirconia interlayers exhibited promising room temperature properties and thus these coatings were applied to fabric samples to produce additional composite samples. Room-temperature flexure strengths of composites with thick and thin oxide interlayers were measured and compared to the properties of $\mathrm{Nicalon} / \mathrm{SiC}$ composites with a graphitic carbon fiber coating. Flexure bars for each of the samples were coated with a protective SiC layer. Bars with and without the protective $\mathrm{SiC}$ coating were exposed to air at $1273 \mathrm{~K}$ for 1000 hours and subsequently tested to assess strength degradation. The resulting fracture surfaces were examined using a scanning electron microscope (SĖM), while the fiber-matrix interface was characterized with a transmission electron microscope (TEM). 


\section{SOL-GEL INTERLAYERS}

Oxide coatings were deposited on Nicalon ${ }^{\star}$ cloth using sol-gel methods developed at Westinghouse Science and Technology Center. Although originally developed as a fabrication method for high-quality ceramics, sol-gel technology has been applied to the fabrication of thin films. There are two different types of sol-gel processing. The first, known as the "colloidal" method, involves dispersing colloidal particles in a liquid, producing a sol. This is followed by the destabilization of the sol to produce the gel. The second method utilizes polymerization of organometallic compounds such as alkoxides to produce a gel with a continuous bond network. Both the "colloidal" and the "polymerization" methods of gel formation may be applied to the deposition of ceramic thin films on Nicalon ${ }^{\otimes}$ cloth. Detailed analyses are available in the literature for both "colloidal"9,10 and "polymeric" methods. ${ }^{10,11}$

The precursor alkoxide, aluminum sec-butoxide $\mathrm{Al}\left(\mathrm{OC}_{4} \mathrm{H}_{9}\right)_{3}$, was hydrolyzed by introducing the alkoxide into excess double-distilled, deionized water at a molar water/alkoxide ratio of $100 / 1$. The initial water temperature was approximately $80^{\circ} \mathrm{C}$. Ti.e resulting wateralcohol-aluminum slurry was briskly stirred for 15-20 minutes over a hot-plate. Following hydrolysis an acid must be introduced into the slurry to achieve the required peptization of the hydroxide. A wide range of acids, including nitric acid, acetic acid, sulfuric acid and hydrochloric acid, were found to be effective in the required peptization of the slurry. ${ }^{12}$ In the application of oxide films on Nicalon ${ }^{\otimes}$ cloth, nitric acid was chosen as the acid least likely to introduce damaging impurities vis-a-vis the $\mathrm{SiC}$ matrix, Nicalon ${ }^{\star}$ fibers and alumina coating. Nitric acid was added to the slurry so that an acid/aluminum molar ratio of $7 / 100$ was achieved. The slurry was then covered and placed in an oven at $80^{\circ} \mathrm{C}$ and left to sit overnight.

Coatings of titania and zirconia were produced from a "polymeric" sol. The precursors, titania ethoxide and zirconia n-propoxide, were dissolved in ethanol at room temperature to produce sols of $3 \mathrm{wt} . \% \mathrm{TiO}_{2}$ and $4 \mathrm{wt} . \% \mathrm{ZrO}_{2}$, respectively. Due to the strongly hydroscopic nature of the precursors, creation of the solution must be carried out in a dry-box. The solutions were stirred with a magnetic rod until the solutions were clear with no precipitates. At this point the sols are ready for deposition onto the substrate.

Nicalon ${ }^{\otimes}$ cloth was cut into strips approximately $26 \times 8 \mathrm{~cm}$. Nicalon ${ }^{\otimes}$ fibers are coated with a polyvinyl acetate sizing to protect the fibers during handling and weaving. The strips, therefore, were washed in multiple acetone baths in order to remove the sizing. The strips were 
then dipped in the appropriate sol. In an aitempt to vary coating thickness, the strips were withdrawn from solution at two different rates, $23 \mathrm{~cm} / \mathrm{min}$ and $80 \mathrm{~cm} / \mathrm{min}$. Due to viscosity effects a slower rate of withdrawal results in a thinner coating. The sol-coated strips were air dried and heated to $450^{\circ} \mathrm{C}$ at a rate of $15^{\circ} \mathrm{C} / \mathrm{min}$. The strips were held at $450^{\circ} \mathrm{C}$ for 30 minutes in static air.

\section{COMPOSITE FABRICATION}

Fibrous preforms were fabricated by stacking multiple layers of the coated Nicalon plainweave fabric rotated in a $0 \pm 30^{\circ}$ sequence within the cavity of a graphite holder. The layers were hand compressed to produce a preform with a nominal fiber loading of $40 \mathrm{vol} . \%$ and were held in place by a perforated graphite lid pinned to the holder. The nominal size of the fibrous preforms was $75 \mathrm{~mm}$ in diameter and $15 \mathrm{~mm}$ thick.

Due to the high reactivity of oxides with $\mathrm{HCl}$, which is a by-product of the infiltration process, a thin carbon coating ( $<0.03 \mu \mathrm{m}$ ) was applied to the preform prior to densification. The coating was deposited isothermally from a propylene/argon gas mixture at $1375 \mathrm{~K}$ and 3.3 $\mathrm{kPa}$. The preforms were then densified using the forced-flow, thermal-gradient chemical vapor infiltration (FCVI) process. The densification of porous structures using the FCVI process has been previously described in detail. ${ }^{13-15}$ The SiC matrix was produced by the decomposition of methyltrichlorosilane $\left(\mathrm{CH}_{3} \mathrm{SiCl}_{3}\right.$ or MTS) in hydrogen at a hot-surface temperature of $1473 \mathrm{~K}$ and atmospheric pressure. The preforms were infiltrated with $\mathrm{SiC}$ to a maximum of 85 to $90 \%$ of theoretical density in $\approx 40 \mathrm{~h}$.

\section{CHARACTERIZATION AND TESTING}

Test bars were cut from the samples parallel to the $0^{\circ}$ orientation of the top layer of cloth using a diamond saw, and tensile and compression surfaces were ground parallel to the long axis of the specimen. The average dimensions of the specimens were $3 \times 4 \times 50 \mathrm{~mm}$ and all specimens were measured and weighed to determine densities. Room temperature flexure strengths were measured in four-point bending. A support span of $40 \mathrm{~mm}$ and a loading span of $20 \mathrm{~mm}$ were used with a crosshead speed of $0.50 \mathrm{~mm} / \mathrm{min}$. The load was applied perpendicular to the layers of cloth. Load-displacement curves were recorded to examine the 
fracture surfaces of the specimens were examined using a scanning electron microscope (SEM). Coating microstructure and compositions were analyzed using transmission electron microscopy (TEM) and energy dispersive X-ray (EDX).

\section{RESULTS}

\section{Mechanical Properties}

As reported previously, the composite samples containing the alumina coating out performed those with both titania and zirconia coatings when tested in the as-fabricated condition. This remained the case after oxidation testing. The bars containing a zirconia interlayer were so weak, they often failed under the load of the fixture only. It was, therefore, impossible to accurately record fracture behavior for these samples. Those bars containing the alumina interface suffered very little loss in strength or toughness. Those samples containing titania and graphite interfaces retained some composite behavior while suffering a noticeable drop in strength. The mechanical behavior of all samples with the protective seal-coat was virtually unchanged from the behavior of the as-fabricated samples. A summary of flexure strengths appears in Table 1. Typical flexure stress-displacement curves for the Nicalon $\otimes / \mathrm{SiC}$ composites with sol-gel oxide interface coatings of alumina, titania and graphite are shown in Figures 1-3 respectively.

\section{Interface Characterization}

Detailed characterization of the microstructures and compositions at the interfaces was conducted on as-fabricated samples using TEM. The analysis revealed that both titania and alumina were unstable under the processing conditions. The alumina coating reacted with the silicon and oxygen present in the Nicalon ${ }^{\otimes}$ fibers to form mullite. TEM analysis showed the alumina thin coating to be continuous and uniform, while the thicker layer was uneven with relatively large grains of coating at the intersections of the fibers. Subsequent examination of remaining alumina-coated fiber samples by SEM revealed the thin coating to be uniform. The thick coating was uneven with large globules of alumina at the intersections of the fiber bundles. 
Table 1. Flexure strengths of Nicalon $\odot / \mathrm{SiC}$ composites after heat treatment in air for 1000 hours at $1273 \mathrm{~K}$.

\begin{tabular}{|c|c|c|c||}
\hline Coating & $\begin{array}{c}\text { As-Fabricated } \\
\text { (MPa) }\end{array}$ & $\begin{array}{c}\text { Heat-Treated } \\
\text { (no seal coat) } \\
\text { (MPa) }\end{array}$ & $\begin{array}{c}\text { Heat-Treated } \\
\text { (sealed) } \\
\text { (MPa) }\end{array}$ \\
\hline $\mathrm{Al}_{2} \mathrm{O}_{3}$-thin & $262 \pm 42$ & $253 \pm 41$ & $275 \pm 57$ \\
\hline $\mathrm{Al}_{2} \mathrm{O}_{3}$-thick & $182 \pm 49$ & $164 \pm 21$ & $221 \pm 57$ \\
\hline $\mathrm{TiO}_{2}$-thin & $198 \pm 30$ & $106 \pm 18$ & $212 \pm 14$ \\
\hline $\mathrm{TiO}_{2}$-thick & $186 \pm 40$ & $121 \pm 40$ & $188 \pm 32$ \\
\hline $\mathrm{ZrO}_{2}$-thin & $68 \pm 11$ & & $76 \pm 15$ \\
\hline $\mathrm{ZrO}_{2}$-thick & $30 \pm 11$ & & $34 \pm 13$ \\
\hline $\mathrm{Graphite}^{2}$ & $325 \pm 20$ & $183 \pm 12$ & $335 \pm 14$ \\
\hline
\end{tabular}

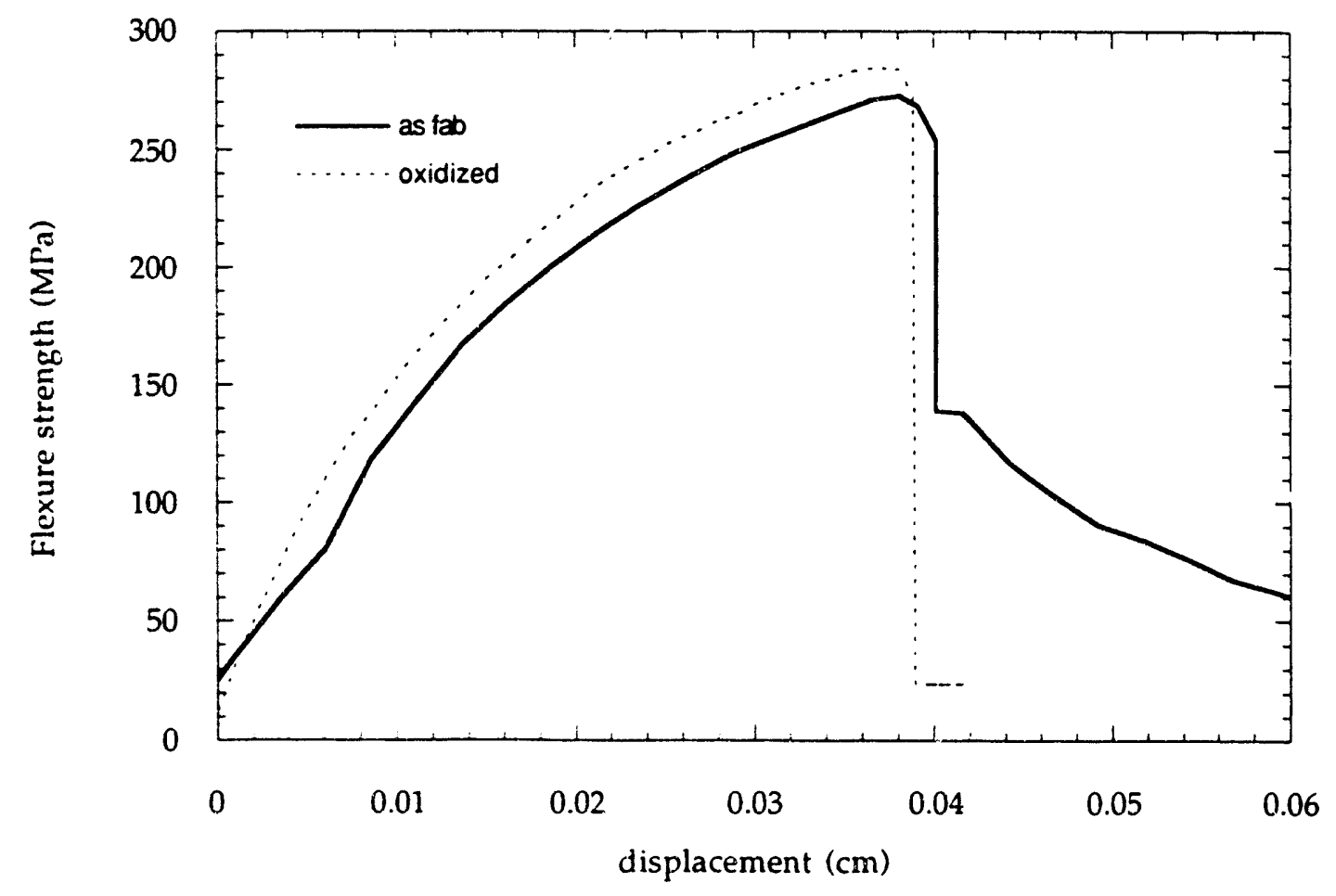

Figure 1. Flexure stress-deflection curves for composites with alumina inıerface coatings. 


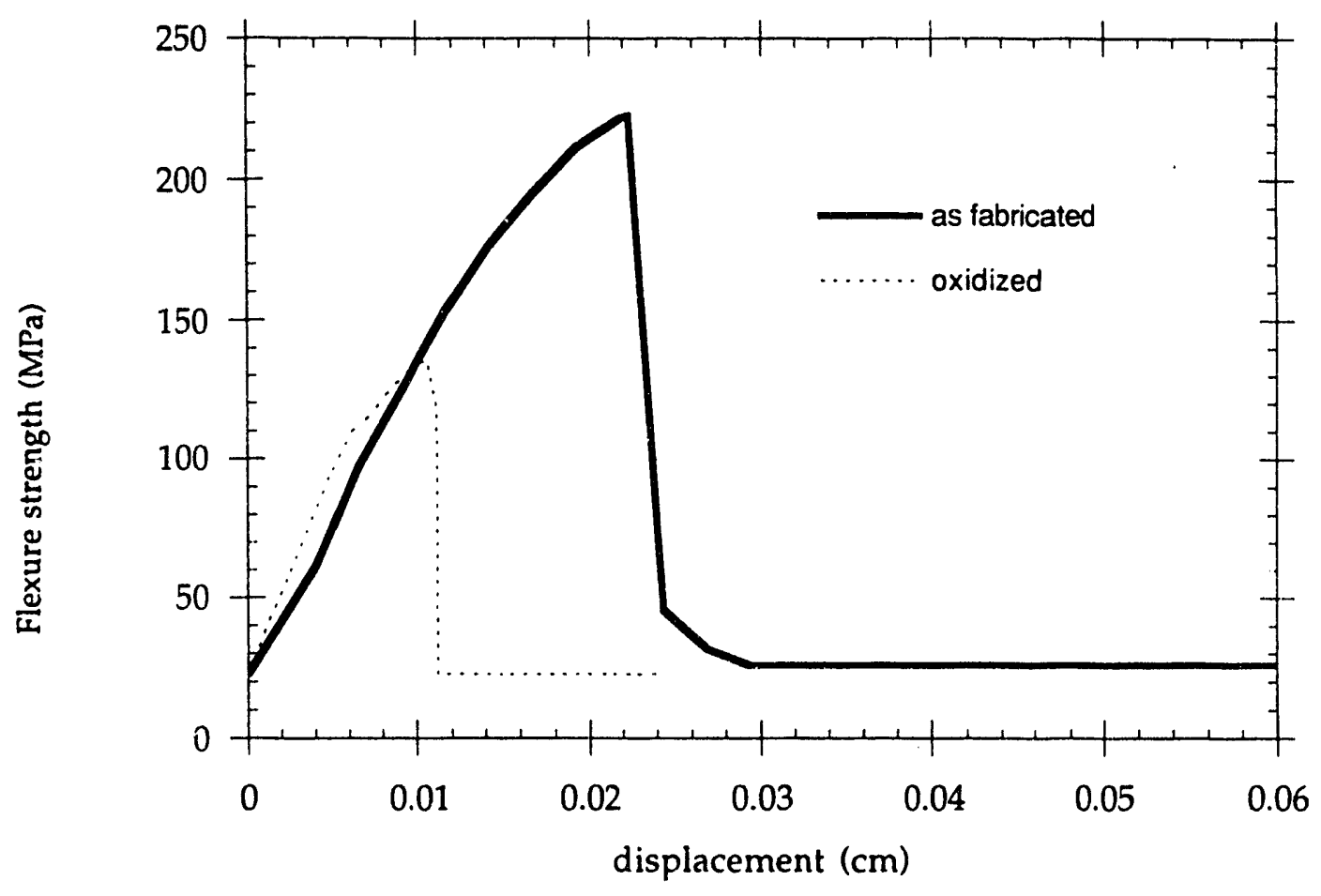

Figure 2. Flexure stress-deflection curves for composites with titania interface coatings.

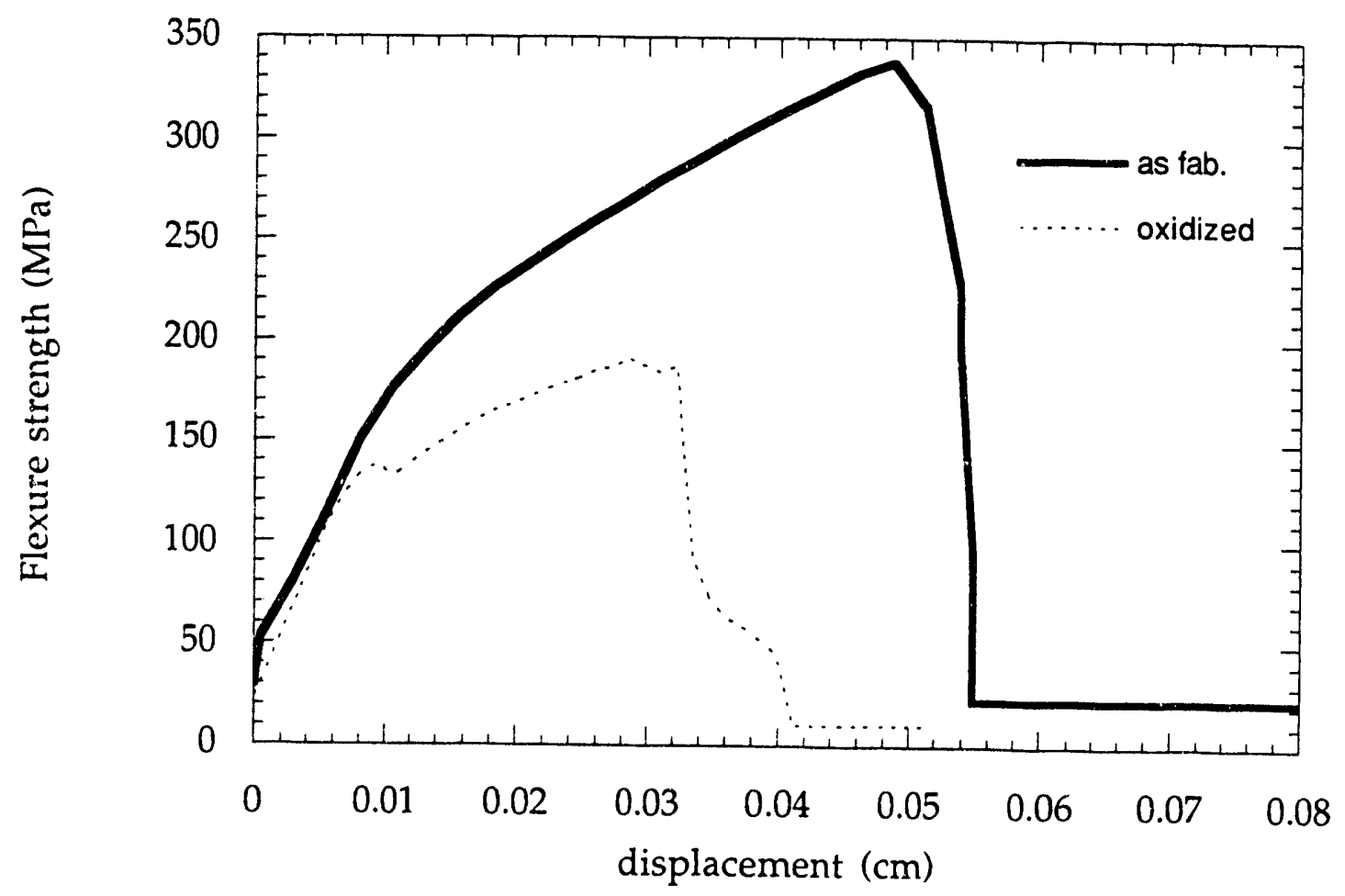

Figure 3. Flexure stress-deflection curves for composites with graphite interface coatings. 
Likewise, the titania coating reacted during processing. EDX analysis of the interface region revealed that titanium and was present only in small inclusions of titanium carbide (TiC) which were interspersed along the interface. Between the $\mathrm{TiC}$ inclusions was an amorphous region depleted of all titanium, which appeared to be composed of silicon, oxygen and carbon. In addition, a large amount of graphite, which cannot be accounted for by the deposition of the protective carbon coating, was detected at the interface. This suggests that graphite and $\mathrm{TiC}$ are the products of a reaction of the titania interlayer and the Nicalon cloth. Preliminary analysis of the zirconia coating suggests that the coating is chemically stable during prosessing.

TEM analysis conducted oxidized samples containing the thin alumina and titania layers as well as a control composite containing a graphite layer. The mullite formed from the alumina during processing proved to be stable. As expected from the flexure test results, no discernible difference was detected after oxidation. SEM analysis revealed fiber pull-out throughout the sample containing the alumina interlayer. The behavior of the titania and graphite interlayers, however, was noticeably changed. While much fiber pull-out was observed in the center of these samples, the regions adjacent to the edges underwent considerable embrittlement as verified by SEM. TEM analysis of the graphite layer in the embrittled regions revealed the formation of silica.

\section{CONCLUSIONS}

Of the three materials chosen only zirconia was stable during processing. However, zirconia apparently bonded strongly with either the matrix or the fiber rendering it unsuitable as an interface material. Alumina was unstable during processing but the reaction product, mullite, was observed to perform adequately under room temperature testing, achieving flexure strengths approaching $300 \mathrm{MPa}$. Under oxidation conditions, the mullite-coating performed very well. Strength and toughness suffered only minor reductions. The reaction product from the titania coating demonstrated mixed results. In the as-fabricated condition, the sample failed in a composite manner but the flexure strengths were only $\approx 200 \mathrm{MPa}$. The reaction products, $\mathrm{TiC}$ and graphite, are unstable in oxygen at high temperature and were, therefore, unable to survive in an oxidizing environment resulting in a pronounced reduction in strength and toughness. The samples containing the zirconia coating demonstrated little, if any, weakening at the interface, suggesting no debonding. 


\section{ACKNOWLEDGEMENTS}

This research is sponsored by the U.S. Department of Energy, Fossil Energy AR\&TD Materials Program, under contract DE-AC05-84OR21400 with Martin Marietta Energy Systems, Inc. The author would like to thank the ORNL High Temperature Materials Laboratory User Center for the use of the scanning electron and transmission electron microscopes and access to the other analytical and mechanical property testing equipment.

\section{REFERENCES}

1. T. M. Besmann, B. W. Sheldon, R. A. Lowden, and D. P. Stinton, "Chemical Vapor Infiltration," Science 253, pp. 1104-1109, September 6, 1991. (1992).

2. R. Warren, Ceramic Matrix Composites, Chapman and Hall, New York, New York

3. R. A. Lowden, "Fiber Coatings and the Mechanical Properties of a FiberReinforced Ceramic Composite," pp. 619-630 in Ceramic Transactions, Vol. 19, Advanced Composite Materials, ed. by Michael D. Sacks, The American Ceramic Society, Westerville, Ohio (1991).

4. R. A. Lowden, "Interface Effects and Fracture in Nicalon/SiC Composites," pp. 97-114 in the Proceedings of the Fourth Annual Conference on Fossil Energy Materials, ed. by R. Judkins, Oak Ridge, TN, May 15-17, 1990.

5. R. A. Lowden, Characterization and Control of the Fiber-Matrix Interface in Ceramic Matrix Composites, ORNL/TM-11039, March 1989.

6. R. A. Lowden and R. D. James, High Temperature Corrosion of Nicalon/SiC Composites, ORNL/TM-11893, August 1991.

7. R. D. James, R. A. Lowden, and K. L. More, "The Effects of Oxidation and Corrosion on the Properties of Nicalon/SiC Composites," pp. 925-935 in Ceramic Transactions, Vol. 19, Advanced Composite Materials, ed. by Michael D. Sacks, The American Ceramic Society, Westerville, Ohio (1991).

8. J. E. Sheehan, "Oxidation-Resistant Carbon-Carbon Composites," pp. 920-923 in Engineered Materials Handbook, Vol. 1: Composites, ASM International, Metals Park, Ohio (1987).

9. Yoldas, B.E., "Hydrolysis of Aluminium Alkoxides and Bayerite Conversion," $J$. appl. Chem. Biotechnol. 23, 803-809 (1973). 
10. Partlow, D.P., and B.E. Yoldas, "Colloidal Versus Polymer Gels and Monolithic Transformation in Glass- Forming Systems," Joumal of Non-Crystalline Solids 46, 153-161 (1981).

11. Guanghua Yi and M. Sayer, "Sol-Gel Processing of Complex Oxide Films," Amer. Ceram. Soc. Bull. 70(7), 1173-1179 (1991).

12. Yoldas, B.E., "Alumina Sol Preparation from Alkoxides," Amer. Ceram. Soc. Bull. 54(3), 289-290 (1975).

13. Stinton, D. P., A. J. Caputo, and R. A. Lowden, "Synthesis of Fiber-Reinforced SiC Composites by Chemical Vapor Infiltration," Am. Ceram. Soc. Bull. 65(2), 347-350 (1986).

14. Caputo, A. J. , D. P. Stinton, R. A. Lowden, and T. M. Besmann, "FiberReinforced SiC Composites with Improved Mechanical Properties," Am. Ceram. Soc. Bull. 66(2), 268-272 (1987).

15. Besmann, T. M., R. A. Lowden, D. P. Stinton, and T. L. Starr, "A Method for the Rapid Chemical Vapor Infiltration of Ceramic Composites," J. de Physique 5(50), Colloque C5, 229-239 (1989). 


\title{
VPI-I-INVESTIGATION OF PROPERTIES AND PERFORMANCE OF CERAMIC COMPOSITE COMPONENTS
}

\author{
K. L. Reifsnider, W. W. Stinchcomb, L. L. S. Oleksuk \\ Materials Response Group \\ Engineering Science and Mechanics Department \\ Virginia Polytechnic Institute and State University \\ Blacksburg, Virginia 24061-0219
}

\begin{abstract}
This report on properties and performance of ceramic composite components includes work performed through September 30, 1992. The emphasis of this report is the characterization of ceramic composite tubes fabricated by filament winding, 3-D braiding, woven cloth winding, and the performance simulation of high temperature ceramic matrix composites.
\end{abstract}

\section{INTRODUCTION}

The research program addresses the need for reliable and durable structural ceramic composites to perform in high temperature, fossil energy environments. The research effort provides an experimental and analytical basis for the transition from properties to performance. The program has provided essential technology needed to make the first step beyond the limited characterization of small samples and coupons to a comprehensive characterization of the mechanical performance of complex engineering components such as ceramic composite tubes subjected to static and cyclic multi-axial loading and elevated temperature over various time periods. Characterization of the mechanical performance of ceramic composite components includes both experimental observations and measurements of long-term behavior and predictions of remaining strength and life under realistic service environments. 
The characterizations are conducted using two unique capabilities developed during Phase I of the program:

- a high temperature, multiaxial mechanical test facility, and

- a mechanistic, performance simulation code (MRLife) which brings together the research results in a predictive model for the performance of ceramic composite components.

\section{PHASE I ACCOMPLISHMENTS}

The objective of integrating the analytical and experimental capabilities of the Materials Response Group (MRG) to support the development of the MRLife code for the prediction of remaining strength and life of ceramic composite components at elevated temperatures has been met, with notable success. Phase I results are presented and described in Reference 1 and include:

* design, construction, installation, and acceptance testing of an Instron computer controlled, high stiffness biaxial test facility with hydraulic grips, high temperature $\left(1500^{\circ} \mathrm{C}\right)$ furnace, and extensometer,

* design, fabrication, and evaluation of chopped graphite fiber (Hercules HMUPVA-3k)/borosilicate glass matrix (Corning CGW-7070) composite tubes,

* investigation and application of nondestructive test methods to monitor the damage development process, ${ }^{2}$

* completion of a data set for room temperature, monotonic and cyclic axial loading of graphite fiber/borosilicate glass matrix tubes,

* development of a high temperature damage model based on the critical element concept,

* development and validation of a life prediction model (MRLife) for ceramic composites. 


\section{PURPOSE}

The purpose of Phase II of the Investigation of Properties and Performance of Ceramic Composite Components is to build on and extend the work completed during Phase I to further advance the transition from properties of ceramic composite materials to performance of ceramic composite components used in fossil energy environments.

Tasks

Specific tasks of Phase II are:

- Develop and validate reliable and accurate high temperature, biaxial mechanical test methods for structural ceramic composite components.

- Test and evaluate ceramic composite components, specifically tubes.

- Characterize long-term, mechanical performance of ceramic composite tubes at high temperatures.

- Develop a fundamental understanding of the mechanical degradation and performance limitations of ceramic composite components under service conditions.

- Develop predictive models for damage tolerance and reliability.

The overall approach to the Phase II program and the approach to specific tasks are described in the following section.

\section{APPROACH}

Phase II is being conducted according to a systematically designed and carefully coordinated series of investigations consisting of laboratory tests, model development, and validations to describe, measure, and reliably predict the long term, high temperature performance of ceramic composite tubes subjected to biaxial mechanical loading. 
The investigative approach used on this program has been developed to provide experimental data that support the modeling activity and to provide a basis for predictive modeling.

The first step in the approach is the establishment of nondestructive evaluation (NDE) methods that are most sensitive and suitable for the examination of the material systems under test, for the conditions of interest. The damage and failure modes may influence this choice, and the material systems will also affect the results.

The second step in the approach is the application of cyclic loading to the specimens, for "long-term" testing. Generally, the number of cycles or time which defines "long-term" will depend on the expected service requirements of the components associated with the materials under test. However, in general, up to about 100,000 cycles of loading and time periods of up to about 36 hours (at temperature) will be used for the present program. Cyclic loading will be done at room and elevated temperature. The focus will be on the determination of the damage and failure modes. Appropriate NDE methods will be applied.

The third step is the establishment of the major modes of damage and (especially) failure at room temperature and at elevated temperature. This will be done in concert with sequential, interrupted mechanical testing and examination of the specimens with appropriate NDE methods (steps one and two). These tests will be conducted on a limited number of material types.

Nicalon and/or Nextel fiber-reinforced silicon carbide matrix tubes will be tested and evaluated by the MRG as the primary material system in the program. The tubes will be supplied by Oak Ridge National Laboratory (ORNL) and by other suppliers as authorized by the Company's Technical Monitor. Approximately three or four tubes will be fabricated using a filament wound preform and a chemical vapor infiltration process developed at ORNL. ${ }^{3}$ Approximately two or three 3D braided tubes will also be provided by ORNL.

The fourth step in the approach is the modeling of those damage and failure modes using mechanics analysis. The experience of the Materials Response Group will be used for this effort. Existing models of fiber-controlled and matrix-controlled failure 
in tension, compression, and shear will be modified as needed for this task. These models will be the basis for the modeling of long term behavior.

The final step in the approach involves more complex combinations of thermal and mechanical loading. Particular attention will be given to creep-fatigue interactions. The basic models of strength will be combined into a mechanistic performance simulation model which will predict remaining strength and life as a function of loading history. This collective model is actually a continuation and refinement of a modeling activity by the Materials Response Group that has produced a code series called MRLife (now in its sixth release).

\section{ACCOMPLISHMENTS}

Three tubes have been received from ORNL. These tubes are shown in Figure 1. The tube labeled $\mathrm{OR} 1$ was manufactured by filament winding; the tube labeled $O R$ 2 was made by winding a woven cloth. OR 3 is the 3D braided tube. Nondestructive evaluation techniques have been adapted to the particular geometry of these tubes. Xrays of these tubes reveal a regular pattern of regions of lower density that presumably correspond to holes in the mandrels. Other variations in the $\mathrm{x}$-rays are apparent, and further study is required to determine if these are manufacturing defects or anomalies in the $\mathrm{x}$-ray procedure. Work is proceeding to prepare these tubes for mechanical testing, including determination of the through the thickness temperature gradient at high temperatures. Current expectations are that the specimens will require only slight modifications to accommodate attachment of strain gages; a ceramic cement has been used in other applications to provide an adequate surface upon which strain gages can be mounted. Decisions regarding the use of end plugs to prevent crushing of the specimens in the grip are being discussed.

In order to interpret the data developed by our experimental program, we are attempting to develop a method of predicting remaining strength and life of ceramic composites using micromechanical strength models in a performance simulation code. Figure 2 illustrates how the micromechanical strength relationships are used in the 


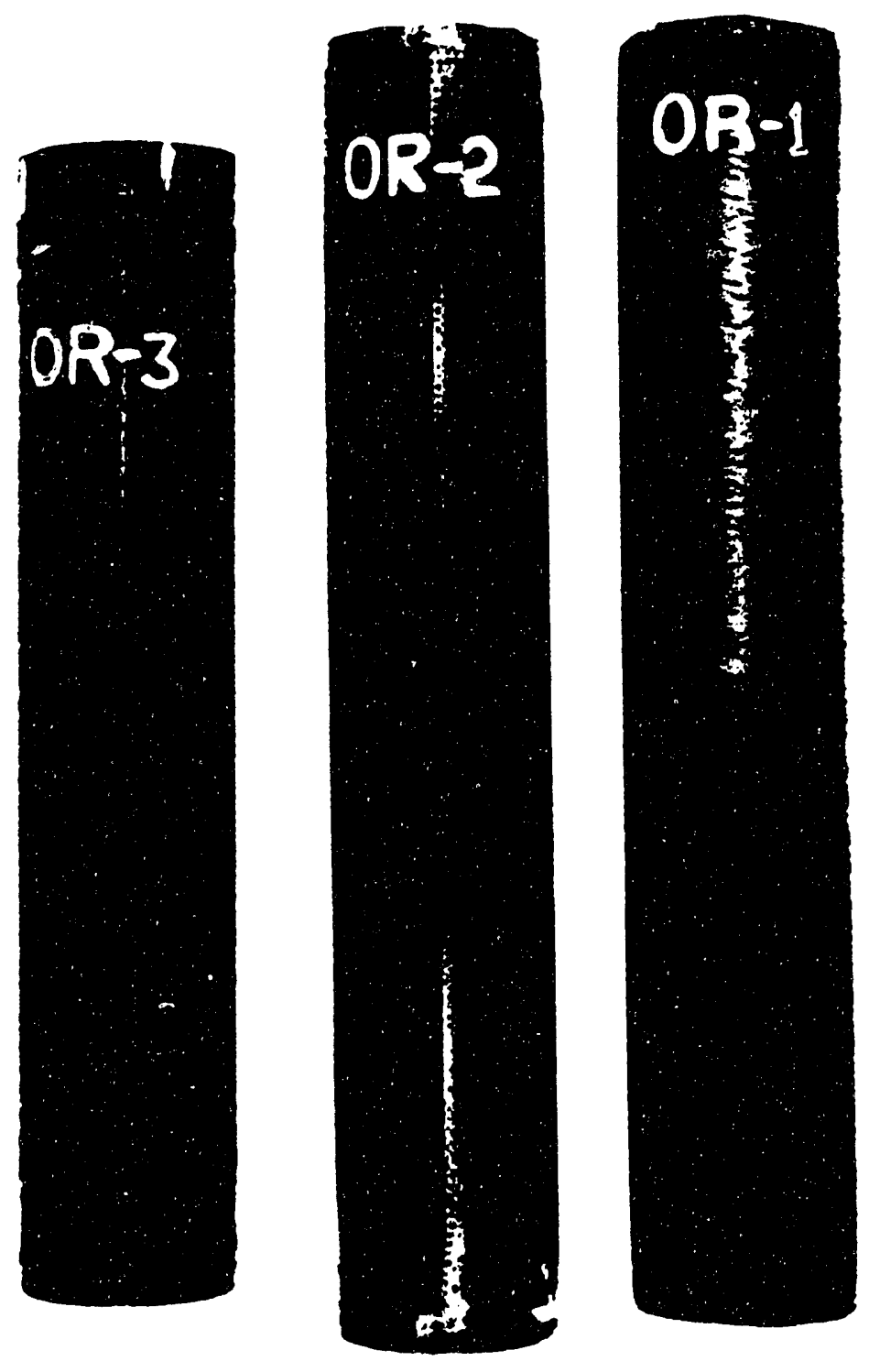

Fig. 1. $\mathrm{SiC} / \mathrm{SiC}$ tubes provided to Virginia Tech. 


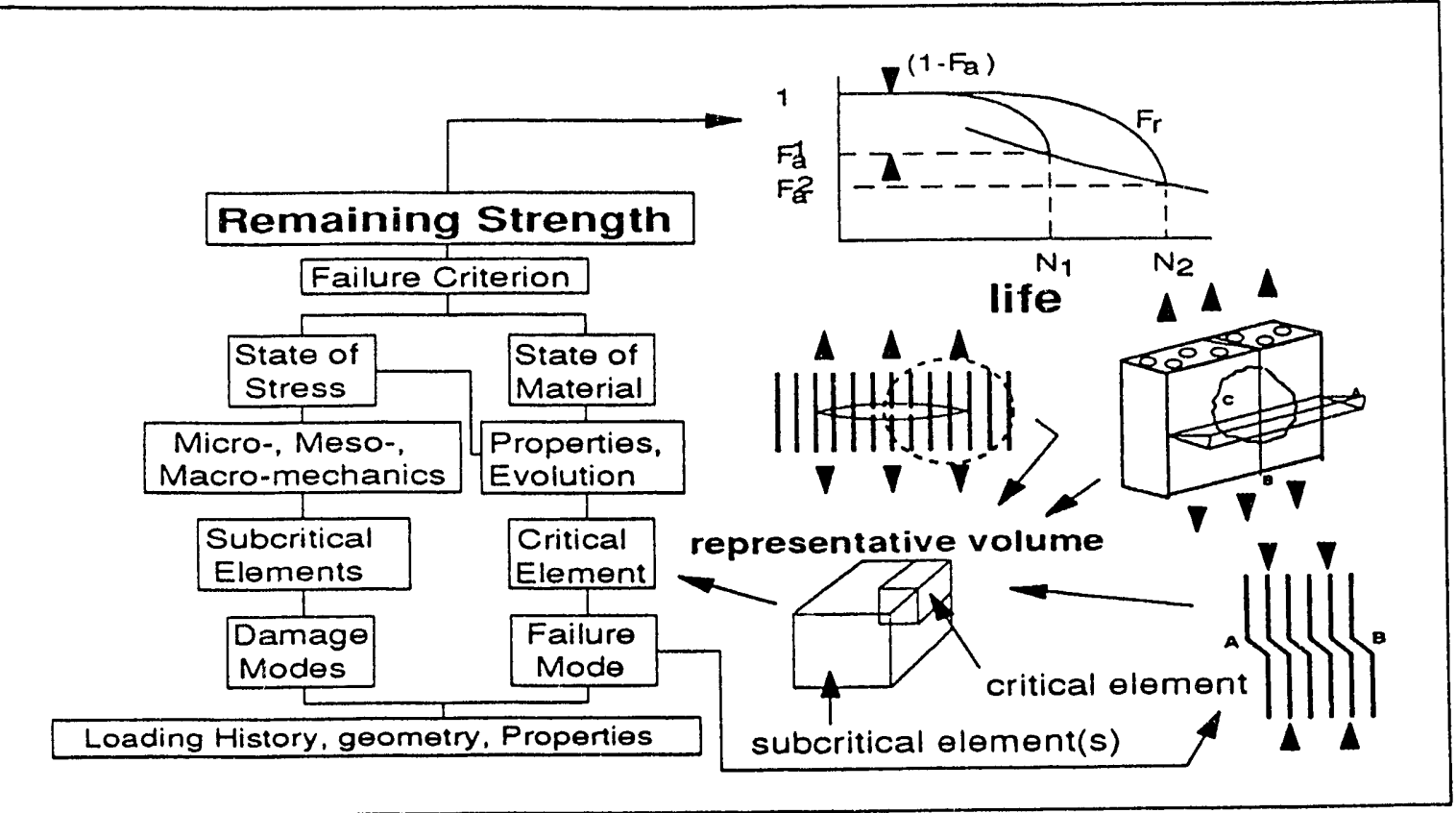

Fig. 2. Simulation of strength degradation by variation of material parameters in micromechanical models of critical failure elements.

simulation model to estimate remaining strength and life. The representative volumes of material that define the micromechanical representations of $\mathrm{Xij}$ components for given failure modes are said to be made up of "critical elements" which control the final failure, and "subcritical elements" that only change the conditions under which the critical elements sustain the local state of stress. Careful laboratory investigation must define the damage modes that act in the subcritical elements, and the failure modes that control the critical element failure--and, therefore, the composite remaining strength and life. Both the local stress state and the local material state are changing. A "failure function, " $F_{a}$, is constructed for each failure mode which compares the current state of stress and state of material as a fractional ratio. That failure function may be something as simple as a phenomenological criterion such as a Tsai-Wu criterion, or it may be a fraction defined by the ratio of current $\mathrm{Xij}$ to initial Xij for a given failure mode. In any case, multidimensional stress, damage processes and rates, and the final failure event 
must be included in that failure function. A remaining strength calculation $\left(F_{r}\right)$ is made, using the relationship shown below. ${ }^{4}$

$$
F_{r}=1-\int_{0}^{1}\left(1-F_{a}\right) i(n / N)^{i-1} d(n / N)
$$

As the constituent and transition layer parameters in the micromechanical models as described above change with time (or generalized time), the local state of stress and material will change, and $X i j, E i j$, and the value of the failure function will change. The integral "sums up" the effect of those changes with time (or cycles, etc.) and compares the remaining strength with the applied stress state to determine "life". The "current life", $\mathbf{N}$, is also a function of the current stiffness, strength, and local stress state, as given by a rate equation such as a representation of the $S-N$ curve of the critical element.

During the last six months, we have added several new features to the performance simulation model, and to the MRLife code that runs the model.

* The manner in which parameters vary in the micromechanical relationships has been improved to allow variations with time and temperature that are fairly general. Micromechanical strength relationships (developed under another program) have been incorporated into the code, and the material parameters (such as matrix and fiber strength and stiffness, and the properties of an interphase region between the fiber and matrix) that appear in these models have been identified explicitly in input screens. The code user can select which of those parameters are to vary during the life of the specimen, based on direct experimental data. The changes now allowed include time dependent changes, and temperature dependent changes, according to several types of (kinetic or thermodynamic) relationships. This is a very extensive change for the program, and will not be completed until about March of 1993.

* In an effort to establish the validity of the code, SiC reinforced CAS has been modeled. Data are available from the literature for cyclic loading of cross ply laminates at 982 degrees $C$. At this temperature, the degradation of the material 
due to oxidation plays an important role in the reduction of strength, i.e., creeprupture and fatigue effects must be combined correctly by the model. Figure 3 shows the results of the simulation.

* The simulation was conducted for a low cyclic load level which would give more than a million cycles of life if oxidation were not present. However, the model predicts that the strength will degrade and the specimen will fail at about 80,000 cycles. Under comparable conditions in the laboratory, the measured life is about 150,000 cycles. At a higher stress level (not shown) the predicted life was about 85 cycles for that fatigue-dominated case, compared to observed values that were of the order of 10 cycles to failure. Although still preliminary, the model shows the capability to predict both fatigue and creep rupture results, and to combine those results with engineering accuracy. This progress is encouraging, and will be the basis for continued work on the details of the approach.

* We identified a nonlinearity in the creep-rupture behavior of some of the materials we are attempting to model. In particular, we have found that the shape of the strength reduction curve for oxidation-driven degradation, alone, depends

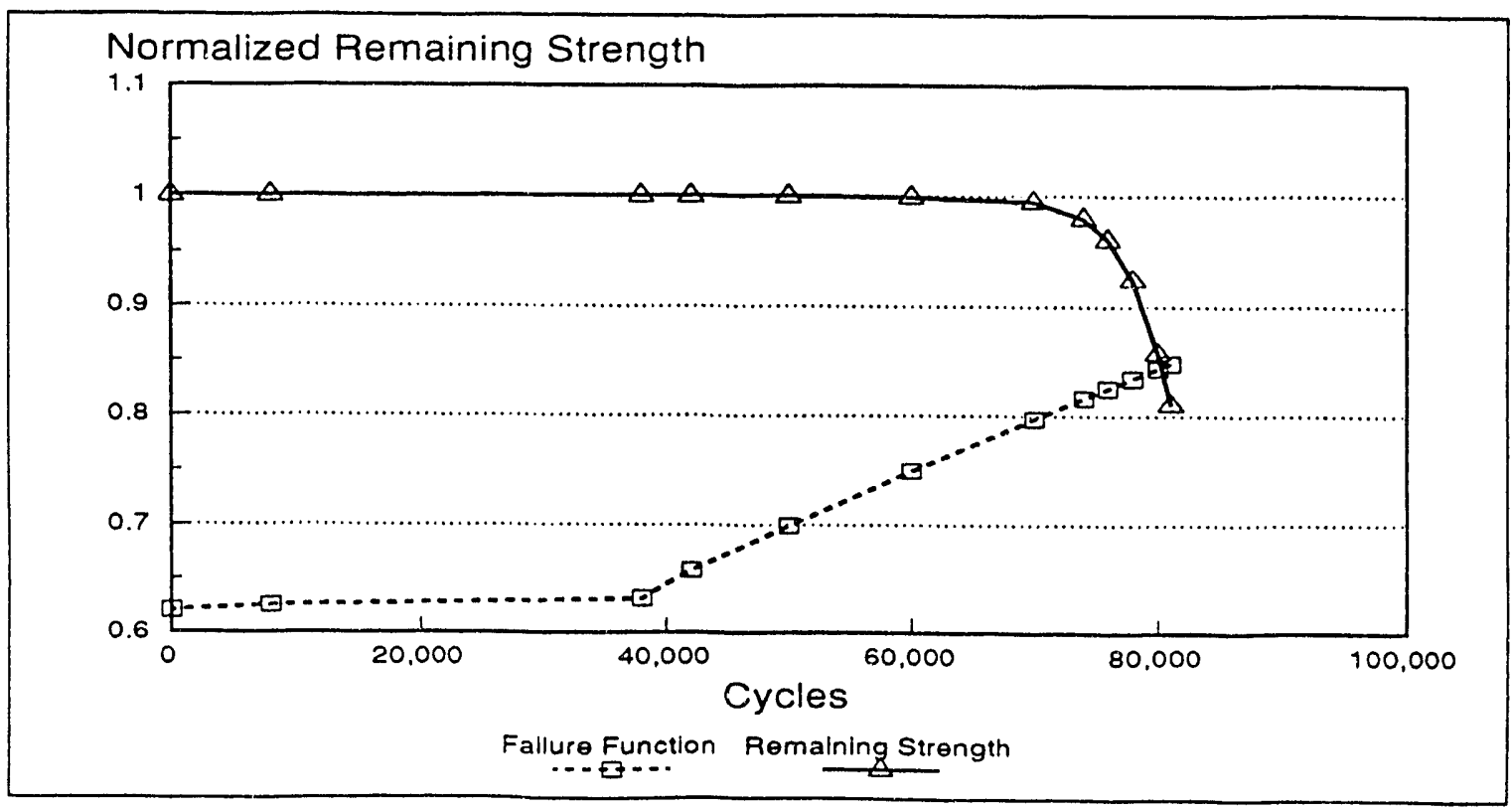

Fig. 3. Simulation of strength reduction for a cross-ply laminate of SiC reinforced CAS during fatigue at 982 degrees Centigrade. 
on the applied stress level. This has created a new challenge for the modeling effort. Efforts are underway to provide a modeling approach to correctly represent this type of behavior.

Achieving an understanding and representation of the fatigue of ceramic composite material systems is critical to the success of many current and planned applications of composite materials. The complexity of the processes that control that phenomenon, and the manner in which that relates to the complexity of the material systems themselves, motivates a highly structured and carefully constructed approach to the achievement of understandings and representations. The present effort is based on a mechanistic approach to this objective that is based on micromechanical representations of strength, and the systematic variation of the parameters in such models to achieve representations of the global changes in properties and performance. This approach seems to hold some promise of general utility and physical fidelity. Initial results predict some surprising effects of micro-properties, and observations appear to support those predictions. Further study of this approach and its application to this project continues.

\section{RELATED WORK}

The experience of the technical community with creep rupture in ductile homogeneous materials as recorded in the literature is extensive, even profuse. However, while the understanding of mechanisms could be said to be relatively "mature", modeling of the behavior is generally empirical, and sometimes anecdotal. Surprisingly few "axioms" seem to lie at the base of the dominant models. However, there is a strong body of experimental literature that identifies the mechar..sms which drive creep rupture tvents for those materials. In an effort to understand our experimental data and in support of our effort to generate interpretative models, we have initiated a study of creep rupture in composite materials. This activity is not a direct objective of the current program, but will be conducted as a secondary objective in support of the program. 
The phenomenon of creep rupture is not well understood or characterized for composite material systems. This is due, in part, to the shortness of the period of opportunity which the community has had to obtain high temperature composite systems and to observe their behavior, and to the extremely large variety of material systems (and consequent behaviors) which are presented by the synthesis and manufacturing community. But it is also due to an attendant lack of understanding of failure processes in such complex systems, in general, especially at elevated temperature. Discussions of mechanisms in homogeneous materials concentrate, primarily, on defects such as cracks and cavities, and focus on the behavior of material interfaces and interphases such as grain boundaries. Composite material systems are made by creating great numbers of boundaries across which the constituents interact to create "the composite effect," and micro-defects such as cracks, debonds, and micro-separations are often present in great numbers.

However, the very foundations of the design of composite materials preclude the "eminent disaster" that this type of microstructure would appear to invite. Composite systems are designed to control properties, in general, and (less often) long-term performance by controlling damage and failure modes. Hence, the extensive network of fiber-matrix boundaries which would appear to be "fatal flaws" from the standpoint of creep rupture, does turn out to be important (probably the most important mechanism in many systems), but does not have the same effect as it would in "homogeneous" materials because these boundaries are so arranged that the primary load bearing constituents do not depend on the integrity of the boundary for stiffness and strength except through secondary interactions. This is especially true for systems in which the fibers are the primary load carrying micro-element. It is less true for systems in which the matrix is stiffer than the fibers and is responsible for carrying the major stress romponents. ${ }^{5}$ Hence, the most obvious mechanism for creep in fiber-reinforced composite material systems at elevated temperatures is fiber matrix interface (or interphase) deformation, but the contribution of that mechanism to failure (creep rupture) is more likely to be through secondary effects (such as redistribution of the local stresses) than would be the case for "conventional" materials. 
This observation serves to remind us that the general problem of creep rupture in material systems involves an inextricable combination of (micro)mechanics and materials considerations. We will argue (following) that it is the key to a viable approach to the problem of predicting creep rupture behavior for such systems. In the present context, this consideration adds another important mechanism to the list of creep rupture mechanisms in composite material systems. Creep deformation itself (viscoelastic or viscoplastic--properly modeled in such systems) may cause sufficient internal redistribution of stress in the "principal elements" of the material at the local level to cause rupture by local "overload" effects. In addition, this type of time dependent deformation may contribute to the growth of "regions of influence" of local defects or discontinuities (such as broken fibers, matrix cracks, debonds) such that these distributed defects eventually "see" each other and combine to create a "fracture line." This is, of course, a special version of the "accumulation" mechanism widely discussed in homogeneous materials. ${ }^{6}$

Because of this damage accumulation, the condition of a fiber reinforced composite material system changes during the creep process. Under constant or time dependent loading, matrix cracks typically initiate in plies having the fiber axis not aligned with the loading axis, and may also develop in plies aligned with the loading axis. As time and/or loading increases, the matrix cracks elongate and increase in number until a uniformly spaced array of cracks is achieved. ${ }^{7,8}$ The regular array of matrix cracks, known as the characteristic damage state, is a property of the material system and the laminate configuration. ${ }^{9}$

The changing state of the material with time is reflected in changes in the viscoelastic properties of the composite. At any time in the life of the composite, prior to the development of the characteristic damage state, the state of damage in the material will depend on the magnitude of stress, or on the number of stress cycles.

How these and other mechanisms control the creep rupture behavior of ceramic composites remains to be determined. In addition to chemical, thermodynamic, and kinetic events (which can be closely related to existing experience with homogeneous ceramics), the role of damage development is more complex and probably more 
important since the damage tolerance of composites is very much greater than that of monolithic materials. It is the intent of our continuing studies to identify these roles, and to construct models that allow us to represent creep rupture behavior in ceramic composite materials. These models will then be incorporated in our performance simulation codes to assist in data interpretation as well as in the design of ceramic composite components. Several research programs in the authors' laboratory, which are complementary to the present one, will assist in this general effort. 


\section{REFERENCES}

1. Stinchcomb, W. W., Reifsnider, K. L. and Dunyak, T. J., "Investigation of Properties and Performance of Ceramic Composite Components," Technical Report ORNL/Sub/87-SA946/02, DOE/Oak Ridge National Laboratory, June 1992.

2. Dunyak, T. J., Reifsnider, K. L. and Stinchcomb, W. W., "An Examination of Selected NDE Methods for Ceramic Composite Tubes," Technical Report ORNL/Sub/87-SA946/01, DOE/Oak Ridge National Laboratory, Dec. 1989.

3. Stinton, D. P., Lowden, R. A., McLaughlin, J. C., Riester, L. and Clark, M. C., "Fiber Reinforced SiC-Matrix Composites," presented at Conference on Fossil Energy Materials, ORNL, Oak Ridge, TN, May, 1991.

4. Reifsnider, K. L., "Life Prediction in Advanced Material Systems," in Fatigue of Advanced Materials, R. O. Ritchie, et.al., Eds., Materials Component Engineering Publications Ltd., Birmingham, U.K. (1991), pp. 85-110.

5. Abbe, F. and Chermant, J. L., "Creep Resistance of SiC/SiC Composites Under Vacuum," in Creep and Fracture of Engineering Materials and Structures, R. Wilshire, R. W. Evans, Eds., Bookcraft Ltd., Institute of Metals, 1990, pp. 439449.

6. Hsia, K. J., Argon, A. S. and Parks, D. M., ibid.

7. Masters, J. E. and Reifsnider, K. L., "An Investigation of Cumulative Damage Development in Quasi-Isotropic Graphite/Epoxy Laminates," ASTM STP 775, Damage in Composite Materials, K. L. Reifsnider, Ed., Am. Soc. for Testing and Materials, Philadelphia, PA, 1982, pp. 40-62.

8. Moore, R. H. and Dillard, D. A., "Time-Dependent Matrix Cracking in CrossPly Laminates," Composite Science and Technology, Vol. 39, 1990, pp. 1-12.

9. Reifsnider, K. L. and Highsmith, A. L., "Characteristic Damage States: A New Approach to Representing Fatigue Damage in Composite Laminates," Materials: Experimentation and Design in Fatigue, Westbury House, Guilford, U.K., 1981, pp. $246-260$. 
PART III - NEW ALLOYS 
ANL 3 - CORROSION AND MECHANICAL PROPERTIES OF ALLOYS IN FBC

AND

MIXED-GAS ENVIRONMENTS

K. Natesan

Argonne National Laboratory

Materials and Components Technology Division

Argonne, IL 60439

\section{INTRODUCTION}

The purposes of this program are to (1) evaluate mechanisms of oxidation, sulfidation, and breakaway corrosion in chromia- and alumina-forming alloys and coatings exposed to mixed-gas atmospheres that span the wide range of oxygen and sulfur partial pressures typical of both combustion and gasification systems; (2) develop an understanding of the role of several microalloy constituents (e.g., $\mathrm{Zr}$, $\mathrm{Nb}, \mathrm{Y}, \mathrm{Ce}$ ) in oxidation/sulfidation processes; (3) characterize the physical, chemical, and mechanical properties of surface oxide scales that are resistant to sulfidation attack; and (4) evaluate the role of deposits, such as fluidized-bed combustor sorbents that contain sulfur and/or chlorine and ash constituents, in the corrosion of metallic alloys and selected coatings.

\section{DISCUSSION OF CURRENT ACTIVITIES}

During the current reporting period, corrosion evaluation of iron aluminide $\left(\mathrm{Fe}_{3} \mathrm{Al}\right)$ bulk alloy, electrospark-deposited coating of $\mathrm{Fe}_{3} \mathrm{Al}$ and $\mathrm{Fe}-\mathrm{Al}$ binary alloys were continued. The corrosion resistance of three heats of iron aluminides were evaluated for application in coal gasification and fluidized-bed combustion environments. Results of these evaluations were reported earlier. ${ }^{1}$ Further, thermogravimetric test data developed for iron aluminides were compared with the corrosion performance of Type 310 stainless steel. The test data obtained over a temperature range of $650-1000^{\circ} \mathrm{C}$ showed that the aluminides developed predominantly alumina scales that were thin and exhibited some propensity to spallation. However, when compared with the catastrophic corrosion behavior of Type 310 stainless steel, the aluminides exhibited superior corrosion resistance in high-sulfur (typical of high sulfur coal feedstock) and in oxygen/sulfur mixed-gas 
environments. One heat of iron aluminide that was tested for times up to $3000 \mathrm{~h}$ in simulated fluidized-bed combustion atmospheres in the presence of $\mathrm{CaSO}_{4}$ or circulating fluid-bed ash showed negligible scaling and virtually no oxide or sulfide penetration of the substrate alloy.

During the current reporting period, thermogravimetric tests were continued on $\mathrm{Fe}-\mathrm{Al}$ binary alloys to evaluate the minimal aluminum concentration that was necessary for sulfur resistance. Binary alloys of $\mathrm{Fe}$ and $\mathrm{Al}$ containing 8,10 , and $12 \mathrm{wt} . \% \mathrm{Al}$ were arc melted and rolled into sheets. Corrosion coupons were prepared from these sheets and thermogravimetric analysis (TGA) was conducted in an oxygen/sulfur mixed-gas environment that contained sulfur in the form of $\mathrm{H}_{2} \mathrm{~S}$. Calculated values for oxygen and sulfur partial pressures established by the oxygen/sulfur mixed gas at $875^{\circ} \mathrm{C}$ were $4.1 \times 10^{-18}$ and $9.4 \times 10^{-7}$ atm, respectively. Tests were also conducted with several commercially available iron-base alloys containing aluminum and a coating of iron-aluminide that was obtained by using the electrospark deposition process. Table 1 is a listing of the compositions of the alloys/coatings used in the present study. In addition, TGA was conducted on $\mathrm{Fe} 3 \mathrm{Al}$ alloy specimens in the presence of a slag deposit, obtained from a slagging combustor run under substoichiometric combustion conditions. Table 2 lists the

Table 1. Nominal or Actual Chemical Composition (wt.\%) of Alloys Used in Corrosion Tests

\begin{tabular}{llllllll}
\hline Material & $\mathrm{Cr}$ & $\mathrm{Ni}$ & $\mathrm{Mn}$ & $\mathrm{Si}$ & $\mathrm{Al}$ & $\mathrm{Fe}$ & Other \\
\hline $\mathrm{Fe}-25 \mathrm{Cr}$ & 25.0 & $<0.01$ & $<0.01$ & $<0.01$ & $<0.01$ & Bal. & - \\
$\mathrm{Fe}-25 \mathrm{Cr}-20 \mathrm{Ni}$ & 24.8 & 19.9 & $<0.01$ & 0.001 & 0.01 & $\mathrm{Bal}$. & - \\
$\mathrm{Fe}-25 \mathrm{Cr}-6 \mathrm{Al}$ & 24.6 & $<0.01$ & $<0.01$ & $<0.01$ & 5.88 & $\mathrm{Bal}$. & - \\
$310 \mathrm{sS}$ & 25.0 & 18.7 & 1.21 & 0.64 & - & $\mathrm{Bal}$. & - \\
$\mathrm{Fe}-8 \mathrm{Al}$ & - & - & - & - & 8 & $\mathrm{Bal}$. & - \\
$\mathrm{Fe}-10 \mathrm{Al}$ & - & - & - & - & 10 & $\mathrm{Bal}$. & - \\
$\mathrm{Fe}-12 \mathrm{Al}$ & - & - & - & - & 12 & $\mathrm{Bal}$. & - \\
$\mathrm{FA} \mathrm{61}$ & - & - & - & - & 13.9 & Bal. & - \\
$8 X X$ & 20.2 & 32.5 & - & - & 3 & Bal. & - \\
GE 1541 & 15.2 & - & 0.001 & 0.07 & 4.95 & Bal. & Y 0.7 \\
RV 8413 & 18.5 & 0.06 & 0.001 & 0.025 & 5.91 & Bal. & Hf 0.50 \\
\hline
\end{tabular}

a Bal. = balance. 
Table 2. Chemical Analysis of Slag Sample

\begin{tabular}{ll}
\hline Compound & $\begin{array}{c}\text { Amount } \\
\text { (wt.\%) }\end{array}$ \\
\hline $\mathrm{SiO}_{2}$ & 50.2 \\
$\mathrm{Al}_{2} \mathrm{O}_{3}$ & 20.9 \\
$\mathrm{Fe}_{2} \mathrm{O}_{3}$ & 10.8 \\
$\mathrm{CaO}$ & 13.3 \\
$\mathrm{Na}$ & 0.22 \\
$\mathrm{~K}_{2} \mathrm{O}$ & 0.72 \\
$\mathrm{TiO}_{2}$ & 1.1 \\
$\mathrm{P}_{2} \mathrm{O}_{5}$ & 0.04 \\
$\mathrm{SO}_{3}$ & 0.07 \\
\hline
\end{tabular}

chemical analysis of combustor slag. The slag material was finely powdered, made into a water-base paste, and applied onto the alloy specimen. The thickness of the deposit layer was in the range of $0.25-0.50 \mathrm{~mm}$. The specimens with the deposit materials were dried at room temperature and visually examined to ensure adherence of the deposit to the substrate. Upon completion of the exposures, specimens from all the tests were examined by scanning electron microscopy (SEM) and energy disrersive X-ray analysis (EDX).

\section{RESULTS AND DISCUSSION}

Figure 1 shows data from TGA of several Fe-Al binary alloys and iron aluminide heat FA 61, tested in an oxygen/sulfur mixed-gas environment at $875^{\circ} \mathrm{C}$. The results indicate significant corrosion of alloys containing 8 and $10 \mathrm{wt} . \% \mathrm{Al}$, whereas the corrosion rate at $12 \mathrm{wt} . \% \mathrm{Al}$ and in FA 61 (with $13.9 \mathrm{wt} . \% \mathrm{Al}$ ) was negligible under the same conditions. Figure 2 shows SEM micrographs of surfaces of $\mathrm{Fe}-\mathrm{Al}$ binary alloys and FA 61 after exposure to a mixed-gas environment. EDX analysis showed that the alloys containing 8 and $10 \mathrm{wt} . \% \mathrm{Al}$ developed predominantly iron sulfide scale, whereas the other two alloys developed aluminum oxide scale. Figure 3 shows SEM micrographs of cross sections of the four alloys after exposure to the mixed gas. The $8 \mathrm{wt} . \% \mathrm{Al}$ alloys were tested for only 1.75 hours, whereas the $10 \mathrm{wt} . \% \mathrm{Al}$ alloy was tested for 5.5 hours; therefore, the absolute values of the scale thicknesses should not be compared. However, indications are that both alloys undergo catastrophic sulfidation in the oxygen/sulfur mixed gas with sulfur levels that are anticipated in coal-gasification systems that utilize high-sulfur 
coal as a feedstock. Figure 3 also shows that the $12 \mathrm{wt. \%} \mathrm{Al}$ alloy and FA 61 develop extremely thin scales after $\approx 90$ hours of exposure to the mixed-gas environment.

Figure 4 shows TGA data for several high-purity $\mathrm{Fe}-\mathrm{Cr}, \mathrm{Fe}-\mathrm{Cr}-\mathrm{Ni}, \mathrm{Fe}-\mathrm{Al}$, $\mathrm{Fe}-\mathrm{Cr}-\mathrm{Al}$ alloys, and FA 61 after exposure to an oxygen/sulfur mixed-gas environment at $875^{\circ} \mathrm{C}$. The weight change data for the $\mathrm{Fe}-\mathrm{Cr}$ binary alloy show that chromium concentration at a high level of $25 \mathrm{wt}$.\% does not improve the sulfidation resistance of the alloy. The alloy developed a scale that consisted of a mixture of iron- and chromium sulfide and exhibited a very high growth rate. Addition of 20 wt.\% nickel to this alloy did not improve its corrosion resistance. In fact, the presence of nickel led to the formation of $\mathrm{Ni}-\mathrm{Ni} 3 \mathrm{~S}_{2}$ eutectic, if the the test was run for a longer time. The composition of this ternary alloy is similar to the base composition of Type 310 stainless steel and its behavior was similar, as reported earlier. ${ }^{1}$ The weight change of the $\mathrm{Fe}-10 \mathrm{wt} . \% \mathrm{Al}$ alloy is similar to that of $\mathrm{Fe}-\mathrm{Cr}$ and $\mathrm{Fe}-\mathrm{Cr}-\mathrm{Ni}$ alloys. Addition of $6 \mathrm{wt} . \% \mathrm{Al}$ to the $\mathrm{Fe}-25 \mathrm{Cr}$ alloy seemed to reduce the corrosion rate somewhat but the external scale consisted of iron sulfide, which is not expected to offer protection against breakaway corrosion. The binary Fe-12 wt.\% $\mathrm{Al}$ alloy and the iron aluminide FA 61 (with 13.9 wt.\% $\mathrm{Al}$ ) exhibited superior corrosion resistance in oxygen/sulfur mixed-gas atmospheres. The scales in these

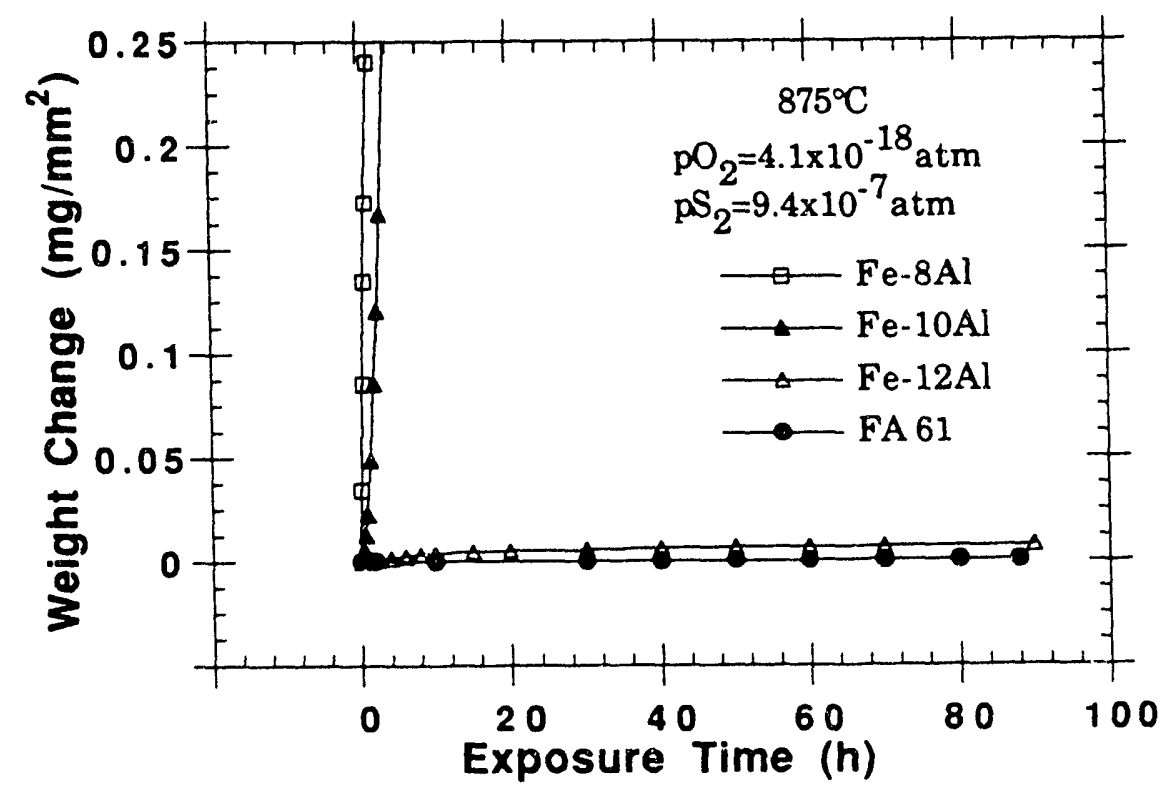

Fig. 1. Weight change data for Fe-A1 binary alloys and iron aluminide FA 61 specimens tested in oxygen/sulfur mixed-gas environment at $875^{\circ} \mathrm{C}$. 

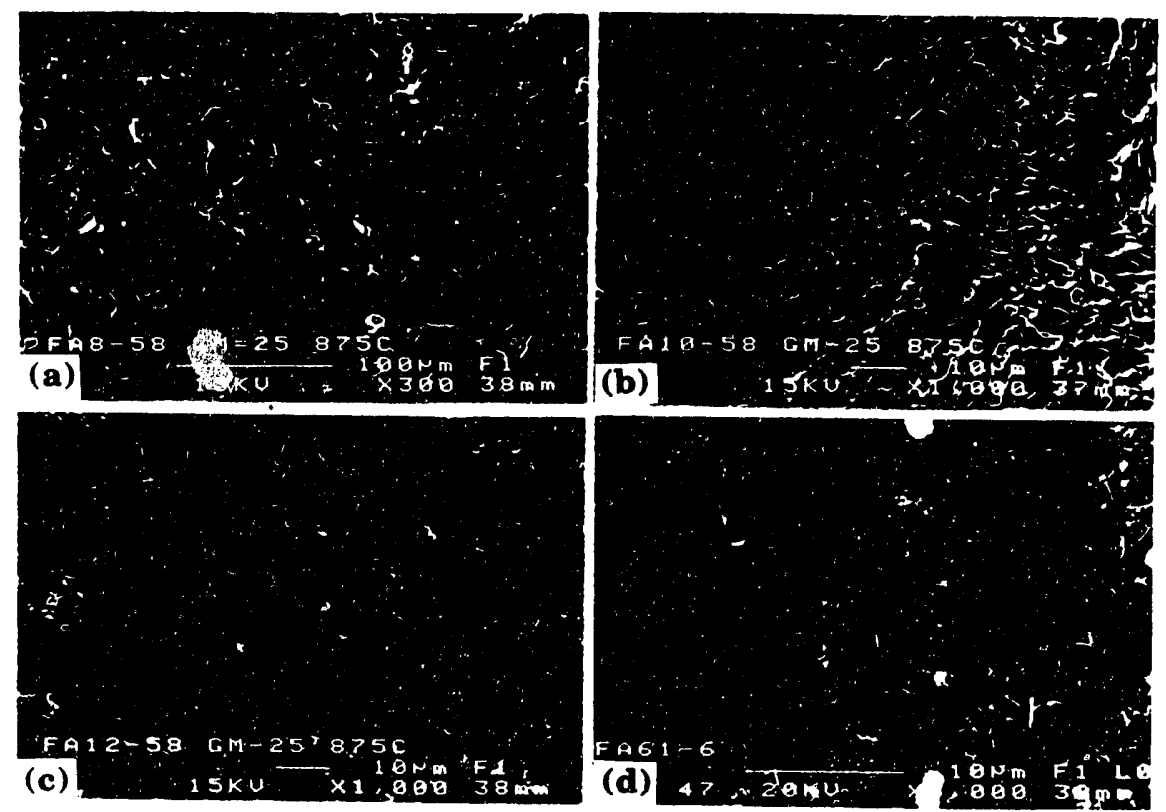

Fig. 2. SEM photomicrographs of surfaces of (a) $\mathrm{Fe}-8 \mathrm{wt} . \% \mathrm{Al}$, (b) Fe-10 wt.\% Al, (c) Fe-12 wt.\% Al, and (d) FA 61 specimens after exposure in oxygen/sulfur mixed-gas environment at $875^{\circ} \mathrm{C}$.

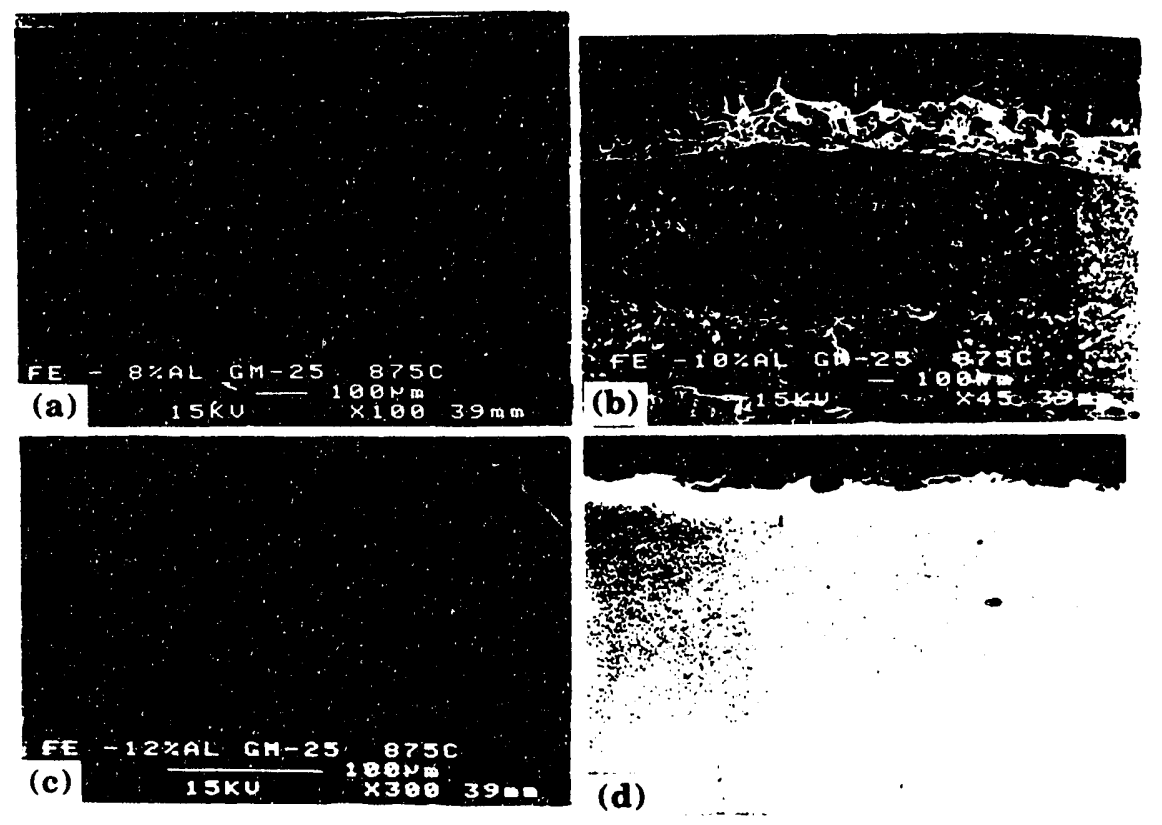

Fig. 3. SEM photomicrographs of cross sections of (a) $\mathrm{Fe}-8$ wt.\% Al, (b) $\mathrm{Fe}-10$ wt.\% $\mathrm{Al}$, (c) $\mathrm{Fe}-12$ wt.\% Al, and (d) FA 61 specimens after exposure in oxygen/sulfur mixed-gas environment at $875^{\circ} \mathrm{C}$. 


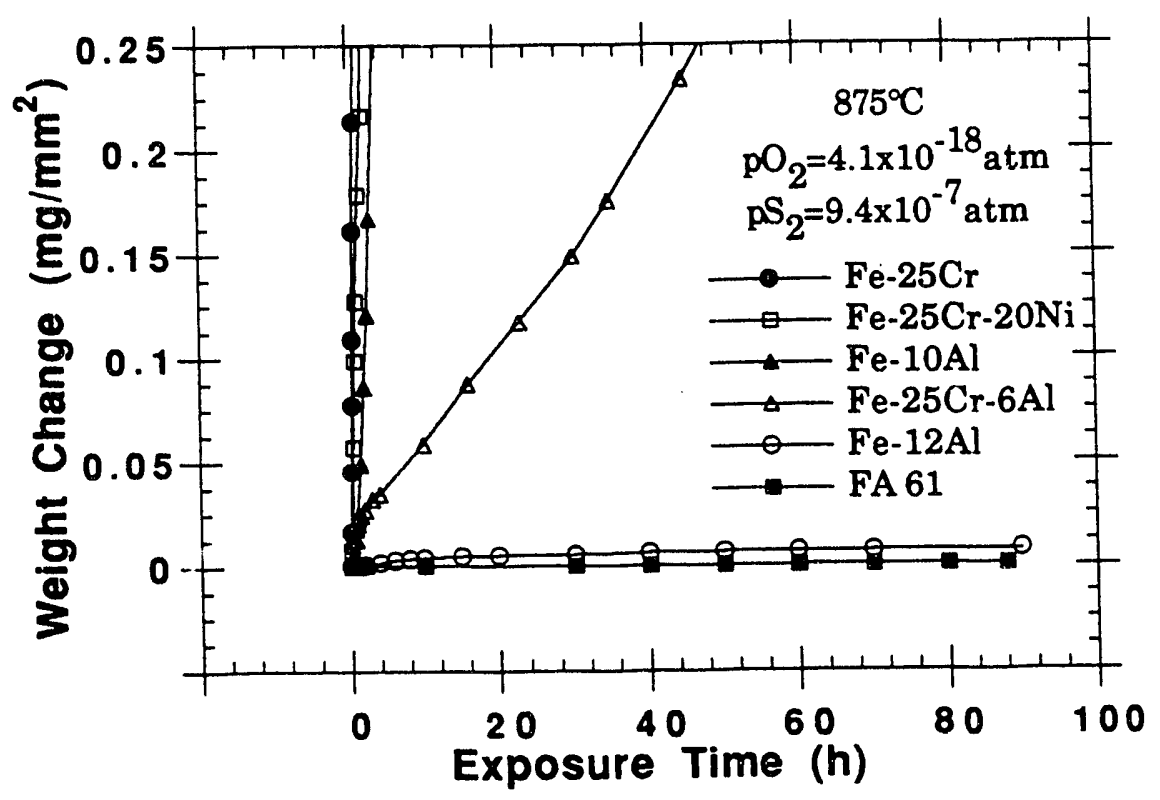

Fig. 4. Weight change data for $\mathrm{Fe}-\mathrm{Cr}, \mathrm{Fe}-\mathrm{Cr}-\mathrm{Ni}, \mathrm{Fe}-\mathrm{Al}$, and $\mathrm{Fe}-\mathrm{Cr}-\mathrm{Al}$ alloys and iron aluminide FA 61 tested in oxygen/sulfur mixed-gas environment at $875^{\circ} \mathrm{C}$.

alloys were aluminum oxide and contained little sulfur. The results indicate that a critical aluminum content of $12 \mathrm{wt} . \%$ is needed for alumina formation on the alloy surface in environments typical of coal-gasification systems.

Figure 5 shows weight change data for several aluminum-containing commercial alloys, along with data for $\mathrm{Fe}-12 \mathrm{wt} . \% \mathrm{Al}$ and FA 61 alloys. The alloy $8 \mathrm{XX}$, which contains $\approx 3-4 \mathrm{wt} . \% \mathrm{Al}$, exhibited catastrophic corrosion, as expected. The cross points in the figure show that the electrospark-deposited coating of nominally Fe3Al exhibited a very high corrosion rate. Detailed microprobe examination of ascoated specimens showed that the coating was substantially diluted and the coated surface contained an average aluminum concentration in the range of $\approx 6-8 \mathrm{wt} . \%$. As a result, the corrosion performance of the coated specimen was similar to that of the $\mathrm{Fe}-$ Al binary alloys that contained 8 and 10 wt.\% aluminum. At present, coatings are being developed from $\mathrm{FeAl}$ (rather than $\mathrm{Fe} 3 \mathrm{Al}$ ) filler wire, so that even with dilution, the aluminum content in the coated region will exceed $12 \mathrm{wt} . \%$. The alloys GE 1541 and RV 8413, for which data are included in Fig. 5, are iron base alloys with moderate 


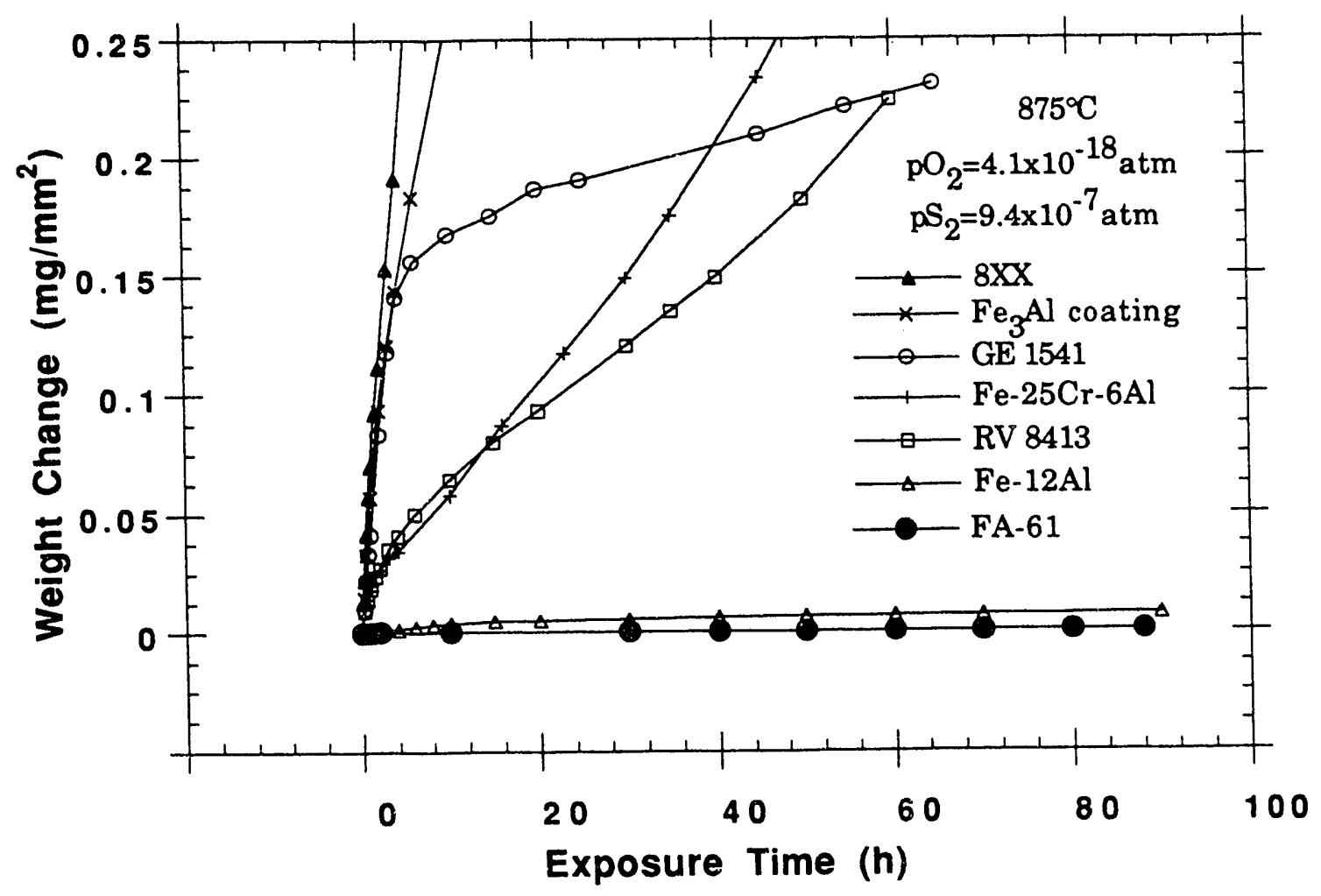

Fig. 5. Weight change data for several commercial alloys, $\mathrm{Fe}-12 \mathrm{wt} \% \mathrm{Al}$ alloy, and iron aluminide FA 61 tested in oxygen/sulfur mixed-gas environment at $875^{\circ} \mathrm{C}$.

chromium content and $\approx 5-6 \mathrm{wt} . \% \mathrm{Al}$. The corrosion performance of these alloys is not adequate for service in coal-gasification environments.

Figure 6 shows SEM micrographs of surfaces of some of the $\mathrm{Fe}-\mathrm{Cr}-\mathrm{Al}$ alloys and the coated sample after exposure to an oxygen/sulfur mixed-gas environment. The scale compositions of all these specimens were similar and consisted of iron- and chromium sulfides. The grain size of sulfide was somewhat smaller in GE 1541, possibly due to grain refinement of the starting material by yttrium addition. Figure 7 shows the SEM micrographs of cross sections of the specimens shown in Fig. 6. All four specimens developed predominantly iron sulfide scale and exhibited substantial internal penetration of the substrate alloys. Because different specimens were exposed for different lengths of time, a direct comparison should not be made of the scale thicknesses for the specimens shown in Fig. 7. For example, alloy $8 \mathrm{XX}$ and the coated specimen were exposed for 15 and $35 \mathrm{~h}$, respectively, whereas $\mathrm{Fe}-25 \mathrm{Cr}-6 \mathrm{Al}$ and GE 1541 alloys were exposed for 50 and $65 \mathrm{~h}$, respectively. 

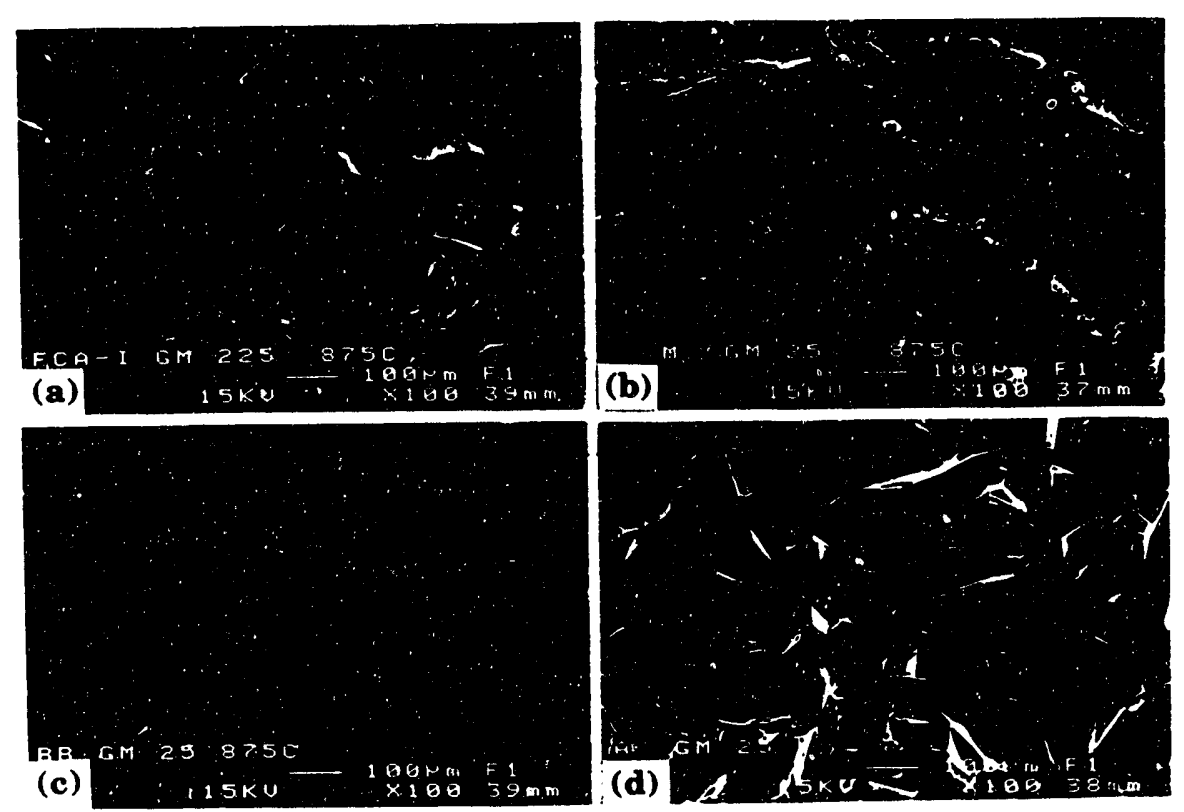

Fig. 6. SEM photomicrographs of surfaces of (a) $\mathrm{Fe}-25$ wt.\% $\mathrm{Cr}-6 \mathrm{wt} . \% \mathrm{Al}$, (b) $8 \mathrm{XX}$, (c) $\mathrm{GE} 1541$, and (d) $\mathrm{Fe}-\mathrm{Al}$-coated specimens after exposure in oxygen/sulfur mixed-gas environment at $875^{\circ} \mathrm{C}$.
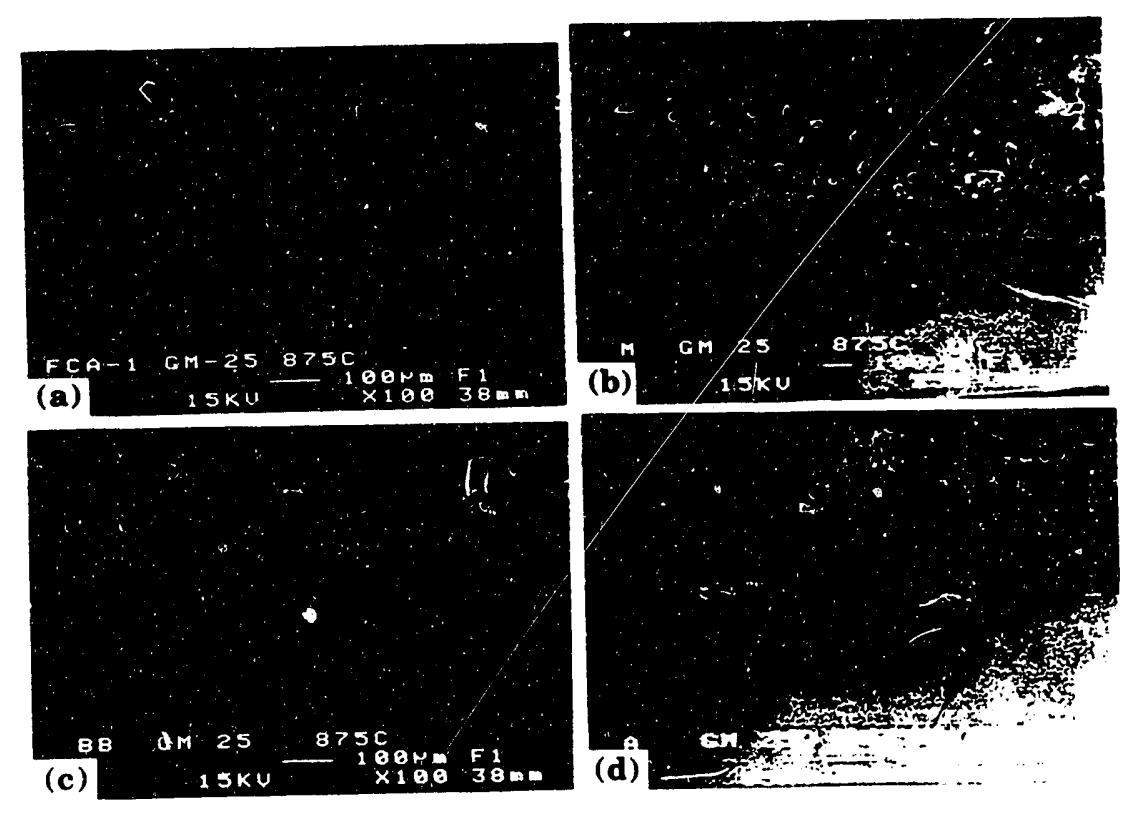

Fig. 7. SEM photomicrographs of cross sections of (a) $\mathrm{Fe}-25 \mathrm{wt} \% \mathrm{Cr}-6 \mathrm{wt} . \% \mathrm{Al}$, (b) $8 X X$, (c) GE 1541, and (d) Fe-Al-coated specimens after exposure in oxygen/sulfur mixed-gas environment at $875^{\circ} \mathrm{C}$. 
Figure 8 shows weight change data for uncoated and slag-coated FA 61 specimens tested in an oxygen/sulfur environment, as well as data for Fe-12 wt.\% $\mathrm{Al}$ alloy tested under isothermal and thermal cycling conditions in the same exposure environment. The test results on the slag-coated specimen shows a sharp increase in weight change during the initial $3-\mathrm{h}$ period but the weight change is still very small (the $y$-axis in this figure is expanded) when compared with the data for the alloys shown earlier in this report. After $\approx 5 \mathrm{~h}$ of exposure, the reaction between slag components and alloy constituents seemed to cease, as evidenced by the plateau in the weight change curve up to $120 \mathrm{~h}$ of exposure. Additional experiments are underway with several of the alloys to evaluate the slag effect, if any, as a function of temperature and alloy chemistry. In the thermal-cycling tests conducted thus far, $\mathrm{Fe}-12$ wt.\% $\mathrm{Al}$ alloy exhibited a lower corrosion rate under cyclic conditions than under isothermal conditions. Additional tests are in progress to evaluate the spallation resistance of the highly protective scales in alloys containing large amounts of aluminum.

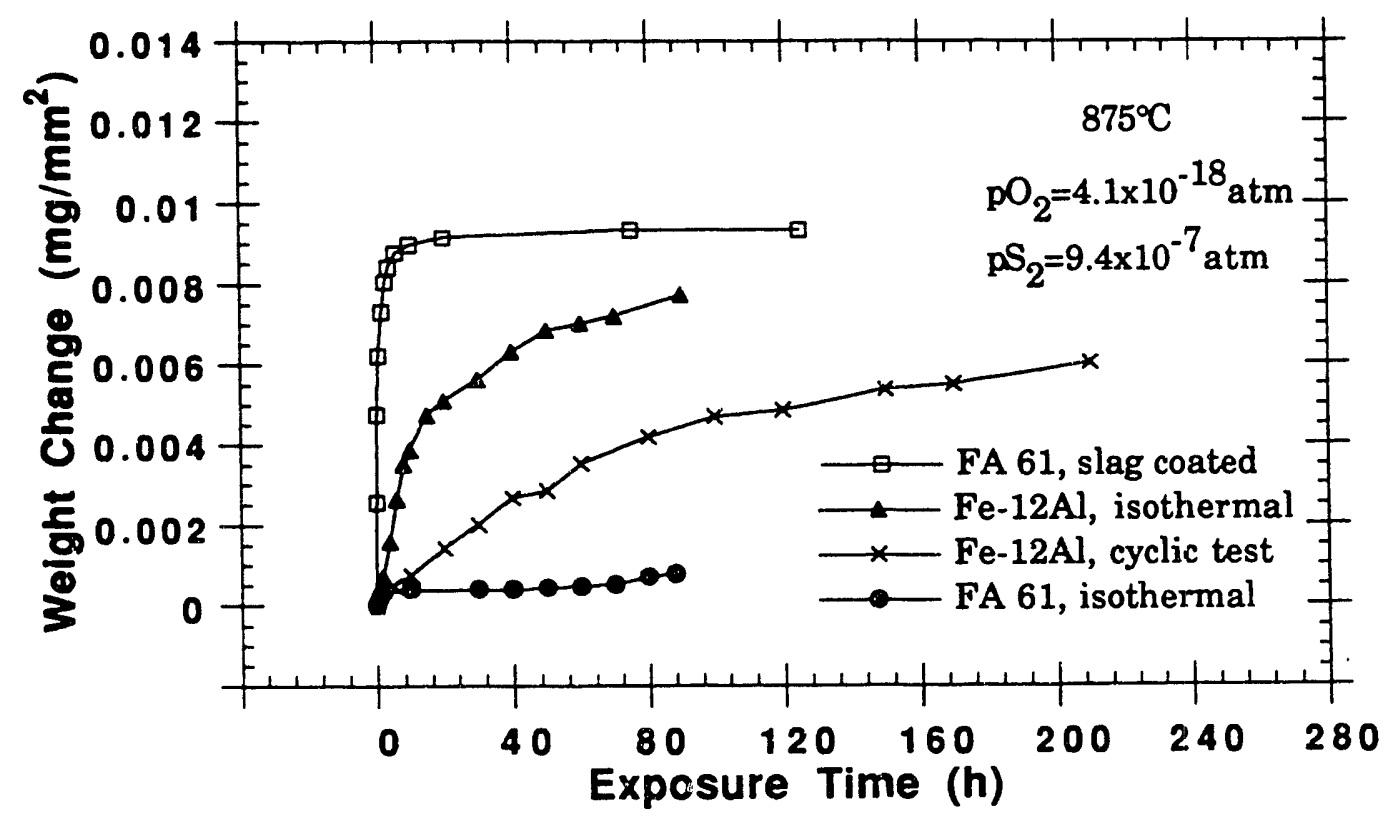

Fig. 8. Weight change data for FA 61 with and without slag coating and Fe-12 wt.\% $\mathrm{Al}$ alloy in isothermal and thermal cycling conditions tested in oxygen/sulfur mixed-gas environment at $875^{\circ} \mathrm{C}$. 


\section{REFERE' + ES}

1. I Natesan, Corrosion Resistance of Iron Aluminides, Proceedings of the Sizst. Arnual Conference on Fossil Energy Materials, ORNL/FMP-92/1, p. $271,1992$. 
CSM-2-WELDABILITY OF POLYCRYSTALLINE ALUMINIDES

\author{
A. A. Fasching ${ }^{\star}$, G. R. Edwards* ${ }^{\star}$, and S. A. David \\ Center for Welding and Joining Research \\ Department of Metallurgical and Materials Engineering \\ Colorado School of Mines \\ Golden, CO 80401 \\ Metals and Ceramic Division \\ Oak Ridge National Laboratory \\ Materials Joining Group \\ Oak Ridge, TN 37831
}

INTRODUCTION

Iron aluminide alloy FA-129 is susceptible to cold cracking during gas-tungsten arc (GTA) welding. Cracking occurs by brittle fracture in the fusion zone, which has been attributed to excessive grain growth during solidification in concert with environmental embrittlement. Previous work has shown that iron aluminide can be susceptible to environmental embrittlement when tested in the presence of water vapor. The suggested mechanism is similar to that observed in aluminum alloys: the reaction of water molecules with freshly exposed aluminum atoms at the crack tip results in the formation of high activity atomic hydrogen, which diffuses into the metal and causes embrittlement. This phenomenon occurs only when the metal is stressed, and therefore, is a dynamic embrittlement phenomenon. ${ }^{1}$ The same effect was not seen in experiments conducted in the presence of hydrogen gas. ${ }^{2}$ To further investigate this embrittlement problem and its effect on welding, GTA welds were conducted in atmospheres of varying amounts of water vapor on base material of varying grain sizes. The varying base material grain sizes were chosen because fusion zone grain size depends, to an extent, on the grain size of the base material. For example, a fine-grained base material should produce a finer grained fusion zone than a coarse-grained base material would. The results of the investigation are presented within this paper. 
DISCUSSION OF CURRENT ACTIVITIES

The material for this investigation, provided by Oak Ridge National Laboratory (ORNL), came from a production vacuum arc remelt (VAR) ingot (Ht\# D53969-1). The ingot was sectioned, extruded and hot rolled to sheet with a nominal thickness of $0.75 \mathrm{~mm}$. The sheet was then sheared into $51 \mathrm{~mm} \times 51 \mathrm{~mm}$ sigmajig test coupons. The coupons were then divided into three groups, and each group was given a different heat treatment, as shown in Table 1. The heat treatments produced three different base material microstructures, including a stress-relieved but unrecrystallized, a fine-grained $(38 \mu \mathrm{m})$, and a coarse grained $(58 \mu \mathrm{m})$ microstructure. Figure 1 shows the base material microstuctures for the coarse-grained, fine-grained and unrecrystallized material. After heat treatment, the oxide layer on the test coupons was removed with the following etch: 10 parts $\mathrm{H}_{2} \mathrm{O}, 1$ part $\mathrm{HNO}_{3}$, and $\frac{1}{2}$ part $\mathrm{HF}$.

Table 1: Summary of Heat Treatments for Iron-Aluminide Alloy FA-129.

\begin{tabular}{|c|c|}
\hline Unrecrystallized & $600^{\circ} \mathrm{C}$ for 1.5 hours \\
\hline Fine Grain Size $(38 \mu \mathrm{m})$ & $750^{\circ} \mathrm{C}$ for 1 hour \\
\hline Coarse Grain Size $(58 \mu \mathrm{m})$ & $750^{\circ} \mathrm{C}$ for 48 hours \\
\hline
\end{tabular}

All welding was conducted in a glove box with an argon atmosphere. In the tests with a measurable water vapor level, the argon was bubbled through warm de-ionized water in an enclosed glass chamber. The argon flow rate and the water temperature were varied to change the water vapor content in the glove box. The chamber was allowed one to two hours to reach equilibrium before welding. A Panametrics Model 2000 hygrometer was used in conjunction with an aluminum oxide probe to measure all moisture levels. For each welding speed, water vapor level, and base metal condition, three coupons were welded. Table 2 shows a summary of the tests that were conducted. Two specimens of each condition were tested in the sigmajig apparatus and a load to fracture 

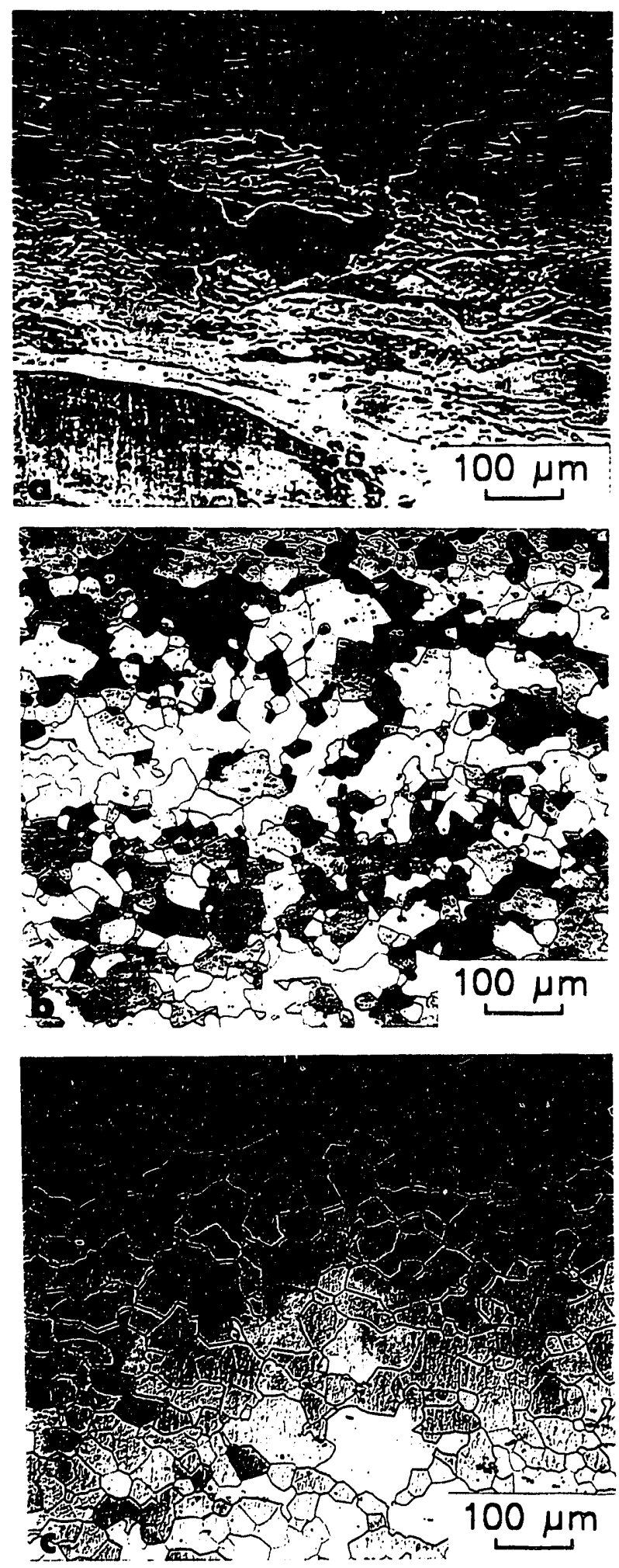

Figure 1: Base material microstructures for Alloy FA-129 a) unrecrystallized and stress-relieved material, b) fine-grained material, and c) coarse-grained material. 
was measured. From the fracture load and the sample thickness, a fracture stress $\left(\sigma_{F}\right)$ was calculated. The third sample was not exposed to a load, but was used for microstructural characterization. The machine settings for the specimens welded at 10 inches per minute (ipm) were 42 amps, 8 volts, and 0.04-in. arc gap, which corresponds to a heat input of $2 \mathrm{~kJ} /$ in. $(553 \mathrm{~J} / \mathrm{mm})$. The machine settings for the specimens welded at $30 \mathrm{ipm}$ were 78 amps, 9 volts and 0.035 -in. arc gap, which correlates to a heat input of $1.4 \mathrm{~kJ} / \mathrm{in}$. $(794 \mathrm{~J} / \mathrm{mm})$.

Table 2: Test Matrix for Effect of Water Vapor on the Weldability of FA-219.

\begin{tabular}{|c|c|c|c|}
\hline Welding Speed (ipm) & \multicolumn{3}{|c|}{ Water Vapor Level (ppm) } \\
\hline & $\sim 0$ & -2000 & $-190,000$ \\
\hline 10 & $\mathrm{x}$ & $\mathrm{x}$ & $\mathrm{x}$ \\
\hline 30 & $\mathrm{x}$ & $\mathrm{x}$ & $\mathrm{x}$ \\
\hline
\end{tabular}

The sigmajig test was developed to study hot cracking susceptibility of thin sheet weldments. When this test is employed to evaluate hot cracking, the specimen is loaded and a transverse stress is applied prior to welding. During welding, a crack will form down the centerline of the specimen. At sufficiently high loads, the specimen will break. ${ }^{3}$ To study the cold cracking susceptibility of FA-129, the specimens were placed in the sigmajig apparatus with no applied preload. After placing an autogenous weld down the center of the coupon, increments of load were applied until complete fracture occurred. The load at which fracture occurred was converted to a fracture stress.

Three different base material microstructures were selected to determine the extent of "memory" the Fusion zone had for the base material microstructure. The fine-grained base material should produce a finer grained fusion zone microstructure than the coarse-grained material under the same welding conditions. Fusion zone grains nucleate from those at the fusion line, and grow epitaxially inward. 
Unrecrystallized and stress relieved FA-129 is considered to be the most ductile form of the alloy; hence its investigation here.

Fracture strength data are shown in Tables 3 and 4 . The results were not unexpected; fracture strength generally decreased as welding speed decreased (heat input increased) and water vapor level increased. Fracture strength decreased only slightly with a decrease in welding speed, but exhibited a dramatic decrease as the water vapor content increased. Samples welded at 30 ipm and $-190,000 \mathrm{ppm}$ water vapor exhibited almost immeasurable fracture strengths. Fracture strength tests were not conducted for samples welded at 10 ipm in the high water vapor atmosphere in expectation of similar results.

None of the samples welded in the pure environment showed cracking in the weld prior to application of the load. Fracture initiated along the centerline, and usually propagated out to the heat affected zone (HAZ). The samples welded in a water vapor atmocrhere always exhibited cracking prior to load application; this cracking appeared both along and transverse to the welding direction. The cracking became more severe as the concentration of water vapor increased. The unrecrystallized samples exhibited the most severe pre-load cracking. In all samples exposed to water vapor, the fracture initiated along the centerline and propagated in and out of the fusion zone and the HAZ along pre-existing cracks.

Upon initial examination, Tables 3 and 4 also suggest a correlation between grain size variation of the base material (and therefore, the fusion zone) and a decrease in fracture strength. However, the difference in fracture strength is relatively small, and measurements of

Table 3: Fracture Strengths for Samples Welded at 10ipm.

\begin{tabular}{||c|c|c|c|}
\hline \multirow{2}{*}{ Base Metal Condition } & \multicolumn{3}{|c|}{ Fracture $\begin{array}{c}\text { Strength in Vater Vapor } \\
\text { Atmosphere (ksi) }\end{array}$} \\
\hline & -0 (dry) & -2000 & $-190,000 \mathrm{ppm}$ \\
\hline Unrecrystallized & 54.5 & 36 & $\ldots$ \\
\hline Fine grain size & 54.5 & 38.5 & $\ldots$ \\
\hline Coarse grain size & 46 & 32.5 & $\ldots$ \\
\hline
\end{tabular}


Table 4: Fracture Strengths for Samples Welded at 30ipm.

\begin{tabular}{||c|c|c|c||}
\hline Base Metal Condition & \multicolumn{3}{|c|}{ Fracture Strength in Water Vapor } \\
& & \multicolumn{3}{|c|}{$\begin{array}{c}\text { Atmosphere (ksi) } \\
\end{array}$} & -0 (dry) & -2000 & $-190,000 \mathrm{ppm}$ \\
\hline Unrecrystallized & -- & 11.5 & $<1.5$ \\
\hline Fine grain size & 60.5 & 28 & 4.2 \\
\hline Coarse grain size & 52 & 26.5 & $<1.5$ \\
\hline
\end{tabular}

fusion zone grain size showed very small difference between the coarseand fine-grained base material. These findings are in agreement with an earlier thermomechanical processing study which revealed the grain size in FA-129 to be extremely stable. As a result, it is difficult to produce base material with significantly different grain sizes. ${ }^{4}$ Table 5 shows the fusion zone grain size, measured using a standard linear intercept method. ${ }^{5}$ The finer grained base material did produce a finer grained fusion zone as expected. The difference in fusion zone grain size was small, as illustrated in Figure 2. Little difference was observed between the $10 \mathrm{ipm}$ and $30 \mathrm{ipm}$ fusion zone grain sizes, probably because the actual cooling rate for samples welded at 10 ipm and those welded at $30 \mathrm{ipm}$ do not differ greatly. The unrecrystallized base material produced much larger fusion zone grain sizes than the recrystallized base material. Also, the fusion zone grain size of the 10 ipm samples was significantly smaller than that of the 30 ipm samples for the unrecrystallized base material. These results are opposite of those expected. Clearly, other factors in addition to cooling rate influence the fusion zone solidification kinetics in this material. Because cold cracking susceptibility is quite sensitive to fusion zone grain size, and an unrecrystallized base material apparently produces a very coarse fusion zone microstructure, welding unrecrystallized material without encountering a cold-cracking problem presents a serious challenge. A better fundamental understanding of the factors which govern fusion zone grain size is badly needed. This topic deserves further investigation. 

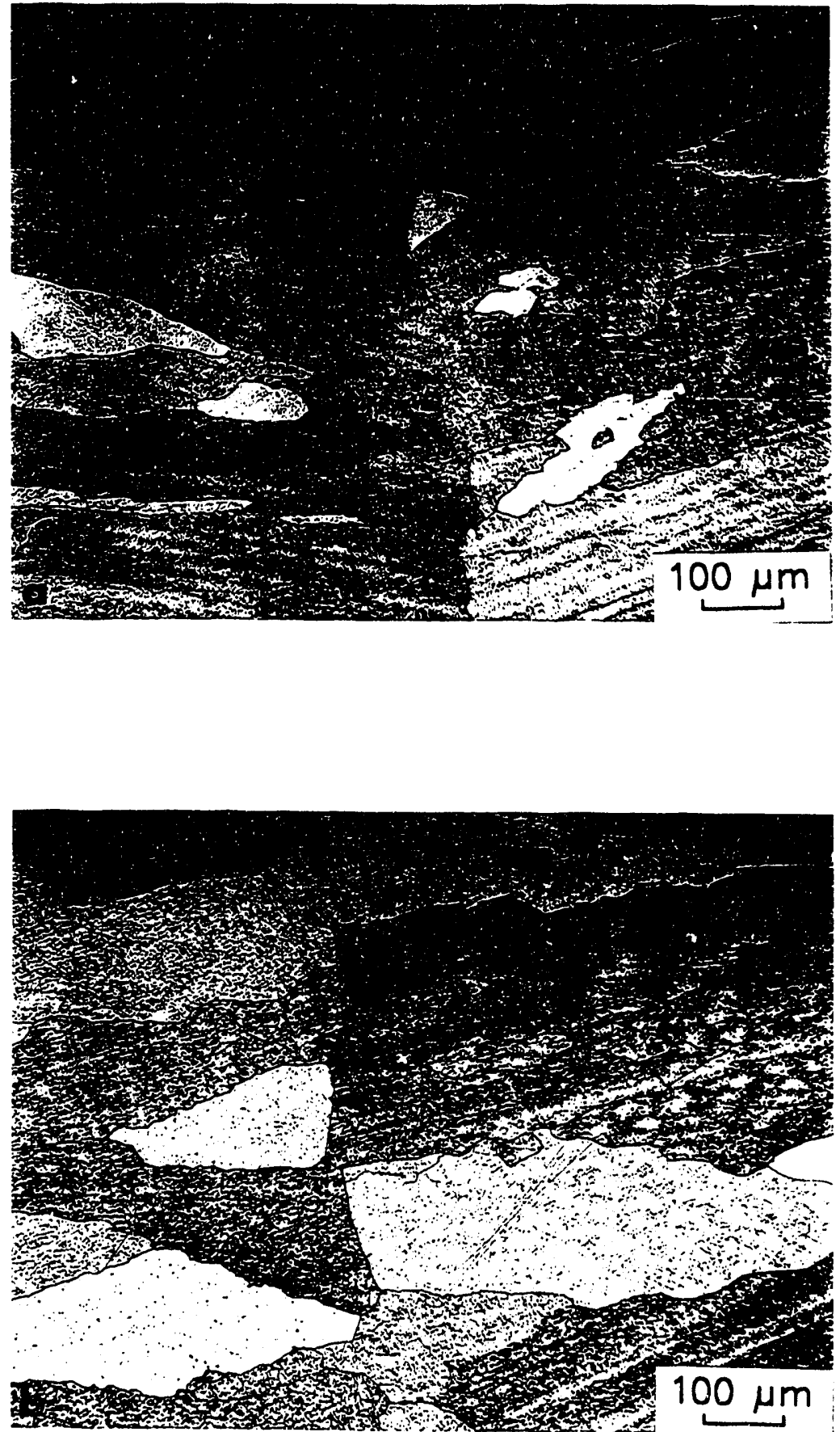

Figure 2: Typical fusion zone microstructures for FA-129 welded in a pure Argon atmosphere at $30 \mathrm{ipm}$, a) fine-grained base material, and b) coarse-grained base material. 
Table 5: Fusion Zone Grain Size.

\begin{tabular}{||c|c|c|}
\hline Base Metal Condition & \multicolumn{2}{|c|}{ Grain Size } \\
\hline & 10 ipm & 30 ipm \\
\hline Unrecrystallized & $300 \mu \mathrm{m}$ & $421 \mu \mathrm{m}$ \\
\hline Fine Grain Size & $214 \mu \mathrm{m}$ & $204 \mu \mathrm{m}$ \\
\hline Coarse Grain Size & $220 \mu \mathrm{m}$ & $243 \mu \mathrm{m}$ \\
\hline
\end{tabular}

DISCUSSION OF FUTURE AND ON-GOING ACTIVITIES

Fracture surfaces from all of the broken weld coupons are yet to be examined thoroughly in a scanning electron microscope (SEM).

Preliminary results indicate that most fractures were brittle fusion zone fractures.

The increase in cooling rate achieved by welding at a heat input of $1.4 \mathrm{~kJ} / \mathrm{in}$. as opposed to a heat input of $2 \mathrm{~kJ} /$ in was not sufficient to significantly refine the fusion zone. Test coupons will be welded at 60 ipm to determine if fusion zone grain size can be significantly refised by further increasing the cooling rate. If so, a test matrix identical to that in Table 2 will be completed at $60 \mathrm{ipm}$. If the fusion zone grain size cannot be significantly reduced by an increased cooling rate, alternative methods of fusion zone grain size refinement will be applied. These include oscillation and pulsation of the arc, and magnetically stirring the weld pool. Finally, the solidification of the fusion zone in the unrecrystallized base material will be studied to determine the factors which cause these microstructures to become excessively coarse.

\section{REFERENCES}

1. C. G. McKamey, V. K. Sikka, C. T. Liu; "ORNL-2(F) Development of Iron Aluminides;" April 1, 1989-Sept. 30,1989; p. 271-279. 
2. C. T. Liu, C. G. McKamey, E. H. Lee, "Environmental Effects on Room-Temperature Ductility and Fracture in $\mathrm{Fe}_{3} \mathrm{Al}, "$ Scripta Metallurgica, 24, p. 385 (1990).

3. G. M. Goodwin, "Development of a New Hot-Cracking Test--The Sigmajig," The Welding Journal, February 1987, 33s-38s.

4. A. A. Fasching, G. R. Edwards, S. A. David, "CSM-2 Weldability of Polycrystalline Aluminides," Oct. 1, 1991-March 30, 1992.

5. ASTM Handbook E112-84. 


\title{
INEL-2-THE INFLUENCE OF THERMOMECHANICAL PROCTESSING ON MICROSTRUCTURE AND PROPERTIES OR IRON AIUUMINIDES
}

\author{
J. K. Wright and R. N. Wright \\ Idaho National Engineering Laboratory \\ P. O. Box 1625 \\ Idaho Falls, ID 83415-2218
}

\begin{abstract}
A series of tensile tests on FA-129 was run to look at ordering, grain size and solutionizing effects on the properties. It appears that grain size, ordering, retained work, and solid solution strengthening have interacting effects that depend on the heat treatment subsequent to rolling. A powder metallurgy processing route for FA-129 is being used to refine the NbC precipitates and improve fracture toughness of the alloy. Also, a new joining technique for FejAl, self-propagating hightemperature synthesis (SHS), shows promising strength despite a less than optimum microstructure in preliminary samples.
\end{abstract}

\section{INTRODUCTION}

Alloys based on the intermetallic compound $\mathrm{Fe}_{3} \mathrm{Al}$ have good resistance to oxidation and sulfidation as well as excellent resistance to abrasion and erosion'. Improved understanding of the effects of alloying and processing on controlling strength and ductility of these alloys has led to interest in employing these materials at elevated temperature in aggressive environments ${ }^{2,3}$. Alloying with chromium has been found to increase the ductility, while additions of niobium, molybdenum and silicon improve the elevated temperature strength, but significantly reduce the ductility 3.4 .

Before any new material can be fully implemented structurally, methods of joining the material to itself and other materials must be developed. Progress has been made in joining $\mathrm{Fe}_{3} \mathrm{Al}$ alloys $\mathrm{s}^{5,6}$, but some difficulties still exist. To date work has concentrated on fusion welding $\mathrm{Fe}_{3} \mathrm{Al}$ pieces together. An alternative processing method, known as self-propagating high-temperature synthesis, has been shown applicable to $\mathrm{Fe}_{3} \mathrm{Al} \mathrm{I}^{7.8}$. This process uses an exothermic reaction between elemental powders to form the intermetallic. Recent work has shown that SHS can be used to join SiC composites'. Now this processing method has been applied to low heat input joining of $\mathrm{Fe}_{3} \mathrm{Al}{ }^{10}$.

Alloys with compositions near $\mathrm{Fe}_{3} \mathrm{Al}$ are random solid solutions above about $900^{\circ} \mathrm{C}$. Between 550 and $900^{\circ} \mathrm{C}$ the equilibrium phase is based on the B2 ordered structure; below the critical temperature of $550^{\circ} \mathrm{C}$, 
the $\mathrm{DO}_{3}$ ordered structure is stable. Alloying with $\mathrm{Cr}$ slows the ordering transformation on cooling and a predominantly B2 structure is formed by quenching from above the critical temperature".

The object of this project is to examine the effect of processing, including alternate joining methods, on the structure and properties of iron aluminides. Current emphasis is on alloy FA-129 with $\mathrm{Nb}$ additions for improved elevated temperature strength. The kinetics of recovery, recrystallization and grain growth and of the $\mathrm{B} 2$ to $\mathrm{DO}_{3}$ order reaction are also being studied.

SHS JOINING OF $\mathrm{Fe}_{3} \mathrm{Al}$

To make joints, a premixed precursor powder of Fe-28\% Al-28 Cr was uniaxially cold pressed to form a thin $13 \mathrm{~mm}$ radius disk. The pressed layer of powder was sandwiched between solid $\mathrm{Fe}_{3} \mathrm{Al}$ hot-extruded material, placed in a graphite fixture, and reacted while hot pressing. A pressure of $20.7 \mathrm{MPa}$ was applied at $500^{\circ} \mathrm{C}$, after which the sample was heated at a rate of $5^{\circ} \mathrm{C} / \mathrm{min}$. to $1100^{\circ} \mathrm{C}$ and held for $1 \mathrm{~h}$ in an argon atmosphere. The resulting $\mathrm{Fe}_{3} \mathrm{Al}$ joint, shown in Figure 1, was near theoretical density and consisted of $5-15 \mu \mathrm{m}$ equiaxed grains with $30-50 \mu \mathrm{m}$ second phase particles. Energy dispersive spectroscopy (EDS) in the scanning electron microscope (SEM) indicated the particles are oxides.

The sample was cut into $3 \times 4 \times 30 \mathrm{~mm}$ bars, with the joint in the center, for bend testing. Significant plasticity was observed in fourpoint bend testing, as shown in Figure 2. As a result, strength calculations could not be made for this configuration; however, a threepoint bend test resulted in failure at the extrusion/sHs material interface, and a strength of $1580 \mathrm{MPa}$, about the same as the tensile fracture strength of the extruded material. This value should be improved when a more homogeneous microstructure is obtained. Work on this joining method is continuing.

TENSILE TESTS OF INGOT FA-129

Tensile samples were punched from $0.7 \mathrm{~mm}$ sheet in the as-rolled condition and heat treated to obtain various defect, order and grain structures according to Table 1. All samples were ultrasonically cleaned with acetone after heat treatment, except FA-129-2. One specimen was tested in each condition at a strain rate of $6 \times 10^{-5} / 8$, except FA-129-1, which had two tensile specimens. 


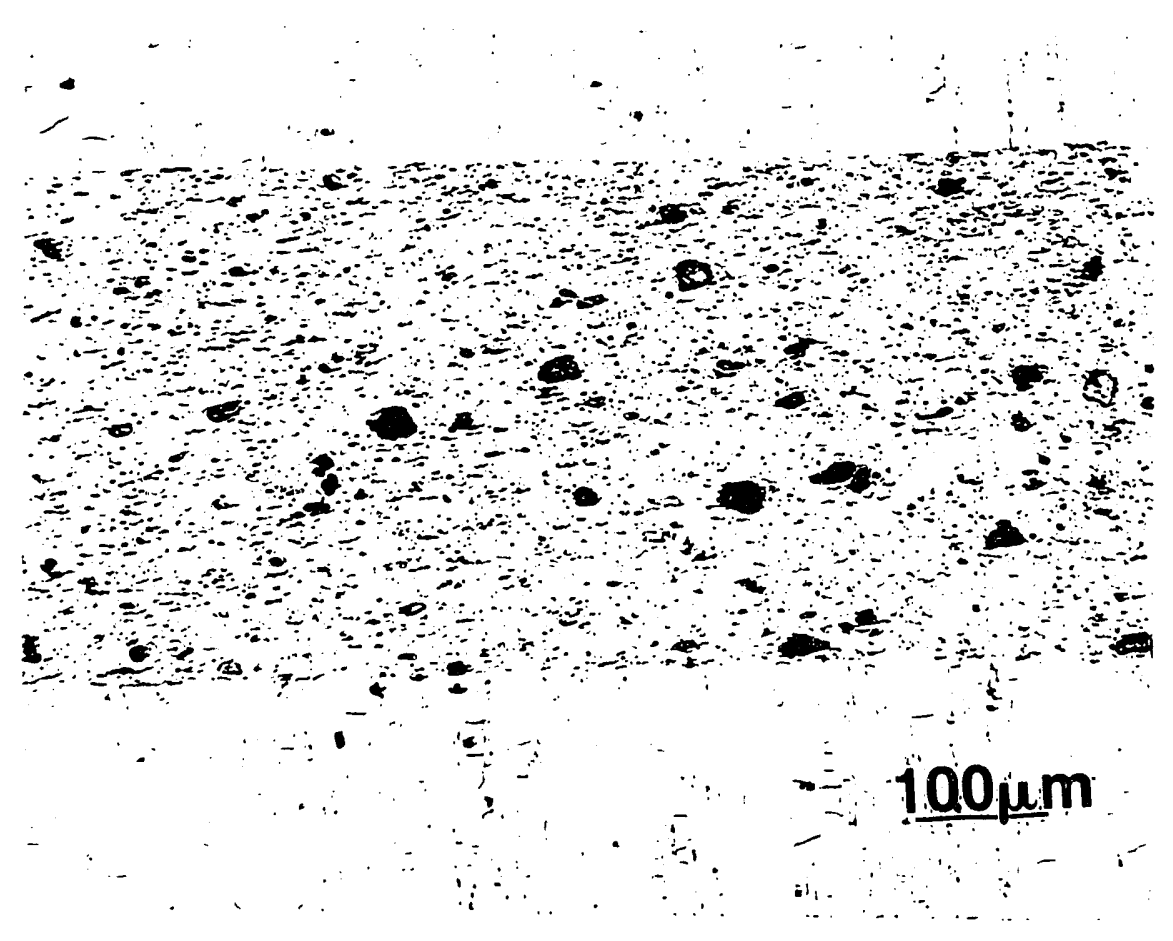

Fig. 1. Microstructure of sHs joint.

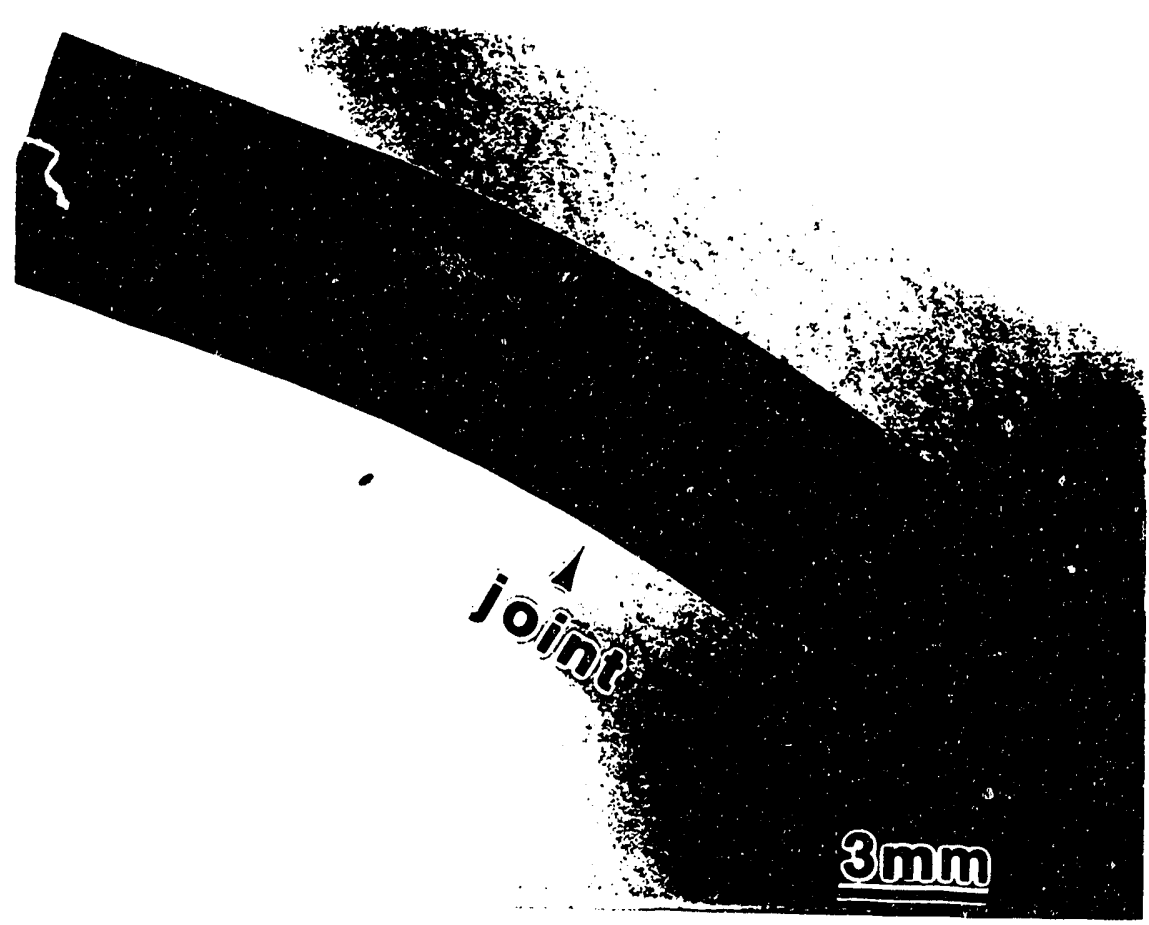

Fig. 2. Macrophoto of jointed $\mathrm{Fe}_{3} \mathrm{Al}$ bar after 4-point bend testing. 
Table 1. Heat treatment conditions.

\begin{tabular}{|c|c|}
\hline Identification & Heat Treatment \\
\hline$F A-129-0$ & as-rolled \\
\hline FA-129-1 & $750^{\circ} \mathrm{C}$ in 00,2 times \\
\hline$F A-129-2$ & $750^{\circ} \mathrm{C}$ in 00,2 times, not cleaned \\
\hline$F A-129-3$ & $750^{\circ} \mathrm{C}$ ih 02,2 times, $450^{\circ} \mathrm{C} 48 \mathrm{~h} \mathrm{AC}$ \\
\hline$F A-129-4$ & $450^{\circ} \mathrm{C} 48 \mathrm{~h} \mathrm{AC}$ \\
\hline$F A-129-5$ & $1100^{\circ} \mathrm{C}$ in AC \\
\hline$F A-129-6$ & $1100^{\circ} \mathrm{C} 10 \mathrm{~h} \mathrm{AC}$ \\
\hline$F A-129-7$ & $1100^{\circ} \mathrm{C} 100 \mathrm{~h} \mathrm{AC}$ \\
\hline$F A-129-8$ & $1100^{\circ} \mathrm{C} 100 \mathrm{~h} \mathrm{AC}, 750^{\circ} \mathrm{C}$ in $\mathrm{OQ}$ \\
\hline$F A-129-9$ & $1100^{\circ} \mathrm{C} 100 \mathrm{~h} \mathrm{AC}, 750^{\circ} \mathrm{C} 10 \mathrm{~h} \mathrm{OQ}$ \\
\hline
\end{tabular}

In addition to tensile testing, microhardness and grain size measurements were made on most of the specimens. A diamond pyramid hardness tester was used to make five to ten indentations in each sample, depending on the scatter observed. Average grain sizes were determined by counting the intercepts with three circles on each of three photographs for a total of nine measurements per condition. $x$-ray diffraction (XRD) was also performed on some of the specimens to determine the type of order present. Table 2 summarizes the data.

Table 2. Summary of data

\begin{tabular}{lcccccc} 
ID & $\begin{array}{c}\text { UTS } \\
(\mathrm{MPa})\end{array}$ & $\begin{array}{c}\text { YS } \\
(\mathrm{MPa})\end{array}$ & $\begin{array}{c}\text { elongation } \\
(8)\end{array}$ & $\begin{array}{c}\text { avg. } \\
\text { hardness } \\
(\mathrm{DPN})\end{array}$ & $\begin{array}{c}\text { grain } \\
\text { size } \\
(\mu \mathrm{m})\end{array}$ & order \\
\hline FA-129-0 & 813 & -- & 4.2 & -- & -- & -- \\
FA-129-1 & $585^{*}$ & $341^{*}$ & $7.4^{*}$ & 276 & 23 & $\mathrm{B2}$ \\
FA-129-2 & 608 & 331 & 7.9 & -- & -- & -- \\
FA-129-3 & 539 & 358 & 4.8 & 280 & 26 & $\mathrm{DO}_{3}$ \\
FA-129-4 & 965 & 562 & 9.4 & 350 & -- & $\mathrm{DO}_{3}$ \\
FA-129-5 & 638 & 352 & 7.9 & 316 & 99 & -- \\
FA-129-6 & 549 & 345 & 5.4 & 311 & 106 & -- \\
FA-129-7 & 410 & 289 & 3.7 & 314 & 143 & $\mathrm{DO}_{3}$ \\
FA-129-8 & 502 & 327 & 6.3 & 298 & 130 & -- \\
FA-129-9 & 459 & 324 & 4.9 & 297 & 182 & $\mathrm{~B}_{2}$
\end{tabular}

- Average of two values 
Heat treatments of 750 or $1100^{\circ} \mathrm{C}$ result in recrystallization, so all samples have an equiaxed grain structure with the exception of 0 and 4. Based on the diffraction measurements that were made, it is assumed that oil quenching from $750^{\circ} \mathrm{C}$ results in $\mathrm{B2}$, while air cooling from $1100^{\circ} \mathrm{C}$ results in some $\mathrm{DO}_{3}$, although not as much as the extended heat treatment at $450^{\circ} \mathrm{C}$.

There is virtually no difference in properties between samples 1 and 2, indicating the presence of an oil film on the sample surface is not an effective barrier to the environmental embrittlement phenomenon.

Samples 1 and 3 , which have the same grain structure but different order structure, have similar strength and hardness, but the $\mathrm{DO}_{3}$ sample appears to have a lower ductility, as seen previously"1. In contrast, sample 4, which was not recrystallized before ordering, has superior strength, hardness and ductility. The strength and hardness are high because of the unrecrystallized structure which has retained work from the rolling process. The high elongation could result from residual stress relief during the $450^{\circ}$ heat treatment, since the as-rolled sample, 0 , displays similar strength but inferior ductility. Samples 5, 6 and 7 have increasing grain sizes, as expected because of the increasing hold times at $1100^{\circ} \mathrm{C}$. All three samples have similar hardnesses, since the micro-indentations were made within the grains. The hardnesses of these samples are greater than those for the $750^{\circ} \mathrm{C}$ heat treated specimens. It has been hypothesized that at $1100^{\circ} \mathrm{C}$ the NbC phase goes into solution, resulting in solid solution strengthening, which could produce the observed hardnesses. However, the strength decreases in these three samples as the heat treatment time increases, indicating the opposing Hall-petch effect is stronger than the impact of the solutionizing. The ductility also decreases as the heat treatment time increases, indicating the solutionizing may cause some embrittlement to the alloy. The large grain size could also adversely affect ductility.

The ductility and strength are partially restored by heat treatment at $750^{\circ} \mathrm{C}$ after $100 \mathrm{~h}$ at $1100^{\circ} \mathrm{C}$, while the hardness falls back to the level of samples 1 and 3 . The reason for this is not yet clear. One possibility is that the NbC reprecipitates at the lower temperature, resulting in the improved properties. Note that sample 9 has significantly larger grains than samples 7 and 8 . This is likely the reason that sample 9 has lower strength and ductility than sample 8 , even though more $\mathrm{NbC}$ is expected to precipitate with longer times at $750^{\circ} \mathrm{C}$. 
ATOMIZATION OF FA-129 POWDER

FA-129 has been fabricated by a powder metallurgy route in an attempt to improve fracture toughness by refining the angular NbC that has been observed in ingot metallurgy FA-129. The alloy was inert gas atomized in He at $1750^{\circ} \mathrm{C}$ using a binary master alloy of Fe-16 wto $\mathrm{Al}$ and arc melted $\mathrm{Cr}, \mathrm{Nb}$ and $\mathrm{C}-\mathrm{rich}$ alloy buttons as feed stock. The powder has been consolidated by hot extrusion at ORNL and samples for fracture toughness testing are being machined. Some material is being rolled for further characterization, such as tensile testing.

The powder particles are fairly spherical (Figure 3) with some internal porosity and a size distribution shown in Figure 4 . X-ray fluorescence measured the actual composition in weight percent as: $0.049 \mathrm{C}, 4.73 \mathrm{Cr}, 14.28 \mathrm{Al}$, and $0.58 \mathrm{Nb}$, somewhat lower in $\mathrm{Cr}, \mathrm{Al}$, and $\mathrm{Nb}$ than the target composition of $0.05 \mathrm{C}, 5.45 \mathrm{Cr}, 15.85 \mathrm{Al}, 0.97 \mathrm{Nb}$. FAL and FAS alloys made by the same process were also low in $\mathrm{Al}$ and $\mathrm{Cr}$, although properties were comparable to the ingot metallurgy counterparts. X-ray diffraction did not indicate the presence of the NbC phase, which has been clearly identified in traditionally processed FA-129. However, elemental $F e$ and $A l$ appear wo be present, unlike previous samples. Coarse and fine size fractions were analyzed separately with XRD, and have similar patterns, although the coarse fraction appears to have a larger relative amount of $\mathrm{Al}$.

\section{SUMMARY}

Preliminary experiments joining $\mathrm{Fe}_{3} \mathrm{Al}$ by sHS indicate substantial strength and ductility. Work is continuing to optimize the microstructure and further improve the properties of the joints.

The room temperature behavior of alloy FA-129 is impacted by ordering, retained work, grain size and solid solution strengthening effects to varying deyrees depending on the heat treatment after rolling. More work is needed to elucidate and verify these results.

FA-129 alloy powder has been produced by inert gas atomization, characterized, and consolidated by hot extrusion. It is hoped that the powder metallurgy processing will result in a refined structure with better fracture toughness. 


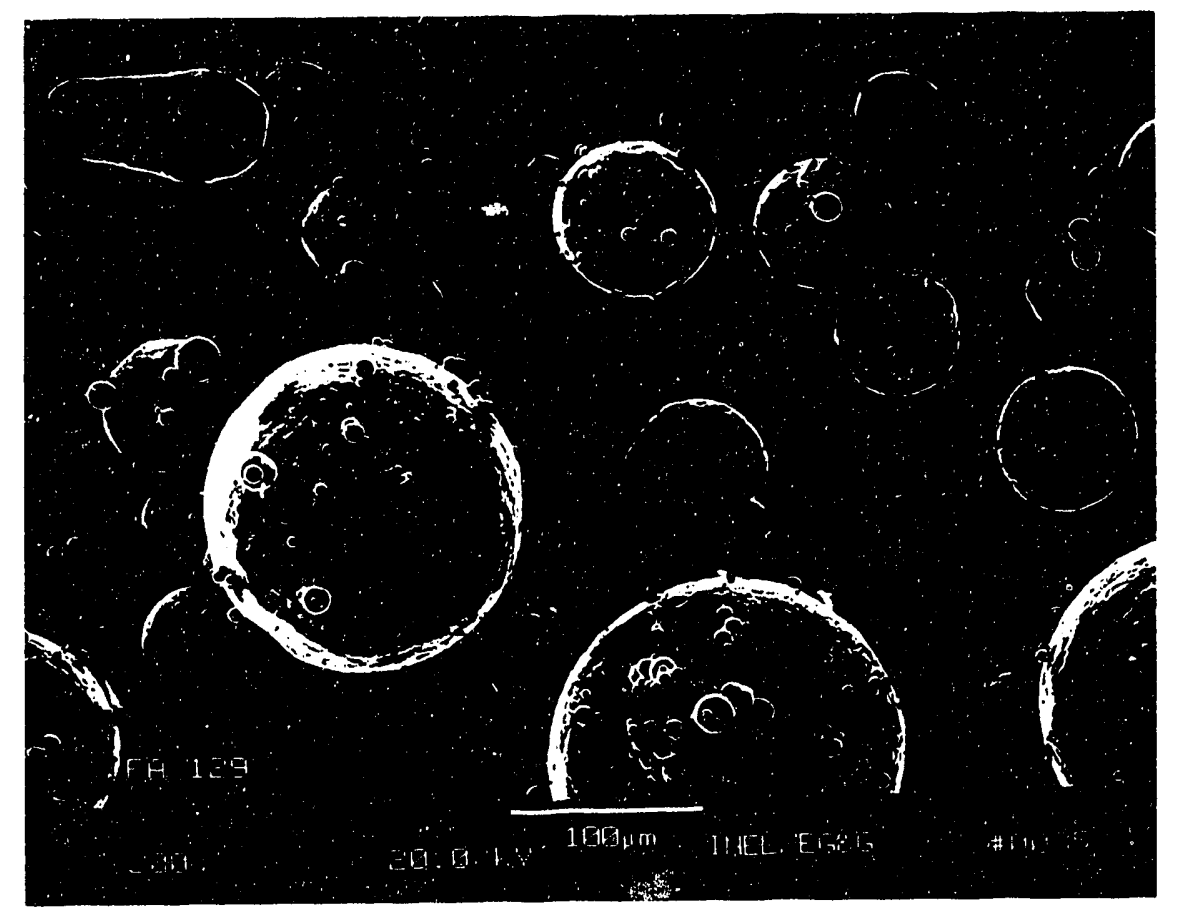

Fig. 3. SEM photo showing FA-129 inert gas atomized powder.

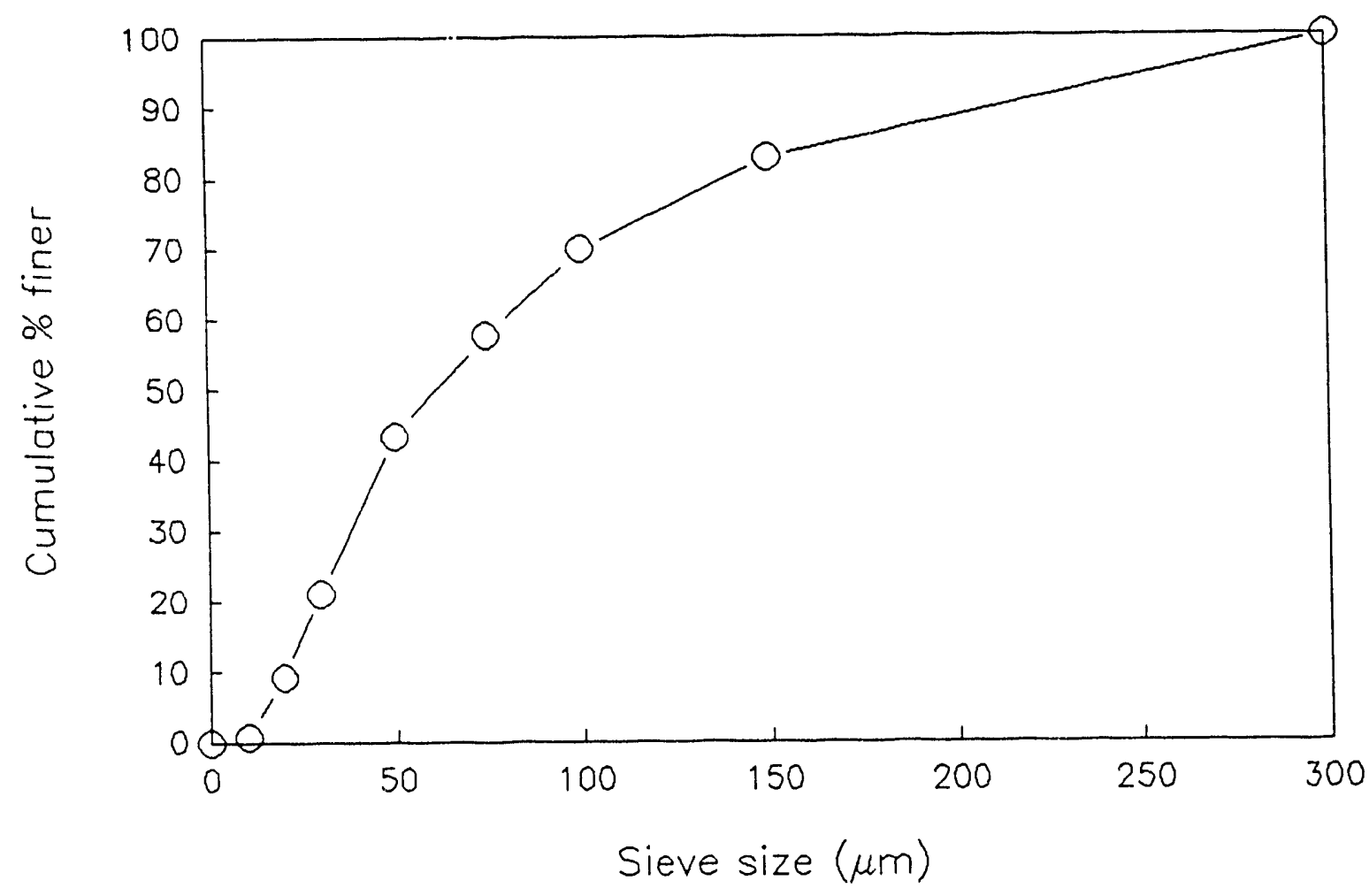
sieving.

Fig. 4. Particle size distribution of FA-129 powder determined by 
1. M. Johnson, D. E. Mikkola, P. A. March, and R. N. Wright, "The Resistance of $\mathrm{Nickel}$ and Iron Aluminides to Cavitation Erosion and Abrasive Wear," Wear, 140 (1990) 279.

2. R. S. Diehm, M. P. Kemppainen, and D. E. Mikkola, "Processing and Alloying of Modified Iron Aluminides," Mater. \& Manufacturing processes, 4 (1989) 61 .

3. R. S. Diehm and D. E. Mikkola, "Effects of Mo and Ti Additions on the High Temperature Compressive Properties of Iron Aluminides Near FeyAl," Mater. Res. Soc. Symp. Proc., 81 (1987) 329.

4. V. K. Sikka, C. G. McKamey, C. R. Howell, and R. H. Baldwin, "Fabrication and Mechanical Properties of FesAl-Based Iron Aluminides", ORNL/TM-11465, 1990.

5. S. A. David, J. A. Horton, C. G. McKamey, T. Zacharia and R. W. Reed, "Welding of Iron Aluminides," Welding Journal, 68 (9) (1989) 3728 .

6. T. Zacharia and S. A. David, "Weldability of Iron Aluminides," Proceedings of the Fifth Annual Conference on Fossil Energy Materials, Oak Ridge, TN, May 1991, 229.

7. B. H. Rabin and R. N. Wright, "Synthesis of Iron Aluminides from Elemental Powders: Reaction Mechanisms and Densification Behavior" Metall. Trans., 22A (1991) 277.

8. B. H. Rabin and R. N. Wright, "Microstructure and Tensile properties of $\mathrm{Fe}_{3} \mathrm{Al}$ Produced by Combustion synthesis/Hot Isostatic Pressing," Metall. Trans., 23A (1992) 35.

9. B. H. Rabin, "Joining of Silicon Carbide/silicon Carbide Composites and Dense Silicon Carbide Using Combustion Reactions in the Titanium-Carbon-Nickel System," J. Am. Ceram. Soc., 75 (1992) 131.

10. J. K. Wright, R. N. Wright, and G. A. Moore, "Combustion Synthesized Iron Aluminide Coatings and Joints," to be submitted to $J$. Mater. Sci. Let.

11. J. R. Wright, R. N. Wright, C. L. Trybus, and V. K. Sikka, "Microstructure and Mechanical Properties of $\mathrm{Fe}_{3} \mathrm{Al}$ Alloys with Chromium," J. Mater. Sci., in press. 


\title{
ORNL-2(A).ENVIRONMENTAL EFFECTS ON IRON ALUMINIDES
}

\author{
J. H. DeVan and P. F. Tortorelli \\ Oak Ridge National Laboratory \\ Oak Ridge, Tennessee 37831-6156
}

\section{INTRODUCTION}

The purpose of this task is to evaluate the corrosion properties of $\mathrm{Fe}_{3} \mathrm{Al}$-based alloys as they relate to fossil energy applications. A primary objective is to investigate the resistance of the alloys to mixed-oxidant (oxygen-sulfur) environments that arise in the combustion or gasification of coal. This includes the determination of effects of sulfur on oxidation kinetics and oxide microstructures, the effects of rare earth additions on sulfidation and oxidation resistance, and the mechanical behavior of reaction product scales in mixed-gas environments. Of additional concern are corrosion processes encountered when equipment is shut down for maintenance purposes, which may lead to attack by sulfur- and chlorine-containing acids. Also included in this task are studies of environmental effects on alloy ductility, especially effects on crack growth kinetics.

Laboratory tests of iron aluminide alloys in $\mathrm{H}_{2} \mathrm{~S}-\mathrm{H}_{2}-\mathrm{H}_{2} \mathrm{O}-\mathrm{Ar}$ at $800^{\circ} \mathrm{C}$ have shown very low corrosion rates for alloys based on $\mathrm{Fe}_{3} \mathrm{Al}$ and $\mathrm{FeAl}$. In more recent tests of binary $\mathrm{Fe}-\mathrm{Al}$ alloys with lower aluminum contents, the corrosion rate in $\mathrm{H}_{2} \mathrm{~S}-\mathrm{H}_{2}-\mathrm{H}_{2} \mathrm{O}-\mathrm{Ar}$ showed little change from that of the $\mathrm{Fe}_{3} \mathrm{Al}$ alloy $(28$ at. $\% \mathrm{Al}$ ) down to a level of $18 \%$ aluminum. ${ }^{2}$ However, the rate increased significantly when the aluminum content was lowered to $16 \%$. Nevertheless, the corrosion rate at the $16 \% \mathrm{Al}$ level was still markedly lower than for the $\mathrm{Fe}-\mathrm{Cr}-\mathrm{Al}$ class of alloys, nominally containing $20 \% \mathrm{Cr}$ and $10 \% \mathrm{Al}$. A 20 at.\% Al level was found ${ }^{2}$ to be critical for sustained oxidation resistance of binary Fe-Al alloys in air at $900^{\circ} \mathrm{C}$ and above, although the addition of 5 at.\% $\mathrm{Cr}$ at the 16 at.\% $\mathrm{Al}$ level reduced the oxidation rate in air to that of alloys containing $\geq 20 \% \mathrm{Al}$.

Further corrosion studies have been conducted to evaluate the potential of alloys containing 16 at. \% $\mathrm{Al}$ for service in high temperature air and combustion gases and to demonstrate the resistance of $\mathrm{Fe}_{3} \mathrm{Al}$-based alloys to both high temperature oxidizing and sulfidizing environments. The oxidation behavior of both classes of alloys has been examined in isothermal and thermal cycling tests in air at temperatures up to $1150^{\circ} \mathrm{C}$. 
The thermal cycling tests focused on the effects of reactive metal (zirconium) and rare earth (yttrium) additions on scale adherence at $900^{\circ} \mathrm{C}$ and above. Test results for $\mathrm{Fe}_{3} \mathrm{Al}$ based alloys being exposed in an operating coal gasifier were received from the Coal Research Establishment (British Coal).

\section{DISCUSSION OF CURRENT ACTIVITIES}

Iron-aluminum alloys containing 16 at. \% aluminum exhibit relatively high ductilities at room temperature and can be cold-worked to produce small cross-section product forms such as wire and thin sheet. ${ }^{3}$ Exposures of these alloys to air at 900 $1000^{\circ} \mathrm{C}$ indicated that the addition of 5 at. \% chromium significantly improved the oxidation resistance under isothermal conditions, while the addition of 0.1 at. \% zirconium was highly beneficial to spalling resistance under thermal transients. ${ }^{2}$ Further modifications to improve the mechanical properties and aqueous corrosion properties of the alloys have led to a reference composition (alloy FAP) containing 16\% aluminum, 5\% chromium, $1 \%$ molybdenum. $0.1 \%$ zirconium, and $0.1 \%$ carbon. Thermogravimetric tests of this latter alloy have been conducted in air at $900^{\circ} \mathrm{C}$ to compare its oxidation properties with those of $\mathrm{Fe}_{3} \mathrm{Al}$-based alloys containing $28 \%$ aluminum and with $\mathrm{Fe}-\mathrm{Cr}$-Al alloys containing $20 \%$ chromium and $10 \%$ aluminum. As shown in Fig. 1, the oxidation

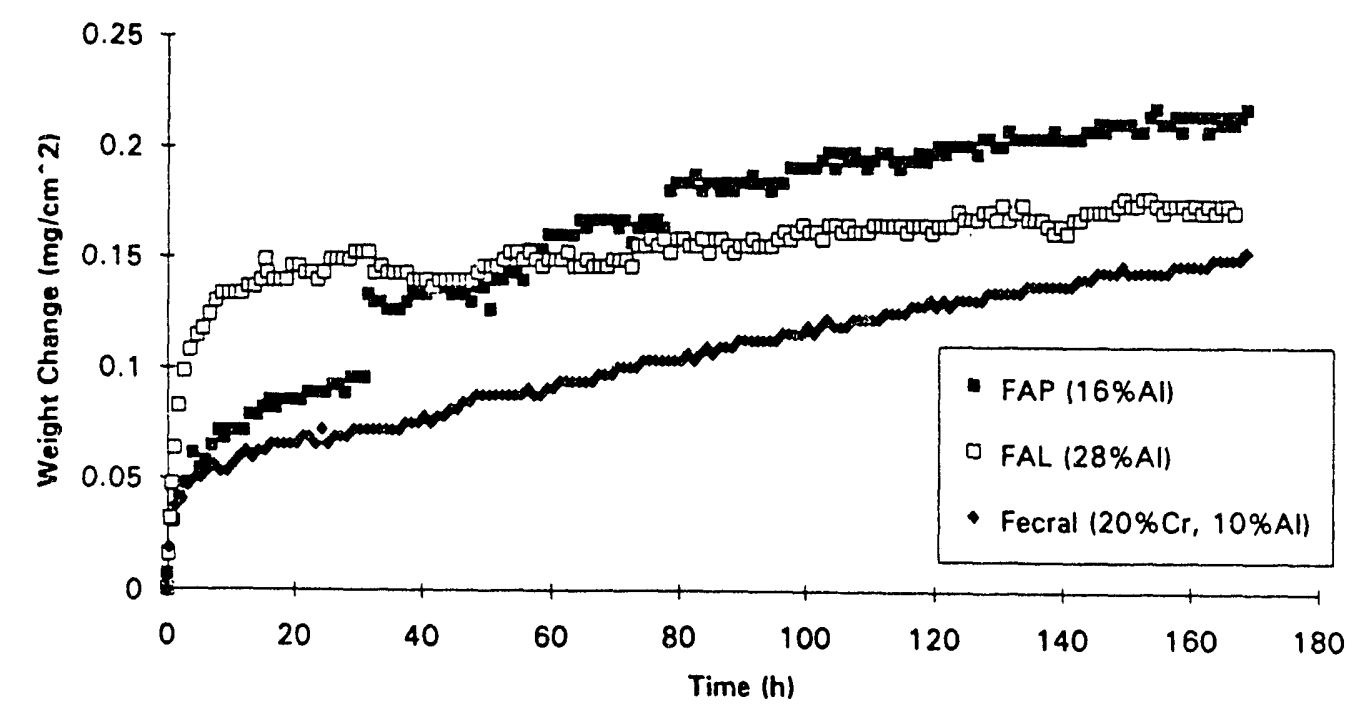

Fig. 1 Isothermal weight gains of FAP alloy (Fe-16\%Al-5\% Cr-1\%Mo-0.1\% Zr$0.1 \% \mathrm{C}$ ) in air at $\quad 900^{\circ} \mathrm{C}$ relative to $\mathrm{Fe}_{3} \mathrm{Al}$-based alloy (Fe-28\% $\mathrm{Al}-5 \% \mathrm{Cr}-.1 \% \mathrm{Zr}$ $0.05 \% \mathrm{~B})$ and Fecral $(\mathrm{Fe}-9.1 \% \mathrm{Al}-20.3 \% \mathrm{Cr}-0.07 \% \mathrm{C})$. 
rate of the FAP alloy is similar to that of the higher aluminum and higher chromium compositions. The molybdenum addition does not appear to affect the air oxidation properties at $900^{\circ} \mathrm{C}$ - Fig. 2 shows little difference between the oxidation rate of the FAP alloy and an alloy of similar composition but without molybdenum. As discussed below, yttrium additions to the FAP composition are being evaluated with respect to oxide spalling resistance. However, as shown in Fig. 3, yttrium does not measurably affect the oxidation kinetics of the alloy under isothermal conditions at $900^{\circ} \mathrm{C}$.

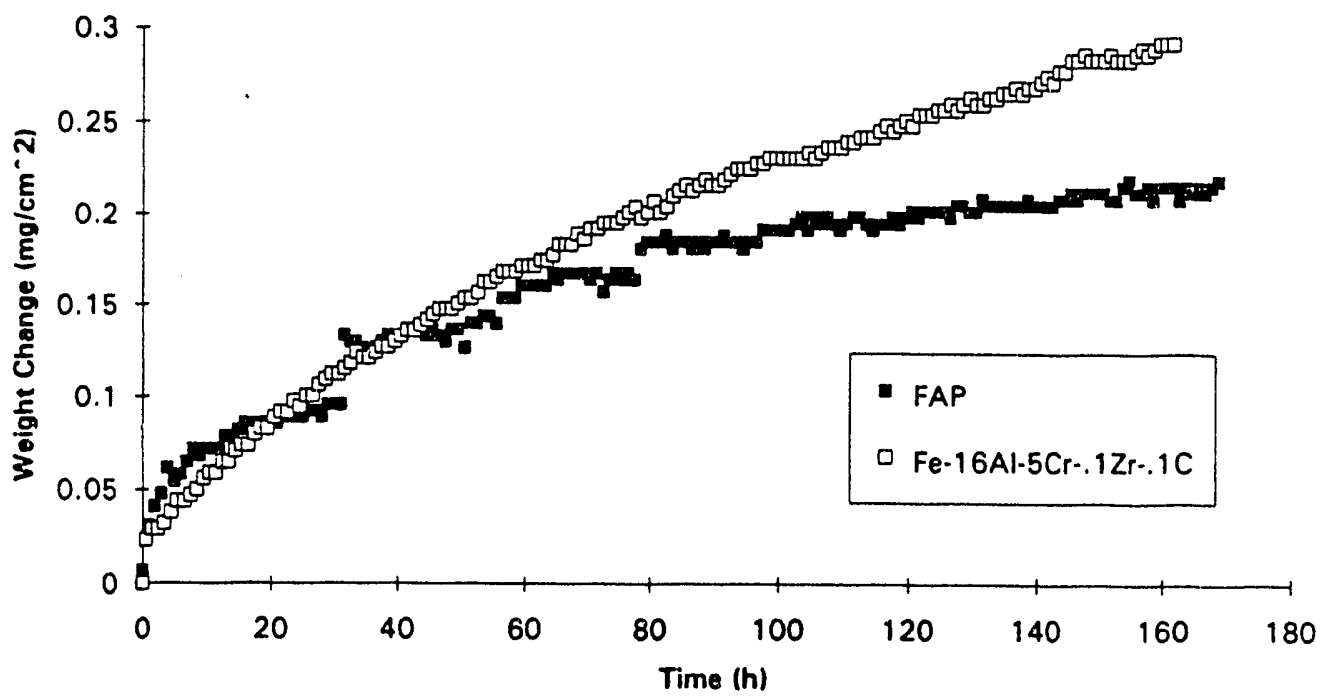

Fig. 2 Comparative oxidation rates of FAP (Fe-16\%Al-5\% Cr-1\%Mo-0.1\% Zr-0.1\%C and similar alloy without molybdenum. (Tests conducted in dry air at $900^{\circ} \mathrm{C}$.)

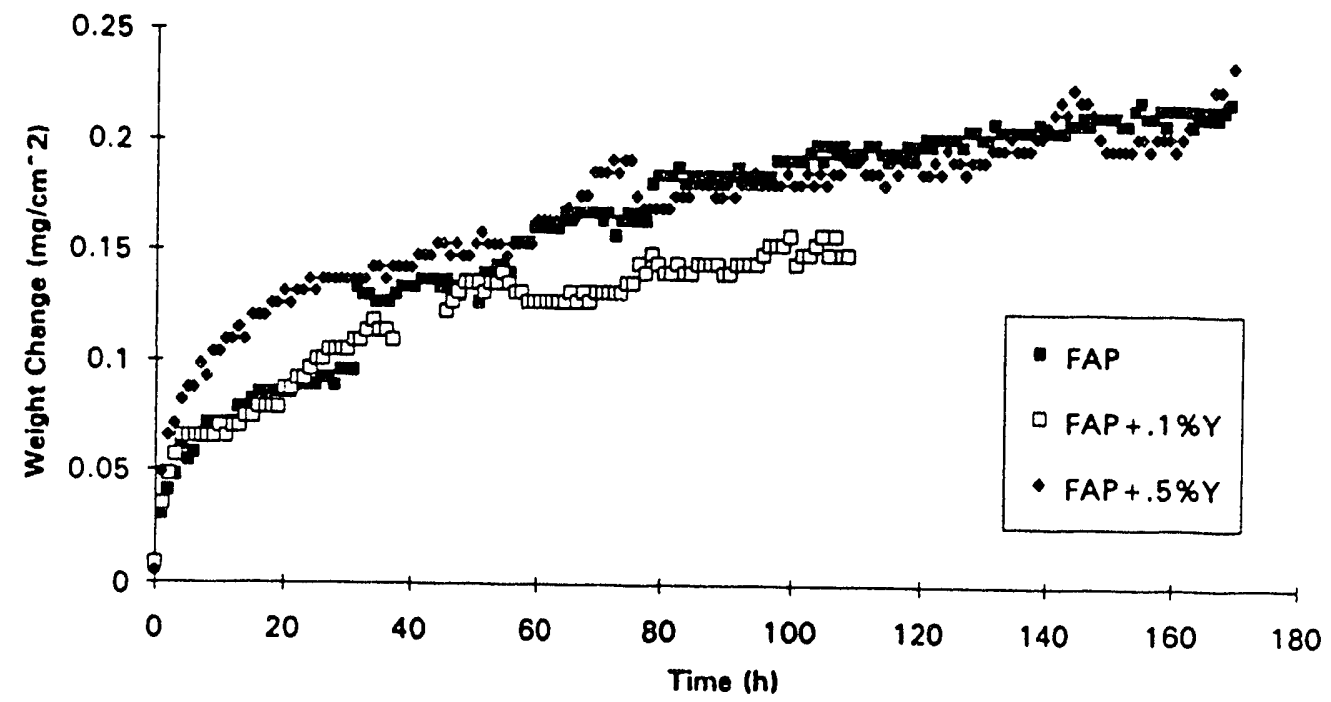

Fig. 3 Effect of yttrium additions on air oxidation behavior of FAP alloy(Fe-16\% Al$5 \% \mathrm{Cr}-1 \% \mathrm{Mo}-.1 \% \mathrm{Zr}-.1 \% \mathrm{C}$ ) in isothermal tests at $900^{\circ} \mathrm{C}$. 
Experiments to evaluate the cyclic oxidation behavior of iron aluminides have been initiated. Specimens were exposed to heated laboratory air at 900,1000 , or $1150^{\circ} \mathrm{C}$ for incremental exposures of 24-72 h. At the completion of each elevated temperature period, the specimens were air quenched by direct removal from the furnaces. Measured weight changes are shown in Figs. 4-6. As already reported for isothermal conditions ${ }^{2}$, the presence of chromium in an alloy with $16 \%$ aluminum (FAP) appears to have a beneficial effect on cyclic oxidation resistance (Figs. 4 and 5). The zirconium present in FAP may also be exerting a positive influence on spallation behavior. ${ }^{2}$ Additions of yttrium (FAP$0.1 \mathrm{Y}$ and FAP- $0.5 \mathrm{Y}$ ) had little effect on the cyclic oxidation results at 900 and $1000^{\circ} \mathrm{C}$ (Figs. 4 and 5), but there was a substantial increase in weight gains for the FAP-0.5Y composition at $1150^{\circ} \mathrm{C}$ (Fig. 6). This susceptibility of the higher Y-containing alloy can be attributed to the rapid formation of $\mathrm{Y}_{2} \mathrm{O}_{3}$. Fig. 6 also shows that, at $1150^{\circ} \mathrm{C}$, the cyclic oxidation resistance of FAP-0.1Y is essentially the same as that for a $\mathrm{Fe}_{3} \mathrm{Al}$ alloy (FAL). Further testing under more severe thermal cycling conditions will be required before a definitive comparison of the relative corrosion rates of 16 and 28 at.\% Al alloys can be made.

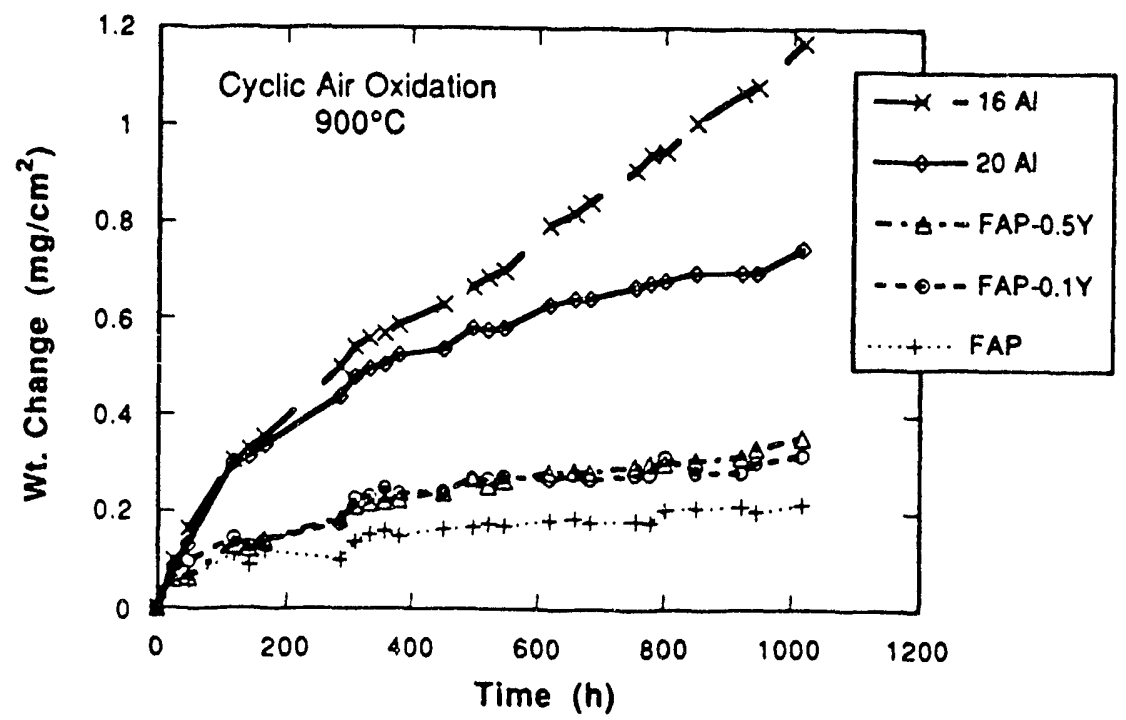

Fig. 4 Weight changes of binary and FAP alloys in air at $900^{\circ} \mathrm{C}$ under thermal cycling conditions. Yttrium concentrations are in at. \%.

$\mathrm{Fe}_{3} \mathrm{Al}$-based alloys have been supplied to the Coal Research Establishment (CRE) of the British Coal Corporation for testing in a 0.5 tonne/h, pressurized, air-blown gasifier located at Stoke Orchard. (The alloy compositions are similar to those tested previously ${ }^{4}$ in a non-pressurized gasifier at Stoke Orchard.) Test results have been received covering 


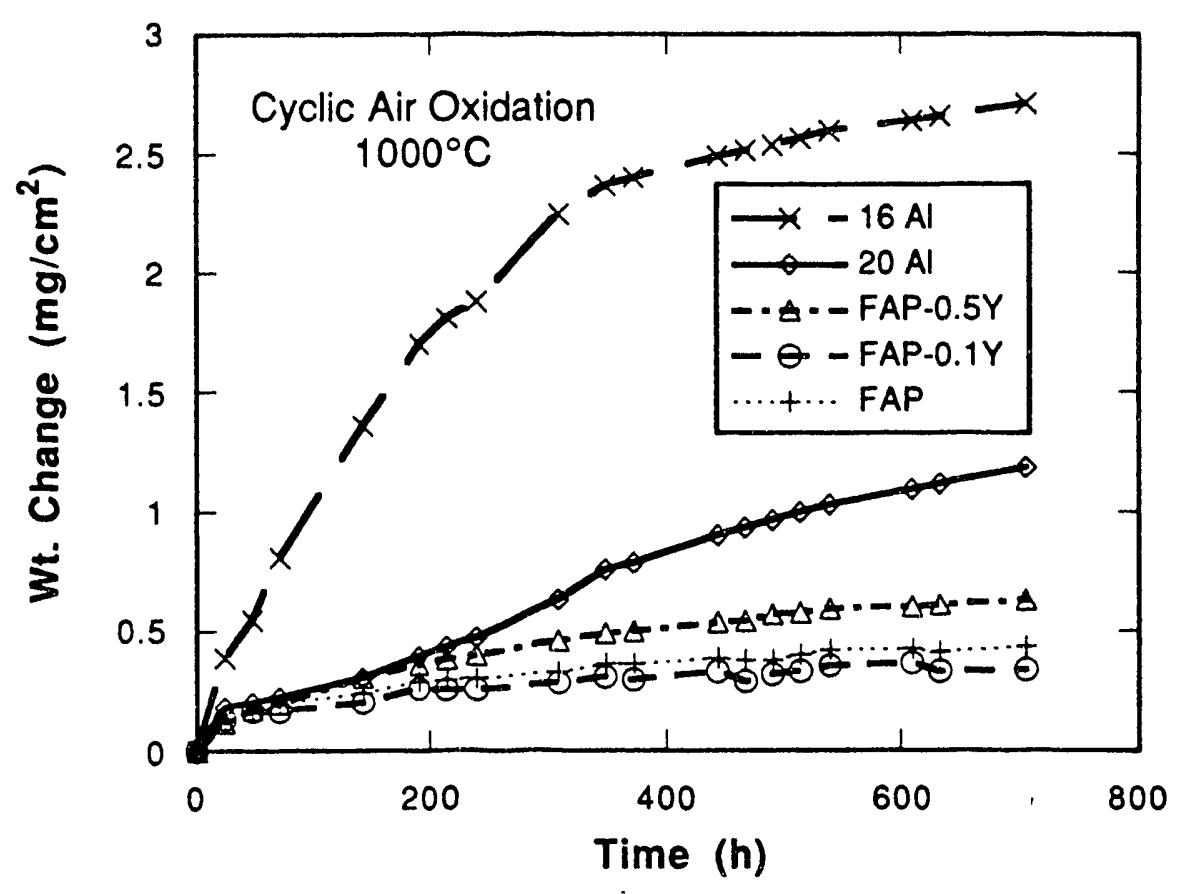

Fig. 5 Weight changes of binary and FAP alloys in air at $1000^{\circ} \mathrm{C}$ under thermal cycling conditions. Yttrium concentrations are in at. \%.

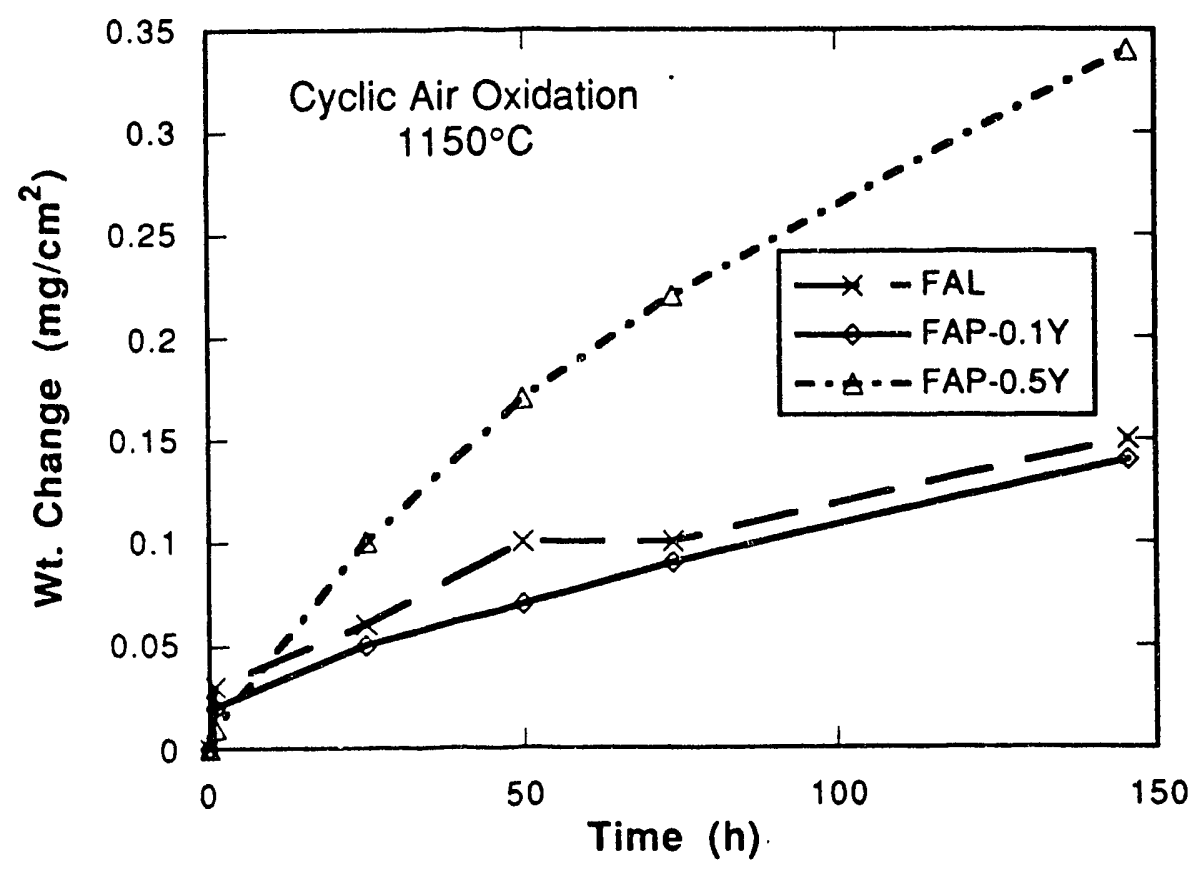

Fig. 6 Weight changes of a $\mathrm{Fe}_{3} \mathrm{Al}(\mathrm{FAL})$ and $\mathrm{FAP}$ alloys in air at $1150^{\circ} \mathrm{C}$ under thermal cycling conditions. Yttrium concentrations are in at. \%. 
alloy performance during two initial runs in the pressurized gasifier. Both runs were essential shake-down tests of the gasifier and involved extended periods when the specimens were exposed to the ambient atmosphere at room temperature. All of the ferritic iron-based samples exposed during these two runs, including $\mathrm{Fe}_{3} \mathrm{Al}$ specimens, showed heavy pitting, while the more highly alloyed austenitic materials were relatively unaffected. This suggests that the main source of corrosion in these two runs was sulfurcontaining acids formed when moist air was admitted during the downtime periods. (The susceptibility of iron aluminides to corrosion by strong sulfur-containing acids has been documented by Buchanan and Kim. $)^{5}$ The design pressure of the gasifier was initially set at 20 bar; however this pressure was not attainable in the unit as presently designed, so the actual operating pressure has been in the range 12-13 bar. This lower pressure resulted in gas temperatures that were lower than initially projected, and the exposure temperature of the samples was correspondingly reduced. The three test sections containing the $\mathrm{Fe}_{3} \mathrm{Al}$ specimens were originally expected to reach 900,700 , and $500^{\circ} \mathrm{C}$, respectively, but the temperatures actually realized were 700,600 , and $500^{\circ} \mathrm{C}$. These latter temperatures are still considered to the test objectives, since the highest metal temperatures projected even for advanced gasifier concepts are generally below $700^{\circ} \mathrm{C}$. The extent of corrosion of the $\mathrm{Fe}_{3} \mathrm{Al}$-based samples, as well as the other ferritic iron-based specimens, appeared essentially the same in all three test sections, a result that again suggests that downtime corrosion was the dominant corrosion process. A new set of $\mathrm{Fe}_{3} \mathrm{Al}$-based alloys, together with the FAP composition (16\% aluminum) discussed above, has been supplied to CRE for testing in upcoming runs.

\section{REFERENCES}

1. J. H. DeVan, "Corrosion Performance of Iron Aluminide $\left(\mathrm{Fe}_{3} \mathrm{Al}\right)$ in Coal Conversion Process Environments," in Heat-Resistant Materials Conference Proceedings, 235-242, ASM International, Materials Park, O, 1991

2. J. H. DeVan, P. F. Tortorelli, and U. K. Abdali, "Environmental Effects on Iron Aluminides," in Proceedings of Sixth Annual Conference on Fossil Energy Materials, ORNL/FMP-92/1, 217-226, Oak Ridge, TN, July 1992

3. S. Vyas, S. Viswanathan, and V. K. Sikka, "Effect of Aluminum Content on Environmental Embrittlement in Binary Iron-Aluminum Alloys," Scr. Metall., 27, 185-190 (1992) 
4. J. H. DeVan, "Development of Surface Treatments and Alloy Modifications for Corrosion-Resistant Oxide Scales," in Proceedings of the Fourth Annual Conference on Fossil Energy Materials, 299-310, ORNL/FMP-90/1, Oak Ridge, TN, August 1990

5. R. A. Buchanan and J. G. Kim, $\mathrm{Fe}_{3}$ Al-Type Iron Aluminides: Aqueous Corrosion Properties in a Range of Electrolytes and Slow-Strain-Rate Ductilities during Aqueous Corrosion, ORNL/Sub/88-07685CT92/02, Oak Ridge, TN, August 1992 


\title{
ORNL-2(B)-INVESTIGATION OF AUSTENITIC ALLOYS FOR ADVANCED HEAT RECOVERY AND HOT-GAS CLEANUP SYSTEMS
}

\author{
R. W. Swindeman
}

Oak Ridge National Laboratory

Oak Ridge, Tennessee 37831-6156

\section{INTRODUCTION}

The purpose of this task is to provide materials technology to aide in the design and construction of advanced components for use in the fossil fuels power industry in the United States. In the near term, life-extension with improved flexibility and reliability in existing plants is an issue of primary concern, and alloys to meet these performance requirements are being investigated. In the longer range, improved efficiency will be needed, and this will come about by the development of advanced steam cycle concepts and combined cycle power plants. Here, the performance requirements for structural materials vary significantly from one application to the next, and the limiting performance criterion may be corrosion resistance, fabricability, or strength. Generally, the materials performance requirements become more demanding with increased service temperature, so a range of materials are being examined.

\section{DISCUSSION OF CURRENT ACTIVITIES}

Alloys for Service to $600^{\circ} \mathrm{C}$

Materials problems associated with the life-extension of existing pulverized coal power plants include erosion/corrorion of waterwall tubing, corrosion and stress-rupture of superheater tubing, fatigue and cracking in headers, stress-rupture and thermal stressinduced cracking of main steamline piping and reheat piping, similar and dissimilar metal weld failures, and cracking in turbine casings. An understanding of the problems in existing plants will provide guidance in the selection of materials for advanced plants, so that the "mistakes" will not be repeated. 
For those plants that have had failures in type 304 or 316 stainless steel piping, there exist several options. One option is the replacement of austenitic alloys by high strength $9 \mathrm{Cr}$ martensitic steels. This has been the selection when significant power cycling is expected. Another option is the selection of improved grades of molybdenumbearing stainless steels. These include types $316 \mathrm{~N}, 316 \mathrm{LN}$, and modifications of type $316 \mathrm{~L}$ stainless steel that are of interest in Europe and Asia (Ref. 1 and 2). In cooperation with South Carolina Electric and Gas Company and Toronado Energy Consultants, type $316 \mathrm{~N}$ stainless steel was examined (Ref. 3) and found to possess excellent strength and ductility properties after long exposure times. Joints in piping were found to be a problem, but the use of controlled residual element (CRE) 16-8-2 stainless steel filler metal was found to be a good match for type $316 \mathrm{~N}$ stainless steel. Most of this work has been completed and only a few tests remain in progress. Many of the advanced steam cycle plants are expected to have Gr 91 components. Super heater tubing, headers, and main steamline piping are potential applications for the steel. Gr 91 was originally developed for service about $540^{\circ} \mathrm{C}$ and is performing quite well at this temperature. The use of Gr91 in advanced steam cycle components operating at $600^{\circ} \mathrm{C}$, however, requires more information about the long-time strength. Work has been undertaken at ORNL in co-operation with The Metals Properties Council to clarify the issue. Stress-rupture testing included heats of various tensile strengths, nitrogen levels, and product sizes. Tests were performed at higher temperatures and lower stresses. Data produced in Europe and Japan were also collected and the final stress-rupture database now exceeds 1000 tests. These data were analyzed in several different ways, and it was deternined that a small reduction (approximately 5\%) in the allowable stresses around $600^{\circ} \mathrm{C}$ would be needed to assure that European steels would not cause problems when used for construction conforming ASME Code rules. Action on this issue will be taken by appropriate Code groups. Work on other problems related to the use of martensitic steels in cyclic service will continue. A key issue relates to methods by which one can calculate damage due to transients related to power cycling. Both aging and straining may produce softening in Gr 91 steel. Higher creep rates and shorter rupture lives result.. To estimate remaining life, several approaches are being examined. These include life-fraction summation by use of parametric analyses, isostress testing, and utilization of the Monkman-Grant correlation. An example of the Monkman-Grant correlation for astempered specimens is shown in Fig. 1a. The trend line has been re-drawn in Fig. 1b, where 
it may be compared to data produced on two heats of aged steel. The aged data fall on the same trend line as the unexposed material, indicating that life in service-exposed material may be estimated once the minimum creep rate of exposeci material is determined.
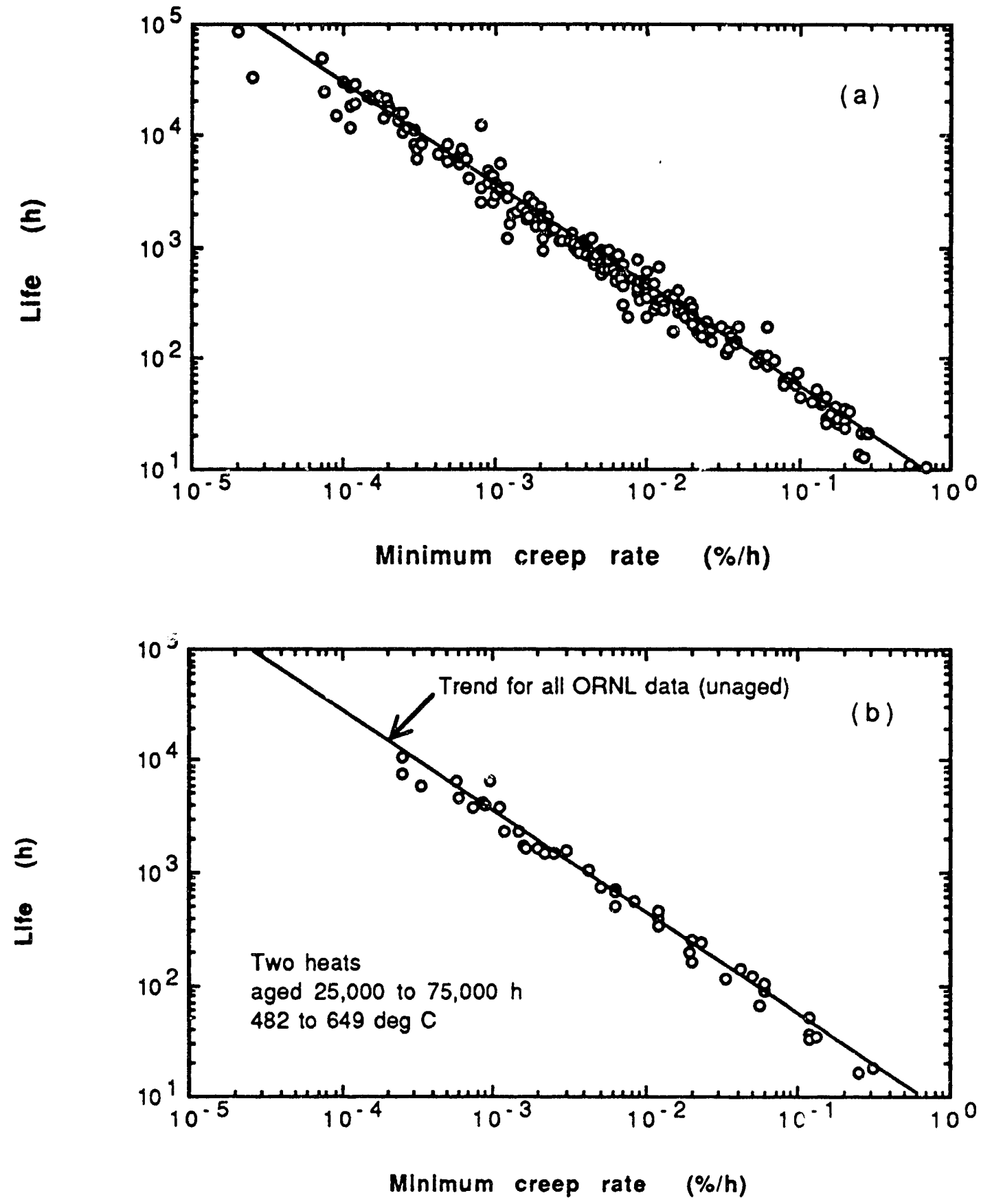

Fig. 1. Monkman-Grant plots for Gr 91 steel (a) as tempered, (b) after long time aging. 
Alloys for Service to $700^{\circ} \mathrm{C}$

Advanced steam cycle plants will require superheater tubing to operate at temperatures approaching $700^{\circ} \mathrm{C}$ and at pressures in excess of $30 \mathrm{MPa}$. Currently, the prime candidate alloys include fine-grained type 347 stainless steel, clad Esshete 1250, and niobium-nitrogen modified type 310 stainless steel $(310 \mathrm{HCbN})$. A high-temperature, ultrafine precipitate strengthened (HT-UPS) steel developed by Maziasz (Ref. 4) was examined for this application, and the evaluation of the steel in the bare and clad conditions has been virtually completed. One test, still in progress after $60,000 \mathrm{~h}$ at $700^{\circ} \mathrm{C}$ demonstrates the remarkable stability of the steel. See Fig. 2a. A modified alloy 800 material was also developed by Maziasz for advanced steam cycle use (Ref. 4). Research on this material has been continued, but the application has changed from superheater tubing to bellows and support structures in the petrochemical process industry. Testing of this material has also reached long times, and ductilities have far exceeded those observed in alloy $800 \mathrm{HT}$. A curve produced at $650^{\circ} \mathrm{C}$ is shown in Fig. $2 \mathrm{~b}$.

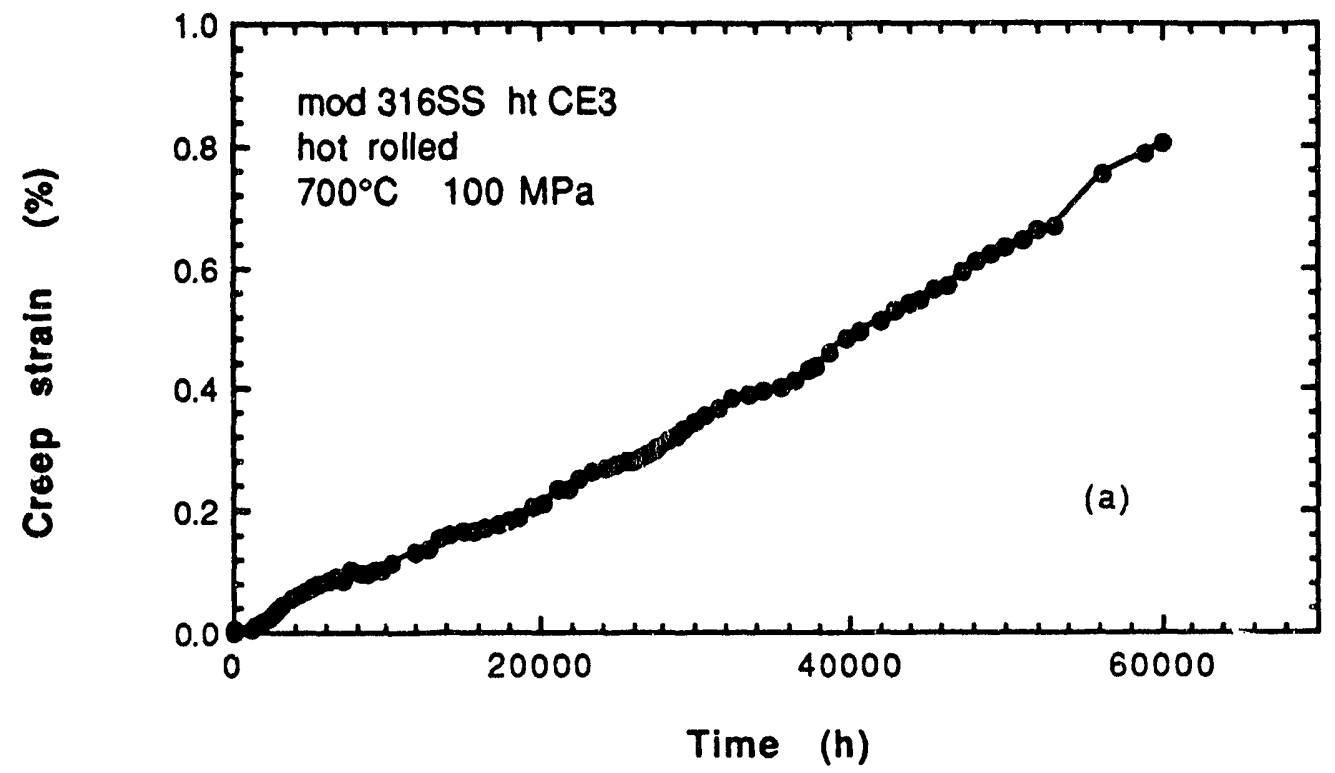




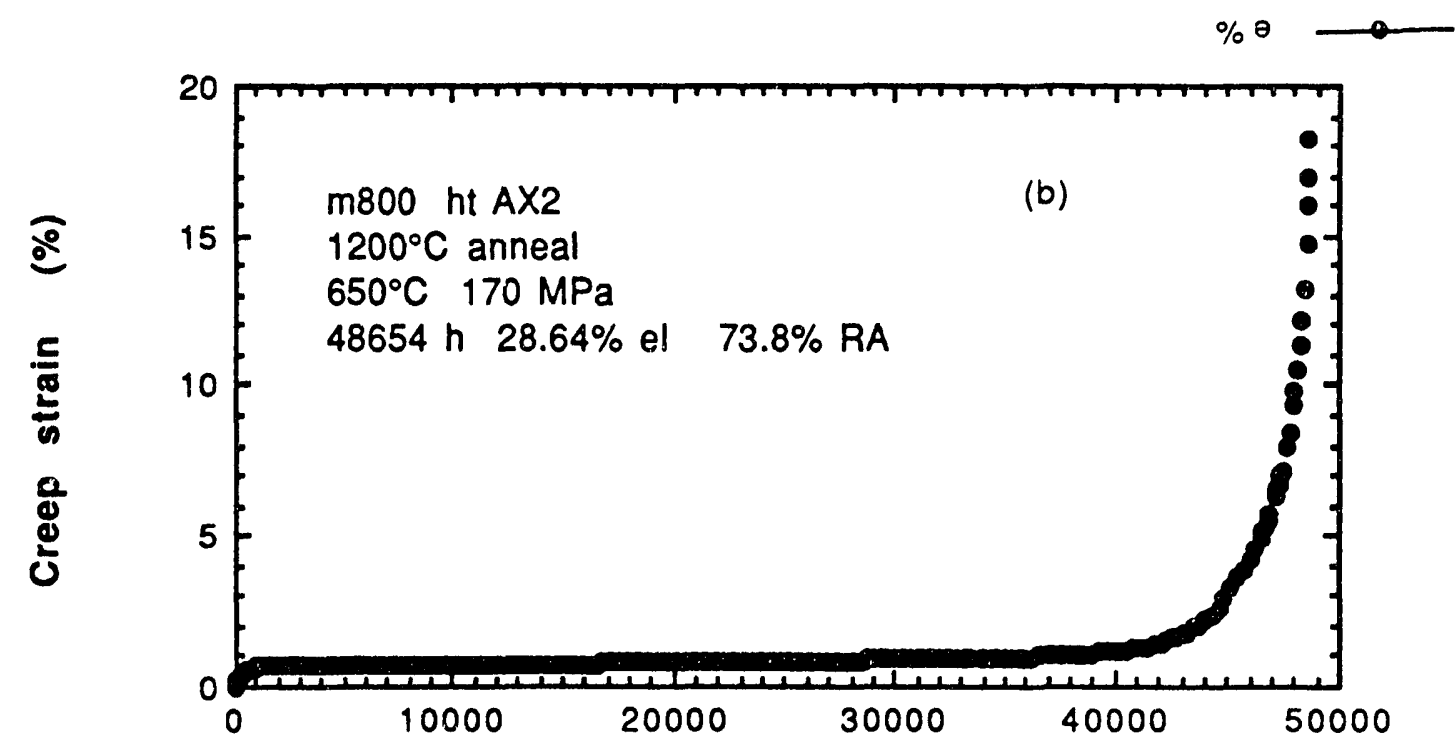

Fig. 2. Long time creep curves for HT-UPS steels (a) heat CE3 in test for $60,000 \mathrm{~h}$ at $700^{\circ} \mathrm{C}$ and $100 \mathrm{MPa}(\mathrm{b})$ heat $\mathrm{AX} 2$ that ruptured after $48,654 \mathrm{~h}$ at $650^{\circ} \mathrm{C}$ and $170 \mathrm{MPa}$.

The weldability of all of the advanced alloys is of concern, and efforts were undertaken in conjunction with the University of Tennessee to evaluate available filler metals. The CRE 16-8-2 stainless steel filler metal, mentioned earlier in connection with its use for type $316 \mathrm{~N}$ stainless steel, continues to be a good match for the HT-UPS steel. The stress-rupture testing of weldments is now approaching 30,000 h. For corrosion resistance and strength, alloy 556 is being investigated, and data on weldments has been gathered for times approaching $20,000 \mathrm{~h}$.

Alloys for Service above $700^{\circ} \mathrm{C}$

Components that may operate above $700^{\circ} \mathrm{C}$ include tubing for advanced steam topping cycles, tubing for heat recovery in fluidized bed combustion and gasifier combined cycles, and support plates and ducting in hot-gas cleanup vessels. Some components will be pressure bearing and will require Code approved materials. Others structures will not require Code-approved materials, although Code-approved materials are often preferred. A variety of old and new alloys are being considered (Ref. 6). 
The possibility of extending the use temperature of the modified alloy 800 was considered, but a few exploratory tests above $760^{\circ} \mathrm{C}$ indicated that modified alloy 800 had no significant strength or ductility advantage over alloy $800 \mathrm{HT}$. A possible exception is HR120 (registered trademark of Haynes Alloys), but testing has not begun on this material. Additional studies of alloy $800 \mathrm{HT}$ were performed at temperatures in the range 760 to $980^{\circ} \mathrm{C}$ to assist the Pressure Vessel Research Council to develop criteria for setting allowable stresses for temperatures above $816^{\circ} \mathrm{C}$. This work has been completed. Other materials being evaluated include $\mathrm{HR}-160^{\circ}, \mathrm{RA} 333^{\circ}$, and type $310 \mathrm{HCbN}$ stainless steel. Modified type 310 stainless steels, such as $310 \mathrm{HCbN}$, appear to be an improvement over types $310 \mathrm{~S}$ and $310 \mathrm{Cb}$ stainless steels, but have not achieved the strength capability of alloy $800 \mathrm{HT}$. A comparison of typical creep curves is provided in Fig. 3 for data collected at

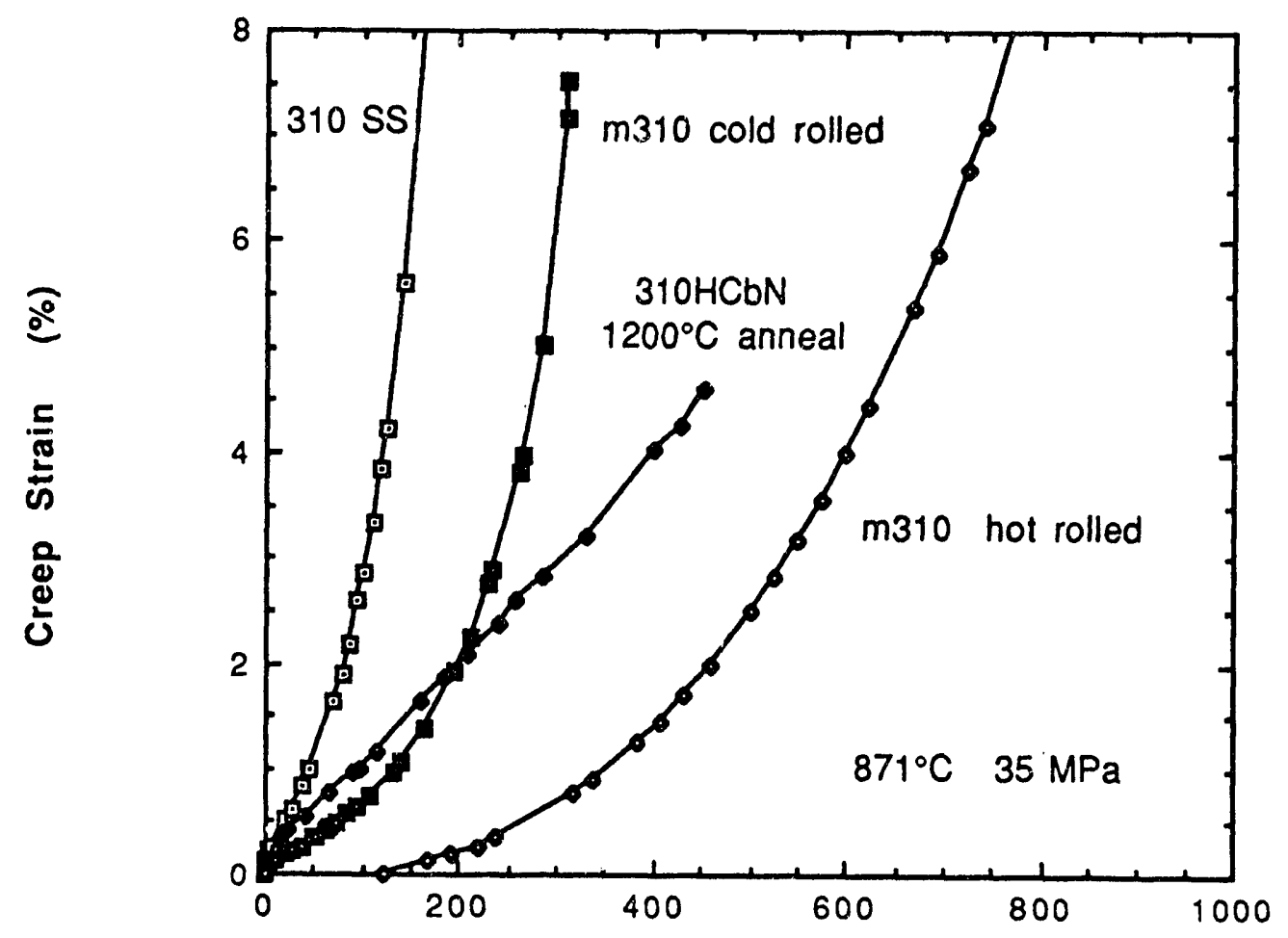

Time (h)

Fig. 3. Comparison of creep curves for modified 310 stainless steels with type 310 stainless steel at $871^{\circ} \mathrm{C}$ and $35 \mathrm{MPa}$. 
$871^{\circ} \mathrm{C}$ and $35 \mathrm{MPa}$. Here, it may be seen that creep rates are lower and lives are longer for the modified 310 stainless steels. It is expected that coarse grain steels will have better creep strength at $871^{\circ} \mathrm{C}$, but some optimization of strength may be possible for alloys that will be used in the temperature range of 760 to $816^{\circ} \mathrm{C}$. Testing is underway to extend rupture data to $10,000 \mathrm{~h}$. A comparison of creep rate data is possible, however, as shown in Fig. 4. This is a plot of $\log$ stress for a minimum creep rate of $0.001 \% / \mathrm{h}$ versus temperature. Comparisons are made between type $310 \mathrm{H}$ stainless steel (Ref. 7), alloy $800 \mathrm{HT}$ (Ref. 8) and modified 310 stainless steel. Based on a small data base, it appears that the modified 310 stainless steel has approximately twice the strength of type 310 stainless steel and is superior to alloy 800 for temperatures below $815^{\circ} \mathrm{C}$.

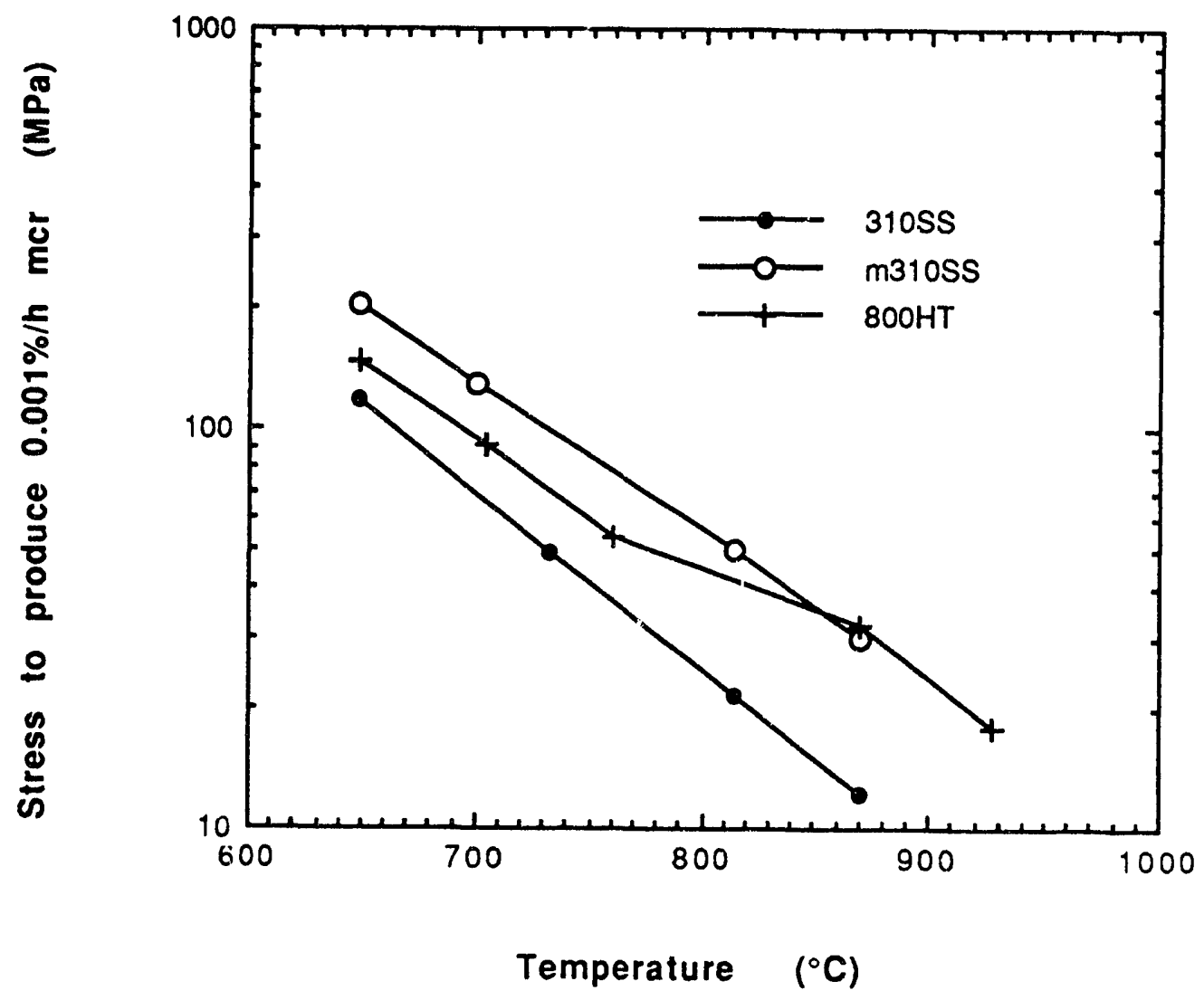

Fig. 4. Comparison of the creep strength of modified 310 stainless steel with 310 stainless steel and alloy $800 \mathrm{HT}$. 


\section{REFERENCES}

1. Y. Asada, et al., "Current Status of the Development of Advanced 316-Steel for FBR Structures," pp. 61 to 66 in Stress Classification, Robust Methods, and Elevated Temperature Design, PVP-Vol. 230, American Society for Mechanical Engineers, New York, 1992.

2. K. Haarmann, "Current Status of Development of Modified 316 Steel for FBR Structures," paper submitted for presentation at the ASME 1993 Pressure Vessels and Piping Conference, Denver, Co., July 25-29, 1993.

3. R. W. Swindeman, G. M. Goodwin, and F. V. Ellis, "Filler Metals for Type 316N Stainless Steel," pp. 33 to 39 in Stress Classification, Robust Methods, and Elevated Temperature Design, PVP-Vol. 230, American Society for Mechanical Engineers, New York, 1992.

4. P. J. Maziasz, Developing an Austenitic Stainless Steel for Improved Performance in Fossil Power Facilities, Journal of Metals, Vol. 41, 1989, pp. 14-20.

5. R. W. Swindeman, The Potential of Modified Type 310 Stainless Steel for Advanced Fossil Energy Applications, ORNL/TM-12057 (March 1992).

6. M. Prager, "Deformation Considerations in the Elevated Temperature Stress Rupture Behavior of 309 and 310 Stainless Steel," pp. 85-100 in Stress Classification, Robust Methods, and Elevated Temperature Design, PVP-Vol. 230, American Society for Mechanical Engineers, New York, 1992.

7. Incoloy alloys 800 and $800 \mathrm{HT}$, INCO Alloys International, Inc., Huntington, WV, 1986. 


\title{
ORNL-2(D)-ULTRAHIGH TEMPERATURE INTERMETALLIC ALLOYS
}

\author{
C. T. Liu, J. A. Horton, E. H. Lee
}

Oak Ridge National Laboratory

P.O. Box 2008

Oak Ridge, TN 37831-6115

\section{INTRODUCTION}

The thermal efficiency of energy conversion systems and heat engines increases by increasing their operation temperatures. At present, many advanced engines and energy systems have to operate at reduced temperatures because of limitation by structural materials whose strength decreases sharply above $800^{\circ} \mathrm{C}$. Nickel-base superalloys, the state-of-the-art materials, can possibly be used at temperatures up to $1000^{\circ} \mathrm{C}$ on a shortterm basis. Hence, there is a pressing need to develop new materials (particularly metallic ones) for use at temperatures above $900^{\circ} \mathrm{C}$.

The intermetallic alloy, $\mathrm{Cr}_{2} \mathrm{Nb}$, with a $\mathrm{C}-15$ cubic structure is attractive for hightemperature structural applications because of its high melting point $\left(1700^{\circ} \mathrm{C}\right)$, relatively low density $\left(7.7 \mathrm{~g} / \mathrm{cm}^{2}\right)$, and some potential resistance to oxidation at $1000^{\circ} \mathrm{C}$. In addition, this intermetallic alloy has a wide range of composition homogeneity, indicating the possibility of improving its mechanical and metallurgical properties by alloying additions.

The major concern of this intermetallic alloy is its poor ductility and fracture toughness at ambient temperatures. The single-phased $\mathrm{Cr}_{2} \mathrm{Nb}$ is very hard $(\mathrm{DPH} \sim 800)$ and brittle at room temperature. Previous studies indicated that the mechanical properties of $\mathrm{Cr}_{2} \mathrm{Nb}$ could be improved by introducing chromium-rich ductile particles through a precipitation reaction. Some two-phase alloys exhibited a compressive ductility of $4 \%$ at room temperature and a yield strength of over $700 \mathrm{MPa}(\sim 100 \mathrm{ksi})$ at $1000^{\circ} \mathrm{C}$. These intermetallic alloys are substantially stronger than existing nickel-base superalloys at temperatures at least to $1250^{\circ} \mathrm{C}$ and offer strengths equivalent to some structural ceramics 
at these temperatures. Limited alloy development effort indicated that the strength and ductility of $\mathrm{Cr}_{2} \mathrm{Nb} / \mathrm{Cr}(\mathrm{Nb})$ alloys were further improved by alloy additions and microstructural control.

In addition to the concern with brittleness, the corrosion resistance of $\mathrm{Cr}-\mathrm{Nb}$ alloys at high temperatures can be problematical due to possible spallation of mutilayer scales, formation of chromium sulfides, and volutilization of chromia above $1100^{\circ} \mathrm{C}$. Careful design of alloys to form more protective scales and/or the use of coatings offer opportunities to ameliorate the corrosion problems.

The results obtained so far indicate that the $\mathrm{Cr}_{2} \mathrm{Nb} / \mathrm{Cr}(\mathrm{Nb})$ alloys have an excellent strength for structural use at ultra-high temperatures (e.g. $1000-1300^{\circ} \mathrm{C}$ ). Potential applications include hot components in advanced fossil energy conversion systems, advanced heat engines, and high-temperature cutting and grinding tools. The alloys, on the other hand, exhibited no tensile ductility at ambient temperatures. They showed some oxidation resistance at $1000^{\circ} \mathrm{C}$, but long-term exposures resulted in spalling oxide scales from surfaces at this temperature. In this task, the mechanical and metallurgical properties of $\mathrm{Cr}_{2} \mathrm{Nb} / \mathrm{Cr}(\mathrm{Nb})$ alloys will be improved by control of alloy composition, impurity level, precipitation reaction, and material processing.

\section{DISCUSSION OF CURRENT ACTIVITIES}

The alloy development effort was initiated by preparation of high-purity $\mathrm{Cr}_{2} \mathrm{Nb} / \mathrm{Cr}(\mathrm{Nb})$ two-phase alloys with minimum cast defects. During the last reporting period, several high-purity $\mathrm{Cr}_{2} \mathrm{Nb} / \mathrm{Cr}(\mathrm{Nb})$ alloys were successfully prepared in a highvacuum arc-melt furnace and cast into a preheated copper mold ${ }^{1}$. This resulted in reduction in cast porosities and microcracks in the alloys. Fine $\mathrm{Nb}_{2} \mathrm{Cr}$ particles $(1 \mu \mathrm{m})$ precipitated out of the chromium-rich solid solution when heat treated at temperatures between 900 and $1300^{\circ} \mathrm{C}$ for 3 to 5 days. The coarsening of the precipitates at $1200^{\circ} \mathrm{C}$ reduces the microhardness from 649 to $502 \mathrm{DPH}$. No microcracks were observed around indents made at a load of $500 \mathrm{~g}$, suggesting that the alloy is able to take plastic deformation without cracking. 
During this reporting period, chemical analyses were made on a $\mathrm{Cr}_{2} \mathrm{Nb}$-base alloy (CN-43) prepared in a high vacuum using high-purity charge materials. The results indicated that the total interstitial (oxygen and carbon) in this alloy is only $170 \mathrm{wt}$ ppm. In comparison, the same type of alloys prepared previously contained as much as 700 to $1000 \mathrm{wt} \mathrm{ppm}{ }^{2}$ Thus, the interstial content in $\mathrm{Cr}_{2} \mathrm{Nb}$ alloys can be effectively reduced by control of melting and casting processes.

In order to explore the hot fabricability of $\mathrm{Cr}_{2} \mathrm{Nb}$-base alloys, the alloy ingot $(\mathrm{CN}-$ 43) was clad in Mo sheets and hot forged at $1100-1200^{\circ} \mathrm{C}$ in air. The alloy cracked quite badly after a reduction of $25 \%$. This result indicates that the alloy had a limited hot fabricability at temperatures to $1200^{\circ} \mathrm{C}$.

Specimens of CN-43 were examined by transmission electron microscopy (TEM). The specimens were prepared by ion milling because the alloy could not be successfully electropolished. Figure 1a shows a micrograph of the as-cast material and Fig. 1b shows the same alloy after an anneal for $5 \mathrm{~d}$ at $900^{\circ} \mathrm{C}$ and then $3 \mathrm{~d}$ at $1200^{\circ} \mathrm{C}$. The eutectic structure (the darker phase in the micrographs) and chromium-rich patches are clearly seen in both conditions. In the as-cast specimen no further precipitations was observed. The $\mathrm{Cr}_{2} \mathrm{Nb}$ phase was extensively internally twinned. Dislocation pileups were observed in the chromium-rich phase impinging on the eutectic phase. (In the figures, the white areas are multiple holes and are a result of the ion milling). In the annealed material, Fig. $1 \mathrm{~b}$, extensive secondary precipitation of the $\mathrm{Cr}_{2} \mathrm{Nb}$ phase has occurred. No dislocations were observed in this material. These secondary precipitates were also internally twinned. Further analysis of these alloys is in progress.

Tensile specimens with a gage section of $3.2 \mathrm{~mm}$ diam $\times 6.4 \mathrm{~mm}$ length were prepared from the alloys $\mathrm{CN}-43$ and 40 . The specimens were first annealed for $5 \mathrm{~d}$ at $1000^{\circ} \mathrm{C}$ plus $3 \mathrm{~d}$ at $1200^{\circ} \mathrm{C}$ and then tensile tested at room temperature in air. Both alloys showed no appreciable plastic deformation and fractured prior to macroscopic yielding. In comparison, the same alloys exhibited an elongation of $7 \%$ in compression. These results suggest that the tensile ductility cannot be simply obtained for these alloys by reduction of interstitiai contents alone. 


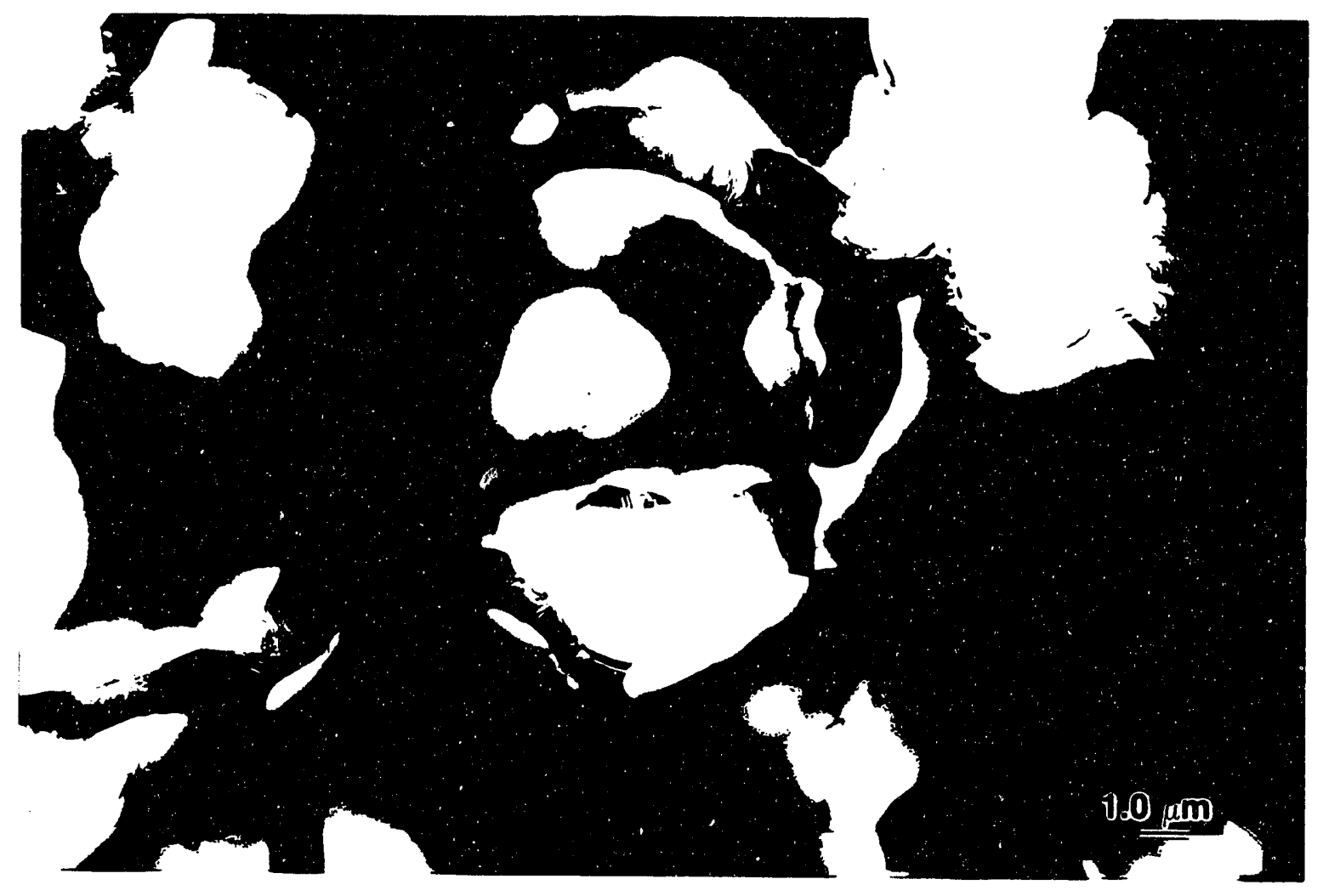

Fig. 1a is a TEM micrograph of the as-cast $\mathrm{CN}-43$ material.

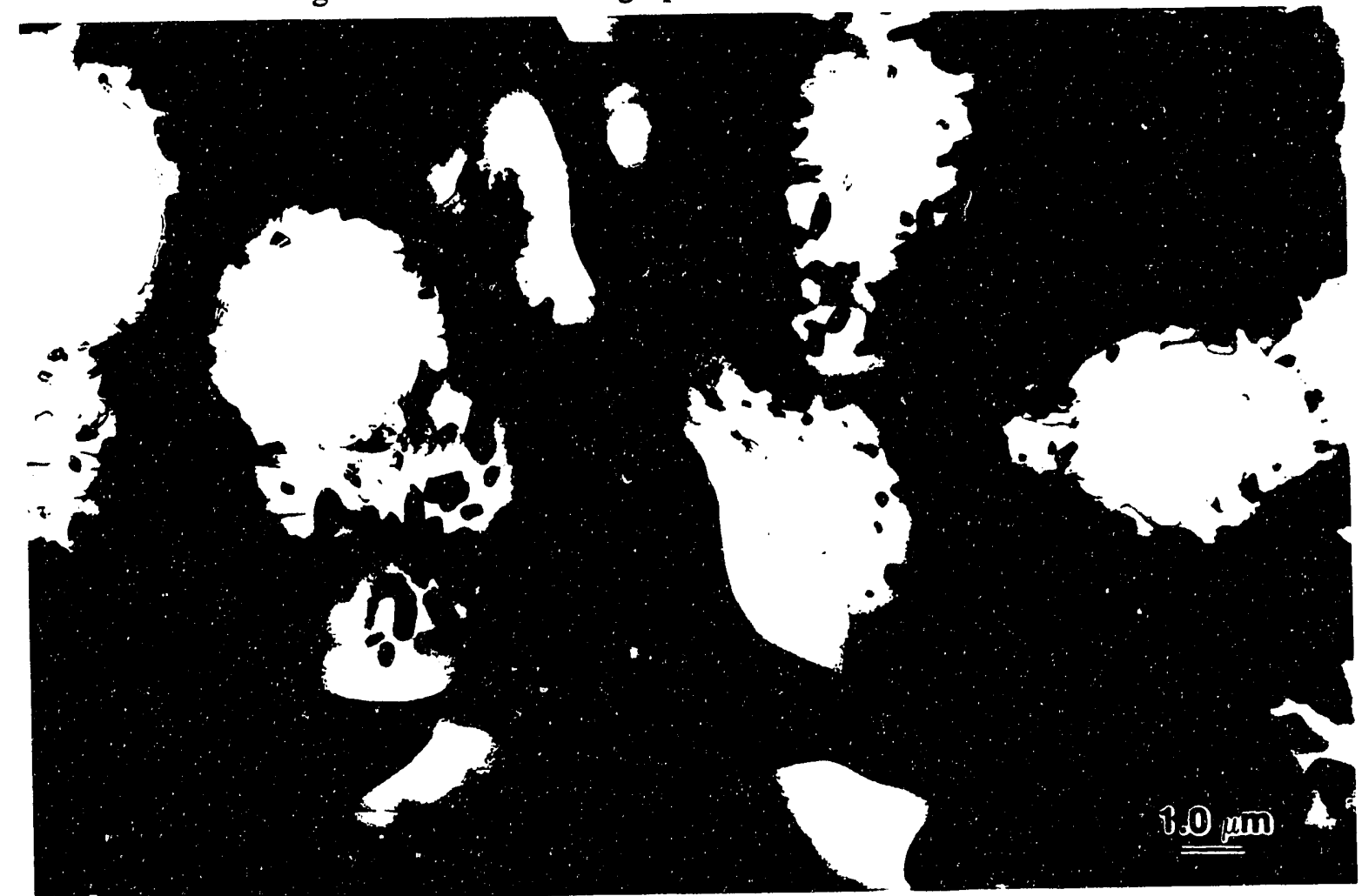

Fig. $1 \mathrm{~b}$ shows the same alloy $(\mathrm{CN}-43)$ after an anneal for $5 \mathrm{~d}$ at $900^{\circ} \mathrm{C}$ and then $3 \mathrm{~d}$ at $1200^{\circ} \mathrm{C}$. 
Further studies will emphasize optimization of alloy composition and microstructure in order to achieve tensile ductilities. Metallographic examination reveals cleavage fracture as the major fracture mode in these alloys.

During this reporting period, three series of new alloys were prepared with cast conditions listed in Table 1. The first series of the alloys CN-46 to 48 contain different levels of the element designated as "X", and the second series of the alloys CN-49 to 51 contain different levels of the element "Z." The third series of the alloys CN-52 to 55 were prepared based on modification of the alloy $\mathrm{CN}-43$. The alloying element $\mathrm{X}$ apparently embrittles $\mathrm{Cr}_{2} \mathrm{Nb} / \mathrm{Cr}(\mathrm{Nb})$ alloys and introduces macroscopic cracks during drop casting.

Table 1. Cast conditions of $\mathrm{Cr}_{2} \mathrm{Nb} / \mathrm{Cr}(\mathrm{Nb})$ alloys

\begin{tabular}{|c|c|}
\hline Alloy number & Cast condition \\
\hline $\mathrm{CN}-46$ & $\begin{array}{l}\text { Good cast ingot with a major } \\
\text { crack at the central region }\end{array}$ \\
\hline $\mathrm{CN}-47$ & $\begin{array}{l}\text { Good cast ingot with a major } \\
\text { crack at the central region }\end{array}$ \\
\hline $\mathrm{CN}-48$ & Several macroscopic cracks \\
\hline $\mathrm{CN}-49$ & $\begin{array}{l}\text { Rough ingot surface, no } \\
\text { macroscopic cracks }\end{array}$ \\
\hline $\mathrm{CN}-50$ & $\begin{array}{l}\text { Rough ingot suiface, no } \\
\text { macroscopic cracks }\end{array}$ \\
\hline $\mathrm{CN}-51$ & $\begin{array}{l}\text { Rough ingot surface, no } \\
\text { macroscopic cracks }\end{array}$ \\
\hline $\mathrm{CN}-52$ & $\begin{array}{l}\text { Good cast ingot, no macroscopic } \\
\text { cracks }\end{array}$ \\
\hline $\mathrm{CN}-53$ & $\begin{array}{l}\text { Good cast ingot with a major } \\
\text { crack near the ingot boucom }\end{array}$ \\
\hline $\mathrm{CN}-54$ & $\begin{array}{l}\text { Excellent ingot condition, no cast } \\
\text { defects }\end{array}$ \\
\hline CN-55 & $\begin{array}{l}\text { Excellent ingot condition, no cast } \\
\text { defects }\end{array}$ \\
\hline
\end{tabular}

The alloy ingots were sectioned and then annealed for $5 \mathrm{~d}$ at $900^{\circ} \mathrm{C}$ plus $3 \mathrm{~d}$ at 1000 to $1200^{\circ} \mathrm{C}$. Metallographic examination reveals a mixture of two-phase structure as shown in Fig. 2. The primary chromium-rich patches (light contrast) were surrounded by an eutectic network (dark contrast). Fine precipitation of the $\mathrm{Cr}_{2} \mathrm{Nb}$ phase is clearly obserzed in chromium-rich patches when specimens were annealed at $1000^{\circ} \mathrm{C}$ or above. The preparation of tensile and compressive specimens are in progress. 


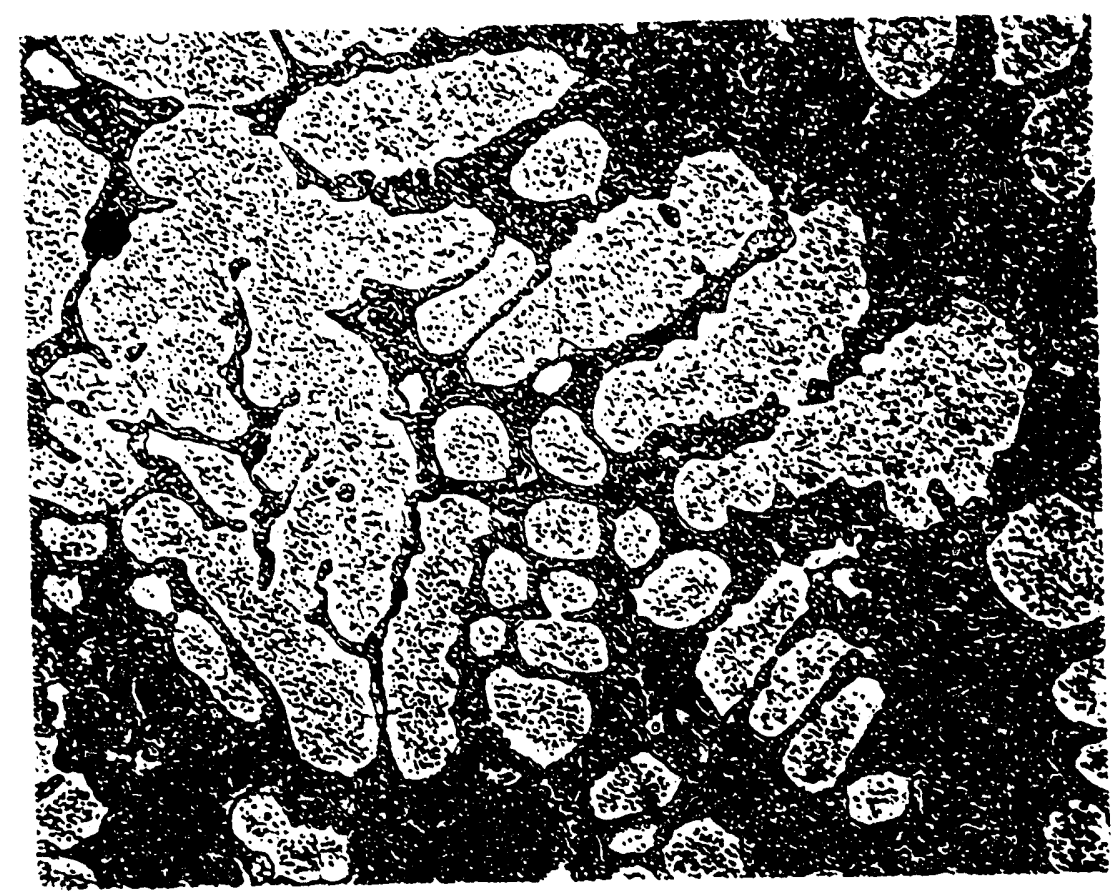

Fig. 2. Optical micrograph of $\mathrm{CN}-46$ annealed for $5 \mathrm{~d}$ at $900^{\circ} \mathrm{C}$ plus $3 \mathrm{~d}$ at $1200^{\circ} \mathrm{C} ; 625 \mathrm{x}$.

\section{REFERENCES}

1. C. T. Liu, to be published in Proceeding of the Sixth Annual Conference on Fossil Energy Materials, ORNL/FMP-92/1, Oak Ridge National Laboratory, Oak Ridge, Tennessee.

2. M. Takeyama and C. T. Liu, Mater. Sci. and Eng. A 132, 61 (1991). 


\section{ORNL-2(F)-DEVFLOPMENT OF IRON ALUMINIDES* \\ V.K. Sikka \\ Metals and Ceramics Division \\ Oak Ridge National Laboratory \\ P.O. Box 2008 \\ Oak Ridge, Tennessee 37831}

\section{INTRODUCTION}

Iron aluminides based on the ordered $\mathrm{Fe}_{3} \mathrm{Al}$ composition have good oxidation resistance and excellent sulfidation resistance. Furthermore, they offer advantages over stainless steels, including lower density and reduced consumption of strategic elements including chromium. In the past, the major drawbacks to the use of these materials in structural applications have been low room-temperature (RT) ductility $(<5 \%)$ and a rapid drop in strength at temperatures above $600^{\circ} \mathrm{C}$ (ref. 1). Recently, by a combination of thermomechanical processing and heat treatment, the RT ductility has been increased into the range of 15 to $20 \%$ (ref. 2), and the high-temperature tensile and creep strengths have been increased by the addition of $1 \% \mathrm{Nb}$ (ref. 3). While there is a growing data base on the properties of sheet material, ${ }^{4}$ little data exists on the mechanical properties of plate products, and no fatigue data are available.

In this paper, the tensile, creep, and fatigue properties of ductile $\mathrm{Fe}_{3} \mathrm{Al}$ plate in two thicknesses are investigated and, when possible, compared to sheet properties. In addition, the results of Charpy-impact toughness tests are reported for one plate. The alloy investigated is designated FA-129, which is an ordered $\mathrm{Fe}_{3} \mathrm{Al}$ alloy with a composition tailored for high-temperature strength. 3 The results show differences in tensile and creep properties for $p_{i .}$, and sheet products. The results of high cycle fatigue tests show that cyclic loading at stresses below the yield strength does not induce fatigue failure at temperatures of 25 and $454^{\circ} \mathrm{C}$ and that there is an effect of plate thickness at $600^{\circ} \mathrm{C}$.

*Data taken from a paper by B. G. Gieseke, D. J. Alexander, V. K. Sikka, and R. H. Baldwin entitled "Mechanical Properties of Ductile $\mathrm{Fe}_{3} \mathrm{Al}$-Based Plates." 


\section{EXPERIMENTAL PROCEDURES}

The $\mathrm{Fe}_{3} \mathrm{Al}$ alloy studied was vacuum-induction melted by Special Metals Corporation (New Hartford, New York) and cast into a $165-\mathrm{kg}$ round ingot with dimensions of $102-\mathrm{mm}$ diam by $203-\mathrm{mm}$ long with a small hot top. The composition of the alloy is given in Table 1. The ingot was homogenized at $1150^{\circ} \mathrm{C}$ for $64 \mathrm{~h}$, followed by $1 \mathrm{~h}$ at $700^{\circ} \mathrm{C}$ then air cooling. Next, the material was heated in air at $1000^{\circ} \mathrm{C}$ for $2 \mathrm{~h}$ and extruded through a rectangular die of $25 \mathrm{~mm}$ by $76 \mathrm{~mm}$. Each piece was rolled at $800^{\circ} \mathrm{C}$ from a thickness of $25 \mathrm{~mm}$ to $19 \mathrm{~mm}$. Rolling passes were $15 \%$ each with reheating times of $600 \mathrm{~s}$ each. Finish rolling was conducted at $650^{\circ} \mathrm{C}$ and two plates were produced: one $12.7-\mathrm{mm}$ thick and the other $16.5-\mathrm{mm}$ thick. The $12.7-\mathrm{mm}$ plate was stress relieved at $700^{\circ} \mathrm{C}$ for $1 \mathrm{~h}$ and oil quenched, and the $16.5-\mathrm{mm}$ plate was stress relieved at $750^{\circ} \mathrm{C}$ for $1 \mathrm{~h}$ and oil quenched.

Table 1. Composition of FA-129 iron aluminide (wt \%)

\begin{tabular}{cccccc}
\hline $\mathrm{Fe}$ & $\mathrm{Al}$ & $\mathrm{Cr}$ & $\mathrm{Nb}$ & $\mathrm{C}$ & $\mathrm{B}$ \\
\hline Balance & 16.30 & 5.31 & 1.00 & 0.054 & $<0.001$ \\
\hline
\end{tabular}

Specimens were machined from the plates as described below. In each case, specimens from the $12.7-\mathrm{mm}$ plate were stress relieved at $700^{\circ} \mathrm{C}$ for $1 \mathrm{~h}$ and oil quenched. Specimens from the $16.5-\mathrm{mm}$ plate were stress relieved at $750^{\circ} \mathrm{C}$ for $1 \mathrm{~h}$ and oil quenched.

Standard size tensile specimens with a nominal gage length diameter of $6.35 \mathrm{~mm}$ were fabricated from the $12.7-\mathrm{mm}$ plate. In addition, miniature $(3.18-\mathrm{mm}$ diam) tensiles were fabricated from the ends of one fatigue specimen from the $16.5-\mathrm{mm}$ plate. Duplicate tensile tests were conducted at 25,454 , and $600^{\circ} \mathrm{C}$ using an initial strain rate of 2.67 by $10^{-3 / s}$ and a resistance-heated, clam-shell furnace.

Hourglass fatigue specimens with a nominal diameter of $5.08 \mathrm{~mm}$ were machined from both plates. Fatigue tests were conducted at 24,454 , and $600^{\circ} \mathrm{C}$ on a servohydraulic test frame using an R-ratio of 0.05 . Prior to testing, the gage length of each fatigue specimen was hand polished using $6-\mu \mathrm{m}$ diamond paste to remove all surface oxidation from the stress-relief process and to provide defect-free surfaces. Specimens were heated 
using a radio frequency induction unit, and the temperature at the center of the gage lengths was maintained to within $\pm 2^{\circ} \mathrm{C}$.

Charpy V-notch tests were conducted on specimens oriented in the T-L orientation so that crack growth was parallel to the rolling direction. Six full size $(10 \times 10 \times 50 \mathrm{~mm})$ Charpys were machined from the $16.5-\mathrm{mm}$ plate. The specimens were tested on a semiautomated Charpy machine at $200^{\circ} \mathrm{C}$ increments from -200 to $800^{\circ} \mathrm{C}$, and the impact energies were fitted to a hyperbolic tangent function to determine the transition temperature.

Creep tests were conducted in air on 2.36-mm-diam specimens machined from plate materials. The small quantity of available plate required that the creep specimens be machined from the ends of fatigue specimens. A total of four specimens were machined. Testing was completed at $650^{\circ} \mathrm{C}$ and $34.5 \mathrm{MPa}$ using dead weight loading to duplicate conditions for which creep data existed on the sheet material.

\section{RESULTS}

Tensile properties obtained on the plates are listed in Table 2 along with those previously determined for the $0.75-\mathrm{mm}$ sheet products. As Table 2 shows, the RT ductility of the $12.7-\mathrm{mm}$ plate (no data exist for the $16.5-\mathrm{mm}$ plate) is reduced by nearly $50 \%$ in reference to the sheet material, yet the yield strengths at RT are quite similar. Furthermore, the RT ultimate strength in the $12.7-\mathrm{mm}$ plate is reduced by $28 \%$. At $454^{\circ} \mathrm{C}$, the yield strengths of the plate materials are lower than that in the sheet material by approximately $18 \%$, while the ultimate strengths are not significantly different. At $600^{\circ} \mathrm{C}$, both the yield and ultimate strengths are slightly higher for the plate products.

Results of the Charpy-impact tests are shown in Fig. 1. The transition temperature, as measured at an energy level midway between the upper and lower shelves, was $308^{\circ} \mathrm{C}$. The upper shelf energy was $37 \mathrm{~J}$ and the lower shelf energy is less than $5 \mathrm{~J}$. The fracture surfaces showed a layered structure with many splits perpendicular to the fracture surface. Visual examination with a stereo microscope suggests that the fracture mode is all cleavage fracture, at least up to $200^{\circ} \mathrm{C}$, with a small amount of ductile fracture present at $400^{\circ} \mathrm{C}$. At 600 and $800^{\circ} \mathrm{C}$, the fracture mode is essentially fully ductile.

The results of the high-cycle fatigue tests at $600^{\circ} \mathrm{C}$ are plotted in Fig. $2(a)$ and show a difference in the fatigue response for differing plate thicknesses at all stresses. At higher stresses, the $16-5-\mathrm{mm}$ plate has better fatigue resistance. Insufficient data are available at lower stresses to determine whether the data are converging to the 
same tend, but this would be expected. Furthermore, insufficient data exist to determine if a fatigue limit exists. Extrapolation of the data suggests that the fatigue strength at $10^{8}$ cycles should be greater than $120 \mathrm{MPa}$, which compares favorably to an estimated $150 \mathrm{MPa}$ for 304 stainless steel. 5

Table 2. Tensile properties of alloy FA-129 plates

\begin{tabular}{|c|c|c|c|c|}
\hline \multirow{2}{*}{$\begin{array}{l}\text { Product } \\
\text { form }\end{array}$} & \multirow{2}{*}{$\begin{array}{c}\text { Temperature } \\
\left({ }^{\circ} \mathrm{C}\right)\end{array}$} & \multirow{2}{*}{$\begin{array}{c}\text { Elongation } \\
(\%)\end{array}$} & \multicolumn{2}{|c|}{ Strength $(\mathrm{MPa})$} \\
\hline & & & $0.2 \%$ Yield & Ultimate \\
\hline $\begin{array}{l}0.75-\mathrm{mm} \text { Sheet } \\
0.75-\mathrm{mm} \text { Sheet } \\
0.75-\mathrm{mm} \text { Sheet }\end{array}$ & $\begin{array}{r}25 \\
454 \\
600\end{array}$ & $\begin{array}{l}15.12 \\
24.45 \\
43.97\end{array}$ & $\begin{array}{l}426.1 \\
415.1 \\
375.1\end{array}$ & $\begin{array}{l}894.3 \\
732.9 \\
445.4\end{array}$ \\
\hline $\begin{array}{l}\text { 12.5-mm Plate } \\
12.5-\mathrm{mm} \text { Plate } \\
12.5-\mathrm{mm} \text { Plate }\end{array}$ & $\begin{array}{r}25 \\
454 \\
600\end{array}$ & $\begin{array}{l}7.78 \\
15.7 \\
63.0\end{array}$ & $\begin{array}{l}433.0 \\
341.4 \\
406.2\end{array}$ & $\begin{array}{l}644.8 \\
696.5 \\
455.2\end{array}$ \\
\hline $\begin{array}{l}\text { 16.5-mm Plate } \\
16.5-\mathrm{mm} \text { Plate }\end{array}$ & $\begin{array}{l}454 \\
600\end{array}$ & $\begin{array}{l}22.7 \\
41.6\end{array}$ & $\begin{array}{l}335.1 \\
418.9\end{array}$ & $\begin{array}{l}730.5 \\
476.1\end{array}$ \\
\hline
\end{tabular}

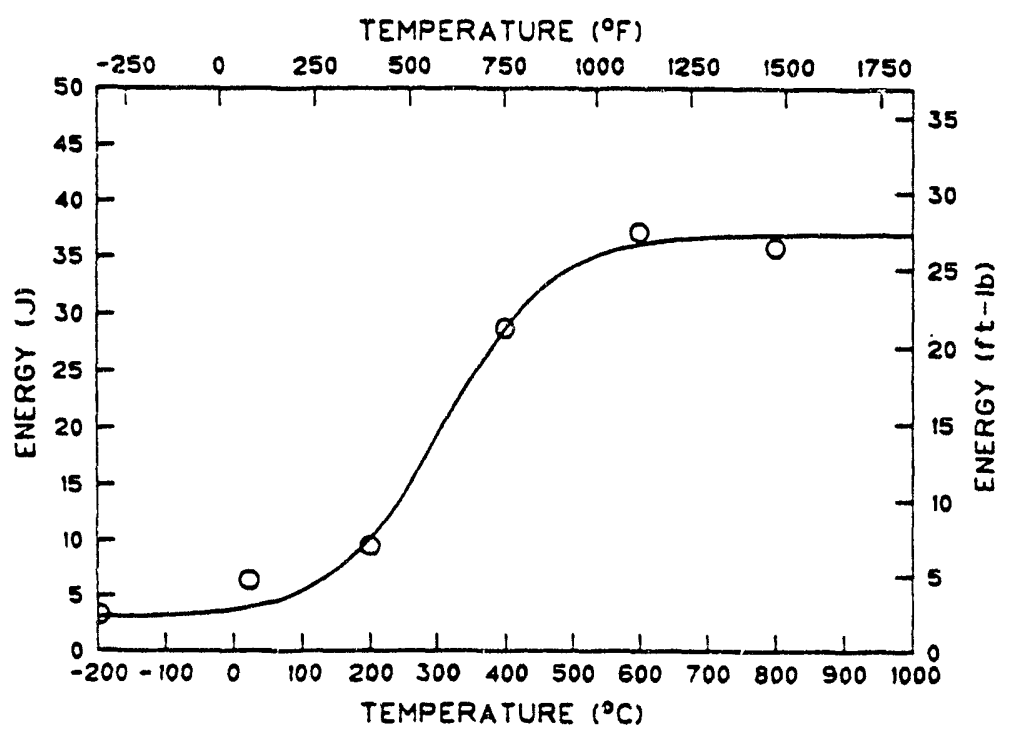
FA-129.

Fig. 1. Absorbed energy versus temperature for full-size T-L specimen of alloy 
Fatigue tests were also conducted at 24 and $454^{\circ} \mathrm{C}$. At RT, two tests were conducted with the maximum stress, $\sigma_{\max }$, equal to $0.95 \sigma_{y s}$, and no failures were observed in $10^{7}$ cycles. At $454^{\circ} \mathrm{C}$, no failures occurred when $\sigma_{\max }$ was below the $0.2 \%$ yield stress. The only three failures observed occurred when $\sigma_{\max }$ equalled 448,467 , and $490 \mathrm{MPa}$, all of which greatly exceed the average yield stress of the plates (338.3 MPa). These data are plotted in Fig. 2(b).

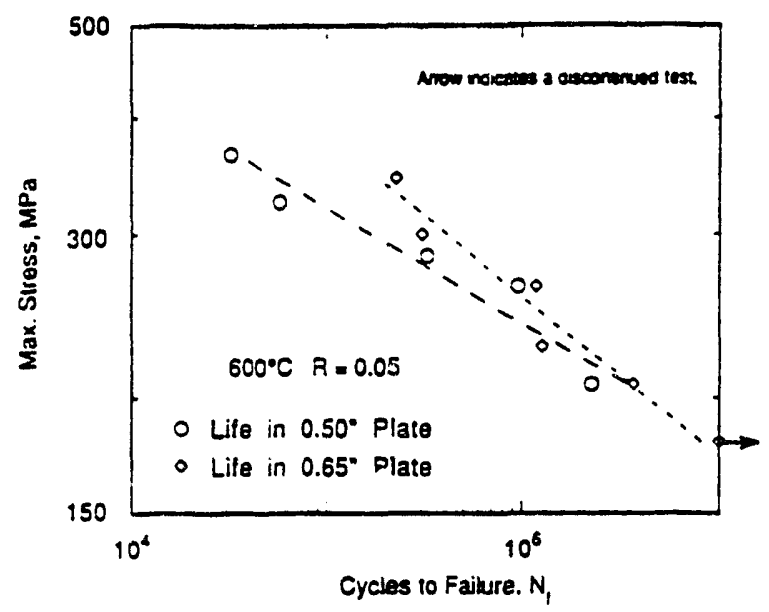

(a)

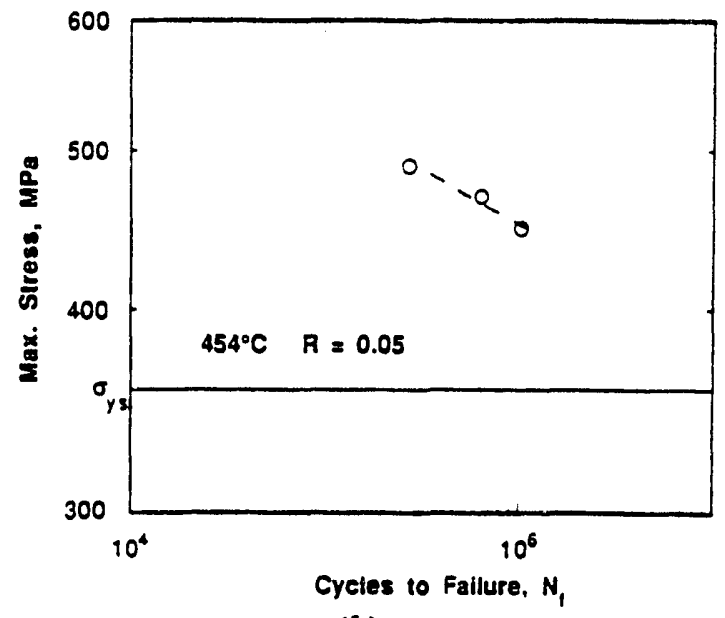

(b)

Fig. 2. Fatigue life as a function of maximum applied stress for alloy FA-129 plates at: (a) $600^{\circ} \mathrm{C}$ and $(b) 454^{\circ} \mathrm{C}$.

Fractur: surfaces from several fatigue specimens were examined in a scanning electron microscope (SEM). At a temperature of $600^{\circ} \mathrm{C}$, initiation always occurred at specimen surfaces. In at least one instance, initiation occurred at a iron-niobium particle on the surface that had oxidized. At $454^{\circ} \mathrm{C}$, several cases of subsurface initiation at $\mathrm{Fe}-\mathrm{Cr}$ - $\mathrm{Al}$ particles were noted. At both 454 and $600^{\circ} \mathrm{C}$, crack propagation is initially very fine as is shown in Fig. 3(a), but the scale is too small to allow determination of the crack growth mode. There is a rapid switch to cyclic cleavage that becomes rougher with increasing crack length, as evidenced in Fig. 3(b).

Of the original four creep specimens, only two yielded useful information. The results of the creep tests are shown in Figs. 4 and 5 along with data from the $0.75-\mathrm{mm}$ sheet material. As Fig. 4 shows, the plate materials have lower creep rates, lower strains at failure, but higher rupture times than the sheet material, suggested improved creep resistance. However, as Fig. 5 shows, when plotted on a Larson-Miller plot, the 
difference is not profound. Knibloe and Wright ${ }^{6}$ have tested rod material of the FAL composition and found the results are similar to that for sheet material.

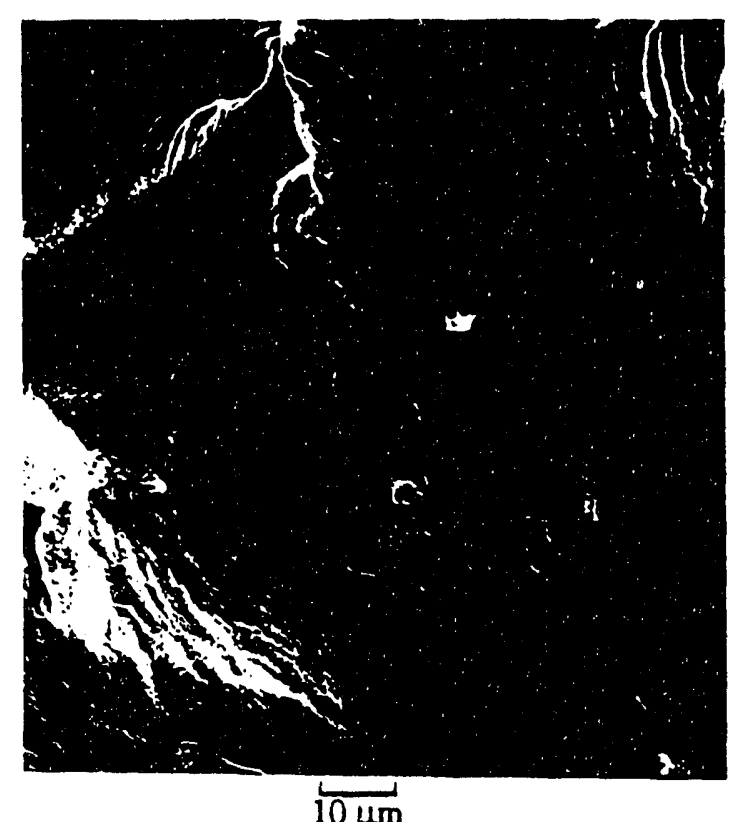

$10 \mu \mathrm{m}$

(a)

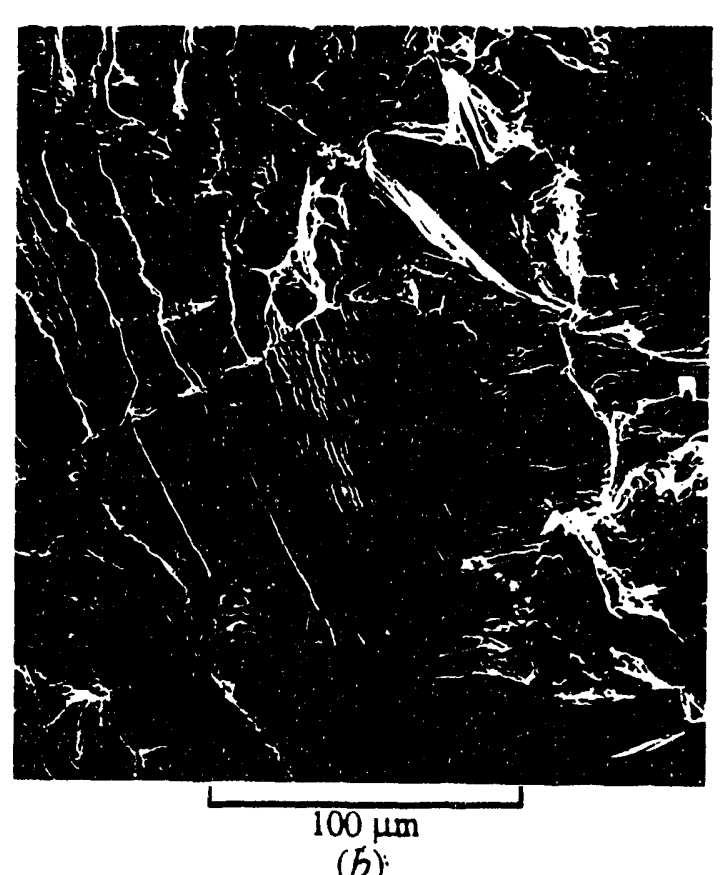

(b):

Fig. 3(a). Area of slow initial crack growth, and $(b)$ region of cyclic cleavage associated with rapid crack growth.

\section{DISCUSSION}

The low ductility commonly observed at RT is the result of moistureinduced environmental embrittlement. ${ }^{1}$ The recent improvements in RT ductility by thermomechanical processing are the result of minimizing the number of transverse grain boundaries, which slows hydrogen diffusion into the specimen interior. ${ }^{7,8}$ The decreased RT ductility observed in the plate materials is attributed to less plastic deformation of the microstructure during fabrication and, hence, the presence of more retained grain boundaries for rapid hydrogen diffusion into the material.

The other differences in the tensile properties are less notable with exception of the reduction in yield stress at $454^{\circ} \mathrm{C}$. These differences are attribut $2 \mathrm{~d}$ to varying levels of plastic deformation imparted to the microstructures during fabrication. With decreasing amounts of reduction in thickness, the yield strength is reduced. 


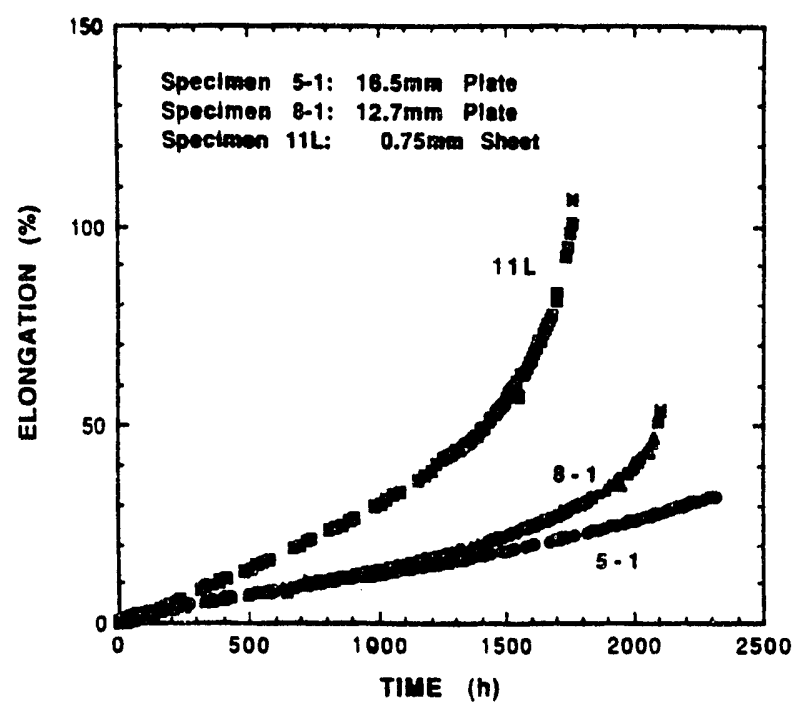

Fig. 4. Creep strain versus time for alloy FA-129 plate and sheet materials at $650^{\circ} \mathrm{C}$ and a stress of $34.5 \mathrm{MPa}$.

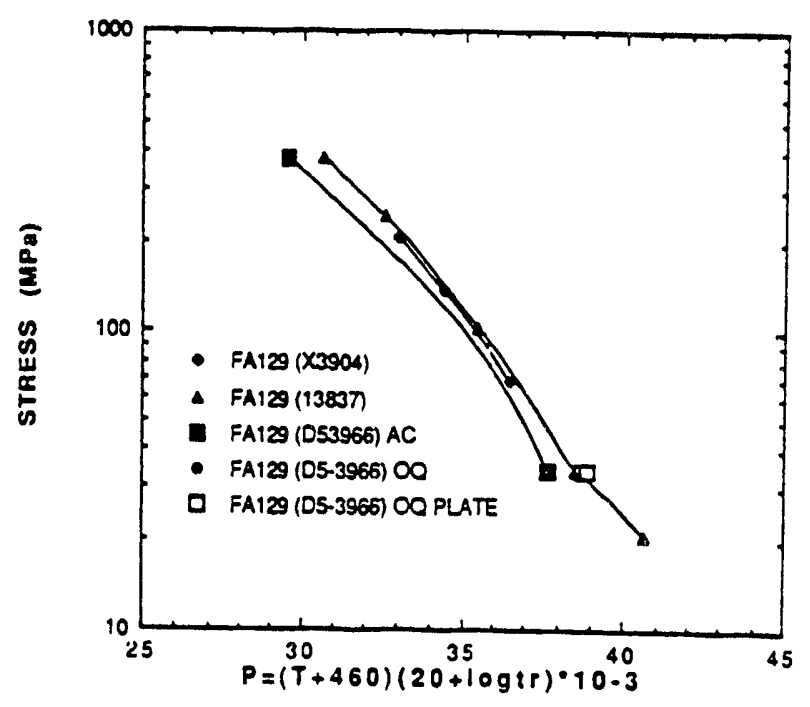

Fig. 5. Larson-Miller plot comparing creep rupture strengths of alloy FA-129 plate and sheet.

The results of the high-cycle fatigue tests are more difficult to interpret. At $600^{\circ} \mathrm{C}$, typical behavior was observed and this will be considered first. In view of the fact that both the yield strength is higher in the $16.5-\mathrm{mm}$ plate, it is not surprising that the fatigue resistance of this plate is better than that of the $12.7-\mathrm{mm}$ plate. Fatigue damage will only occur when cyclic plastic strains are present, ${ }^{9}$ and for a given material, larger plastic strains result in reduced fatigue lives. Higher yield strengths reduce the amount of plasticity, and hence, increase the resistance to fatigue.

There is little environmental attack at either 454 or $600^{\circ} \mathrm{C}$, available to contribute to crack initiation. Only a very thin oxide film, on the order of Angstroms thick ${ }^{10}$ and oxidized inclusions are visible on the specimen surfaces at $600^{\circ} \mathrm{C}$. Yet, the density of oxidized inclusions is identical in both plates and the presence of these for nucleation sites cannot be used to explain the differences in observed fatigue lives. Furthermore, no signs of ratcheting (resulting from creep deformation) were observed on the sides of specimens using either optical or SEM techniques. The lack of creep strains is attributed to the lack of time for thermal processes to occur. Hence, differing creep responses of the two plates also cannot be used to explain a difference in fatigue properties.

At both $\mathrm{RT}$ and $454^{\circ} \mathrm{C}$, no fatigue failures were observed at stresses below the measured $0.2 \%$ yield strength. This may suggest that the yield stress is sensitive to strain rate. At the much higher strain rates in the fatigue tests, the yield stress is undoubtably higher, though the magnitude of the difference is not known. The high resistance of 
FA-129 to cracking has been observed by Stoloff and co-workers ${ }^{11}$ while conducting fatigue crack growth tests on various allotropes of FA-129. They measured threshold values between 20 to $30 \mathrm{MPa} \vee \mathrm{m}$, which are very high considering how brittle this material is.

As the creep data show, the plate materials have a better resistance to creep deformation. It is well documented that, in general, a large-grain microstructure will resist creep better than an equivalent fine-grain microstructure. Hence, it is no surprise that the plates with their larger grain sizes have better creep resistance.

The Charpy-impact data, both the low-absorbed energies (3.5 to $37 \mathrm{~J}$ ) and the high ductile-to-brittle transition temperature $\left(308^{\circ} \mathrm{C}\right)$ are still limiting factors in the use of FA-129 for certain structural applications. Work needs to continue to make improvements in these two areas.

\section{CONCLUSIONS}

Data on the tensile properties of ductile $\mathrm{Fe}_{3} \mathrm{Al}$-based plates indicate a complex effect of plate thickness. Most notably, at RT in the thicker material, the ductility is cut in half and the ultimate strength is also reduced. At $600^{\circ} \mathrm{C}$, the ductility and both the yield and ultimate strengths in the plates are improved over those in the sheet material. The fatigue data at $600^{\circ} \mathrm{C}$ suggest that the fatigue strength at $10^{8}$ cycles is similar to that for 304 stainless steel. At temperatures of 25 and $454^{\circ} \mathrm{C}$, fatigue failure could not be induced at stress levels below the yield stress.

However, while the tensile, creep, and high-cycle fatigue properties of the plates suggest this alloy is suitable for engineering applications, the Charpy-impact data indicate that research is still necessary in the area of improved toughness.

\section{REFERENCES}

1. C. G. McKamey, J. H. DeVan, P. F. Tortorelli, and V. K. Sikka, J. Mater. Res., 6, 1779 (1991).

2. P. G. Sanders, V. K. Sikka, C. R. Howell, and R. H. Baldwin, Scripta Metall., 25, $2365\left(199^{\prime}\right)$.

3. C. G. McKamey, P. J. Maziasz, and J. W. Jones, submitted to J. Mater. Res. 
4. V. K. Sikka, C. G. McKamey, C. R. Howell, and R. H. Baldwin, Properties of Large Heats of $\mathrm{Fe}_{3} \mathrm{Al}$-Based Alloys, ORNL/TM-11796, Martin Marietta Energy Systems, Inc., Oak Ridge National Laboratory, March 1991.

5. R. W. Swindeman, Handbook of Applied Thermal Design, McGraw-Hill, New York, 1989.

6. J. R. Knibloe, R. N. Wright, V. K. Sikka, R. H. Baldwin, and C. R. Howell, "Elevated Temperature Behavior of $\mathrm{Fe}_{3} \mathrm{Al}$ with Chromium Additions," Materials Science and Engineering A153 (1992) 382-386.

7. V. K. Sikka et al., Fabrication and Mechanical Properties of FezAl-Based Aluminides, ORNL/TM-11465, Martin Marietta Energy Systems, Inc., Oak Ridge National Laboratory, March 1990.

8. C. G. McKamey and P. J. Maziasz, "Development of Iron Aluminides," pp. 175-185 in Proc. Fifth Annual Conference on Fossil Energy Materials, ORNL/FMP-91/1, Martin Marietta Energy Systems, Inc., Oak Ridge National Laboratory, 1991.

9. R. W. Hertzberg, Deformation and Fracture Mechanics of Engineering Materials, John Wiley \& Sons, New York, 1976.

10. Personal conversation with J. H. DeVan, September 1992.

11. A. Castagna and N. S. Stoloff, "Investigation of Moisture-Induced Embrittlement of Iron Aluminides," pp. 305-314 in Proceedings of the Sixth Annual Conference on Fossil Energy Materials, ORNL/FMP-92/1, Oak Ridge National Laboratory, 1992. 


\title{
ORNL-2(G) - MICROALLOYED IRON ALUMINIDES
}

\author{
C. G. McKamey \\ Oak Ridge National Laboratory \\ P. O. Box 2008 \\ Oak Ridge, TN 37831-6114
}

\section{INTRODUCTION}

Development efforts at this laboratory have indicated that by controlling alloy chemistry and thermomechanical processing, environmental embrittlement of $\mathrm{Fe}_{3} \mathrm{Al}$-based alloys can be minimized. ${ }^{1-3}$ Ambient temperature tensile ductilities of $10-20 \%$ and tensile yield strengths as high as $500 \mathrm{MPa}$ can be achieved in alloy FA-129 (Fe-28Al-5Cr-0.5Nb-0.2C, at.\%). ${ }^{2-3}$ However, the tensile strength of $\mathrm{Fe}_{3} \mathrm{Al}$-based alloys decreases dramatically above $600^{\circ} \mathrm{C}$ and creep-rupture strengths of the FA-129 type iron aluminides at temperatures of $550^{\circ} \mathrm{C}$ and above remain unsatisfactory. ${ }^{4}$ Additions of elements such as $\mathrm{Ti}, \mathrm{Mo}, \mathrm{Zr}, \mathrm{Hf}$, and $\mathrm{Nb}$ can improve high temperature strength, but at the expense of room temperature ductility. ${ }^{1,5-7}$

Welding is another major area of concern in the development of iron-aluminide alloys for structural applications. The welding processes used must be capable of producing high quality weldments under field and shop conditions which are free of defects and have mechanical properties comparable to the base metal. Initial work on the weldability of iron aluminides has identified a propensity for cold-cracking and a possible degradation of the mechanical properties of the weldment in comparison to the base metal. ${ }^{8.9}$ Weldability of alloy FA-129 has been greatly improved by optimizing the welding process and parameters (e.g., using pre- and post-weld heat treatments). ${ }^{9}$ Studies have also shown that the weldability of iron aluminides is very sensitive to minor changes in composition of the base metal. ${ }^{9,10}$

The objective of this task is to use macro- and microalloying techniques on alloy FA129 to produce an $\mathrm{Fe}_{3} \mathrm{Al}$-based alloy with improved creep-rupture resistance and tensile strength to temperatures as high as $700^{\circ} \mathrm{C}$. At the same time, the alloy should have adequate room temperature tensile ductility ( $>10 \%$ ), good weldability and fabricability, and maintain the excellent corrosion resistance identified with iron aluminides. The scope of this task will include studying alloying effects on creep-rupture strength, high-temperature tensile strength, and weldability, and identifying positive and negative synergisms, which appear to play very 
important roles in all properties of this alloy system. This work is being coordinated with related efforts sponsored by the AIC Materials Program.

\section{DISCUSSION OF CURRENT ACTIVITIES}

During the last reporting period, composition FA-170 (Fe-28Al-5Cr-0.5Nb-0.4Mo$0.025 \mathrm{Zr}-0.05 \mathrm{C}$, at.\%) was chosen for further study because the preliminary data had indicated a potential for a good combination of properties. ${ }^{11}$ During that same period, it became

evident that the control of boron and carbon levels was necessary to maximize weldability. ${ }^{10}$ Also, previous studies had suggested that too much carbon can greatly degrade the creeprupture properties, ${ }^{4}$ and that large niobium-based precipitates in FA-129 were providing initiation sites for premature fracture during Charpy impact tests. ${ }^{12}$

During tiiis reporting period, five new alloys were prepared with nominal compositions based on FA-129 and FA-170. The purpose of making these alloys was to determine the level of boron, carbon, and niobium necessary to maximize ductility, strength, and weldability. The compositions chosen are listed in Table I. All alloys were prepared as 500-g ingots by arcmelting and drop-casting into chilled copper molds. Fabrication to 0.76-mm-thick sheet was accomplished by first forging $50 \%$ in two steps at $1000^{\circ} \mathrm{C}$ (to $15 \mathrm{~mm}$ thickness), then hot rolling at $800^{\circ} \mathrm{C}$ to $2.5 \mathrm{~mm}$ thickness and warm rolling at $650^{\circ} \mathrm{C}$ to the final thickness. After a stress relief heat treatment of $1 \mathrm{~h}$ at $700^{\circ} \mathrm{C}$, flat tensile specimens $(0.76 \times 3.18 \times 12.7 \mathrm{~mm})$ were mechanically punched from the rolled sheet and were further annealed for $1 \mathrm{~h}$ at $750^{\circ} \mathrm{C}$. Tensile tests were conducted at room temperature and $600^{\circ} \mathrm{C}$ in air at a strain rate of $3.3 \times 10^{-3} \mathrm{~s}^{-1}$. Creep-rupture tests were conducted in air at $593^{\circ} \mathrm{C}$ and $207 \mathrm{MPa}$.

Table I shows the compositions produced in this reporting period, designated as FA174 through -178. All contain Fe-28Al-5Cr-0.4Mo-0.025Zr but with various combinations of $\mathrm{Nb}, \mathrm{C}$, and $\mathrm{B}$. In order to guarantee, for comparison purposes, that the starting microstructures were similar, part of ingot FA-170R was also rolled to sheet along with FA174 to -178 . Tests of alloys FA-170R, -174 , and -175 show the effect of reducing the niobium content, while alloys FA-176, -177 , and -178 show the combined effect of adding boron and reducing niobium. In order to promote creep resistance, the carbon level was kept at 0.05 at.\%, which is much lower than the $0.2 \%$ in FA-129. Two tests of each alloy were conducted; the data from each test are listed in the tables that follow. Except for the creep tests of FA174 , the data for each alloy tested in both tension and creep-rupture were very reproducible, indicating good quality sheet and punched specimens without fracture-initiating edge flaws. 
Table I. Compositions and tensile properties of FA-170-based iron aluminides.

\begin{tabular}{|c|c|c|c|c|c|c|c|}
\hline \multirow{2}{*}{$\begin{array}{l}\text { Alloy } \\
\text { FA- }\end{array}$} & \multirow{2}{*}{$\begin{array}{c}\text { Nominal } \\
\text { Composition (at.\%) }\end{array}$} & \multicolumn{3}{|c|}{$\mathrm{RT}^{\mathrm{b}}$} & \multicolumn{3}{|c|}{$600^{\circ} \mathrm{C}^{\mathrm{b}}$} \\
\hline & & $\begin{array}{c}\text { YS } \\
(\mathrm{MPa})\end{array}$ & $\begin{array}{l}\text { UTS } \\
(\mathrm{MPa})\end{array}$ & $\begin{array}{l}\text { Elong. } \\
(\%)\end{array}$ & $\begin{array}{c}\text { YS } \\
(\mathrm{MPa})\end{array}$ & $\begin{array}{l}\text { UTS } \\
(\mathrm{MPa})\end{array}$ & $\begin{array}{l}\text { Elong. } \\
(\%)\end{array}$ \\
\hline FA-129 & $\begin{array}{c}\text { Fe-28Al-5Cr-0.5Nb-0.2C } \\
\begin{array}{c}\text { Fe-28Al-5Cr-0.4Mo- } \\
0.025 \mathrm{Zr}\end{array}\end{array}$ & 385 & 930 & 16 & 415 & 515 & 38 \\
\hline 170R & $+0.5 \mathrm{Nb}-0.05 \mathrm{C}$ & $\begin{array}{l}423 \\
419\end{array}$ & $\begin{array}{l}707 \\
738\end{array}$ & $\begin{array}{l}6.2 \\
7.2\end{array}$ & $\begin{array}{l}450 \\
461\end{array}$ & $\begin{array}{l}472 \\
501\end{array}$ & $\begin{array}{l}48.8 \\
52.7\end{array}$ \\
\hline 174 & $+0.2 \mathrm{Nb}-0.05 \mathrm{C}$ & $\begin{array}{l}334 \\
339\end{array}$ & $\begin{array}{l}583 \\
573\end{array}$ & $\begin{array}{l}45 \\
4.2\end{array}$ & $\begin{array}{l}387 \\
393\end{array}$ & $\begin{array}{l}427 \\
434\end{array}$ & $\begin{array}{l}43.5 \\
47.9\end{array}$ \\
\hline 175 & $+0.05 \mathrm{C}$ & $\begin{array}{l}356 \\
353\end{array}$ & $\begin{array}{l}663 \\
681\end{array}$ & $\begin{array}{l}7.2 \\
8.1\end{array}$ & $\begin{array}{l}394 \\
372\end{array}$ & $\begin{array}{l}437 \\
407\end{array}$ & $\begin{array}{l}44.0 \\
54.6\end{array}$ \\
\hline 176 & $+0.5 \mathrm{Nr}-0.05 \mathrm{C}-0.005 \mathrm{~B}$ & $\begin{array}{l}531 \\
545\end{array}$ & $\begin{array}{l}793 \\
815\end{array}$ & $\begin{array}{l}7.4 \\
7.8\end{array}$ & $\begin{array}{l}490 \\
499\end{array}$ & $\begin{array}{l}500 \\
508\end{array}$ & $\begin{array}{l}36.1 \\
43.1\end{array}$ \\
\hline 177 & $+0.2 \mathrm{Nb}-0.05 \mathrm{C}-0.005 \mathrm{~B}$ & $\begin{array}{l}363 \\
365\end{array}$ & $\begin{array}{l}630 \\
635\end{array}$ & $\begin{array}{l}6.3 \\
6.4\end{array}$ & $\begin{array}{l}396 \\
410\end{array}$ & $\begin{array}{l}430 \\
445\end{array}$ & $\begin{array}{l}40.9 \\
52.1\end{array}$ \\
\hline 178 & $+0.05 \mathrm{C}-0.005 \mathrm{~B}$ & $\begin{array}{l}360 \\
355\end{array}$ & $\begin{array}{l}692 \\
681\end{array}$ & $\begin{array}{l}7.9 \\
7.7\end{array}$ & $\begin{array}{l}387 \\
383\end{array}$ & $\begin{array}{l}421 \\
414\end{array}$ & $\begin{array}{l}52.4 \\
48.0\end{array}$ \\
\hline
\end{tabular}

aAll alloys were heat treated $1 \mathrm{~h}$ at $700^{\circ} \mathrm{C}$ before punching specimens, then specimen were annealed for $1 \mathrm{~h}$ at $750^{\circ} \mathrm{C}$.

${ }^{b}$ Tested in air at a strain rate of $3.3 \times 10^{-3} / \mathrm{s}$.

Table I also shows the tensile properties at room temperature and at $600^{\circ} \mathrm{C}$. Average data for alloy FA-129 has been included for comparison purposes. Reducing the amount of niobium below $0.5 \%$ tended to reduce significantly the tensile yield strength at both room temperature and $600^{\circ} \mathrm{C}$. Adding boron to the composition containing $0.5 \% \mathrm{Nb}$ resulted in an increase in yield strength at both room temperature and $600^{\circ} \mathrm{C}$. Room temperature tensile ductilities of 6-8\% were noted for all the alloy compositions except for FA-174 containing $0.2 \% \mathrm{Nb}$ and no boron. In general the addition of $0.005 \% \mathrm{~B}$ increased room temperature ductilities slightly. As expected, ductilities at $600^{\circ} \mathrm{C}$ were good.

The creep-rupture tests at $593^{\circ} \mathrm{C}$ and $207 \mathrm{MPa}$ (Table II) indicate that reducing niobium below about 0.5 at.\% greatly reduces the creep life and increases the minimum creep 
Table II. Creep-rupture properties of FA-170-based iron aluminides.

\begin{tabular}{|c|c|c|c|c|}
\hline \multirow[b]{2}{*}{ Alloy $^{2}$} & \multicolumn{4}{|c|}{ Creep at $593^{\circ} \mathrm{C}, 207 \mathrm{MPa}$} \\
\hline & $\begin{array}{c}\text { Test } \\
\#\end{array}$ & $\begin{array}{l}\text { Life } \\
\text { (h) }\end{array}$ & $\begin{array}{c}\text { Elong. } \\
(\%)\end{array}$ & $\begin{array}{l}\text { MCR } \\
(\% / \mathrm{h})\end{array}$ \\
\hline FA-129 & & $15-25$ & $65-80$ & $1-3$ \\
\hline \multirow[t]{2}{*}{ FA-170R } & 330 & 37.8 & 72.5 & 0.7 \\
\hline & 331 & 29.0 & 64.3 & \\
\hline \multirow{2}{*}{ FA-174 } & 320 & 35.5 & 76.2 & 0.8 \\
\hline & 327 & 9.4 & 67.8 & 2.9 \\
\hline \multirow[t]{2}{*}{ FA-175 } & 321 & 4.4 & 68.7 & 6.6 \\
\hline & 326 & 3.6 & 68.6 & 8.0 \\
\hline \multirow[t]{2}{*}{ FA-176 } & 322 & 49.9 & 67.2 & 0.5 \\
\hline & 325 & 50.8 & 56.6 & 0.4 \\
\hline \multirow[t]{2}{*}{ FA-177 } & 323 & 13.0 & 68.0 & 2.2 \\
\hline & 328 & 14.8 & 68.5 & 1.8 \\
\hline \multirow[t]{2}{*}{ FA-178 } & 324 & 5.0 & 70.8 & 6.0 \\
\hline & 329 & 4.6 & 66.8 & 6.5 \\
\hline
\end{tabular}

rate (MCR). Also, at the $0.5 \%$ level of niobium, adding $0.005 \% \quad B$ increased the creeprupture life slightly, while boron added to alioys with $0.2 \%$ or no niobium gave no added benefit. The alloy with the best creep strength was the same one which had the best tensile strength, FA176.

We have begun to investigate the effect of heat treatment on the creep rupture life. Table III shows the data to date on single tests. The results indicate that, at least with alloy

composition FA-176, some improvement in creep life can be obtained by optimizing the microstructure. In general, the results of room temperature and $600^{\circ} \mathrm{C}$ tensile tests, as well as the $593^{\circ} \mathrm{C}$ creep results, indicate that alloy FA-176 has improved strength properties compared to alloys FA-170 and FA-129. We are presently beginning metallographic characterization of the microstructures with regards to grain size and precipitate size and composition. Also, weldability tests, including Sigmajig tests to determine sensitivity to fusion zone cracking, ${ }^{13}$ will be performed in the next reporting period.

\section{REFERENCES}

1. C. G. McKamey, J. H. DeVan, P. F. Tortorelli, and V. K. Sikka, J. Mater. Res. 6(8), $1779(1991)$. 
Table III. Effect of heat treatment on creep-rupture properties of FA-170-based alloys.

\begin{tabular}{|c|c|c|c|c|c|}
\hline \multirow{3}{*}{$\begin{array}{c}\text { Alloy } \\
\text { FA- }\end{array}$} & Heat treatment & \multicolumn{4}{|c|}{ Creep at $593^{\circ} \mathrm{C}, 207 \mathrm{MPa}$} \\
\cline { 2 - 6 } & $\begin{array}{c}\text { Test } \\
\#\end{array}$ & $\begin{array}{c}\text { Life } \\
(\mathrm{h})\end{array}$ & $\begin{array}{c}\text { Elong. } \\
(\%)\end{array}$ & $\begin{array}{c}\mathrm{MCR} \\
(\% / \mathrm{h})\end{array}$ \\
\hline \multirow{2}{*}{174} & $1 \mathrm{~h} / 750^{\circ} \mathrm{C}$ & 320 & 35.5 & 76.2 & 0.8 \\
& $1 \mathrm{~h} / 750^{\circ} \mathrm{C}+70 \mathrm{~min} / 950^{\circ} \mathrm{C}$ & 333 & 11.8 & 53.2 & 1.8 \\
& $24 \mathrm{~h} / 900^{\circ} \mathrm{C}$ & 336 & 8.6 & 66.1 & 3.6 \\
& & & & & \\
176 & $1 \mathrm{~h} / 750^{\circ} \mathrm{C}$ & 325 & 50.8 & 56.6 & 0.4 \\
& $1 \mathrm{~h} / 750^{\circ} \mathrm{C}+70 \mathrm{~min} / 950^{\circ} \mathrm{C}$ & 332 & 107.6 & 49.1 & 0.1 \\
& $24 \mathrm{~h} / 900^{\circ} \mathrm{C}$ & 334 & 59.9 & 63.4 & 0.3 \\
\hline \multirow{2}{*}{ All alloys were given $1 \mathrm{~h} / 700^{\circ} \mathrm{C}$ before punching tensile specimens. } \\
\hline
\end{tabular}

2. V. K. Sikka, C. G. McKamky, C. R. Howell, and R. H. Baldwin, Fabrication and Mechanical Properties of $\mathrm{Fe}_{3}$ Al-Based Aluminides, ORNL/TM-11465, (Oak Ridge National Laboratory, Oak Ridge, TN, March 1990).

3. V. K. Sikka, C. G. McKamey, C. R. Howell, and R. H. Baldwin, Properties of Large Heats of $\mathrm{Fe}_{3}$ Al-Based Alloys, ORNL/TM-11796, (Oak Ridge National Laboratory, Oak Ridge, TN, March 1991).

4. C. G. McKamey and P. J. Maziasz, pp. 175-85 in Proceedings of the Fifth Annual Conference on Fossil Energy Materials, ORNL/FMP-91/1, (Oak Ridge National Laboratory, Oak Ridge, TN, September 1991).

5. R. G. Bordeau, Development of Iron Aluminides, AFWAL-TR-87-4009, (Air Force Wright Aeronautical Laboratories, Wright-Patterson Air Force Base, OH, May 1987).

6. G. Culbertson and C. S. Kortovich, Development of Iron Aluminides, AFWAL-TR85-4155, (Air Force Wright Aeronautical Laboratories, Wright-Patterson Air Force Base, OH, March 1986).

7. C. G. McKamey, P. J. Maziasz, and J. W. Jones, J. Mater. Res. 7(8), 2089 (1992).

8. S. A. David, J. A. Horton, C. G. McKamey, T. Zacharia, and R. W. Reed, Weld. J. 68(9), 372s (1989).

9. T. Zacharia and S. A. David, pp. 229-37 in Proceedings of the Fifth Annual Conference on Fossil Energy Materials, ORNL/FMP-91/1 (Oak Ridge National Laboratory, Oak Ridge, TN, September 1991).

10. T. Zacharia, to be published in Proceedings of the Sixth Annual Conference on Fossil Energy Materials, ORNL/FMP-92/1 (Oak Ridge National Laboratory, Oak Ridge, TN).

11. C. G. McKamey, T. Zacharia, and P. J. Maziasz, to be published in Proceedings of the Sixth Annual Conference on Fossil Energy Materials, ORNL/FMP-92/1 (Oak Ridge National Laboratory, Oak Ridge, TN).

12. D. J. Alexander, to be published in Proceedings of the Sixth Annual Conference on Fossil Energy Materials, ORNL/FMP-92/1 (Oak Ridge National Laboratory, Oak Ridge, TN).

13. G. M. Goodwin, Weld. J. 77(2), 33s (1987). 
ORNL-2(H)-LOW-ALUMINUM CONTENT IRON-ALUMINUM ALLOYS

\author{
V. K. Sikka \\ Metals and Ceramics Division \\ Oak Ridge National Laboratory \\ P.O. Box 2008 \\ Oak Ridge, Tenmessee 37831
}

\title{
INTRODUCTION
}

The objective of this task is to develop a conventionally fabricable low-cost and lower density iron-aluminum-based alloy with a good combination of strength, ductility, weldability, and corrosion resistance for use as components in advanced fossil energy conversion systems. Initial emphasis will be on the development of iron-aluminide alloys for heat-recovery applications in coal gasification systems. Specific progress on this project during the last six months is described below:

The low ductility of the $\mathrm{Fe}_{3} \mathrm{Al}$-based illoys has been improved through composition modification and thermomechanical processing to produce a microstructure resistant to environmental embrittlement. The $\mathrm{Fe}_{3} \mathrm{Al}$-based compositions identified can be used for some of the coal gasification applications such as porous-sintered metal gas cleanup filters. However, for many applications, additional improvements in room-temperature (RT) ductility are required for both the product form production and component manufacturing.

\section{RESULTS AND DISCUSSION}

In an eifort to further improve ductility, binary compositions with four different aluminum levels were investigated. Two of the four compositions were in the disordered, solid-solution alpha range; one in the single-phase $\mathrm{D}_{3}$ range; and one in the alpha $+\mathrm{DO}_{3}$ range. The exact location of these compositions is shown in the iron-aluminum phase diagram (see Fig. 1). The three selected binary iron-aluminum alloys with aluminum levels of $8.5,12$, and $15.9 \mathrm{wt} \%$ were processed identically to 30 -mil-thick sheet and tensile tested. The tensile tests were conducted on specimens after air cooling and oil quenching from the heat-treatment temperature. The oil- and air-quenched specimens were tested in air, and the air-cooled specimens were also tested in vacuum. The RT elongation 


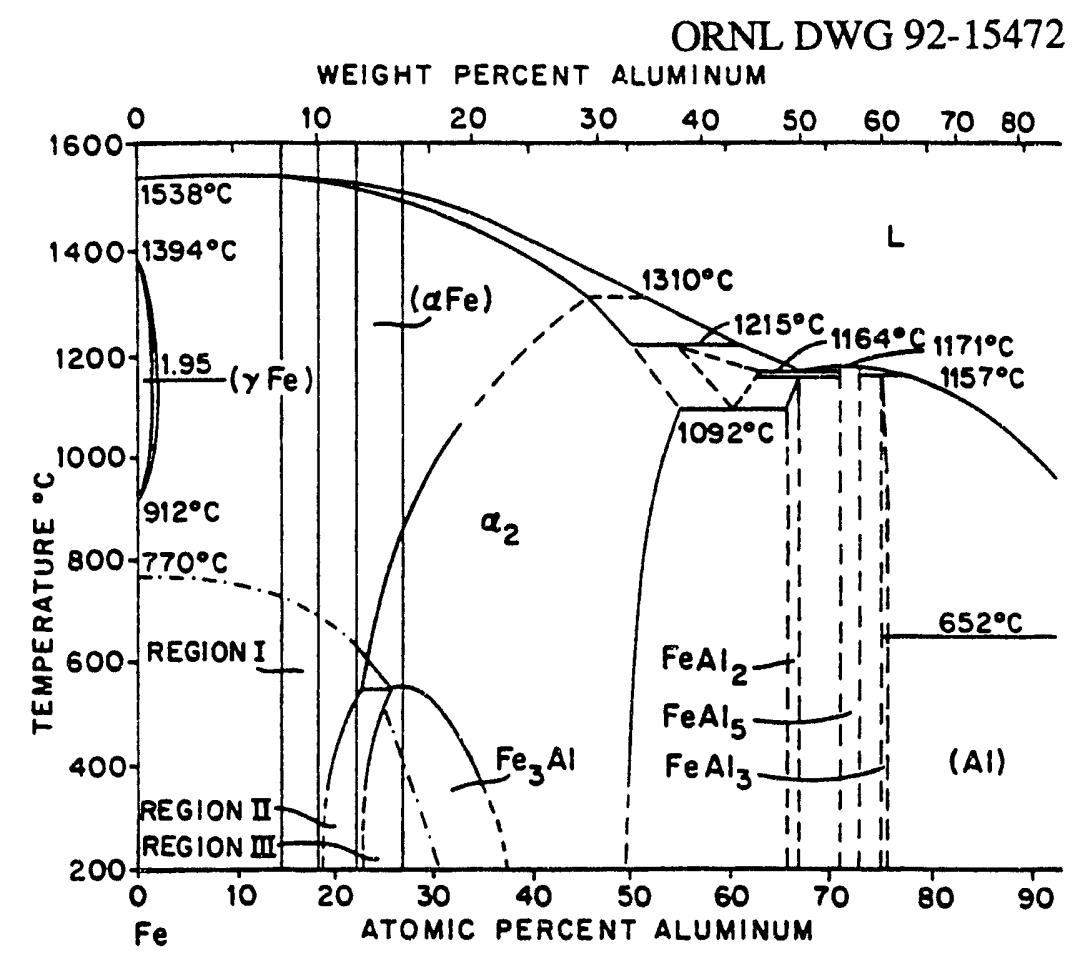

Fig. 1. Iron-aluminum phase diagram showing the three regions from which the experimental alloys were selected.

ORNL DWG 92-15473

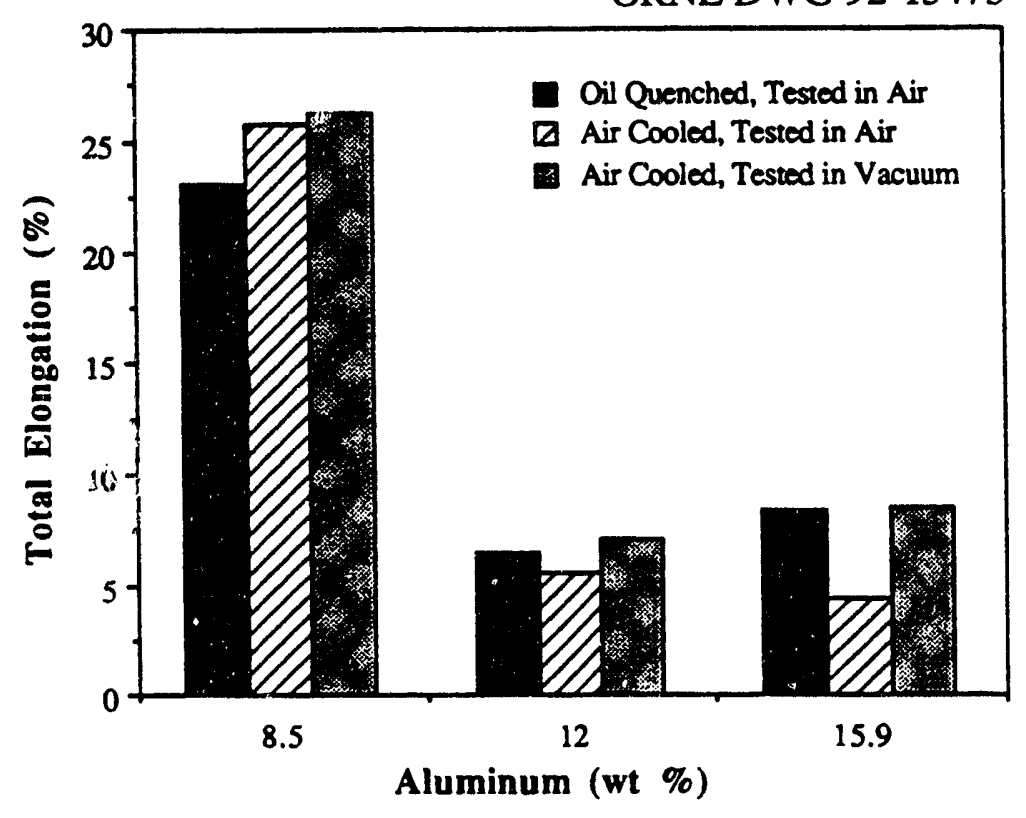

Fig. 2. Effect of aluminum content, quenching medium, and testing environments on room-temperature ductility of binary iron-aluminum alloys. 
from these tests is compared in Fig. 2. For the Fe-15.9 wt \% Al alloy, tensile ductility was higher for specimens tested in vacuum or tested in air after quenching in oil. Similar results were observed for the $\mathrm{Fe}-2 \mathrm{wt} \% \mathrm{Al}$ alloy specimens; however, the difference in elongation between the samples was not as large as that observed for the Fe$15.9 \mathrm{wt} \% \mathrm{Al}$ alloy samples. Specimens from the Fe-8.5 wt \% $\mathrm{Al}$ alloy showed elongation values of $25 \%$, independent of the test environment. The oil-quenched samples showed a value of $23 \%$. The lower value of elongation for specimens tested in air as compared to vacuum is related to the environmental effect. Also, moisture in the air-tested specimens is the cause for the lower ductility. It causes the reduced ductility through the generation of hydrogen and its diffusion into the test bar along the grain boundaries. A vacuum environment, which eliminates the moisture, prevents the hydrogen generation and, thus, the reduced ductility. Fince it is the aluminum content of the alloy that causes the hydrogen generation, its reduced amount in the alloy is expected to produce lesser elongation reduction. This is evident from the results shown in Fig. 2. This figure also shows that the alloy containing Fe- $8.5 \mathrm{wt} \% \mathrm{Al}$, which showed the same elongation for tests in air and vacuum, is essentially free of any environmental effect. The higher ductility values for oil-quenched specimens tested in air are explained below.

The oil-quenching process leaves a thin oil film on the specimen surface. This film is not removed even after wiping the surface with a cloth. The surface oil prevents the aluminum in the alloy from reacting with moisture in the air; thus, hydrogen is not generated on the specimen surface. For the specimens cooled in air from the heattreatment temperature, hydrogen can be generated and diffused into the specimen interior along the grain boundaries. The Fe-8.5 wt \% Al alloy shows high ductility that is not degraded by the hydrogen-related embrittlement.

The $\mathrm{Fe}-8.5 \mathrm{wt} \% \mathrm{Al}$ alloy was used as a basis for designing an engineering alloy for fossil energy applications. The alloying additions were made to gain specific properties. These include: chromium for improving the aqueous corrosion resistance, molybdenum for improving the pitting resistance, zirconium and carbon for obtaining the grain refinement and precipitate strengthening, and a small addition of yttrium for improving the high-temperature oxidation resistance. Even after alloying additions, the room-temperature ductility of Fe-8.5 wt \% Al-based alloys still exceeded 20\%. This is demonstrated in Fig. 3. For an FAP alloy containing Fe-8.5\% Al, 5.5\% Cr, $2 \% \mathrm{Mo}$, $0.2 \% \mathrm{Zr}$, and $0.03 \% \mathrm{C}$ (by weight), the $\mathrm{RT}$ elongation values were $28 \%$ and remained over $20 \%$ up to $500^{\circ} \mathrm{C}$ and increased sharply at the higher test temperature. The reduction of area value was $43 \%$ at RT and followed the temperature dependence similar to total 


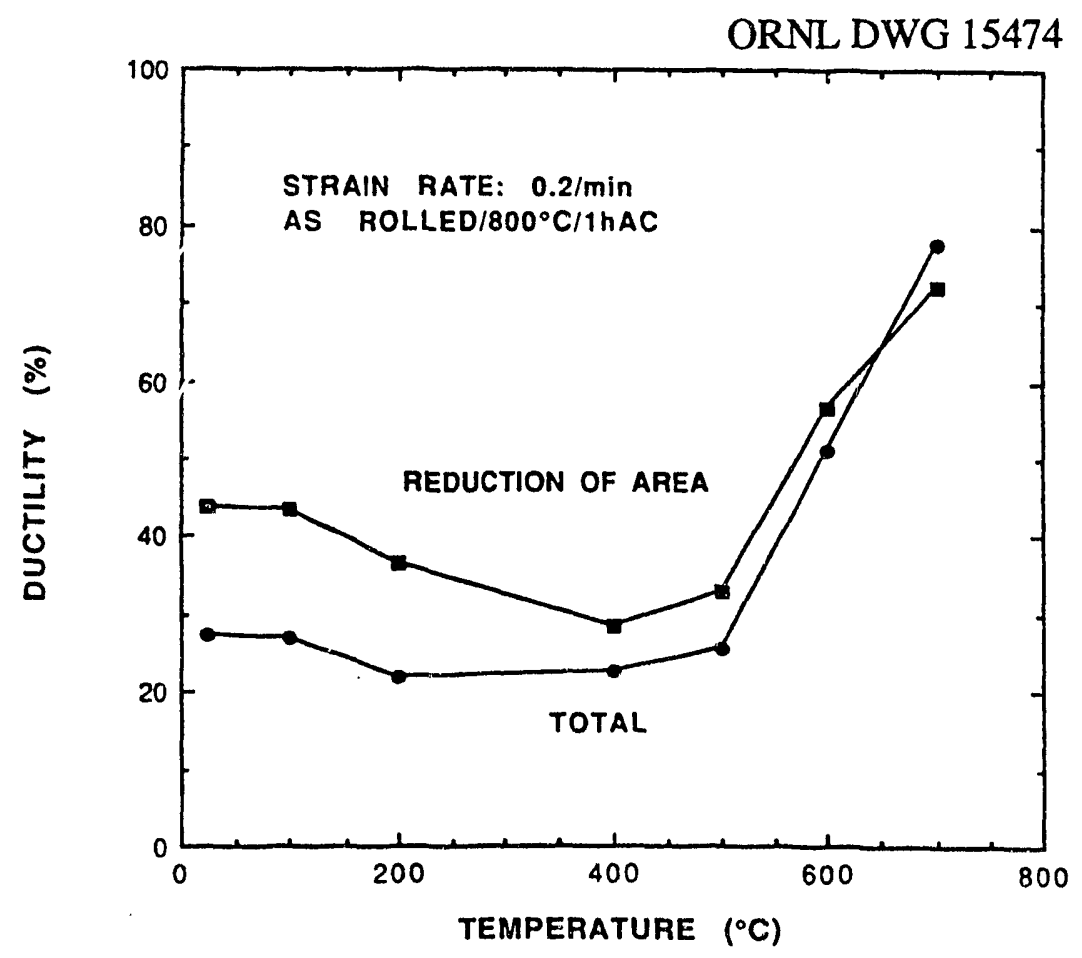

Fig. 3. Total elongation and reduction of area versus test temperature plot for Fe-8.5 wt \% Al-based FAP alloy.

elongation. The $0.2 \%$ yield and ultimate tensile strength data for this alloy are shown as a function of test temperature in Fig. 4.

The newly developed composition has wrought ductility that exceeds $20 \%$ at room temperature. However, the cast ductility of the same composition is nearly $1 \%$. Further composition modifications are under way to improve the cast ductility.

\section{TECHNOLOGY TRANSFER}

Data on the Fe-16 at. \% Al-based alloys were shared with the current licensees for $\mathrm{Fe}_{3} \mathrm{Al}$-based alloys: Ametek Specialty Metal Products Division (Eighty Four, Pennsylvania), Hoskins Manufacturing Company (Hamburg, Michigan), and Harrison Alloys (Harrison, New Jersey). Hoskins and Harrison are already attempting to gain experience with the new alloys. In fact, Harrison made the first $200-1 \mathrm{~b}$ heat at their cost. Cast Masters, a casting company, has also made a $300-\mathrm{lb}$ heat of the alloy at their expense and cast into two different shapes. Their initial observation is that the alloy is meltable and castable in air into reasonably complex shapes. However, the cast ductility at RT needs to be increased to levels of approximately $5 \%$. Work is under way in this direction. 


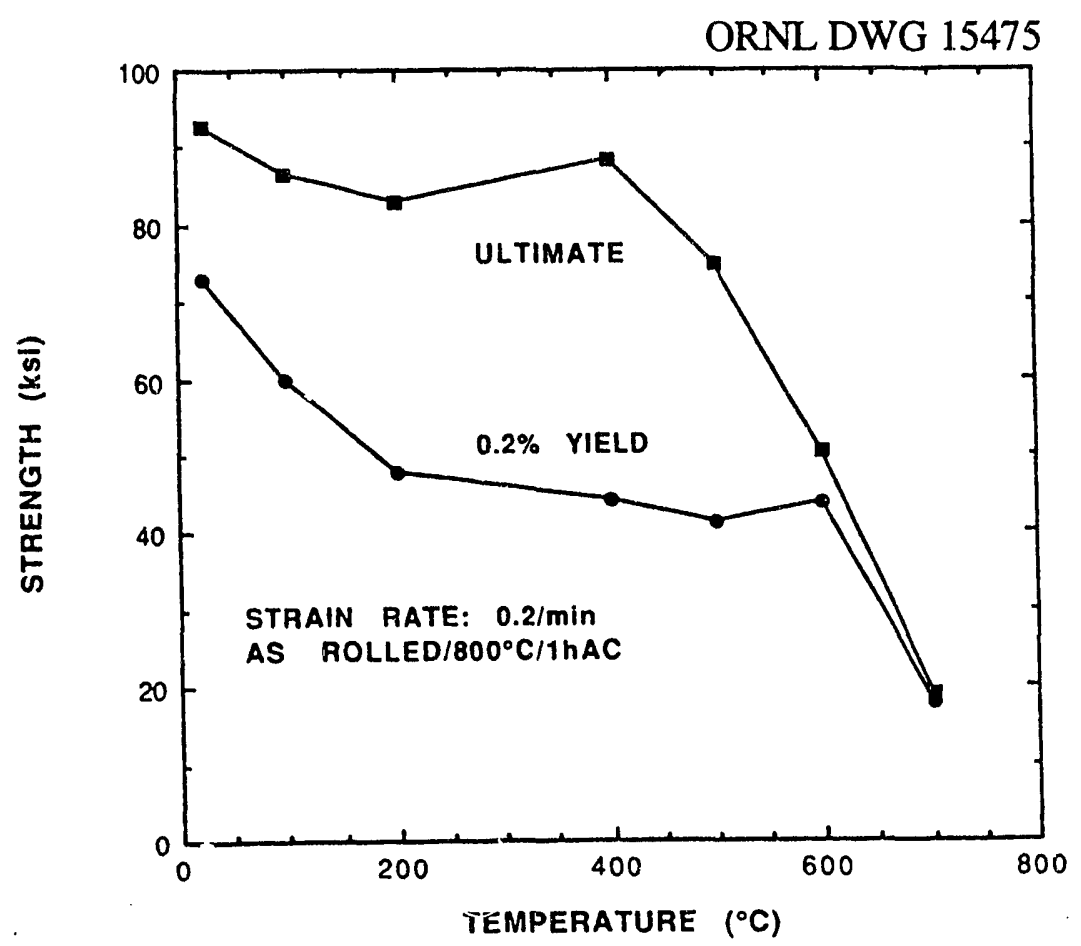

Fig. 4. Yield and ultimate tensile strength versus test temperatures Fe-8.5 wt \% Al-based FAP alloy.

\section{Publication}

S. Vyas, S. Viswanathan, and V. K. Sikka, "Effect of Aluminum Environmental Embrittlement in Binary Iron-Aluminum Alloys," Scr. Metall. 27, 185-90 (1992).

\section{Presentation}

Vinod K. Sikka, "Casting, Processing, and Mechanical Properties of Nickel- and IronAluminide Alloys," Technology Transfer Conference and Workshop on Nickel and Iron Aluminides, Oak Ridge, Tennessee, August 4-5, 1992.

\section{Patent}

V. K. Sikka and C. G. McKamey, "Iron-Aluminum Alloys Having High RoomTemperature Ductility and Method for Making Same," patent disclosure ESID-1132X, June 26, 1992, Washington, D.C.

\section{Licensee}

Cast Masters (Bowling Green, Ohio): Terms of a license for use of iron-aluminide alloys as cast parts were negotiated. This license will be based on patent disclosure ESID-1132X. 


\title{
ORNL-3(A)-CORROSION PROTECTION OF ULTRAHIGH TEMPERATURE INTERMETALLIC ALLOYS
}

\author{
P. F. Tortorelli and J. H. DeVan \\ Oak Ridge National Laboratory \\ Oak Ridge, Tennessee 37831-6156
}

\section{INTRODUCTION}

At present, any advances in operating temperatures and, hence, thermal efficiencies, of heat engines and energy systems are limited by strength or corrosion considerations. There is thus a pressing need to develop new materials (particularly metallic ones) that can be used in hostile environments at elevated temperatures. Laves-phase alloys based on $\mathrm{Cr}_{2} \mathrm{Nb}$ may offer a possible solution to the materials problems associated with such high temperature deployment. In compression, $\mathrm{Cr}_{-} \mathrm{Cr}_{2} \mathrm{Nb}$ alloys have been shown to be substantially stronger than conventional nickel-based superalloys at high-temperature while exhibiting some ductility. ${ }^{1}$ However, much more development is needed to overcome poor ambient temperature ductility and low fracture toughness. In addition, there is some concern regarding the corrosion resistance of $\mathrm{Cr}-\mathrm{Nb}$ intermetallic alloys in the temperature range of interest due to possible spallation of the multilayer scales that form on such materials, the rapid formation of chromium sulfides, and volatilization of chromia above about $1100^{\circ} \mathrm{C}$.

The effort to develop ultrahigh temperature $\mathrm{Cr}$-base intermetallic alloys that will not seriously degrade in high temperature corrosive environments consists of two interrelated parts: (1) improvements in the protective ability of the naturally formed scales and (2) the evaluation of a coating, or set of coatings, that would offer better corrosion resistance than the native oxide product. It is anticipated that while both scale improvements and coatings may be effective at the initial target temperatures $\left(1000-1100^{\circ} \mathrm{C}\right)$, coatings or other surface treatments would have to be used at higher temperatures. The scale subtask involves close collaboration with Task ORNL-2(D) in the exanination of the effects of alloying elements and microstructure on basic oxidation resistance at elevated temperatures. For the various developmental compositions, evaluation of scale protectiveness in terms of oxidation kinetics, composition, mechanical properties and spallation tendencies are conducted. The second part of the task involves the evaluation of possible coatings for use with the $\mathrm{Cr}-\mathrm{Nb}$ alloys. This effort involves interactions with Ohio State University (Task OSU-3[A]), 
which will prepare coated specimens using halide-activated pack cementation and conduct some characterization of the as-coated materials. The work on the high temperature corrosion of the coated alloys will be closely linked to the other subtask, that is, maximizing the corrosion resistance of the alloys within the limits of other properties, because any improvement in this regard increases the margin of protection provided by the coating.

\title{
DISCUSSION OF CURRENT ACTIVITIES
}

\author{
High Temperature Oxidation of $\mathrm{Cr}-\mathrm{Cr}_{2} \mathrm{Nb}$ Alloys
}

It was previously reported that the oxidation of $\mathrm{Cr}-6$ and -12 at. $\% \mathrm{Nb}$ alloys in air resulted in the formation of multilayer scales with an outer layer of chromia and inner products containing niobium. ${ }^{2} \mathrm{The} \mathrm{Cr}-12$ at.\% $\mathrm{Nb}$ binary alloy had significantly better oxidation resistance, in terms of overall weight gain and resistance to spallation, than one containing 6 at.\%. This was thought to be associated with its decreased volume fraction of the $\mathrm{Cr}$-rich phase, which appeared to preferentially react to form a distinctly different inner corrosion product. ${ }^{1}$ Detailed analysis of a polished cross section of oxidized $\mathrm{Cr}$ 12 at.\% $\mathrm{Nb}$ by scanning electron microscopy (SEM) and energy-dispersive $\mathrm{x}$-ray analysis has now revealed that the scales were composed of chromia at the gas-solid interface, underlying products containing chromium and niobium, and a porous inner layer that only formed on the Cr-rich phase (Fig. 1). (Such porosity was not obvious when only optical imaging was sed $\left.{ }^{2}\right)$ An as-oxidized $\left(950^{\circ} \mathrm{C}\right) \mathrm{Cr}-12 \% \mathrm{Nb}$ specimen was fractured by bending and examined in cross section by SEM. Preliminary results indicated the presence of some voids along parts of the matrix-scale interface. This would indicate that the porosity observed in the inner layer found on the Cr-rich phase (Fig. 1) most likely formed during oxidation rather than from the loss of a brittle product during metallographic preparation of the cross section. The apparent porosity (possibly due to an agglomeration of voids caused by the outward flow of chromium cations ${ }^{3}$ or to impurities ${ }^{4}$ ) could be the reason for the previously-reported ${ }^{2}$ tendency of the $\mathrm{Cr}-6 \% \mathrm{Nb}$ alloy to be more susceptible to spallation because it contains a greater volume fraction of the $\mathrm{Cr}$-rich phase on which this layer grows. 


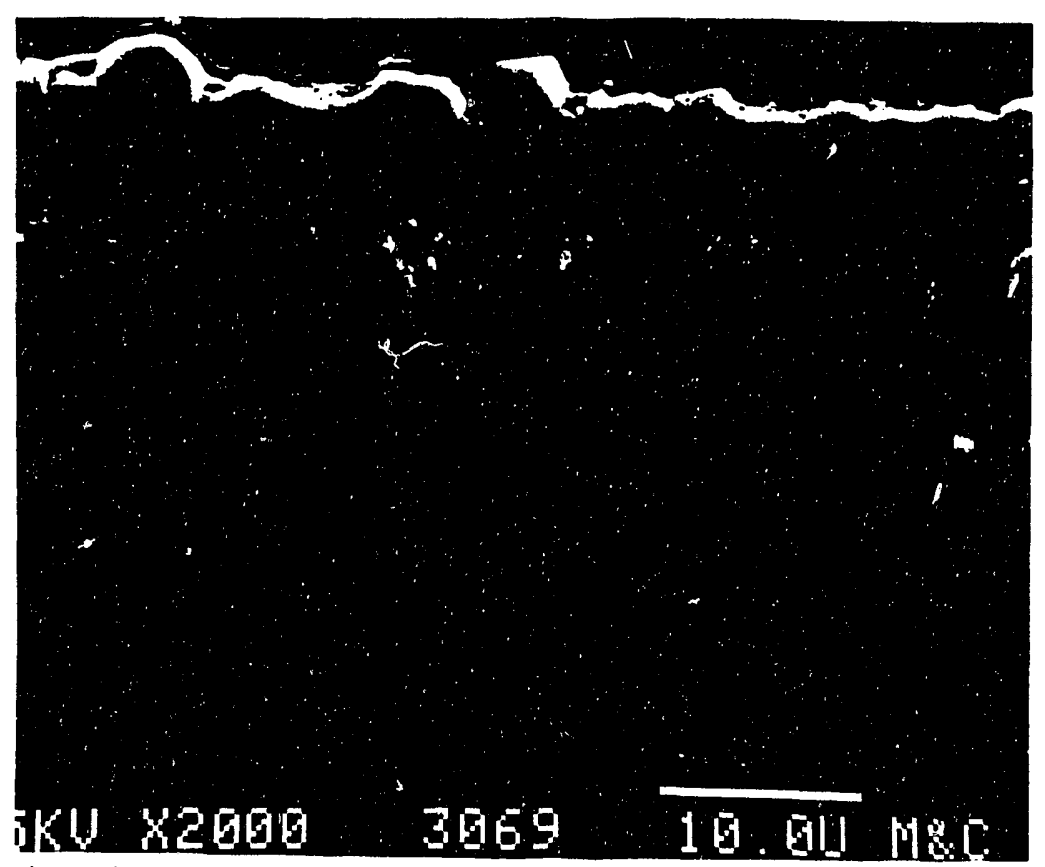

Fig. 1. Scanning electron micrograph of a polished cross section of $\mathrm{Cr}-12$ at. $\% \mathrm{Nb}$ exposed to air at $900^{\circ} \mathrm{C}$ for $168 \mathrm{~h}$.

The results from the study of the isothermal oxidation of the binary $\mathrm{Cr}-\mathrm{Nb}$ alloys indicated that increasing the volume fraction of the eutectic phase at the expense of the $\mathrm{Cr}$ rich region by using niobium concentrations of at least 12 at. \% appears to reduce scaling and spallation. . It was therefore appropriate to examine the effects of macro- and microalloying on the oxidation resistance of $\mathrm{Cr}_{-} \mathrm{Cr}_{2} \mathrm{Nb}$ alloys containing 12 at.\% $\mathrm{Nb}$. The res'llts for several such compositions are all summarized in Fig. 2, which also contains the data for the $\mathrm{Cr}-12 \% \mathrm{Nb}$ binary alloy. There were no dramatic effects of alloying additions on the rate of scaling. Indeed, the binary alloy showed better isothermal oxidation behavior than any of the more highly alloyed compositions. Approximate parabolic rate constants (for times greater than $40 \mathrm{~h}$ ) ranged from $5-16 \times 10^{-5} \mathrm{mg}^{2} / \mathrm{cm}^{4} \cdot \mathrm{s}$ for the other alloys compared to $2 \times 10^{-5}$ for the binary composition.. However, no gross spallation during cooling after the isothermal exposures (as previously reported for $\mathrm{Cr}-6 \% \mathrm{Nb}^{2}$ ) was noted for any of the alloys. Furthermore, there are some indications from preliminary cyclic oxidation experiments that alloying of the binary composition may offer some benefit in certain cases. Detailed characterization of alloying effects on oxidation resistance is currently underway. 


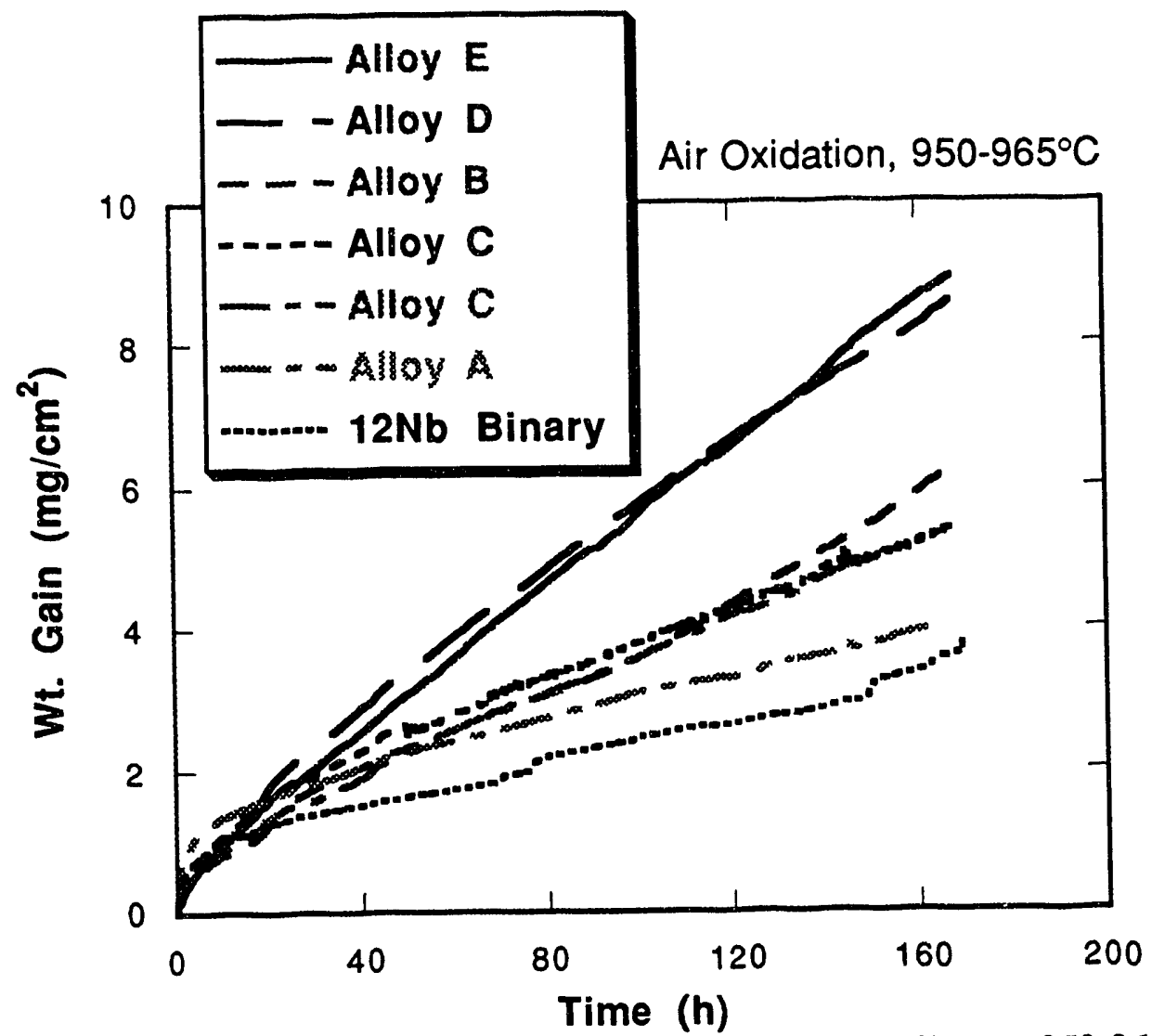

Fig. 2. Weight gain versus time for air oxidation of $\mathrm{Cr}-\mathrm{Nb}$ alloys at $950-965^{\circ} \mathrm{C}$

Coatings

An approach and plan for the coatings subtask supporting the development of $\mathrm{Cr}$ $\mathrm{Nb}$ alloys was prepared. The plan called for preliminary work on coating development to be done as part of the Ohio State University subcontract using $\mathrm{Cr}-12$ at.\% $\mathrm{Nb}$ as the baseline material. A decision on more appropriate compositions for specific coatings development will then be made at the end of FY93 based on consideration of progress made in the ORNL-2(D), ORNL-3(A), and OSU-2 subtasks. If warranted, evaluation of coatings performance will be initiated as part of ORNL-3(A) in FY94.

\section{REFERENCES}

1. M. Takeyama and C. T. Liu, "Microstructure and Mechanical Properties of LavesPhase Alloys Based on $\mathrm{Cr}_{2} \mathrm{Nb}$," Mater. Sci. Eng. A132, 61, (1991). 
2. P. F. Tortorelli and J. H. DeVan, "High-Temperature Oxidation of $\mathrm{Cr}_{-} \mathrm{Cr}_{2} \mathrm{Nb}$ Alloys," pp. 385-394 in Proc. Sixth Annual Conf. Fossil Energy Materials, N. C. Cole and R. R. Judkins (comp.), U. S. Department of Energy, July 1992

3. P. Kofstad, High Temperature Corrosion, Elsevier Applied Science, London, 1988.

4. H. J. Grabke and H. Viefhaus, "Applications of LEED and Auger Electron Spectroscopy in the Study of High Temperature Corrosion Mechanisms," pp. 19-33 in Microscopy of Oxidation, M. J. Bennett and G. W. Lorimer (eds.), The Institute of Metals, London, 1991. 


\title{
RPI-2-INVESTIGATION OF MOISTURE INDUCED EMBRITTLEMENT OF IRON ALUMINIDES
}

\author{
A. Castagna and N.S. Stoloff \\ Rensselaer Polytechnic Institute \\ Troy, Ny 12180-3590
}

\section{INTRODUCTION}

The purpose of this investigation is to examine the fatigue crack growth resistance and notched and unnotched tensile properties of the $\mathrm{Fe}_{3} \mathrm{Al}$ type intermetallic compound FA129. Fatigue crack growth and tensile tests have been performed in various environments and in two ordered states, the $\mathrm{B} 2$ and $\mathrm{DO}_{3}$. Transmission electron microscopy has been performed at ORNL through the SHaRE program to characterize the microstructure and dislocation structure of FA129, and to compare changes when tested in fatigue in various environments.

\section{DISCUSSION OF CURRENT ACTIVITIES}

It has been a concern of several researchers at ORNL that crack closure of the compact tension specimens during fatigue crack growth tests is responsible for the unexpectedly high threshold stress intensities being measured in FA129. To determine if this is the case, crack closure measurements have been made during a fatigue crack growth test at room temperature. An extensometer strapped to a pair of bolts set in the specimen face was used to measure displacement at crack length intervals of $0.1 \mathrm{~mm}$, and the corresponding values of COD were calculated. The traces of COD vs. load applied indicated no crack closure at any crack length. Some plasticity was observed at long crack lengths just prior to failure.

Another explanation for the high thresholds was that the compact tension specimens were not sufficiently precracked. Load shedding was performed in several fatigue crack growth experiments in order to extend the crack away from the blunt machined notch before collecting data. Load shedding was performed to ASTM standards with the exception of a larger $d(\Delta K) / d(a)$ slope. No significant changes in fatigue behavior were found with load shedding. The fatigue crack growth curves with and without load shedding are shown in figure 1.

The effect of annealing temperature on recrystallization in B2 ordered FA129 has been examined. Previous work had been performed on material which received a 1 hour 
anneal at $700^{\circ} \mathrm{C}$, resulting in a microstructure which was only $50 \%$ recrystallized. New material was prepared with a 2 -stage anneal, the first at a higher temperature for recrystallization, and the second at $700^{\circ} \mathrm{C}$ to obtain $\mathrm{B} 2$ order. When the first anneal was carried out at $900^{\circ} \mathrm{C}$ for 1 hour, $90 \%$ recrystallization was achieved. Crack growth experiments on this material resulted in slightly higher apparant fracture toughness, $\Delta \mathrm{K}_{\mathrm{C}}$, but not much change in crack growth rate. These results are shown in figure 2.

High temperature fatigue crack growth has been performed on $\mathrm{B} 2$ and $\mathrm{DO}_{3}$ ordered FA129 in air. The $\mathrm{DO}_{3}$ ordered material was tested at $150^{\circ} \mathrm{C}, 300^{\circ} \mathrm{C}$, and $450^{\circ} \mathrm{C}$, and the $\mathrm{B} 2$ ordered material was tested at $150^{\circ} \mathrm{C}$. In all elevated temperature tests the material demonstrated a higher apparant fracture toughness than at room temperature. The fracture surfaces were all predominantly transgranular with some evidence of microvoid coalescence. A summary of these results is shown in Table I along with room temperature data. The crack growth curves are shown in figures 3 and 4.

Table I

$\mathrm{DO}_{3}$

B2

$\begin{array}{lllll}\text { Temperature }\left({ }^{\circ} \mathrm{C}\right) & \Delta \mathrm{K}_{\mathrm{TH}} & \Delta \mathrm{K}_{\mathrm{C}} & \Delta \mathrm{K}_{\mathrm{TH}} & \Delta \mathrm{K}_{\mathrm{C}} \\ 25 & 19 & 24 & 30 & 44 \\ 150 & 26 & 52 & 32 & 65 \\ 300 & 25 & 49 & - & - \\ 450 & 21 & 48 & - & -\end{array}$

An unexpected result from these tests is that the $\mathrm{DO}_{3}$ ordered FA129 tested at $150^{\circ} \mathrm{C}$ showed the highest threshold and critical stress intensities, with toughness decreasing as temperature increased.

Transmission electron microscopy on the FA129 specimens fatigued at elevated temperature has been performed through the Oak Ridge SHaRE program. TEM foils were prepared at RPI, and examined at Oak Ridge on 200 and $300 \mathrm{KV}$ Phillips electron microscopes. Increased dislocation density in the higher toughness conditions was observed, as expected. The fine subgrain structure which was observed in the B2 ordered FA129 fatigued at room temperature was observed in some of the $\mathrm{DO}_{3}$ ordered material fatigued at higher temperatures. Many superlattice dislocations were observed and analysis is underway to determine the nature (two-fold or four-fold) and spacing of these dislocations. 


\section{FUTURE WORK}

Fatigue crack growth experiments on B2 ordered FA129 at $600^{\circ} \mathrm{C}$, as well as a repeat of the high temperature tests in dry oxygen, are currently underway. Tensile specimens of FA129 are currently being electro-polished in preparation for notch sensitivity experiments. Crack closure measurements have been performed previously using an extensometer to measure COD, and no measurable crack closure was detected. In order to confirm this result, a compact tension specimen will be instrumented with a back face strain gauge and fatigued. The back face strain gauge will detect closure in the form of a nonlinear strain along the back face of the compact tension specimen.

\section{FIGURES}

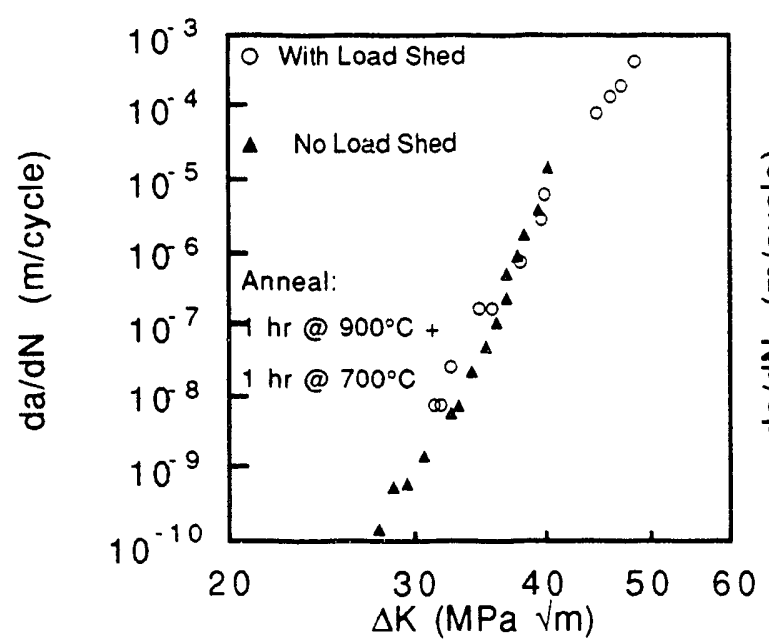

Figure 1. Effect of load shedding in $\mathrm{B} 2$ ordered FA129 in $25^{\circ} \mathrm{C}$ air.

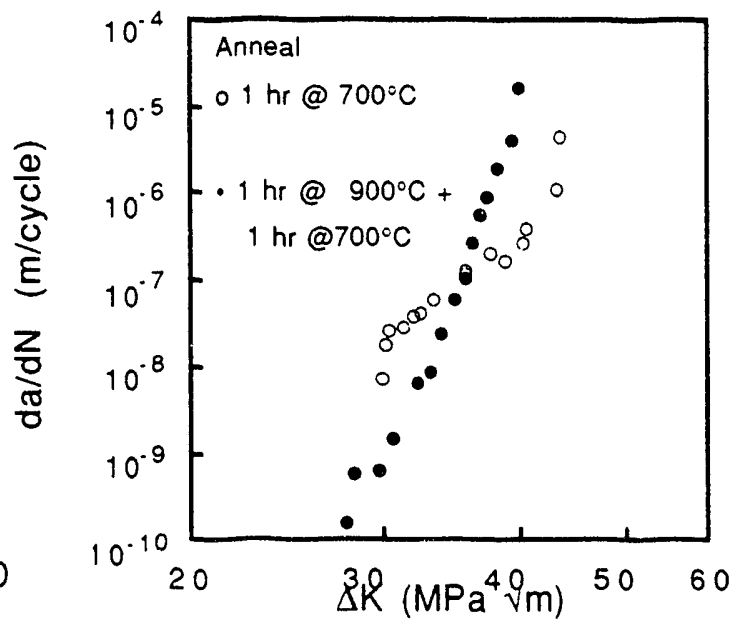

Figure 2.Comparison of annealing conditions in $\mathrm{B} 2$ ordered FA129 in $25^{\circ} \mathrm{C}$ air. 


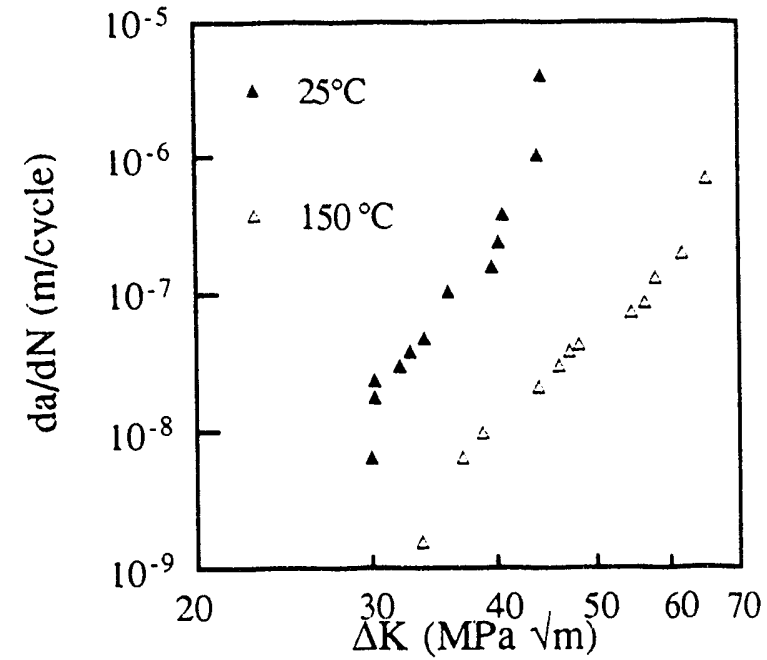

Figure 3. Fatigue crack growth at elevated temperature in B2 ordered FA129 in air.

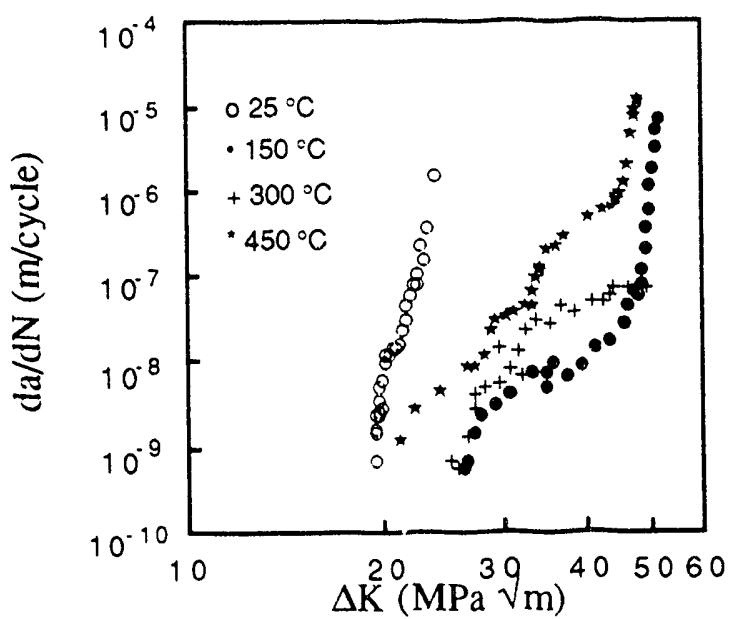

Figure 4. Fatigue crack growth at elevated temperature in $\mathrm{DO}_{3}$ ordered FA129 in air. 
UTN-2-Investigation of the Weldability of Modified 800H Alloys

C.D. Lundin, C.Y.P. Qiao and C. Shi

Materials Joining Research Group

Materials Science and Engineering Department The University of Tennessee, Knoxville, TN 37996

Introduction

A comparative study of commercially available advanced austenitic alloys and experimental modified $800 \mathrm{H}$ alloys is a part of this project. varestraint hot cracking tests on two heats $25 \mathrm{Cr}-20 \mathrm{Ni}-\mathrm{Nb}-\mathrm{N}$ alloys were accomplished during this reporting period. Weldability comparison between modified $800 \mathrm{H}$ and $25 \mathrm{Cr}-20 \mathrm{Ni}-\mathrm{Nb}-\mathrm{N}$ type advanced zustenitic stainless steels is based upon the varestraint hot crack test results. A HAZ microstructural invescigation in a modified $800 \mathrm{H}$ with thermal simulated samples wis performed.

An advanced austenitic stainless steel $(25 \mathrm{Cr}-20 \mathrm{Ni}-\mathrm{Nb}-\mathrm{N}$ Japanese specification HR3C) was adapted from conventional 25Cr-20Ni (AISI 310) fully austenitic stainless steel mainly by adding $\mathrm{Nb}, \mathrm{N}$, and a small amount of $\mathrm{V}$ and $\mathrm{Ti}$. It is claimed [1] that the strength level of the niobium and nitrogen containing alloys is higher than that of the alloys which contain nitrogen but without niobium with the same solutiontreated condition. The ductility of $\mathrm{HR} 3 \mathrm{C}$ is similar to that of 310 stainless steel according to the evaluation results reported by sumitomo [1].

One heat of sumitomo HR3C tubing (Heat A222403) and one heat of $A B B$ Combustion Engineering Systems fabricated $25 \mathrm{Cr}$ 20Ni-Nb-N (Heat V35623) type advanced austenitic stainless steel were used for hot cracking evaluations. For heat v35623, the A1 and A2 designates the same composition but different base metal grain sizes. une small laboraiory heat of 310 and 
one small laboratory heat of modified $800 \mathrm{H}$ (Heat P) were used for comparison. The composition of the materials evaluated is listed in Table 1 . The grain size measurements are also indicated in Table 1.

Table 1. Compositions of materials.

\begin{tabular}{|c|c|c|c|c|c|}
\hline & $\begin{array}{c}25 \mathrm{Cr}-20 \mathrm{Ni} \\
-\mathrm{Nb}-\mathrm{N} \\
(\mathrm{V} 35623) \\
\end{array}$ & $\begin{array}{c}25 \mathrm{Cr}-20 \mathrm{Ni} \\
-\mathrm{Nb}-\mathrm{N} \\
(\mathrm{A} 222403)\end{array}$ & $310 \mathrm{Ta}$ & $\begin{array}{c}\text { Modified } \\
800 \mathrm{H} \\
\text { (P) }\end{array}$ & $\begin{array}{c}\text { Modified } \\
800 \mathrm{H} \\
\text { (V988-1) }\end{array}$ \\
\hline$C$ & 0.051 & 0.06 & 0.051 & 0.113 & 0.10 \\
\hline$S$ & 0.01 & 0.001 & 0.003 & & 0.006 \\
\hline $\mathrm{P}$ & 0.018 & 0.014 & - & & 0.022 \\
\hline $\mathrm{Cr}$ & 24.23 & 25.65 & 24.87 & 19.49 & 20.13 \\
\hline $\mathrm{Ni}$ & 18.68 & 20.15 & 20.21 & 29.95 & 30.09 \\
\hline MO & 0.18 & - & - & 0.97 & 1.89 \\
\hline $\mathrm{Mn}$ & 1.61 & 1.22 & 1.53 & 2.61 & 2.00 \\
\hline $\mathrm{si}$ & 0.64 & 0.40 & 0.33 & 0.29 & 0.19 \\
\hline $\mathrm{V}$ & 0.008 & - & - & 1.81 & 0.59 \\
\hline AI & - & - & $=$ & - & 0.01 \\
\hline $\mathrm{Ti}$ & 0.009 & - & - & 0.09 & 0.28 \\
\hline $\mathrm{Nb}$ & 0.32 & 0.47 & - & 0.32 & 0.22 \\
\hline $\mathrm{N}$ & 0.202 & - & - & 0.097 & 0.007 \\
\hline $\mathrm{Cu}$ & 0.08 & 0.246 & $=$ & - & 0.01 \\
\hline$B$ & - & - & $\overline{-}$ & $=$ & 0.006 \\
\hline 0 & 0.044 & - & - & - & - \\
\hline $\mathrm{CO}$ & 0.12 & $=$ & & - & - \\
\hline $\mathrm{Ta}$ & - & - & 1.60 & - & - \\
\hline$W$ & - & - & - & 2.00 & - \\
\hline $\mathrm{Fe}$ & $\mathrm{BaI}$. & $\mathrm{Bal}$ & $\mathrm{Bal}$. & $\mathrm{Bal}$. & EZI. \\
\hline $\begin{array}{l}\text { Grain Size } \\
\text { (ASTM No.) }\end{array}$ & 8 & 8 & 7 & 8 & 5 \\
\hline
\end{tabular}

DISCUSSION OF CURRENT ACTIVITIES

\author{
Varestraint Testing of \\ 25Cr-20Ni-Nb-N Advanced Stainless steels
}

The University of Tennessee (UT) standard Varestraint test procedures [2] were used for conducting hot cracking evaluations. Assessment on the hot cracking susceptibility of the materials studied was made using the UT Varestraint hot 
cracking testing criteria, notably, maximum crack length, total crack length and cracked HAZ length [2].

Figures 1 and 2 show the fusion zone hot cracking behavior in terms of total crack length and maximum crack length for the varestraint hot cracking test. It is clear that Heats A1 and A2 basically showed a similar fusion zone hot cracking tendency. Heat $B$ exhibits a lower hot cracking tendency than the $A 1$ and $A 2$ materials. It is a reasonable result that Heat $B$ possess a higher fusion zone hot cracking resistance as contracted to Heats $A 1$ and $A 2$ since the $P, S$, and Si contents for Heat $B$ are less than those of Heats $A 1$ and $A 2$. Although Heat $A 1$ and Heat $A 2$ possess different base metal grain sizes Heat $A 1$ and $A 2$ showed the same fusion zone hot cracking tendency since base metal grain size will not substantially affect fusion zone microstructure and therefore, solidification cracking propensity.

Figures 3 and 4 show weld metal HAZ hot cracking behavior for all three $25 \mathrm{Cr}-20 \mathrm{Ni}-\mathrm{Nb}-\mathrm{N}$ materials. Heat $\mathrm{Al}$ showed the highest weld metal HAZ hot cracking tendency among the three materials evaluated while the other heats have a similar but reduced tendency. Detailed metallographic examinations will be conducted in order to provide a precise explanation.

Finures 5 and 6 show base metal HAZ hot cracking behavior for all three $25 \mathrm{Cr}-20 \mathrm{Ni}-\mathrm{Nb}-\mathrm{N}$ materials. It is evident that Heat A2 showed the highest HA.Z hot cracking tendency. Heat A1 and Heat $B$ have a similar hot cracking tendency in terms of the total crack length and maximum crack length.

Comparison of Base Metal HAZ Liquation Cracking Tendency between $25 \mathrm{Cr}-20 \mathrm{Ni}-\mathrm{Nb}-\mathrm{N}$ Allovs, $310 \mathrm{Ta}$ and Modified $800 \mathrm{H}$

A bar graph comparison between three materials in terms of base metal HAZ hot cracking tendency for $4 \%$ augmented strain is indicated in Figure 7. It is clear that all three materials have a similar hot cracking tendency. Therefore, it can be 


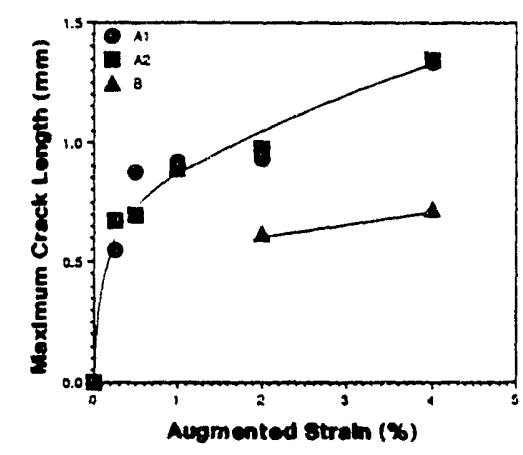

Figure 1. Fusion zone hot cracking behavior of $25 \mathrm{Cr}-$ $20 \mathrm{Ni}-\mathrm{Nb}-\mathrm{N}$ alloys in terms of maximum crack length in the varestraint test.

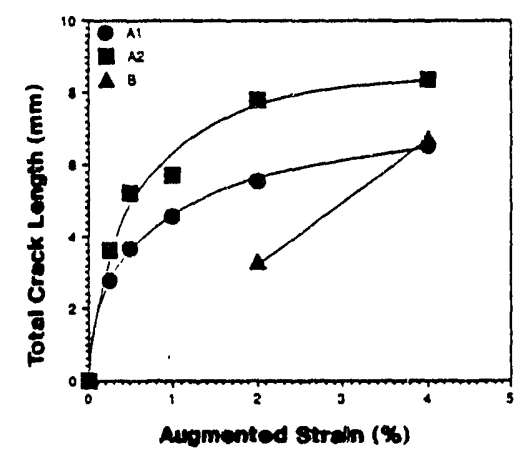

Figure 2. Fusion zone hot cracking behavior of $25 \mathrm{Cr}-$ $20 \mathrm{Ni}-\mathrm{Nb}-\mathrm{N}$ alloys in terms of total crack length in the varestraint test.

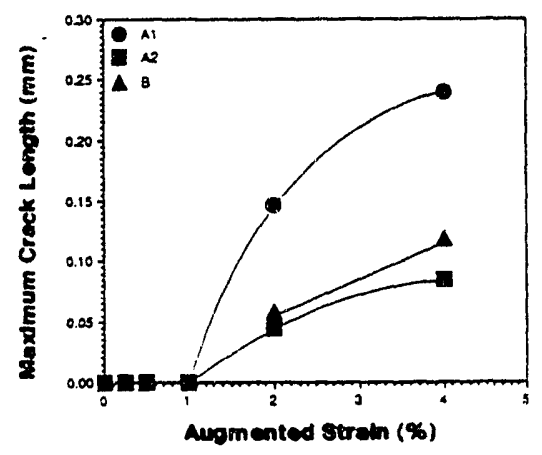

Figure 3. Weld metal HAz hot cracking behavior of $25 \mathrm{Cr}$ $20 \mathrm{Ni}-\mathrm{Nb}-\mathrm{N}$ alloys in terms of maximum crack length in the Varestraint test.

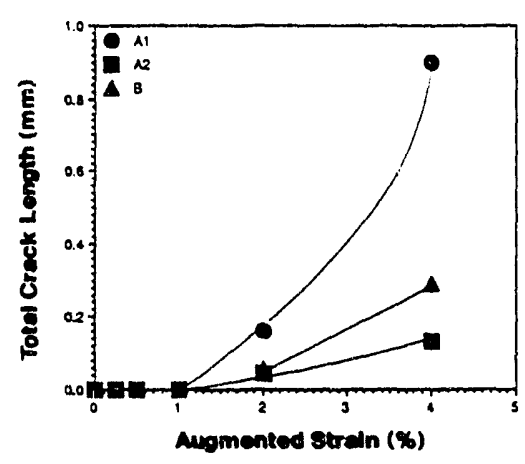

Figure 4. Weld metal $\mathrm{HAZ}$ hot cracking behavior of $25 \mathrm{Cr}$ 20NO-Nb-N alloys in terms of total crack length in the Varestraint test.

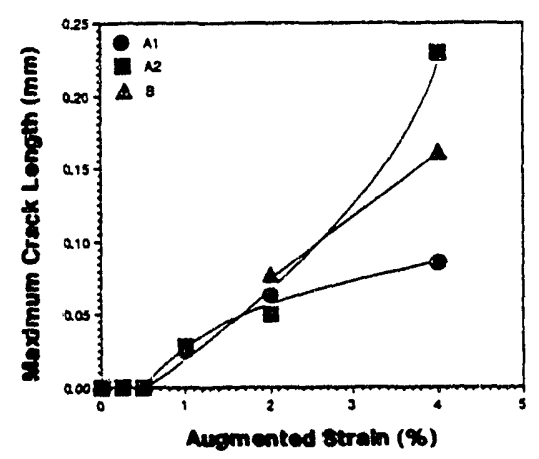

Figure 5. Base metal $\mathrm{HAZ}$ hot cracking behavior of $25 \mathrm{Cr}-$ $20 \mathrm{Ni}-\mathrm{Nb}-\mathrm{N}$ alloys in terms of maximum crack length in the varestraint test.

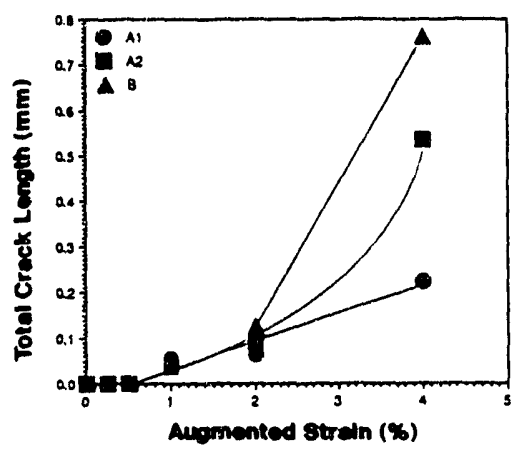

Figure 6. Base metal HAz hot cracking behavior of $25 \mathrm{Cr}-$ $20 \mathrm{Ni}-\mathrm{Nb}-\mathrm{N}$ alloys in terms of total crack length in the varestraint test. 
stated that the modified $800 \mathrm{H}$ alloys with proper controlled base metal microstructure will have an equivalent or slightly lower hot cracking tendency than that of the $25 \mathrm{Cr}-20 \mathrm{Ni}-\mathrm{Nb}-\mathrm{N}$ type alloys. Metallographic examination and chemical analysis will be conducted for a detailed interpretation for these test results.

\section{HAZ Microstructural Evaluations of Modified $800 \mathrm{H}$ Alloys}

\section{Microstructural Morphologies}

The Gleeble HAZ specimens employed for this study were prepared by using a 1500 Model Gleeble thermal mechanical simulator. The thermal cycle represents the SMAW process with an energy input of $70 \mathrm{~kJ} /$ in on a $1 \& 1 / 2$ inch thickness plate and the preheat temperature is $22^{\circ} \mathrm{C}$. Seven peak temperatures (which represent different distances perpendicular to the fusion line) $1001^{\circ} \mathrm{C}, 1090^{\circ} \mathrm{C}, 1145^{\circ} \mathrm{C}, 1200^{\circ} \mathrm{C}, 1260^{\circ} \mathrm{C}, 1285^{\circ} \mathrm{C}$ and $1320^{\circ} \mathrm{C}$ were simulated. The OLM and SEM were used to perform metallographic examinations. Precipitate extractions from the Gleeble simulated samples were conducted and the EDS and $x$-ray diffraction analysis on the particles extracted were conducted.

The base metal HAZ microstructure of modified $800 \mathrm{H}$ (Heat V988-1) is shown in Figure 8. As indicated in the figure the cold worked microstructure is noted in the matrix and the precipitates are non-uniformly distributed. Most of the precipitates were defined as $\mathrm{M}_{23} \mathrm{C}_{6}$, $\mathrm{MC}$ type carbides and/or $\mathrm{M}(\mathrm{CN})$ type carbonitrides.

Figure 9 shows the microstructure in a sample which was HAZ simulated with a peak temperature of $1001^{\circ} \mathrm{C}$. It is clear that significant grain growth is manifest under this thermal history at this temperature as compared to the base metal microstructure. Figure 10 shows the microstructure in a sample with a HAZ simulated peak temperature of $1090^{\circ} \mathrm{C}$. Evidence of recrystallization can be observed in this figure. Dissolution of secondary phase particles is revealed contrasted to the base 


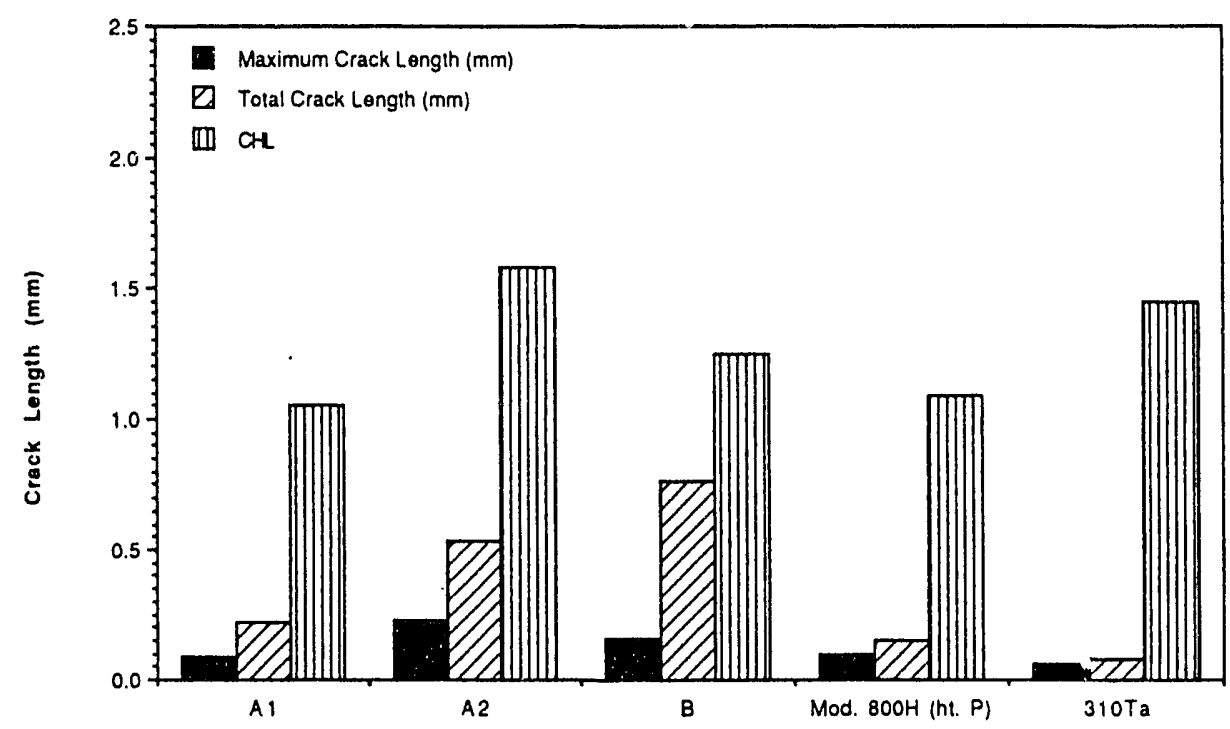

Figure 7. A bar graph showing the comparison between three $25 \mathrm{Cr}-20 \mathrm{Ni}-\mathrm{Nb}-\mathrm{N}$ materials at $4 \%$ augmented strain in the varestraint test.

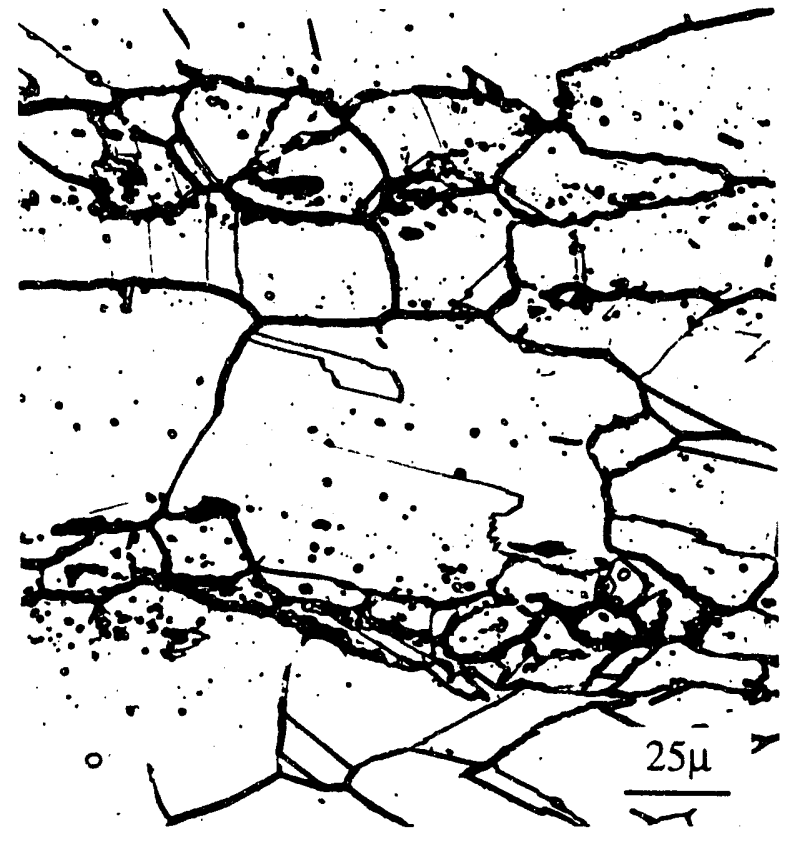

Figure 8. Base metal microstructural morphology of the modified $800 \mathrm{H}$ (heat V988-1).

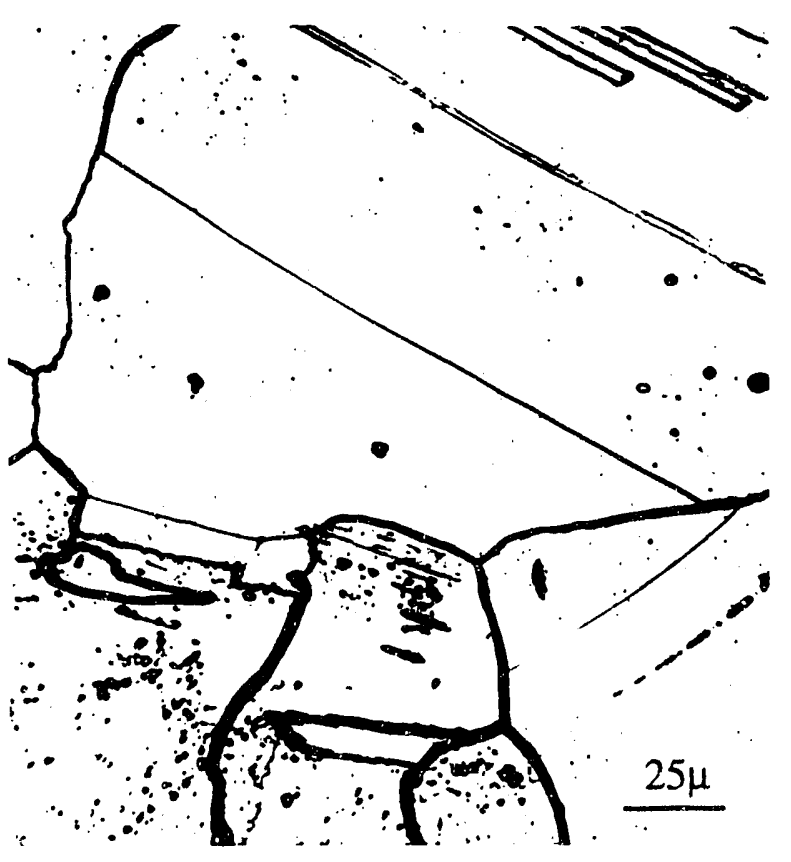

Figure 9. Microstructural morphology in the Gleeble simulated sample with a peak temperature of $1001{ }^{\circ} \mathrm{C}$. 
material and the sample simulated with a peak temperature of $1001^{\circ} \mathrm{C}$. Figure 11 shows the microstructure in a HAZ sample simulated with a peak temperature of $1145^{\circ} \mathrm{C}$. A recrystallized microstructure was observed in this sample. Extensive precipitate dissolution was observed in this sample as compared to the sample HAZ simulated with a peak temperature of $1090^{\circ} \mathrm{C}$. As indicated in Figure 12, a microstructure with an uniform grain size is revealed in the sample HAZ simulated with a peak temperature of $1200^{\circ} \mathrm{C}$. The size of the particles at grain boundaries decreased for this sample as compared to these in the sample HAZ simulated with a peak temperature of $1001^{\circ} \mathrm{C}$. This phenomenon can be more clearly observed at a higher magnification. Liquation was exhibited in the sample HAZ simulated with a peak temperature of $1260^{\circ} \mathrm{C}$ (see Figure 13). Significant liquation occurred in the sample simulated with a peak temperature of $1285^{\circ} \mathrm{C}$ compared to that in the sample HAZ simulated with a peak temperature of $1260^{\circ} \mathrm{C}$ (see Figure 14). Grain boundary migration and constitutional liquation were noted. In the sample HAZ simulated with a peak temperature of $1320^{\circ} \mathrm{C}$, liquation appeared both intergranularly and intragranularly. Constituents produced by eutectic reactions along grain boundaries are shown in Figure 15.

The above observations reveal that several reactions can occur in the HAZ of modified $800 \mathrm{H}$ alloys. These include grain boundary liquation, grain growth, recrystallization, secondary phase precipitation and dissolution. All of these reactions may enhance hot crack formation in the HAZ. Precipitate characterization and the distribution in the modified $800 \mathrm{H}$ weld HAZ will be performed in order to determine the inter relationship between precipitate distribution and hot cracking tendency.

\section{Grain Size Measurements}

The grain sizes (ASTM grain size number) for all Gleeble HA. thermally simulated samples were measured and are 


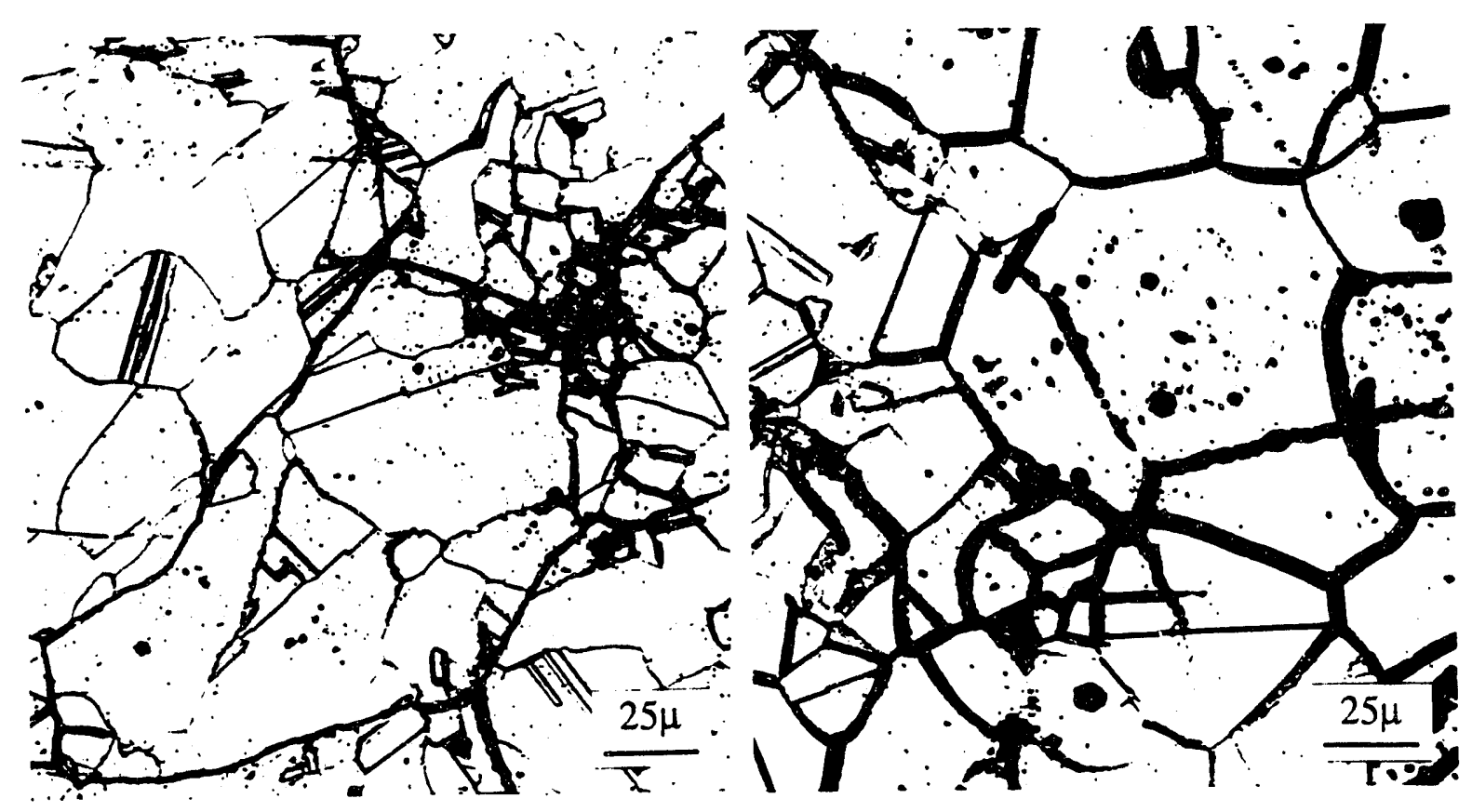

Figure 10. Microstructural morphology in the Gleeble simulated sample with a peak temperature of $1090^{\circ} \mathrm{C}$.
Figure 11. Microstructural morphology in the Gleeble simulated sample with a peak temperature of $1145^{\circ} \mathrm{C}$.

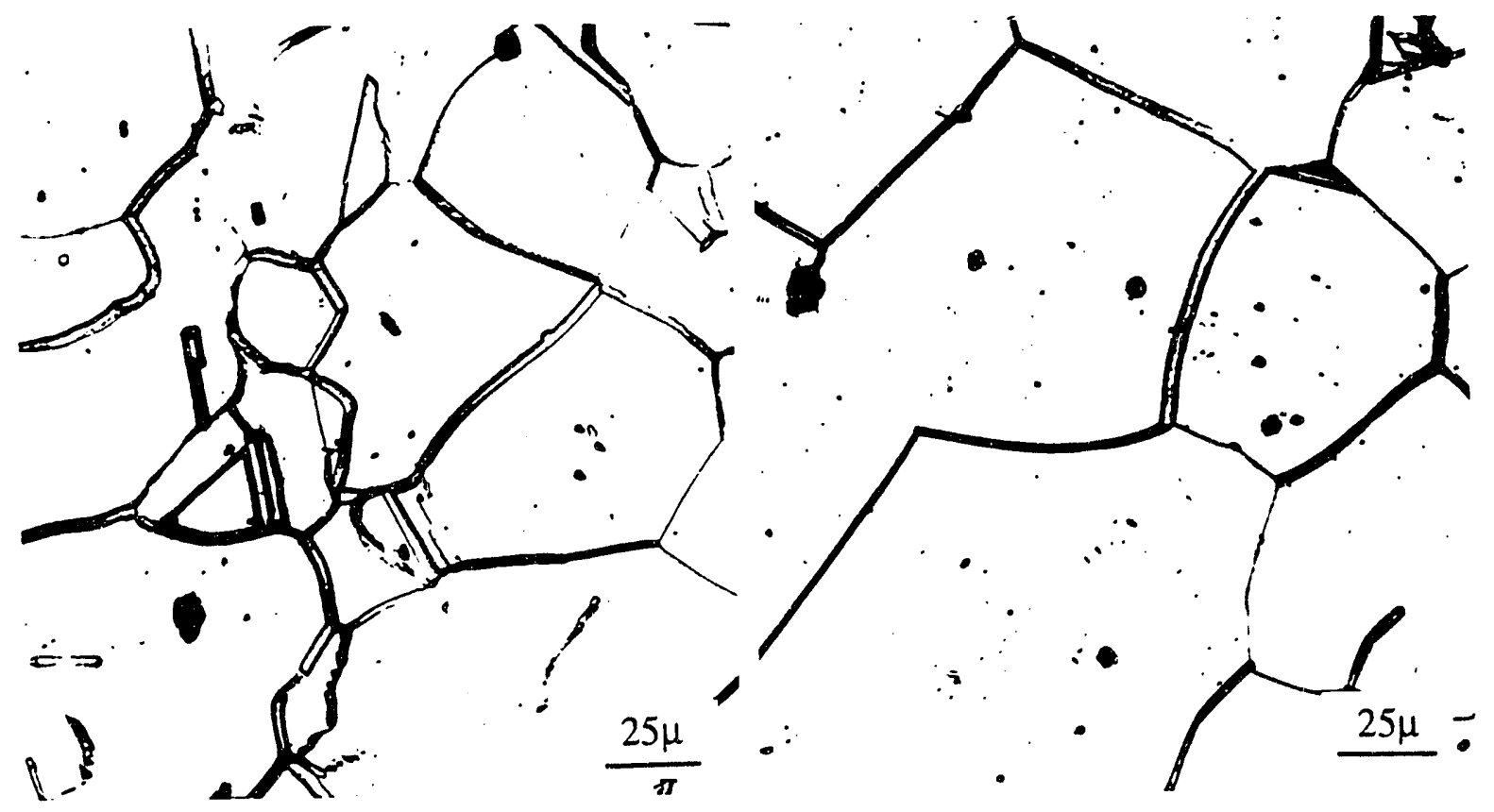

Figure 12. Microstructural morphology in the Gleeble simulated sample with a peak temperature of $1200^{\circ} \mathrm{C}$.
Figure 13. Microstructural morphology in the Gleeble simulated sample with a peak temperature of $1260^{\circ} \mathrm{C}$. 


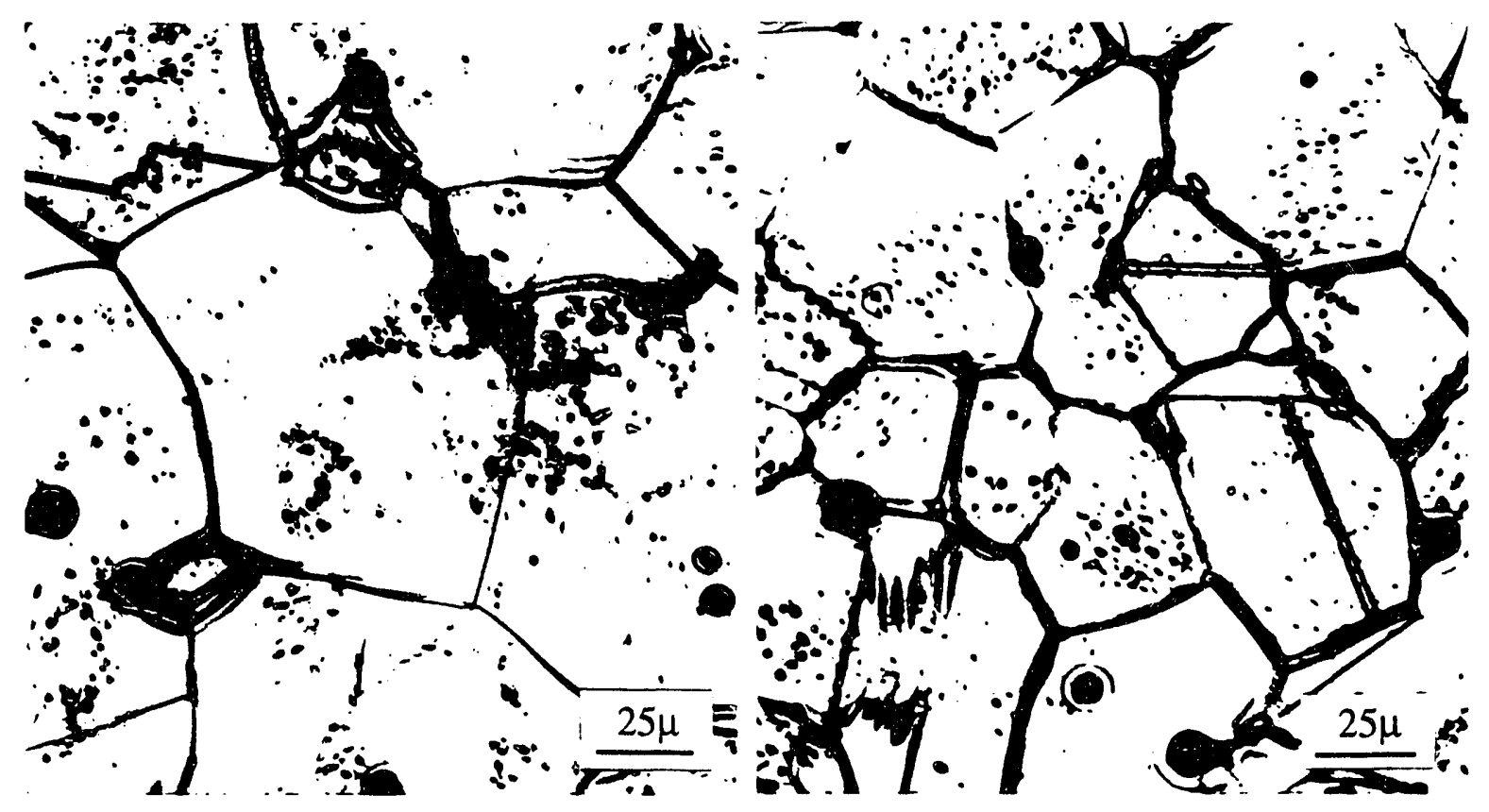

Figure 14. Microstructural morphology in the Gleeble simulated sample with a peak temperature of $1285^{\circ} \mathrm{C}$.
Figure 15. Microstructural morphology in the Gleeble simulated sample with a peak temperature of $1320^{\circ} \mathrm{C}$.

summarized in Table 3. It is clear that changes in the HAZ grain size agree with the metallographic examination resuits described above. At high temperatures liquation which occurs along the grain boundaries has a pinning effect retarding grain boundary migration. Therefore, there is almost no grain growth (as compared to the base material) at $1320^{\circ} \mathrm{C}$ and $1285^{\circ} \mathrm{C}$. In the sample $\mathrm{HAZ}$ simulated with a peak temperature of $1260^{\circ} \mathrm{C}$ grain growth was evident. The same grain size was exhibited by the sample HAZs simulated with peak temperatures of $1200^{\circ} \mathrm{C}$ and $1260^{\circ} \mathrm{C}$. With simulated HAZ peak temperatures of $1090^{\circ} \mathrm{C}$ and $1145^{\circ} \mathrm{C}$, recrystallization occurred, therefore, the grain size in this sample was reduced. For the samples with a HAZ simulated peak temperature of $1001^{\circ} \mathrm{C}$ grain growth is significant. It is noticed that in an actual weld HAz this temperature range is in a narrow zone and higher resolution is 
required to identify microstructures related to each of the simulated HAZ temperature regions. Thus, the Gleeble thermally simulated samples provided an approach to precisely evaluate HAZ microstructures and reactions occurring in the HAZ.

Table 3. Summary of grain size measurements.

\begin{tabular}{|c|c|}
\hline Simulated HAZ Peak Temperature $\left({ }^{\circ} \mathrm{C}\right)$ & Grain Size (ASTM No.) \\
\hline Base Material $\left(22^{\circ} \mathrm{C}\right)$ & 5 \\
\hline $1001^{\circ} \mathrm{C}$ & 1 \\
\hline $1090^{\circ} \mathrm{C}$ & 1.5 \\
\hline $1145^{\circ} \mathrm{C}$ & 5.5 \\
\hline $1200^{\circ} \mathrm{C}$ & 4.5 \\
\hline $1260^{\circ} \mathrm{C}$ & 4.5 \\
\hline $1285^{\circ} \mathrm{C}$ & 5 \\
\hline $1320^{\circ} \mathrm{C}$ & 5 \\
\hline
\end{tabular}

\section{Hardness Measurements}

A summary of the hardness measurements is tabulated in Table 4. As indicated in Table 4, hardness decrease occurred in all thermally simulated HAZ samples. The hardness decrease is from a combination of several mechanisms. These included precipitate growth, precipitate dissolution, grain growth, and recrystallization. The results of hardness measurements indicate that a softened zone will existed in the HAZ adjacent to the fusion boundary in the modified $800 \mathrm{H}$ material. Further metallographic examination is needed in order to provide a precise explanation from the metallographic point of view.

Table 4. Summary of hardness measurements results.

\begin{tabular}{|c|c|}
\hline Simulated HAZ Peak Temperature $\left({ }^{\circ} \mathrm{C}\right)$ & HV $(0.1)$ \\
\hline Base Metal $\left(22^{\circ} \mathrm{C}\right)$ & 250 \\
\hline $1001^{\circ} \mathrm{C}$ & 192 \\
\hline $1090^{\circ} \mathrm{C}$ & 199 \\
\hline $1145^{\circ} \mathrm{C}$ & 156 \\
\hline $1200^{\circ} \mathrm{C}$ & 155 \\
\hline $1260^{\circ} \mathrm{C}$ & 156 \\
\hline $1285^{\circ} \mathrm{C}$ & 153 \\
\hline $1320^{\circ} \mathrm{C}$ & 185 \\
\hline
\end{tabular}


Electrolytical Extraction of Precipitates and Precipitate Analysis

A summary of the results from the electrolytic precipitate extraction is given in Table 5. Precipitate extraction revealed precipitate dissolution and reprecipitation. This study will be beneficial the understanding of liquation cracking mechanisms in modified $800 \mathrm{H}$ alloys. Characterization of the precipitates electrolytically extracted will be carried out in the near future. Therefore, the relationship between secondary phase precipitation evolutionary processes and intergranular liquation/liquation cracking is anticipated as a result of this study. HAZ softening is also related to precipitate dissolution and reformation. The information obtained thus far indicates that the amount of the precipitates collected is related to the simulated peak temperature. For modified $800 \mathrm{H}$ alloys, $\mathrm{M}_{23} \mathrm{C}_{6}$ and $\mathrm{Nb} / \mathrm{Ti}$ rich $\mathrm{MC}$ type carbides are dominant in the matrix. Thus, the data shown in Table 5 reflect the evolutionary processes for these two precipitates. $\mathrm{M}_{23} \mathrm{C}_{6}$ type carbide has a lower precipitate dissolution temperature (beginning at about $910^{\circ} \mathrm{C}$ in a fully austenitic alloy). MC type carbides have a higher dissolution temperature (approximately $1200^{\circ} \mathrm{C}$ for $\mathrm{Nb} / \mathrm{Ti}$ rich carbide). Therefore, there are two minima in the precipitates extraction results. Total amount of precipitate extracted from the samples is a combination of $\mathrm{M}_{23} \mathrm{C}_{6}$ and $\mathrm{MC}$ type carbides.

Table 5. Electrolytic precipitates extraction results.

\begin{tabular}{|c|c|}
\hline Simulated Peak Temperature $\left({ }^{\circ} \mathrm{C}\right)$ & Wt.\% of Precipitates \\
\hline Base Metal $\left(22^{\circ} \mathrm{C}\right)$ & 0.25 \\
\hline $1001^{\circ} \mathrm{C}$ & 0.17 \\
\hline $1090^{\circ} \mathrm{C}$ & 0.16 \\
\hline $1145^{\circ} \mathrm{C}$ & 0.14 \\
\hline $1200^{\circ} \mathrm{C}$ & 0.28 \\
\hline $1260^{\circ} \mathrm{C}$ & 0.25 \\
\hline $1285^{\circ} \mathrm{C}$ & 0.33 \\
\hline $1320^{\circ} \mathrm{C}$ & 0.11 \\
\hline
\end{tabular}


SUMMARY

The Varestraint hot cracking test results indicate that $25 \mathrm{Cr}-20 \mathrm{Ni}-\mathrm{Nb}-\mathrm{N}$ and modified $800 \mathrm{H}$ (fine grain heats, such as heat $\mathrm{P})$ basically have an equivalent hot cracking resistance. Grain size has a significant influence on hot cracking resistance, especially, for the materials which have substantially the same composition.

Metallographic examinations of the thermally simulated HAZ samples show that HAZ liquation cracking tendency and HAZ softening issues are related to HAZ reactions under welding • thermal exposures. Further metallographic examinations along with microchemical analysis will be applied in order to reveal the inter relationships between hot cracking tendency and secondary phases precipitation/reformation behavior.

\section{REFERENCES}

1. Sumitomo Metal Industries, Ltd., Technical Report, "Characteristics of a New steel Tube (HR3C) with High Elevated Temperature Strength and High Corrosion Resistance for Boiler," December 1987.

2. Lundin, C.D., and Qiao, C.Y.P., "Weldability of Nuclear Grade Stainless steels," Proceedings of the International Conference on New Advances in welding and Allied Processes, Vol. 2, pp. 3-10, May 1991.

3. Swindeman, R.W., "Investigation of Austenitic Alloys for Advanced Heat Recovery and Hot - Gas Clean up Systems," Technical Report, ORNL/FMP - 91/2, pp. 223-230, September 1991.

4. Edmonds, D.V., and Honeycombe, R.W.K., "Precipitation in Iron-Base Alloys," Proceedings of a symposium on Precipitation Processes in Solids, pp. 121-160, september 1976 . 


\title{
UTN-3-AQUEOUS CORROSION OF IRON ALUMINIDES IN CHLORIDE AND SULFUR-COMPOUND SOLUTIONS
}

\author{
R.A. Buchanan and J.G. Kim \\ Department of Materials Science and Engineering \\ The University of Tennessee \\ Knoxville, Tennessee 37996-2200
}

\section{INTRODUCTION}

Several aspects of previously-reported studies on the aqueous-corrosion behavior of $\mathrm{Fe} 3 \mathrm{Al}$-based iron aluminides suggested additional investigations. 1,2 First, prior results indicated the FAL-Mo alloy (Fe-28Al-5Cr-1Mo-0.04B-0.08Zr, at. \%) to be highly resistant to uniform and localized corrosion under non-creviced conditions at room temperature in three chloride solutions [a mild acid-chloride solution $(\mathrm{pH}=4,200 \mathrm{ppm}$ $\left.\mathrm{Cl}^{-}\right), 3.5 \mathrm{wt} . \% \mathrm{NaCl}(\mathrm{pH} \approx 7)$, and synthetic seawater]. With regard to these results, the question arose as to whether this excellent performance would be retained at higher test temperatures $\left(48,72\right.$ and $\left.95^{\circ} \mathrm{C}\right)$ in the $3.5 \mathrm{wt}$ \% $\mathrm{NaCl}$ solution. Next, prior results indicated the FAL-Mo alloy to be highly resistant to aqueous corrosion under creviced conditions at room temperature in the mild acid-chloride solution; the resistance of FALMo was shown to be comparable to that of $304 \mathrm{~L}$ stainless steel. With regard to these results, the question arose as to whether this excellent resistance to crevice corrosion would continue in a higher chloride-containing solution, $3.5 \mathrm{wt} . \% \mathrm{NaCl}$. And finally, prior results indicated that the iron aluminides, FA-84 (Fe-28Al-2Cr-0.05B, at. \%), FA129 (Fe-28Al-5Cr-0.2C-0.5Nb, at. \%), and FAL-Mo, all performed poorly, with veryhigh corrosion rates, in the two relatively-concentrated sulfur-compound solutions, $0.1 \mathrm{M}$ $\mathrm{Na}_{2} \mathrm{~S}_{2} \mathrm{O}_{3}$ (sodium thiosulfate) and $0.1 \mathrm{M} \mathrm{Na}_{2} \mathrm{~S}_{4} \mathrm{O}_{6}$ (sodium tetrathionate). These solutions, at concentrations depending on conditions, can be formed at material surfaces during shut-down periods (with possible water condensation) of combustion systems utilizing sulfur-containing fuel. With regard to these results, the question arose as to how the three aluminides would perform in lower-concentration thiosulfate and tetrathionate solutions $(0.01 \mathrm{M}$ and $0.001 \mathrm{M})$. 


\section{DISCUSSION OF CURRENT ACTIVITIES}

Variation of FAL-Mo Pitting Resistance with Temperature

Earlier work has shown that the Fe3Al-based iron aluminides which contain both $\mathrm{Cr}$ (4-6 at. \%) and Mo (1-2 at. \%) offer the best resistance at room temperature to chloride-induced pitting corrosion. FAL-Mo is an example of such an alloy. To study the effect of temperature on the pitting resistance of FAL-Mo, cyclic anodic polarization behaviors were evaluated in $3.5 \mathrm{wt}$. $\% \mathrm{NaCl}$ solution at $25,48,72$ and $95^{\circ} \mathrm{C}$. Before corrosion testing, the specimens were annealed in air for one hour at $750^{\circ} \mathrm{C}$ and oil quenched, thereby producing the B2 superlattice structure. During corrosion testing, each specimen was allowed to stabilize in the solution for one hour, then the potential was scanned at a rate of $0.17 \mathrm{mV} / \mathrm{s}$, first in the positive direction to a reversing current density of $10^{5} \mu \mathrm{A} / \mathrm{cm}^{2}$, then in the negative direction until the current density reached a low value of approximately $1 \mu \mathrm{A} / \mathrm{cm}^{2}$.

Before presenting the polarization results, a schematic cyclic anodic polarization curve, typical of the results, is shown in Figure 1. The curve starts at the freelycorroding open-circuit potential, $E_{\mathrm{corr}}$. From $\mathrm{E}_{\mathrm{c}(\mathrm{rr}}$ to the breakdown potential, $\mathrm{E}_{\mathrm{B}}$, the material is passivated with a resultant very-low corrosion rate (anodic current density). For the iron aluminides in chloride solutions, $E_{B}$ corresrunds to the onset of pitting corrosion. Above $\mathrm{E}_{\mathrm{B}}$, the corrosion rate increases rapidly due to pitting. At the reversing current density, $i_{R}$, the potential scan direction is reversed. However, the current density remains high due to pit propagation until the potential reaches the protection potential, $\mathrm{E}_{\mathrm{P}}$, where the current density again reaches the low passivation value, i.e. at $E_{P}$ the pits have passivated and no longer propagate. With regard to pitting resistance, two factors are important. First, $E_{B}$ should be as far above $E_{c o r r}$ as possible. As the quantity $\left(E_{B}-E_{c o r r}\right)$ increases, the likelihood of pit initiation decreases. And second, EP should be above $E_{\text {corr, }}$, as shown in the down-scan path 1 of Figure 1, such that a "safe" potential range exists between $E_{c o r r}$ and $E_{p}$ where pits neither initiate nor propagate. Therefore, the resistance to pitting also increases as the quantity $\left(\mathrm{E}_{\mathrm{p}}-\mathrm{E}_{\mathrm{cor}}\right)$ increases. Howe:er, $\mathrm{E}_{\mathrm{p}}$ not only depends on the material and electrolyte, but also on the pre-selected value for $\mathrm{i}_{\mathrm{R}}$. As $i_{R}$ increases, deeper pits are produced, and the measured value for $E_{P}$ decreases. Thus, $E_{P}$ may be below $E_{c o r r}$ as shown in the down-scan path 2 of Figure 1. Nevertheless, the two factors described above remain important in characterizing the 
relative resistance to pitting corrosion: as both $\left(E_{B}-E_{c o r r}\right)$ and $\left(E_{P}-E_{c o r r}\right)$ increase, the resistance to pitting corrosion increases.

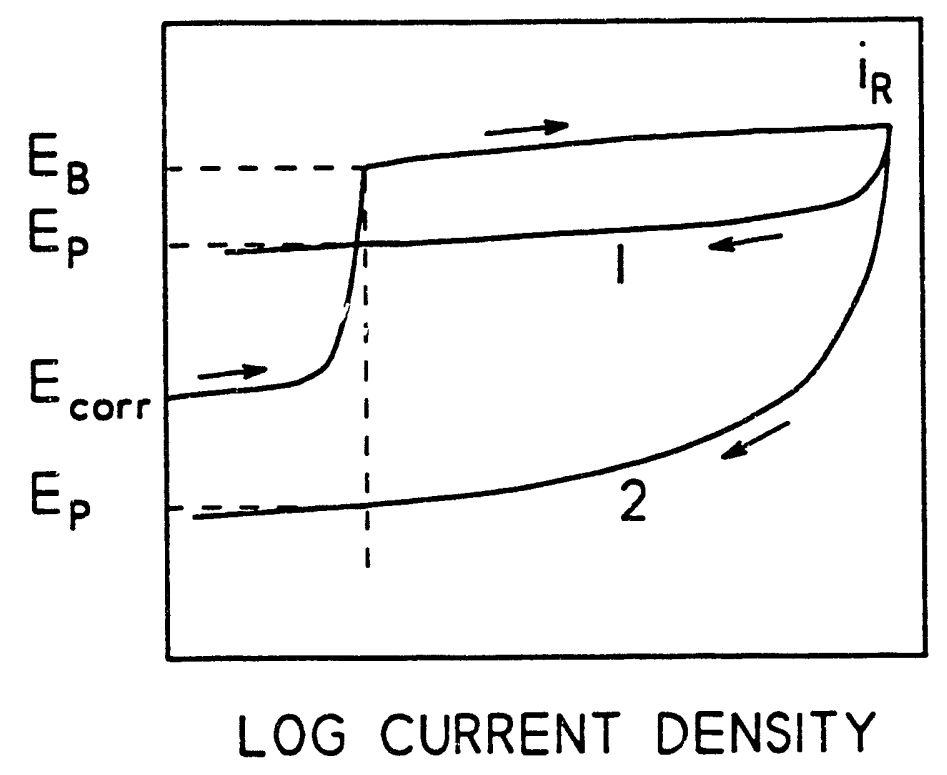

Fig. 1 - Schematic cyclic anodic poirization behavior.

The results of the cyclic anodic polarization tests of FAL-Mo in $3.5 \mathrm{wt} . \% \mathrm{NaCl}$ solution at $25,48,72$ and $95^{\circ} \mathrm{C}$ are shown in the Figure 2 . Generally, the $\mathrm{E}_{\text {corr }}$ values did not differ greatly with temperature, but the breakdown potential for pitting corrosion, $E_{\mathrm{B}}$, and the protection potential, $E_{\mathrm{F}}$, both decreased with increasing temperature. The values for $\left(E_{B}-E_{c o r r}\right)$ were $+200,+90,+140$ and $+110 \mathrm{mV}$ at $25,48,72$, and $95^{\circ} \mathrm{C}$, respectively. The values for $\left(E_{P}-E_{c o r r}\right)$ were $-60,-240,-340$ and $-320 \mathrm{mV}$ at $25,48,72$ and $95^{\circ} \mathrm{C}$, respectively. Thus, hased on these electrochemical results the resistance to pitting corrosion for FAL-Mo is predicted to decrease significantly with increasing temperature, with the sharpest decrease occurring over the temperature range of $25-48^{\circ} \mathrm{C}$. 


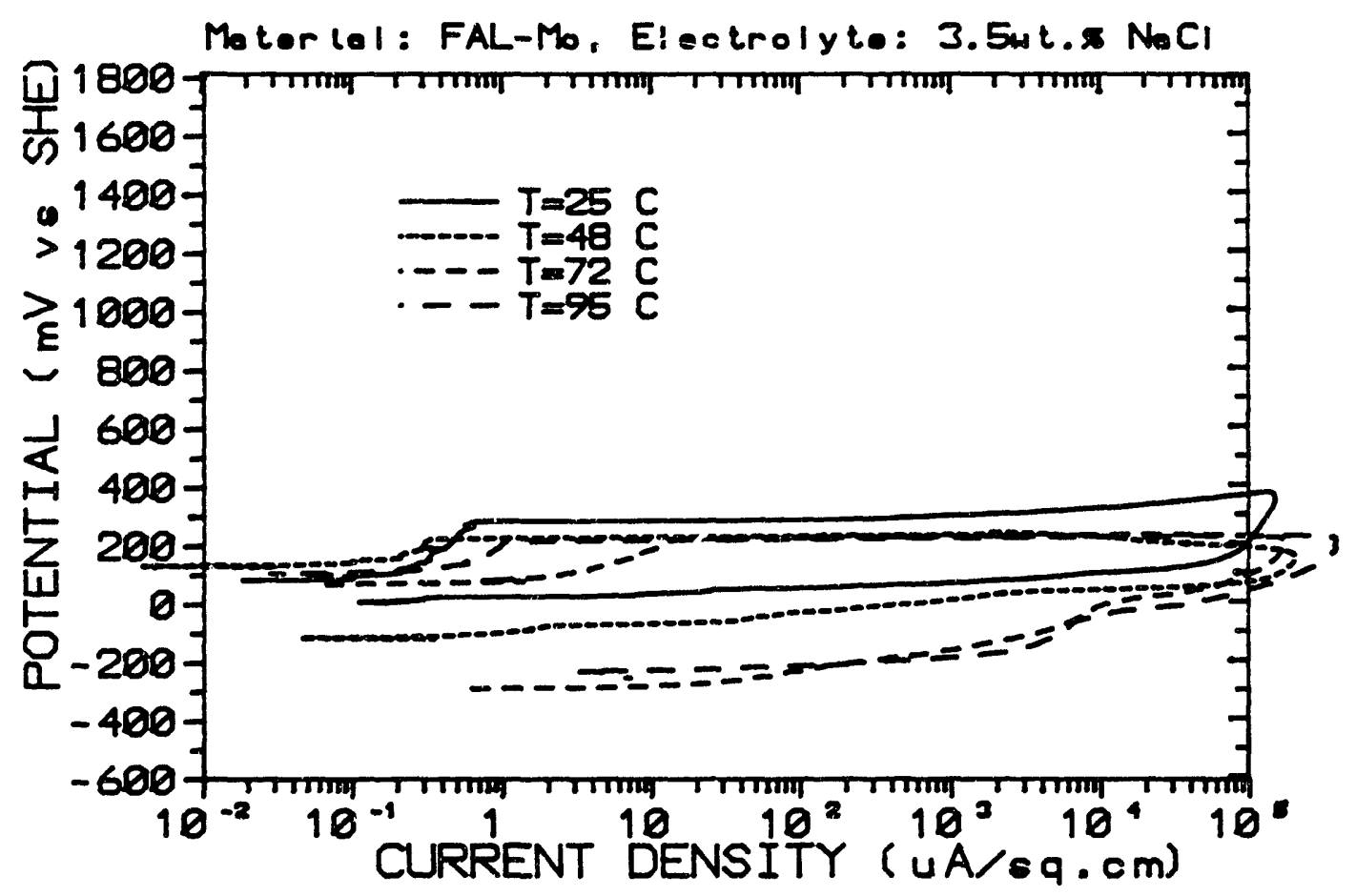

Fig. 2 - Cyclic anodic polarization hehavior of FAL-Mo in $3.5 \mathrm{wt} . \% \mathrm{NaCl}$ at $25,48,72$ and $95^{\circ} \mathrm{C}$.

\section{Crevice Corrosion of FAL-Mo in Chloride Solutions}

Crevice-corrosion test results were previously reported on FAL-Mo in the mild acid-chloride solution ( $\mathrm{pH}=4,200 \mathrm{ppm} \mathrm{Cl}$ ) at room temperature. As reference materials, FA-84 and annealed $304 \mathrm{~L}$ stainless steel (SS) were also evaluated. Before testing, the FAL-Mo and FA-84 materials were annealed for one hour at $750^{\circ} \mathrm{C}$, then oil quenched, thereby producing the B2 structure. The three-week crevice-corrosion tests were conducted by using crevice-forming acetal-resin serrated washers, in accordance with ASTM G78, bolted to the specimens at a torque of $1.13 \mathrm{~m} \cdot \mathrm{N}$ (10 in. lbs.). Each of the two washers per specimen provided 30 plateau-contact sites; thus, each assembly provided 60 crevice sites per specimen. The results produced in the mild acid-chloride solution are presented in Table 1. It is seen that severe crevice corrosion resulted on FA84 (containing $2 \% \mathrm{Cr}$ ), that mild attack resulted on $304 \mathrm{~L} \mathrm{SS}$, but that no crevicecorrosion attack resulted on FAL-Mo (contjining $5 \% \mathrm{Cr}$ and $1 \% \mathrm{Mo}$ ). 
Table 1. Three-week immersion test results for creviced specimens in mild-acid-chloride and $3.5 \mathrm{wt}$. $\% \mathrm{NaCl}$ solutions.

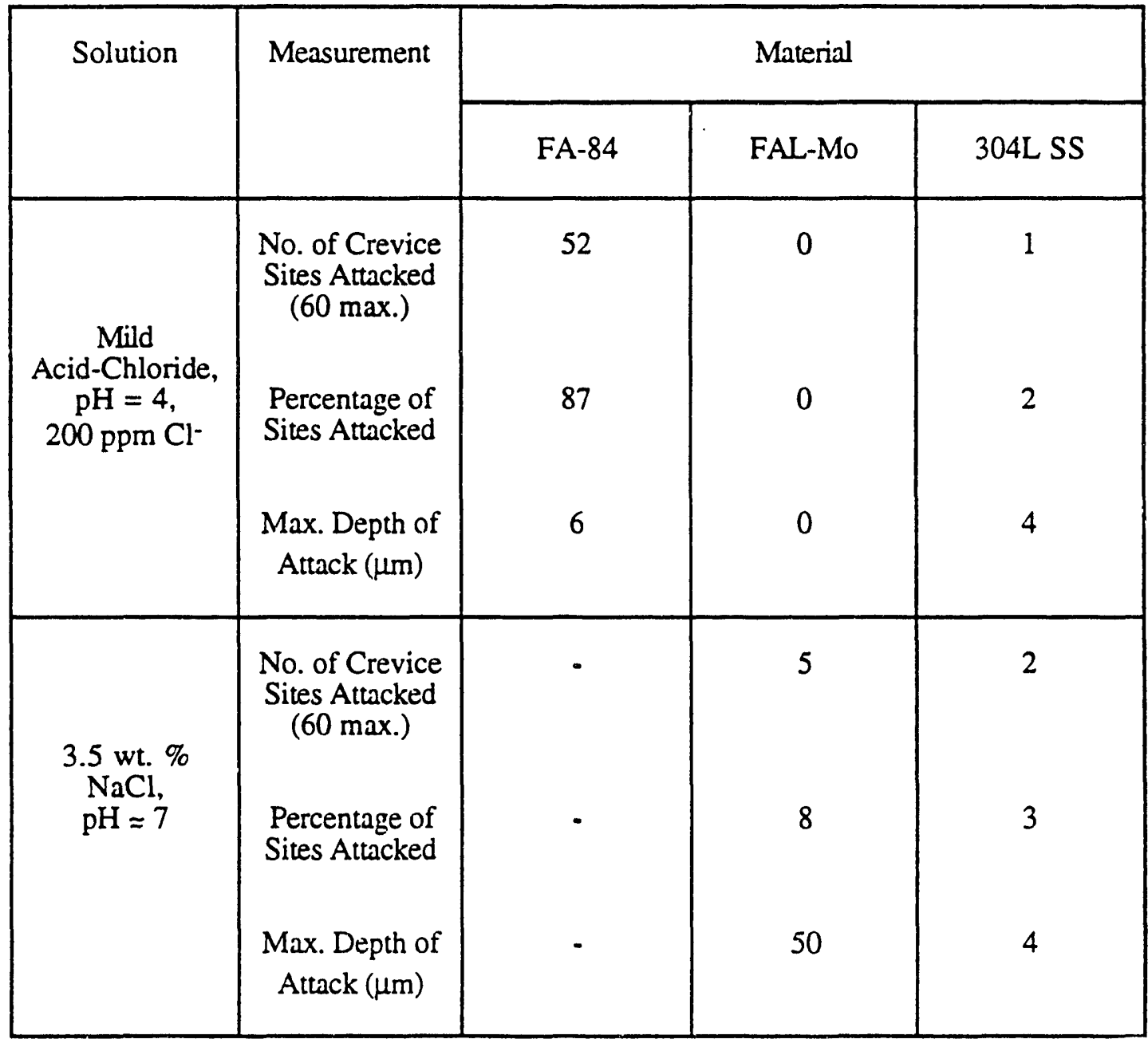

In view of the excellent results for FAL-Mo in the mild acid-chloride solution, it was decided to extend the evaluation to a much-higher chloride-containing solution, 3.5 wt. \% $\mathrm{NaCl}$, again at room temperature and following the procedures previously described. The results are also presented in Table 1. In these tests, only 304L SS was evaluated as a reference material. In this much-higher-chloride solution, it is seen that FAL-Mo did not perform as well as the 304L SS; more crevice sites were attacked and the depths of attack were considerably greater for FAL-Mo in comparison to 304L SS. 
The overall results in Table 1 suggest that the crevice-corrosion resistance of FALMo would be quite good, and comparable to that of 304L SS, in fresh-water systems (i.e. at $\mathrm{pH}$ values down to approximately 4 , and at chloride levels up to approximately 200 $\mathrm{ppm}$ ), but that the resistance would not be adequate in higher-chloride marine environments.

\section{Corrosion in Sulfur-Compound Solutions}

Earlier work reported poor corrosion performance for FA-84, FA-129 and FALMo in relatively-high concentrations $(0.1 \mathrm{M})$ of sodium thiosulfate $\left(\mathrm{Na}_{2} \mathrm{~S}_{2} \mathrm{O}_{3}\right)$ and sodium tetrathionate $\left(\mathrm{Na}_{2} \mathrm{~S}_{4} \mathrm{O}_{6}\right)$. Since actual in-service concentrations will vary depending on conditions (e.g. sulfur content of the fuel, humidity conditions, etc.), it was decided to evaluate the relative performances of these iron aluminides at progressively lower concentrations of thiosulfate and tetrathionate ions. After heat treating the specimens as previously described, polarization tests were conducted to determine active or passive behavior, and polarization-resistance measurements were made which by application of Faraday's law allowed calculation of the average corrosion penetration rates (mils per year, mpy). The electrochemical measurements were performed at room temperature in sodium thiosulfate and sodium thtrathionate solutions at concentrations of $0.1,0.01$ and $0.001 \mathrm{M}$.

Before presenting the results, reference is made to the schematic anodic polarization curves in Figure 3, which are typical of the results to follow. With curve 1, the anodic current density (proportional to the dissolution rate) continuously increases to high values at potentials above the freely-corroding potential, $E_{\text {corr. }}$ This behavior is characteristic of active corrosion whereby a protective passive film is never formed at the material surface. On the other hand, in curve 2 the current density only increases to relatively low values, and stays at these low values until a breakdown potential, $E_{B}$, is reached at a high potential. This hehavior is characteristic of passivation at $E_{c o r r}$, with the passive film remaining in tact until $E_{B}$ is reached. 


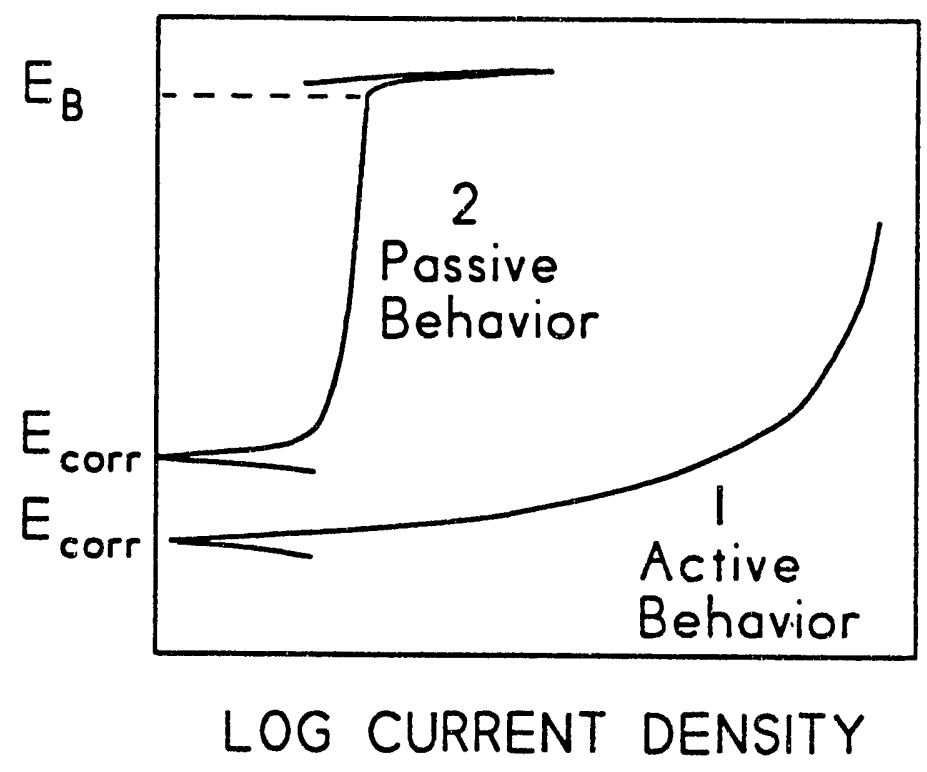

Fig. 3 - Schematic anodic polarization curves representing active and passive behaviors.

The anodic polarization curves in ().1, ().01 and $0.001 \mathrm{M}$ sodium thiosulfate for FA-84, FA-129 and FAL-Mo are presented in Figure 4. It is seen that active corrosion behaviors were produced in all three concentration by FA-84 (2\% Cr) and FA-129 (5\% $\mathrm{Cr}$ ), and that active corrosion behavior was produced in the highest concentration by FAL-Mo ( $5 \% \mathrm{Cr}-1 \% \mathrm{Mo})$. However, passive behaviors were produced by FAL-Mo in the two lower concentrations, 0.01 and $0.001 \mathrm{M}$. The polarization results in the sodium tetrathionate solutions are presented in Figure 5. These results are very similar to those in the thiosulfate solutions. Only the FAl-Mo exhibited passive behavior and only at the two lower concentrations of sodium tetrathionate, 0.01 and $0.001 \mathrm{M}$. 

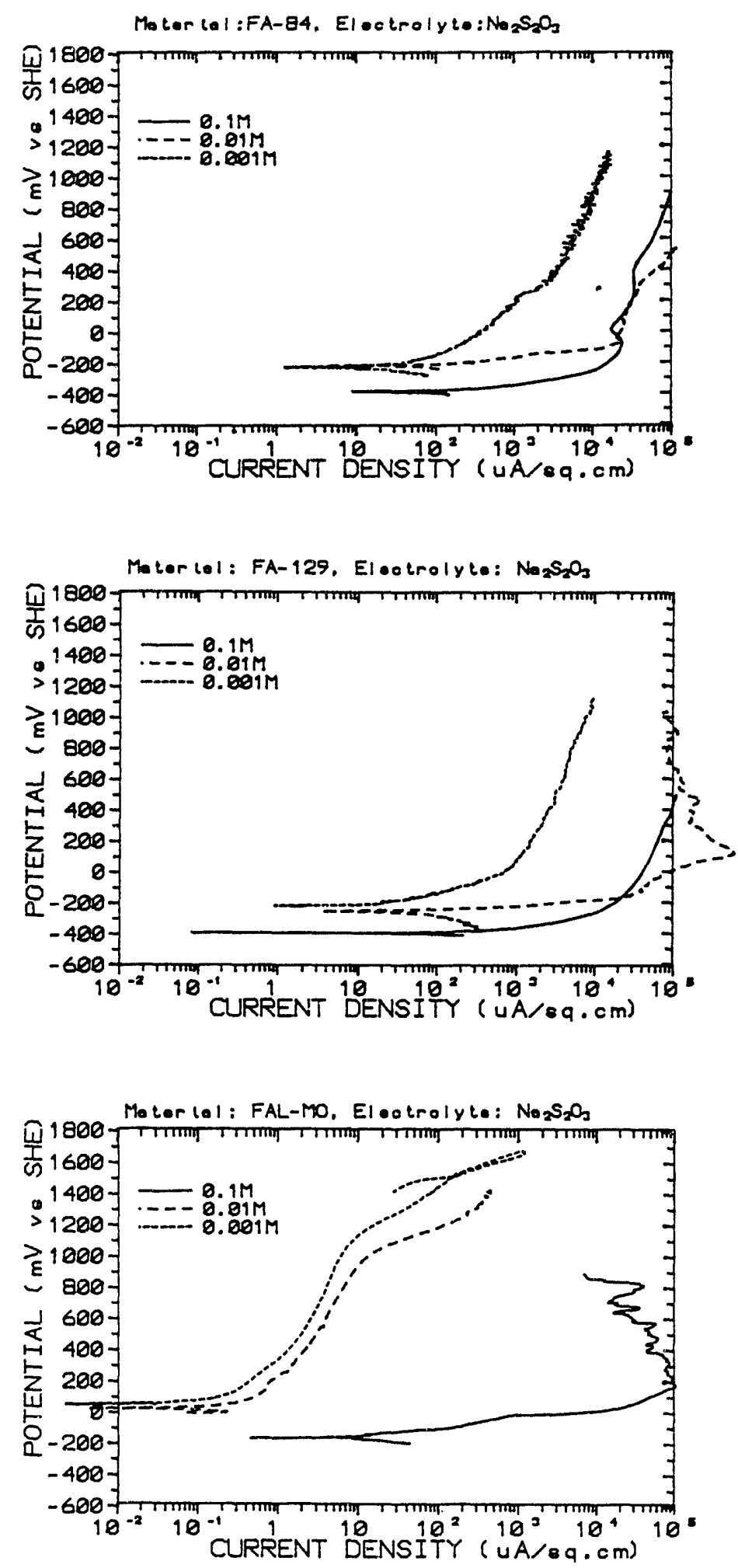

Fig.4 - Anodic polarization behaviors of FA-84, FA-129 and FAL-Mo in $0.1,(0.01,() .(0) 1 \mathrm{M}$ sodium thiosulfate. 

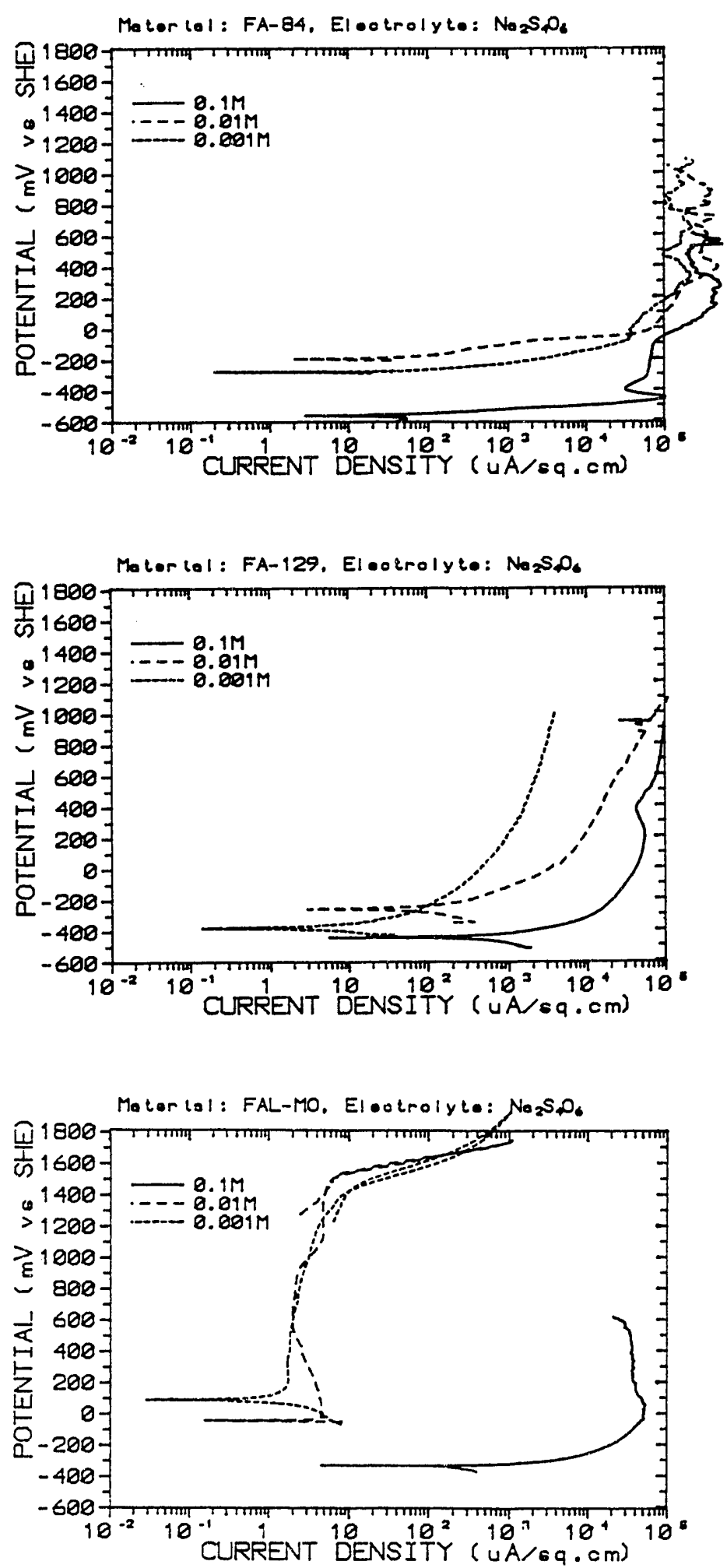

Fig. 5 - Anodic polarization behaviors of FA-84, FA-129 and FAL-Mo in $0.1,0.01$ and $0.001 \mathrm{M}$ sodium tetrathionate. 
The results of the polarization-resistance average-corrosion-rate measurements are given in Table 2. In general, the corrosion rates were high for the materialelectorlyteconcentration combinations that exhibited active polarization behaviors, and lower for those combinations that exhibited passive behaviors, i.e. FAL-Mo in 0.01 and $0.001 \mathrm{M}$ thiosulfate and tetrathionate solutions. It is noted that the passive corrosion rates for FAL-Mo were lower in the 0.01 and $0.001 \mathrm{M}$ thiosulfate solutions than in the 0.01 and $0.001 \mathrm{M}$ tetrathionate solutions.

Table 2. Average corrosion rates by the polarization-resistance method for iron aluminides in thiosulfate and tetrathionate solutions.

\begin{tabular}{|c|c|c|c|c|c|c|}
\hline \multirow{2}{*}{ Material } & \multicolumn{4}{|c}{ Average } & \multicolumn{3}{c|}{ Penetration } & \multicolumn{3}{c|}{$\mathrm{Na}_{2} \mathrm{~S}_{2} \mathrm{O}_{3}$} \\
\cline { 2 - 7 } & \multicolumn{3}{|c|}{$\mathrm{Na}_{2} \mathrm{~S}_{4} \mathrm{O}_{6}$} & & \\
\cline { 2 - 7 } & $0.1 \mathrm{M}$ & $0.01 \mathrm{M}$ & $0.001 \mathrm{M}$ & $0.1 \mathrm{M}$ & $0.01 \mathrm{M}$ & $0.001 \mathrm{M}$ \\
\hline FA-129 & 291 & 118 & 4.2 & 142 & 31.5 & 43.5 \\
\hline FA-84 & 47 & 33.5 & 46.2 & 112 & 124.4 & 12 \\
\hline FAL-MO & 410 & 18.2 & 2.4 & 40.2 & 0.2 & 0.1 \\
\hline
\end{tabular}

Overall, the polarization and polarization-resistance evaluations indicated considerably better performance for FAL-Mo $(5 \% \mathrm{Cr}-1 \% \mathrm{Mo})$ as compared to FA-84 $(2 \% \mathrm{Cr})$ and $\mathrm{FA}-129(5 \% \mathrm{Cr})$ in the sulfur-compound solutions considered. Thus, as with the chloride solutions, additions of both $\mathrm{Cr}$ and $\mathrm{Mo}$ to the $\mathrm{Fe}_{3} \mathrm{Al}$-based aluminides also improved the aqueous corrosion resistance in sulfur-compound solutions. 


\section{REFERENCES}

1. R.A. Buchanan and J.G. Kim, "Aqueous Corrosion Characteristics and Corrosion-Related Cracking Susceptibilities of $\mathrm{Fe}_{3} \mathrm{Al}-\mathrm{Type}$ Iron Aluminides," Department of Energy, Fossil Energy Advanced Research and Technology Development Materials Program, Report ORNL/Sub/88-07685CT92/01, National Technical Information Service, Springfield, VA, April 1991.

2. R.A. Buchanan and J.G. Kim, "Fes Al-Type Iron Aluminides: Aqueous Corrosion Properties in a Range of Electrolytes and Slow-Strain-Rate Ductilities During Aqueous Corrosion," Department of Energy, Fossil Energy Advanced Research and Technology Development Materials Program, Report ORNL/Sub/88-07685CT92/02, National technical Information Service, Springfield, VA, August, 1992. 


\title{
WHC-2-ELECTRO-SPARK DEPOSITED COATINGS FOR \\ FOSSIL ENERGY ENVIRONMENTS
}

\author{
R. N. Johnson \\ Westinghouse Hanford Company \\ P. O. Box 1970, L6-39 \\ Richland, WA 99352
}

INTRODUCTION

The objective of this program is to develop advanced materials coatings capable of operation in fossil energy environments beyond current materials limits, and to provide improvements in materials performance, durability and cost effectiveness for both new and existing power systems. Ultimately, new materials performance limits can enable new systems concepts.

A corollary objective is to further advance the Electro-Spark Deposition (ESD) technology and equipment, and to develop broad commercial applications through technology transfer activities.

The ESD process contributes a new dimension to materials for fossil energy applications by allowing the investigation of surface compositions that are difficult or impractical to achieve by other processes. A wide range of both stable and meta-stable surface alloys and structures can be produced by the ESD alloying and by the rapid solidification inherent in the process. Not only can the standard corrosion-resistant alloys be formed or deposited, for example, but it is also possible to apply refractory metal alloy diffusion barriers on the surface or between the substrate and primary corrosion protection coatings.

Coatings of current interest include single or multi-layer deposits of commercially available hardfacing alloys, as well as custom formulations of metal aluminides, chromium alloys, refractory metals, carbides, silicides, and borides. Materials to be protected include low alloy steels, Alloy 800 , and various stainless steels, including the modifled ("lean") stainless steels. Coatings will also be developed for 
use on the iron aluminides to further enhance their performance and to develop resistance to hydrogen embrittlement.

\section{Background}

Electro-spark eposition is a pulsed-arc micro-welding process that uses short-duration, high-current electrical pulses to weld a consumable electrode material to a metallic substrate. The short duration of the electrical pulse allows an extremely rapid solidification of the deposited material and results in an extremely fine-grained, homogeneous coating that may be amorphous for some materials. The microstructures produced by ESD can provide exceptional corrosion-resistance and wearresistance for many materials.

The ESD process is one of the few methods available by which a fused, metallurgically-bonded coating can be applied with such a low total heat input that the bulk substrate material remains at or near ambient temperatures. This eliminates thermal distortions or changes in metallurgical structure of the substrate. Since the coating is metallurgically bonded, it is inherently more resistant to damage and spalling than the mechanically-bonded coatings produced by most other low-heat-input processes such as detonation gun, plasma spray, electrochemical plating, etc. Nearly any electrically-conductive metal, alloy or cermet can be applied by ESD to metallic substrates.

Further background information on the ESD process is provided in Reference 1 .

\section{DISCUSSION OF PRIOR ACTIVITIES}

Data collected so far indicate that ESD coatings tend to show lower corrosion rates in most environments than the same material would in either bulk form or as a coating applied by other processes. For example, ESD-applied coatings of chromium carbide-15\% nickel exhibit significantly lower corrosion rates in aqueous and liquid metal environments than similar detonation-gun applied coatings. ${ }^{2}$ The 
superior performance of the former is attributed to the extremely finegrained, nearly amorphous structure inherent to the ESD coatings compared to the larger-grained, more heterogeneous detonation-gun coatings.

In tests at Argonne National Laboratory (ANL), this same ESD coating (chromium carbide-15\% nickel) showed four times better sulfidation resistance than Type 310 stainless steel at $875^{\circ} \mathrm{C} .^{3}$ Normally, this composition would not be expected to perform that well because of the strong susceptibility of a nickel matrix to sulfidation attack. Again, the fine grain structure is believed to be a major factor in the corrosion resistance. This observation is in agreement with other Fossil Energy Materials Program work that indicates one mechanism of improving lifetimes of protective oxide films and scales is to maintain as fine a grain structure as possible. ${ }^{4}$ Further improvement in corrosion resistance of the chromium carbide coating was achieved by alloying aluminum into the surface by a further ESD treatment. 5

One of the most significant advances in ESD coatings for use in sulfidation environments has been the successful development of $\mathrm{Fe}_{3} \mathrm{Al}$ as a coating material. Oak Ridge National Laboratory (ORNL) has demonstrated the exceptional corrosion properties of $\mathrm{Fe}_{3} \mathrm{Al}$ in bulk form, but alloying the $\mathrm{Fe}_{3} \mathrm{Al}$ to achieve acceptable mechanical properties so far appears to somewhat compromise the corrosion performance. As one alternative approach, ORNL supplied electrode materials to Westinghouse Hanford Company (WHC) for use in ESD coating development. (Using $\mathrm{Fe}_{3} \mathrm{Al}$ as a coating material allows the selection of the substrate material for optimum mechanical properties and economy while retaining the corrosion resistance offered by the coating.) The coating results to date have been outstanding. The ESD parameters have been developed to the point that consistent, defect-free coatings over $100 \mu \mathrm{m}$ thick can be applied relatively rapidly with good transfer efficiency. The $\mathrm{Fe}_{3} \mathrm{Al}$ appears to produce some of the best coatings of all the materials evaluated for ESD application.

Further coating development is proving that the corrosion performance of the $\mathrm{Fe}_{3} \mathrm{Al}$ coating can be significantly enhanced by the 
use of multi-layer ESD coating techniques. Sulfidation corrosion tests at $\mathrm{ANL}^{5,6}$, for example, showed the beneficial effects of applying a $\mathrm{Nb}$ $12 r$ diffusion barrier coating. The corrosion rate of an ESD coating of $\mathrm{Fe}_{3} \mathrm{Al}$ was reduced by a factor of 2 in tests at $500^{\circ} \mathrm{C}$ when an intermediate ESD coating of $\mathrm{Nb}-1 \mathrm{Zr}$ was first applied to the steel, when compared to the same $\mathrm{Fe}_{3} \mathrm{Al}$ coating applied directly to the steel.

\section{DISCUSSION OF CURRENT ACTIVITIES}

\section{Improved Fe 3 Al Coatings}

Analyses of the $\mathrm{Fe}_{3} \mathrm{Al}$ coatings with and without the $\mathrm{Nb}-1 \mathrm{Zr}$ diffusion barrier coating led to the conclusion that one of the principal reasons for the improved corrosion performance of the $\mathrm{Fe}_{3} \mathrm{Al}$ coating over the $\mathrm{Nb}-1 \mathrm{Zr}$ layer was the higher aluminum content of the coating surface. 7,8 Scanning Electron Microprobe (SEM) analyses showed that the intermediate diffusion barrier reduced the dilution of substrate elements into the coating weld zone and resulted in about $50 \%$ more aluminum in the surface of the coating (15\% vs. 9.5\%).

An obvious next step in developing improved coatings is to further increase the aluminum content of the surface by ESD treatments and to explore the effects of various levels of aluminum in the composition. We used commercially pure aluminum electrodes to directly alloy aluminum into the $\mathrm{Fe}_{3} \mathrm{Al}$ coating surface by ESD. The results so far have been disappointing. Although aluminum is successfully alloyed into the surface, the resulting alloy contains too many defects and cracks to be acceptable as a corrosion barrier coating. Further development of the ESD coating parameters has reduced, but so far not eliminated, the cracking tendencies.

We believe the most likely method of producing an acceptable coating will include the use of a prealloyed electrode, such as the FeAl compositions in development at ORNL. A specimen of FeAl was obtained from ORNL. Although the material was not a practical electrode geometry, we were able to show that the deposition of FeAl is feasible, 
and that development of corrosion-resistant FeAl coatings should be achievable. We are awaiting the fabrication of the higher aluminum content materials into suitable electrode geometries for further coating parameter development.

Development efforts on further improvements in the $\mathrm{Fe}_{3} \mathrm{Al}$ coatings have produced several new candidates for corrosion evaluation. The new coatings represent various combinations of $\mathrm{Fe}_{3} \mathrm{Al}$ with $\mathrm{Nb}$ or Mo diffusion barriers, and Pt or Pd surface treatments, all applied to type 316 SS or Alloy 800 substrates. These and other coatings in development will be used to evaluate the relative effectiveness of the various refractory metals as diffusion barrier coatings for their contribution to the corrosion performance. The surface treatments with Pt and Pd are based on gas turbine coating experience demonstrating that light alloying additions of platinum to aluminide coatings increase the stability and life of protective oxide film formation. (The ESD process is being used commercially to economically apply Pt to gas turbine components.)

Candidate coatings now in sulfidation corrosion testing at ANL include the following:

1. $\mathrm{Fe}_{3} \mathrm{Al}$ on $316 \mathrm{SS}$

2. $\mathrm{Fe}_{3} \mathrm{Al}$ on Alloy 800

3. $\mathrm{Fe}_{3} \mathrm{Al}$ on $\mathrm{Nb}-1 \mathrm{Zr}$ on $316 \mathrm{SS}$

4. $\mathrm{Fe}_{3} \mathrm{Al}$ on $\mathrm{Nb}-1 \mathrm{Zr}$ on Alloy 800

5. $\mathrm{Fe}_{3} \mathrm{Al}$ on $\mathrm{Mo}$ on $316 \mathrm{SS}$

6. Pt on $\mathrm{Fe}_{3} \mathrm{Al}$ on $\mathrm{Nb}-1 \mathrm{Zr}$ on $316 \mathrm{SS}$

7. Pt on $\mathrm{Fe}_{3} \mathrm{Al}$ on $\mathrm{Nb}-1 \mathrm{Zr}$ on Alloy 800

8. Pd on $\mathrm{Fe}_{3} \mathrm{Al}$ on $\mathrm{Nb}-1 \mathrm{Zr}$ on $316 \mathrm{SS}$

9. Pd on $\mathrm{Fe}_{3} \mathrm{Al}$ on $\mathrm{Nb}-1 \mathrm{Zr}$ on Alloy 800

Coating designs and compositions will be modified in response to the corrosion results as data become available. The surface modifications possible by the ESD process ultimately should be capable of tailoring a material surface chemistry to a given oxidation or sulfidation environment in a fossil energy system. 
Surface Modifications for Fe 3 Al-Base Alloys

Some $\mathrm{Fe}_{3} \mathrm{Al}$ and $\mathrm{FeAl}$-base alloys are subject to hydrogen eubrittlement at room temperature in moisture-containing atmospheres. ORNL has been making progress in mitigating these effects through alloying additions and special heat treatments ${ }^{9}$. Another approach may be through the use of ESD treatments to modify the surface chemistry or the metallurgical structure to produce resistance to the hydrogen embrittlement. Initial experiments involved ESD coatings of $\mathrm{Fe}_{3} \mathrm{Al}$ on $\mathrm{Fe}_{3} \mathrm{Al}$ substrates to reduce the surface grain size (using the rapid solidification inherent to the ESD process). Although a thin layer of fine-grained $\mathrm{Fe}_{3} \mathrm{Al}$ was achieved, hydrogen embrittlement was not prevented. Further experiments in producing a thicker layer of finegrained material and in modification of compositions by surface alloying will be performed when additional $\mathrm{Fe}_{3} \mathrm{Al}$ substrates become available from ORNL.

\section{Applications Development and Technology Transfer}

The author attended the Fourth Annual Fuel Cells Review Meeting at the Morgantown Energy Technology Center to investigate potential applications of ESD technology to fuel cell materials. Although the meeting emphasis was not on materials, at least two potential applications of ESD atings were identified. These included developing intermediate coatings for the bonding of $\mathrm{LiFeO}_{2}$ to $316 \mathrm{SS}$, and applying corrosion-resistant coatings to metal-to-metal electrical contacts in fuel cell environments.

We are involved in assistir. in the start-up of a new business near Portland, OR, aimed at further commercialization of the ESD process. Activities have included training of personnel, recommendations for equipment and materials, and consulting on techniques and process parameters. Successful commercial applications of ESD now in production or in production preparation at the new organization include: 
a) Coating of punch and die sets. A 200-300 percent improvement

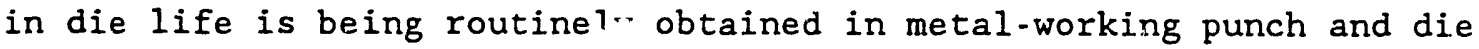
sets.

b) Extrusion dies. Carbide coatings were applied to the interior of extrusion dies used by General Electric Company in the extrusion of titanium forging blanks for gas turbine engine components. The dies are now in test. The coatings have the potential of producing major savings in die fabrication costs and in production efficiency.

\section{REFERENCES}

1. R. N. Johnson, "Principles and Applications of Electro-Spark Deposition", Surface Modification Technologies, T. S. Sudarshan and D. G. Bhat, eds., The Metallurgical Society, January 1988, pp. 189-213.

2. R. N. Johnson, "Coatings for Fast Breeder Reactors", in Metallurgical Coatings, Elsevier Sequoia, S. A., New York, 1984, pp. $31-47$.

3. K. Natesan and R. N. Johnson, "Corrosion Resistance of Chromium Carbide Coatings in Oxygen-Sulfur Environments", Surface and Coatings Technology, Vol, 33, 1987, pp. 341-351.

4. I. G. Wright and J. A. Colwell, "A Review of the Effects of Micro-Alloying Constituents on the Formation and Breakdown of Protective Oxide Scales on High Temperature Alloys at Temperatures Below $700^{\circ} \mathrm{Cl}$, ORNL/Sub/86-57444/01, September 1989.

5. K. Natesan and R. N. Johnson, "Development of Coatings with Improved Corrosion Resistance in Sulfur-Containing Environments", presented at the International Conference on Metallurgical Coatings, San Diego, April 1990, published in Surface and Coatings Technology, Vol. 43/44, 1990, pp. 821-835.

6. R. N. Johnson, "Electro-Spark Deposited Coatings for Protection of Materials in Sulfidizing Environments", Proceedings of the Fourth Annual Conference on Fossil Energy Materials, ORNL/FMP-90/1, August 1990, pp. 321-329.

7. R. N. Johnson, "Electro-Spark Deposited Coatings for Protection of Materials in Sulfidizing Atmospheres", Proceedings of the Fifth Annual Conference on Fossil Energy Materials, ORNL/FMP-91/1, Septei jer 1991, pp. 281-288. 
8. F. N. Johnson, "Electro-Spark Deposited Coatings for Fossil Energy Environments," Proceedings of the Sixth Annual Conference on

Fossil Energy Materials, ORNL/FMP-92/1, July 1992, PP. 257-264.

9. C. G. McKamey and C. T. Liu, "Environmental Embrittlement of Iron Aluminides in Moisture-Containing Atmospheres", in Proc.

Environmental Effects on Advanced Materials. NACE Conference, June 1991. 
PART IV - TECHNOLOGY DEVELOPMENT AND TRANSFER 


\title{
3M-4FABRICATION OF COMMERCIALSSCALE FIBER-REINFORCED HOT GAS FILTERS BY CHEMICAL VAPOR DEPOSITION
}

\author{
Robert G. Smith \\ Bldg 203-1-01 \\ 3M Center \\ St. Paul, MN 55144-1000
}

\section{INTRODUCTION}

Since the oil crisis of 1973 , more efficient coal to energy processes have been sought and pressurized fluidized bed combustion (PFBC) and coal gasification combined cycle (IGCC) are attractive technologies. Hot gas cleanup is needed for both PFBC and IGCC for turbine protection. High efficiency cyclones have been used but do not remove particles smaller than about five micrometers so that additional cleanup is needed in order to satisfy environmental constraints. Hot gas filtration using rigid ceramic filters will protect turbines and meet New Source Performance Standards (NSPS). Testing has demonstrated dust removal at high efficiency and at an acceptable pressure loss. 1,2 Major concerns have been thermal shock caused by pulse-cleaning, chemical attack by alkali vapor and cleanability.

Dust has been captured upstream of gas turbines in either PFBC or IGCC in a fashion analogous to baghouse filtration where dust is collected on a filter and periodically removed by back-pulsing.

Rigid ceramic filters tested so far are called candles. They are shaped like large test tubes and are made from ceramic particles and fibers which are bonded with a glassy phase. The gas path through candles is $1.5 \mathrm{~cm}$ in length, and candles are fairly heavy, each one weighing about six kilograms.

Thicker ceramic structures are less tolerant of thermal shock than thinner ones, other things being equal, and lighter filters would be easier to support than heavier ones. Thinner filters should also offer less resistance to flow. The tubesheet from which filters are suspended is exposed to about $850^{\circ} \mathrm{C}$ and must be constructed of a refractory metal. The more weight it must support, the more expensive it will be and the more complicated will be its design.

The goal of the work reported here is to make a light, thin, rigid ceramic filter and the approach taken is to make it as a ceramic fiber reinforced ceramic matrix composite.

As engineering materials, ceramic/ceramic composites which have brittle matrices are very old, however mechanical behavior is less well understood than is the behavior of materials like fiberglass reinforced plastic (FRP). In composites such as FRP the matrix is much less stiff than the reinforcement, the bond between matrix and reinforcement is 
strong, and the strength of the composite is determined by the strength of the reinforcement.

Ceramic/ceramic composites which display toughness differ from FRP. In particular, the bond between reinforcement and matrix must be loose. Ceramic/ceramic composites with a tight bond between matrix and reinforcement have been observed to be brittle. In contrast, ceramic/ceramic composites with a loose bond between reinforcement and matrix have been observed to be damage-tolerant. $3,4,5$

Conventional ceramics processing techniques such as hot pressing mixtures of ceramic particles and fibers do not produce good composites because fibers are damaged by pressures and temperatures required in processing. Also, decoupling the matrix from the reinforcement is difficult. Chemical vapor infiltration (CVI) is a technique which avoids these problems. Making high temperature filters by CVI of fibrous substrates is a reasonable method of fabrication, especially since CVI lends itself to producing porous structures. 6

To understand the advantages which this technology offers to the making of filters, it is helpful to review experience with candles.

Candle filters are constructed of large-grained silicon carbide particles bonded with a glassy phase. Large pores for relatively unimpeded flow of gas characterize the structure. The filtering surface is the outside of the tube and is a thin, porous layer of much finer-grained material reinforced with silica-alumina fibers. Thus the filter consists of an outer layer of fine pores over a structural support having much larger pores.

From the standpoint of filtration, this is a desirable structure. It fosters cake filtration where dust forms a layer on the surface. Depth filtration, where dust is captured within the filter itself, is undesirable since such filters are difficult to clean.

During cleaning, a pulse of high pressure air is introduced into the center of the candle and the dust cake is removed by reverse flow. Pulse air is not heated and candles are exposed to thermal shock. Cleaning may be required as often as every two minutes, depending on dust load and dust characteristics, and a large number of cleaning pulses must be endured if filters are to last thousands of hours. Economics require filters to last approximately 10,000 hours.

Examination of candles after 790 hours of PFBC service showed cracks due to thermal shock and tests showed significant loss in strength, at least for some of the candles. $^{7}$ Evidence of chemical attack of the glassy, bond phase was not found. Nevertheless, it is a concern especially given the long life which filters must display, and the evidence of attack of refractories and ceramic fibers by alkali vapor which is in the literature. 8.9 .10

The goal of the work described here has been to develop a filter, similar to a candle, but which is lighter, thinner, less sensitive to alkali attack, and less sensitive to thermal shock. Making such a filter from a ceramic fiber reinforced, ceramic matrix composite is the approach which has been followed. 
The approach of this phase of the program has been to fabricate a set of 2 -inch diameter by 4 -inch long substrates that filter samples can be quickly fabricated over and tested to determine filter characteristics without going through the entire candle filter fabrication process. Perforated metal or metal screening is used as the substrate. As a second step, CVD coated filter substrates are being prepared on which the best filter surfaces can be applied and tested in 4-inch lengths. Filter surface bonding experiments can also be run on these 4-inch long substrates. Following these steps, complete filters will be fabricated in 12 to 18 -inch lengths as a step towards full length candle filters.

\section{DISCUSSION OF CURRENT ACTIVITIES}

\subsection{Substrate Preparation}

Twelve perforated metal filter substrates, 2 inch diameter by 4 inch long, were prepared from perforated metal welded into cylinders for filament winding filter samples. Four metal screen filter substrates for slurry coating filters were prepared by covering small, 2 inch diameter by 4 inch long, air exhaust mufflers with fine gauge screening. Four braided preforms were made for use as substrates of selected filter surfaces.

The four foot long preforms were CVD coated at 3M-Delta $\mathrm{G}$ in one coating run.

The four foot long performs were chemical vapor deposition (CVD) coated with silicon carbide matrix at 3M-Delta $\mathrm{G}$ in one set of coating runs.

The preform was suspended in a graphite reactor which was within a vacuum envelope. The graphite reactor was induction heated. Methyltrichlorosilane (MTS) was the silicon carbide precursor and was admitted to the reactor together with hydrogen and nitrogen.

Four filament wound preforms based on the original program's filament winding experience were attempted using the $3 \mathrm{M}$ Ceramic Materials Department filament winder in Building 60 . The run resulted in establishing good winding procedures including resin curing but the samples were not usable as filter substrates. Changes must be made to open up the winding patterns as the final ply sealed off the substrates' pores. Some of the physical setup must be changed to improve removal of the preform from the winding mandrel.

\subsection{Application of Filter Surface}

Twenty filter surfaces using nine winding patterns and several Nextel ${ }^{\mathrm{TM}} 312$ and 440 yarn or roving constructions have been filament wound onto the perforated metal substrates and prepared for testing. The variation in winding patterns involve angle of winding to mandrel axis, center to center fiber spacing, and a number of pattern cycles.

All the parts for the full size slurry coater have arrived except the tank which has been delayed by the vendor. In the mean time, we have assembled a small table top slurry coater from a $3 \mathrm{M}$ lab vacuum pump, spray paint reservoir, and plastic cylinder for working with the small four inch length samples. Several samples were slurry coated onto metal screen substrates and a first sample is in testing. The first, slurry coated filter surfaces have been made from $1 / 8$ inch length Nextel ${ }^{\mathrm{TM}} 312$ chopped fibers in a water-methyl 
cellulose solution. The initial filter surfaces suffered the same surface roughness or spiked surface problems Lloyd White experienced at Refractory Products when making the full size candle filters. Initial slurry coating samples have been aimed at producing a smooth surface. Combinations of fiber compositions and sizes will be tried next, once a consistent flat filter surface is produced.

A third filter construction is also being tested in the 2 inch diameter by 4 inch long size samples. It is fabricated from a $3 \mathrm{M}$ proprietary material that can be discussed in more detail as the necessary protection is obtained on the material.

\subsection{Bonding of Filter Surface}

Sol Gel samples have been prepared to be ready for bonding experiments as soon as filter surfaces are available on the CVD coated substrates. Initial samples of the $3 \mathrm{M}$ proprietary filter material have been CVD bonded as part of a larger $3 \mathrm{M}$ experiment on the material at the 3M-Delta $G$ facility. Four of the six samples appear to be heavily coated. Additional sets of samples will be CVD coated in our laboratory specifically for filtration usage.

\subsection{Filter Testing}

Two members of our team are now trained to operate the TSI 8110 filter tester in the 3M Ceramic Materials Department. The tester can be used to determine pressure drop versus flow rate and/or be used to load the filter with 0.1 micron diameter particles of sodium chloride to determine pressure drop and efficiency. We fabricated a dozen flat aluminum disks with 1.5 inch diameter holes in the center as fixtures for mounting and testing the four inch long filter samples in the TSI 8110 tester. The four inch long samples are sealed to the disk with RTV Silicone and the open and plugged with a stopper and RTV Silicone. After curing overnight the disk with filter can be quickly inserted into the tester and tested. The disk and sealing method eliminated several complicated procedures previously used for cylindrical filters. Filament wound filters, slurry coated filters, and several $3 \mathrm{M}$ proprietary material filters have been tested.

A sample of a Schumacher filter with the same four inch length as our test filters has also been tested to determine target filter characteristics. Figures 1 through 4 show the pressure drop and efficiency for the Schumacher filter and several of the test filters.

Figure 1 shows the Schumacher filter performance. the initial filament wound sample filters quickly plugged and had high pressure drops as shown in Figure 2. Initial improvements in both the filament winding patterns and fiber, the slurry coating, and the proprietary material have moved us towards the Schumacher target. Figure 3 shows the first improvements in the filament wound filter surfaces while Figure 4 shows the $3 \mathrm{M}$ proprietary material before bonding. Work is continuing to improve the filter surface and match or better the Schumacher filter properties.

The pulse tester has been moved to our building at the $3 \mathrm{M}$ Center due to the prior location being vacated. The tester is reconnected to the utilities and will be tested during December. 


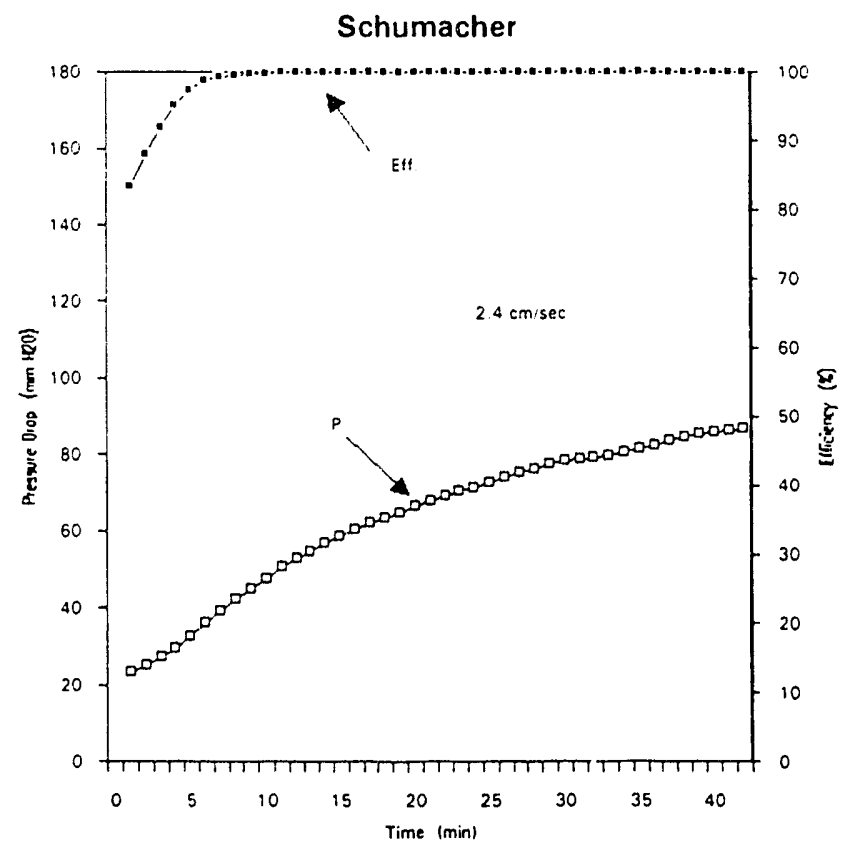

Figure 1: Schumacher Filter Performance

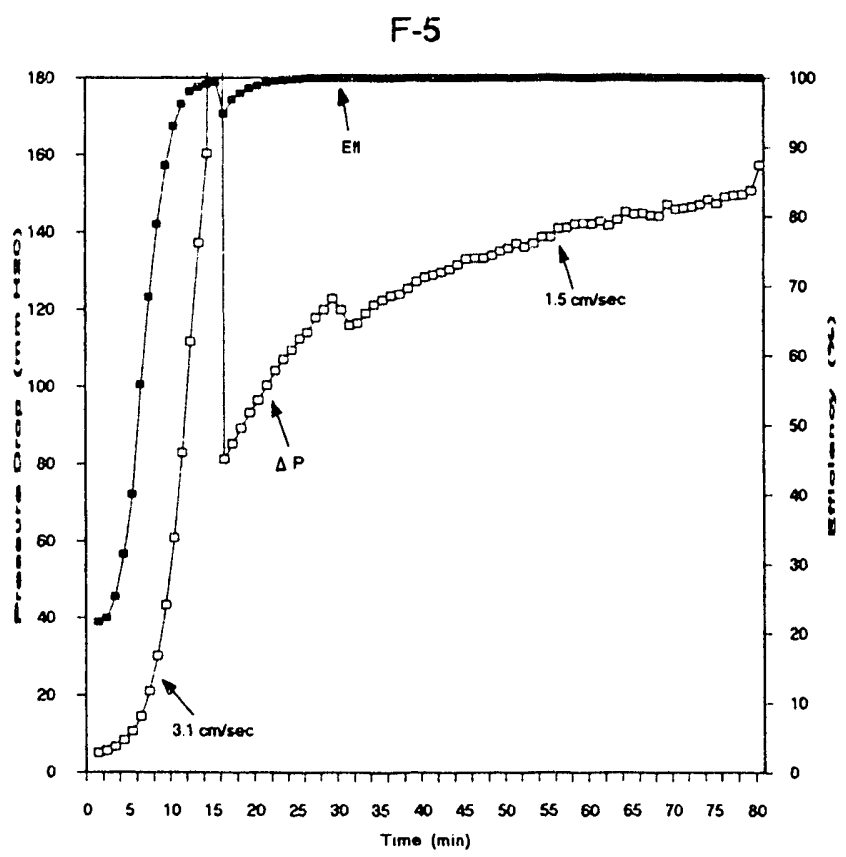

Figure 2: Initial Filament Wound Filter Performance 


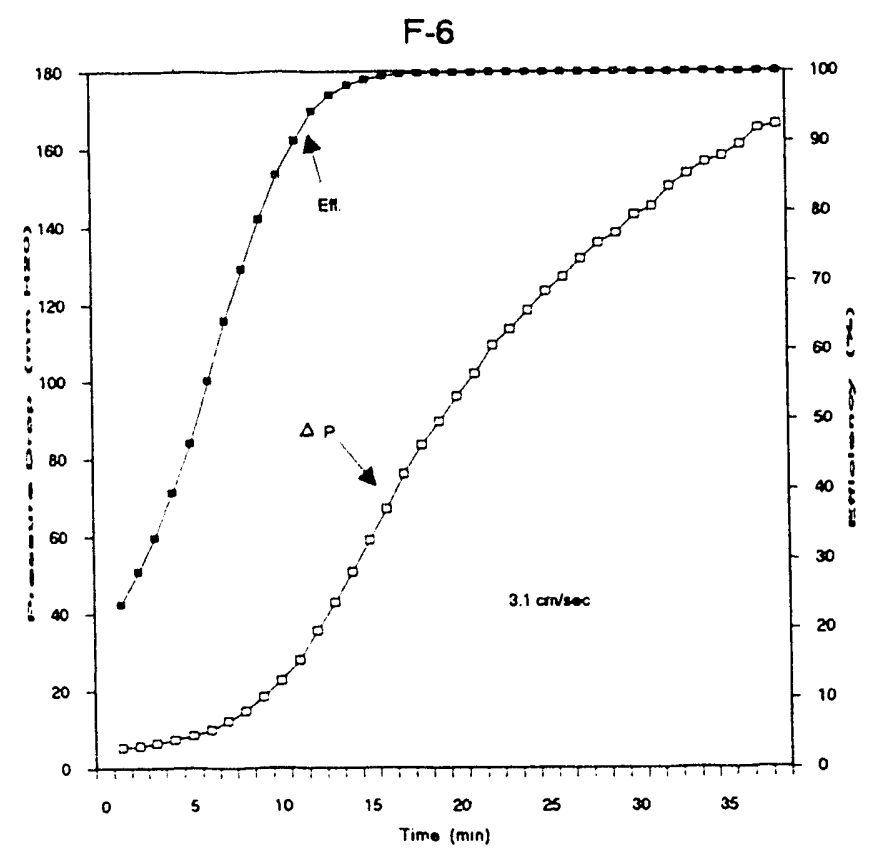

Figure 3: First Improvements in Filament Wound Filter Performance

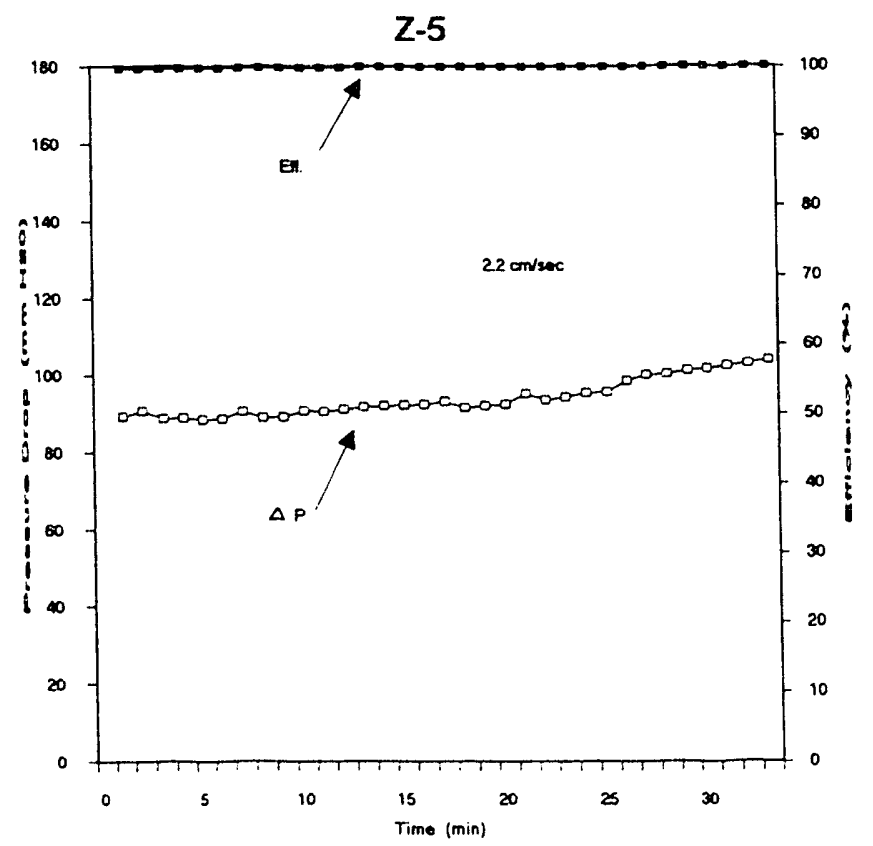

Figure 4: 3M Proprietary Material Filter Performance 


\subsection{Demonstration Filters}

Preparation of the demonstration filters is scheduled to start at the latest in February, 1993 with the performance testing scheduled to start March 1, 1993 at the latest.

\subsection{Analytical Testing}

Polished cross sections and SEM analysis are in process on the Schumacher filter sample to better understand the current product construction and capabilities.

\subsection{Conclusions}

Initial development work at the four-month stage indicates several possible methods of fabricating a useful candle filter surface over a porous ceramic composite substrate formed from Nextel ${ }^{\mathrm{TM}}$ ceramic fibers and a silicon carbide matrix.

\section{REFERENCES}

1. T. E. Lippert, M. A. Alvin, D. M. Bachovchin, G. B. Haldipur, R. A. Newby, and E. E. Smelzer, Development and Commercialization of Hot Gas Filtration Systems. In Proceedings of the 1991 International Conference on Fluidized Bed Combustion, Montreal, Canada, 1073-1080, April 21-24, 1991. ASME, NY, NY.

2. John Stringer, A. J. Leitch, and R. K. Clark, The EPRI Hot Gas Filter at Grimethorpe: What Worked. What Broke and Where Do We Go Now? In Proceedings of the 1991 International Conference on Fluidized Bed Combustion, Montreal, Canada, 971-984, April 21-24, 1991. ASME, NY, NY.

3. M. J. Chappell and R. S. Millman, The fabrication of ceramic-coated carbon fibre duplex elements, J. Material Sci., 1933-1948, (1974).

4. L. Boyne, J. Hill and K. Turner, CVD Strengthening of Carbon Fibre-Glassy Carbon Composites, in the Proceedings of the Conference on Chemical Vapor Deposition, 5th International Conference, 577-588, (1975).

5. J. Aveston, G. A. Cooper and A. Kelly, Single and Multiple Fractures in the Properties of Fibre Composites, Conference Proceedings Nat. Physical Lab., IPC Science and Technology Press LTD Surrey, England, 15-25, (1971).

6. D. P. Stinton, R. A. Lowden, and Ramsey Chang, Ceramic Engineering \& Science Proceedings, vol. 9, no. 9-10, p. 1233-1244, 1988.

7. John Stringer, et. al., op. cit.

8. John Sawyer, R. J. Vass, N. R. Brown, and J. J. Brown, Corrosion and Degradation of Ceramic Particulate Filters in Direct Coal-Fired Turbine Applications, presented at the Gas Turbine and Aeroengine Congress and Exposition, June 11-14, 1990, Brussels, Belgium. 
9. J. E. Oakey and G. P. Reed, The Behavior of High Temperature Filter materials in Hot Gasifier and Combustor Atmospheres, I. Chem. E. Symposium Series No. 99, $421-444,1986$

10. P. Dietrichs and W. Kronert, The Effect of Different Gas Atmospheres on Ceramic Eibre Materials, Interceram, p. 223-236, NR.3, 1982 


\title{
B\&W-4-EVALUATION OF THE FABRICABILITY OF ADVANCED IRON ALUMINIDE-CLAD AUSTENITIC STAINLESS STEEL TUBING
}

W.R. Mohn and M.J. Topolski

\author{
Babcock \& Wilcox Company \\ Research \& Development Division \\ 1562 Beeson Street \\ Alliance, $\mathrm{OH} 44601-2196$
}

\section{INTRODUCTION}

The objectives of this work are to develop and demonstrate a process to produce iron aluminide-clad austenitic stainless steel tubing for applications in fossil energy generation systems. Successful fabrication of this type of duplex structural material will present unique opportunities for improving elevated temperature corrosion resistance and extending the useful lifetimes of critical components such as superheater and reheater tubes in power boilers. ${ }^{1-6}$ Based on the results of iron aluminide/base alloy compatibility studies completed in an earlier part of this program, 304 austenitic stainless steel was chosen as the preferred substrate material for continued development. ${ }^{\text {? }}$

Most of the activities for this reporting period have involved the detailed planning and preparations for conducting the clad tube fabrication trials and have included procurement of necessary materials, selection of initial processing parameters, and scheduling use of required metalworking and inspection equipment at various commercial facilities. A preliminary process specification has been prepared which incorporates the recommendations and practical considerations for producing the $\mathrm{Fe}_{3} \mathrm{Al}$-clad 304 stainless steel tubing. An assessment of the technical and economical merits of $\mathrm{Fe}_{3} \mathrm{Al}$-clad austenitic stainless steel components in power gtieration systems, initiated at the beginning of the Program, has been completed by the Babcock \& Wilcox Fassil Power Division. 


\title{
DISCUSSION OF CURRENT ACTIVITIES
}

\author{
Technical and Economic Assessment
}

The technical and economic merits of $\mathrm{Fe}_{3} \mathrm{Al}$-clad austenitic stainless steels were examined by the Babcock \& Wilcox Fossil Power Division (FPD) and assessed with respect to potential power boiler applications. The assessment was based on the understanding that the developed clad tubing would have the necessary properties and characteristics to allow its use at about $1100^{\circ} \mathrm{F}$ to $1300^{\circ} \mathrm{F}$ for extended service. A summary of the FPD observations are given below.

* To be commercially feasible, $\mathrm{Fe}_{3} \mathrm{Al}$-clad austenitic stainless steel tubing must be formable, capable of small bend radii. Superheater and reheater sections currently have bend radii as small as two tube diameters, accumulating a total strain of nearly $50 \%$. Bends with R/D ratios of 3 or 4 are common. If such bends cannot be made cold (room temperature), then the feasibility of hot bending, as well as the resultant effects on clad tube properties, must be determined.

* The cost of clad tubing, due to a more complex production sequence, will be greater than that of monolithic alloy tubing. Accordingly, the gains in extended life and performance provided by the clad tubing will have to justify the greater initial cost.

* For consideration as superheater and reheater applications, $\mathrm{Fe}_{3} \mathrm{Al}$-clad tubing must be evaluated for resistance to coal ash and oil ash corrosion, as well as for resistance to other typeis of corrosion and erosive degradation.

* Practical use of $\mathrm{Fe}_{3} \mathrm{Al}$-clad tubes will require effective methods for fusion welding and for protecting all welds (during service) which are required for assembly, attachment, and installation.

* Since commercial use of $\mathrm{Fe}_{3} \mathrm{Al}$-clad austenitic stainless steel tubes will always be sensitive to cost, they will first be utilized only in the hottest parts of superheaters. These initial applications will provide a relatively small market compared to the less expensive alloy tubing. 
Potential applications for fully developed $\mathrm{Fe}_{3} \mathrm{Al}$-clad tubing include superheaters for syngas coolers, conventional utility boilers, and advanced boiler systems where creep and coal ash corrosion are especially problematic.

\section{Selection of $\mathrm{Fe}_{3} \mathrm{Al} / 304 \mathrm{SS}$}

The results of an initial phase of the Program, which investigated the compatibility of $\mathrm{Fe}_{3} \mathrm{Al}$ with four different austenitic stainless steel substrates, showed that the $\mathrm{Fe}_{3} \mathrm{Al} / 304 \mathrm{SS}$ combination offered the highest potential for successful fabrication of clad tubing. This joint assessment between ORNL and B\&W was based on the relative characteristics of the diffusion layers that formed during elevated temperature processing, Figure 1.
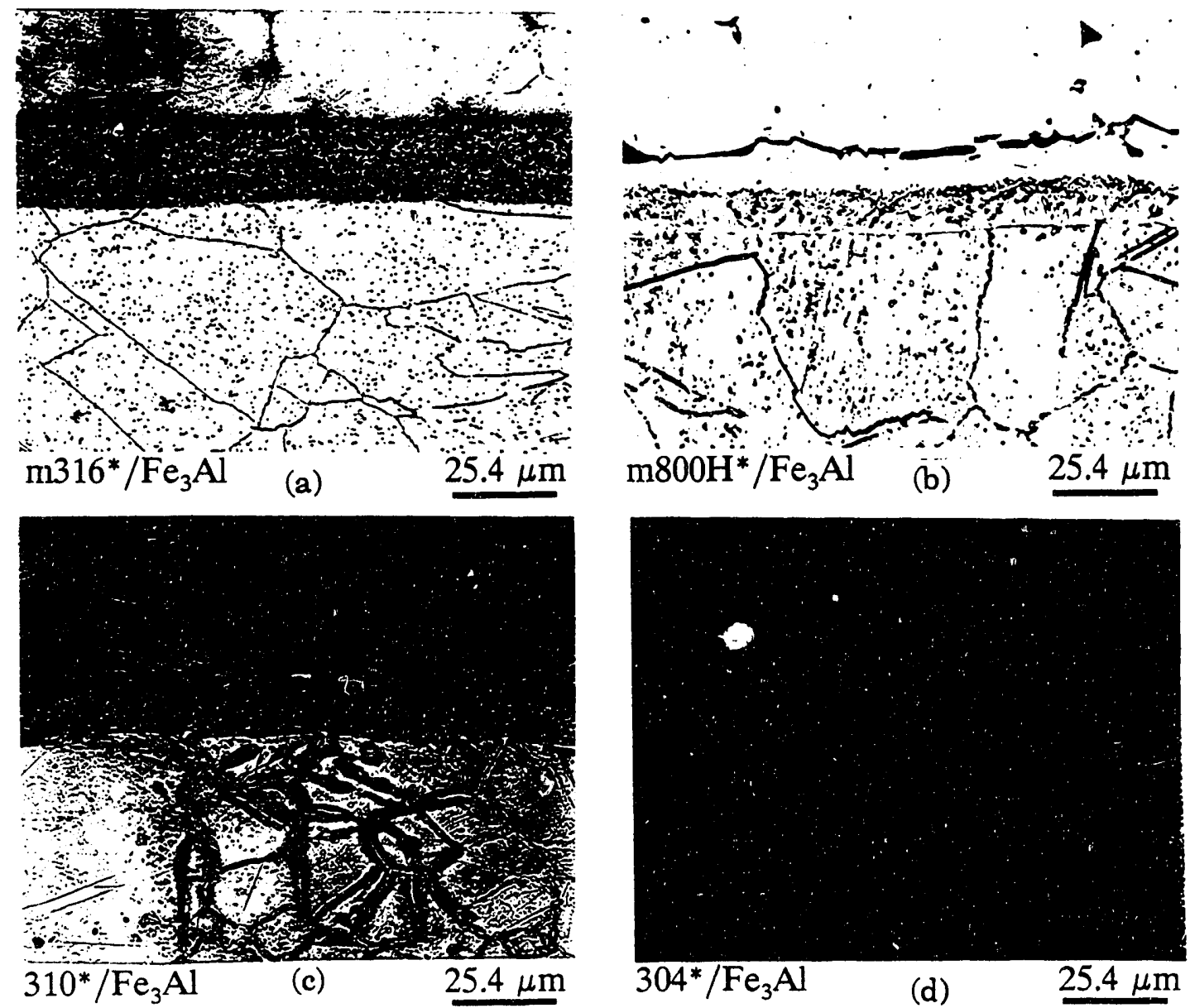

Fig. 1. Comparison of microstructures showing diffusinn zones at interfaces for $\mathrm{Fe}_{3} \mathrm{Al}$-clad substrates, including a) modified 316 (LSS), b) modified $800 \mathrm{H}$, c) standard 310 , and d) standard 304 . 
The significant features that were considered in the photomicrographs of Figure 1 were the well defined diffusion zones which extend from the interface into the stainless steel substrate for four separate material combinations. Within the boundaries of these distinct layers, having widths ranging from about 13 micrometers ( 0.5 mils) to about 22 micrometers $(0.9$ mils $)$, are precipitates determined to be nickel aluminides. The presence of a two-phase diffusion zone could significantly reduce the ductility, resulting in fracture within the layer during clad tube fabrication. Since the $\mathrm{Fe}_{3} \mathrm{Al} / 304 \mathrm{SS}$ diffusion zone displayed the least amount of second phase nickel aluminide precipitation (with the probability of having the greatest ductility), this combination was the logical choice for continued development during the fabrication trials planned for the next phase of the Program.

\section{Status of Clad Tube Fabrication}

The processing sequence planned for fabricating $\mathrm{Fe}_{3} \mathrm{Al}$-clad 304SS tubing during two trials has been devised, in part, on the results of earlier work conducted at ORNL and is depicted in Figure 2. ${ }^{8-10}$ The sequence includes 1) procurement of materials, 2) hot isostatic pressing to consolidate $\mathrm{Fe}_{3} \mathrm{Al}$ powder and encase two $304 \mathrm{SS}$ hollow billets, 3) machining to remove the HIP cans and to prepare the $\mathrm{Fe}_{3} \mathrm{Al}$ surfaces of the two hybrid billets, 4) ultrasonic inspection to characterize bond integrity between the $\mathrm{Fe}_{3} \mathrm{Al}$ encasements and the 304SS billet substrates, 5) Hot extrusion of the two hybrid billets into clad tubes, and 6) ultrasonic inspection to characterize the bond integrity between the $\mathrm{Fe}_{3} \mathrm{Al}$ clad layers and the 304SS tube substrates.

\begin{tabular}{|ll|}
\hline - & Procurement of Materials \\
- & Hot Isostatic Pressing \\
- & Ultret Machining and Preparation Inspection of Billets \\
- & Hot Extrusion of Clad Tubing \\
- & Ultrasonic Inspection of Tubing \\
\hline
\end{tabular}

Fig. 2. Processing sequence for fabricating $\mathrm{Fe}_{3} \mathrm{Al}$-clad 304 stainless steel tubing. 
Ai the writing of this report, all materials have been procured, and preparations for hot isostatic pressing are in progress.

\section{Procurement of Materials}

For the fabrication trials, 200 pounds of $\mathrm{FAS} \mathrm{Fe}_{3} \mathrm{Al}$ powder (-100 mesh) were procured from an ORNL approved vendor. Another vendor supplied the annealed 304 stainless steel extruded stock from which two 19.5-inch long, 5-inch diameter billets were machined, each with a 0.75 -inch hollow core. The chemical compositions of the FAS iron aluminide powder and the 304 austenitic stainless steel billets are shown in Table 1.

\begin{tabular}{||c|c|c|c|c||}
\hline \multicolumn{1}{|c|}{ Alloy } & $\mathbf{C r}$ & $\mathrm{Ni}$ & $\mathrm{Fe}$ & $\mathbf{A l}$ \\
\hline \hline $\mathrm{Fe}_{3} \mathrm{Al}$ (FAS) & 2.2 & -- & $\mathrm{Bal}$ & 15.0 \\
\hline $304 \mathrm{SS}$ & $18.0-20.0$ & $8.0-11.0$ & $\mathrm{Bal}$ & -- \\
\hline
\end{tabular}

Table 1. Chemical compositions of iron aluminide powder and Type 304 austenitic stainless steel substrate (wt.\%).

\section{Hot Isostatic Pressing}

HIP processing has been incorporated into the fabrication sequence to simultaneously effect full powder consolidation and to ensure complete encasement and bonding of the $\mathrm{Fe}_{3} \mathrm{Al}$ to the machined 304SS substrate billets. The billet assemblies will be prepared for HIP by canning the 304SS substrates and $\mathrm{Fe}_{3} \mathrm{Al}$ powder in carbon steel jackets. To remove residual water vapor and gasses, the assemblies will be evacuated and baked out at $500^{\circ} \mathrm{F}$ until a steady state (isolated) container pressure of 10 micrometers $\mathrm{Hg}$ can be maintained. The assemblies will then be weld sealed and HIP'ed at $100 \mathrm{MPa}$ (14.5 ksi) pressure at $2065^{\circ} \mathrm{F}$ for 4 hours.

\section{Machining of HIP'ed Assemblies}

The HIP'ed assemblies will be machined to remove the carbon steel cans and to dress the $\mathrm{Fe}_{3} \mathrm{Al}$ exterior surfaces of the hybrid billets in preparation for hot extrusion. 


\section{Ultrasonic Inspection of Hybrid Billets}

The machined hybrid billets will be ultrasonically inspected to characterize the integrity of the bond between the $\mathrm{Fe}_{3} \mathrm{Al}$ encasement and the 304SS substrate.

\section{Hot Extrusion of Clad Tubing}

The first hybrid billet will be induction heated to $2200^{\circ} \mathrm{F}$ and hot extruded at a pressure and ram speed chosen to match, as closely as possible, the flow stresses of the $\mathrm{Fe}_{3} \mathrm{Al}$ encasement and the 304SS substrate. The specific extrusion process conditions will be established by $B \& W$ based on information obtained from the technical literature, recommendations by ORNL, and production experience of the vendor. The load versus ram displacement curve generated during the initial extrusion will be correlated with the surface condition and overall quality of the extruded clad tube. The information will then be utilized to adjust the processing parameters, as necessary, for the extrusion of the second hybrid billet. After the second extrusion, the clad tubes will be cropped, packaged, and shipped to another location for ultrasonic inspection.

\section{Ultrasonic Inspection of Clad Tubes}

The extruded clad tubes will be ultrasonically inspected to characterize the integrity of the bond between the $\mathrm{Fe}_{3} \mathrm{Al}$ clad layer and the 304SS tube substrate.

\section{PLANS FOR FUTURE ACTIVITIES}

After successful fabrication the clad tubing, selected sections will be metallographically prepared for microstructural examination to characterize the bond between the $\mathrm{Fe}_{3} \mathrm{Al}$ clad layer and the 304SS substrate. Appropriate lengths of the clad tubing will be delivered to ORNL for further evaluation.

\section{SUMMARY}

Detailed planning and preparations for conducting iron aluminide-clad 304SS tube fabrication trials are proceeding on schedule. All materials have been procured, and hybrid billet processing is currently in progress. An assessment of the technical and economical merits of $\mathrm{Fe}_{3} \mathrm{Al}$-clad austenitic stainless steel components in power generation systems has been completed by the Babcock \& Wilcox Fossil Power Division. 


\section{REFERENCES}

1. C.G. McKamey, "Development of Iron Aluminides," ORNL/FMP-90/1, August 1990.

2. V.K. Sikka, C.G. McKamey, C.R. Howell, and R.H. Baldwin, "Fabrication and Mechanical Properties of $\mathrm{Fe}_{3} \mathrm{Al}$-Based Aluminides," ORNL/TM-11465, March 1990.

3. R.W. Swindeman, P.J. Maziasz, E. Bolling, and J.F. King, "Evaluation of Advanced Austenitic Alloys Relative to Alloy Design Criteria for Steam Service: Part 1 - Lean Stainless Steels," ORNL-6629/P1, May 1990.

4. R.W. Swindeman and P.J. Maziasz, "Evaluation of Advanced Austenitic Alloys Relative to Alloy Design Criteria for Steam Service: Part 2-20 to 30\% Chromium Alloys," ORNL-6629/P2, June 1991.

5. R.W. Swindeman, "The Potential of Modified Type 310 Stainless Steel for Advanced Fossil Energy Applications," ORNL/TM-12057, April 1992.

6. M.J. Topolski and H.A. Domian, "Evaluation of the Fabricability of Advanced Austenitic Tubing," ORNL/FMP-90/1, August 1990.

7. W.R. Mohn and M.J. Topolski, "Evaluation of the Fabricability of Advanced Iron Aluminide-Clad Austenitic Stainless Steel Tubing," ORNL/FMP-92/1, July 1992.

8. V.K. Sikka and J.R. Weir, "IRON ALUMINIDES: Properties and Progress in the Development of a Family of Alloys Based on the Intermetallic Compound $\mathrm{Fe}_{3} \mathrm{Al}$," ORNL/Contract DE-AC05-840R21400 with the U.S. Department of Energy, 1990.

9. V.K. Sikka, C.G. McKamey, C.R. Howell, and R.H. Baldwin, "Properties of Large Heats of $\mathrm{Fe}_{3} \mathrm{Al}$-Based Alloys," ORNL/TM-11796, March 1991.

10. C.G. McKamey, C.T. Liu, S.A. David, J.A. Horton, D.H. Pierce, and J.J. Campbell, "Development of Iron Aluminides for Coal Conversion Systems," ORNL/TM-10793, July 1988. 


\title{
BCL-4 - MATERIALS AND COMPONENTS IN \\ FOSSIL ENERGY APPLICATIONS" NEWSLETTER
}

\author{
I. G. Wright \\ Battelle \\ 505 King Avenue \\ Columbus, Ohio 43201-2693
}

\section{INTRODUCTION}

The DOE Newsletter on Materials and Components in Fossil Energy Applications is intended as a vehicle to provide timely dissemination of information concerning developments in, or performance results of, materials and components in conventional or new processes for the utilization of coal, or for the conversion of coal to other energy forms. In recent years, emphasis has been placed on the direct utilization of coal as a chemical feedstock or as a fuel, rather than for providing a substitute for natural gas. Process efficiency and compliance with present and anticipated environmental regulations are currently the two most important factors driving developments, and strongly influence not only new processes, but also existing systems.

The role of the newsletter has been to provide a guide to developing materials and components technology, and a forum for the presentation of the latest results and experience.

\section{DISCUSSION OF CURRENT ACTIVTTIES}

During this reporting period, three issues of the newsletter have been published. The articles in these editions were entitled:

\section{Issue No. 98 (6/01/92)}

- Refractories in Circulating Fluidized-Bed Combustors

- The Wear Potential of Bed Material in Fluidized-Bed Combustors

- Clean Coal Programs in the European Community 
- Grimethorpe Experience with Hot-Gas Filters-II

- Industrial Developments

- Books and Articles

- Meeting Calendar

Issue No. 99 (8/01/92)

- Japanese Research Efforts in High-Performance/ High-Temperature Materials

- Burner Rig Test Data for Furnace Wall Alloys Under Low NO Conditions in Cyclone-Fired Boilers

- Selection of Coating Materials for Boiler Tube Protection

- $\quad$ Fuel Cell News

- $\quad$ Fixed Bed-Type Hot-Gas Cleanup Technology Development

- Industrial Developments

- $\quad$ Books and Articles

- Meetings Calendar

Issue No. $100(10 / 1 / 92)$

- Trends in Materials Research and Engineering

- Changing Materials Requirements for Coal Gasifiers

- $\quad$ Historical Perspectives on Fossil Energy Materials R\&D

- Contributions of the NACE Unit Committee T-2F to Technology Transfer in Fossil Fuel Combustion and Conversion

- Initial Run of a Gas Turbine on Coal-Water Slurry

- High-Temperature Erosion of Turbine Coatings

- Ceramic Filter Development for British Coal

- $\quad$ Meetings Calendar 


\title{
CARB-4 - ENGINEERING-SCALE DEVELOPMENT OF THE \\ VAPOR-LIOUID-SOLID
(VLS) PROCESS FOR THE PRODUCTION OF SILICON CARBIDE FIBRILS
}

\author{
William E. Hollar Jr. \\ The Carborundum Co. \\ Technology Division \\ P.O. Box 832 \\ Niagara Falls, NY 14302 \\ W. Mills \\ BP America \\ Warrensville, OH 44128

\section{INTRODUCTION}

The goal of this program is to develop the VLS SiC Fibril process to an engineering scale in order to establish a commercially viable process. Specifically, the program calls for obtaining reliable critical process design data for a reactor which is $12^{\prime \prime}$ wide $\times 40^{\prime \prime}$ long $\times 12^{\prime \prime}$ high, and which is capable of producing $200-500 \mathrm{~g}$ of fibrils per 12-hour cycle.

Preliminary economic evaluation of the VLS process has indicated that certain aspects of the VLS process concept require either improvement or further development in order to reduce the production costs of the VLS fibrils. The targeted areas include increased growth process productivity, and the development of beneficiation and process gas recycle processes. The present program has focused efforts in each area to evaluate the commercial viability of the process.

Efforts have focused on optimization of the synthesis process to maximize process productivity and product quality. Four process variables have been identified which exert a direct control on growth behavior: methane partial pressure, temperature, catalyst chemistry and time. These variables define process throughput and product quality. The total mass of fibrils formed is linearly proportional to the total amounts of $\mathrm{C}$ and $\mathrm{Si}$ added to the system, which indicates that the $\mathrm{SiC}$ fibril formation reaction is first order in $\mathrm{SiO}$ and $\mathrm{CH}_{4}$. In addition, $\mathrm{CH}_{4}$ delivery appears to be affected by side reactions which have an important influence on the growth process scaleup characteristics.

A computer simulation model is under development as a means of compiling critical scaleup data in a form useful for the design of an engineering scale reactor. The modelling effort has identified key model features necessary to simulate growth 
rate profiles in the fibril reactor. Implementation of new mechanisms describing the decomposition of methane in the reactor have been used to obtain excellent agreement between model predictions and experimental results.

\section{DISCUSSION OF CURRENT ACTIVITIES}

\section{Fibril Growth}

An earlier report has described the results of growth experiments which have identified critical synthesis process variables. ${ }^{1}$ These variables include time, temperature, gas phase composition and catalyst chemistry. Time series experiments in this program have indicated that there are two independent mechanisms involved in the fibril synthesis process: nucleation, followed by growth. The approach which has been used to guide process improvements has been to separately analyze the process requirements for fibril nucleation and fibril growth.

Growth process optimization experiments have been completed. The goal of the experiments was to evaluate the effect of three synthesis process variables:

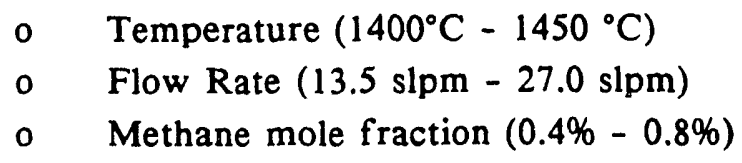

The remaining process conditions were fixed. Temperature affects SiO generation rates, with increasing temperatures leading to increased $\mathrm{SiO}$ partial pressures.

Temperature also controls a variety of other physiochemical processes, such as catalyst ball interactions with the substrate/fibril and the rates of side reactions. Flow rate affects the mixing condition, and impacts the mass supply rate of the carbon source. Methane mole fraction modifies the carbon supply rate and the driving force for growth.

In each case the growth experiment was initiated with a two-hour nucleation condition of $0.4 \% \mathrm{CH}_{4}$ and $1425^{\circ} \mathrm{C}$. This process condition appeared to produce the best combination of high active site density and reduced non-needle surface growth density. A five-hour growth period with the specified process condition completed the growth cycle. Postexperimental analysis included measurement of fibril mass, product diameter, reactant utilization and microscopic evaluation of product characteristics.

Figure 1 illustrates the effects of temperature and methane partial pressure on total fibril growth at a total process gas flow rate of 27 slpm. There are two important effects: 
o increasing temperature increases $\mathrm{SiO}$ formation rates and the Si supply for fibril formation

- increasing the input methane mole fraction increases the mass supply of $\mathrm{C}$ for SiC fibril formation

Increases in each variable lead to corresponding increases in the total mass of fibrils. These effects are essentialiy first order; i.e., SiC formation rates can be effectively represented by a first-order expression in $\mathrm{p}_{\mathrm{CH} 4}$ and $\mathrm{p}_{\mathrm{SiO}}$ :

$$
\mathrm{d}\left(\mathrm{SiC}_{\mathrm{f}}\right) / \mathrm{dt}=\mathrm{k}_{\mathrm{g}}{ }^{*} \mathrm{p}_{\mathrm{SiO}}{ }^{*} \mathrm{p}_{\mathrm{CH} 4}
$$

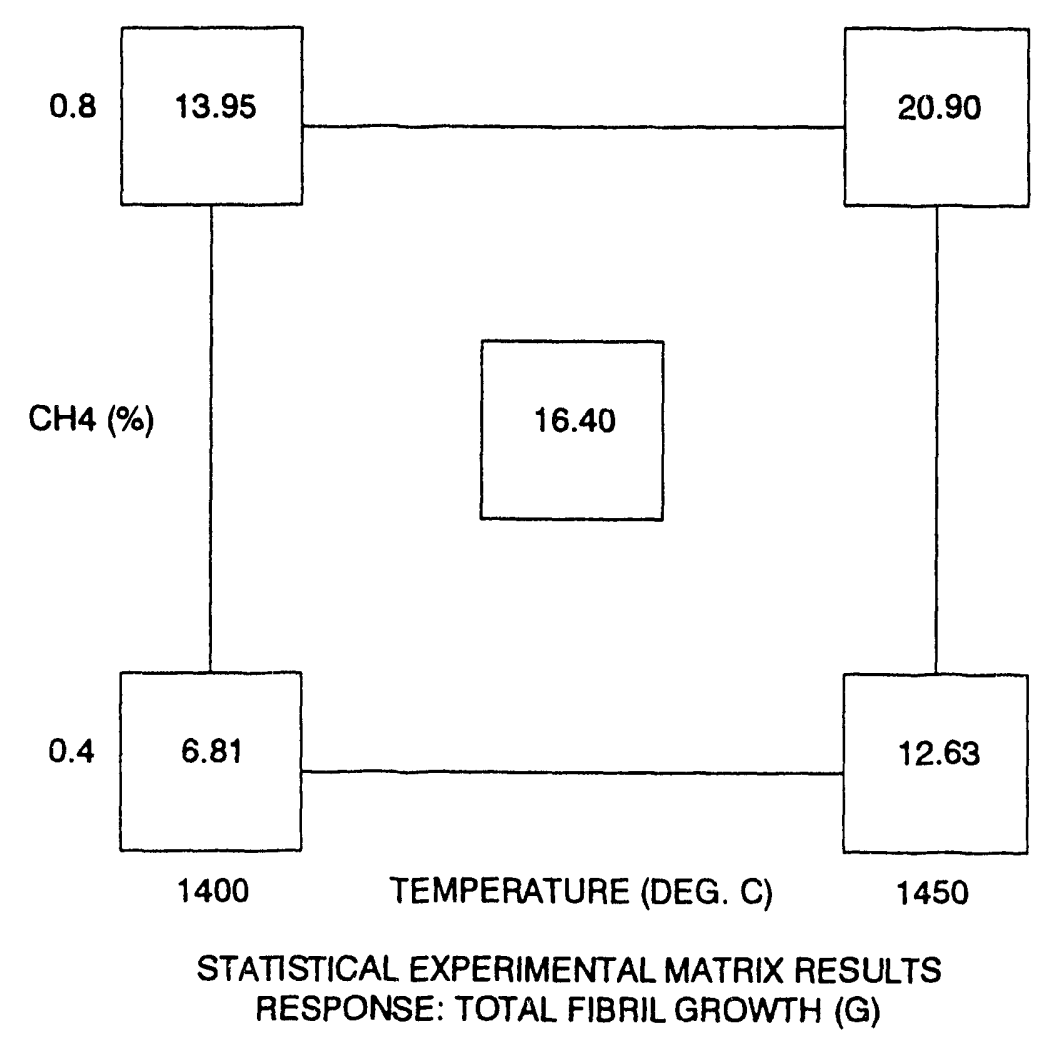

Fig. 1 - Effect of Temperature and $\% \mathrm{CH}_{4}$ on Total Fibril Mass 
Figure 2 shows a plot of the integrated product of total Si and $\mathrm{C}$ supply versus total fibril growth. The linearity of the data appears to confirm the validity of Equation 1, since the Figure 2 data represents an integrated form of equation 1.

The results in Figure 1 only represent total fibril growth and do not take into account product morphology. The fibril product produced at high methane partial pressures contains substantially more branched and/or ball product. ${ }^{2}$ In addition, the product formed at high methane partial pressures has a tendency to include larger amounts of bent needle surface growth. High methane synthesis process conditions also appear to promote wider differences in the product morphology on different types of growth substrates. The best operating condition from the standpoint of both growth rate and highest yield of needle type product is $0.4 \% \mathrm{CH}_{4}$ and $1425^{\circ} \mathrm{C}$. This process condition represents the best balance of $\mathrm{Si}$ and $\mathrm{C}$ supply and leads to mostly needle-like product.

Understanding the behavior of methane in the reactor is crucial to successful scaleup of the process. Methane can be consumed by several routes. The desired reaction is the fibril formation reaction; approximately $10 \%-20 \%$ of the input methane is consumed by this reaction. Methane is also consumed by decomposition reactions. Equilibrium calculations at typical growth process conditions indicate that the methane is unstable. There are a number of products which could potentially form at synthesis conditions, including solid carbon, hydrocarbon and carbon-hydrogen-nitrogen species. ${ }^{3,4}$

To evaluate the kinetics of methane decomposition, an experiment was developed to measure decomposition rates in the absence of fibril growth. In this experiment process gas is fed to the reactor at typical process temperatures and the outlet concentration of $\mathrm{CH}_{4}$ is monitored by gas chromatography (GC). By varying the flow rate, initial $\mathrm{CH}_{4}$ concentration and temperature, a kinetic equation for the methane decomposition reactions can be obtained, including Arrhenius activation energies. While this effort is continuing, initial results are shown in Figure 3. This plot shows the activation energy for the reaction, based on decomposition rates measured at a fixed chemical and flow condition. The activation energy is quite large--of the order of $250 \mathrm{~kJ}$.

The importance of this type of data is twofold. First, independent measurement of controlling reaction rates allows the simulation model to become more predictive and less empirical. Addition of this reaction has led to simulation model predictions similar to observed experimental growth rate trends; this was not found using earlier versions of the model. 


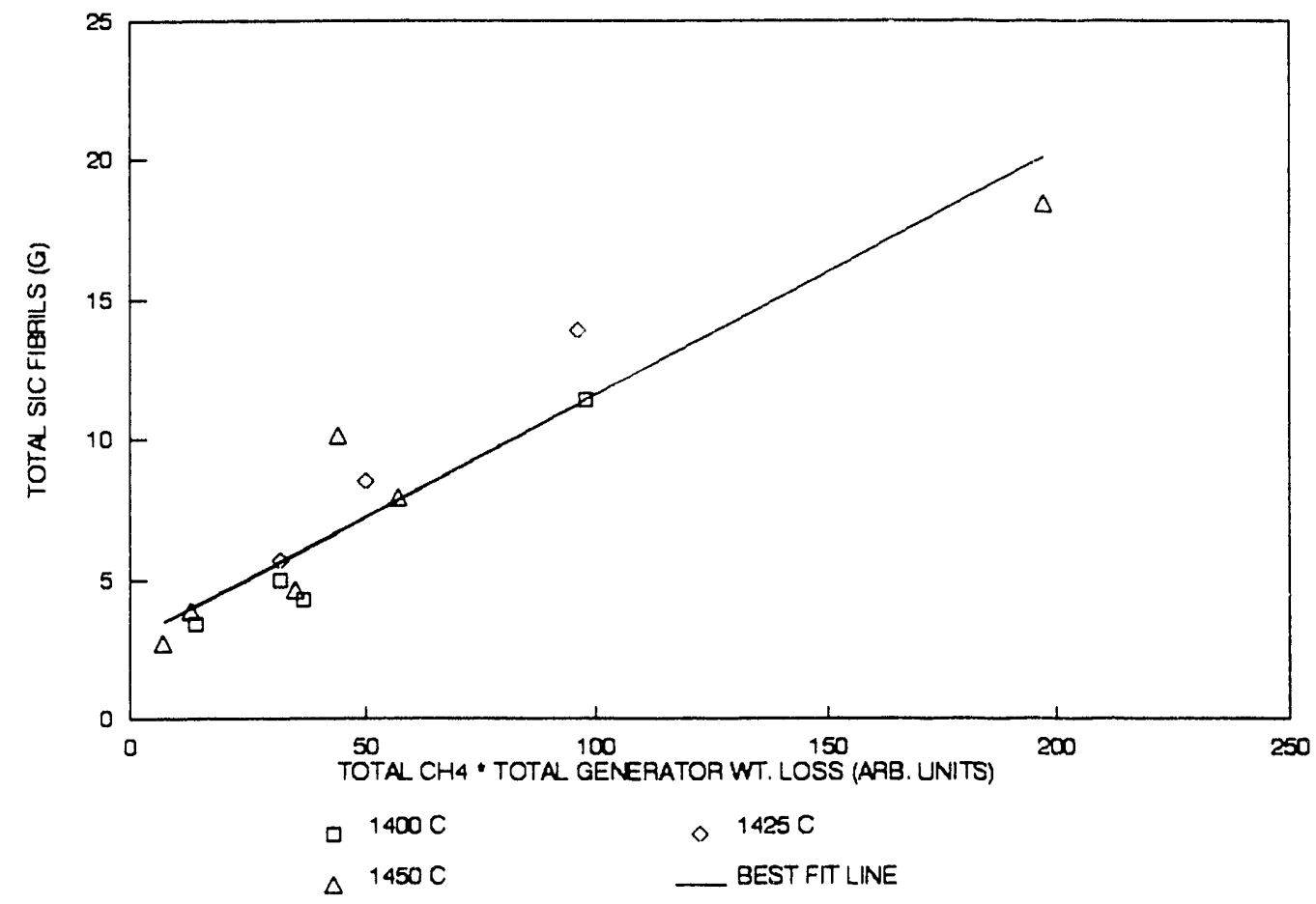

Fig. 2 - Relationship Between Total SiC Fibrils and Product of Total C and Si Supply

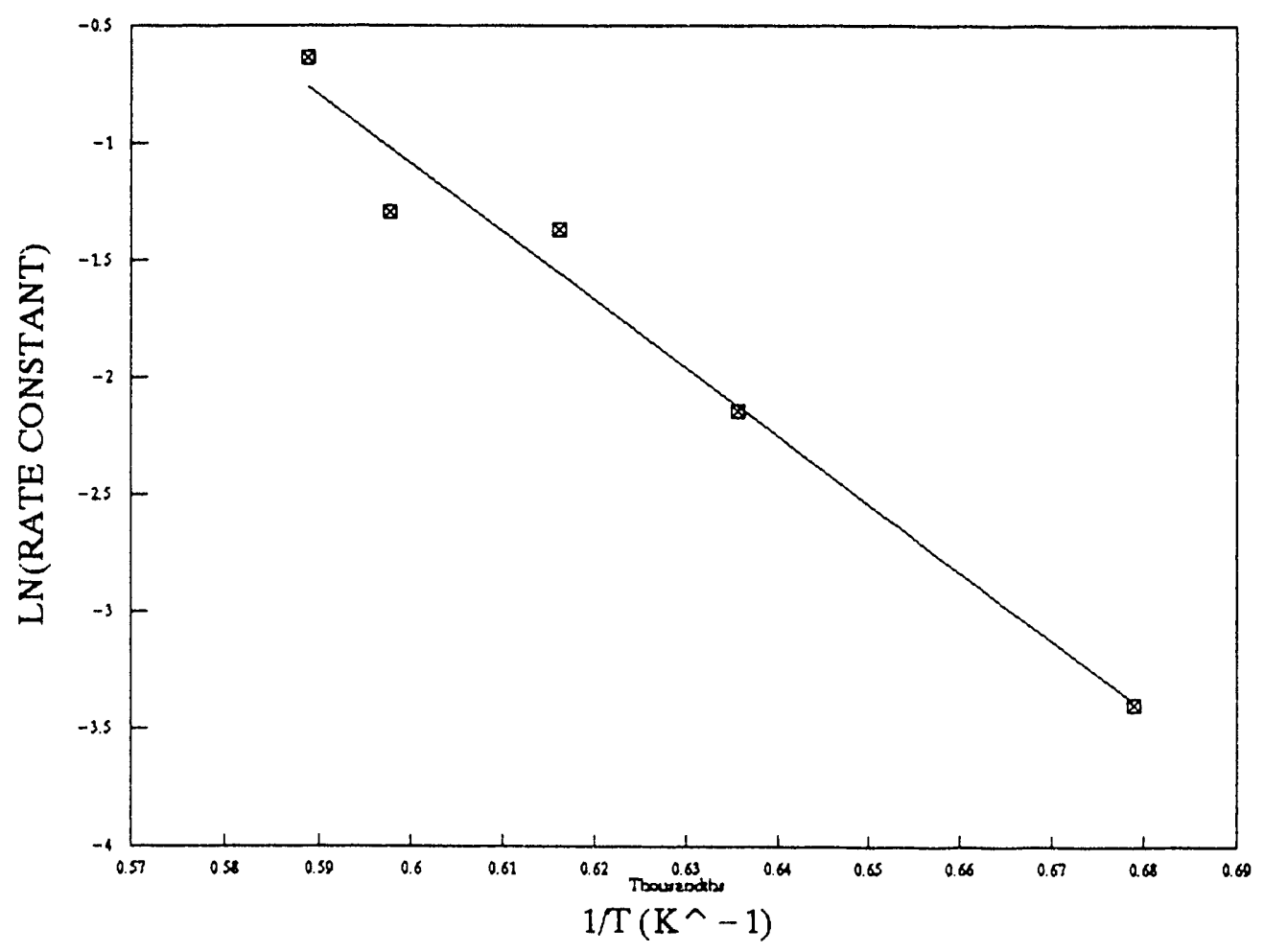

Fig. 3 - Temperature Effect on Methane Decomposition Rate Constant 
The current focus of the synthesis experimental effort is to evaluate the adaptability of the process for producing different fibril physical characteristics, i.e., fibrils with different lengths and diameters. Different applications of the fibrils as a reinforcement may require different product characteristics. For example, yarn forming of fibrils may require longer product. Also, improved diameter distributions have potential benefits in tailoring the product for different applications and in reducing the concentration of small diameter by-product fibrils.

Los Alamos National Laboratory (LANL) has demonstrated the feasibility of growing longer fibrils through reactor design modifications. A key parameter which controls product length is the spacing of the growth substrates. Other work done by Los Alamos has shown that catalyst chemistry can impact both length and diameter of the fibril product. ${ }^{2}$ Based on these results and experimental observations from the current program, an experimental program to evaluate the feasibility of changing the fibril product length and diameter was undertaken.

Table 1 summarizes the experimental approach. The process variables included process gas flow rate, catalyst chemistry, catalyst concentration and reactor configuration. Longer product lengths were promoted by reduced process gas flow rates, increased separation of substrate spacing and use of FeSi catalyst. Fibrils to 4 $\mathrm{cm}$ in length were grown by this process. It is important to note that the overall volumetric productivity dropped in the long fibril reactor configuration. Volumetric growth rates were $25 \%$ of the baseline process condition, due to reduction in the substrate area and use of lowered process gas flow rates. This preliminary result would indicate that very long fibrils may be more expensive to produce than shorter fibrils, and that there may be tradeoffs in the fibril cost versus its formability into aligned yarn products.

Table 1 Experimental program to evaluate product modifications

\begin{tabular}{|l|l|l|}
\hline Product Characteristic & \multicolumn{1}{|c|}{$\begin{array}{c}\text { Process Variables } \\
\text { Evaluated }\end{array}$} & Controlling Process Variables \\
\hline Diameter & $\begin{array}{l}\text { Catalyst Concentration } \\
\text { Catalyst Chemistry } \\
\text { Gas Composition }\end{array}$ & $\begin{array}{l}\text { Catalyst Concentration } \\
\text { Gas Composition }\end{array}$ \\
\hline Length & $\begin{array}{l}\text { Gas Flow Rate } \\
\text { Catalyst Chemistry } \\
\text { Reactor Geometry }\end{array}$ & All \\
\hline
\end{tabular}


As mentioned earlier, it would be desirable to modify the diameter distribution of the fibril product. Preliminary diameter evaluation experiments have indicated that the fibril product has a wide distribution of diameters, ranging from submicron to 20 microns. This is similar to results reported by researchers at LANL. ${ }^{2}$ In the present program the impact of catalyst chemistry, process gas composition and catalyst loading were evaluated as potential routes for diameter modifications. The fibril diameter distribution was measured by an automated image analysis technique in which 100 fibril fragments are measured. This procedure is expected to yield meaniagful distribution data.

Two approaches appear to have merit in modifying diameter. Increasing methane concentration produced fibrils with increasing amounts of fine diameter fibrils (i.e., fibrils $<3 \mu$ in diameter). This appears to be further justification for maintaining low input methane concentrations. Conversely, increasing the fraction of $\mathrm{N}_{2}$ in the process gas appears to increase the average product diameter. This effect has not been fully explored. One possible explanation is that the process gas composition influences the rates of fibril side reactions like branching which can then lead to variable diameter product.

Changes in the catalyst concentration also appear to change the average fibril diameter. Increasing the starting catalyst concentration by a factor of four led to a $20 \%$ increase in the average fibril diameter, using the sol catalyst technique as the catalyst application method. 5 The significance of this result is that for a fixed process condition, changes in the product diameter can be obtained if the starting catalyst droplet size can be modified. Preliminary results indicate that a similar trend occurred using the FeSi particulate catalyst.

\section{Process Gas Recycle}

A major factor in the production cost of VLS SiC fibrils is the process gas, which consists of the following species: $\mathrm{H}_{2}(80-90 \%), \mathrm{N}_{2}(5-10 \%), \mathrm{CO}(3-10 \%)$ and $\mathrm{CH}_{4}$ $(0.5-1 \%)$. High flow rates of process gas, consisting mostly of hydrogen, are required to promote rapid and uniform growth of VLS SiC fibril product. Preliminary economic evaluation has indicated that hydrogen costs, in the absence of gas recycling, could double or triple the production cost for fibrils. A lab-scale unit is under development to demonstrate a utilization or recycle ratio of $90 \%$.

An external recycle system has been engineered and designed for the recycle of VLS SiC recycle process gas. The system process concept is relatively straightforward, as shown in Figure 4. The process steps include cooling and filtering of the exhaust gas, followed by recompression of the gas using a compressor. A certain fraction of 
gas is bled off to remove by-product gas species formed during the fibril synthesis reaction. The remaining recycle gas is then mixed with make-up gas to achieve the desired reactor inlet composition.

Two potential problem areas will have to be evaluated and resolved in the current program. The first will be the impact of gas phase side reactions which could form undesirable gas phase species. Detailed gas analysis by gas chromatography and mass spectrometry will be used to determine the magnitude of these reactions, and to evaluate the need for remedial measures.

The other process requirement will be effective cleanup and cooling of the exhaust gas, which will contain precipitated $\mathrm{SiO}$ in a fumed form. Careful attention to the filtration process is necessary to ensure the system operability.

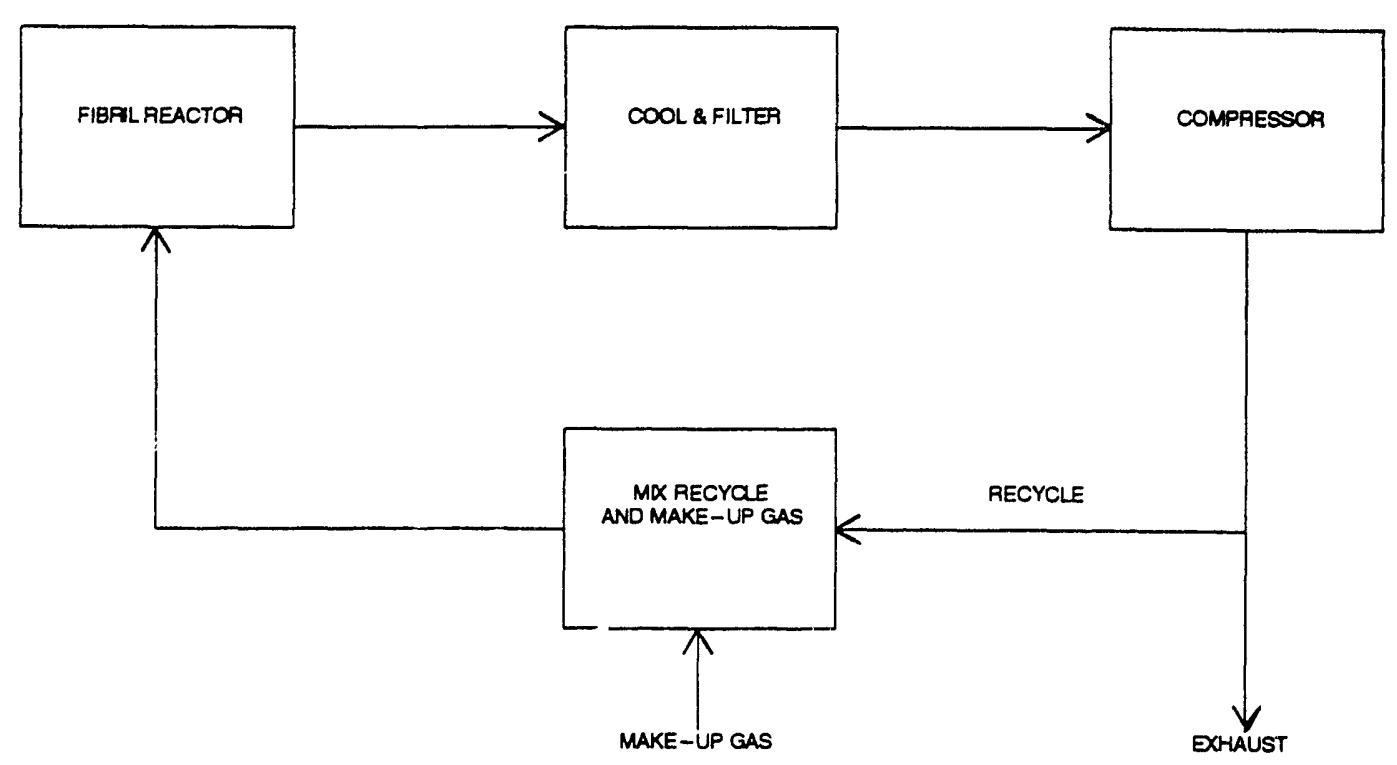

Fig. 4 - Process Gas Recycle Concept

\section{Harvesting and Beneficiation}

The focus of this effort was to specify the postprocessing steps required to make the as-synthesized fibril product useful as an oriented reinforcement for high temperature composite applications. Processing steps under evaluation include leaching to remove residual catalyst and screening to separate short and long fibrils. The process concept has been discussed in an earlier report. ${ }^{3}$ 
One difficulty with the wet screening step is that the fibril dispersion process reduces the product length. Fibrils below $1 \mathrm{~cm}$ may only have limited tow formability. One alternative process for producing yarn-formable beneficiated product is air harvesting. This approach yields a product containing only the longest fibrils, and appears to promote a separation between desired product and shorter surface growth. The other advantage of this process is that the product is relatively untangled compared to the screened product, which should reduce difficulties in subsequent processing steps. Preliminary experiments indicate air harvest yields of $40 \%-50 \%$. Material losses remain a problem with this technique; improvements in the accountability of the process will be evaluated.

Air harvested product can be leached immediately after harvesting, or after subsequent processing operations. A screening experiment to evaluate the feasibility of leaching the product after tow forming indicates that this concept is feasible. As mentioned in an earlier report, ${ }^{1}$ leaching appears to be a critical step for using VLS SiC fibrils in high temperature composites.

\section{Simulation Model Development}

Earlier reports have described the simulation model in detail.1,6 The goal of this effort is to consolidate scaleup information obtained in this program in a format suitable for design of an engineering scale reactor.

Recent efforts have focused on incorporating methane decomposition kinetics into the model. Initial values of the decomposition rate constant were evaluated by assuming that the methane decomposition reaction controlled the growth rate behavior as a function of height. Based on these assumptions, first-order methane decomposition kinetics were predicted. Subsequent experiments have confirmed this approximate first-order dependence. In the modelling effort the methane decomposition rate constant was treated as an adjustable parameter, and growth rate profiles were matched to experimental data. This parameter was then held constant and the flow rate effect was evaluated. Excellent agreement with the experimental results was found. This represents an important improvement in the inndel accuracy. Figure 5 compares old and new simulation model predictions of the flow rate effect.

The modified simulation model has been used to evaluate the reactant concentrations as a function of distance into the reactor. Methane is supplied at the reactor bottom, and its concentration decays rapidly due to the first-order decomposition reaction. SiO shows the opposite trend--it increases in concentration almost linearly with height into the reactor. The reaction rate appears to be 
silicon-limited at the reactor bottorn and carbon-limited at the top of the reactor. These results suggest possible strategies with potential for improving process productivity and product uniformity.

\section{Fibril Characterization}

Fibril characterization is being performed to determine baseline product properties and guide improvements in the product features. Fibril characteristics of interest include physical, chemical and mechanical properties of the product.

Preliminary evaluation of fibril strengths by single fiber tensile testing have indicated average strengths in the $300-700 \mathrm{ksi}$ range for a limited number of $2.5 \mathrm{~cm}$ samples. Continued concern regarding the accuracy of this type of testing has led Carborundum to pursue single-fiber-composite (SFC) testing. The theory behind this type of mechanical testing has been reported elsewhere. ${ }^{7}$ Evaluation of a single sample through SFC testing can generate data equivalent to multiple single fiber tensile tests, and is an effective method of measuring strengths over short gauge lengths. The technique will be evaluated during the next quarter.

Product diameter is a critical product characteristic. Fibril diameter distributions are being obtained using an automated image analysis technique. Product diameter distributions are being evaluated as a function of synthesis process conditions and postprocessing conditions. This work will help identify strategies to produce narrower fibril diameter distributions and reduce the fraction of product below $3 \mu$

Figure 6 shows the diameter distribution plot for a typical baseline fibril product. Number average diameters of $6-8 \mu$ have been achieved in the current baseline product. This distribution curve also shows that the fraction of fibrils less than $3 \mu$ is a relatively low percentage. Work is continuing on establishing a database for typical product diameters, and the reproducibility of these results.

This diameter measurement technique also allows semiquantitative measurement of non-needle morphology levels. The operator notes the existence and type of defect in the fibril as the diameter is obtained. Preliminary measurements have indicated defect fractions around $10 \%$ are typical, consisting of primarily branches and bamboo structures. This technique represents a first attempt at quantitative measurements of fibril morphological characteristics, and has potential for being a powerful tool for product improvements efforts.

Efforts on the hand-formed tows have focused on building inventory for composite evaluation experiments. Hand forming of tows from air-harvested material has also been demonstrated. 


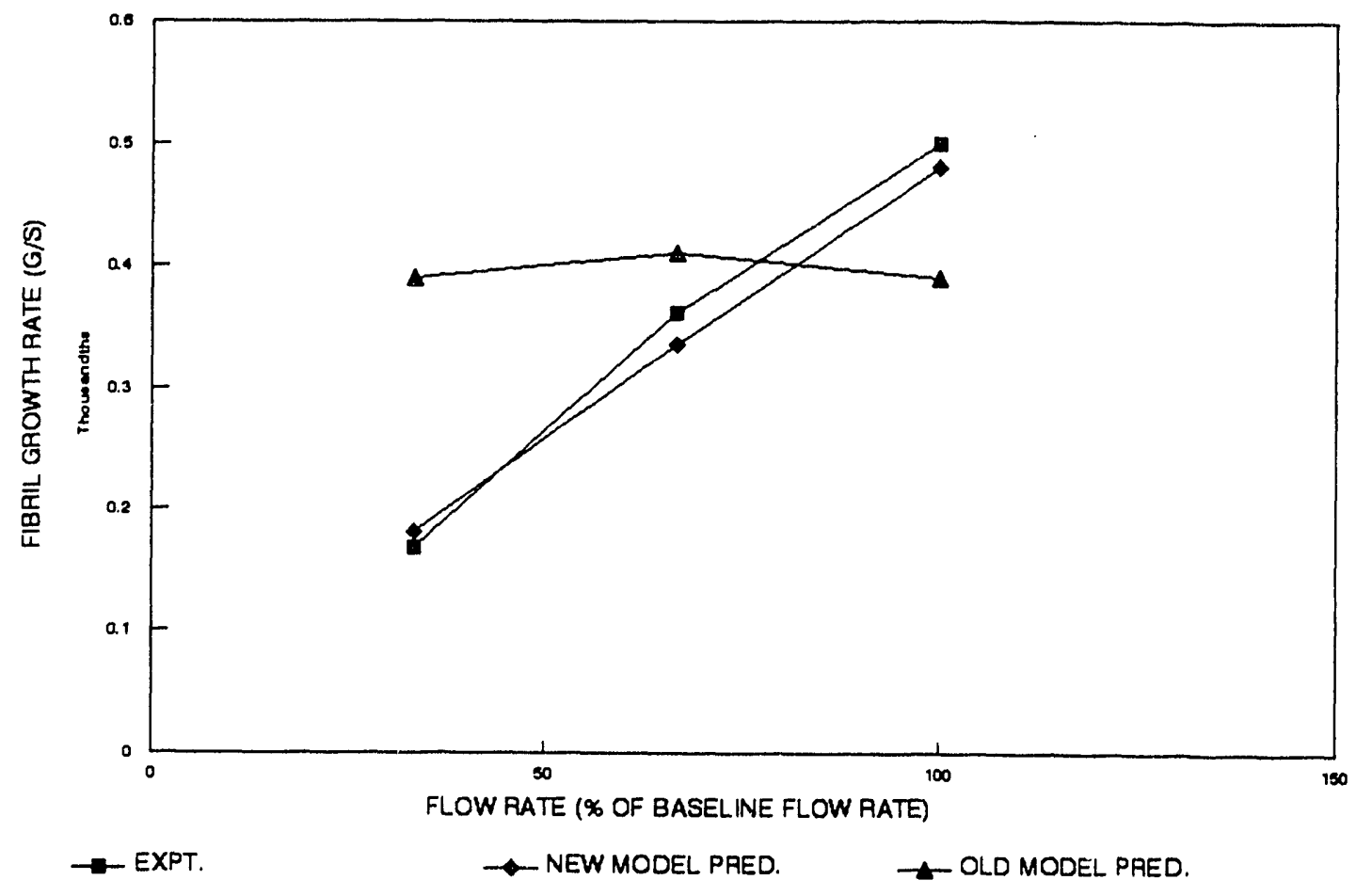

Fig. 5 - Comparison of Simulation Model Predictions and Experimental Results

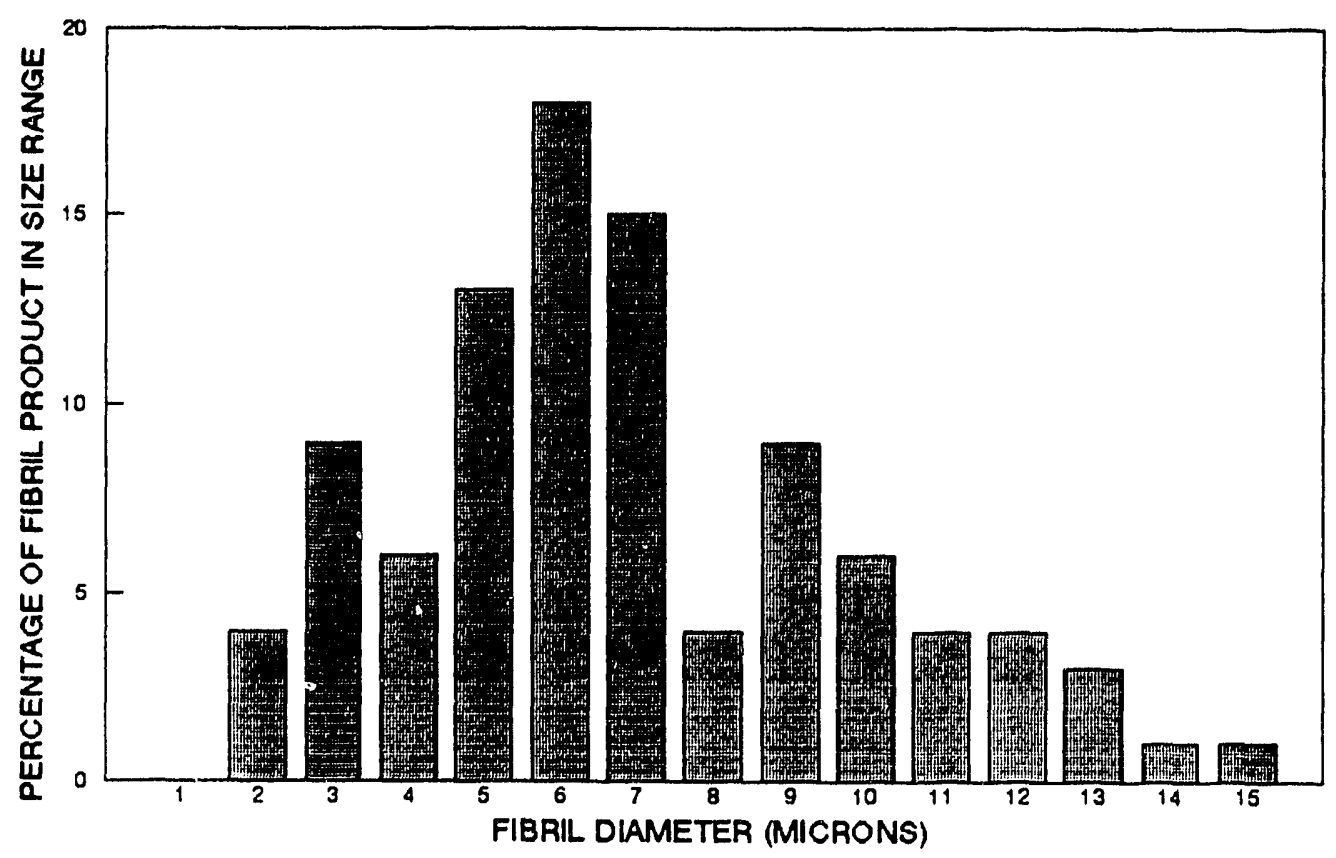

Fig. 6 - Fibril Diameter Distribution 


\section{REFERENCES}

1. W. E. Hollar, J. J. Kim and W. H. Mills, "Engineering Scale Development of the Vapor-Liquid-Solid (VLS) Process for the Production of SiC Whiskers," Proceedings of the Sixth Annual Conference on Fossil Energy Materials, Oak Ridge, TN, May 12 - 14, 1992.

2. P. D. Shalek, D. E. Christiansen, F. D. Gac, R. E. Honnell, G. F. Hurley, J. D. Katz, W. J. Parkinson, J. J. Petrovic, and D. S. Phillips, "Scale-up and Optimization of the VLS Growth Process for Beta-SiC Whiskers", DARPA Final Report, 1992.

3. J. Biernacki, "Formation of Silicon Monoxide and Application to the Growth of Vapor Liquid Solid Silicon Carbide Whiskers:, Ph.D. Dissertation, Cleveland State University, 1987.

4. W. Hollar, Unpublished thermodynamic calculations, 1989.

5. J. R. Fox and D. A. White, "VLS Fiber Growth Process," U.S. Patent Number 4,911,781, March 27, 1990.

6. W. E. Hollar, Jr., J. J. Kim and W. Mills, "The Growth Kinetics of VLS SiC Whiskers," presented at the Sixteenth Annual Conference on Composites and Advanced Ceramics, Cocoa Beach, FL, 1992.

7. A. N. Netravali, L. T. T. Topoleski, W. H. Sachse and S. L. Phoenix, "An Acoustic Emission Technique for Measuring Fiber Fragment Length Distributions in the Single-Fiber-Composite-Test, " Comp. Sci. and Tech., 35, 13 - 29 (1989). 


\title{
ORAU-4-SOLIDIFICATION BEHAVIOR OF IRON ALUMINIDES
}

\author{
S. Viswanathan, P. J. Maziasz, and V. K. Sikka \\ Metals and Ceramics Division \\ Oak Ridge National Laboratory \\ P. O. Box 2008 \\ Oak Ridge, TN 37831-6083
}

\section{INTRODUCTION}

The understanding and control of cast structures are important steps in making iron-aluminide alloys viable engineering materials. This includes understanding the various components of cast structure, their evolution, their properties, their behavior during further processing, and finally their effect on mechanical properties. For example, fracture initiation at second-phase particles has been identified as one cause of poor notched-impact properties in 13-mm plates of the FA-129 iron-aluminide alloy. ${ }^{1}$ Consequently, the first phase of this research evaluates the morphology, composition, and evolution of second-phase particles in the FA-129 alloy, as well as characterizes the ordered matrix phase and microstructure. Table 1 shows the aim composition for the FA-129 alloy.

Table 1. Aim composition for FA-129 alloy

\begin{tabular}{lcccc}
\hline & \multicolumn{4}{c}{ Weight percent } \\
\cline { 3 - 5 } \cline { 3 - 5 } Iron & Aluminum & Chromium & Niobium & Carbon \\
\hline Balance & 15.9 & 5.5 & 1.0 & 0.05 \\
\hline
\end{tabular}

\section{DISCUSSION OF CURRENT ACTIVITIES}

Studies of the FA-129 alloy conducted during the previous reporting period ${ }^{2}$ showed that the as-cast microstructure had two types of precipitates: a rod-shaped precipitate found in the grain and a globular interdendritric phase found at the as-cast 
grain boundaries. Interrupted solidification tests indicated that the rod-shaped precipitate formed due to a solid-state phase transformation shortly after the completion of solidification, while the globular interdendritric phase precipitated from the "last liquid to freeze." Energy dispersive spectroscopy (EDS) analysis showed no significant segregation of iron, aluminum, or chromium in the matrix. Both the rod-shaped precipitates and the interdendritic region contained high levels of niobium, indicating the presence of niobium-rich phases, including at least $\mathrm{NbC}$ (niobium carbide). Homogenization of alloy samples at $1200^{\circ} \mathrm{C}$ caused the globular precipitates to coarsen while the rod-shaped precipitates did not show a comparable change, indicating there were two kinds of phases present. Transmission electron microscopy (TEM) of the ascast specimens revealed that the rod precipitates were actually clusters of small rods or laths rather than a single rod. Electron-diffraction patterns indicated the presence of $\mathrm{DO}_{3}$, probably mixed with the B2-ordered phase. The size of the ordered domains was fairly small, and the amount of $\mathrm{DO}_{3}$ was substantial. Also, very few dislocations were found in the matrix of the as-cast alloy. The dislocations were large compared to the size of the $\mathrm{D0}_{3}$ domains, and their appearance was bowed, suggesting that they may be pinned by the $\mathrm{DO}_{3}$ antiphase boundaries. Both the very low dislocation content and the finely dispersed $\mathrm{DO}_{3}$ domain structure may contribute to the poor ductility and brittle fracture behavior observed in the as-cast material.

This report presents results on the electron microprobe analysis of the as-cast specimens, analytical electron microscopy (AEM) analysis of the rod precipitates, and further investigations on the effects of homogenization on precipitate morphology and the matrix-ordered phase.

\section{Characterization of As-Cast Structure}

Figure 1 shows the microstructure obtained in FA-129 alloy cast into a $152 \times 102$ $\times 25$-mm graphite slab mold. The alloy contains rod-shaped precipitates in the grain and globular precipitates in the interdendritic region. Samples from the ingot were analyzed using an electron microprobe. The compositional analyses obtained were very similar to those obtained previously from the EDS measurements. ${ }^{2}$ No segregation of aluminum or chromium was observed in the matrix, while both globular interdendritic precipitates and rod-like precipitates showed high concentrations of niobiuın. The niobium composition in the matrix was uniform and about $0.5 \mathrm{wt} \%$, approximately half the overall aim composition. The low concentration of niobium in the matrix may be attributed to the 


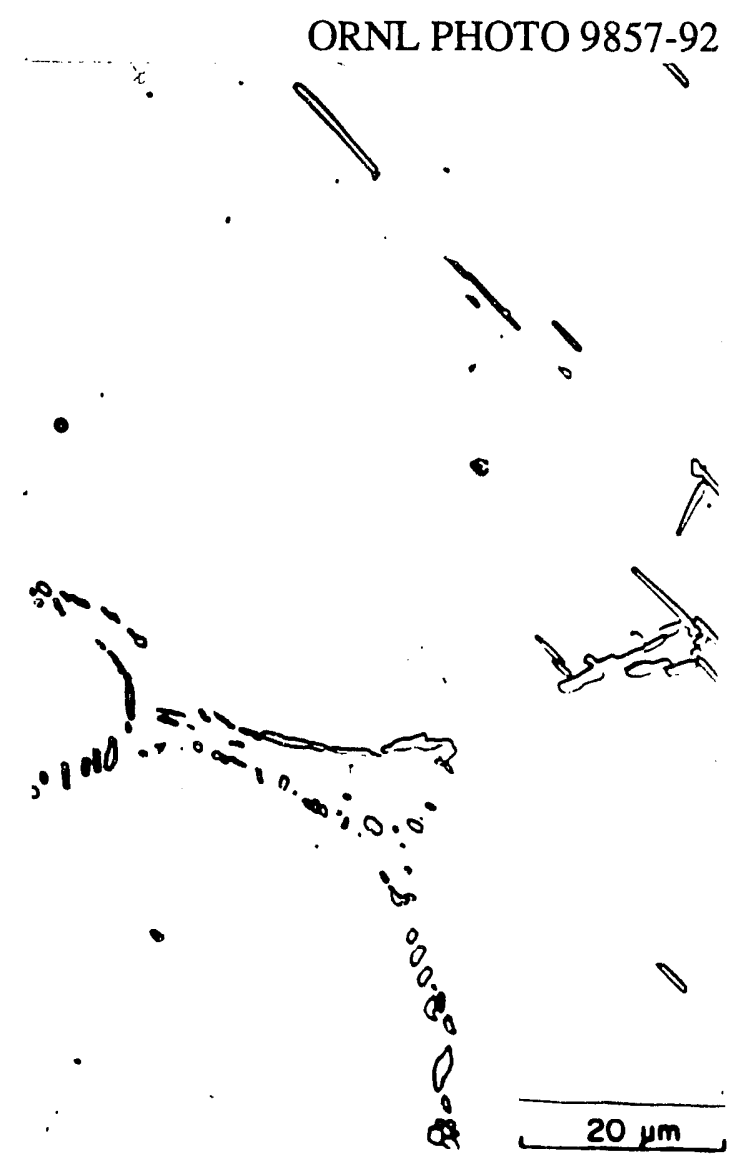

Fig. 1. Optical micrograph of a 7-kg FA-129 ingot cast in a graphite mold.

increased concentration of niobium in the precipitates. Table 2 lists the results obtained. Figure 2 shows the microstructure obtained in an FA-129 alloy sample from an interrupted solidification test. The sample was melted at $1500^{\circ} \mathrm{C}$, cooled to $1460^{\circ} \mathrm{C}$ in $12 \mathrm{~min}$, held at $1460^{\circ} \mathrm{C}$ for $12 \mathrm{~min}$, and quenched in ice water. Figure 3 shows composition traces obtained across a grain for the sample shown in Fig. 2 . The results indicate that there is no appreciable solidification-induced segregation in the as-cast alloy. The peaks in the niobium-composition profile shown in Fig. 3(d) indicate niobium-rich precipitates. They correspond closely to the dips in the iron composition profile shown in Fig. 3(a).

The size and shape of the rod-shaped precipitates make accurate microcornpositional analysis in the scanning electron microscope (SEM) difficult due to contribution from the matrix. Consequently, AEM was used to obtain a more accurate analysis. The results are shown in Table 3 and indicate that the rod-shaped precipitates 
Table 2. Electron microprobe analysis of as-cast specimens

\begin{tabular}{lccrr}
\hline & \multicolumn{4}{c}{ Weight percent } \\
\cline { 2 - 5 } & Aluminum $^{a}$ & Chromium $^{a}$ & Niobium $^{a}$ & Iron $^{a}$ \\
& & & & \\
& & 5.63 & 5.46 & 79.39 \\
Matrix & 15.03 & 2.79 & 53.81 & 33.71 \\
Interdendritic globule & 5.55 & 4.30 & 29.25 & 55.09 \\
Rod-shaped precipitate & 9.90 & 3.34 & 44.81 & 40.67 \\
Rod-shaped precipitate & 7.04 & & & \\
& & & &
\end{tabular}

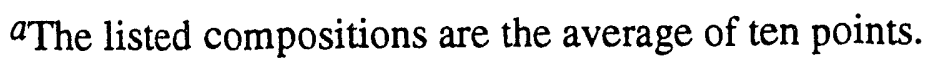

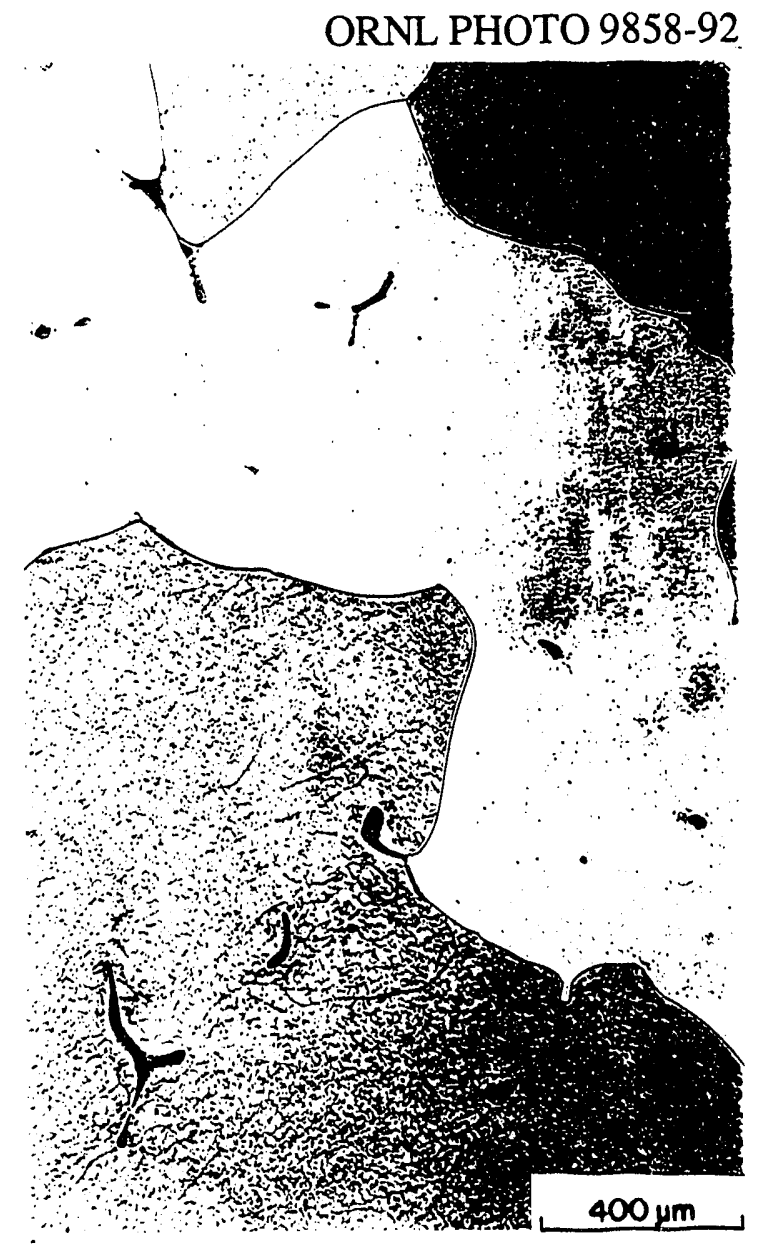

Fig. 2. Optical micrograph showing the result of an interrupted solidification test on a sample quenched from $1460^{\circ} \mathrm{C}$ showing grains and quenched in interdendritic liquid pools. 


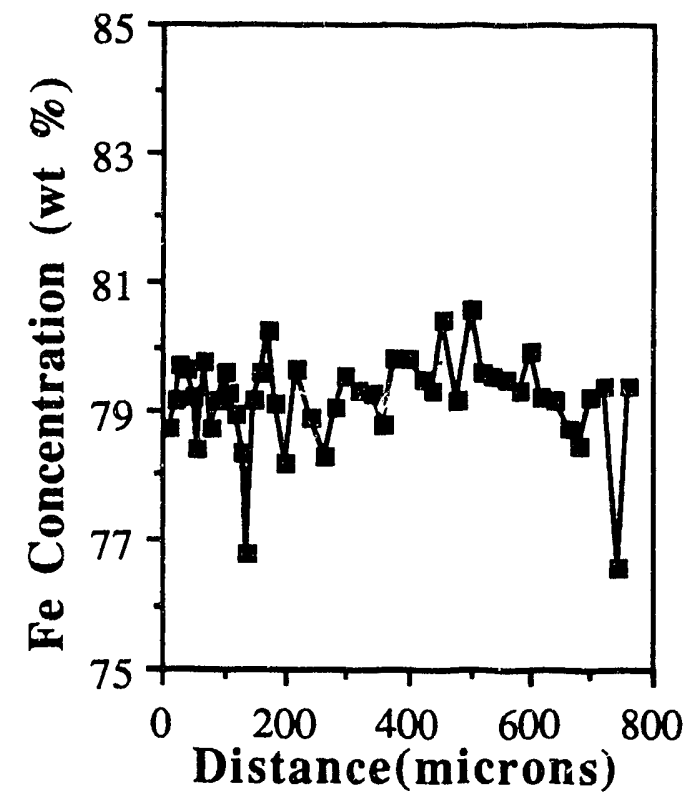

(a)

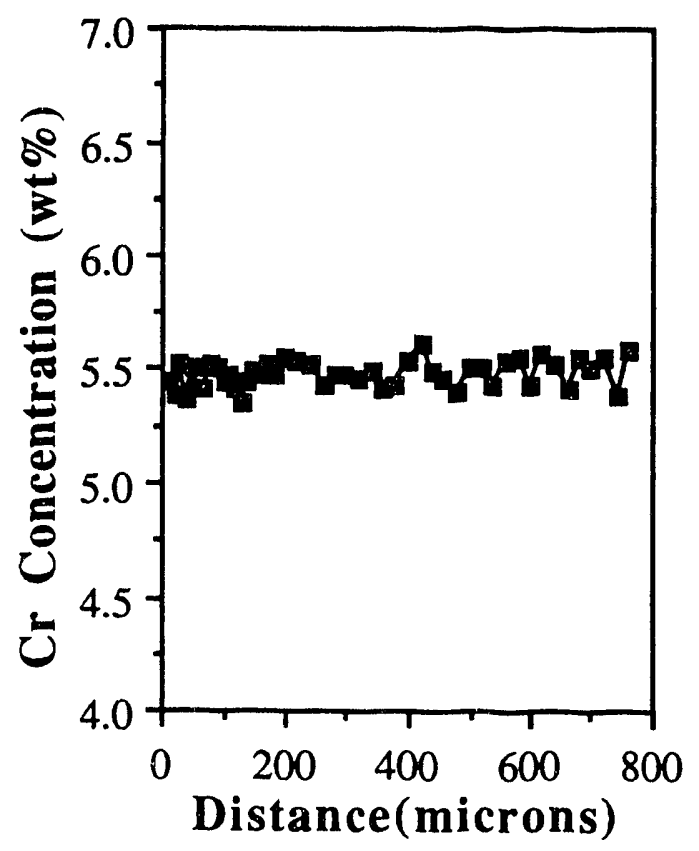

(c)

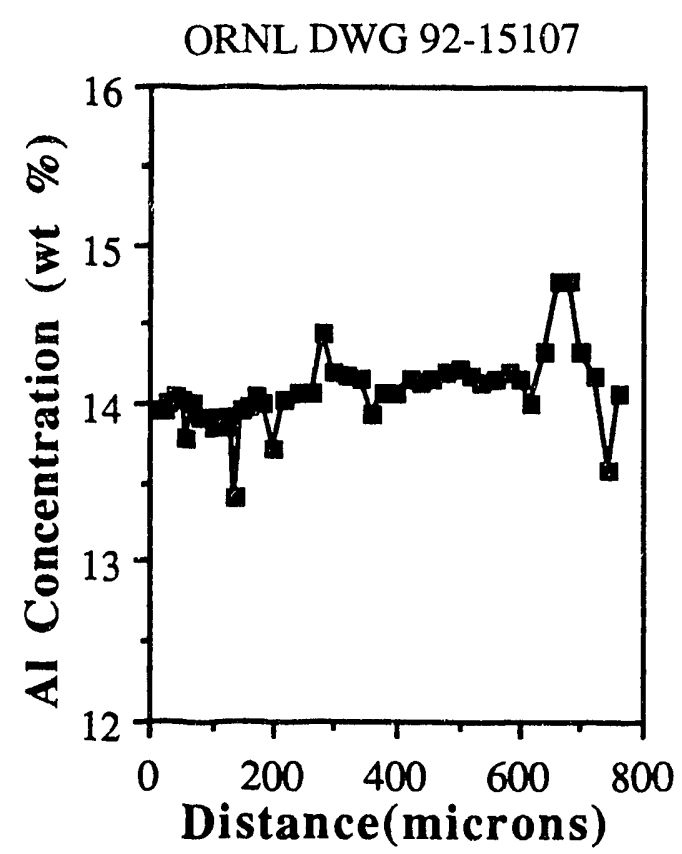

(b)

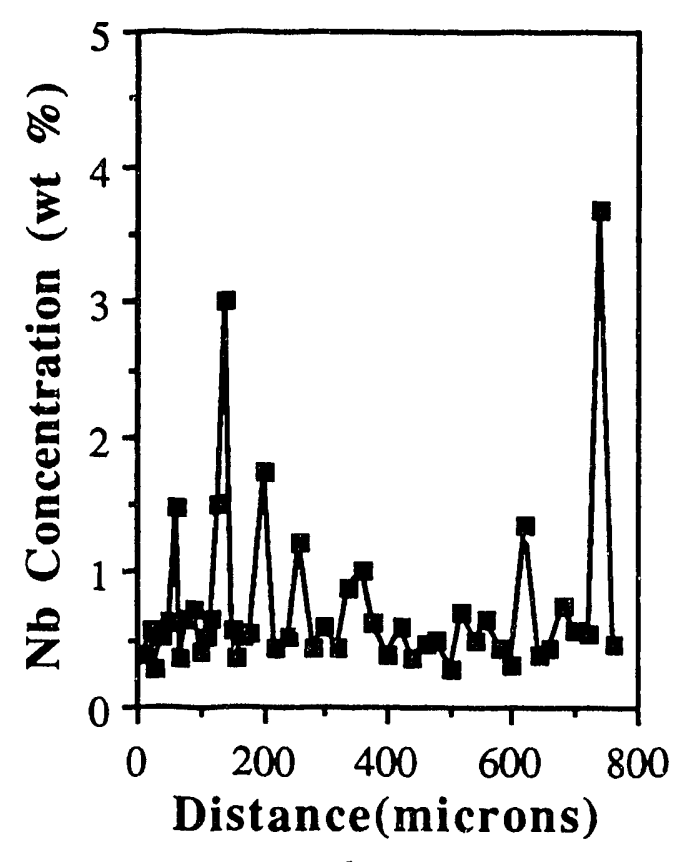

(d)

Fig. 3. Composition profiles of: (a) iron, (b) aluminum, (c) chromium, and (d) niobium in an as-cast specimen of FA-129 alloy obtained from an AEM analysis. 
Table 3. Analytical electron microscopy analysis of rod-shaped precipitates

\begin{tabular}{cccc}
\hline & \multicolumn{3}{c}{ Weight percent } \\
\cline { 2 - 4 } Point & Chromium & Niobium & Iron \\
\hline 1 & -- & 99.03 & -- \\
2 & -- & 98.44 & -- \\
3 & -- & 98.40 & -- \\
\hline
\end{tabular}

are about $98 \%$ niobium, suggesting that the precipitates are niobium carbide, since carbon is present in the alloy.

\section{Homogenization Studies}

Previous homogenization studies ${ }^{2}$ showed that the two types of precipitates found in FA-129 alloy behave differently during homogenization at 1200 and $1300^{\circ} \mathrm{C}$. In order to further characterize the behavior of the two precipitates, one sample was homogenized at $1350^{\circ} \mathrm{C}$ for $2 \mathrm{~h}$ and quenched in water. Homogenization at $1350^{\circ} \mathrm{C}$ caused the rodshaped precipitates to dissolve partially. As in previous studies, globular precipitates dissolved completely and reprecipitated at the grain boundary. Figure 4 shows an optical micrograph of the sample homogenized at $1350^{\circ} \mathrm{C}$ for $2 \mathrm{~h}$. The results of the homogenization studies indicate that the rod-shaped precipitates found in the FA-129 alloy are unlikely to go into solution during thermomechanical srocessing, as they are stable up to temperatures very close to the solidus temperature.

A sample of the FA- 129 alloy homogenized at $1200^{\circ} \mathrm{C}$ for $32 \mathrm{~h}$ was examined in a TEM. Figure 5 $(a)$ is a bright field image of the homogenized specimen showing large B2 domains. Closer examination and comparison of the micrograph with previous TEM micrographs of as-cast specimens reveal fine $\mathrm{D}_{3}$-phase domains in the background and within the larger B2 domains, so that a significant fraction of both ordered phases is present. Electron-diffraction patterns from the area indicate the presence of B2 structure. However, the evidence from the micrographs sugg sts a mixed microstructure, and the $\mathrm{DO}_{3}$-pnase domains appear too fine for adequate diffraction spot intensity. Figure $5(b)$ is 
ORNL PHOTO 9859-92

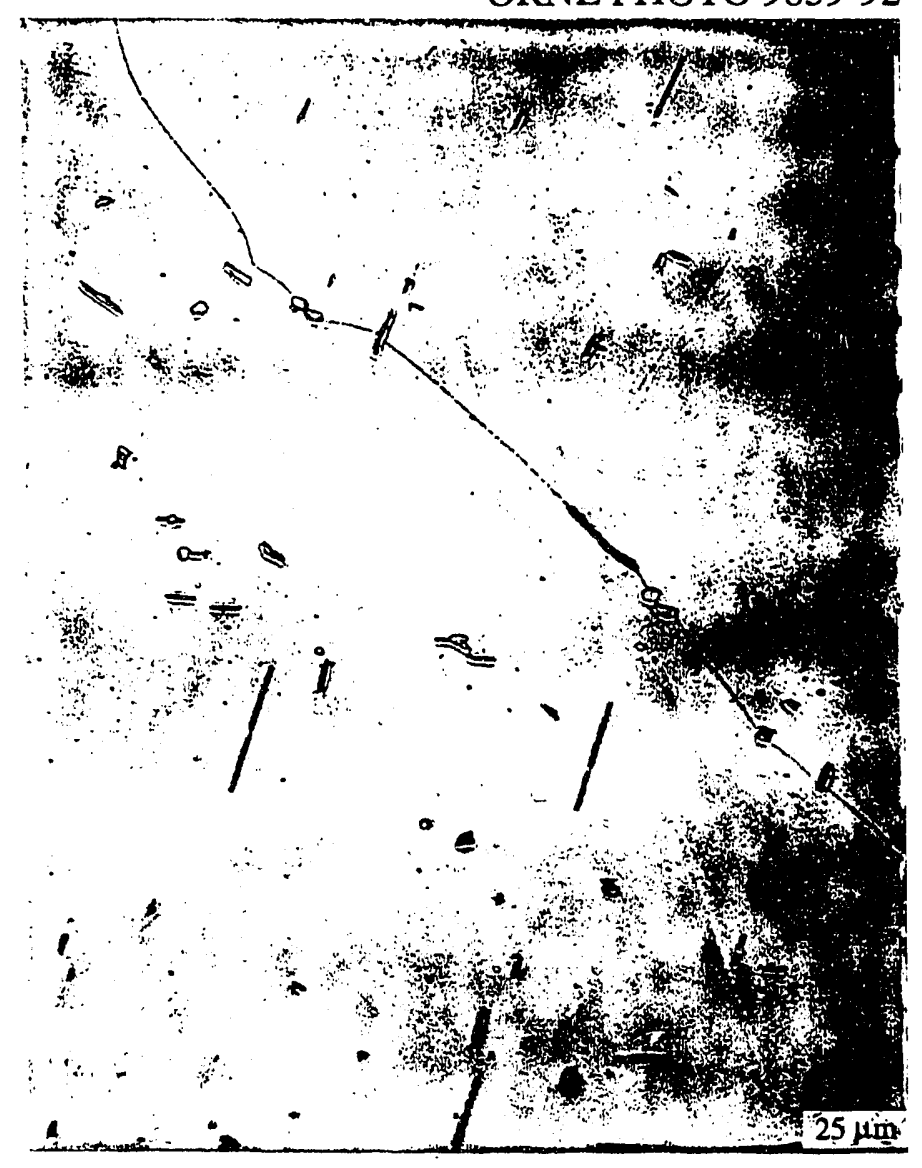

Fig. 4. Optical micrograph of an as-cast FA-129 alloy sample homogenized at $1350^{\circ} \mathrm{C}$ for $2 \mathrm{~h}$.

a TEM micrograph showing the formation of fine precipitates on dislocations. Figure $5(c)$ is a micrograph at lower magnification, indicating the presence of numerous dislocations and fine precipitates in the homogenized structure. The presence of precipitates upon or adjacent to dislocations suggests that precipitates are nucleated on dislocations and may serve to pin dislocations temporarily. Also, the presence of large numbers of two-fold dislocations suggests a significant fraction of the B2-ordered phase in the matrix microstructure. These results indicate that several important microstructural changes are taking place during homogenization and during cooling to room temperature. These changes could have important effects on the mechanical behavior of the as-cast FA-129 alloy. 


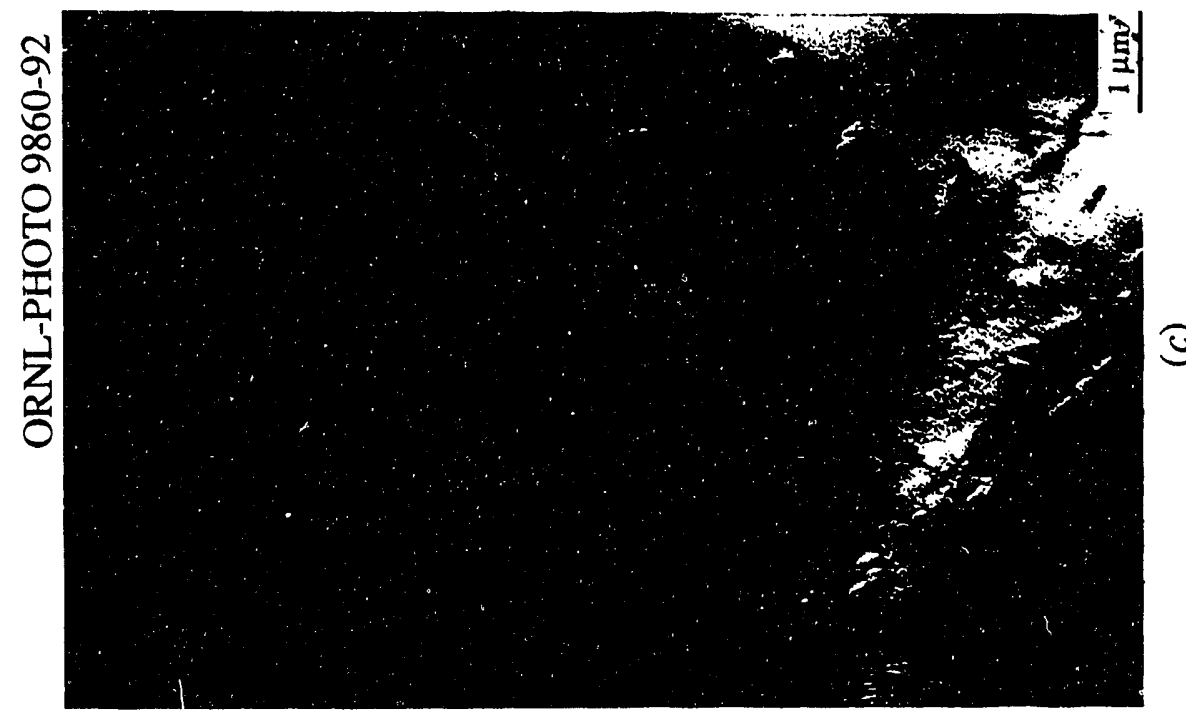

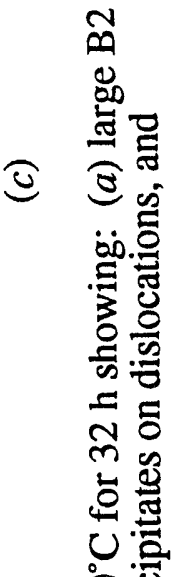

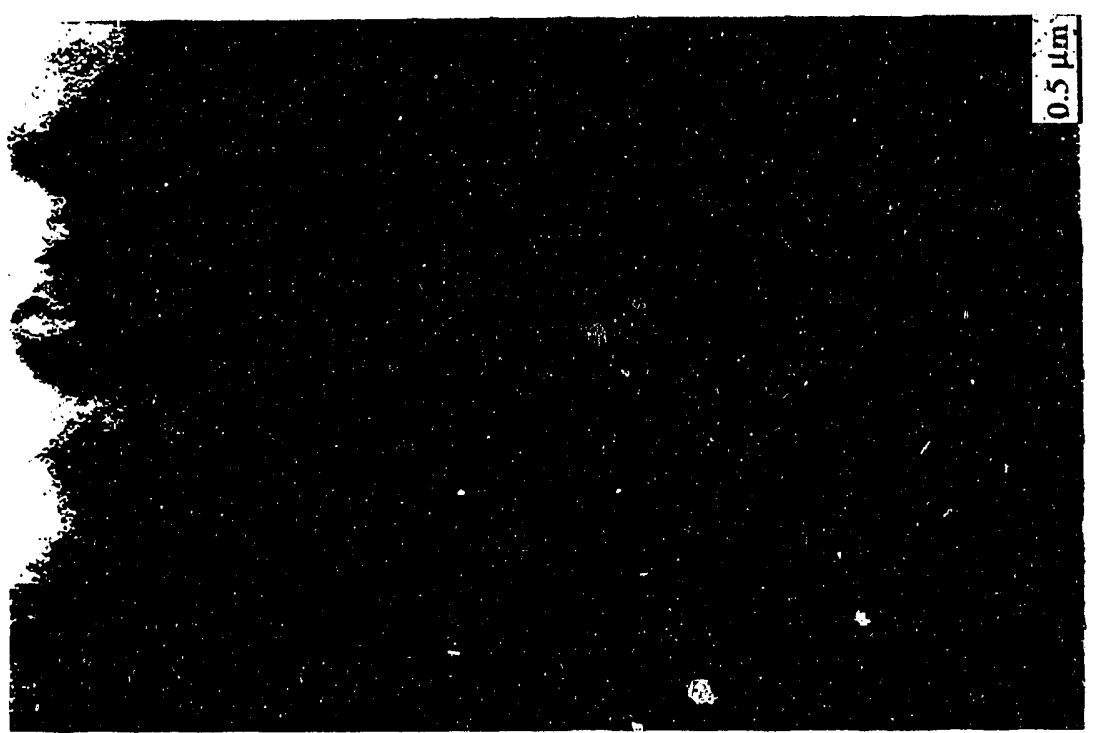

웅

호

式

N

롱.으

플

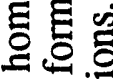

(2)융

हु용

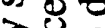

증응

크웜를

잉

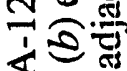

II की

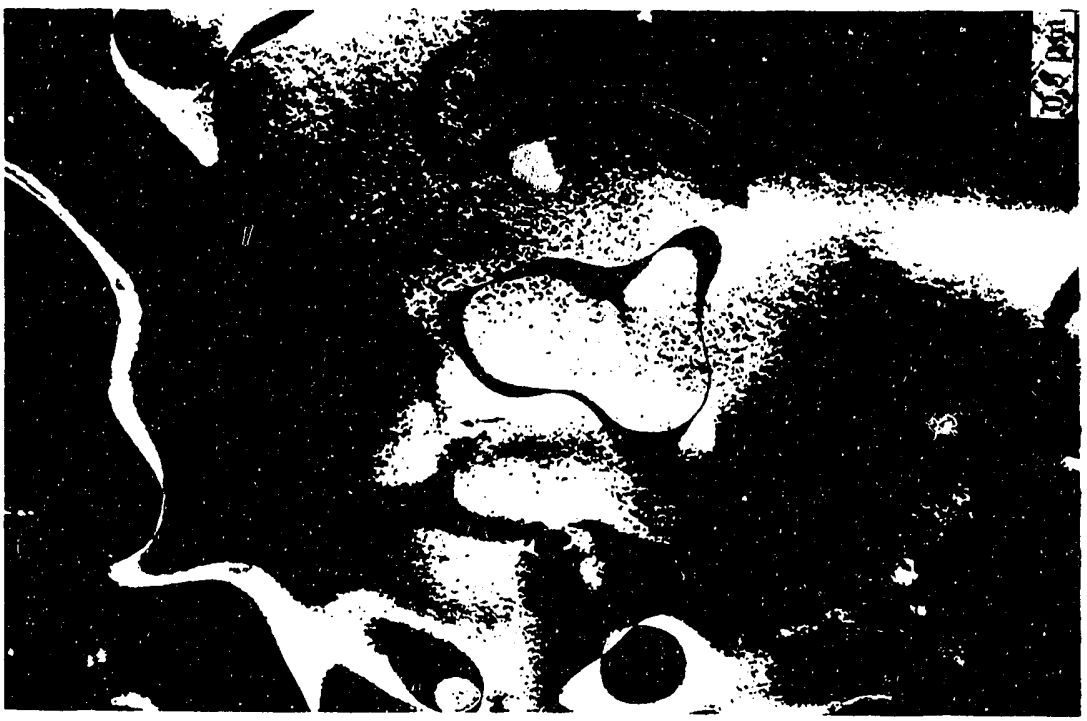

昰.

흐의

पु

48

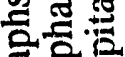

윤? क्ष 윰듬 记 结 (3) $\sum_{11} 000$ 볼

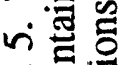
o 诖记 . 范宅 


\section{SUMIMARY}

Continued homogenization of cast FA-129 alloy specimens at temperatures up to $1350^{\circ} \mathrm{C}$ cause the rod-shaped precipitates to only dissolve partially, indicating that the rod-shaped precipitates are unlikely to go into solution during thermomechanical processing. Quantitative compositional analyses on the electron microprobe and TEM are used to verify previous EDS results obtained with the SEM. The results cCuffirm that there is no segregation of iron, aluminum, or chromium in the matrix. AEM analysis indicates that the rod-shaped precipitates found in the FA-129 alloy are about $98 \%$ niobium, suggesting that the precipitates are niobium carbide, since carbon is present in the alloy. Samples that had previously been homogenized at $1200^{\circ} \mathrm{C}$ for $32 \mathrm{~h}$ are also examined in the TEM. The TEM micrographs reveal the presence of numerous dislocations and fine precipitates that were previously absent in the as-cast structure. In most cases, fine precipitates appear to have nucleated upon dislocations. Electron diffraction patterns indicate a $\mathrm{B} 2$-ordered structure, but extremely fine, $\mathrm{D}_{3}$-phase domains are also detected within the $\mathrm{B} 2$ domains. By contrast, the as-cast structure was almost completely $\mathrm{DO}_{3}$ and had very few dislocations. The results indicate that several important changes are taking place in the microstructure during homogenization and during cooling to room temperature.

\section{REFERENCES}

1. D. J. Alexander and V. K. Sikka, "Fracture Behavior of Fe 3 Al Alloy FA 129," Proceedings of the Fifth Annual Conference on Fossil Energy Materials, ORNL/FMP-91/1, Martin Marietta Energy Systems, Inc., Oak Ridge Natl. Lab., September 1991.

2. S. Viswanathan, P. J. Maziasz, and V. K. Sikka, "Solidification Behavior of FA-129 Iron-Aluminide Alloy," Proceedings of the Sixth Annual Corference on Fossil Energy Materials, ORNL/FMP-92/1, Martin Marietta Energy Systems, Inc., Oak Ridge Natl. Lab., July 1992. 


\title{
ORNL-4(B)- COAL CONVERSION AND UTILIZATION \\ PLANT SUPPORT SERVICES
}

\author{
J. R. Keiser and T. J. Henson \\ Oak Ridge National Laboratory \\ Oak Ridge, Tennessee 37831-6156
}

\section{INTRODUCTION}

A 1987 visit to Japan by Oak Ridge National Laboratory (ORNL) and Department of Energy (DOE) staff members was the first in a series of exchange meetings to share information on materials for coal liquefaction. During this visit discussions were conducted that contributed to a formal agreement between the Japanese New Energy and Industrial Technology Development Organization (AIST/NEDO) and the United States Department of Energy. One feature of this agreement is a plan for an exchange of corrosion samples such that samples supplied by Japanese researchers would be exposed in a U.S. coal liquefaction plant and U.S. supplied samples would be exposed in a Japanese liquefaction facility. Following the exposure of such samples, examination of each would be conducted by researchers in the host country.

The exchange of corrosion samples was first implemented in August and September, 1991, and exposure of samples took place during the last few months of 1991 and the first months of 1992. This report describes the results of the examination of the fourteen samples supplied by Japan, exposed in the U.S. liquefaction plant, and examined at Oak Ridge National Laboratory.

\section{EXPOSURE CONDITIONS}

Fourteen samples, two each of seven different materials, were supplied on behalf of the Japanese NEDO by Mitsui SRC Development Co., Ltd. The reported compositions of these samples is listed in Table 1 . These samples were cylindrically shaped with a length of about $20 \mathrm{~mm}$ and an outer diameter of about $25 \mathrm{~mm}$. A total of seven samples, one of each type, was assembled on a support rod. The samples were separated by ceramic coated spacers also supplied by Mitsui SRC.

It was arranged that the samples would be exposed in the two liquefaction reactor vessels located at the Wilsonville, Alabama, Advanced Coal Liquefaction Research and 
Development Facility which was operated by Southern Clean Fuels Division of Southern Electric International under a contract from the U.S. DOE. These reactors are relatively long, small-diameter stainless steel vessels that can be connected in several different ways. During these studies, the plant was operated in the close-coupled integrated two-stage liquefaction (CC-ITSL) mode. In this operating mode, the two ebullated-bed reactors, R1235 and R1236, are connected in sequence followed by the unit used to remove the mineral matter and unreacted coal. The first reactor was operated in the thermal mode while the second was in the catalytic mode. In the thermal mode of operation, no supported transitional metal catalyst is used. However, fine iron oxide ( + dimethyl disulfide) and a dispersed molybdenum catalyst were externally added to the first stage reactor during the run. There is no pressure letdown between the two reactors, and heating or cooling is done only to the extent required to achieve the desired second stage reactor conditions. A simplified flow diagram showing the vessel connections during CCITSL operation is shown in Figure 1.

The samples were inserted into the vessels through nozzles near- the top of the vessels, such that the racks were held horizontally so that the samples were positioned in the center of the vessels. Because the nozzles were near the top of the reactors and the reactors were operated with liquid at the $50 \%$ level, the samples were primarily exposed to organic vapors. The temperature near the top of each reactor where the samples were located is proprietary information, but it is presumed that the actual value was somewhat lower than the temperature of the slurry.

These samples were exposed from October 31, 1991, through February 22, 1992 , for an on-coal time of 2497 hours, which was all of run 263. Both run 263 and the previous run, 262, used Black Thunder subbituminous coal mined from the Wyodak Anderson seam of the Powder River Basin which is in Campbell County, Wyoming. This coal contains $20-25 \mathrm{wt} \%$ moisture and also has 6-8 wt\% ash when measured on a moisture free basis.

During run 262, the previous run, the first reactor was operated as a thermal reactor with an average temperature of $441^{\circ} \mathrm{C}\left(825^{\circ} \mathrm{F}\right)$ and a hydrogen partial pressure at the preheater inlet of $18.6-19.2 \mathrm{MPa}$ (2700-2850 psi). During the same time period, the second reactor was operated in a catalytic mode with average temperatures of about 
$404 / 421 / 432^{\circ} \mathrm{C}\left(760 / 790 / 810^{\circ} \mathrm{F}\right)$ and an inlet hydrogen partial pressure of $17.4 \mathrm{MPa}(2530$ psi). During run 263, the first reactor continued operation as a thermal reactor with average temperatures of $441 / 449^{\circ} \mathrm{C}\left(825 / 840^{\circ} \mathrm{F}\right)$ and a hydrogen partial pressure of 18.619.3 MPa (2700-2800 psi). The operating conditions of the second reactor were changed during run 263 in order to evaluate the effect of a dispersed catalyst containing molybdenum and sulfur with and without the customary supported catalyst. This dispersed molybdenum and sulfur-rich catalyst (Molyvan L or Molyvan 822 as the catalyst precursor) was used during run 262 to reduce solids accumulation in the transfer lines resulting from coking and/or mineral deposition from the high calcium content of the coal. This catalyst was tried because of its success in the petrochemical industry in eliminating coking. This dispersed catalyst was in the form of an oil-soluble organic compound which was injected into the liquefaction slurry feed stream at a selected rate rather than being used as a solid material which was recirculated by the ebullating pump.

During run 262, it was found that the dispersed molybdenum catalyst, when used with the supported catalyst, aided hydrogenation and improved coal conversion 3-5\%, resid conversion $5-10 \%$ and distillate production $30-60 \%$, compared to using catalysts separately. Consequently, plant engineers changed conditions during the first part of run 263 to assess the effect of the dispersed catalyst without the supported catalyst. It was found that the improvement in coal and resid conversions required both the dispersed and supported catalysts, so both catalysts were used during the remainder of run 263. A low molybdenum addition rate of $100 \mathrm{ppm}$ MF coal was sufficient to give a good process performance.

The use of the dispersed catalyst with and without the supported catalyst affected the coal conversion rate during run 263. However, since the same coal was used and the temperature and hydrogen partial pressure were kept relatively constant during this run, it is not expected that the variation in catalyst usage affected corrosion of the samples. Thus, corrosion rates of samples exposed during this run were calculated assuming the rate remained constant independent of catalyst usage.

\section{EXAMINATION RESULTS}

The samples were first cleaned, then measured and weighed before being mounted on the racks. Following exposure, the sample racks were photographed, then the samples were removed and cleaned to remove organic material, mineral matter and loosely 
adherent scale. Both racks of exposed samples are shown in Figure 2. It is evident that some materials appear unchanged by exposure while others have a surface deposit or a reaction layer.

Dimensionai measurements of the samples showed significant changes that varied from sample to sample as is evident in Table 2. All six samples with aluminum or alumina coatings decreased in OD and length but increased in ID. The $9 \mathrm{Cr}-1$ Mo samples increased in OD and length and decreased in ID, presumably because of the development of an adherent corrosion product. The other three materials showed relatively small dimensional changes.

Weight change measurements confirmed that some materials underwent significant corrosion while others were relatively unaffected. Tables 3 and 4 give the calculated corrosion rates for samples exposed 2497 hours in reactor vessels R1235 and R1236, respectively. These rates were calculated on the basis that material removal occurred in a uniform manner and not as a result of pitting or other localized corrosion.

As shown in the tables, the aluminum coated samples showed the highest corrosion rates; appreciably higher than all other materials tested. The other five materials had corrosion rates below $0.025 \mathrm{~mm} / \mathrm{y}(1 \mathrm{mil} / \mathrm{y})$. The stainless steel samples identified by the supplier as type 321 showed little or no weight change while the $\mathrm{Al}_{2} \mathrm{O}_{3}$ plasma sprayed samples both showed slight weight gains. The porosity in the layers on the plasma sprayed samples could have trapped organic material resulting in a misleadingly low weight loss (or a small weight gain).

After the measuring and weighing were completed, each sample was cut longitudinally (along the central axis of the cylinder). One section of each sample was mounted in epoxy, then it was polished for microscopic and microprobe examination. Low and high magnification photomicrographs taken of each of the samples are included in the figures. A JEOL Superprobe 733 electron microprobe was used to determine the approximate concentration of the material near the surface on all the samples. For most samples, quantitative measurements were made at $2 \mu \mathrm{m}$ intervals using a $1 \mu \mathrm{m}$ diameter beam. The results of these microprobe examinations on each sample are summarized in figures accompanying the photomicrographs. A discussion of the results for each pair of samples follows. 


\section{Alumina Plasma Sprayed Coating on $2.25 \mathrm{Cr}-1$ Mo Steel}

The micrographs of the cross-sectioned alumina plasma sprayed samples from vessel R1235 are shown in Figure 3. These micrographs show that the samples have an outer layer about $100 \mu \mathrm{m}$ thick and an inner layer $\$ 50-200 \mu \mathrm{m}$ thick. Using the electron microprobe, it was determined that the outer layer was predominately alumina while the inner layer was an approximately equal mixture of chromium and nickel as shown in Figure 4. An especially important feature of these concentration profiles is the high sulfur concentration at the interface between the chromium-nickel layer and the $2.25 \mathrm{Cr}-1 \mathrm{Mo}$ base metal that is evident in this figure. The data indicate that aluminum and chromium also have higher concentrations at this interface suggesting that sulfur in the process stream penetrated beneath this coating and formed these metal sulfides. Aluminum Hot-Dip Coating on $2.25 \mathrm{Cr}-1$ Mo Steel

The hot-dip aluminum coating specimens each had a cracked non-continuous layer with evidence in some places of another layer which was missing over most of the samples. The microprobe analyses revealed the subsurface layer as an aluminum-iron alloy that is about $55 \mathrm{wt} \% \mathrm{Al}$ and $40 \mathrm{wt} \% \mathrm{Fe}$ while the base alloy has the chromium and molybdenum concentrations typical of $2.25 \mathrm{Cr}-1$ Mo steel. The original surface iayer which is missing over most of the surface is predominately aluminum. There is no indication of sulfur enrichment along the interface or anywhere in the coating, but there was evidence of a sulfide on the surface.

\section{Aluminum Cementation Coating on $2.25 \mathrm{Cr}-1$ Mo Steel}

The $2.25 \mathrm{Cr}-1$ Mo samples with the aluminum cementation coating was severely degraded in these tests. The coating is present on the sample exposed in R1235, but only a few remnants of the coating were visible in the photographed area of the sample exposed in R1236. However, other areas of the R1236 sample retained the coating, and the thickness of the coating on both samples averaged about $20 \mu \mathrm{m}$. The microprobe studies surveyed areas on both samples where the coatings were intact, and the results indicate both samples have an aluminum concentration of slightly more than $20 \mathrm{wt} \%$ at the surface that decreases to less than $1 \%$ about $100 \mu \mathrm{m}$ below the surface. The iron, chromium and molybdenum content show a progressive increase with depth so that the chromium and molybdenum concentrations reach the levels of $2.25 \mathrm{Cr}-1 \mathrm{Mo}$ at a depth of 40-50 $\mu \mathrm{m}$ below the surface. Both samples show a higher than background concentration of sulfur within the outer $10 \mu \mathrm{m}$, but no significant sulfur concentration below that level. 
Titanium Nitride CVD Coating on $2.25 \mathrm{Cr}-1$ Mo Steel

A sample of $2.25 \mathrm{Cr}-1 \mathrm{Mo}$ with the TiN chemical vapor deposition (CVD) coating is shown in Figure 5. This less than $10 \mu \mathrm{m}$ thick coating appears to be continuous and adherent over all surfaces shown in the micrograph. The microprobe data shown in Figure 6 indicates a titanium concentration greater than $70 \mathrm{wt} \%$ for the first $4-8 \mu \mathrm{m}$. There is a significant chlorine concentration that follows the titanium profile, arid it is presumed this chlorine is a result of the precursors used in the CVD process rather than a result of deposition from the liquefaction process stream. Microprobe data not shown in the figure indicate negligible levels of sulfur in or around the coating.

\section{$3 \mathrm{Cr}-1$ Mo Steel}

A $3 \mathrm{Cr}-1$ Mo from R1235 sample is shown in Figure 7 and there is minimal evidence of corrosion. The lower magnification micrograph clearly show the machining marks which suggest very little corrosion of this sample. The microprobe data shown in Figure 8 indicates the composition of the sample fits well in the range expected for $3 \mathrm{Cr}-1$ Mo. The sample exposed in R1236 apparently had a chromium and sulfur rich deposit on the surface which likely was chromium sulfide.

\section{Cr-1 Mo Steel}

As with the $3 \mathrm{Cr}-1$ Mo samples, machining marks were clearly visible on the surface of the $9 \mathrm{Cr}-1$ Mo samples suggesting that very limited corrosion of these samples occurred. A portion of the $9 \mathrm{Cr}-1$ Mo sample exposed in $\mathrm{R} 1235$ had a surface layer that was not removed by standard cleaning techniques, so the microprobe examination covered that area. The results of the microprobe examination show a silicon-rich layer on the surface. For both samples, no evidence of a concentration of sulfur was found.

\section{Type 321 Stainless Steel}

As was the case for the uncoated Cr-Mo steels, the machined surfaces of type 321 stainless steel appear undamaged by the 2497 hour exposure. The microprobe data show this material is nominally an 18-8 stainless steel. The presence of titanium, which would indicate this stainless steel is type 321, could not be confirmed with a Texas Nuclear Alloy Analyzer or with the electron microprobe.

\section{SUMMARY AND CONCLUSIONS}

Fourteen samples provided by Mitsui SRC Development Co., Ltd. were exposed for 2497 hours through nozzles near the top of the two liquefaction reactors at the 
Wilsonville, Alabama, coal liquefaction facility. The samples were exposed during the entirety of run 263 which was the final run conducted at this facility. Examination of the samples provided the following information.

1. Both sets of samples with aluminum coatings had significantly greater weight losses than any of the other samples. The hot-dipped aluminum coating spalled in many areas leaving a layer rich in aluminum and iron.

2. The alumina plasma sprayed sample had an inner chromium-nickel layer, and there was a significant accumulation of metal sulfides between this inner layer and the base metal.

3. The titanium nitride CVD coated sample had an adherent, continuous coating and a very low corrosion rate. Chlorine, likely a result of the CVD process, was present in the coating.

4. The three uncoated metals, $2.25 \mathrm{Cr}-1 \mathrm{Mo}, 9 \mathrm{Cr}-1 \mathrm{Mo}$, and the material labeled as 321 stainless steel, had low calculated corrosion rates and showed no evidence of significant corrosion in the microscopic or microprobe examinations.

\section{ACKNOWLEDGMENTS}

We gratefully recognize the efforts of Southern Clean Fuels engineers Andrew Patko, Oliver Davies and Dr. J. M. Lee for their help in coordinating the exposure of samples and providing information. Michael Howell of ORNL was responsible for the dimensional and weight measurements on the samples, and Jackie Mayotte and Paul Haltom performed the metallographic examinations. 
MATERIALS SUPPLIED BY MITSUI SRC DEVELOPMENT CO., LTD. FOR EXPOSURE IN THE WILSONVILLE COAL LIQUEFACTION REACTORS

$\mathrm{Al}_{2} \mathrm{O}_{3}$ plasma spray coating on $2.25 \mathrm{Cr}-1$ Mo steel

Al hot dip coating on $2.25 \mathrm{Cr}-1$ Mo steel

Al cementation coating on $2.25 \mathrm{Cr}-1$ Mo steel

TiN CVD coating on $2.25 \mathrm{Cr}-1$ Mo steel

3 Cr-1 Mo steel

$9 \mathrm{Cr}-1$ Mo steel

Type 321 stainless steel

Table 1. Identification of samples supplied by Mitsui SRC Development Co., Ltd., for exposure in the two reactor vessels at the Wilsonville, Alabama, Advanced Coal Liquefaction Research and Development Facility. This information was taken from a listing in the July 4, 1991 letter from Mr. Sadao Wasaka. 
CHANGES IN SAMPLE DIMENSIONS

$\begin{array}{ccc}\begin{array}{l}\text { OD change } \\ \text { (inches) }\end{array} & \begin{array}{c}\text { ID change } \\ \text { (inches) }\end{array} & \begin{array}{c}\text { Length change } \\ \text { (inches) }\end{array}\end{array}$

Alumina plasma spray on $2.25 \mathrm{Cr}-1$ Mo steel

$\begin{array}{llll}\mathrm{R} 1235 & -0.025 & +0.006 & -0.029 \\ \mathrm{R} 1236 & -0.026 & +0.001 & -0.032\end{array}$

Aluminum hot dip coating on $2.25 \mathrm{Cr}-1$ Mo steel

$\begin{array}{llll}R 1235 & -0.009 & +0.011 & -0.008 \\ R 1236 & -0.013 & +0.007 & -0.012\end{array}$

Aluminum cementation coating on $2.25 \mathrm{Cr}-1$ Mo steel

$\begin{array}{llll}\mathrm{R} 1235 & -0.007 & +0.005 & -0.005 \\ \mathrm{R} 1236 & -0.005 & +0.006 & -0.006\end{array}$

Titanium nitride CVD coating on $2.25 \mathrm{Cr}-1$ Mo steel

$\begin{array}{lccc}R 1235 & +0.008 & -0.010 & -0.007 \\ R 1236 & 0.0 & -0.012 & +0.004\end{array}$

3 Cr-1 Mo steel

$\begin{array}{llll}\mathrm{R} 1235 & 0.0 & +0.004 & -0.003\end{array}$

$\begin{array}{llll}\mathrm{R} 1236 & 0.0 & -0.001 & -0.001\end{array}$

9 Cr-1 Mo steel

$\begin{array}{llll}\mathrm{R} 1235 & +0.024 & -0.001 & +0.022 \\ \mathrm{R} 1236 & +0.025 & -0.007 & +0.035\end{array}$

321 stainless steel

$\begin{array}{llcc}\text { R1235 } & +0.005 & -0.005 & +0.008 \\ \text { R1236 } & +0.001 & -0.003 & 0.0\end{array}$

Table 2. Dimensional change of samples exposed 2497 hours in reactors R1235 and R1236 at the Wilsonville, Alabama, Advanced Coal Liquefaction Research and Development Facility. 
CALCULATED CORROSION RATES

\begin{tabular}{|c|c|c|}
\hline Material & $\mathrm{mm}^{\mathrm{v}} \mathrm{vr}$ & $\mathrm{mil} / \mathrm{yr}$ \\
\hline $\begin{array}{l}\text { Al cementation coating } \\
\text { on } 2.25 \mathrm{Cr}-1 \mathrm{Mo}\end{array}$ & 0.382 & 15.0 \\
\hline $\begin{array}{l}\text { Al hot dip nating } \\
\text { on } 2.25 \mathrm{Cr}-1 \mathrm{Mo}\end{array}$ & 0.292 & 11.5 \\
\hline $3 \mathrm{Cr}-1 \mathrm{Mc}$ & 0.02 .4 & 0.9 \\
\hline $9 \mathrm{Cr}-1 \mathrm{Mo}$ & 0.005 & 0.2 \\
\hline $\begin{array}{l}\text { TiN coating on } \\
2.25 \mathrm{Cr}-1 \mathrm{Mo}\end{array}$ & $<0.003$ & $<0.1$ \\
\hline 321 stainless steel & $<0.003$ & $<0.1$ \\
\hline $\begin{array}{l}\mathrm{Al}_{2} \mathrm{O}_{3} \text { plasma spray coating } \\
\text { on } 2.25 \mathrm{Cr}-1 \mathrm{Mo}\end{array}$ & $<0.003$ & $<0.1$ \\
\hline
\end{tabular}

Table 3. Corrosion rates of samples supplied by Mitsui SRC Development Co., Ltd. and exposed for 2497 hours in the R1235 reactor at the Wilsonville, Alabama, coal liquefaction facility. The sample exposure was done under the terms of an exchange agreement between the US DOE and the Japanese AIST/NEDO. Corrosion rates are calculated with the assumption of uniform material removal. 


\section{CALCULATED CORROSION RATES}

\begin{tabular}{lcc} 
Miterial & $\mathrm{mm} / \mathrm{yr}$ & $\mathrm{mil} / \mathrm{yr}$ \\
\hline $\begin{array}{l}\text { Al hot dip coating } \\
\text { on } 2.25 \text { Cr-1 Mo }\end{array}$ & 0.835 & 32.9 \\
$\begin{array}{l}\text { Al cementation coating } \\
\text { on } 2.25 \text { Cr-1 Mo }\end{array}$ & 0.472 & 18.6 \\
3 Cr-1 Mo steel & & \\
9 Cr-1 Mo steel & 0.016 & 0.6 \\
$\begin{array}{l}\text { TiN coating on } \\
2.25 \text { Cr-1 Mo }\end{array}$ & 0.007 & 0.3 \\
$\begin{array}{l}321 \text { stainless steel } \\
\mathrm{Al}_{2} \mathrm{O}_{3} \text { plasma spray coating } \\
\text { on } 2.25 \text { Cr-1 Mo }\end{array}$ & 0.003 & 0.1 \\
\end{tabular}

Table 4. Corrosion rates of samples supplied by Mitsui SRC Development Co., Ltd. and exposed for 2497 hours in the R1236 reactor at the Wilsonville, Alabama, coal liquefaction facility. The sample exposure was done under the terms of an exchange agreement between the US DOE and the Japanese AIST/NEDO. Corrosion rates are calculated with the assumption of uniform material removal. 


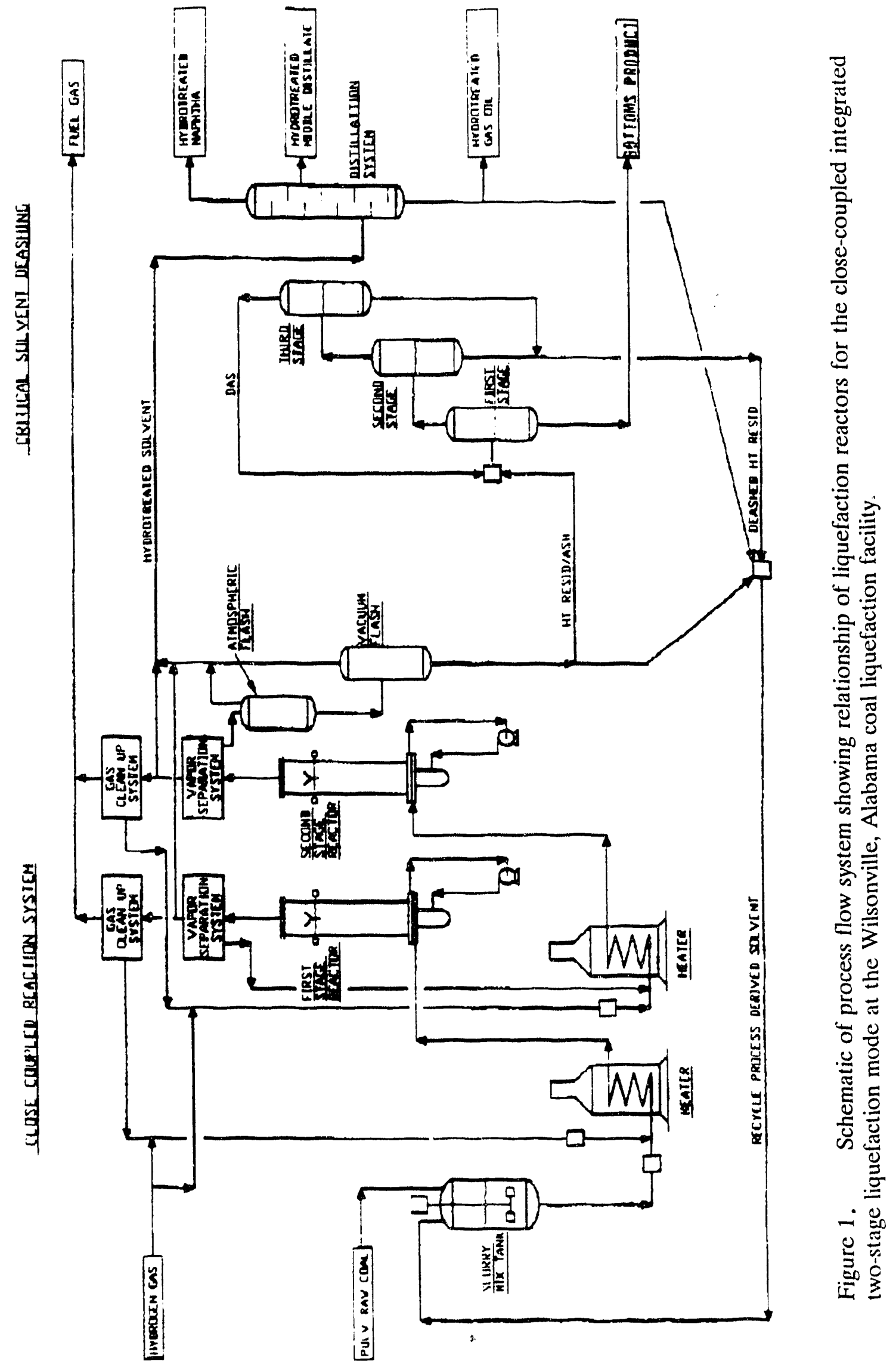



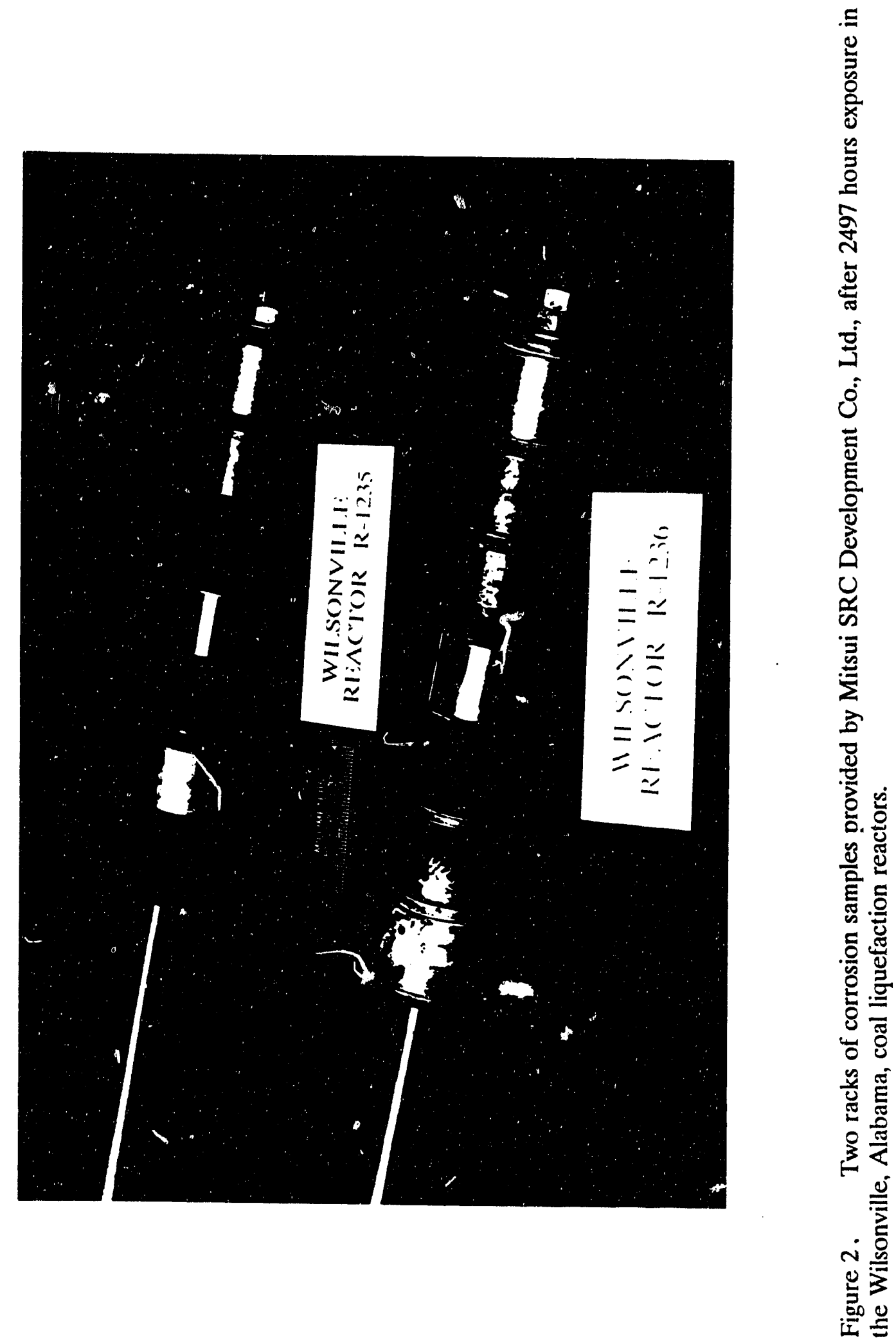


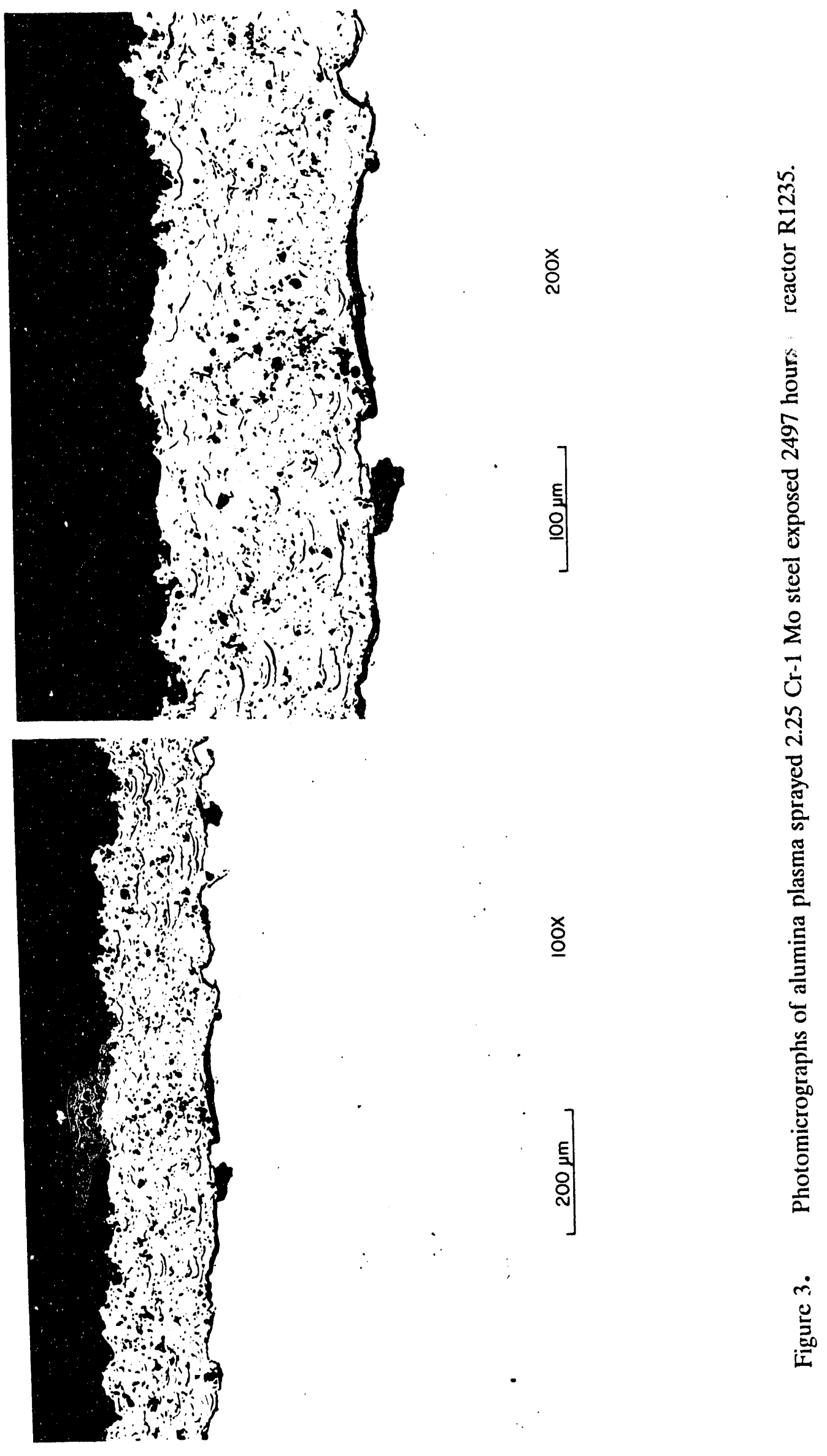



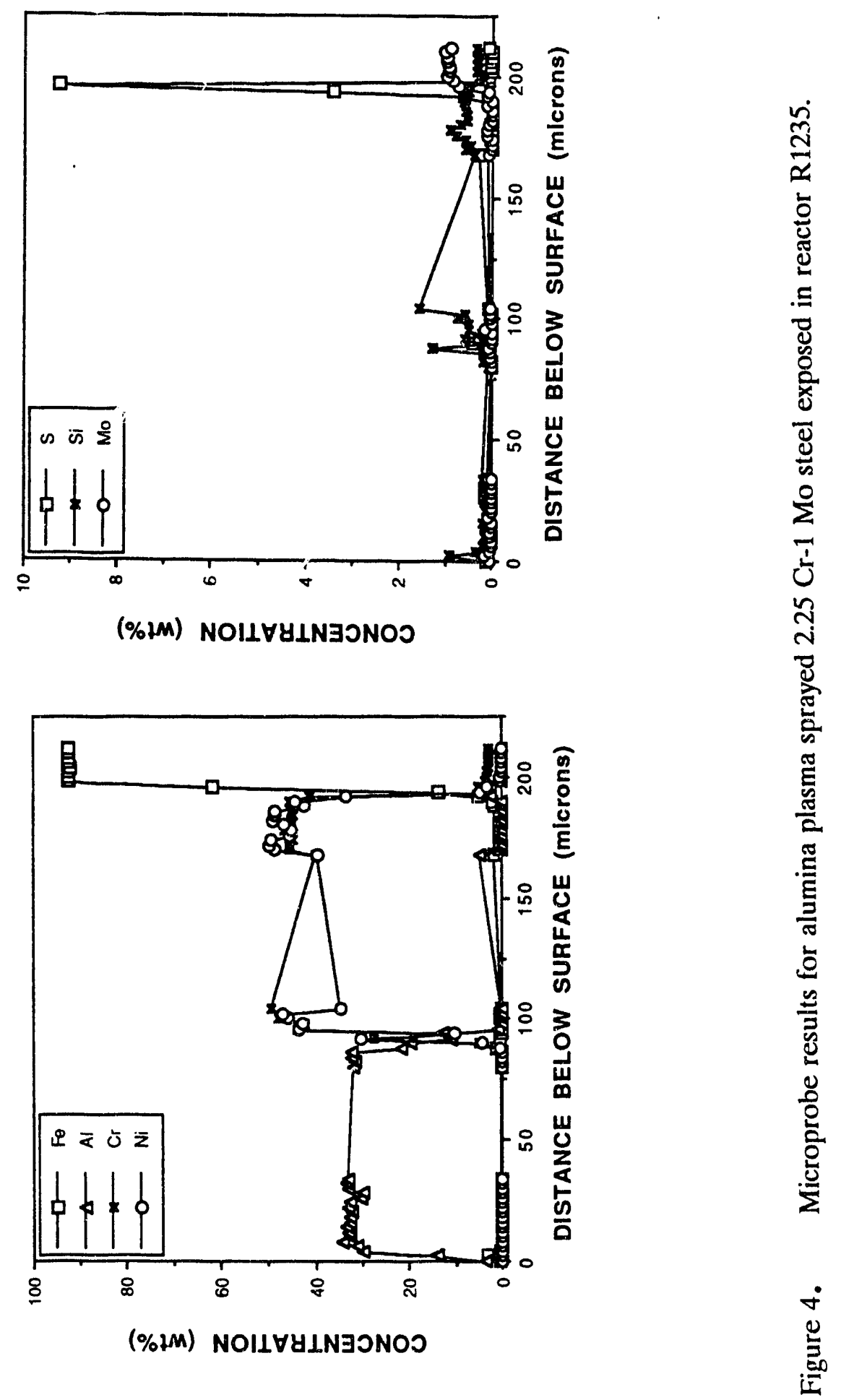


$$
1
$$



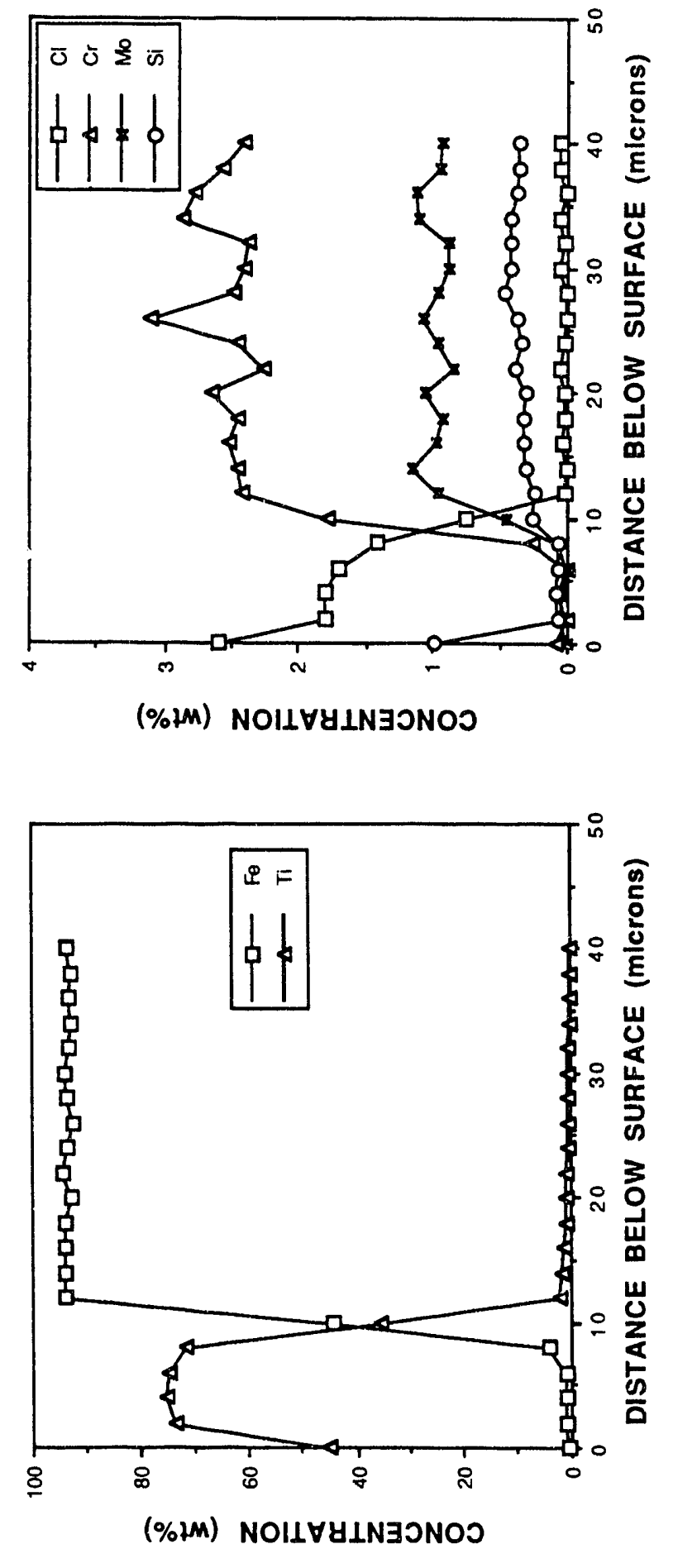

8

를

है

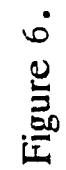




$$
\mid
$$




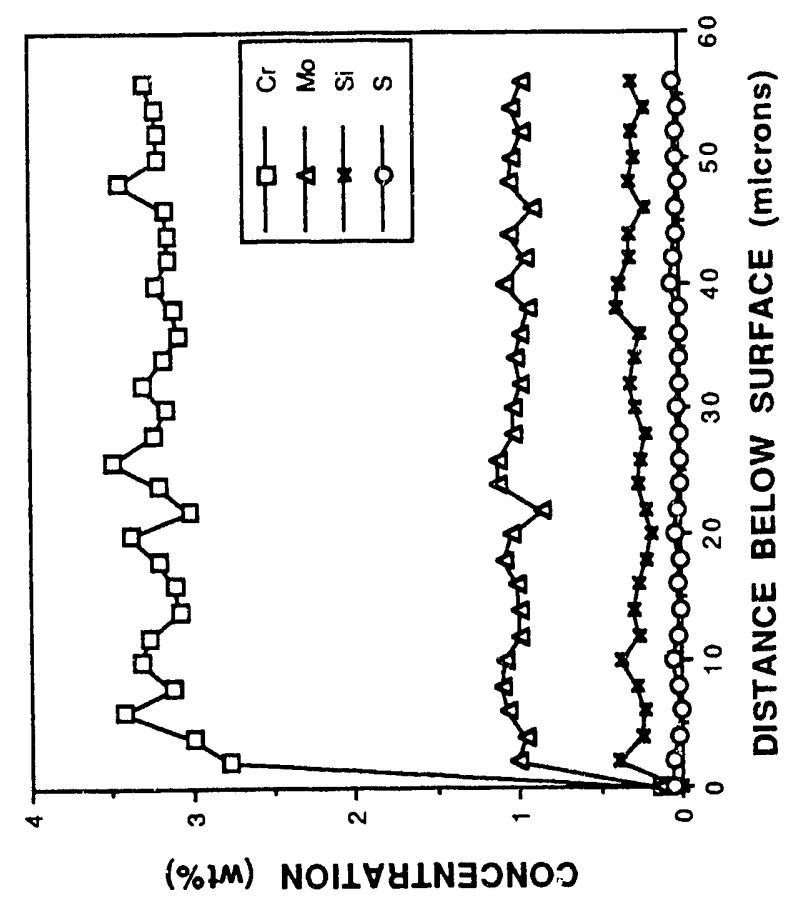


ORNL/FMP-92/2

\section{INTERNAL DISTRIBUTION}

1. D. J. Alexander

2. T. M. Besmann

3. R. A. Bradley

4. R. S. Carlsmith

5. P. T. Carlson

6. N. C. Cole

7. D. F. Craig

8. S. A. David

9. J. H. DeVan

10. D. E. Fain

11. W. Fulkerson

12. G. M. Goodwin

13. M. A. Janney

14. D. R. Johnson

15. R. R. Judkins

16. J. R. Keiser

17. C. T. Liu

18. R. A. Lowden
19. D. J. McGuire

20. C. G. McKamey

21. V. K. Sikka

22. G. M. Slaughter

23. D. P. Stinton

24. R. W. Swindeman

25. V. J. Tennery

26. T. N. Tiegs

27. P. F. Tortorelli

28. S. Viswanathan

29. J. R. Weir, Jr.

30-31. Central Research Library

32. Document Reference Section

33-34. ORNL Patent Section

35-36. Laboratory Records Department

37-38. M\&C Records Office

39-40. Laboratory Records, ORNL-RC

\section{EXTERNAL DISTRIBUTION}

41. 3M COMPANY, 3M Center, St. Paul, MN 55144

M. A. Leitheiser

42. AIR PRODUCTS AND CHEMICALS, P.O. Box 538, Allentown, PA 18105

S. C. Weiner

43. ALBERTA RESEARCH COUNCIL, Oil Sands Research Dept., P.O. Box 8330, Postal Station F, Edmonton, Alberta, Canada T6H5X2

L. C. Gray 
44. ALLIED-SIGNAL AEROSPACE COMPANY, 7550 Lucerne Drive, Suite 203, Middlesburg Heights, OH 44130

S. D. Thompson

45-46. ALLISON GAS TURBIN 2 OPERATIONS, P.O. Box 420, Indianapolis, IN 46206

P. Khandelwal, MS W-5

R. A. Wenglarz, MS W-16

47. AMAX RESEARCH AND DEVELOPMENT CENTER, 5950 McIntyre St., Golden, CO 80403

T. B. Cox

48-50. ARGONNE NATIONAL LABORATORY, 9700 S. Cass Ave., Argonne, IL 60439

W. A. Ellingson

K. Natesan

J. P. Singh

51. ARMCO, INCORPORATED, 705 Curtis St., Middletown, OH 45043

R. E. Hook

52. ATLANTIC RICHFIELD COMPANY, 8840 Iris Court, West Minister, CO 80020-4454

D. W. Bailey

53. AVCO RESEARCH LABORATORY, 2385 Revere Beach Parkway, Everett, MA 02149

R. J. Pollina

54. BABCOCK \& WILCOX, Domestic Fossil Operations, 20 S. Van Buren Avenue, Barberton, $\mathrm{OH} 44203$

M. Gold

55. BABCOCK \& WILCOX, Lynchburg Research Center, P.O. Box 11165, Lynchburg, VA 24506

D. L. Hindman

56. BABCOCK \& WILCOX, 1562 Beeson St., Alliance, OH 44601

W. Mohn

57. BATTELLE COLUMBUS LABORATORIES, 505 King Avenue, Columbus, OH 43201

I. G. Wright

58. BERGBAU-FORSCHUNG GMBH, Postfach 130140, D-4300 Essen 13, Federal Republic of Germany

Gunter Fauth 
59-60. BETHLEHEM STEEL CORPORATION, Homer Research Laboratory, Bethlehem, PA 18016

B. L. Bramfitt

J. M. Chilton

61. BRITISH GAS CORPORATION, Westfield Development Centre, Cardenden, Fife, Scotland KY50HP

J. E. Scott

62-63. CANADA CENTER FOR MINERAL AND ENERGY TECHNOLOGY, Physical Metallurgy Research Laboratories, 568 Booth Street, Ottawa, Ontario, Canada KlA OGI

R. Winston Revie

M. Sahoo

64. CASE WESTERN RESERVE UNIVERSITY, Department of Metallurgy and Materials Science, 10900 Euclid Avenue, Cleveland, OH 44106

K. M. Vedula

65. CENTER FOR APPLIED RESEARCH, 3572 Iron Works Pike, Lexington, KY 40511

R. E. Gonzalez

66. CENTRAL ELECTRIC RESEARCH LABORATORIES, Technology Planning and

Research Division, Kelvin Avenue, Leatherhead, Surrey KT22 7SE, England

D. B. Meadowcroft

67. CERAMATEC, INC., 163 West 1700 South, Salt Lake City, UT 84115

D. W. Richerson

68. COLORADO SCHOOL OF MINES, Dept. of Metallurgical Engineering, Golden, CO 80401

G. R. Edwards

69-70. CONSOL INC, 4000 Brownsville Road, Library, PA 15129-9566

F. P. Burke

D. Nichols

71. CORNELL UNIVERSITY, Materials Sciences and Engineering Dept., Bard Hall, Ithaca, NY 14853

Che-Yu Li

72-73. DOW CHEMICAL COMPANY, Midland, MI 48674

P. A. Doty

G. S. Shier 
74. DOW CORNING CORPORATION, 3901 South Saginaw Road, Midland, MI 48686-0995 W. H. Atwell

75. DUPONT FIBERS, Experimental Station, E302, Wilmington, DE 19880-0302

C. W. Lundgren

76. DUPONT FIBERS, Pencader Plant, CMC, P. O. Box 6100, Newark, DE 19714

W. D. Hewett

77. DUPONT FIBERS, Experimental Station, E262, W'ilmington, DE 19880-0262

J. K. Weddell

78. EBASCO SERVICES, INC., P.O. Box 1002, Glen Rose, TX 76043

T. A. Flynn

79. EC TECHNOLOGIES INC., 3614 Highpoint Dr., San Antonio, TX 78217

D. J. Kenton

80-82. EG\&G IDAHO, INC., Idaho National Engineering Laboratory, P.O. Box 1625, Idaho Falls, ID 83415

D. W. Keefer

B. H. Rabin

R. N. Wright

83-87. ELECTRIC POWER RESEARCH INSTITUTE, P.O. Box 10412, 3412 Hillview Avenue, Palo Alto, CA 94303
S. B. Alpert
W. T. Bakker
C. J. Kulik
J. Stringer
R. H. Wolk

88. ENERGETICS, INC., 9210 Route 108, Columbia, MD 21045

C. C. Carey

89. EUROPEAN COMMUNITIES JOINT RESEARCH CENTRE, Petten Establishment, P.O. Box 2, 1755 ZG Petten, The Netherlands

M. Van de Voorde

90. EXXON RESEARCH AND ENGINEERING COMPANY, Clinton Township, Route 2 East, Annandale, NJ 08801

M. L. Gorbaty 
91. FOSTER WHEELER DEVELOPMENT CORPORATION, Materials Technology Dept., John Blizard Research Center, 12 Peach Tree Hill Road, Livingston, NJ 07039

J. L. Blough

92. GAS RESEARCH INSTITUTE, 8600 West Bryn Mawr Avenue, Chicago, IL 60631

H. S. Meyer

93. GENERAL APPLIED SCIENCE LABS, 77 Raynor Avenue, Ronkonkoma, NY 11779

Martin Novack

94. GENERAL ATOMICS, INC., P.O. Box 85608, San Diego, CA 92138

T. D. Gulden

95. GEORGIA INSTITUTE OF TECHNOLOGY, Georgia Tech Research Institute, Atlanta, GA 30332

T. L. Starr

96. ILLINOIS INSTITUTE OF TECHNOLOGY, METM Dept., Perlstein Hall, Chicago, IL 60616

J. A. Todd Copley

97-98. INCO ALLOYS INTERNATIONAL, P. 0. Box 1958, Riverside Drive, Huntington, WV 25720

J. J. DeBarbadillo

S. Tassen

99. INSTITUTE OF GAS TECHNOLOGY, 3424 South State Street, Chicago, IL 60425

Robert Remick

100. KENNAMETAL, INC., Philip McKenna Laboratory, 1011 Old Salem Rd., P.O. Box 639, Greensburg, PA 15601

B. North

101. LANXIDE CORPORATION, 1 Tralee Industrial Park, Newark, DE 19711

E. M. Anderson

102. LAVA CRUCIBLE-REFRACTORIES CO., P.O. Box 278, Zelienople, PA 16063

T. Mulholland

103. LAWRENCE LIVERMORE LABORATORY, P.O. Box 808, L-325, Livermore, CA 94550

W. A. Steele

104. MASSACHUSETTS INSTITUTE OF TECHNOLOGY, Departinent of Civil Engineering, Room 1-280, 77 Massachusetts Avenue, Cambridge, MA 02139

O. Buyukozturk 
105. NATIONAL MATERIALS ADVISORY BOARD, National Research Council, 2101 Constitution Avenue, Washington, DC 20418

K. M. Zwilsky

106-107. NATIONAL INSTITUTE OF STANDARDS AND TECHNOLOGY, Materials Building, Gaithersburg, MD 20899

S. J. Dapkunas (Materials Bldg.)

S. Malghan (Bldg. 220, Rm. A-215)

108 NAVAL AIR SYSTEMS COMMAND, Propulsion and Power Division, AIR-536T, Washington, DC 20361-5360

L. E. Sloter

109. NEW ENERGY DEVELOPMENT ORGANIZATION, Sunshine 60 Bldg., P.O. Box 1151, 1-1 Higashi-lkebukuro 3-Chrome, Toshima-Ku, Tokyo, 170, Japan

S. Ueda

110. OHIO STATE UNIVERSITY, Department of Metallurgical Engineering, 116 W. 19th Avenue, Columbus, $\mathrm{OH} 43210$

R. A. Rapp

111. PACIFIC NORTHWEST LABORATORY, P.O. Box 999, Richland, WA 99352

J. L. Bates

112. PROMON ENGENHARIA S.A., Praia do Flamengo, 154-90 Andar, 22210 Rio de Janeiro, RJ Brazil

M. Saddy

113. PSI TECHNOLOGY COMPANY, 20 New England Business Center, Andover, MA 01810 C. L. Senior

114. RENSSELAER POLYTECHNIC INSTITUTE, Materials Engineering Department, Troy, NY 12180-3590

N. S. Stoloff

115. RISOE NATIONAL LABORATORY, P.O. Box 49, DK-4000, Roskilde, Denmark Aksel Olsen

116. SANDIA NATIONAL LABORATORIES, Albuquerque, NM 87185

D. Doughty

117. SHELL DEVELOPMENT COMPANY, P.O. Box 1380, Houston, TX 77251-1380

L. W. R. Dicks 
118. SORELL CONSULTING SERVICES, 49 Brookside Terrace, North Caldwell, NJ 07006 G. Sorell

119. SOUTHWEST RESEARCH INSTITUTE, 6620 Culebra Road, P.O. Drawer 28510, San Antonio, TX 78284

F. F. Lyle, Jr.

120. SRS TECHNOLOGIES, 990 Explorer Blvd., Huntsville, AL 35806

R. Bradford

121. SUPER FIBERS INC., 56 Finley Road, Princeton, NJ 08540

Dr. H. A. Huckins

122. TENNESSEE CENTER FOR RESEARCH AND DEVELOPMENT, P. 0. Box 23184, Knoxville, TN 37933-1184

A. H. von der Esch

123. TENNESSEE EASTMAN, P. 0. Box 511, Kingsport, TN 37662

L. M. Long

124. TENNESSEE TECHNOLOGICAL UNIVERSITY, Manufacturing Center, P. 0. Box 5077, Cookeville, TN 38505

T. C. Ramaraz

125. TENNESSEE VALLEY AUTHORITY, 3N66A Missionary Ridge Place, Chattanooga, TN 37402-2801

J. B. Brooks

126. TEXAS EASTERN TRANSMISSION CORPORATION, P.O. Box 2521, Houston, TX 77252

D. H. France

127-128. THE CARBORUNDUM COMPANY, P. O. Box 337, Niagara Falls, NY 14302

W. Hollar

R. S. Storm

129. THE JOHNS HOPKINS UNIVERSITY, Materials Science and Engineering, Maryland Hall, Baltimore, MD 21218

R. E. Green, Jr.

130. THE MATERIALS PROPERTIES COUNCIL, INC., United Engineering Center, 345 East 47th Street, New York, NY 10017

M. Prager 
131. THE NORTON COMPANY, High Performance Ceramics Division, Goddard Road, Northboro, MA 01532-i545

N. Corbin

132. THE TORRINGTON COMPANY, Advanced Technology Center, 59 Field Street, Torrington, CT 06790

W. J. Chmura

133-134. U. S. BUREAU OF MINES, Tuscaloosa, AL 35405
J. Bennett
T. Clancy

135. U. S. BUREAU OF MINFS, 1450 Queens Ave. S. W., in'hany, OR 97321-2198

$$
\text { J. Woodyard }
$$

136. U.S. TREASURY, Office of Synthetic Fuels Projects, 80615 th Street NW, Suite 410, Washington, DC 20220

J. B. Eeuton

137. UNION CARBIDE CORPORATION, Linde Divisio ר, P.O. Box 44, 175 East Park Drive, Tonawanda, NY 14151-0044

H. Cheung

138. UNITED TECHNOLOGIES RESEARCH CENTER, Silver Lane, MS 24, East Hartford, CT 06108

K. M. Prewo

139. UNIVERSAL ENERGY SYSTEMS, INC., 4401 Dayton-Zenia Road, Dayton, OH 45432

V. Srinivasan

140-141. UNIVERSITY OF CINCINNATI, Department of Aerospace Engineering and Applied Mechanics, Cincinnati, OH 45221

R. Y. Lin

W. Tabakoff

142. UNIVERSITY OF DELAWARE, Department of Chemical Engineering, Colburn Laboratory, Newark, DE 19716

W. A. Calkins

143. UNIVERSITY OF KENTUCKY, Mechanical Engineering Departmer.t, Lexington, KY 40506-0046

O. J. Hahn 
145. UNIVERSITY OF NOTRE DAME, Department of Materials Science and Engineering, P.O. Box E, Notre Dame, IN 46556

T. H. Kosel

146-149. UNIVERSITY OF TENNESSEE, Materials Science and Engineering Department, 434 Dougherty Building, Knoxville, TN 37996-2200
R. A. Buchanan
J. G. Kim
C. D. Lundin
D. M. Walukas

150. UNIVERSITY OF TENNESSEE SPACE INSTITUTE, Tullahoma, TN 37388

J. W. Muehihauser

151. UNIVERSITY OF WASHINGTON, Department of Materials Science and Engineering, 101 Wilson, FB-10, Seattle, WA 98195

T. G. Stoebe

152-153. VIRGINIA POLYTECHNIC INSTITUTE AND STATE UNIVERSITY, Department of Materials Engineering, Blacksburg, VA 24061-0219

K. L. Reifsnider

W. W. Stinchcomb

154-155. WEST VIRGINIA UNIVERSITY, 617 Spruce St., P. 0. Box 6064, Morgantown, WV 26506-6064

C. I. Irwin

L. Wilson (Department of Physics)

156. WESTINGHOUSE HANFORD COMPANY, P.O. Box 1970, W/A-65, Richland, WA 99352

R. N. Johnson

157. DOE, CHICAGO FIELD OFFICE, 9800 South Cass Avenue, Argonne, IL 60439-4899

J. E. Jonkouski

158. DOE, IDAHO FIELD OFFICE, 785 DOE Place, Idaho Falls, ID 83402

R. B. Loop

159-165. DOE, MORGANTOWN ENERGY TECHNOLOGY CENTER, P.O. Box 880, Morgantown, WV 26507-0880
R. A. Bajura
R. C. Bedick
F. W. Crouse, Jr.
N. Holcombe
W. J. Huber
J. E. Notestein
J. S. Wilson 
165-166. DOE, OAK RIDGE FIELD OFFICE, P.O. Box 2008, Oak Ridge, TN 37831-6269 Manager, National Materials Program E. E. Hoffman

167. DOE, OFFICE OF BASIC ENERGY SCIENCES, Materials Sciences Division, ER-131, GTN, Washington, DC 20585

J. B. Darby

168. DOE, OFFICE OF CONSERVATION AND RENEWABLE ENERGY, Energy Conversion and Utilization Technologies Division, CE-12, Forrestal Building, Washington, DC 20585

J. J. Eberhardt

169-170. DOE, OFFICE OF FOSSIL ENERGY, Washington, DC 20585

J. P. Carr, FE-72 (B-127/GTN)

T. B. Simpson, FE-231 (C-177/GTN)

171. DOE, OFFICE OF VEHICLE AND ENERGY R\&D, CE-151, Forrestal Building, Washington, DC 20585

R. B. Schulz

172-177. DOE, PITTSBURGH ENERGY TECHNOLOGY CENTER, P.O. Box 10940, Pittsburgh, PA 15236

S. Akhtar

J. Hickerson

T. C. Rupel

R. Santore

T. M. Torkos

J. W. Wiggins

178. DOE, SBIR PROGRAM OFFICE, ER-16 GTN, Washington, DC 20545

S. J. Barish

179-180. DOE, OFFICE OF SCIENTIFIC AND TECHNICAL INFORMATION, P.O. Box 62, Oak Ridge, TN 37831

For distribution by microfiche as shown in DOE/TIC-4500, Distribution Category UC-114 (Coal Based Materials and Components) 
DATE

FILMED

$2 / 10 / 93$ 
